
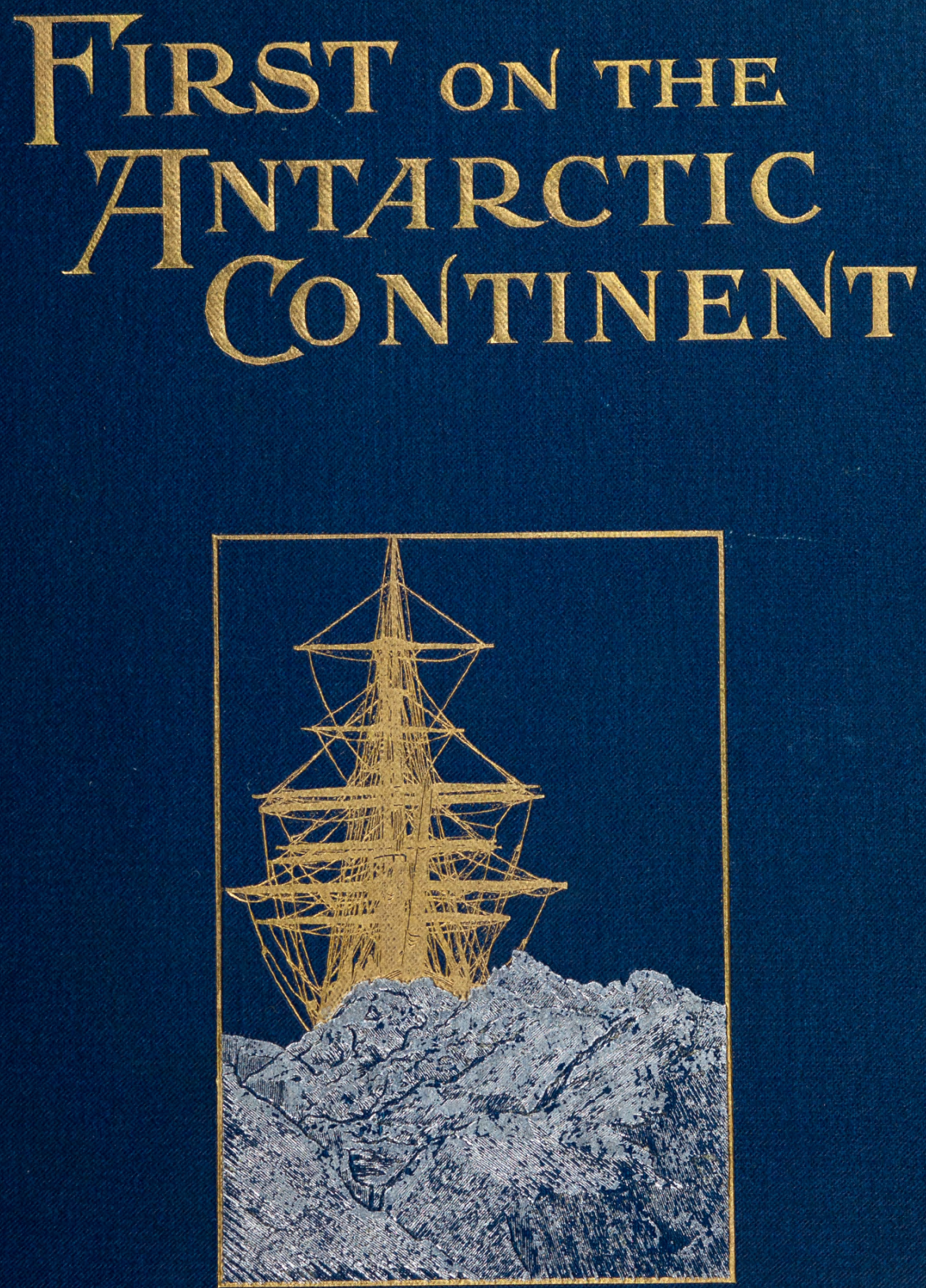

C.E.BORCHGREVINK. 


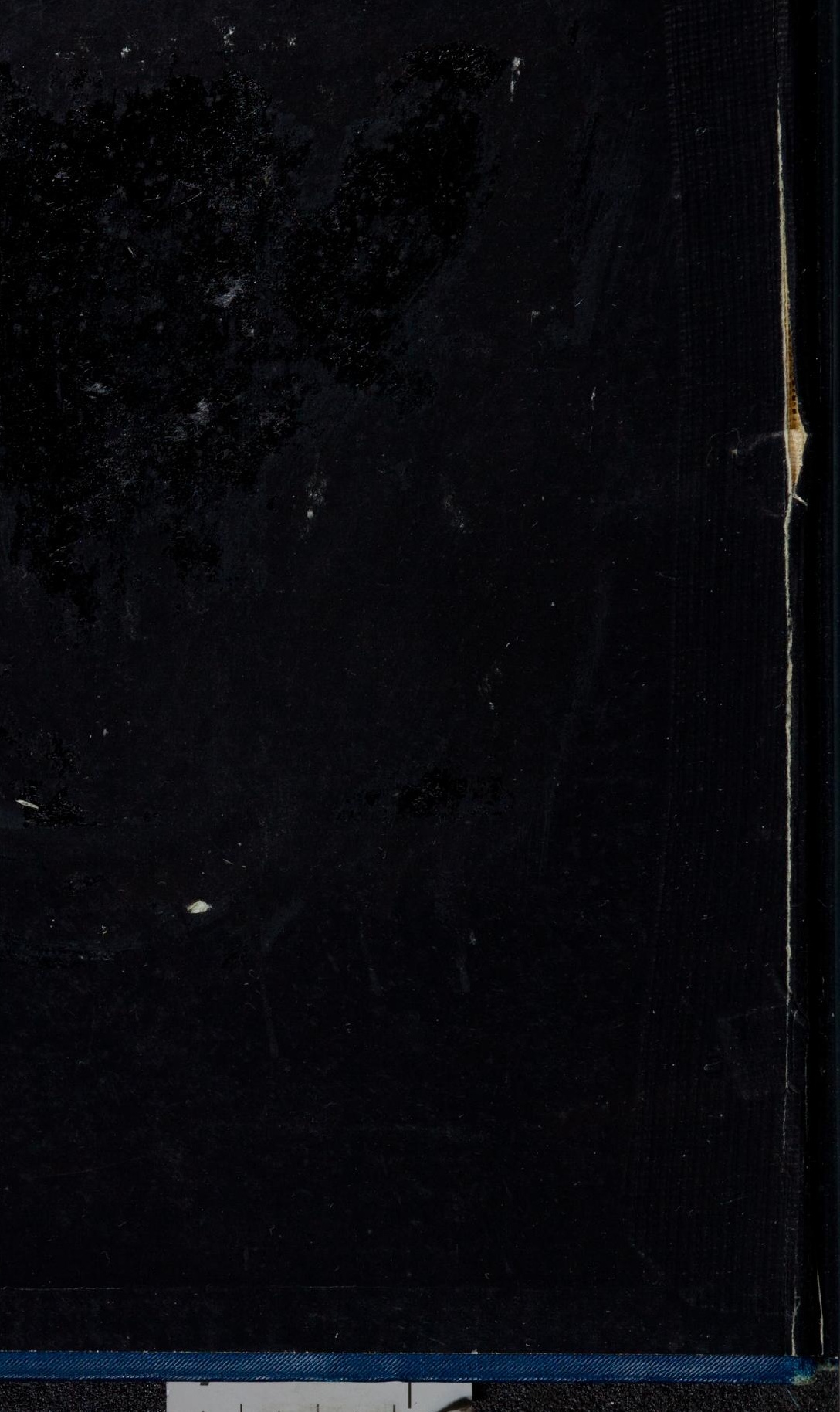




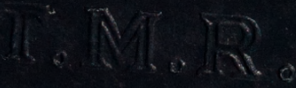 \\ WREATE SF \\ $F \cdot M=R A N=A Y$}


$+4$ 
Thomas Ramiay
Donatis:

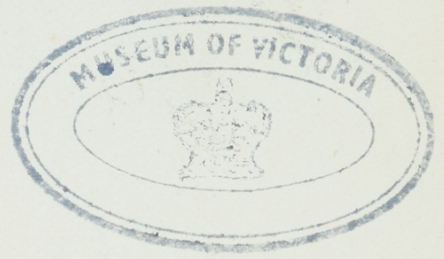

FIRST ON THE

ANTARCTIC CONTINENT 




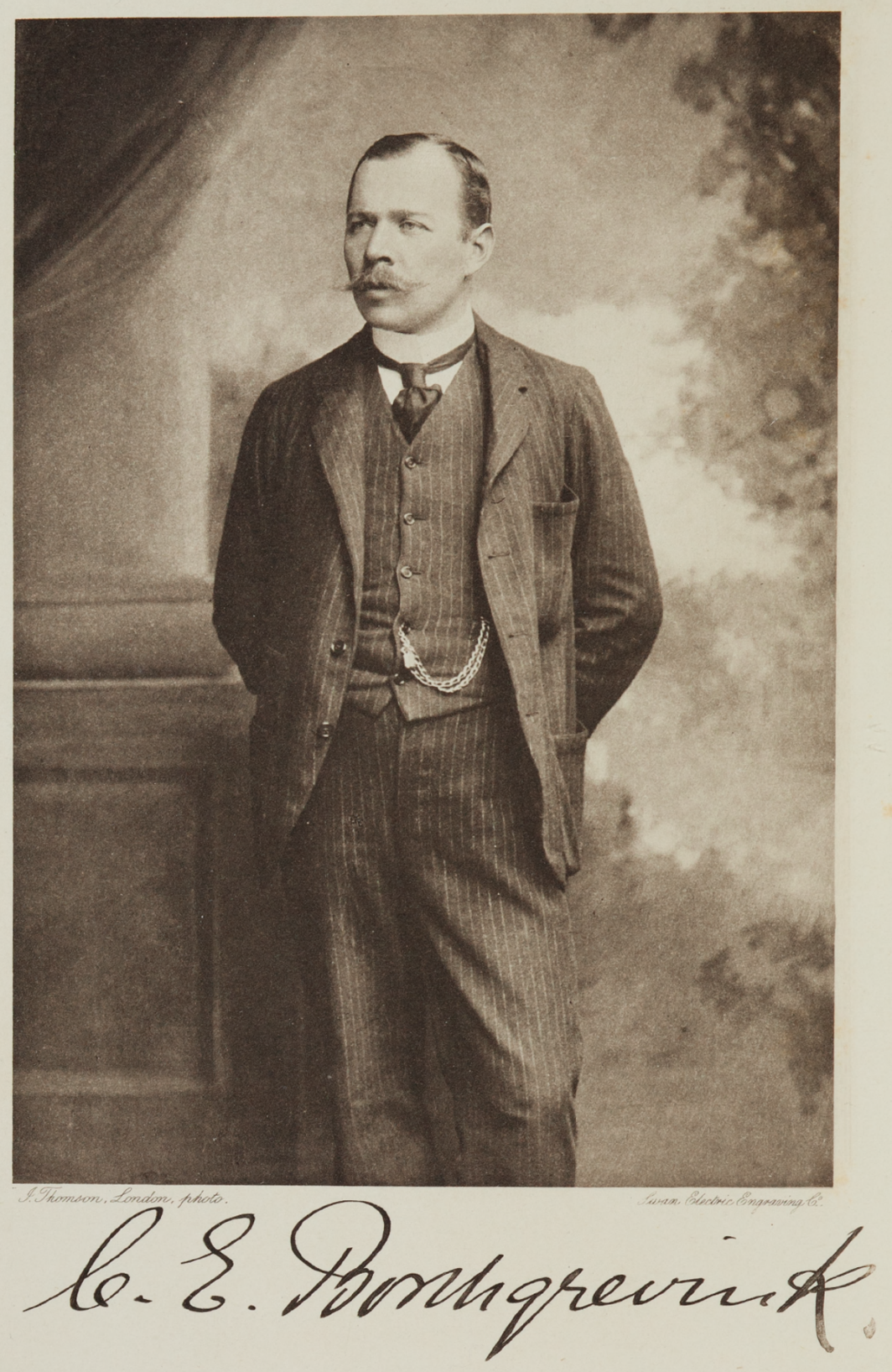




\title{
FIRST ON THE
}

\section{ANTARCTIC CONTINENT}

BEING

\author{
AN ACQOUNT OF THE
}

BRITISH ANTARCTIC EXPHDIHIOY
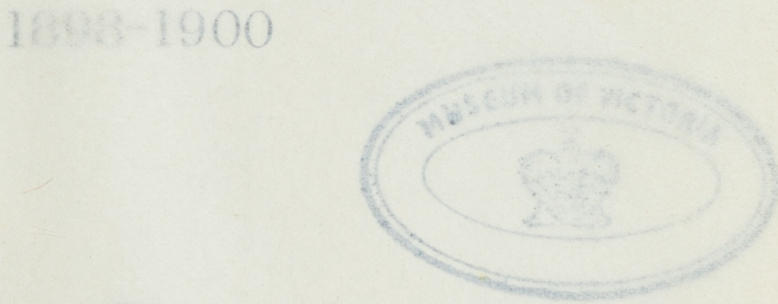

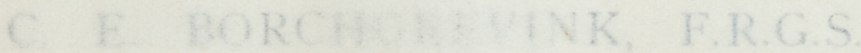

WITH PORTRAITS, HEQA AM 186 ILLUSTRATHORA

\section{LONDON}

GEORGE NEWNES, HIMIILI

SOUTHAMRTON.STREET, STRAMH 

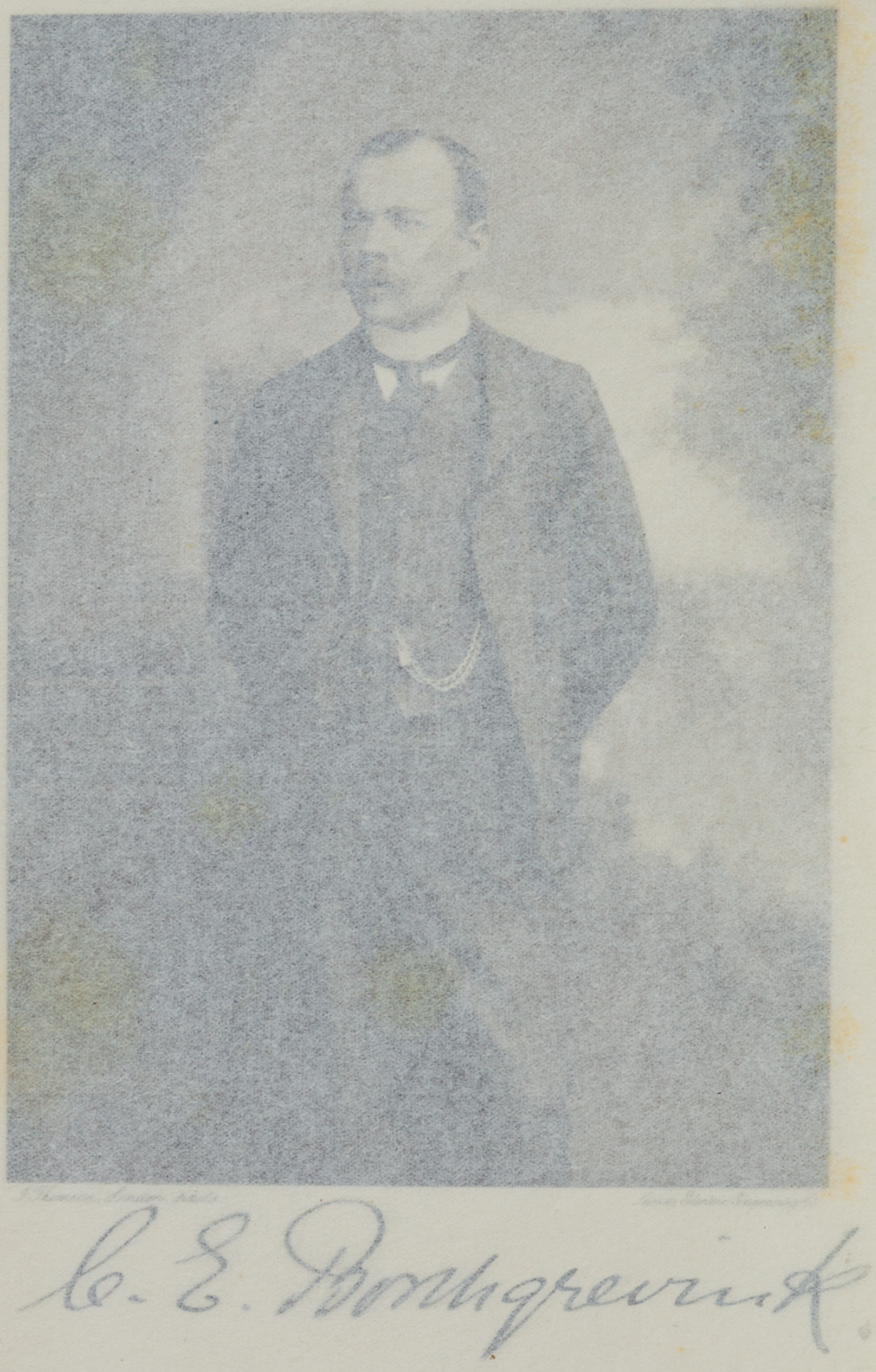


\section{FIRST ON THE}

\section{ANTARCTIC CONTINENT}

BEING

AN ACCOUNT OF THE

\section{BRITISH ANTARCTIC EXPEDITION}

$$
1898-1900
$$

BY

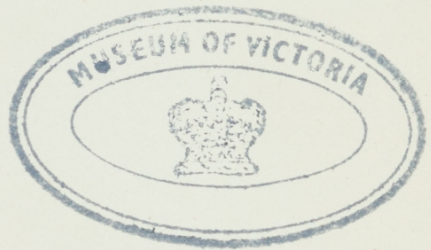

C. E. BORCHGREVINK, F.R.G.S.

WITH PORTRAITS, MAPS, AND I86 ILLUSTRATIONS

LONDON

GEORGE NEWNES, LIMITED

SOUTHAMPTON STREET, STRAND 
<smiles>C#CC#C</smiles> 


\section{Dedicated}

BY PERMISSION

TC

H.R.H. THE DUKE OF YORK, K.G., K.T., K.P., G.C.V.O., REAR-ADMIRAL 



\section{PREFACE}

To Sir George Newnes, Bart., to my staff, the officers and crew of the Southern Cross, my thanks are first of all due.

Next, I wish to express my gratitude to those who stood by me while my plans were still young, also to those whose friendly rivalry stimulated me, in my fight for the Antarctic cause. I would specially mention :-

England: Sir Clements Markham, K.C.B., Kt. St. Olaf, F.R.S., F.S.A., President of the Royal Geographical Society, London ; Admiral Sir Erasmus Ommaney, K.C.B.; Dr. Scott Keltie, LL.D. ; Admiral Sir Leopold McClintock, K.C.B., D.C.L., F.R.S. ; Dr. Hugh Mill, D.S.C. ; Dr. Bowdler Sharp.

Scotland: Sir John Murray, K.C.B., D.S.C., Edinburgh ; Paul Rottenburg, Esq., Glasgow.

Australia: A. Archer, Esq.; His Excellency Sir John Madden; Professor David, Sydney University; H. J. Crummer, Esq.

Norway: Professor Dr. Yngvar Nielsen; Professor Collett; Professor Mohn; Dr. Hjorth: all of 
Christiania University; Colonel Haffner, Director of the Government Survey.

Germany: Professor Dr. Neumayer, Hamburg.

Two closely-related sea-faring nations harmoniously carried this expedition to a successful termination.

May the work accomplished serve to help those who are destined to follow in our wake-lessening their difficulties and risks.

C. E. Borchgrevink. 


\section{CONTENTS}

CHAPTER I.

INTRODUCTORY .

CHAPTER II.

From Hobart to South Victoria Land. . . . . 52

CHAPTER III.

Life in South Victoria Land. . . . . . . . . 85

CHAPTER IV.

Cut Off from All the World . . . . . . . IOO

CHAPTER V.

The Winter in Victoria Land . . . . . . . I25

CHAPTER VI.

Sledge Journey in Winter. . . . . . . . . I56

CHAPTER VII.

Among the Penguins . . . . . . . . . . . 198

CHAPTER VIII.

Return of the Southern Cross. . . . . . 250 
CHAPTER IX.

Farthest SOUth . . . . . . . . . . . . 254

CHAP'TER X.

Towards Civilization . . . . . . . . . . . . 287

Appendix I. . . . . . . . . . . 299

Appendix II. . . . . . . . . . . . . . . 3I6

MAPS AT END OF THE VOLUME.

Robertson Bay, Victoria Land.

Track of the Southern Cross over “Wilkes Land.'

Coast of Victoria Land.

The illustrations on pages 25, 30, 33 and 34 are from negatives by Mr. W. Plank, and that on page 296 by Mr. Nicolls, of New Zealand. The remainder are the work of Mr. L. Bernacchi and other members of the staff. 


\section{LIST OF ILLUSTRATIONS}

Portrait of C. E. Borchgrevink

PAGE

Hoisting the Union Jack

Sir George Newnes

Frontispiece

Part of our splendid engines

Mr. C. E. Borchgrevink $\mathrm{xvi}$

Captain Jensen

Mr. W. Colbeck

Mr. Bernacchi .

Mr. Anton Fougner

Mr. Hugh Evans

Dr. Herlof Klövstad

Mr. Nikolai Hanson

In the engine-room

"At last all was in St. Katharine's Dock ..+25

"At last all was ready" . . . . . . . . . . . . 30

"The last box with provisions had been brought on board" . $3^{\mathrm{I}}$

"God-speed and a safe return" . . . . . . . . . 32

"The yards were manned for us" . . . . . . . . . 33

"Greeted from the yards as we passed" . . . . . . . 34

"But in every new glorious sunset we saw it all once more" . 35

"Everyone had to make himself useful" . . . . . . . 37

In the N.E. trades . . . . . . . . . . . . . 38

Calm weather . . . . . . . . . . . . . . . . 39

"Dog overboard" . . . . . . . . . . . . . 40

"All eighty, regardless of nationality, joined in one penetrating Arctic volapuk" . . . . . . . . . . . $4 \mathrm{I}$

"Birds followed in our track" . . . . . . . . . . 43

Santa Cruz . . . . . . . . . . . . . . 44

On palmy shores . . . . . . . . . . . . 45

Rebecca at the well at St. Vincent . . . . . . 46

In summer seas . . . . . . . . . . . . . . 47

"We passed close to the County of Kinross and spoke her" . 48

County of Kinross . . . . . . . . . . . . . . 49

Always southwards . . . . . . . . . . . . 50

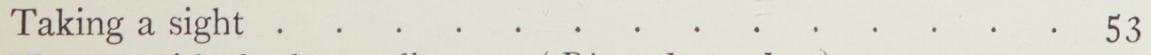

Hanson with the large albatross (Diomeda exulans) . . . . 54

An ocean visitor . . . . . . . . . . . . . 55

"It grew colder" . . . . . . . . . . . 56 
Anxious hours in the crow's nest . . . . . . . . . 57

Slack ice in the pack . . . . . . . . . . . 58

From the crow's nest . . . . . . . . . . . . . 59

View from the crow's nest . . . . . . . . . 60

"She was eleven feet of solid oak at the bows" . . . . . 6I

"The ice slackened somewhat" . . . . . . . . . 62

Mr. Nikolai Hanson taking sea temperatures . . . . . 65

Seal shooting from the bowsprit . . . . . . . . . 66

Theodolite work in the pack . . . . . . . . . 67

Seal shooting . . . . . . . . . . . . . 69

Seal hunting . . . . . . . . . . . . . 70

Mr. Colbeck, Mr. Bernacchi and Mr. Evans skinning a seal . $7 \mathrm{I}$

Seal hunting in the pack . . . . . . . . . . . 72

Penguins in the pack . . . . . . . . . . . 73

Two captive emperors . . . . . . . . . . . . . . . 74

Fast in the pack . . . . . . . . . . . . 75

Filling our tanks with fresh water in the pack . . . . 76

Taking exercise in the pack . . . . . . . . . 77

Savio travelling with Indian gear . . . . . . . . . 78

"The pack commenced to screw violently" . . . . . . 79

Still fast in the pack . . . . . . . . . . . . 80

Weddellii and the white seal (Lobodon carcinopaga) . . . . 8I

A faithful companion . . . . . . . . . . . . 83

"The Southern Cross was about to leave us at our pioneer settlement" . . . . . . . . . . 87

Camp Ridley in spring. . . . . . . . . . . . . 89

The thermometer screen . . . . . . . . . . . 90

The meridian pole at Cape Adare. . . . . . . . . 92

Pack in Robertson Bay . . . . . . . . . . . 93

Borchgrevink and Mr. Hanson on the top of Cape Adare . . 94

Our approach to the top of Cape Adare . . . . . . . . 95

Survey sketch of Admiralty Range by C. E. Borchgrevink . . 97

Weddellii and Rossii . . . . . . . . . . . . 103

"He repeatedly asked it to look pleasant". . . . . . 108

A Weddellii seal . . . . . . . . . . . 109

The ridge of Cape Adare . . . . . . . . . . . . I Io

View on the coast . . . . . . . . . . . . . . III

Lagoon at Camp Ridley . . . . . . . . . . . . I I 2

Fish from Robertson Bay . . . . . . . . . . . II3

The two sisters. . . . . . . . . . . . . . . I I 4

On the march . . . . . . . . . . . . . . 116

Coast-line in Robertson Bay . . . . . . . . . . I I 7 
Refuge camp . . . . . . . . . . . . . . тा8

"We had to cut footsteps in the icy slope to reach the ridge

5,000 feet above us" . . . . . . . . . . II9

"It was one moving wall of grinding ice-blocks" . . . . I 20

"The dogs were great companions" . . . . . . . . I 2 I

Entrance to the hut in winter . . . . . . . . . I22

"Their tongues stuck to the metal" . . . . . . . . I23

"It was a rough pavement on which to travel" . . . . . I 26

Antarctic monarchs . . . . . . . . . . . . I27

The frozen sea near Cape Adare . . . . . . . . . 129

"The anemometer snapped in two on the roof". . . . . I3I

Ice formations near the coast-line . . . . . . . . . I33

Cave in the rock at Cape Adare . . . . . . . . . I35

A crystal palace . . . . . . . . . . . . . I37

"The mountains first showed themselves in their full defiance

as we arrived at their foot" . . . . . . . . I4 I

"They did not know the bloodthirstiness of civilisation . . . I43

"It was a cold job" . . . . . . . . . . . . I44

"Seldom were there more than two together" . . . . . I45

"The seals leave a snake-like track in the snow" . . . . I 48

A seal blow-hole . . . . . . . . . . . . . . I49

"Dr. Klövstad from time to time tested our pulse with a pulsometer" . . . . . . . . . . . . . I5I

The cave in which an oak cask with a report of the Expedition was placed. . . . . . . . . . . . 157

Midwinter Camp . . . . . . . . . . . . . I59

Borchgrevink in his sleeping-bag . . . . . . . . . I6 I

Dugdale Glacier . . . . . . . . . . . . . 163

Stern Victoria Land . . . . . . . . . . . . I65

Looking towards Cape Adare from Duke of York Island . . I66

Camp pitched near Duke of York Island. . . . . . . I67

Mr, Colbeck and the Finn Must leaving Midwinter Camp, at the

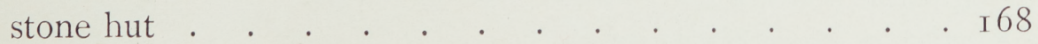

Crescent Bay, Duke of York Island . . . . . . . I69

The interior of Duke of York Island . . . . . . . . I 70

In the centre of an iceberg . . . . . . . . . . I I I

Crevasses blocked our road . . . . . . . . . I72

Sir John Murray Glacier . . . . . . . . . . . 173

Moraine at Geikie Land . . . . . . . . . . . I74

Sir John Murray Glacier . . . . . . . . . . . I 75

Afternoon tea . . . . . . . . . . . . . . . I76

"Roped together we struggled upwards" . . . . . . I77 
On the moraine of Dugdale Glacier

On the coast of Duke of York Island

Moraine study

Duke of York Island

Before the sun rose above the horizon

Termination of the medial moraine at Dugdale Glacier . I 84

View in Victoria Land.

Near Sir John Murray Glacier I 86

From twenty fathoms

Beautiful caves

Ice-formation

The penguins invading the peninsula in the spring

At Hanson's grave .

Ice-formation

Cape Adare in spring

"Wedded" (Eudyptes Adeliae).

Eudyptes Adeliae in the act of turning their eggs .

Eudyptes Adeliae on their nests

"Their nests were found as far as I,000 feet up"

Collecting eggs in the spring

Eudyptes Adeliae on the ice

Springtide

Bird's-eye view of Camp Ridley

Eudyptes Adeliae with their young ones

London Antarctica

202

. 203

. 204

- 208

Family troubles

Aptenodytes Forsterii

Royal London Yacht Club's ensign at Cape Adare

Found in shallow water

From shallow water

Pagodroma Nivea on its nest

Pagodroma caught on its nest .

Fish from Robertson Bay .

Jelly-fish weighing ninety pounds .

Mr. Fougner with Jelly-fish weighing ninety pounds

Leopard basking in the sun

Duke of York Island 
In Victoria Iand near Sir John Murray Giacier "

235

Mother and child (Weddellii) . . . . . . . . . . 237

The Finn Savio in spring, 1900 . . . . . . . . . 239

Borchgrevink in kayak . . . . . . . . . . . 240

A busy day in Camp Ridley . . . . . . . . : . 24I

Borchgrevink and Savio leaving for a kayak expedition . . . 243

The largest vegetation from South Victoria Land: Reindeer moss (Lichen) . . . . . . . . . . . . 249

The return of the Southern Cross . . . . . . . 25 I

Possession Island . . . . . . . . . . . . . 255

On the beach of Possession Island . . . . . . . 257

On Possession Island, at the pole left there in 1895 . . $\quad 258$

In the interior of Possession Island . . . . . . . . 259

Possession Island with Peak Archer . . . . . . . . 260

Peak Archer . . . . . . . . . . . . . . 26 I

Mr. Colbeck taking observations with the artificial horizon . . 263

Southern Cross in Lady Newnes Bay . . . . . . . . 264

Magnetic work in Lady Newnes Bay . . . . . . . . 265

Coulman Island . . . . . . . . . . . . . 266

Cape Washington . . . . . . . . . . . . 267

Mount Melbourne . . . . . . . . . . . . 269

Mount Melbourne . . . . . . . . . . . . $27 \mathrm{I}$

Land near Mount Melbourne . . . . . . . . . 272

Newnes Island . . : . . . . . . . . . . 273

Sir George Newnes Land in Southern Cross Fjord . . . . 276

Cape Bernacchi on Franklin Island . . . . . . . . 277

Franklin Island . . . . . . . . . . . . . 278

The peninsula at Franklin Island . . . . . . . . . 279

Mr. Colbeck taking Dip observations on Franklin Island . . 280

At the foot of Mount Terror, where Borchgrevink and Jensen nearly lost their lives . . . . . . . . . . 28I

Cape Crozier . . . . . . . . . . . . . 283

Fast again . . . . . . . . . . . . . . . 284

Ice weighed her down . . . . . . . . . . . . . 285

Seals were dotted about on the white carpet . . . . . . 288

The Southern Cross Farthest South . . . . . . . . 289

On the top of the great barrier on the journey Farthest South . 29I

A hurried meal . . . . . . . . . . . . 293

Farthest South ever reached by man . . . . . . . . 295

Mr. Borchgrevink on board the Ruruhau . . . . . . 296

Heavy screw in the pack ice . . . . . . . . . . 297

Slips from the thermograph and barograph . . . . 309 


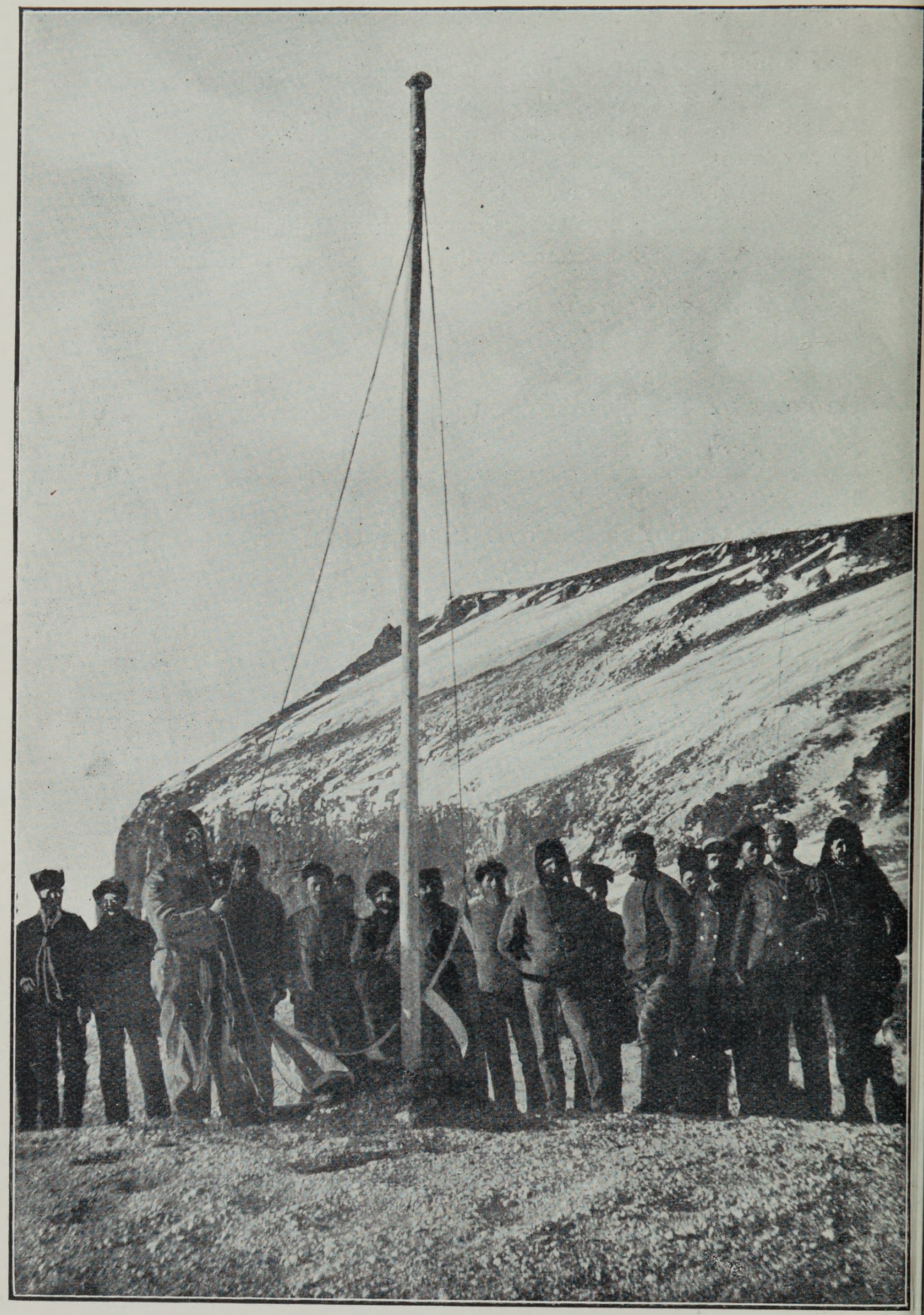

March 2nd, 1899.- "Hereby I HAVE the HONOUR OF HOISTING THE FIRST Flag on the gReat Antarctic Continent. It is the Union JACK OF GREAT BRITAIN." 


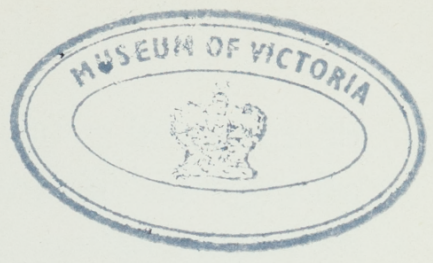

\section{BRITISH}

\section{ANTARCTIC EXPEDITION \\ $1898-1900$.}

\section{CHAPTER I. \\ INTRODUCTORY.}

WhiLE man's knowledge of this Globe has continued to increase by the sacrifice of energy terminating many lives, the difficulties of obtaining further knowledge of the unknown territories have increased with the decrease of the unknown space.

But centuries have rolled onwards.

Strengthened by difficulties, man's philosophy has forced the Arctic and Antarctic ice, and reached the glittering gates of the Poles where eternity rules in stern silence, awaiting the hour when time is ripe through the sacrifice of mortals, for man to be allowed to follow his philosophy and to enter the Polar crystal palaces, and to satisfy his thirst for certainty.

y Expeditions of discovery have set out, and one by one they have returned, or one by one they have 
disappeared; but all were destined to succeed by adding to knowledge. Felix quem facuunt aliena pericula cautum.

Perchance it was through the sacrifice of the one that the other achieved success!

Each sacrifice on the altar of science has driven man onwards in the wake of his philosophy, until science has conquered the pioneer work of the last terra incognita on the Globe.

Although it seems remarkable that this work has been delayed until the beginning of the twentieth century, the experiences gained in the North were, however, necessary, before even a beginning could be made to solve those mysteries of natural phenomena which are kept within the ancient walls of the extreme South.

And not until man has followed where his mind travelled before him towards the South as far as he has done it in the North, will it be possible to secure those facts which make knowledge out of theories.

\section{History of Antarctic Exploration.}

The honour of being the first man to discover the Antarctic Continent probably belongs to Captain James Cook, who, in the year I 772 , reached lat. $7 \mathrm{I}^{\circ}$ IO $^{\prime} \mathrm{S}$., in long. Io6 $54^{\prime} \mathrm{W}$., where he sighted the great ice barrier which forms the seaward boundary of Antarctica. Speaking of this discovery, Sir James Clark Ross says:- "I confidently believe that the enormous mass of ice which bounded his view when at his extreme south latitude was a range of 
mountainous land covered with snow." In I8I9 William Smith, in the brig William, discovered the archipelago of the South Shetlands, south of Cape Horn. In I820-23 Weddell visited the South Shetlands, including the active volcano Bridgman. Powell, the discoverer of the South Orkneys, visited the volcanic island of Bridgman in 1822 , and found it to be at that time $200 \mathrm{ft}$. high. Weddell, who visited it in the following year, estimates its height at $400 \mathrm{ft}$. Weddell penetrated to $74^{\circ} \mathrm{S}$. in 1823 , thus attaining a higher latitude than Captain Cook, but he saw no land anywhere in that neighbourhood. In I83 I Biscoe, in the brig Tula, discovered Enderby Land. In I 839 Balleny discovered Balleny Islands, a volcano I 2,000 ft. high. In I839 the important French Expedition under Dumont D'Urville explored the South Shetlands. In I 840 Commander Wilkes, in the U.S.A. corvette Vincennes, discovered Wilkes Land.

In 184I Sir James Clark Ross made his memorable discovery of South Victoria Land. With the object of trying to find the South Magnetic Pole, as he had already found the North Magnetic Pole, he forced his well-fortified ships through the pack-ice which he encountered in lat. about $67^{\circ} \mathrm{S}$. and long. $174 \frac{\mathrm{I}}{2} \mathrm{E}$. He forced his way through it, and entered comparatively open water beyond, a great ocean pool about 600 miles in diameter. Bounding this on the west was the magnificent chain of snowclad volcanoes of Victoria Land. Ross traced the coast for 500 miles southwards, where he encountered the great ice barrier, terminating seawards in a sheer wall of ice from I $80 \mathrm{ft}$. to $200 \mathrm{ft}$. high. 
In 1874 H.M.S. Challenger visited the neighbourhood of the supposed Termination Land of Wilkes. In I 893-4 the whaler Fason, with Capt. C. H. Larsen, visited the north-western portion of Antarctica.

In 1894 the whaler Antarctic crossed the Antarctic Circle and effected a landing on South Victoria Land, and at Possession Island, and reached $74^{\circ} \mathrm{Io} \mathrm{O}^{\prime} \mathrm{S}$. I was on board the Antarctic at the time, and discovered, for the first time, a land flora on the Antarctic Continent in the form of a small lichen, and saw in the water near Cape Adare a live jelly-fish.

The following extract from my speech before the Sixth International Geographical Congress in the Imperial Institute gives a short summary of what I observed at my first landing on the peninsula at Cape Adare in I894, and which also may have its interest, as it became an important factor among those which weighed when I decided to choose the place for my pioneer camp. As the visit that time only lasted some few hours, my report of the place was then naturally very short.

"The peninsula on which we landed at Cape Adare must be some seventy acres in extent; on the top of the guano were lying the primitive nests of the penguins, composed of pebbles. Some hundreds of yards up these landslips I came upon two dead seals, which, from their appearance, must have lain there several years. I made a thorough investigation of the landing-place, because I believed it to be a place where a future scientific expedition might safely stop, even during the winter months. Several accessible spurs lead up from the place where we were to the top of the cape, and from 
there a gentle slope leads on to the great plateau of South Victoria Land. The presence of the penguin colony, their undisturbed old nests, the appearance of the dead seals, the vegetation on the rocks, and lastly, the flat table of the cape above, all indicated that here the unbound forces of the Antarctic Circle do not display the whole severity of their powers. Neither ice nor volcanoes seemed to have prevailed at the peninsula at Cape Adare, and I strongly recommend a future scientific expedition to choose this spot as a centre for operations. At this place there is a safe situation for houses, tents and provisions. I myself am willing to be the leader of a party, to be landed either on the pack or on the mainland near Coulman Island, with ski, Canadian snow-shoes, sledges and dogs.”*

M. Gerlache in the Belgica sailed southwards in 1897 , and returned in the autumn of 1898 without having effected a landing on the Antarctic Continent, and without reaching further than $7 \mathrm{I}^{\circ} 24^{\prime} \mathrm{S}$. (?). But he added valuable data to the meteorology within the Antarctic Circle, as the observations on board the Belgica extended over a whole year, and that expedition was the first to over-winter within the Antarctic Circle. However, the first to invade the Antarctic Continent were the members of the Southern Cross under my command, who, with me, successfully landed on the peninsula of Cape Adare in I899, with a complete outfit for exploration on land and at sea.

What I claim as the principal work accom-

* From the report of the Sixth International Geographical Congress, London, I896. 
plished by the expedition under my command is this: The pioneer work in Victoria Land extending over a period of one year, (I) for the first time proving the possibility for an expedition to live on South Victoria Land in winter; (2) recording the meteorological and magnetic conditions of Victoria Land during one year; (3) the present approximate position of the South Magnetic Pole ascertained to be approx. in lat. $73^{\circ} 20^{\prime} \mathrm{S}$., and long. $146^{\circ} \mathrm{E}$., about $22^{\circ} \mathrm{W}$. by N. from Wood Bay; (4) discovering new species in Antarctic biology, viz:, insects, and shallow-water fauna, proving bipolarity, and adding new features to our knowledge of the geology of South Victoria Land, and the discovery of vegetation, some of which has proved the existence of bi-polarity in the flora. There was also (5) a careful investigation and mapping of the coast-line round Robertson Bay, where a new island was discovered in lat. $7 \mathrm{I}^{\circ} 35^{\prime} \mathrm{S}$., and long. I $70^{\circ} 23_{4}^{\prime}$ E., which I named after H.R.H. the Duke of York; (6) the coast-line from Cape Adare to Mt. Terror surveyed and mapped, whereby new geographical discoveries were made, amongst these being two new islands, one of which I named after His Majesty King Oscar, and the other after Sir Clements Markham, as well as alterations in the map of Sir James Clark Ross, whose excellent work could, of course, not possibly be exact owing to the fact that the Erebus and the Terror, lacking the aid of steam, could not be navigated so close to the shores of Victoria Land as could the Southern Cross. (7) For the first time a landing was effected on Coulman Island, Franklin Island, Wood Bay, and 


\section{Introductory.}

Mt. Terror, whereby a most important geographical discovery was made in the discovery of Southern Cross Fjord, as well as the excellent camping place discovered on Newnes Land at the foot of Mt. Melbourne. (8) A careful study of the great ice barrier was made while the Southern Cross was navigated as far south as $78^{\circ} 34^{\prime} 37^{\prime \prime}$, thus further than any vessel had been brought before, and having crossed the Antarctic Circle four times-once to and from $7 \mathrm{I}^{\circ} \mathrm{I} 8^{\prime}$ (Cape Adare), and once to and from her furthest south; (9) and lastly, I proved the possibility of scaling the great ice barrier on which I, with two companions, and by the help of dogs and sledges, reached the latitude of $78^{\circ} 5 \mathrm{O}^{\prime}$, the furthest south ever reached by man.

It is thus that Antarctic exploration in the year I 900 has opened up a new era in Geographical Science with a scope the greater because of its responsibility towards the past work done within the Arctic Circle, as well as towards the maiden field of the great white world around the Southern Pole.

I believe further that in the history of culture of nations of the Southern Hemisphere the awakened interest in Antarctic research in the year I 900 must needs, in time to come, be recognised as a conspicuous and bright intellectual land-mark.

In the years I894-5, I visited for the first time the great Antarctic Continent. On Thursday, August Ist, I895, I had the honour of laying the results of my scientific observations within the Antarctic Circle before the Sixth International Geographical Congress assembled in London at the Imperial Institute. 
Immediately after my lecture the following resolution was moved:-

"The Sixth International Geographical Congress, assembled in London in the year I 895, with reference to the exploration of the Antarctic Regions, expresses the opinion that this is the greatest piece of geographical exploration still to be undertaken, and in view of the addition to knowledge in almost every branch of science which would result from such a scientific exploration, the Congress recommends that the various scientific societies throughout the world should urge, in whatever way seems to them most effective, that this work should be undertaken before the close of the century.'

Upon being put to the meeting the resolution was carried unanimously.

Ten years previously that resolution had been carried in my mind, but not so clearly did I then realize those difficulties which, from unexpected quarters, arose out of the mist-like ice-pack to delay the pioneer-work which I, however, was destined to accomplish.

It was up a steep hill I had to roll my Antarctic boulder!

For a number of years my Antarctic work had been limited to that of private correspondence-a correspondence which, however, grew so rapidly, that in 1892 I was enabled to give that thought to the cause which gave birth to my independent Antarctic expedition plans.

First, in I 894, I visited Victoria Land and compared my theories with reality, and in I895 I delivered my first lecture in the Town Hall of 


\section{Introductory.}

Melbourne before the Royal Geographical Society of Australasia. Shortly afterwards I spoke in Sydney before the New South Wales branch of the same society. My hope was that my observations

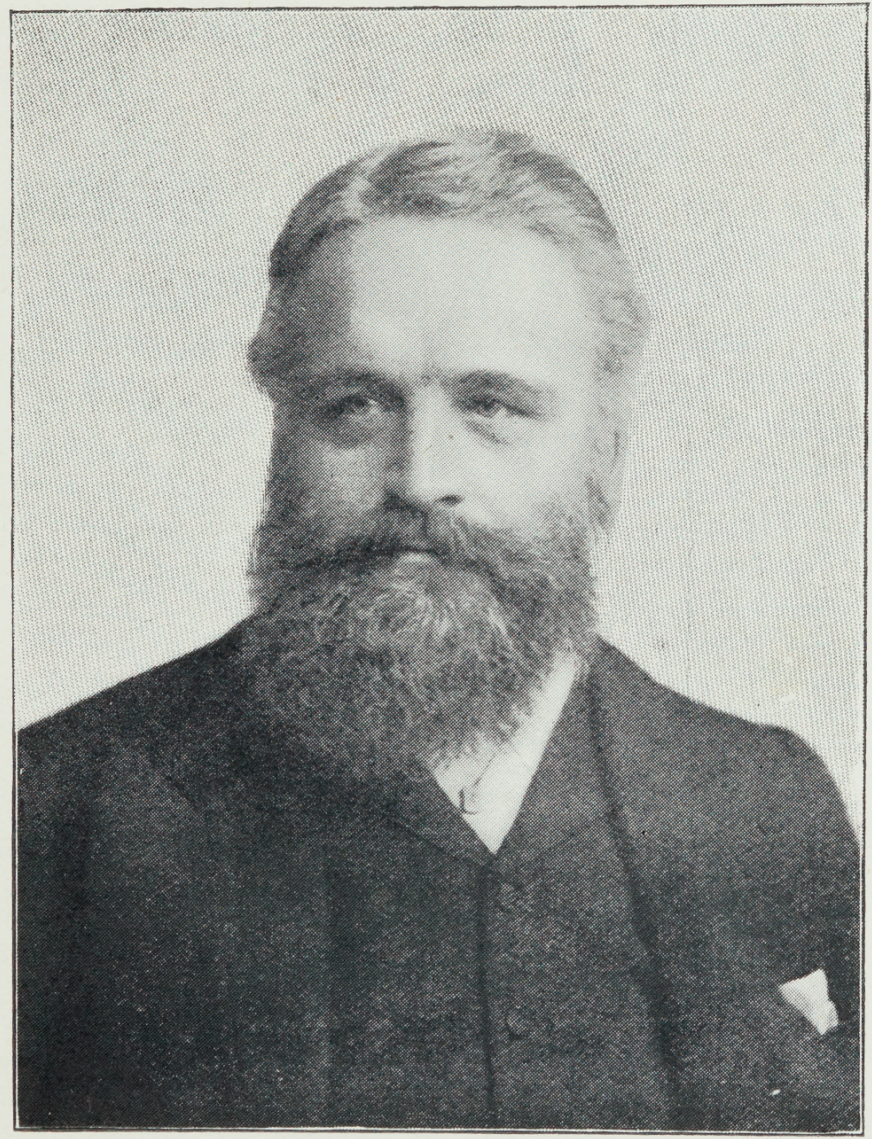

SIR GEORGE NEWNES.

and experiences within the Antarctic Circle might stimulate the Australian interest in Antarctic work.

My hope was not disappointed. In less than one month I found myself surrounded by the greatest thinkers of Australasia. But great and noble thinkers 
in the Australian colonies rarely can afford to accompany their thoughts on far journeys, nor despatch others, less worthy, perhaps, in pursuit of their philosophy.

While thus the importance of the cause which I advocated was recognised everywhere, and tons of moral support was lavishly presented to me from all sides, the funds for my enterprise did not come before my work acquainted me with one of those rare men whose brains, heart, and funds were only equalled by his spirit of enterprise.

In I896 I first met Sir George Newnes, and laid my plans before him.

In 1898 he placed the necessary funds at my disposal for the realization of my Antarctic expedition plans.

My plans were then but slightly altered from those which I laid before the Sixth International Geographical Congress in London in 1895 . (See page I74 of the report of the Sixth International Geographical Congress, I 895), and I may here give a. statement of the tonnage and dimensions of the

\section{Southern Cross.}

Gross Tonnage

Net Tonnage .

Length .

Breadth .

Depth of Hold

Draught.

$$
\begin{aligned}
& 521 \cdot 70 \text { tons. } \\
& 276 \cdot 72 \quad " \\
& \text { I } 46 \cdot 5 \text { feet. } \\
& 30 \cdot 7 \quad " \\
& 17 \cdot 6 \quad " \\
& 18 \cdot 0 \quad "
\end{aligned}
$$

Two decks ; stern round; barque rigged; built in Arendal (Norway); designed by Colin Archer, who also designed the Fram. 
The engine as well as the boilers were made to order by I. and A. Jensen, of Dahl, Fredrikstad, Norway.

This work was to have been done in England, but a big strike of mechanics at the time made it impossible to get the work finished up to the time in Britain.

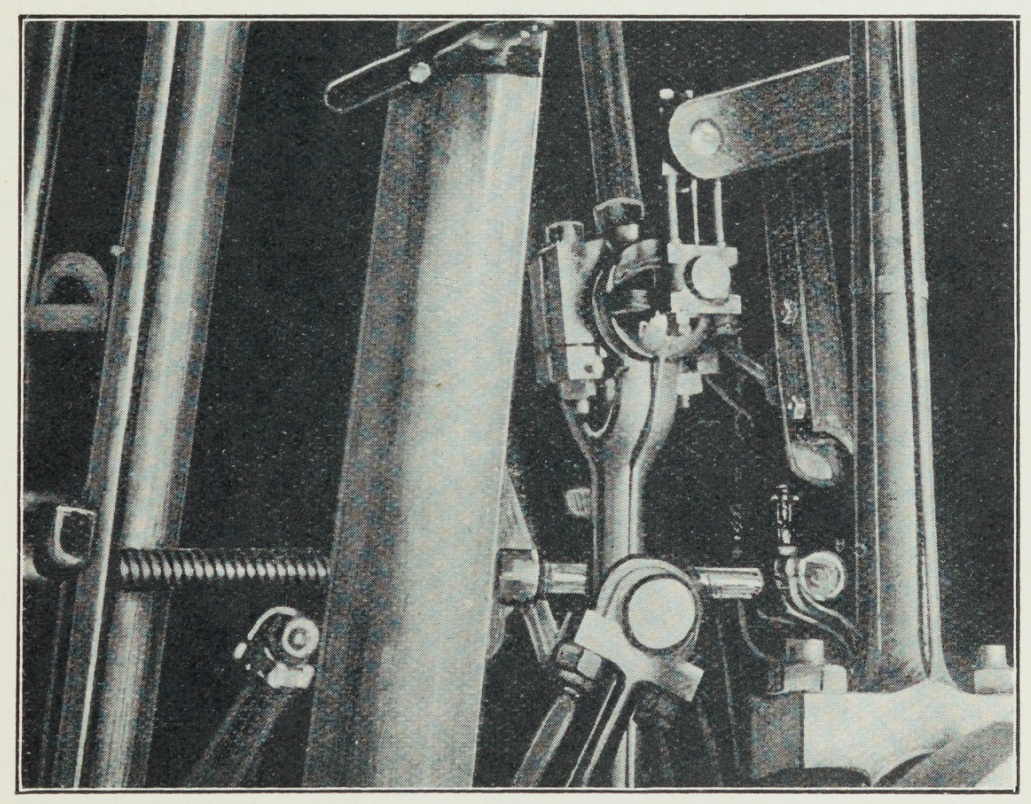

PART OF OUR SPLENDID ENGINES.

The engine is a direct working vertical tripleexpansion engine of the following dimensions :-

High Pressure Cylinder, Diameter . . $\quad$ I $2 \frac{1}{2}$ ins.

Intermediate Pressure Cylinder, Diameter . I $9^{\frac{1}{2}}$,

Low Pressure Cylinder, Diameter . . 3I "

Length of Stroke (for all Cylinders) . . $25^{\frac{1}{2}}$ "

The high-pressure cylinder has a round slide, while the intermediate and low-pressure cylinders have the ordinary flat slides. 
The low-pressure cylinder has a piston rod going straight through. The engine has a surface condenser, and is in other details furnished with all

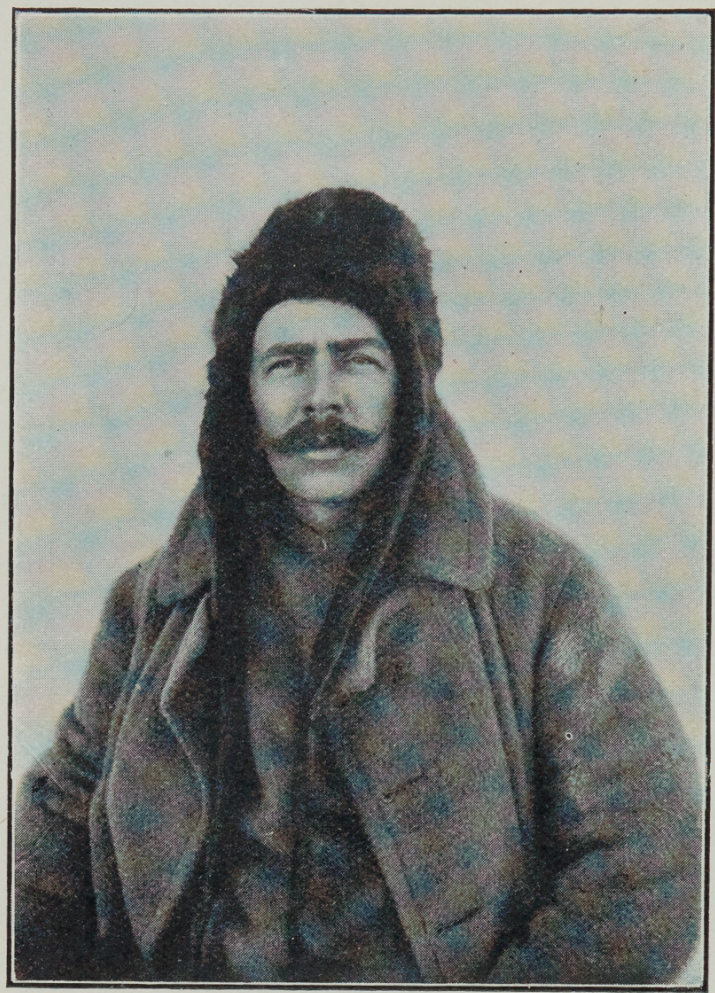

C. E. BORCHGREVINK. modern applia n c e s of a marine engine, with soo revolutions a minute, and a pressure of 170 lbs. per square inch, I. H. P. 360. The propeller has two blades, and has a $10 \mathrm{ft}$. diameter, with 9 ft. 3 in. (grad ual rise) (Norwegian Stigning). To this engine is attached combined furnace and boiler tubes of steel, to withstand a pressure of $170 \mathrm{lbs}$. to the square inch. The boiler is I $\mathrm{ft} .3$ in. in diameter and $9 \mathrm{ft}$. Io in. long. The two furnace waving plates are $3 \mathrm{ft} .3$ in. in diameter. Each of the $15^{8}$ pieces of horizontal tubes are $3 \frac{\mathrm{I}}{2} \mathrm{in}$. in diameter outside. The heating surface is I,IOO sq. ft. The grate area 43 sq. $\mathrm{ft}$. The engine as well as the boiler and the tubes were executed according to the rules of the Norwegian Veritas, 
In selecting my staff and crew of the vessel, I purposely selected men who were able to collect reliable data, judging this more important than having a staff of specialists. In my opinion it is neither desirable nor possible to work out the raw material collected by a pioneer expedition under such conditions in which we lived and worked; and I think it is one of the difficulties of selecting men for an Antarctic expedition, to get professional, capable, and practical scientific men, who, however, will not also attempt minute analyses of their observations and collections. It is altogether undesirable that well - collected material should be meddled with before it is delivered into the hands of thoroughly experienced specialists. With this in view I selected the following officers for my staff and for my vessel :

Capta in Bernhard Jensen with master-

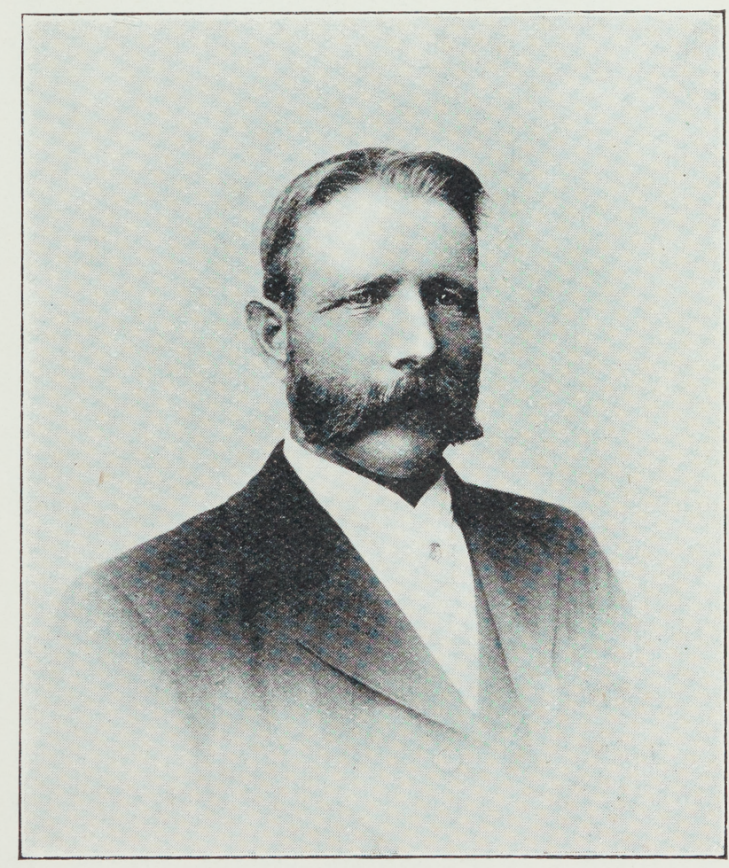

CAPTAIN JENSEN. mariner's certificate, born I853, Norwegian by birth; has had twenty years' experience in ice navigation; has once before passed the Antarctic 
Circle with me. I selected him for his responsible position as Captain of the Southern Cross because of his experience, courage, carefulness and tact; which never deserted

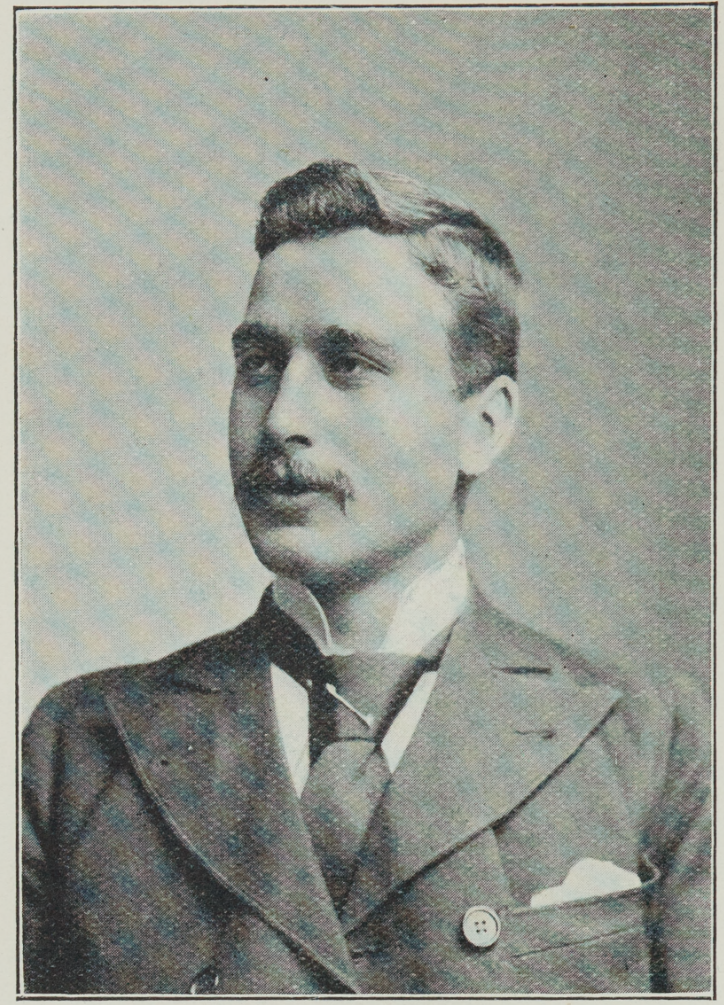

MR. W. COLBECK. him during the expedition.

\section{Mr. William} Colbeck, R.N.R. Born August 8th, I87 I. Educated at Hull G r a m m a r School, went through a sixmonths' course of navigation before going to sea. Term of apprenticeship ( $1886-$ i 890 ) served in the Loch Torridon of Glasgow in the East India trade, under

Captain Pattman. Obtained second-mate's certificate in Calcutta, November, I890, and joined the Avon of London, employed in the Government Emigrant Service. He spent three years in this service and obtained his first-mate's certificate in July, I892; and master's certificate March, I894. He then joined the firm of Thos. Wilson, Sons \& Co., Ltd., of Hull. At the time of appointment he was serving on that Com- 
pany's boat, the R.M.S. Montebello, as second mate under the able and courteous Capt. Pepper. In addition he passed for extra master in November I 897, and was gazetted sub-lieutenant R.N.R. in June, I 898. Subsequently he studied on behalf of the expedition at the Kew Observatory, making a special feature of magnetism, and it was as Magnetic Observer that he accompanied the expedition under my command. His father, Mr. Christopher Colbeck, is of the firm of Messrs. Colbeck and Walker, of Hull.

Louis Bernacchi. Born in Tasmania on November 8th, I 876, his father, Mr. A. G. D. Bernacchi, being a well-known $\mathrm{T}$ a s m a n i $\mathrm{n}$ colonist. Educated at the Hutchins School of Hobart, and privately, he entered the Melbourne Observatory in I 895 , where

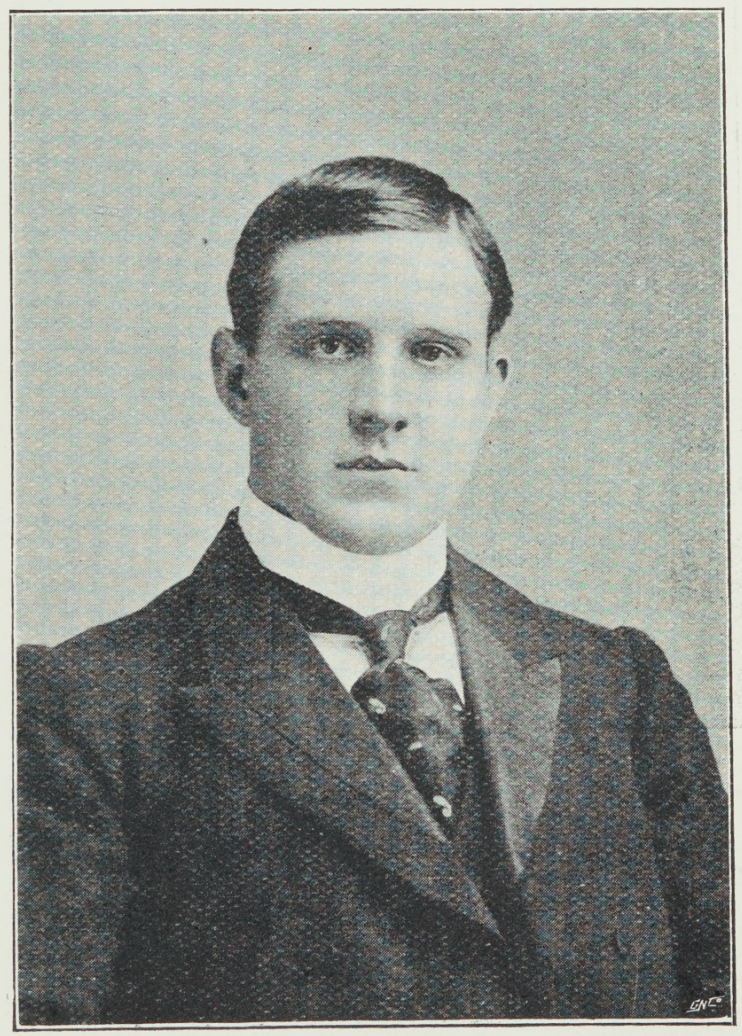

MR. BERNACCHI.

he spent; about three years studying magnetism and meteorology. In 1897 he was appointed to the Belgian Antarctic expedition. He was to have 


\section{i6 British Antarctic Expedition.}

joined the ship in Melbourne, but on account of its being caught in the ice-pack off Cape Horn, and therefore not being able to call at Melbourne, he could not join. In May,

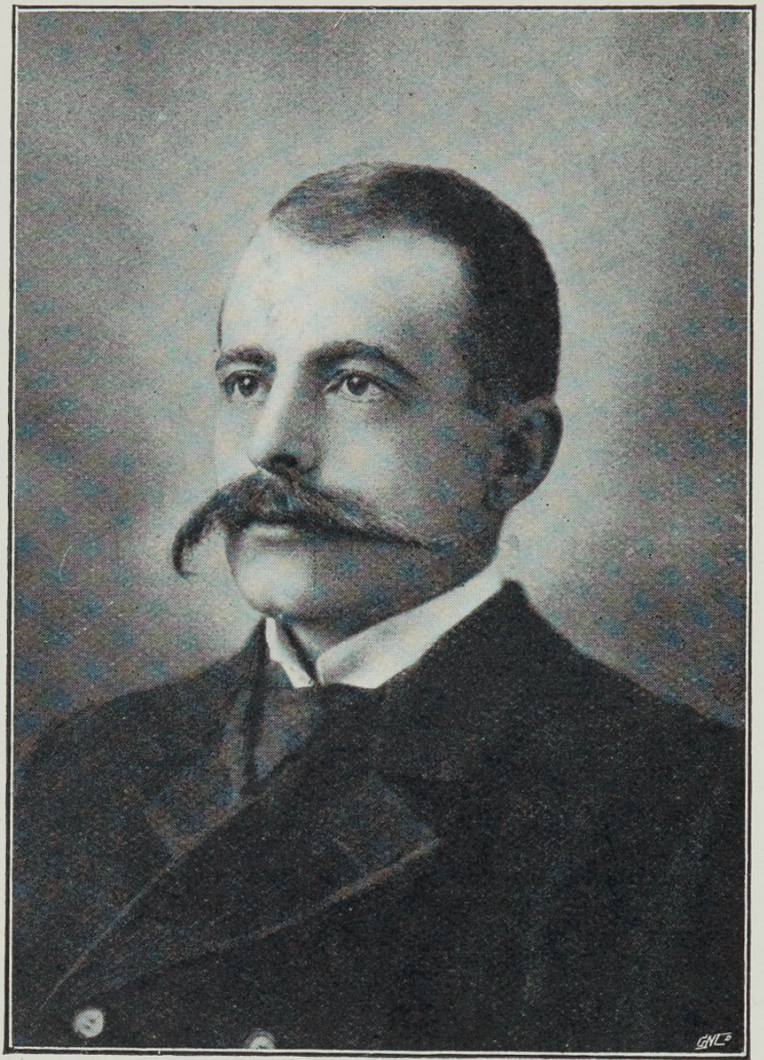

MR. ANTON FOUGNER,
I 898, Mr. Bernacchi came from Melbourne to London on the off-chance of being able to join the expedition under my command.

Anton Fougner, "handyman"; educated at college, Christiania; mate's certificate; experienced sailor; good snow-shoe runner; born s 870 ; at time of appointment clerk in an office in Christiania. Hugh Blackwall Evans. Born November 19th, 1874. His father is the Rev. Edward Evans, of Bishopston Vicarage, Bristol. He was educated at King's School, Gloucester, after which he went to Canada for four years, spending the first year at the Agricultural College in the North-West Territories, and the remaining three on a cattle ranch, where he had a deal of hunting and shooting. On return- 
ing to England he proceeded to Melbourne, where he joined a sealing expedition to Kerguelen Island. On again returning home he joined my expedition to the Antarctic as assistant zoologist.

Dr. Herlof Klövstad, M.A., M.D., Christiania University. At the time of appointment resident doctor in a lunatic asylum, near Bergen, Norway. Born i 868.

Nikolai Hanson, zoological taxidermist, experienced hunter and collector, born at Christiansund, Norway, i 870. At the time of appointment employed in collecting for the British Museum and for the Zoological Museum in Christiania.

C o 1 b e in Ellefsen, cook; Civil Service examination; experienced sailor; at the time of a ppointment in an office in Tonsberg, Norway.

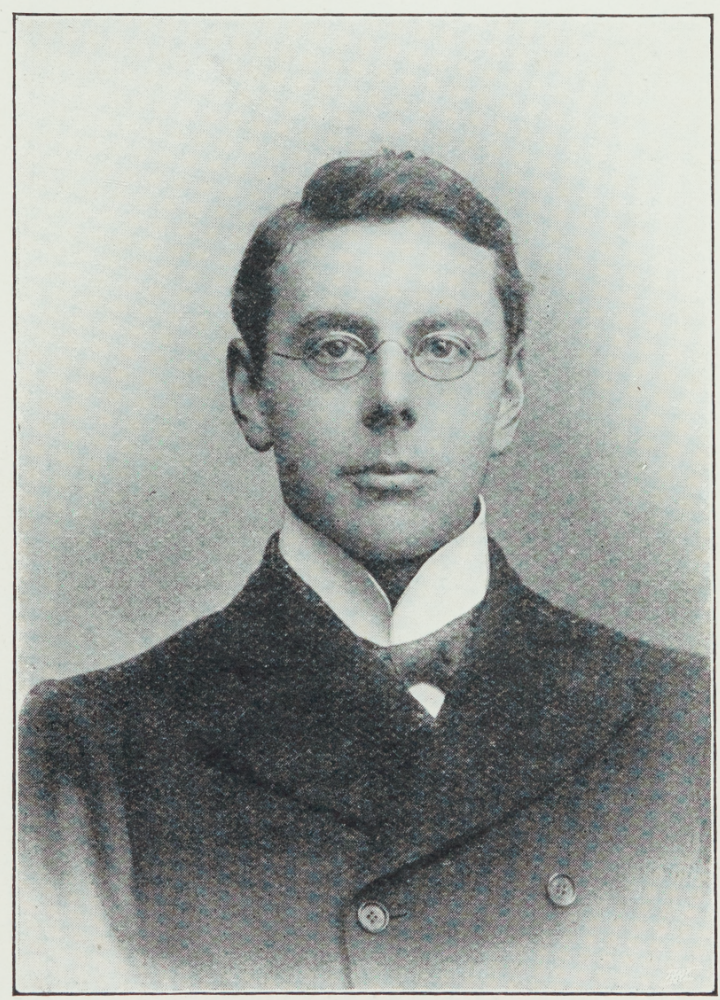

MR. HUGH EVANS.

Jorgen Petersen, first mate; experienced ice navigator. Died 23 rd of September, igoo, on the voyage from Australia. 
Hans Hansen, second mate; experienced ice navigator and hunter; born 1877 .

Hans Ulis, professional carpenter.

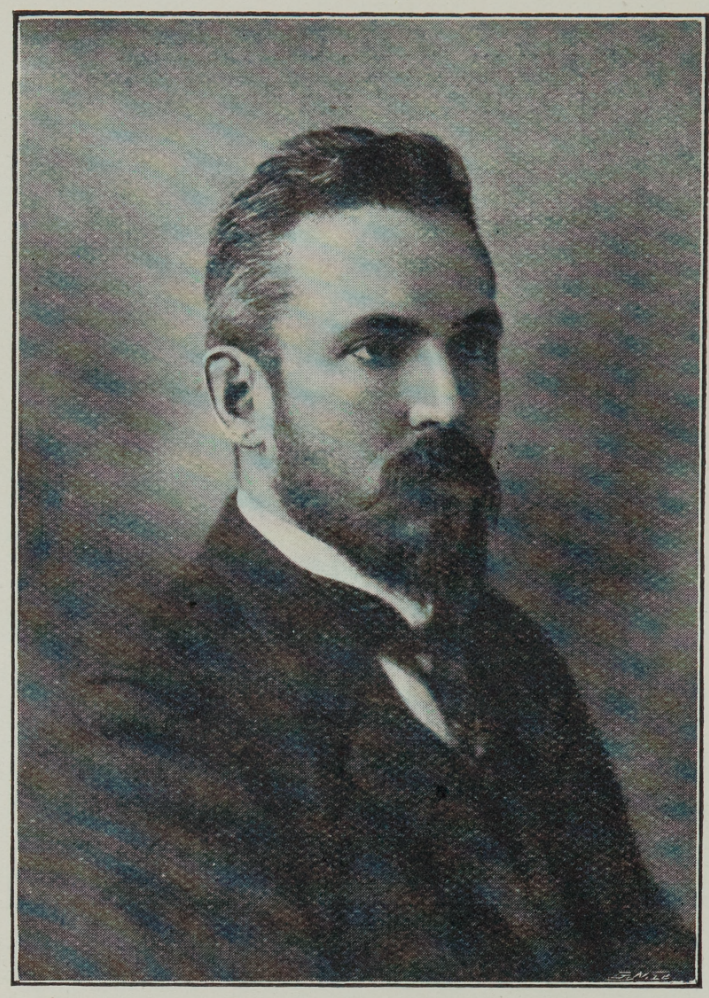

DR. HERLOF KLÖVSTAD.

Lars Andersen, steward ; born 1850 .

J. Cristian Olsen, first engineer ; firstclass certificate. Experienced engineer and boilermaker. At the time of appointment professional engineer at Jensen and Dahl's shipbuilding yard, Friedrikstad, Norway.

Julius Johanesen, second engineer, professional engineer. At the time of appointment at the same yard as the nirst engineer. In addition to the above there were fourteen hardy and strong. Norwegian sailors.

\section{The Crew of the "Southern Cross."}

Klemet Klemetsen, boatswain; Johannes Jahnsen, cook; Franz Johan Magnūssen, A.B.; Oscar M. Bjarko, A.B. ; Hans Nielsen, A.B. ; Ingvard Samuel- 
sen, A.B. ; Hans J. Johnson, A. B. ; Johan A. Andersen, A.B. ; Olof Larsen, A.B. ; Lars A. Larsen, A.B. ; Adolf M. Karlsen, O.S. ; Carl H. J. Been, fireman ; Axel Johansen, O.S. ; Karl Brynildsen, fireman.

The Norwegian Lapp Savio, born I877; well known for his faithful character, hardihood, and intelligence.

The Norwegian Lapp Must, born I877; like Savio, an experienced snow-shoe runner.

The second mate was a real descendant from the old Vikings. About 6 ft. 3 in. in height, he was proportionately broad, with long muscular arms, while his walk, by c o nstantly moving on a ship's deck, had become similar to that of the penguins. $\mathrm{He}$ $\mathrm{h}$ ad seen a good deal of hard life in

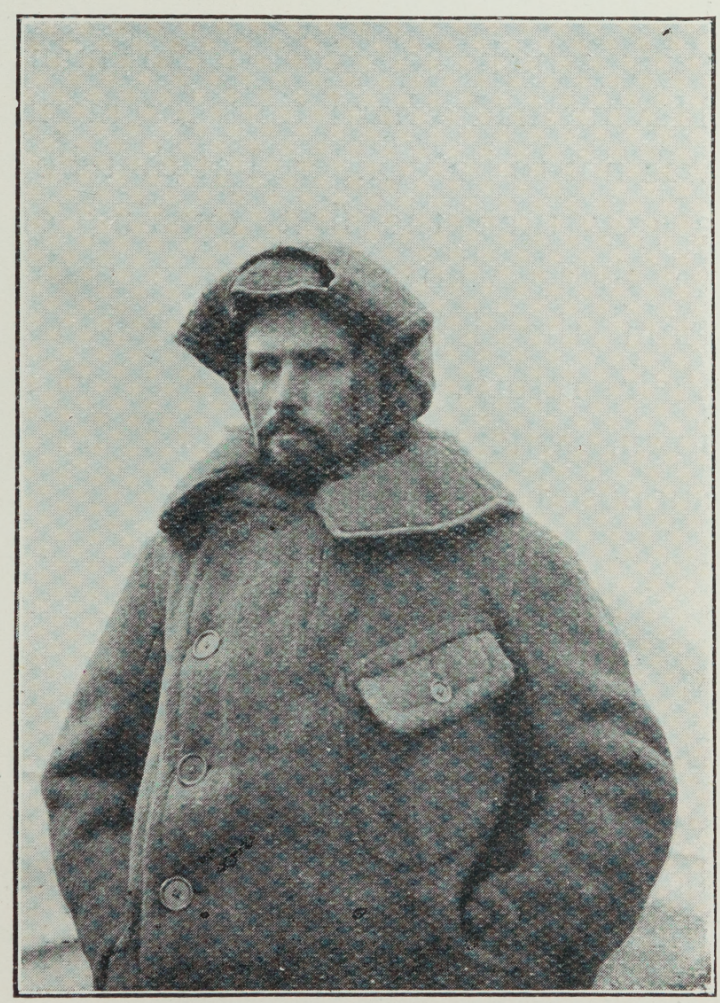

MR. NIKOLAI HANSON.

Died at Cape Adare, Thursday, October r4th, i898. the Arctic, which was marked in his weatherbeaten face. He would tell numerous and interesting tales of the Arctic regions. He was on 


\section{British Antarctic Expedition.}

the Fason when Nansen was landed on the pack at Greenland. He had taken a part in the fight against the ice in the North, as he had to fight with me against the Antarctic ice-pack; but besides this he had had fights of a warmer kind when he, in former days, returned from the North with his Viking comrades, and landed in some town on the coast of Norway, having in their pockets a small fraction of the value of that blubber which they, through risking their lives, had brought on board, and of the skins of seals which had cost them many a frozen finger. Having had a hard time for months at such work, it was not to be wondered at that he and his fellows had a gay time the first evening on shore, and woe to those who crossed the path of these Vikings from the icy regions when they, in delight at their return, went their way through the small town, where probably one feeble policeman was supposed to keep everyone in order, including these sailors, whose extravagant frivolities richly deserved all that sympathy and forbearance which they generally received.

Once, he told me, they had returned from a very successful sealing expedition, where they had worked hard in dragging the seal skins into large heaps on the ice, while the captain came along with the vessel in the open channels and picked up the great heaps dotted about on the ice-fields. They had all this fresh in mind, and so had their gallant captain, who, also in celebration of their success, had sought some well-earned comfort from Bacchus in his quarter of the town. Singing and laughing these descendants of the Vikings proceeded through the 


\section{Introductory.}

small Norwegian village, with its wooden houses on both sides of the road, when suddenly an unusually corpulent policeman appeared on the scene. Assisted by the strict citizen contingent of the village he endeavoured to subdue the happy band. Thereupon a general quarrel began, which culminated in a free

JOHANSEN.

OLSEN.

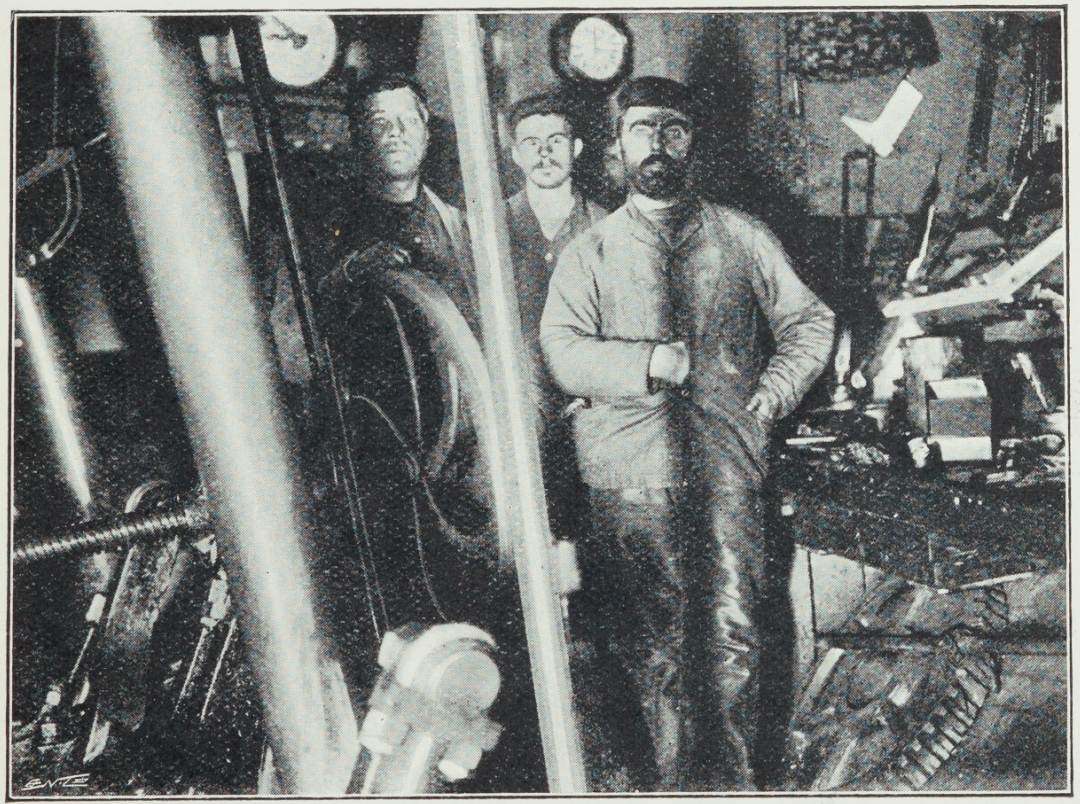

IN THE ENGINE-ROOM.

fight, until the happy young captain appeared on the scene. Seeing his sealers in full work, he called out, "That's right, lads, kill, skin, and drag-in-heap ; I'll come round with the vessel!" This just had the desired effect, both parties indulging in a peaceful laugh.

Such is the character of a typical Norwegian Arctic sealer, rough but true, and brave as a lion; he 
does not know the meaning, of the word "fear." I had twenty-one of such men who helped me to success.

The chief engineer was a man of great ability, and also of a great family, the former quality very desirable for the latter blessing. A better engineer it would be difficult to find, and with special interest and care for the welfare of the boilers, he worked away with a will, which generally left him at a temperature similar to these (his protégés), when the steam in them was at full pressure. $\mathrm{He}$ was a Norwegian, and he must needs be acknowledged to have contributed greatly to the success of the expedition.

Although I had theoretically organised the enterprise years before, and had one year to fit out my expedition, I found that there was a tremendous labour before me ere the Southern Cross, with officers, crew, provisions, instruments, sledge-dogs and travelling gear, all lay ready for the arduous task, in St. Katharine's Dock in London.

When at last all was ready H.R.H. The Duke of York presented the expedition with a Union Jack.

\section{Departure From Christiania.}

From Afterposten, July 3 oth, 1898 .

"On board the South Polar vessel Southern Cross, a solemn and appropriate function took place to-day. The British Union Jack was hoisted. At 2 P.M. Mr. Borchgrevink gave a lunch on board. All the members of the Government were invited. The British Consul-General, the Professors at the 
University, the Mayor of the town, and Mr. Borchgrevink's family, as well as representatives of the Press and a great many interested in Polar research, were on board. A steam launch brought the guests out to the Southern Cross. Lunch was served on the quarter-deck. First of all Mr. Borchgrevink welcomed the guests, after which he proposed the toast of 'Queen Victoria,' which was responded to with three cheers. The Consul-General, the Hon. S. Dundas, returned thanks for the toast, and said that, although the flag was English, the commander of the expedition was a Norwegian. The vessel was built in Norway, and was at the present time in Norwegian waters; he therefore found it appropriate, in returning the toast of 'Mr. Borchgrevink,' to ask everybody to drink to the health of ' King Oscar, the Science King.'

"After this the Union Jack, the gift of H.R.H. the Duke of York, was hoisted under salute and cheers. Then His Excellency Minister Lovenskiold spoke for Mr. Borchgrevink and his wife, and said how much the Norwegians would have liked to see the expedition go under their own flag. He felt, however, that some of the honour also belonged to Norway. It was two sea-faring nations who cooperated in this expedition-two nations who were accustomed to success at sea. Then he addressed some few words to the commander, and said that, while he wished luck and success to the enterprise, he would not forget her who was to sit and wait alone at home, and hoped that the Almighty might protect him and his wife. The speech was received with cheers. The Mayor of the town spoke for 
the Southern Cross, and prophesied that as the constellation Southern Cross was shining brightly in the South, so would the name of the vessel in time to come shine like a star in the Northern Hemisphere."

After a voyage of five days the Southern Cross entered St. Katharine's Dock, in London, where most of the provisions and outfit was taken on board, and here the English members of the expedition joined me. Before we left, Sir George Newnes gave a farewell luncheon on board, of which the Times gave the following report on August 20th, 1898:-

Sir George Newnes's Luncheon on Board the "Southern Cross."

From the Times, August 20th, 1898 .

"Within the next three days the Southern Cross will start on her voyage to Hobart Town, and yesterday a numerous company accepted the invitation of Sir G. Newnes to luncheon on board, and to give a hearty 'send off' to Mr. Borchgrevink and his companions.

"The preparations are nearly complete. The deck of the barque was crowded with sledges, kayaks, snow-shoes, ice-axes, and stores and implements of all kinds, a large space being occupied by nearly one hundred Samoyed dogs for sledging purposes.

"Among the guests were Admiral Sir E. Ommanney, Mr. W. Ridley Richardson, Mr. Borchgrevink, Mrs. Borchgrevink, Sir Guyer Hunter, Captain Tom- 
kins, Captain Brooke Greville, Mr. Fieldhouse, Mr. E. Hudson, Dr. Mill, Dr. Bowdler Sharpe, and Mr. F. Newnes.

"After the toasts of 'The Queen' and 'King' Oscar,' from whose subjects a large proportion of the crew are engaged,

"Dr. Mill proposed success to the expedition,

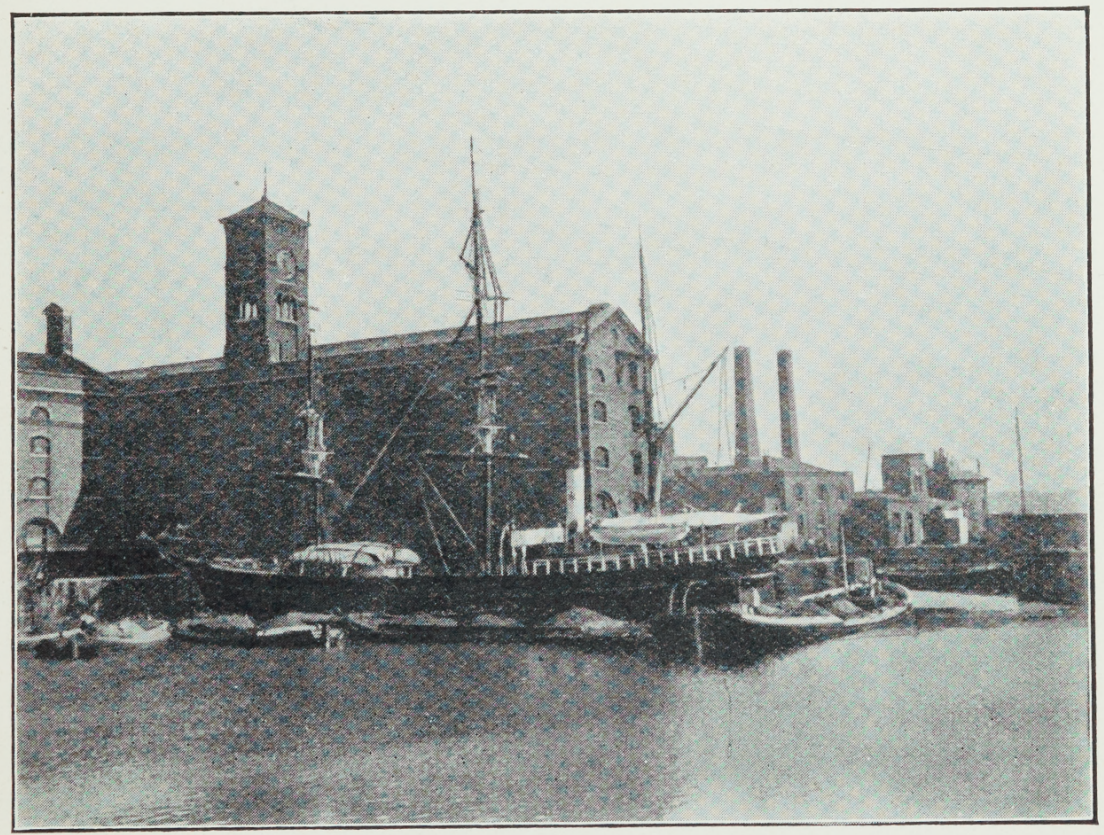

"SOUTHERN CROSS" IN ST. KATHARINE'S DOCK.

which was about to undertake a work of international importance. It was a reproach to human enterprise that there were parts of this ridiculously small earth that civilised man had never reached, and never attempted to reach, and this reproach, in so far as it referred to the Antarctic regions, the munificence of Sir George Newnes, combined with the courage of Mr. Borchgrevink, would, he hoped, remove. 
Mr. Borchgrevink had already shown that he could do good work as an explorer, and that was recognised three years ago when the International Geographical Congress passed a resolution to the effect that it would be a misfortune if the nineteenth century should close without an effort to explore the Antarctic regions. Alone and unaided Sir George Newnes had fitted out the present expedition, from which great results might be expected, possibly not results of sensational interest, but of enduring value for geographical science. In the name of British geographers he wished the expedition God speed, useful work, and a safe and quick return. (Cheers.)

"Admiral Sir E. Ommanney expressed his interest in the object and admiration of the equipment of the expedition.

"Mr. Borchgrevink said he was grateful to the man who had helped him in this endeavour to accomplish the object of his ambition. He hoped to be worthy of that confidence, and sailing under a British flag presented by the Duke of York, he would be mindful of the British naval motto :- 'England expects every man to do his duty.' (Cheers.)

"Sir George Newnes said it was difficult on the crowded deck, and amid all the dock noise, to prolong the proceedings, and the heat almost induced a wish for Antarctic regions. (Laughter.) He had not intended any public function on the starting of the expedition, remembering that putting on the armour was not the time for boasting, and he would rather have waited until the vessel returned and those on board could say they had done the world some service. 


\section{Introductory.}

He would avoid saying much. No doubt the possibilities of the expedition were enormous, and he reminded them of the paper read this year before the Royal Society by Dr. Murray on 'The scientific advantages of an Antarctic expedition.' Many eminent men declared their opinion that the thing ought to be done, and if the Royal Geographical Society undertook the task, Mr. Borchgrevink would be glad if they followed his excellent example. He took the opportunity to say that Mr. Borchgrevink and himself had received every courtesy at the hands of the Royal Geographical Society. The reasons of the expedition he would not go into. The scientific reasons were so obvious, and had been so much discussed, that all who had studied the subject would admit the possibilities were enormous, and there might be a commercial side to them. (Hear, hear). At the meeting of the Royal Society the opinion was expressed that a big whaler should be selected and fitted out with the best modern appliances, and that was exactly what had been done, with the best crew experience could select. How long the Southern Cross would be away could not, of course, be foreseen, but he hoped that tidings would reach England in six months, and that in the year I9oo he would welcome Mr. Borchgrevink on his return. It was generally known that a Belgian expedition under Captain Gerlache had gone out in another direction, and was last heard of at the Falkland Islands. It had been thought possible that the expedition was in trouble, and Sir Clements Markham had suggested that the Southern Cross should go to the Falkland Islands in search of them. 
After giving the fullest consideration to this, he thought that to go to the Falkland Islands would be a mistake. Captain Gerlache had knowledge of the route of the Southern Cross, and would try to meet Mr. Borchgrevink, who, of course, acknowledged the first duty to humanity, and would put everything else aside to assist Captain Gerlache. He hoped he expressed the feeling of all present, as he felt sure he did of thousands throughout the country, that kind thoughts would follow Mr. Borchgrevink and his gallant companions, in the hope and belief that they would triumphantly return, having done something the world would call heroic. (Cheers.)

"Dr. Bowdler Sharpe said the keenest interest and sympathy was felt at the British Museum in the expedition, and he bore testimony to the high qualifications of Mr. Nikolai Hanson, one of the zoologists on the staff.

"Sir Guyer Hunter in proposing the health of Mrs. Borchgrevink, said she might comfort herself with the assurance that all that human foresight and experience could suggest had been done to secure the success and safe return of the Southern Cross.

"The proceedings closed with the singing of the 'National Anthem.'

Farewell telegrams with good wishes were received from all parts of the world-from scientific societies as well as from private individuals interested in Antarctic research. 


\section{Departure Scenes.}

From the Westminster Gazette, August 23 rd, 1898.

"It was just half-past four o'clock yesterday afternoon when the Southern Cross glided out of the gates of St. Katharine's Dock. Once in the main stream she swept as gracefully as a swan in and out among the busy craft that filled the Thames. In appearance the ship was as gay as a ladybird-her black hull shone like a mirror; from deck to mast floated a stream of bunting, whilst from the mainmast flew the Union Jack, the gift of H.R.H. the Duke of York; the foremast bore the Norwegian flag, and the mizzen-boom that of the pilot.

"As she passed down the river she was greeted by an orchestra of whistles, some with notes as full of music as those of the nightingale, others with only the croak of a rook, but from the siren of the biggest liner down to that of the oiliest, tiniest, barge tug, all joined in 'Hip, hip, hurrah!'

"And all the time that the down-river voyage lasted the whistles kept up the inciting melody. At Greenwich the waterside was crowded; there were cheers and counter cheers, and as the Southern Cross passed the boys' training ships every yard was manned; bands played, and the bugle cry sounded its greeting from the topmast stay, and, to make the harmony quite complete, a good number of the ninety picked Siberian dogs on board took up the chorus. To tempt fair weather always to surround the ship three of the crew had fixed their chests of clothes up in the cross-trees; and for yesterday afternoon at least the charm worked, for the sun shone 
all down the route, till one of the most remarkable sunsets happened that has been seen on the Thames for many a day. The west was a sheet of crimson gold, and the river a sheet of fire. The moon rose pale and silvery, then the stars came out in a crowd;

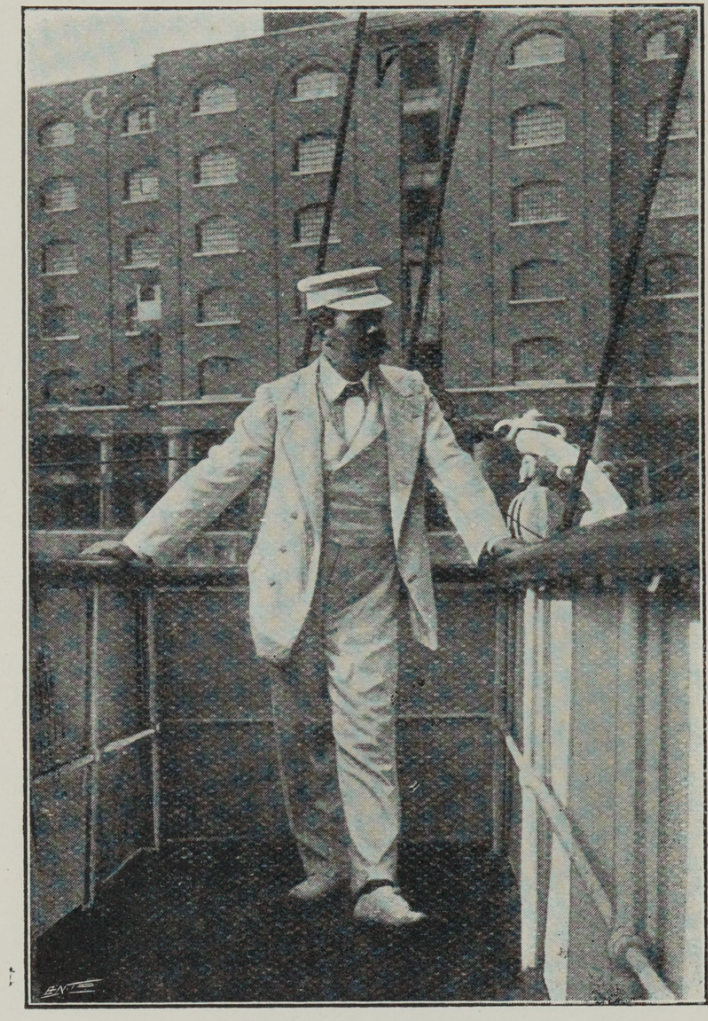

"AT LAST ALL WAS READY."

up went the lights, the bright white on the foremast and the red light on the larboard, and the green light on the starboard. The craft on the river lost form ; their lights only were visible-a great mysterious crowd of willo'- the-wis ps. Gravesend was approached at 8. I 5 , and it was decided to coal at the hulk. So the Southern

Cross took up her station, and black diamonds began to rattle aboard. Three or four boatmen now came alongside, and the few friends who had to go on shore crept down the side of the ship into the boats, and with them some four of the younger men of the expedition, for there is to be a 
last breaking of bread (at least for some time) in the Mother Country.

"The Clarence, close by the pilot's landing pier, is the rendezvous selected; and here we sit down to a supper of cold roast beef and foaming ale. There are toasts, and everybody wishes that the young men may live to grow grey beards and often to shake

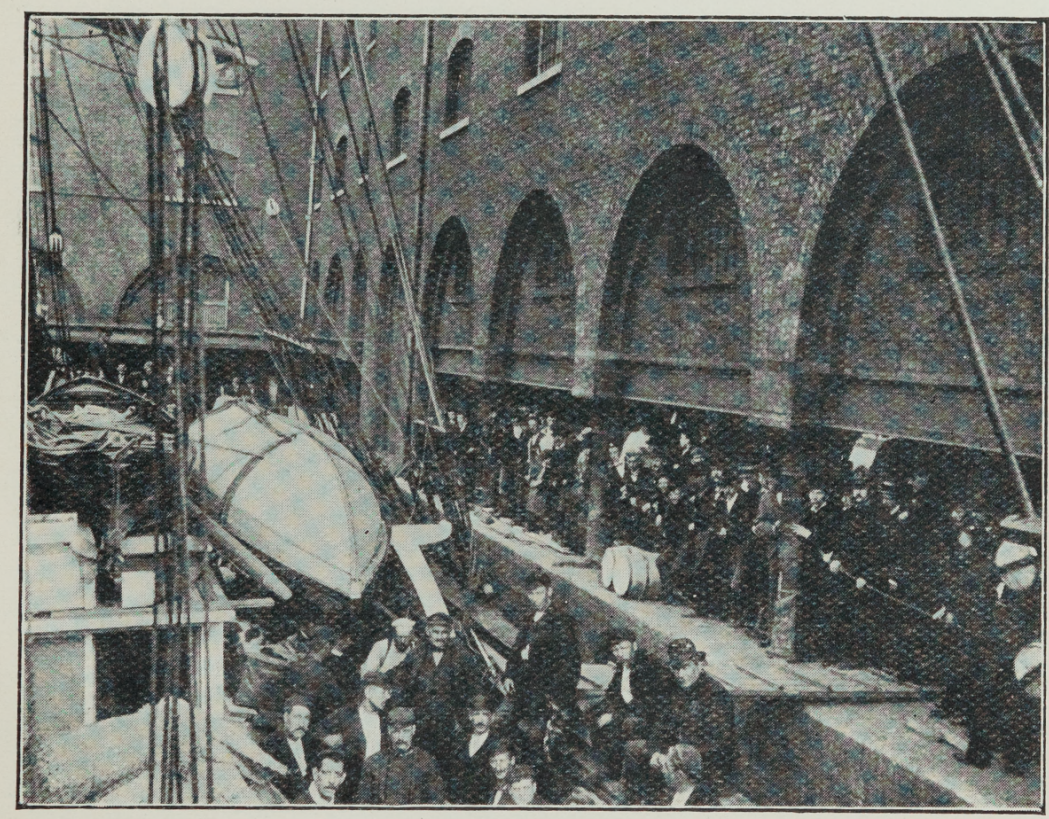

"THE LAST BOX WITH PROVISIONS HAD BEEN BROUGHT ON BOARD."

hands across the table-cloth again and again in good fellowship. The leave on shore is for one hour only. "At 9.50 we rise from the table, and leave those who have mothers and fathers and little sisters to bid au revoirs in quiet corners where even the stars do not reach. It is only three minutes to the pier. At the gateway the young explorers tread on English soil for the last time for many months to come. We 
go down to the pier with its pilots lolling there on the seats on the look-out for ships to come and ships to go. One member of the expedition hangs behindthe mother has to say good-bye to her only boy in England-and we wait and wait on the landing, and we talk of home, of our hopes, and of home-coming. Everyone is as full of spirits as a cricket.

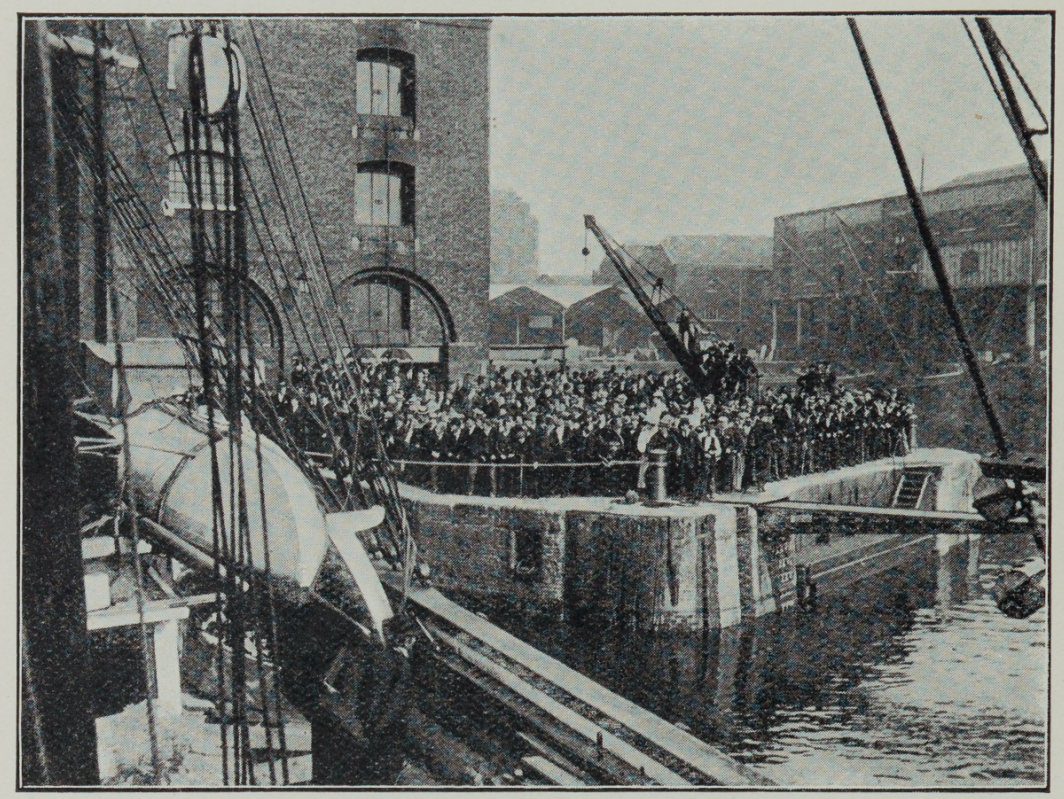

"GOD-SPEED AND A SAFE RETURN."

"The Southern Cross sounds her whistle again and again to tell the 'boys' to come aboard; at last there is a footfall on the pier. We are all present. The waterman says 'Now, gentlemen, please,' and down the steps of the landing-stage in file they go. 'Shove her off the mud-keep her away,' are the words. 'Good luck! Au revoir! Bon voyage!' we cry. There is a dip of oars, through the reflections of the green, red and white lights of the 
next landing stage she passes, and then disappears into the night. The lights of the ships reflect in the Thames like a myriad of floating stars, and away in the distance above, and more brilliant than them all, glows the white light on the foremast of the Southern Cross.

"Before the morning is here the good ship will have gone down the river, and possibly by to-morrow night will have for the time being had her last

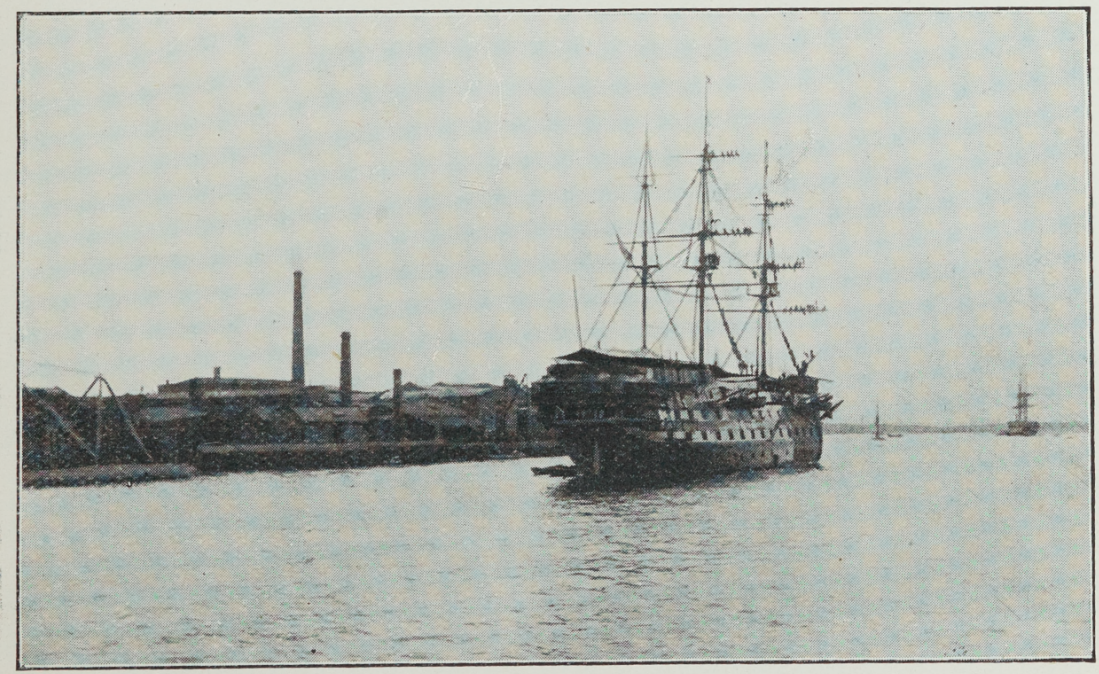

"THE YARDS WERE MANNED FOR US."

glimpse of the white cliffs of Albion. Most cordial wishes go with all on board. May they all reach that goodly age of fourscore years and ten when men would sleep in Abraham's bosom!"

When the shores of Old England had disappeared, and the Southern Cross rose and fell in the Atlantic swell, we lived it all over again ; those last moments of departure from London stood more clearly before us then than reality had a week before. 


\section{4 \\ British Antarctic Expedition.}

Again the cheers for the Queen, for the Union Jack and for Sir George Newnes, seemed to rise like a mighty wave from thousands of enthusiastic Britons; again the Southern Cross wound her way from the dock into the Thames, into that road towards victory and prosperity.

Again we saw the black mass of spectators on

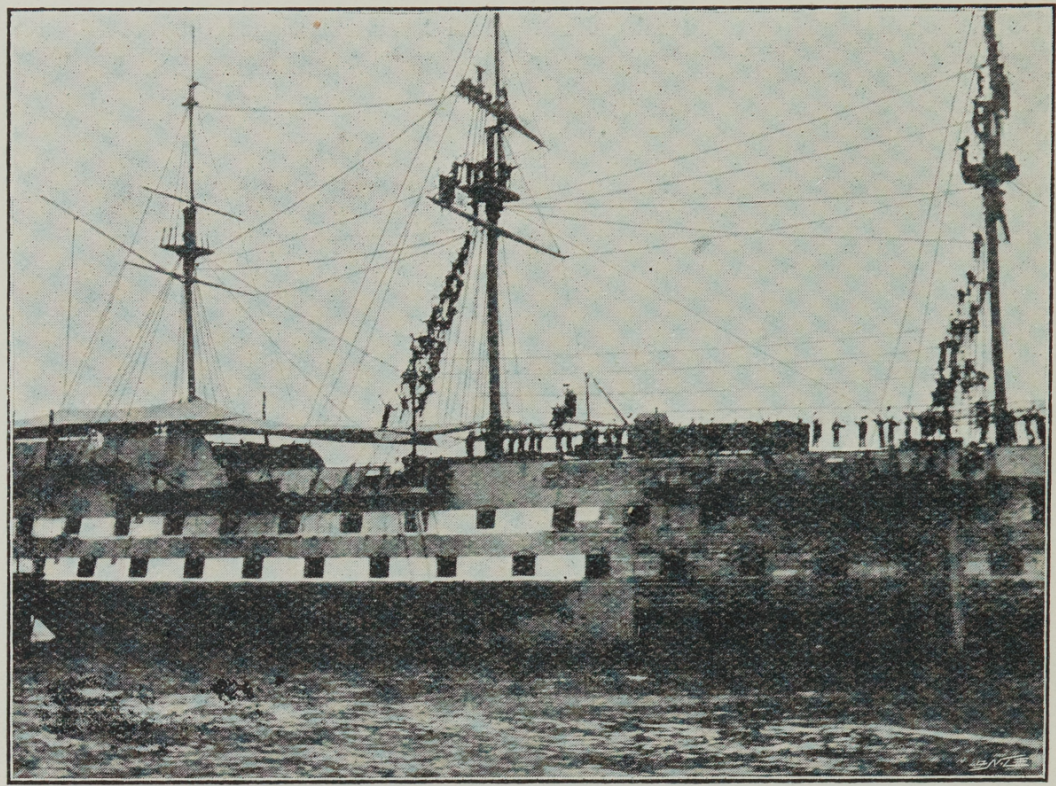

"GREETED FROM THE YARDS AS WE PASSED."

the enormous gallery on Tower Bridge, as their voices gradually grew fainter as we glided into new greetings of farewell at every turn of the river.

"God-speed! A happy return" rang again in our ears.

The bugles of the Warspite, Cornwall, and Arethusa sounded again, and yet again we saw the bluejackets as they manned the yards for us.

Then all melted away in the glorious sunset of 
August 22nd, 1898. Towers, buildings, chimneys, masts, London went with the sun; but in every new glorious sunset we saw it all once more.

During the first few days we were in the Channel most of us were busily storing away provisions in the ship's hold, while others like sad spendthrifts had to throw provisions overboard-their offerings to Neptune!

It was fortunate for us that the fine weather prevailed, for our decks were covered with boxes, ropes, casks, odds and ends, etc., and where there was nothing else there would be

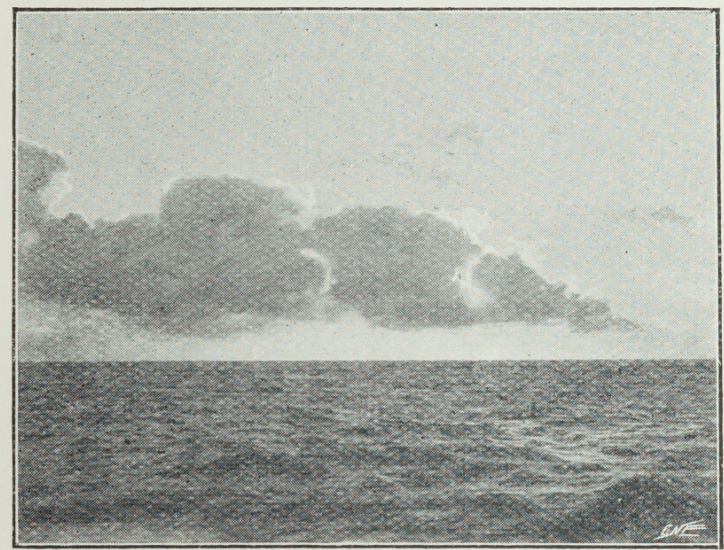

“BUT IN EVERY NEW GLORIOUS SUNSET WE SAW IT ALL ONCE MORE."

a sledge dog

from Greenland growling in his Esquimo bark at his brethren from Siberia, until all eighty, regardless of nationality, joined in one penetrating Arctic volapuk as harmonious as a concert of the Powers.

The cabins were full of instruments and books. All the staff were busy and working with a will in storing away; but, nevertheless, first one member and then another would stop his work while his thoughts flew back homewards, home! Never, maybe, was that word mentioned more tenderly than just when the "boys" of the Southern Cross saw the last of England's cliffs sink into the rolling ocean. 


\section{British Antarctic Expedition.}

As soon as the vessel had left London, my scientific staff, like the crew, had to take their part of hard work when necessary; they helped in getting up and setting the sails, painting the vessel, arranging boxes, tarring the netting on sledges, giving a hand with the dogs, and at all times making themselves useful and growing into the life and custom on board. Thus I had an opportunity to study the physique and character of everyone on board at an early stage of the Expedition. Any work, if ever so hard, was done without a murmur by my staff, and I found that the fact that all had to take their part materially helped to make things smooth and pleasant in the life on board. As soon as we left Hobart every one of my staff had to take a watch with the other officers on board, thereby doing excellent service in the look-out for icebergs, and also gradually hardening themselves for the life which lay before them. It was promising to see the members of my scientific staff at one time with hands and faces black with tar, and presently clean, and working with the most delicate instruments, or carefully working out observations just taken. It is clear that in a vessel with thirty-one men, the ordinary routine of ship discipline must be kept up, but still, on special occasions, they were permitted to mix freely all over the vessel. From time to time concerts were given, when the staff as well as the crew took part in the entertainments. Amongst the crew a very good quartette was formed, and our concerts were by no means on the level which might be expected from an ordinary ship's crew. Of course, very many of those who 
nominally acted as ordinary seamen were men of considerable mental training. There were no less than five navigators in the forecastle alone, who held their mate's certificates; and cons dering that there were also six navigating officers aft - two of whom had captain's certificates - I think it will be seen that possible accidents to one or more of the

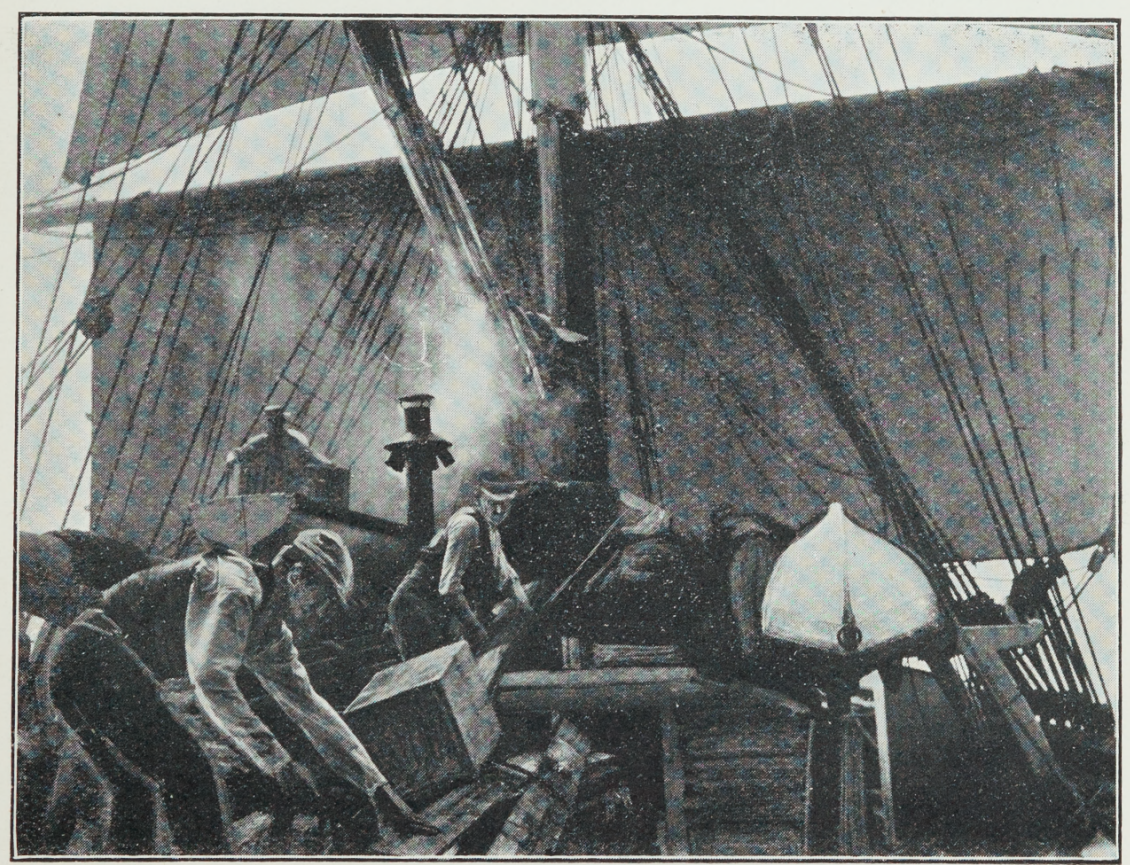

"EVERY ONE HAD TO MAKE HIMSELF USEFUL."

navigators were provided for. At the entertainments given aft in the cabin, recitations were also given, both in English and Norwegian; and the Finns, with their characteristic earnestness, sang long Lappish songs, either of a stern religious strain, or of the hottest love-songs of Finnmarken. Those evenings were pleasant, and on such occasions everyone indulged in reveries, and thoughts went 


\section{$38 \quad$ British Antarctic Expedition.}

back to the homes in the North. I gave personally some lectures, both on board and from time to time on shore.

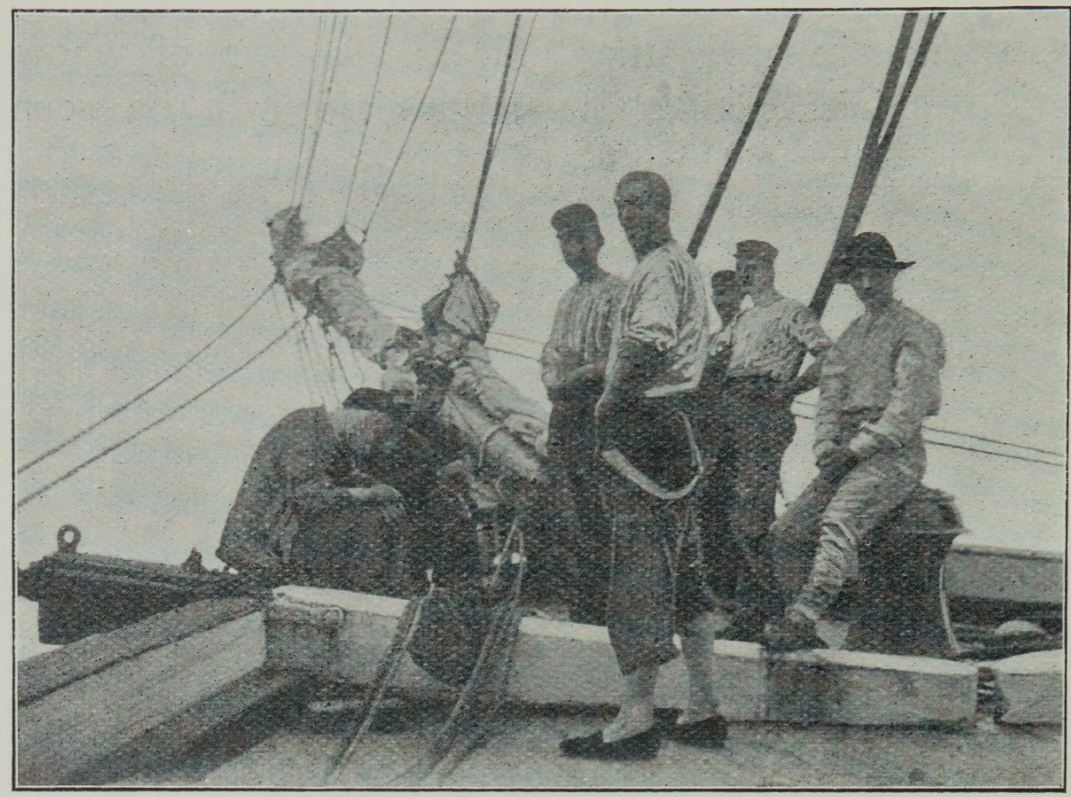

IN THE N.E. TRADES.

The day before we reached Madeira, and before we sighted land, a small African pigeon settled first in the rigging and, later on, on the bulwark, some forty feet away from the bridge where Mr. Hanson and myself were standing. We had just been practising shooting at a target under difficulties, with the vessel moving in a high swell. Both because we desired to secure the pigeon as a specimen, and because of the sport, Mr. Hanson and I quickly decided that we should have every second shot as the chances came when the pigeon settled, with a smal pea-rifle at hand. When the pigeon settled on the bulwark I had my first chance; quickly I took aim 
and fired, and I need not say that it was through considerable luck the pigeon dropped dead on the spot without a movement, which fact alone prevented it from falling overboard at once. I succeeded in getting it before the strong movement of the vessel had caused it to roll overboard, and found, after careful investigation, that the bullet had just merely touched the upper part of its skull, so slightly that some few feathers only had been disordered, while the bullet had just made impression enough on the bone of the skull to kill the bird instantaneously. I was glad that another pigeon did not arrive for me to prove that there was no luck in my first shot!

Arriving at Madeira the commander of H.I.M. man-ofwar Die Nixie called on me on board the Southern Cross - a visit which I was pleased to return the next day, as well

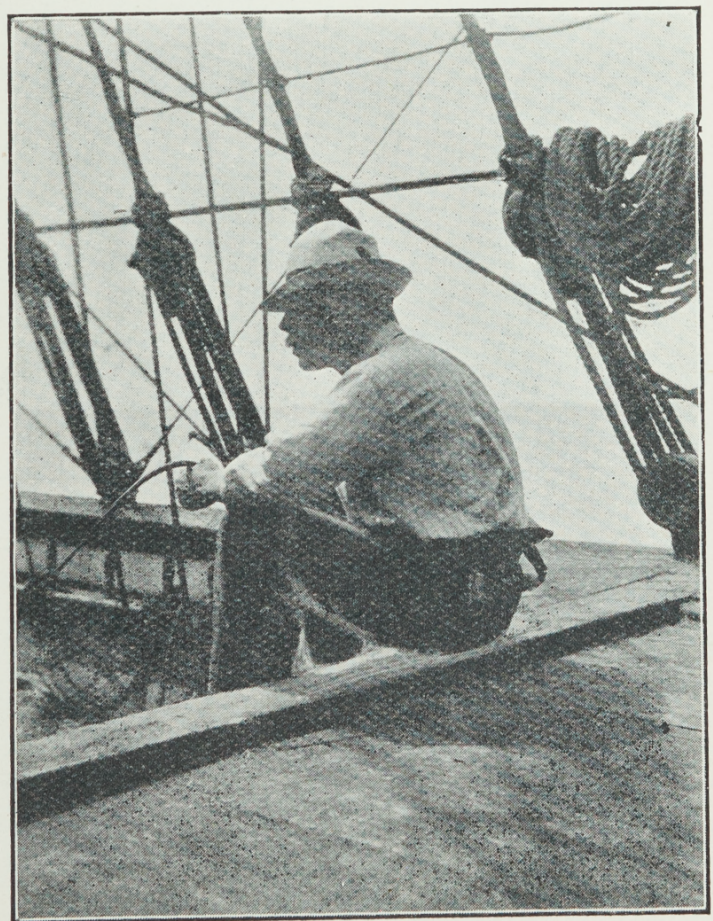

CALM WEATHER.

as paying my official visit to Her Britannic Majesty's Consul-General in Funchal.

My staff were delighted to get on shore. They 
40 British Antarctic Expedition.

rushed down the mountain side in the well-known carros, and on one occasion they went for a ride on horses of different heights, and looked very comical

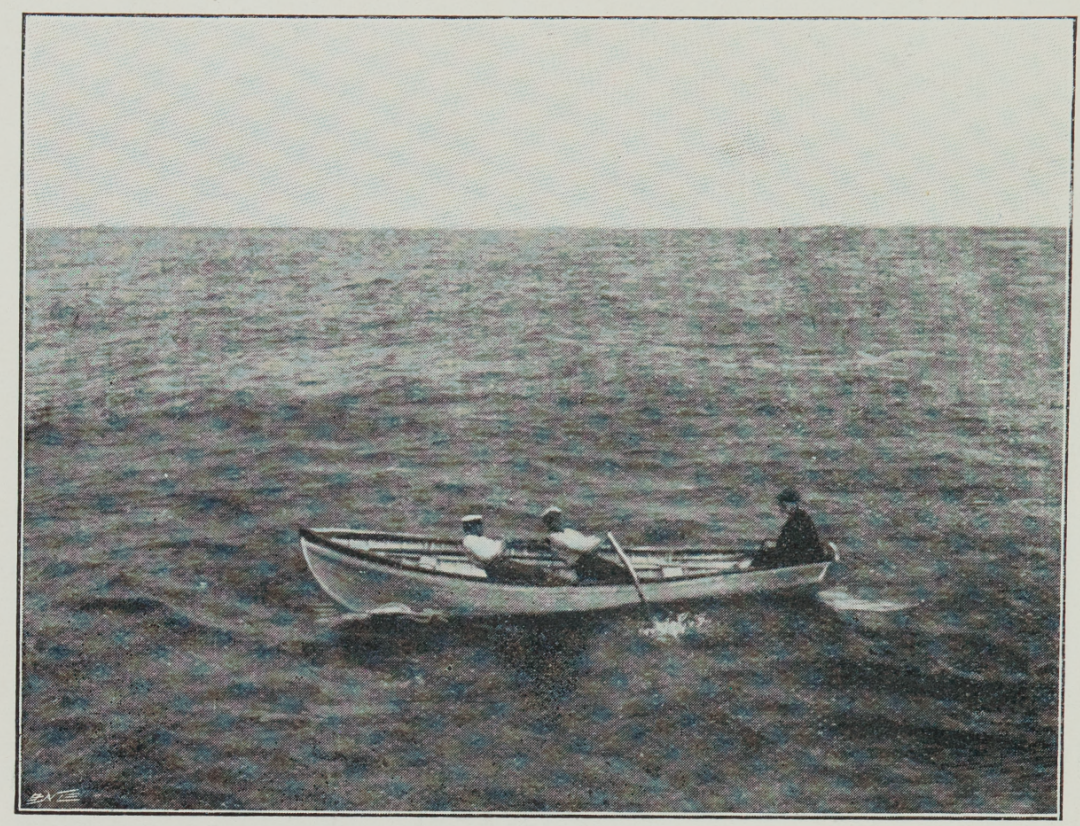

"DOG OVERBOARD！"

as they galloped off for a day's enjoyment. One of the members, who had a very small horse, had to keep his knees uncomfortably near his ears to avoid touching the ground, and I believe, had it not been for the dignity of the thing, he would have walked.

The dogs gave much trouble, but much entertainment, on the outward voyage. It is no joke to have ninety savage beasts from Siberia and Greenland on the deck of a vessel of only 276 tons, when, besides the dogs, thirty-one men have to move about. By the noise they made, whether in a quarrel or while singing sentimentally in chorus to the big moon in 
the tropics, these faithful companions of ours often tried the tempers of the members of the Expedition beyond control. However, it was remarkable to see how already early in the voyage certain dogs took to certain men, and in their leisure hours you could see some of the members selecting a quiet corner underneath the boat, on the top of a barrel, or on the anchor in the forecastle, quietly petting their favourite dog. Zembla, the finest $\operatorname{dog}$ of the pack, was only six months old when we started from London, and was a dog of extraordinary intelligence. Hardy, and with the characteristic courage of his race, he was, besides, a more than ordinarily well-

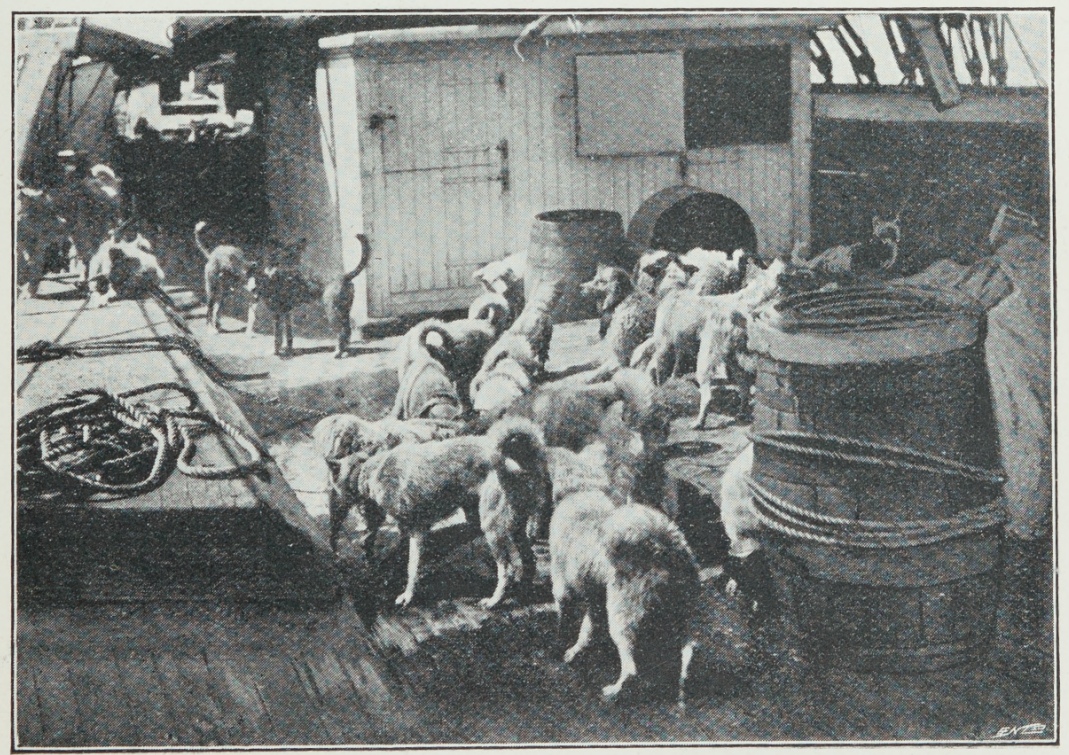

"ALL EIGHTY, REGARDLESS OF NATIONALITY, JOINED IN ONE PENETRATING ARCTIC VOLAPUK."

proportioned and beautiful dog. Of colour like a wolf, yellowish-grey with the fur black at the end, black points, and magnificent dark brown eyes, he 
soon became the favourite of everyone on board, and was one of those few dogs which were allowed on the quarter-deck. This he very soon realised, and whenever one of the other dogs, not privileged, happened to intrude on the quarter-deck, he was beside himself with indignation. In spite of the notice which throughout was taken of this dog, he was never spoilt, and turned out one of our best sledge dogs. To me he became devoted, and innumerable are those stories which I could tell of his unselfish way of showing his faithfulness. All ninety were named, and it was remarkable to notice how they came to know their own names.

Subjoined is a list of some of the names of the dogs, together with the weights of a few :-

lbs.

lbs.

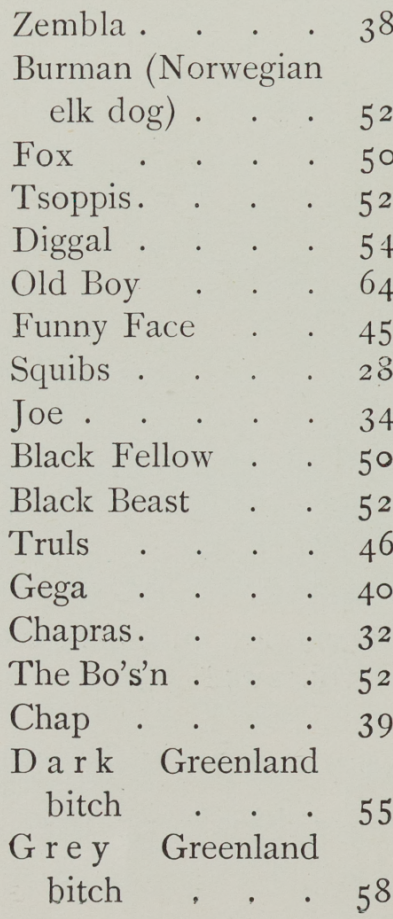

Ollo. . . . 47

The Snake . . 33

The Wolf . . 50

The Howler . . 48

The Cook . . 42

Hunter . . . $4 \mathrm{I}$

Jack • . . $4^{\mathrm{I}}$

Nick . . 47

Murderer . . 34

Dilco . . . 40

Bear . . . $4^{\mathrm{I}}$

Esquimo . . 39

Lars . . . -

Sakko

Peter

Florrie

Berita

Hulloa

Pickles

Samson .

Leif 
lbs.

lbs,

The Watchman . -

Nigger • • .

Hardy . . . . - Leo . . . . -

Erebus . . . -

Finn

Nansock

Most of these names seemed to settle upon the dogs without any special christening ceremony, and, as a rule, the Finns, who looked after the dogs, hit

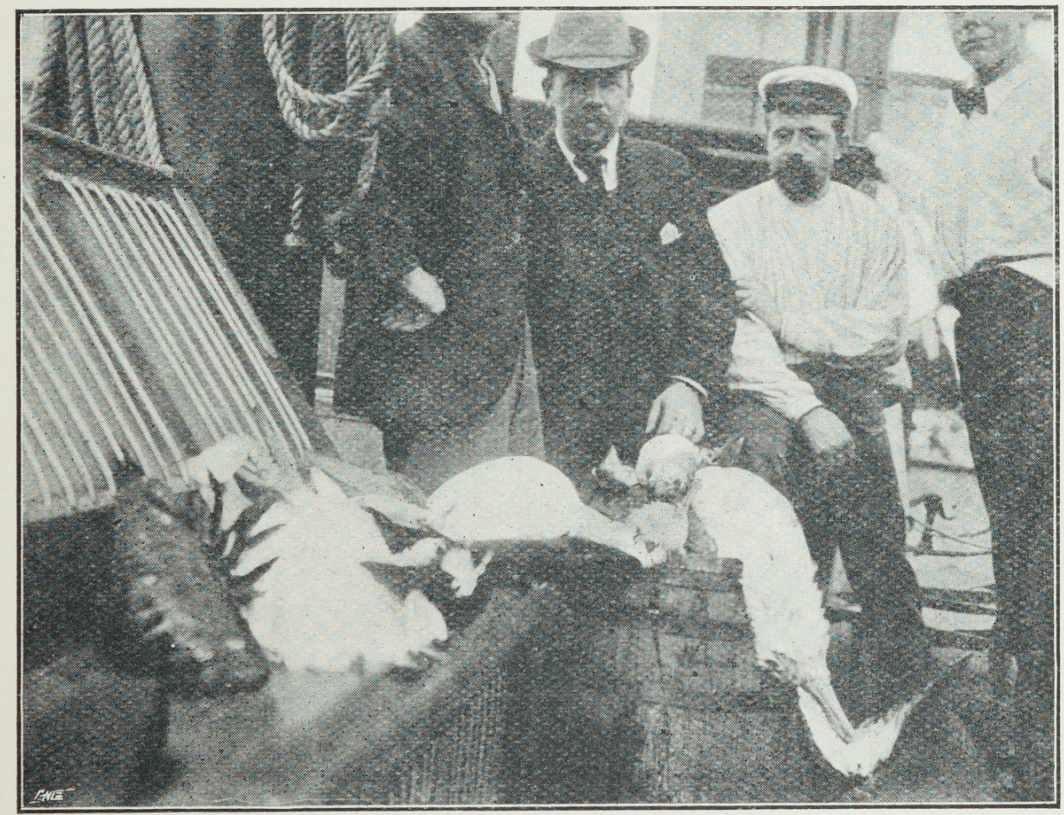

"BIRDS FOLLOWED IN OUR TRACK."

upon names familiar to them at home. On the outward voyage in the heat we had considerable trouble in keeping most of them alive. They suffered greatly through the heat, and several of them died; and the smell and discomfort which those ninety dogs caused on board will not easily be realised by any one but those who followed the expedition. We had to stretch awnings over them in the daytime, 
and keep the awnings continually wet to make it somewhat cooler for them. In heavy weather they were constantly wet, and the salt water caused them

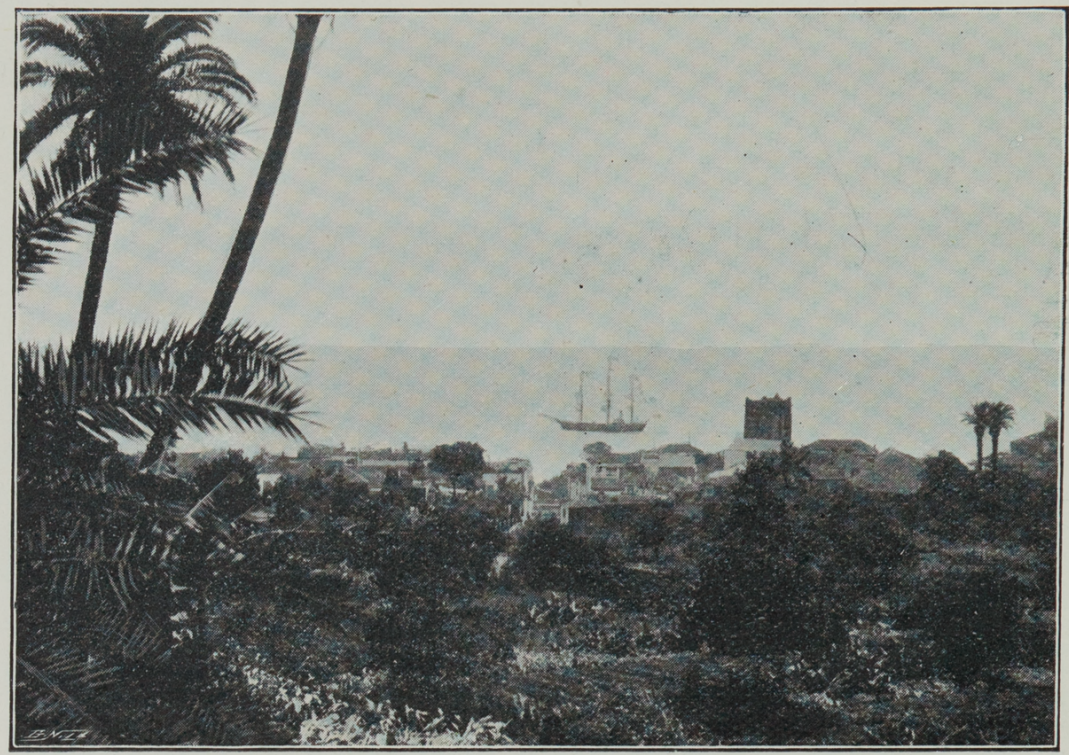

SANTA CRUZ.

a skin disease, so the doctor had his hands full on the outward journey to get them over the line alive.

The cook, like the rest, had his favourite dog. I do not know whether the cook selected the dog, or the dog the cook; anyhow the dog showed considerable judgment in his preference of a master. He seemed to know on which side his bread was buttered, and the cook buttered it for him. They grew very devoted to each other, to the great amusement of the sailors, who delighted in playing practical jokes on the two : hiding the $\mathrm{dog}$ in the most unexpected places, and telling the cook that the dog had fallen 
overboard, while they delighted in the cook's illconcealed grief.

At Madeira a grey parrot joined us which was supposed, alas, to talk Portuguese ; so in the beginning we did not know whether he was speaking that language, or the natural language from his happy home in the jungle in Africa. However, the talented bird very quickly picked up some of the roughest jokes which he could find in the forecastle.

The meals were, of course, great events. Then all the members came together, and as a rule the time went pleasantly. In spite of having a Norwegian

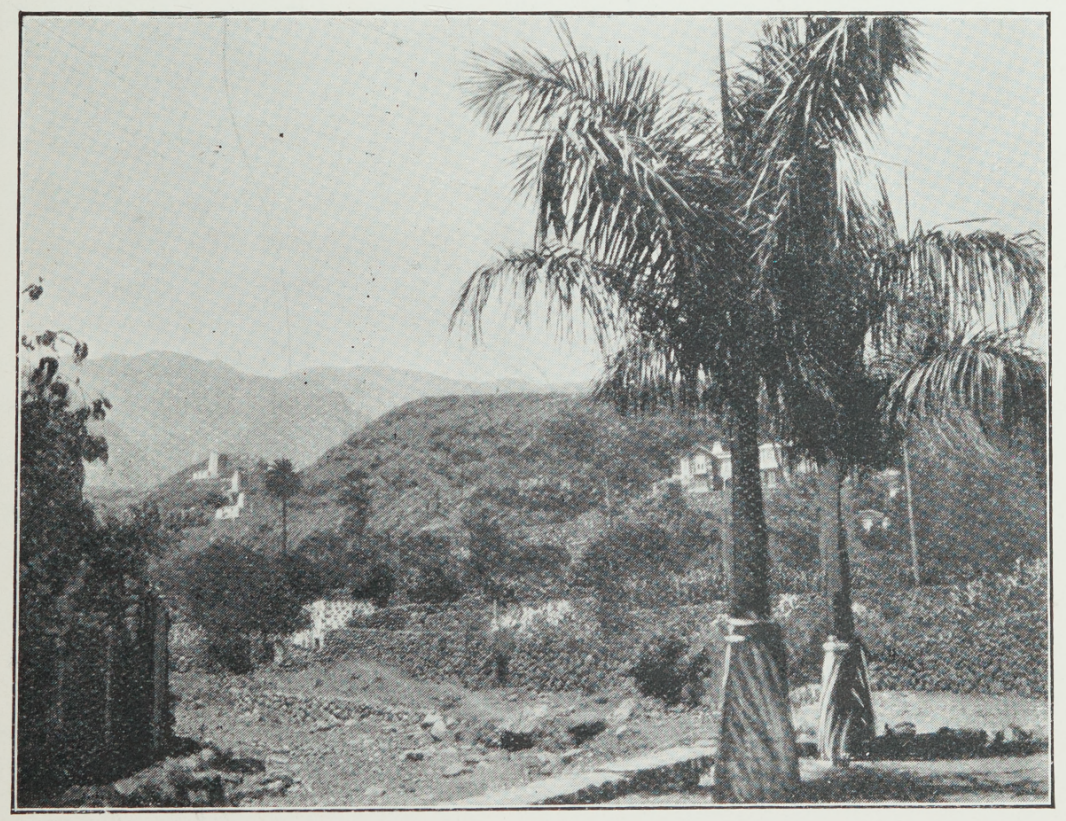

ON PALMY SHORES.

cook, the English members kept well. His cooking was good with the exception of his puddings, which were both food and ballast all in one. One of the 
46 British Antarctic Expedition.

members spitefully remarked when the pudding appeared once on the day of a heavy gale, and when the vessel was heeling over heavily, "Cook, place the pudding to

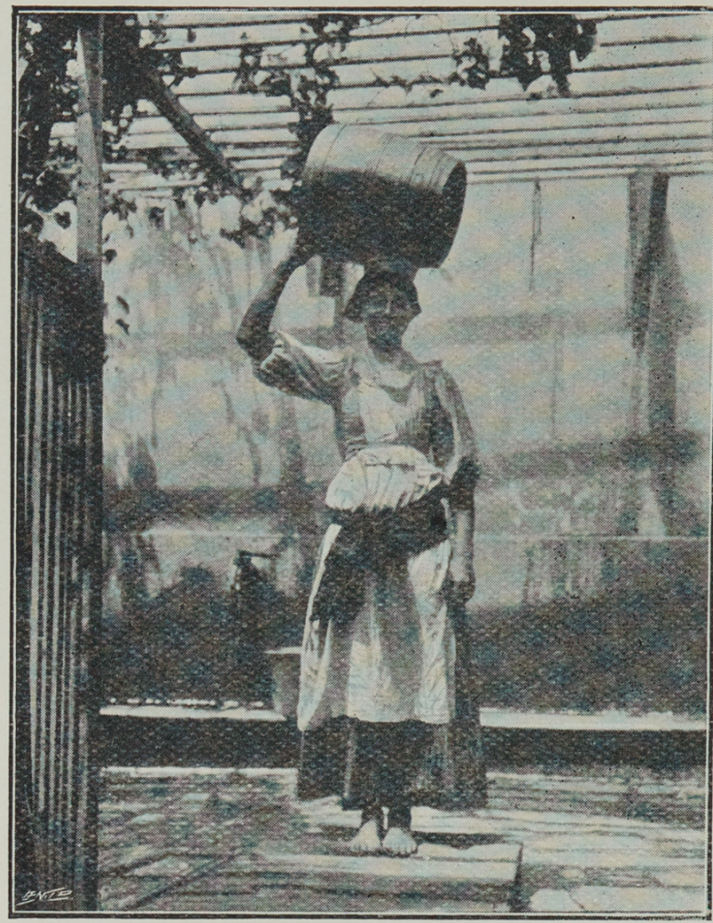

REBECCA AT THE WELL AT ST. VINCENT. w i n d w a r d !" The cook obediently followed the advice, but a week later he had discovered the point and was offended.

We called at Santa Cruz and St. Vincent, at which latter place we took in coal. My staff went on shore and several photos were taken. Just before the Southern Cross departed several of the British residents paid a visit on board and looked at our sledges, dogs and outfit with great interest, and wished us a hearty farewell.

Like ordinary vessels crossing the Equator, the Southern Cross was visited by Neptune. Tall, and with a long grey beard, he came up over the bows, dripping wet and with a spear in his hand. A crown he had on his head, and he was followed by his courtiers and the necessary officials for the christening of those who had not before crossed the 


\section{Introductory.}

Equator. A mermaid, who was introduced as his wife, also put in an appearance: it was Mr. Evans, who, in light draperies, charmed everybody as Mrs. Neptune, and leant tenderly on her husband, who,

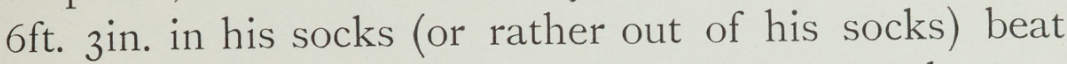
his better half by an inch. After them came the men with the shaving pot, the barber with his razor, which measured three feet, and the necessary attendants for holding those who were to be christened by Neptune during the soaping in with lamp-soot and oil. One man in a fantastic costume

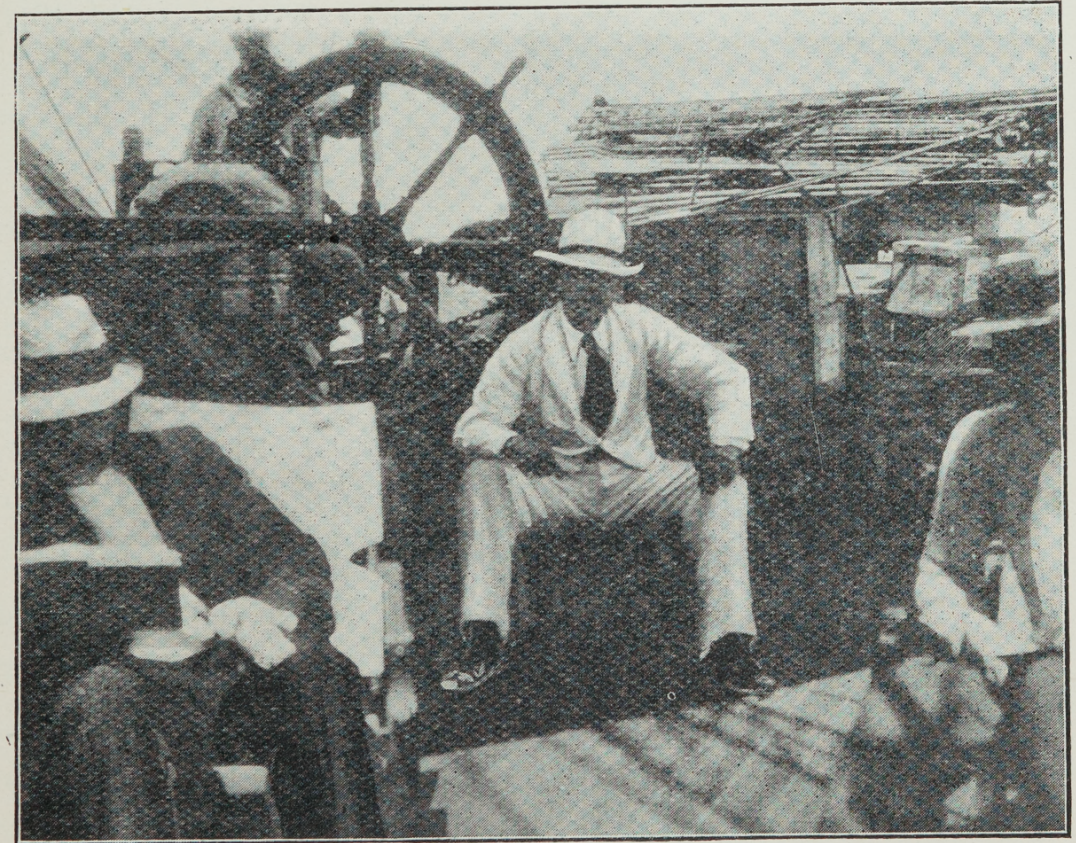

IN SUMMER SEAS.

resembling a porpoise, worked a hand-organ with great energy. On the quarter-deck a big tank filled with water had been placed in such a way that it 
could only be seen by those who had crossed the "line" before. A movable seat was placed on the edge of this tank, where the Doctor, the first to be honoured

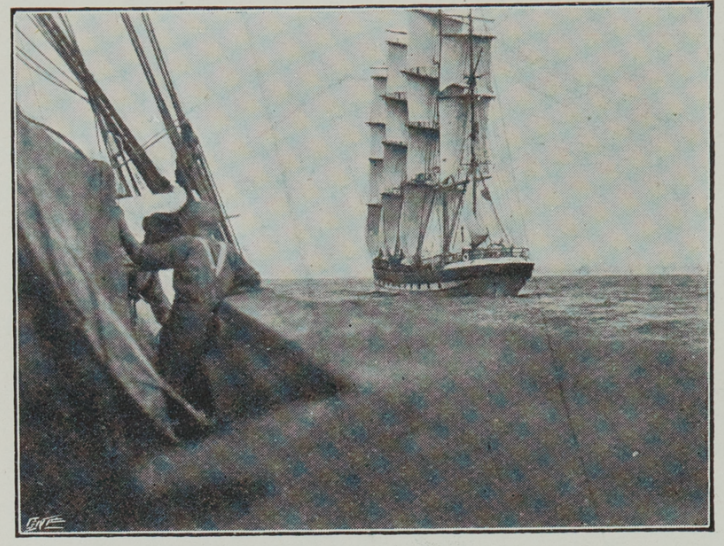

"WE PASSED CLOSE TO THE "COUNTY OF KINROSS,' AND SPOKE HER." by Neptune, was placed.

$\mathrm{N}$ e p t un e then produced a large and important-looking document which he, by the light of a torch, read with a deep and i m pressive voice. It ran as follows :

"Unworthy land-lubbers who want to go too far, do you not know that the line must be drawn somewhere? and I have drawn it here! Without my permission you may not cross it, but as I know you are going to the furthermost part of my dominion, in fact to the Antarctic Regions, from where I have not for more than half a century had any news, I will let you pass when you have submitted to the necessary formalities. I hope that at some future time you may be here again, when you, with a cargo of knowledge, again turn homewards towards the North. Then I expect to come on board, pump the vessel, and take with me some of your treasures."

This over, the Doctor's face was quickly smothered with lamp-soot and oil with a large brush. The "barber" caught him by the nose, and the large wooden razor was drawn down his cheeks, 
then, caught by the legs by the proper official, he went head first backwards into the tank. When he after some trouble was fished out, the next one, who in the meantime had not seen these proceedings, was placed on a seat and put through, and so on until all had passed muster before Neptune. As it was beautifully clear we spent a gay and memorable evening. Songs were sung, toasts drunk, and both Neptune and his wife departed as happy as those who had been for the first time soaped, shaved, and washed at the Equator.

Fair weather prevailed nearly throughout this voyage to Hobart, where we arrived ninety-eight days after our departure from London.

We dropped anchor at Adventure Bay shortly after dark, cleared up the vessel, fixed our steam launch, and all made ourselves ready to appear at our best

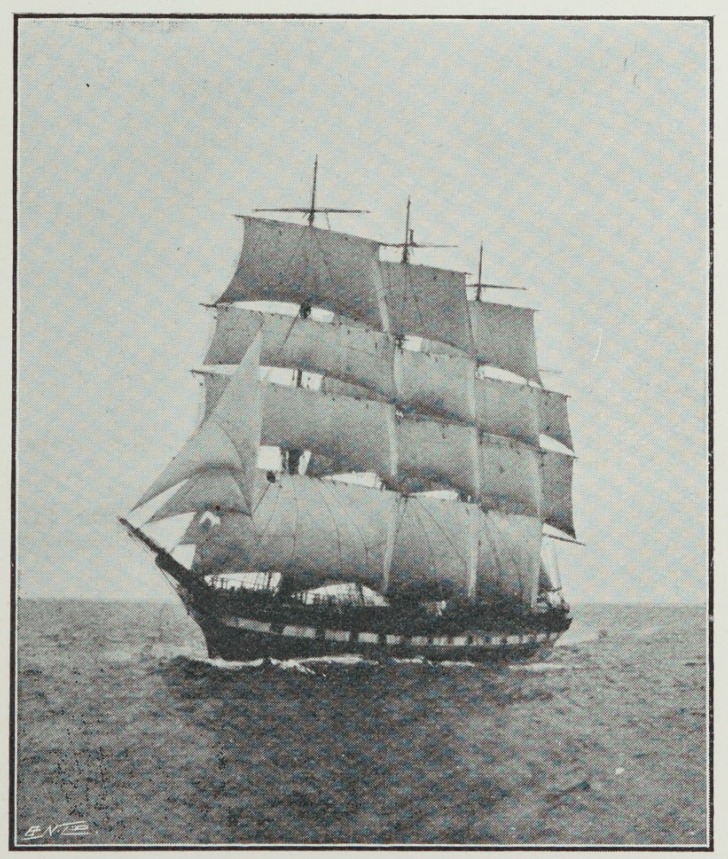

" COUNTY OF KINROSS." when going up to Hobart. Half way up the Hobart Fjord we were met by small steamers and boats with a display of bunting. A swift little 
white Government launch with the Harbour Master and Mr. Alexander Morton, F.R.S.Tas., Curator of the Hobart Museum, on board, was the first to come alongside. The reception we received in Hobart was kindness itself. Everyone, from the Governor, Lord Gormanston, and the Government officials downwards, all tried to make our stay as interesting and enjoyable

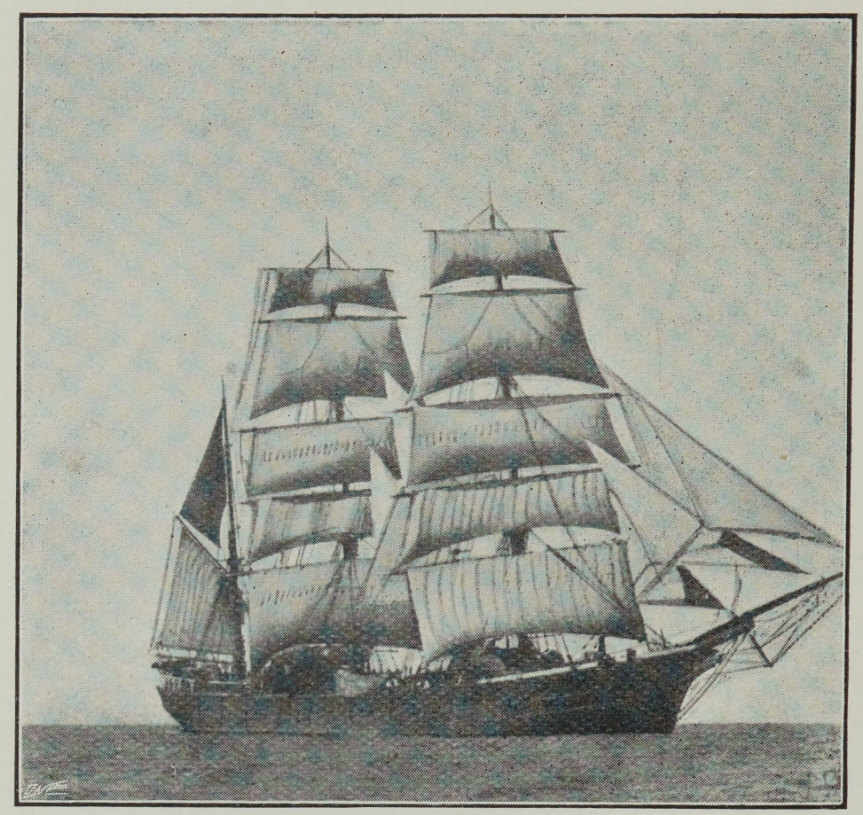

ALWAYS SOUTHWARDS.

as possible. His Excellency presided at a conversazione which was arranged in honor of our arrival, and welcomed us officially in the warmest of terms.

During our stay in Hobart, the Finns Per Savio and Ole Must, in their original and comical kilts and remarkable Finn boots with the straw sticking out at the tops, had rather a good time. They were rather handsome fellows, and great favourites with the fair 


\section{Introductory.}

sex; in fact, during the time they were staying in London before our departure for the South, I lived in constant anxiety for the welfare of these children of nature. I expected any day to see them involved in some breach of promise case, or other complication. In Hobart, however, things seemed to run smoothly, and the Finns enjoyed themselves thoroughly.

The day before we left I placed a large wreath at the foot of the statue of Sir John Franklin in Franklin Square. The wreath was composed of laurels, ivy leaves and white lily blooms; with the wreath was placed a card bearing the following inscription- "A tribute to the memory of Sir John Franklin, Kt., R.N., K.C.H., Lieut.-Governor of Tasmania, I837-43, from the Commander and members of the British Antarctic Expedition, 1898.

"Not here: the white North has thy bones; and thou, Heroic sailor soul, Art passing on thine happier voyage now Toward no earthly pole." 


\section{CHAPTER II.}

From Hobart to South Victoria Land.

After a fortnight's stay in Hobart we left for Adventure Bay, cheered by thousands of people on the main pier of Hobart. Our live stock on board was now augmented by some sheep, a pig, and a big bullock, the latter being a present from Mr. Gray, living at Adventure Bay.

As we left Adventure Bay on the igth December, I 898 , we saw a shoal of porpoises; there must have been over one hundred of them; it was the biggest shoal of them I ever saw. Then we let loose the two first carrier pigeons (of which we had taken a supply on board), with Christmas greetings for Hobart. At eight o'clock in the evening the coast of Tasmania was just sinking in the mist at the horizon, and we steamed towards the south, towards our work, and towards our fate. Bright, calm weather prevailed during the first days southward. Not before the 24th December were we able to proceed by sails only. The days went pleasantly, each member busy in his own department laying his plans for his modus operandi. The Zoologist, Mr. Hanson, whenever opportunity occurred, secured specimens of the fauna.

Some few birds followed our track. There were two kinds, the short-tailed albatross and the mutton- 
From Hobart to South Victoria Land. 53

bird. On the 2oth the short-tailed albatross was no more to be seen; but the Diomeda Exulans and the mutton-birds were plentiful. Besides these were the little white-bellied petrel and the Prion Vittatus.

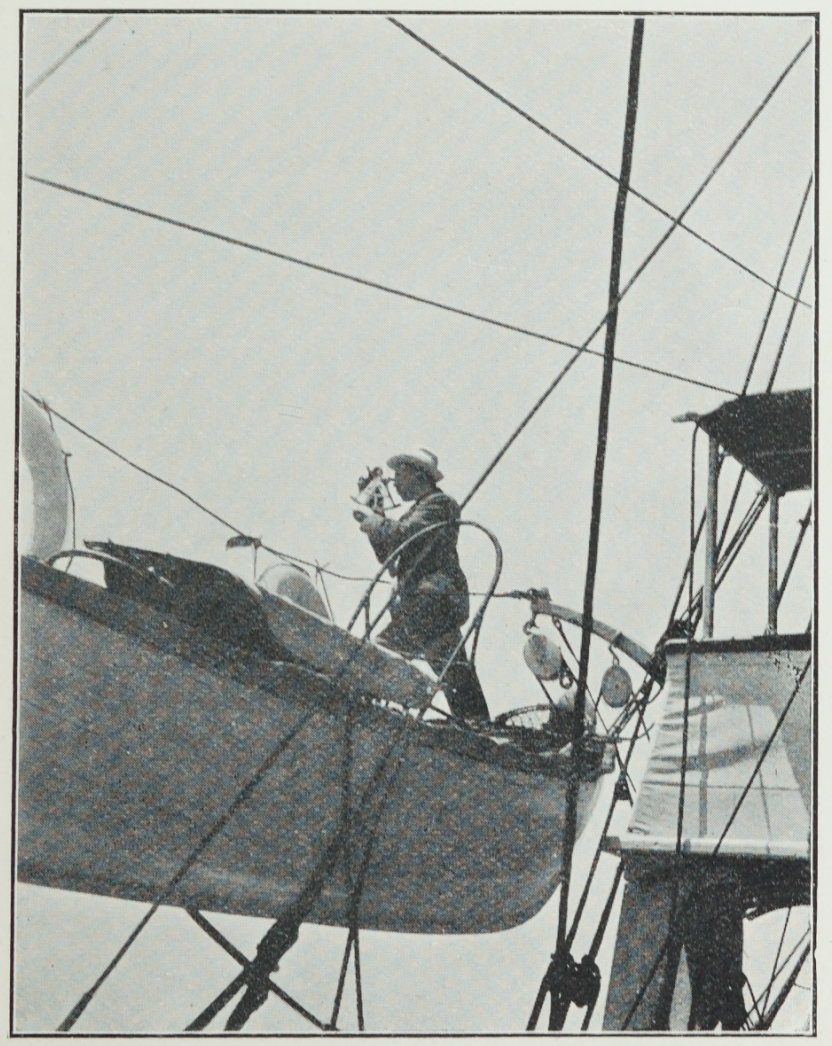

TAKING A SIGHT.

On the 2ist we saw, besides the birds above mentioned, some Diomeda Melanophrys. On the 22nd there were no birds at all to see. On the 23 rd some Diomeda Exulans and also some Prion Vittatus were seen. On the 24 th no petrels were seen. We now saw some Diomeda Fuliginosa and Melanophrys, 
54 British Antarctic Expedition.

as also a lestris. On the 26 th we saw some Diomeda Chlororhyncha, and a few penguins. Mr. Evans reported that he had seen some whales early in his morning watch. On the 28 th, besides the ordinary birds, a giant bird and a small white-bellied petrel followed us; a mutton-bird also appeared again ; there were also a few sooty albatrosses. The birds followed us now all the night. On the 29th some

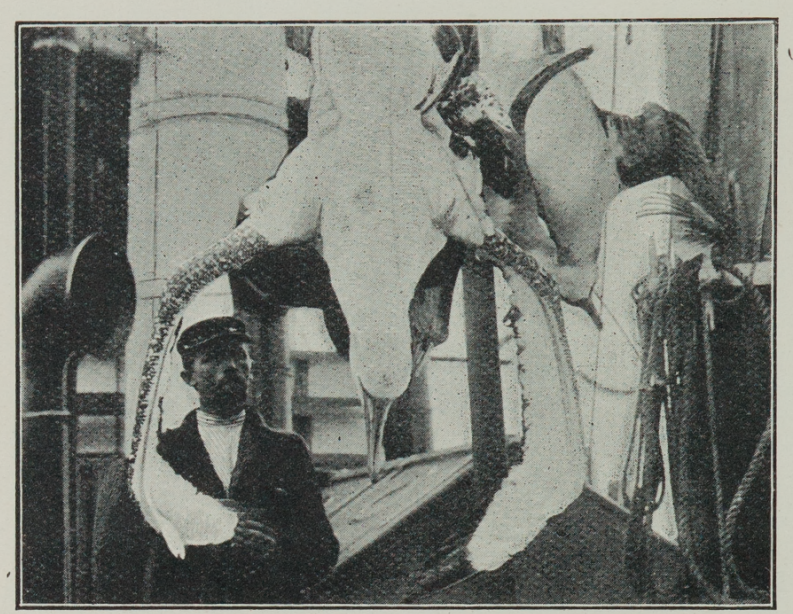

HANSON WITH THE LARGE ALBATROSS

(Diomeda exulans). few muttonbirds were seen, some Diomeda $M e$ lanophrys, as also Prion Vittatus. The latter were in far greater quantities than I had ever seen them before. On the 3 oth we saw eight different kinds of birds, but of seven of these we only saw one specimen of each; they were: Diomeda Fuliginosa, Diomeda Melanophrys, Daption Capensis, Astrelata Lessoni, Prion Vittatus, Cymodroma Grallaria, and Oceanites Oceanicus.

The Daption Capensis was in the midst of moulting and was flying with some difficulty. The specimen of the Oceanites Oceanicus was flying round the vessel several times, and sometimes straight into the rigging. We passed some drift-ice, and in the 
From Hobart to South Victoria Land. 55

evening we entered the pack. Here two new birds appeared, one quite grey, and the other white underneath, greyish brown above, and a white border on the extremities of the wings. Both were about the size of the Daption Capensis.

On the 3oth December, I898, when the Southern Cross first struck the scouts of Antarctic ice-pack, in lat. $6 \mathrm{I}^{\circ} 56^{\prime} \mathrm{S}$., and long. $\mathrm{I} 53^{\circ} 53^{\prime} \mathrm{E}$., it was somewhat sooner than I expected. There was, of course, reason to believe that we should encounter ice early on the sout hward voyage by going so far west, and particularlyat the point chosen,

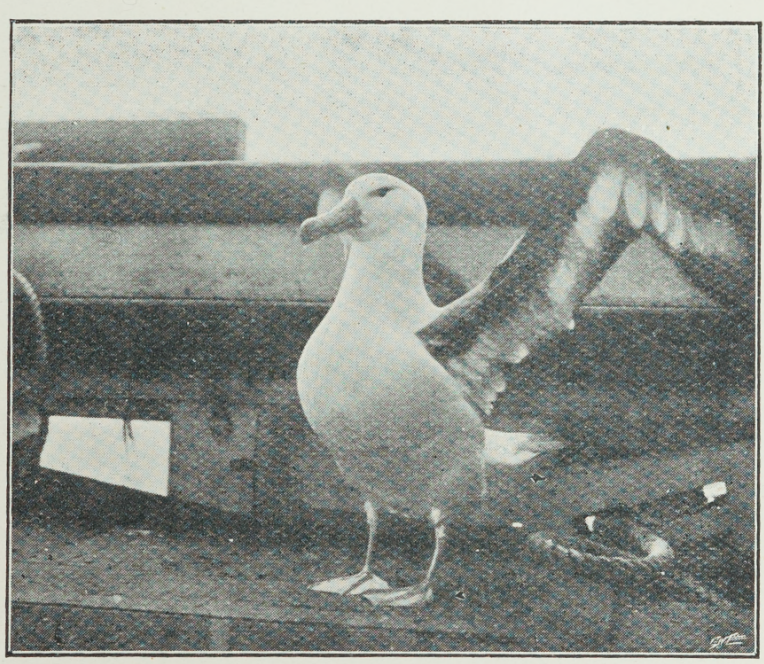

AN OCEAN VISITOR.

where my experiences from I $894-5$ justified such anticipation ; but still the appearance of the first pack took me by surprise at the latitude where we met it, and in the beginning $I$ took it as a promising sign of early Antarctic spring. Interested as I naturally have been in the controversy between my predecessor, Sir James Clark Ross, and Captain Wilkes, in regard to the land reported by the latter, and anxious to be enabled to judge for myself the cause of Captain Wilkes' mistake, I purposely took that course, although 
56 British Antarctic Expedition.

I knew there would probably be much and heavy ice about Balleny which might cause a delay in the progress of the Southern Cross. To me it seems clear that it was Balleny which Captain Wilkes saw, and while underrating his distance from this group, he judged it to be a new land discovered.

After we had entered the ice I let some four

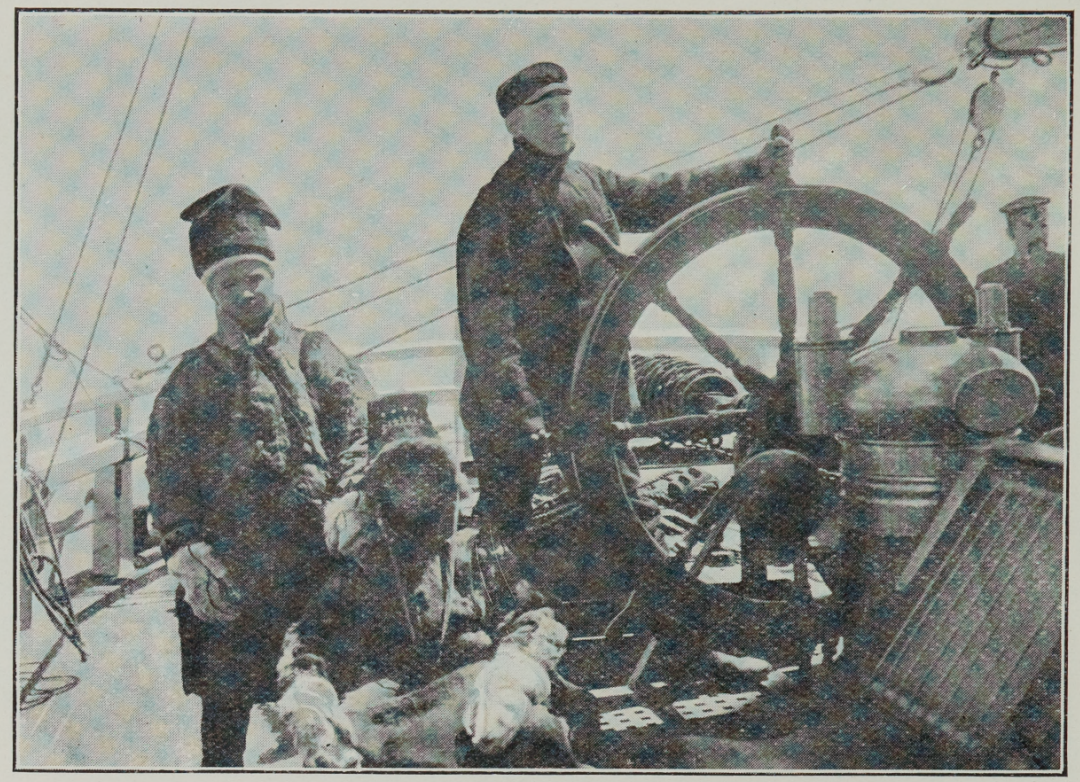

"IT GREW COLDER."

pigeons fly, with messages and a number on a ring, placed on their legs. Two of these came back after three days' absence; the fourth, the strongest of the lot I let go, remained away for a week, then it came back in a very low condition, and I had to kill it.

It was an anxious but interesting moment in the crow's nest as I watched the vessel as she rose on the swelling ocean and dashed in among the grinding ice-blocks. Trembling and shaking she trod her way 
From Hobart to South Victoria Land. 57

onwards, while the swell grew rapidly less as we successfully fought our way forwards into the inner ice-pack. Captain Jensen and myself took entire charge of this ice navigation. Great was the enth u s i a s m amongst those on board who saw Antarctic pack for the first time.

To crawl u $\mathrm{p}$ in the crow's nest at the top of the

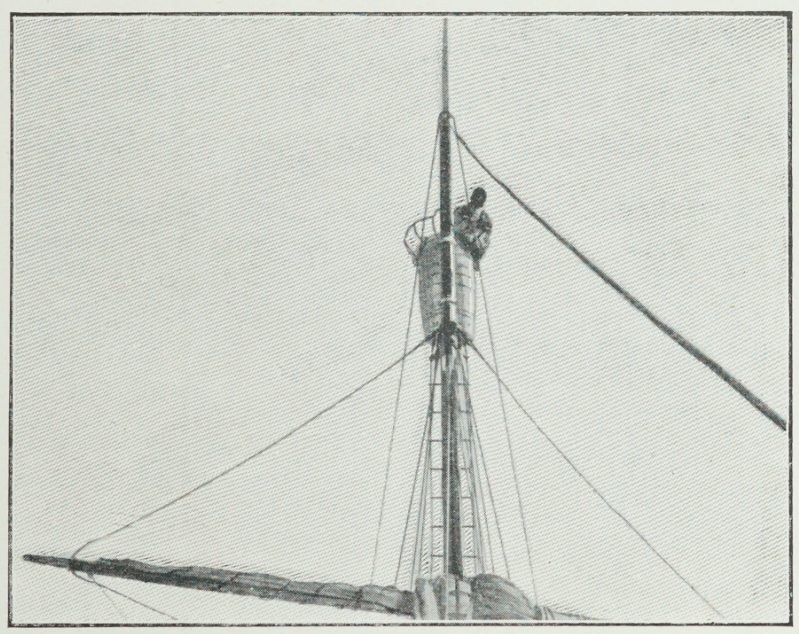

ANXIOUS HOURS IN THE CROW'S NEST. main-mast when you are dressed in Arctic fur and mittens on your hands is not so easily done as writing the description down. Whether the vessel at the time moves in a heavy swell, or is shaking under the pressure of the ice-screw, considerable caution must be used. All ropes and stays are covered with ice, your mittens stick to the ropes, and if care is not used you might lose your hold while the mittens are left sticking to the ropes. When you then try to avoid the danger by climbing without the mittens on, your hands get stiff and hard in a minute, and the chance of your dropping to the deck is greater than ever. The last approach to the crow's nest is by a ladder running from the head of the undermast outwards, and you literally hang on to the rungs of the ladder, suspended, as it were, in mid- 
air. You arrive at the bottom of the cask, which moves on hinges, which you have to lift up. This bottom acts both as a floor and as a trap-door. You lift it up with your head, catch hold of a frozen icy rope with a knot in the end made fast to the upper end of the crow's nest; by dint of pulling and shoving you squeeze yourself and your fur through the narrow passage, shut the door under you, which then forms the floor, and like a minor god you look down upon the miserable little world below. However, it is from the crow's nest that you get a proper view of Antarctic scenery. You see the ice as it closes and opens far out towards the horizon, where the sky and ice seem to meet, while here and there icebergs are floating about in halos of the most dazzling pink and crimson. You have the delightful feeling of all depending upon your correct

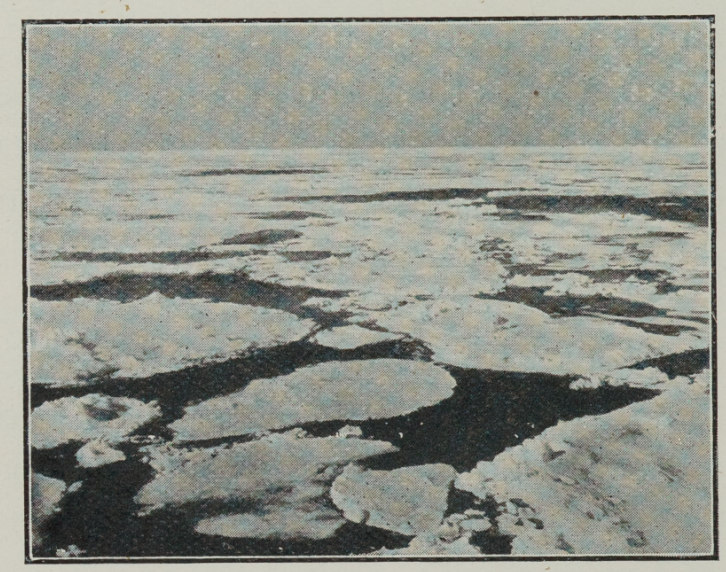

SLACK ICE IN THE PACK. judgment for the safety of the vessel, and for progress among the grinding icebergs. At places the channels between the icefloes are blocked by broad or narrow isthmuses of ice, and the vessel is not able to work her way; then you back her with the engines into the open space behind where you have already cleared your road, then by telegraph from the 
From Hobart to South Victoria Land. 59

cask to the engine-room in the depths below you give the signal, "Full speed ahead," and swiftly the Southern Cross would wind her way through the icy water towards the ice-block. With a crash her steel-covered bows ram into the barrier. Great green blocks of ice rear on end, overturn and plunge

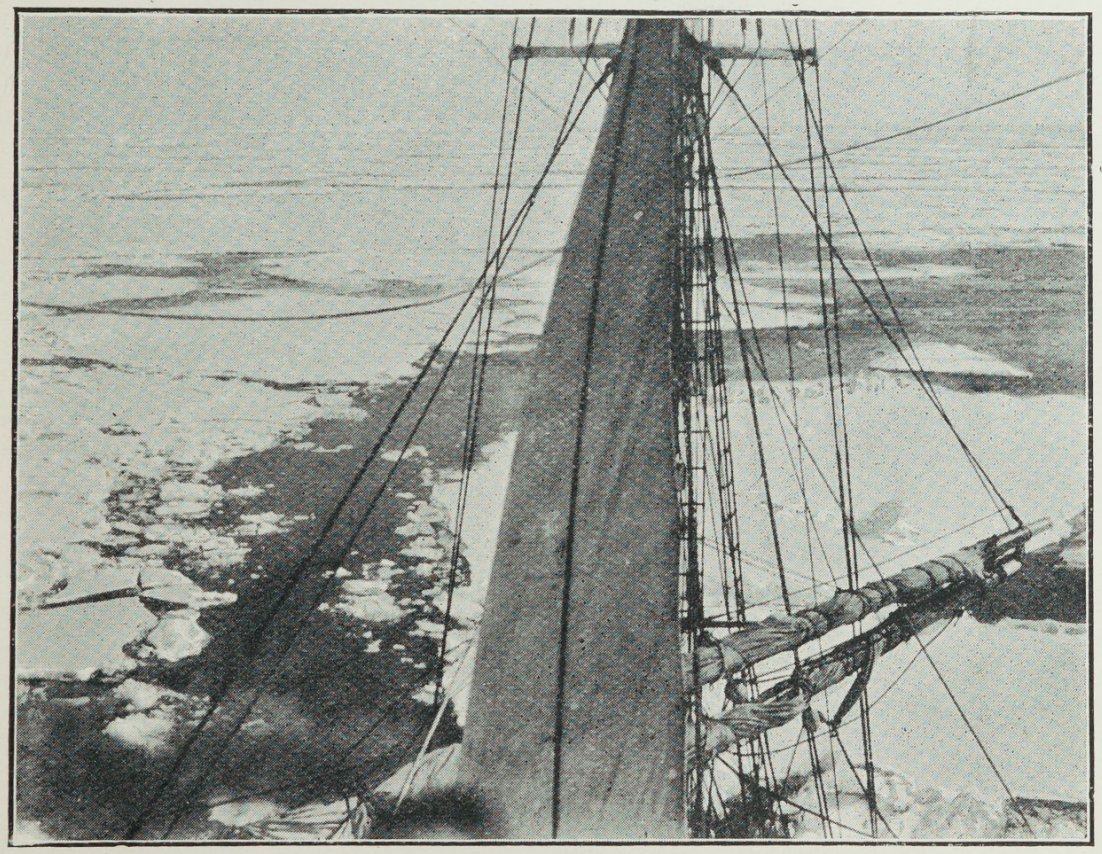

FROM THE CROW'S NEST.

against her fortified sides, while the entire crew watch the magnificent spectacle from the forecastle. The ship shivers, and the shock is felt tremendously in the crow's nest. But often this ramming has to be repeated several times before the vessel again runs into an open channel by which she can proceed on her way. The shape of the Southern Cross, her weight, her magnificent engines, all helped her 
through, and were, indeed, necessary if she should not have been caught or crushed. When ramming in hard ice she was often momentarily stuck when the ice barrier proved too hard, but she never stopped abruptly, and her bows, which sloped off in an appropriate gradient, rose out of the ocean, and thus gradually equalised the tremendous strain which

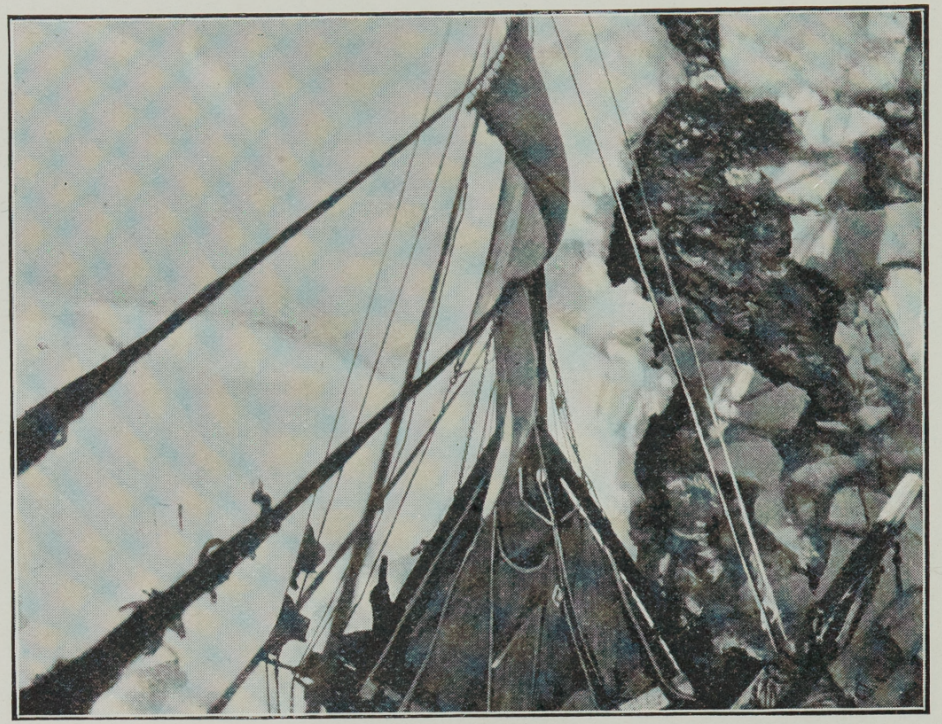

VIEW FROM THE CROW'S NEST.

the impact brought upon her. The roar and noise in the forecastle as the ice-pack rubbed up against the vessel's sides was deafening, and well I remember from my first experiences within the Antarctic Circle the difficulties of a sleep, even if tired out by hard work.

Such moments were anxious ones for those who had not been in Antarctic ice before, and ten cold successive hours in the crow's nest, and with such responsible work on my shoulders, even made me 
feel the strain when Captain Jensen came to relieve me, and the reaction of those long but delightful hours of important work is felt now while I write it down. From your lofty perch in the crow's nest you seem lifted above all the pettiness and difficulties of the small world below you. Wide is your horizon, and while you sweep the ice-field with a long telescope which threatens to lift you in see-saw fashion out of your nest, your mind is concentrated on one thing only

- to bring the vessel onwards to success, unhurt, through those obstacles only visible from your lofty position.

As I observed during my previous experience within the Antarctic pack, I

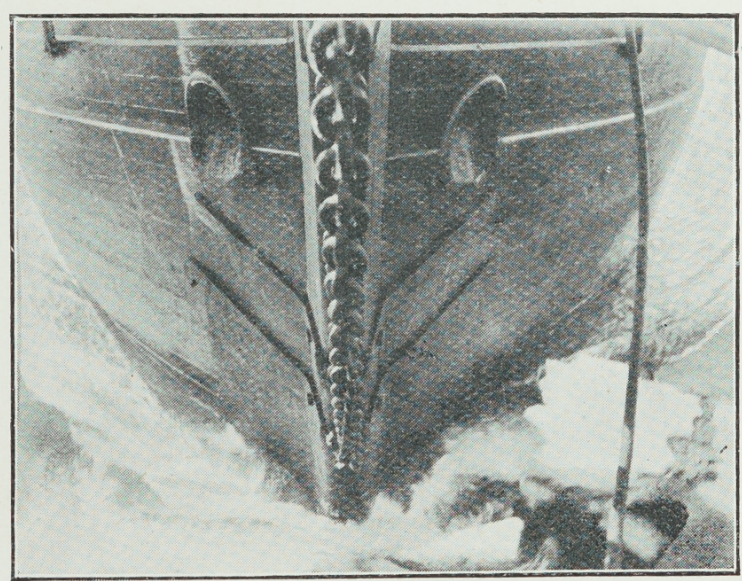

SHE WAS ELEVEN FEET OF SOLID OAK AT THE BOWS.

again found the characteristic ice-blink in the air where large ice-fields were, and dark vapour clouds always indicating open water. It is, of course, of the utmost importance to watch the constant change in the air when looking for a likely direction in which to proceed. This is just as important as to watch the ice-field itself, and also the direction of the swell, -I mean the direction from which the swell comes. To determine this is, of course, under certain conditions, a matter of "to be, or not to be," as in a 
heavy screw caused by swell, the life of the vessel may entirely depend upon whether the vessel is worked away from the direction from which the swell comes, and into the quiet pack or not. Those who have not experienced the dangers of swell in the ice, and have not had to determine the direction whence it comes, would not realise the difficulty, and it takes an ex-

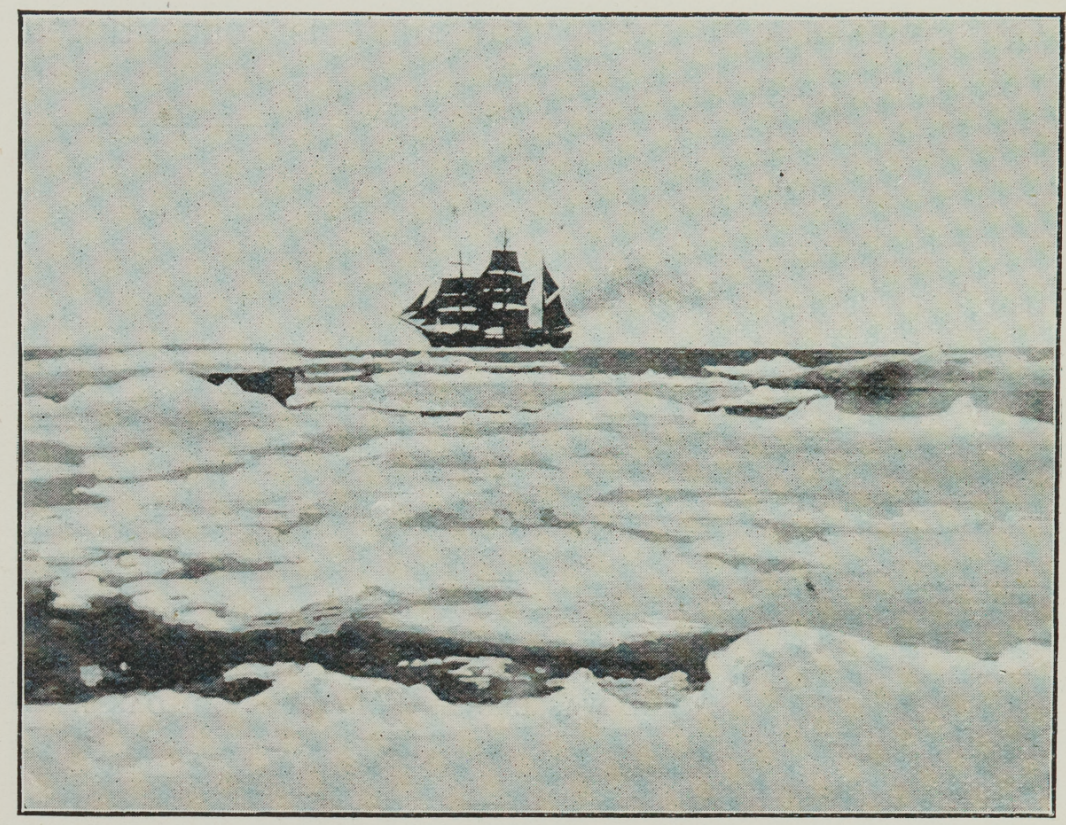

"THE ICE SLACKENED SOMEWHAT."

perienced man to ascertain it under certain conditions. The best way is to lie down upon the ice and listen to the roar of the crushing ice. The roar of the grinding ice masses travels in the air in waves like the swell itself. Only by lying down upon the ice can you ascertain whence this noise comes, and determine the direction in which you have to work the vessel into safety. 
From Hobart to South Victoria Land. 63

January i 4 th we came in sight of land, supposed to be Balleny Island. Sights were taken with Io-in. sextant, by Cary. Index error carefully determined by the sun's diameter and horizon line, and found to be 14 in. off the arc.

Times with Chron. Watch.

$$
\begin{aligned}
& \text { H. M. S. } \\
& \begin{array}{lll}
5 & 26 & 25
\end{array} \\
& \begin{array}{lll}
5 & 27 & 39 \cdot 7
\end{array} \\
& \begin{array}{lll}
5 & 28 & 10 \cdot 3
\end{array} \\
& \begin{array}{lll}
5 \quad 27 & 25^{\circ} \cdot 06
\end{array} \\
& +3 \text { 10.70 Error of watch on Marine Chron. } \\
& 530 \quad 45 \cdot 76 \\
& \text { - } 450^{\circ} \cdot 20 \text { Error of Marine Chron. }
\end{aligned}
$$

G. M. T. $5 \quad 25^{2} \quad 55^{\circ} 5$

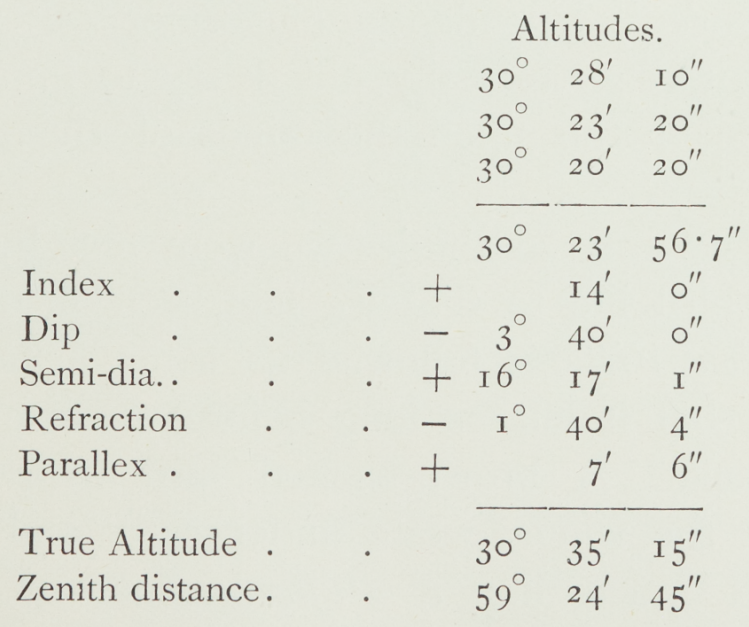

Declination of Sun on $3^{\text {th }} . \quad 21^{\circ} \quad 28^{\prime} \quad 0 \cdot 5^{\prime \prime} \mathrm{S}$.

Correction . . - $\quad 7^{\prime} 27 \cdot I^{\prime \prime} \mathrm{S}$

Declination . . $\quad 2 \mathrm{~T}^{\circ} 20^{\prime} 33^{\circ} 4^{\prime \prime} \mathrm{S}$.

Latitude at noon $=65^{\circ} 42^{\prime} \mathrm{o}^{\prime \prime} \mathrm{S}$. Run $2 \mathrm{~m}$. since noon $=$ $65^{\circ} 44^{\prime} 0^{\prime \prime}$. 
British Antarctic Expedition.

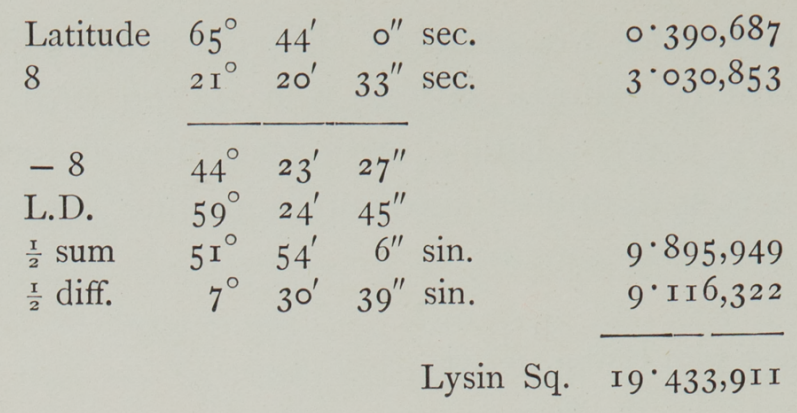

\begin{tabular}{|c|c|c|c|c|}
\hline & & $\begin{array}{r}\mathrm{H} . \\
4\end{array}$ & $\begin{array}{l}\text { M. } \\
\text { I I }\end{array}$ & $\begin{array}{l}\text { S. } \\
\text { I } 6 \cdot 2\end{array}$ \\
\hline Equation . & . & 9 & I 2 & 3 \\
\hline Mean Time & . & 4 & 20 & $28 \cdot 5$ \\
\hline G. M. T. . & . & 17 & 25 & $55 \cdot 5$ \\
\hline Long. Time & . & IO & 54 & $33^{\circ} \circ$ \\
\hline
\end{tabular}

On January 3 rd I formally impressed upon the scientific staff how important it would be for every one to work independently of former observers in those latitudes; especially did I try to impress the importance of this upon the minds of the magnetic observers.

Since we entered the ice we were met by quite a different bird life to that we had seen in the open sea. Prion Vittatus followed us some distance into the pack, but it left us long before we came to the dense pack. A brown-backed bird with a white border at the wings, white underneath, and in body and back much like a Puffinus, met us at once when we came into the pack, and was usually seen as long as the ice was slack, but after the pack got denser, seldom appeared. We saw from time to time specimens of Ossifraga Gigantea, Oceanites Oceanicus, as well as Daption Capensis; some penguins (Eudyptes Adaliea) have also been seen. Pagodroma Nivea, 
From Hobart to South Victoria Land. 65

and also Tagalassoica Glacialoides, were best represented. They were always seen swimming about in the open spaces in the ice, seeking food which mainly consisted of crustacea. Only in a few instances a very small fish, like a herring in shape, has been found in them.

Among the seals we saw about this time there

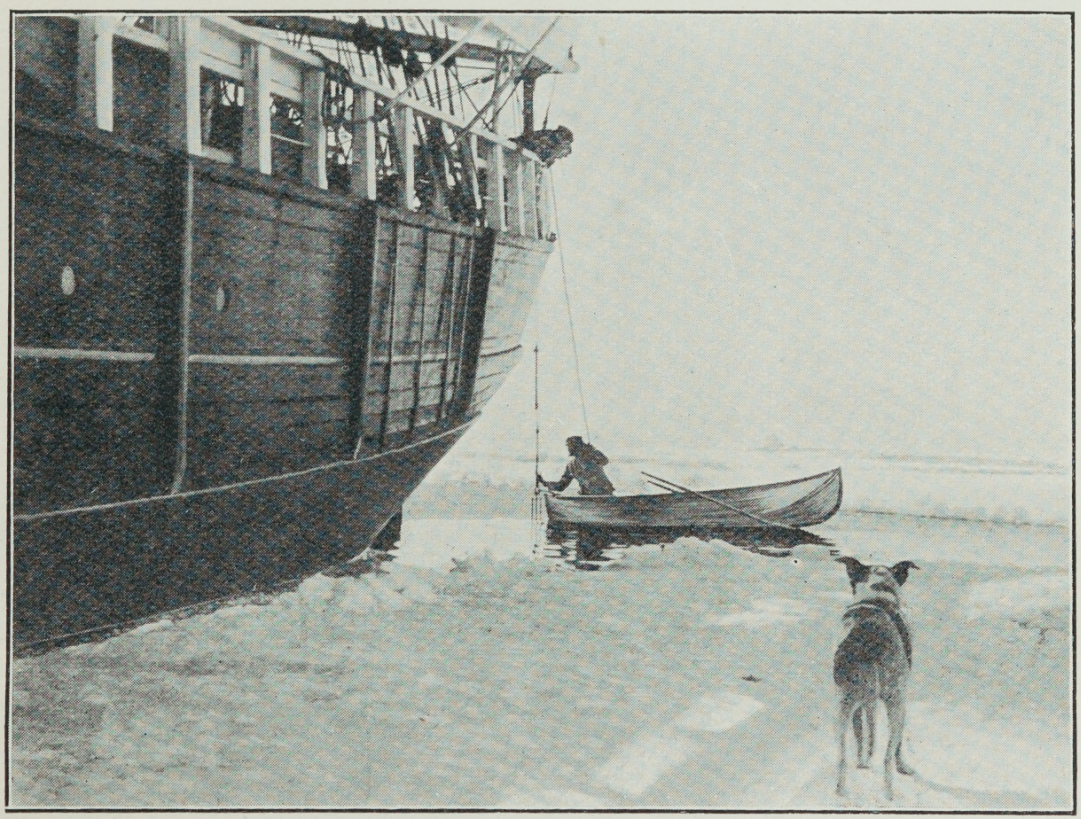

MR. NIKOLAI HANSON TAKING SEA TEMPERATURES.

were two young sea-leopards, as well as some white seals. Of the latter we secured ten up to this date. The first nine of these were of the same kind, but the last one must be of quite another kind, judging from the skull, while in skin and size it was exactly like the rest. In the large sea-leopard the remains of an octopus was found. The stomachs of the white seals were all absolutely empty. As I observed during 
my Antarctic voyage in 1895 , I also found now that the seals we met were perfectly tame, or ignorant of the bloodthirstiness of civilization. We could go straight up to them before they started to move.

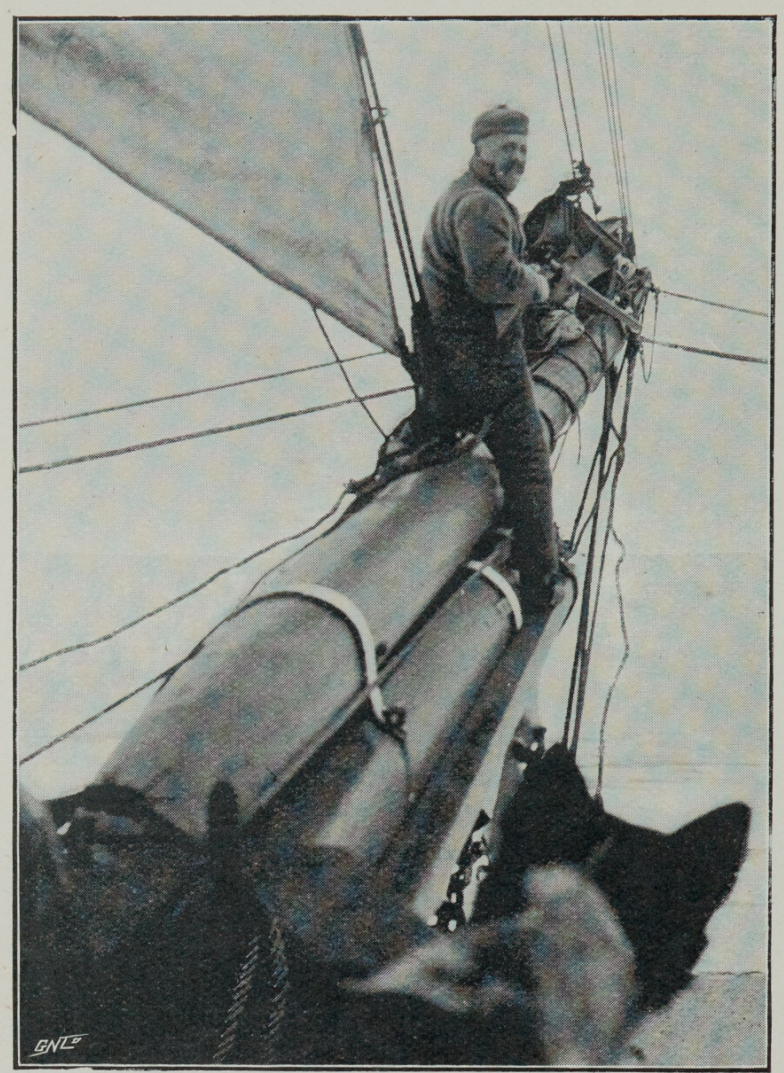

SEAL SHOOTING FROM THE BOWSPRIT.

On January 8 th we saw the first specimen of the Aptenodytes Forsterii, but we did not succeed in securing it. In the afternoon we found three white seals on a floe. There were two females a n d o n e male. Only one of them had started moulting, a n d the

new hair seemed much darker than the old.

On January i th the bird life was very rich. Especially were Pagodroma Nivea and Tagalassoica Glacialoides plentiful, and many of these latter, as well as the Daption Capen is, were swimming about in the open water catching crustacea. In the evening 


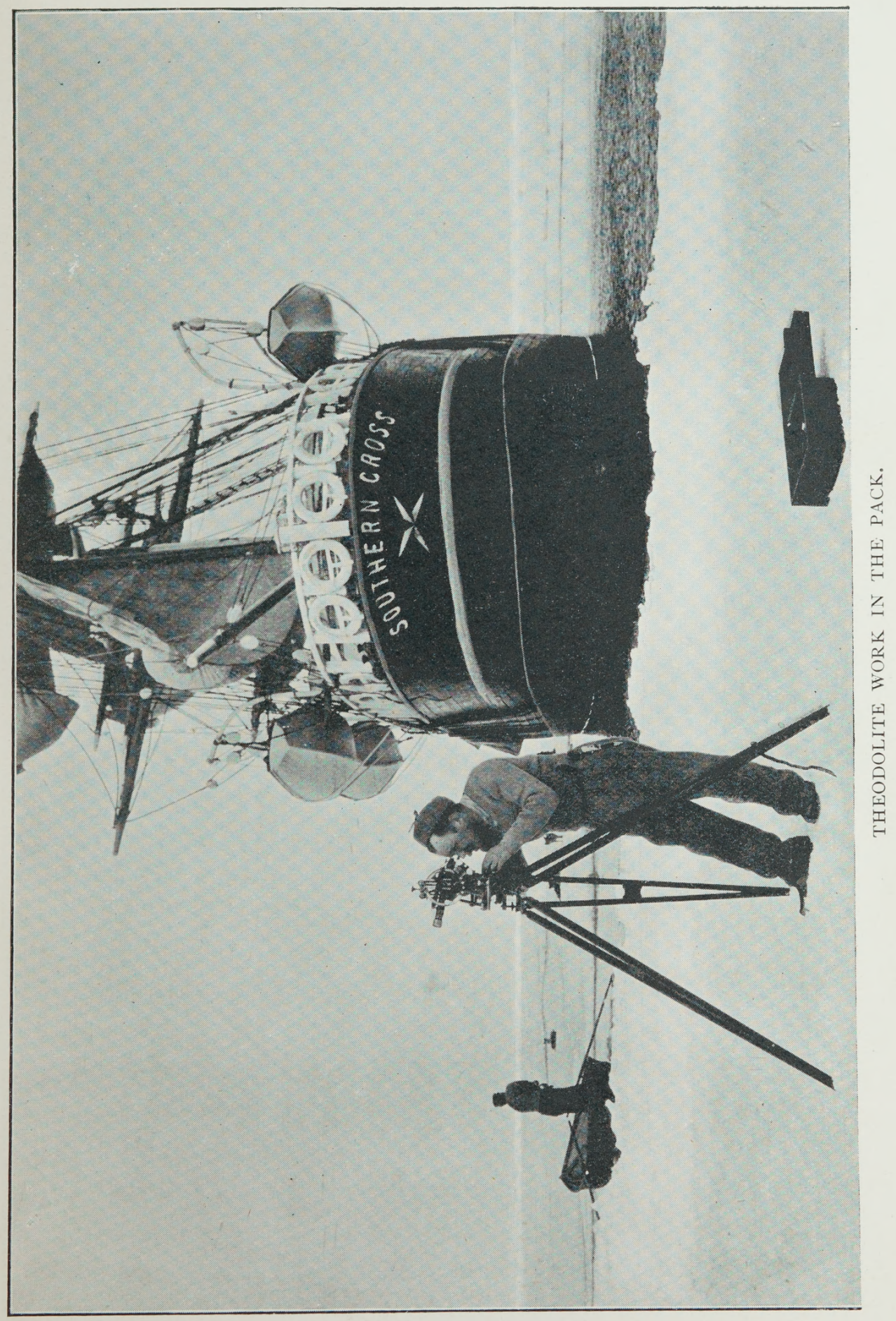





\section{From Hobart to South Victoria Land. 69}

Mr. Hanson did some valuable work with the plankton bag, and brought in, amongst other things, a great many shrimps. While he was occupied with this a fish some six inches long was seen repeatedly swimming about, but we were unable to catch it.

On the I 4 th January, I 899 , when approximately in lat. $65^{\circ} 42^{\prime} \mathrm{S}$., and long. $163^{\circ} \mathrm{E}$., I entered the crow's nest at midnight and discovered high snow-

SEAL SHOOTING.

covered land to the south. The land stood out sharply in a haze of crimson and gold which grew more brilliant as the sun rose, until the contours of peaks and crevasses suddenly caught the beauty of the young day, and reflected it all over the immense ice-pack, where the dark water-pools between the floes changed suddenly from deepest azure to blood-red, while the young snow on the ice blushed in delicate crimson, and the snow crystals 


\section{$70 \quad$ British Antarctic Expedition.}

glittered like diamonds on the white bosom of the Antarctic Ocean. This was Balleny Island which we sighted.

On the I6th January those seals which were shot during the last

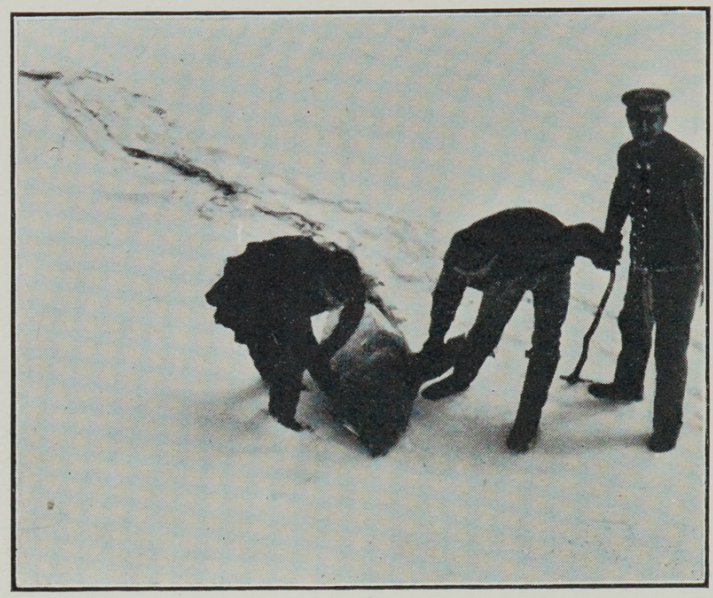

SEAL HUNTING. days seemed to have got far advanced in the moulting, and they looked a good deal darker in their new coats. The moulting starts on the back in a straight line from nose to tail. A seal which I myself shot on the I 3 th had a stripe about five inches broad along the back where the old yellow-grey hair had gone, and the new steel-grey coat was visible. The moulting had progressed regularly on both sides of the spinal column and narrowed off towards head and tail. It is remarkable that in the stomachs of the white seals there has been no food of any kind found, nor in the intestines.

The bird life was about the same.

Some few whales were seen, mostly of the blue kind.

We were still lying fast in heavy pack. It had been blowing very hard from the S.W. We were then in lat. $65^{\circ} 43^{\prime} \mathrm{S}$., and long. $164^{\circ} 9^{\prime} \mathrm{E}$. The compass error $26 \cdot 5 \mathrm{E}$. 
From Hobart to South Victoria Land. 7 I

On January i 8th we saw two large penguins (A. Forsterii). It was a pair. The female was just moulting. The male had just finished moulting, but its feathers were not quite developed. The female was sitting to the leeward at the back of a block of ice, and looked as if it had occupied that place for some time, as a road was trod all round the block of ice, and it was full up with old quills and dirt. It looked rather miserable and seemed to suffer from the cold. While we were steering down so as to be able to catch her we discovered its mate in the wake of the vessel. It however dived until it suddenly jumped up on the ice-floe where the female was sitting. These penguins must have a wonderful power of location, as the male bird must have been about three hundred yards from the vessel when we last saw him, until it appeared on the floe where its mate was camping. The space between where it dived and the block of ice was covered with ice-floes. The

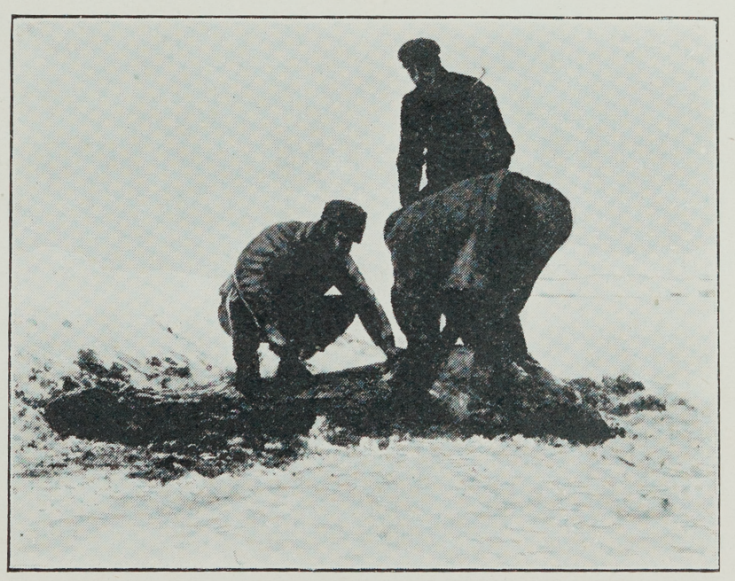

MR. COLBECK, MR. BERNACCHI, AND MR. EVANS SKINNING A SEAL.

contents of the

stomach of the female bird consisted mainly of half-digested algæ, also some pebbles; and in the case of the male, of a great amount of small shrimps and small fish; the latter were, however, 
in a state of decomposition, so it was difficult to classify them. Some pebbles were also found in the stomach of the male, the largest of which was of about the size

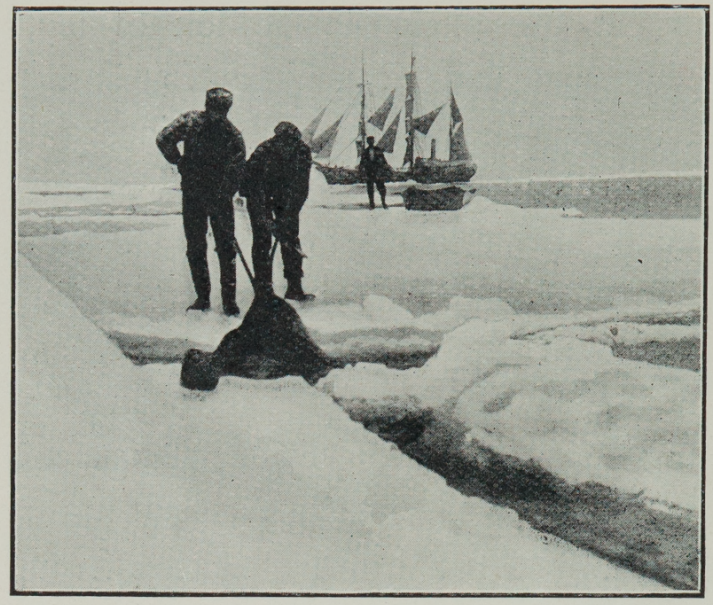

SEAL HUNTING IN THE PACK. of an ordinary nut.

In the pack one day one of the members, who evidently had not been accustomed to a gun, was going to shoot a white petrel on the wing. The bird was swift, and the member with the gun tried to be likewise; and in the excitement of following the bird with the gun he fired just as it was in the direction of the vessel. I was standing on the quarter-deck at the time, and some few of the shots struck the deck beside me. Poor Mr. Hanson, who was taking sea temperatures, received a shower of the shot on his back, and was not much pleased. The shooting restrictions, which from the beginning had been strict, I from that moment made still more so.

That same member was generally unlucky with a gun. Once he borrowed my little pea-rifle, which had been specially given to me before my departure from Norway, to shoot a penguin on the ice. It was the first penguin he had seen, and he got very excited. We all saw him chase the bird, which he 


\section{From Hobart to South Victoria Land. 73}

first tried to catch alive. The bird, however, got frightened, and instead of waddling about in an upright position, when it moves rather awkwardly forward, it suddenly laid down upon its stomach and propelled itself forward, as they generally do when they want to move quickly. The excited hunter caught the rifle by the barrel and struck out after the unhappy penguin, who, however, just escaped, as he struck a block of ice instead, and the gun broke at the stock. When the pieces were brought to me, I found that a serious accident had been avoided more through luck than management. $A$

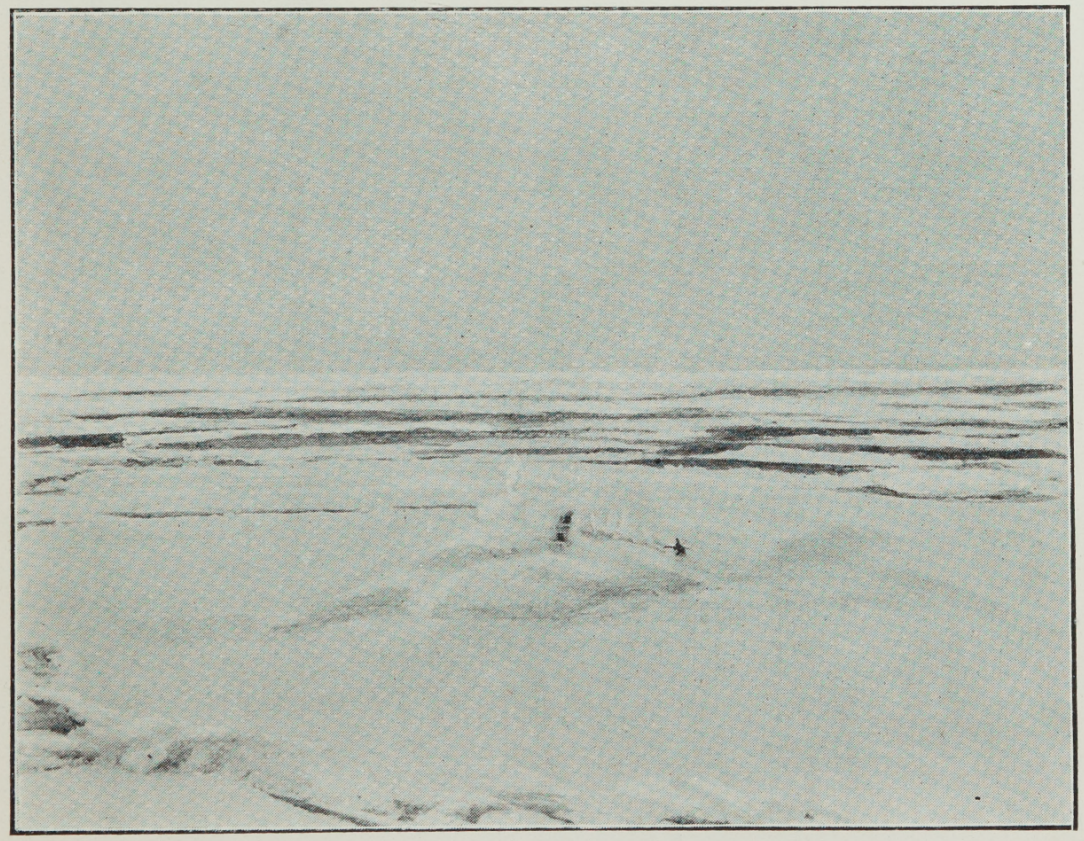

PENGUINS IN THE PACK.

bullet cartridge was in the rifle, and the hammer was at full cock.

On the 2ist January we secured a big penguin 
74 British Antarctic Expedition.

some five hundred yards from the vessel. Mr. Hanson thought that day to have discovered a new seal, which, however, proved to be Rossii.

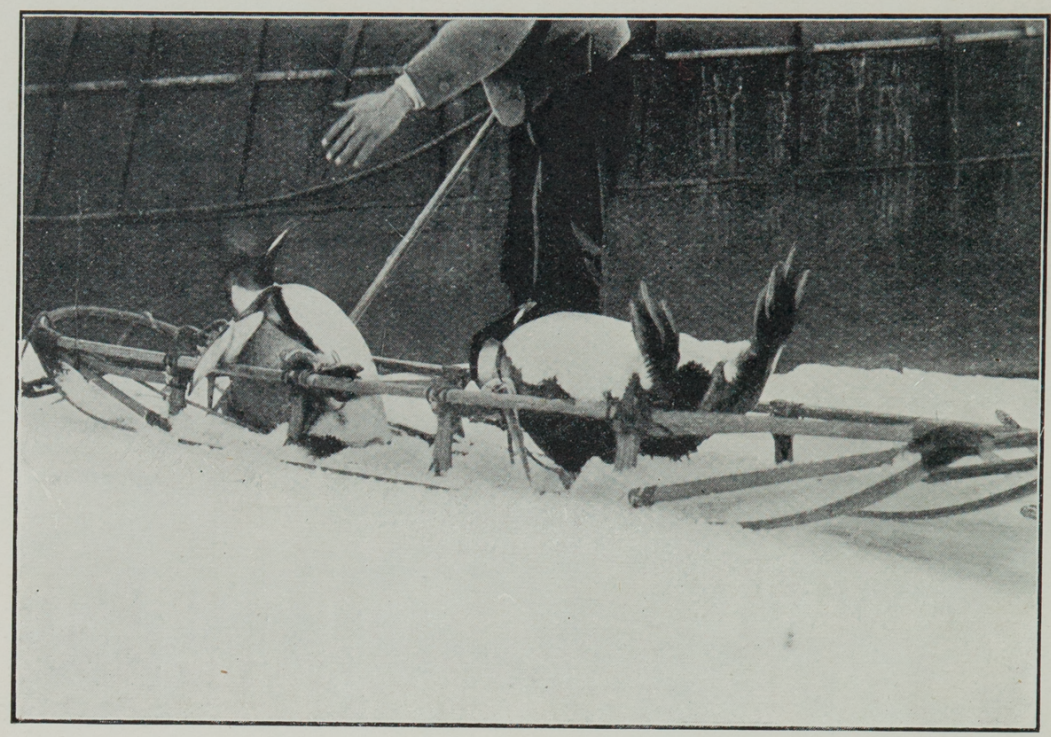

TWO CAPTIVE EMPERORS (Aptenodytes Forsterii).

The body of this seal was not unlike that of the ordinary seal, but the neck was of more than ordinary thickness, and under the chin it extended to a great round muscular purse. The head was short and broad, large protruding eyes, and a short mouth. The eyes were somewhat slanting, after the fashion of those of the Mongolian human race. It had six front teeth in the upper jaw, two in the under jaw, but no back teeth.

In connection with the killing of the Emperor penguin some five hundred yards from the ship, we had rather a good joke. When killed by Mr. Hanson the bird was skinned on the spot, and as he came 


\section{From Hobart to South Victoria Land. 75}

back on board Mr. Hanson met Mr. Evans and Mr. Bernacchi, who, tired after a long walk on ski, had also just returned to the vessel from another direction.

Mr. Hanson was one generally up to a practical joke, and upon whom also practical jokes had been played, especially by Mr. Evans and Mr. Bernacchi; and the former was one to the bad at this time, and so was determined to get even with them. All the rest of us were standing on the quarterdeck when Mr. Hanson suddenly called out to Mr. Evans and Mr. Bernacchi that an Emperor penguin was lying on the ice some five hundred yards away from the vessel. These two, who had never seen an Emperor penguin, were very anxious to secure it before all our eyes. Being, however,

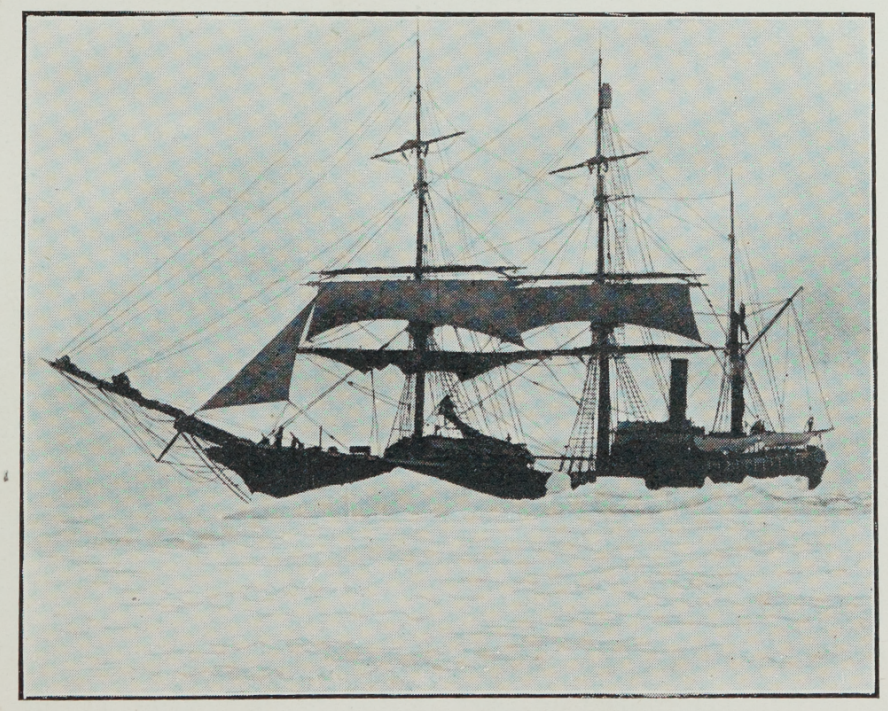

FAST IN THE PACK.

somewhat suspicious, they made a bet with $\mathrm{Mr}$. Hanson, who had a good telescope, that if it should prove not to be a penguin he should be 
$76 \quad$ British Antarctic Expedition.

liable to a heavy fine in their favour, for Mr. Evans and $\mathrm{Mr}$. Bernacchi were not over-anxious to set off again, being tired already. Hanson maintained that it was a penguin. The bet was closed, and off the

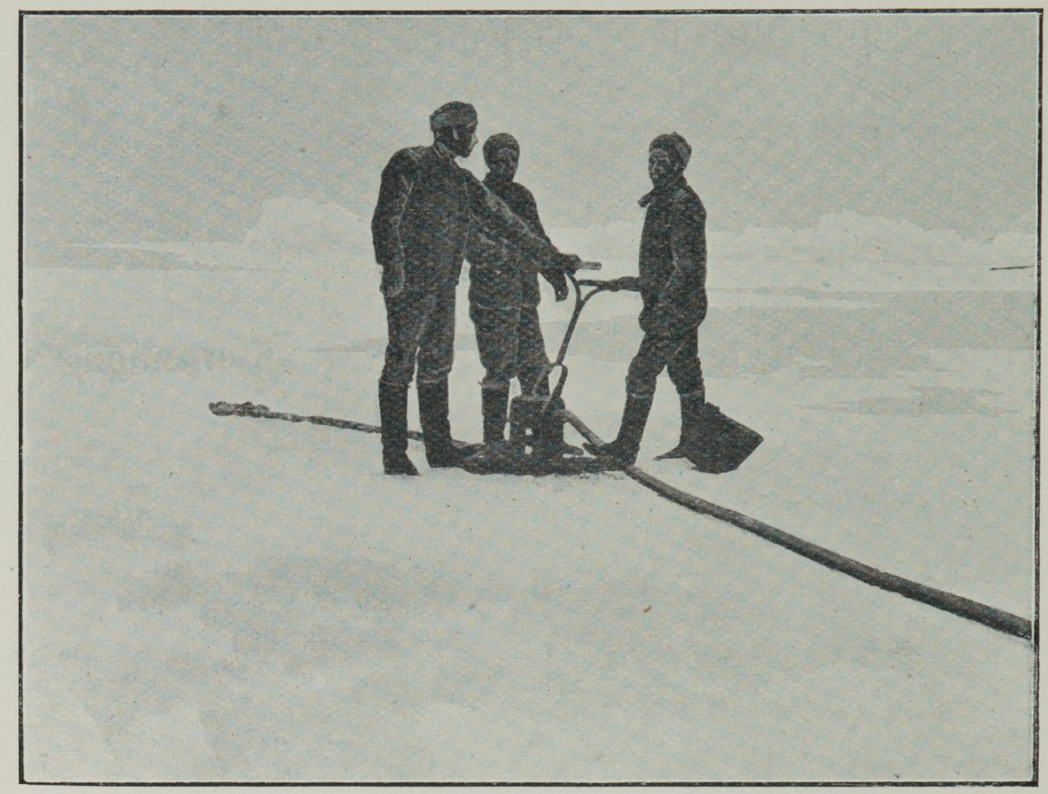

FILLING OUR TANKS WITH FRESH WATER IN THE PACK.

two went, waddling away on Norwegian ski which they had had on that day for the first time. Meanwhile Hanson had explained to all on board that he had the skin of the penguin which was lying on the ice in his possession, and we all enjoyed what happened intensely. On went the two hunters, further from the ship, and nearer to the dark spot on the ice. It was evident that the nearer they got the more excited they became. They stopped, discussed the modus operandi, and took off their ski. Like two Indians they noiselessly crept over 
the soft snow, nearer to their prey, and all the while loudly cheered by Mr. Hanson, who from time to time recommended carefulness in their enterprise. At last came the final dash; then they stopped short, hesitated, and then slowly wended their way back to the vessel under the roars of laughter from all on board. Very little things seemed now to amuse.

On January $22 \mathrm{nd}$ and $23^{\mathrm{rd}}$ the pack-ice commenced to screw violently, causing us much anxiety. The Southern Cross sighed and groaned under the heavy pressure brought to bear upon her. We made preparations to get out upon the ice in case we should lose the vessel, but the good ship proved equal to her

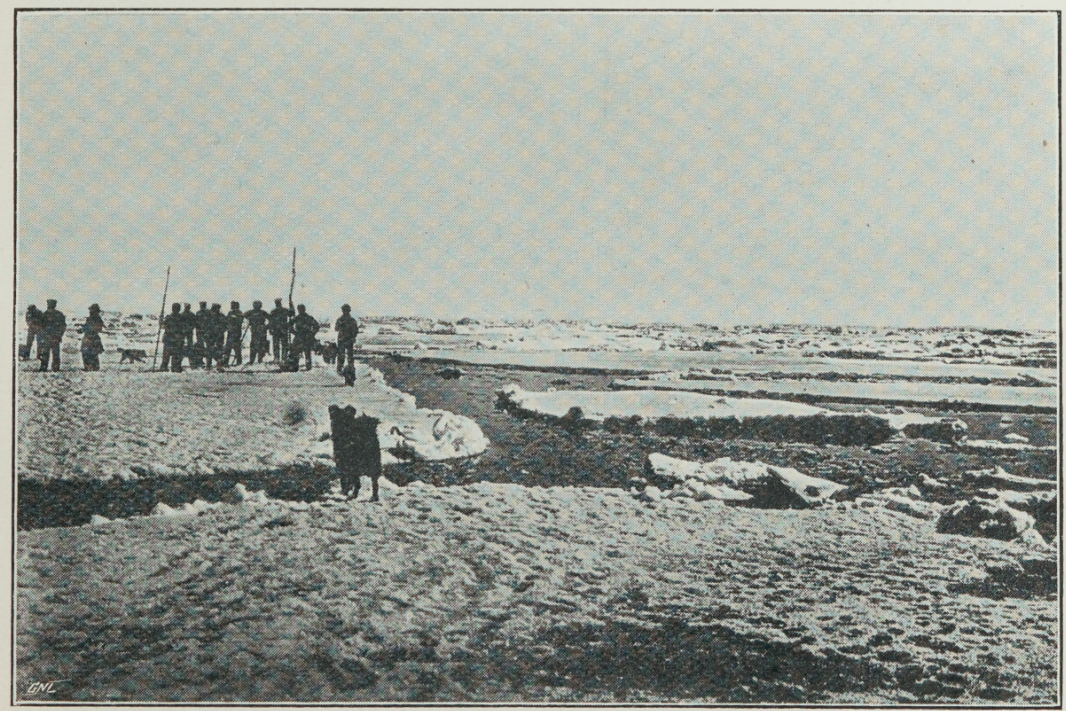

TAKING EXERCISE IN THE PACK.

task. On the night of the $23 \mathrm{rd}$ January she lifted $4 \mathrm{ft}$. bodily out of the water. Days and nights the screwing continued, crew and staff working energetically.

On January 3Ist, I899. Meridian altitude of sun 


\section{8}

British Antarctic Expedition.

carefully observed with artificial horizon, with $6 \frac{3}{4}$ inch sextant, using reversing telescope. Approximate lat. $66^{\circ} 45^{\prime}$ S., long. $165^{\circ} 29^{\prime}$ E. Barometer $29^{\circ} 75^{\circ}$

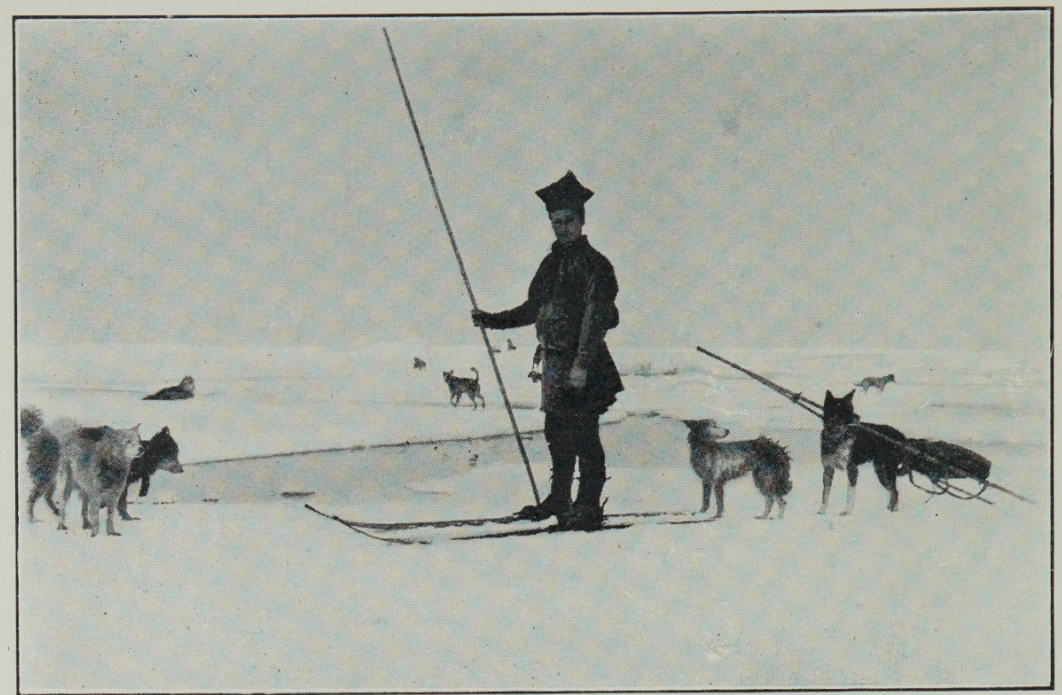

SAVIO TRAVELLING WITH INDIAN GEAR.

inch. Att. ther. $50^{\circ} \cdot 3$. Temperature of air $30^{\circ} \cdot 0$ Fahr. Sun's upper limb observed. Index error of sextant (on and off arc) $-5^{\prime} \mathrm{IO}^{\prime \prime}$.

Double altitude.$\quad 82^{\circ} 8^{\prime} 10^{\prime \prime} \quad$ G. M. T. by Chron. I3- I3-37. Index error

$$
\begin{aligned}
& \begin{array}{rrrr}
- & 5 & \text { 10 } & \\
\hline 82 & 3 & \circ \\
4 \mathrm{I} & \mathrm{I} & 30
\end{array} \text { Apparent alt. of upper limb. } \\
& \text { - I6 }{ }^{5} 4 \text { Semi-diameter of. }
\end{aligned}
$$

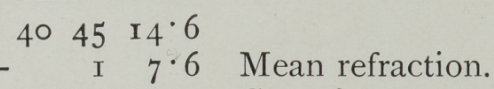

$$
\begin{aligned}
& +\quad 03.0 \text { Corr. for temp. of air. } \\
& \text { - } \quad 0 \quad 0.7 \text { Corr. for height of barometer. } \\
& \begin{array}{r}
4044 \text { II. } 3 \\
+\quad 6.6 \quad \text { Parallax. }
\end{array} \\
& 40 \quad 44 \quad 17 \cdot 9 \text { True alt. of sun's centre. }
\end{aligned}
$$


From Hobart to South Victoria Land. 79

49 I.5 $48 \cdot 7$ Zenith distance.

I $73022 \cdot$ I S. Declination of sun.

Lat. of ship at noon $\quad 664600 \cdot 8 \mathrm{~S}$.

Declination on 3 oth at noon $=17^{\circ} 37^{\prime} 55^{\prime \prime} \cdot 7 \mathrm{~S}$.

Variation in I I hours . $\quad=-733.6$

True S. . . . $=173022 \cdot \mathrm{I} S$.

Central peak of land bearing S. $20^{\circ} \mathrm{W}$. true.

Distance of land thirty miles approximately.

On February 7 th we were lying fast to an iceberg during the night, a beautiful berg formed into three high peaks. The dogs have been let on to the ice to

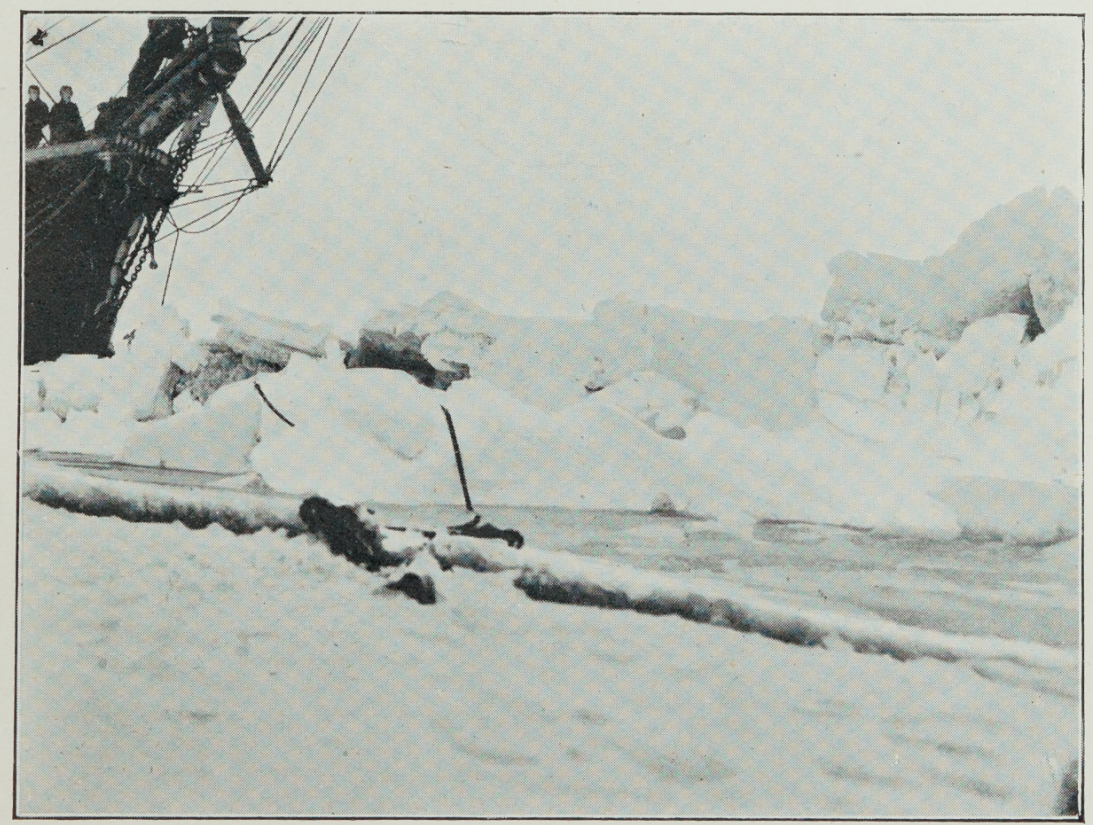

"THE PACK COMMENCED TO SCREW VIOLENTLY."

get exercise. We are in lat. $66^{\circ} 37^{\prime} \mathrm{S}$., and long. I $64^{\circ} 49^{\prime} \mathrm{E}$. We have lost "Grandfather," the finest and strongest of the whole pack. He was supposed 
to have made a journey through Greenland with Lieutenant Peary. Probably he walked into the open water and was unable to get on to the ice again. We

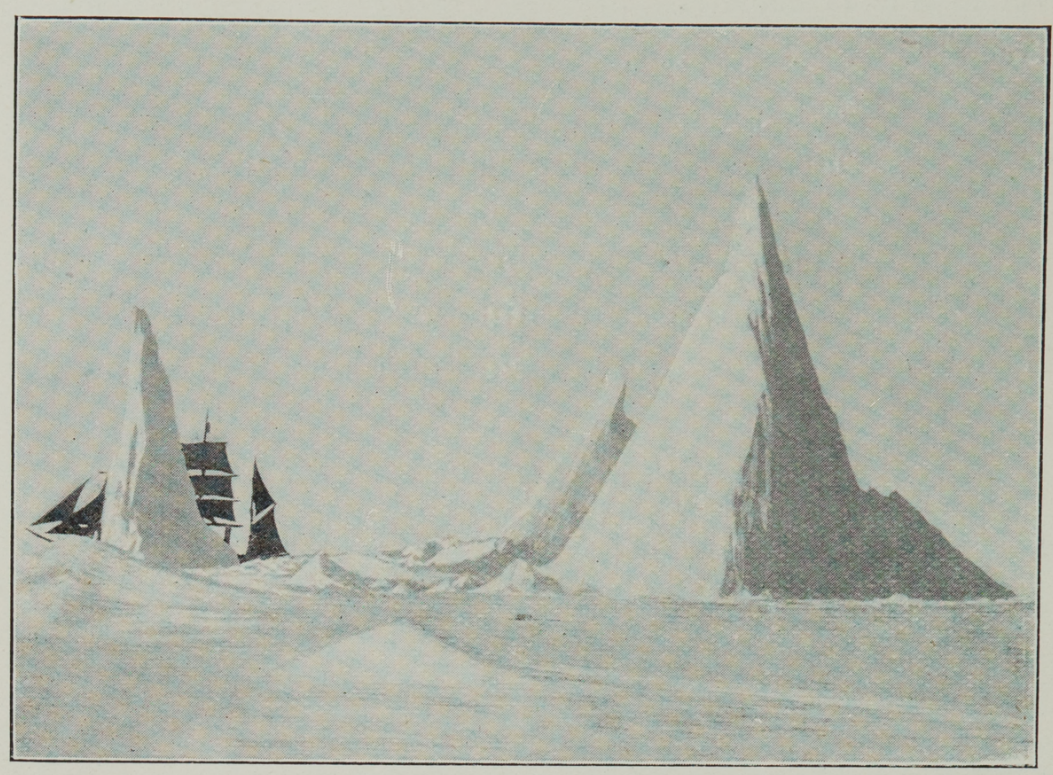

STILL FAST IN THE PACK.

had often noticed him in great difficulties in the water on account of his long hair, which, when wet, weighed him down.

For weeks we remained buried in the snow and ice, and as the summer advanced I began to see a possibility of not being able to get through with the vessel southwards. Then I resolved to land on the ice with instruments, provisions, sledges and dogs, choosing Mr. Fougner as my comrade, he being an experienced ski-runner. Just when we had begun to make our preparations for a lonely journey to Victoria Land the ice-pack slackened somewhat; but instead of using the doubtful chance of getting 


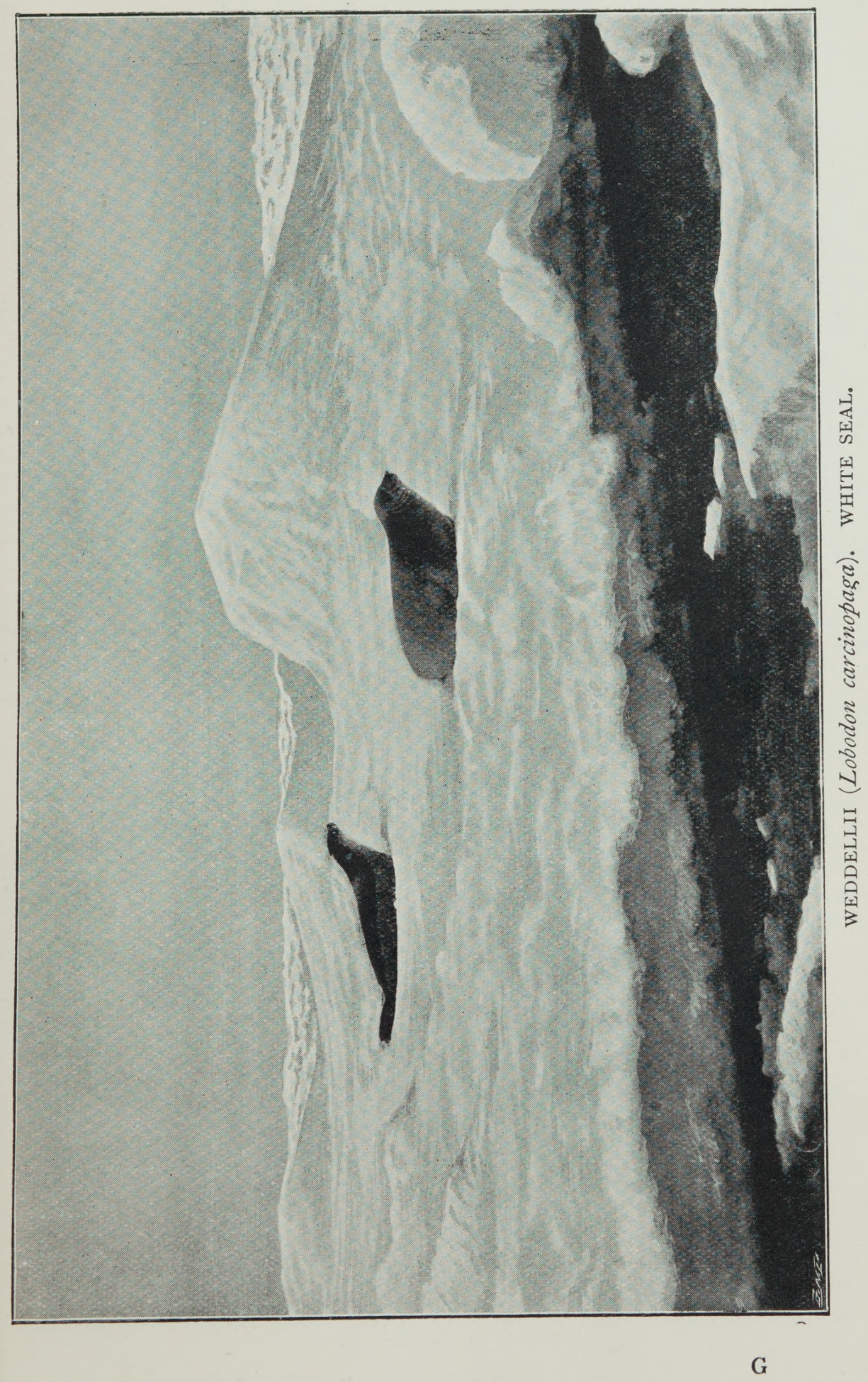


From Hobart to South Victoria Land. 83

southwards at the vicinity of Balleny, the advanced season determined me, after consultations, to use the opportunity and work towards open water, with the intention of making a fresh attack on the ice-pack further east. This plan was followed, and after a hard fight in the pack for forty-eight days the Southern Cross ran into open water, lat. $70^{\circ} \mathrm{S}$., and long. $174^{\circ} \mathrm{E}$.

On the I Ith February we were making eastwards

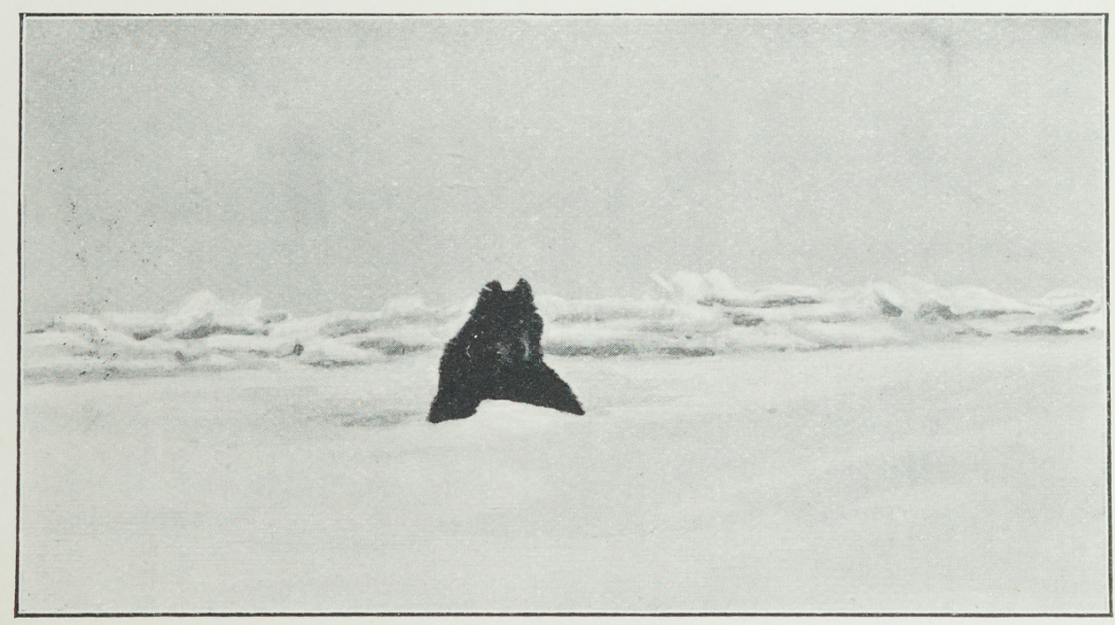

A FAITHFUL COMPANION.

by steam and sail. On the I 2 th we had rather a big swell from the N.W.; it was foggy and the barometer was $28 \cdot 7 \cdot$ I. No ice was within sight. At I I P.M. the vessel was shaking as if by an earthquake, the phenomenon being noticed simultaneously by several of the members of the Expedition in different parts of the ship. The phenomenon, if so it might be called, lasted for two seconds, then stopped for about three seconds and then again repeated itself. It was independently reported to me by those who 
noticed it. I myself was in my cabin at the time, and also noticed the shaking.

On the I5th and I6th February the Southern Cross was compelled to lay to in a storm of blinding sleet, decks and rigging being completely covered with snow and ice. On the evening of the r6th we sighted land, and entered into Robertson Bay on the I th February, 1899. The rocks of Cape Adare stood out dark and conspicuous as we steamed into the Bay. We could not sight the low-lying peninsula at Cape Adare until we were very close to the shore. Only a yellow border at the foot of the rocks of the Cape was visible, and indicated the place where I intended to pitch the pioneer camp. It seemed, at a distance, so small and inhospitable that some of my staff felt constrained to remark at first sight of the place, that if it was there I proposed to live for a year, they had better send letters of farewell back with the vessel. It was a moment which, I believe, will always remain in the memory of my staff and self as we slowly moved towards the low beach whereon man had never ventured to live before, and where we were to live or perish, under conditions which were as an unopened book to ourselves and to the world. 


\section{CHAPTER III.}

\section{Life in South Victoria Land.}

At i I P.M. on the i 7 th February, i 899, for the first time in the world's history an anchor fell at the last terra incognita on the globe. The Southern Cross dropped anchor at South Victoria Land in ten fathoms of water, and before even the spray from the falling anchor had settled on the icy surf, an echo from her salute of four guns, mingled with energetic cheers from thirty-one enthusiastic men, pierced the frosty air, and gradually died away as it travelled far in between those lofty snow-clad peaks above us. At once I landed from a boat, taking with me Mr. Bernacchi and the Finn Savio. On landing Mr. Bernacchi took occasion to heartily congratulate me. Already, while far out to sea, it had struck me that the Cape and its surroundings seemed much more free from ice and snow than was the case on the occasion of my first visit in I894. Then the Cape had several feet of ice and snow on the top, now it was absolutely bare. The beach where we landed was almost exactly in the same condition as when I first trod upon it; only here and there some ice-blocks were left; the rest was dark and bare, and on the peninsula itself 
were the guano deposits, while, as it was late in the season, only a few penguins were left. My visit on shore was brief, and we returned to the vessel; all was quickly arranged for a speedy commencement of landing our stores, instruments, dogs and outfit. Much to my surprise Robertson Bay was free from ice at the time, but I knew that it might fill up again at any moment. Already on the I8th we were hard at work landing stores. We lowered the boxes into small whale boats and pulled them near the shore, where some of us had to wade into the breakers and carry the things ashore. Up to the armpits in water at $28^{\circ}$ Fahr., it was a cold job.

When the huts had been built, some four yards apart, I decided to use the north-western as the dwelling, and the other for provisions and outfit. The middle space between them I covered over with wood, seal-skin and canvas, and continued, this cover towards the eastern side in the run with the slope of the roofs of both houses down to the ground, forming a continued sloping roof from the entire ridge of both houses, including that of the middle space and down to the ground. A strong framework of wood formed the rest for the canvas and seal-skin. By this means a great space was gained at the eastward side of the huts as well as a protected approach between the huts. In the space to the east a great quantity of provisions and the coal necessary for the winter were placed. In the middle space, sledges, ski, tools and gear of all kinds were kept. At the end of this passage towards the west a wall was also built of wood with an extra door. Thus precautions were taken against heavy 


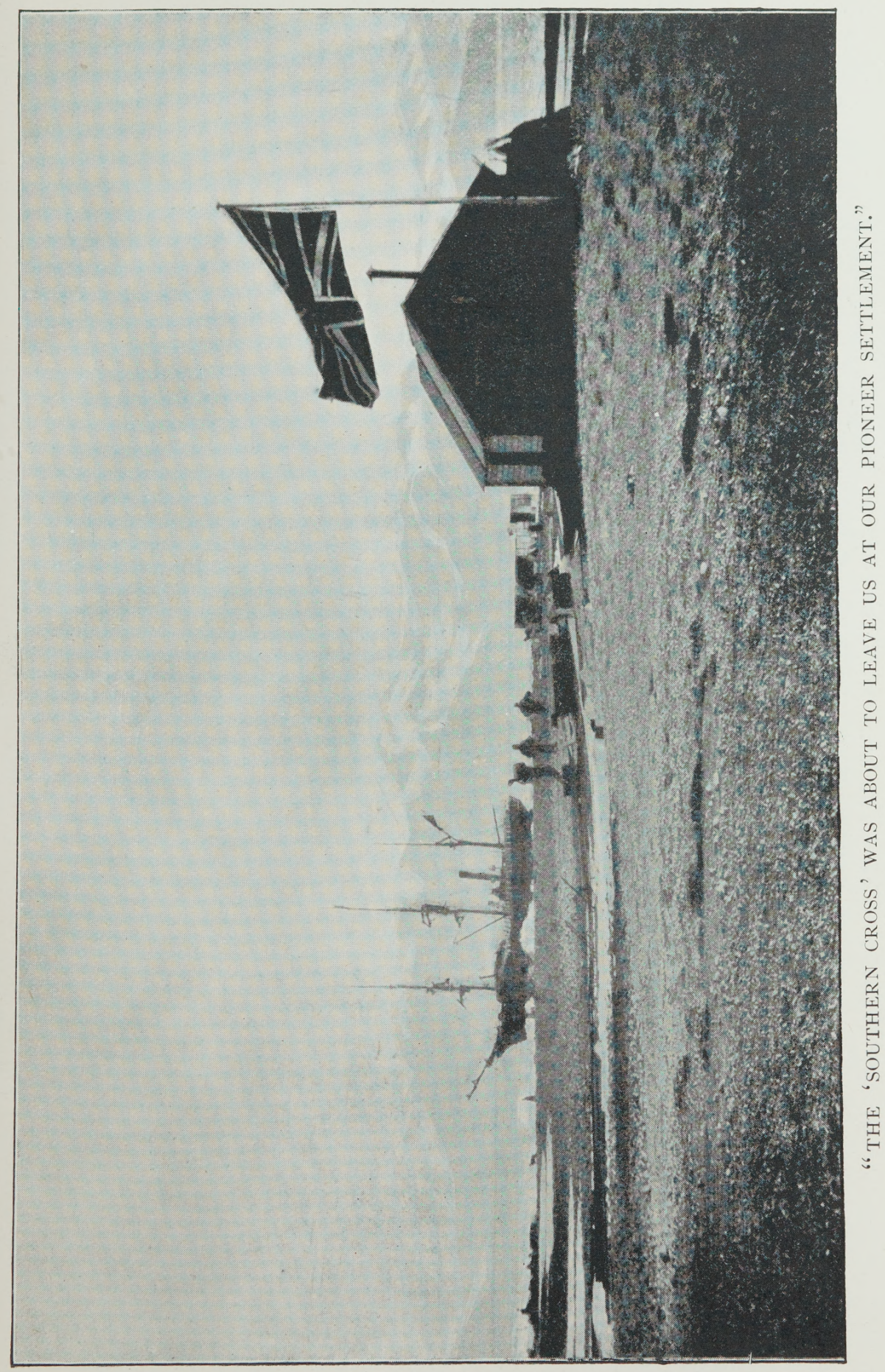



snow-drift which might have prevented us from reaching from one hut to another. The dwelling hut had three separate doors to its centre, one to a kind of hall four feet wide, and two towards the inner dwelling; the doors moving inwards so as to enable us to dig ourselves out in case great snow-drift should block the way. At both sides of this four-feet hall I

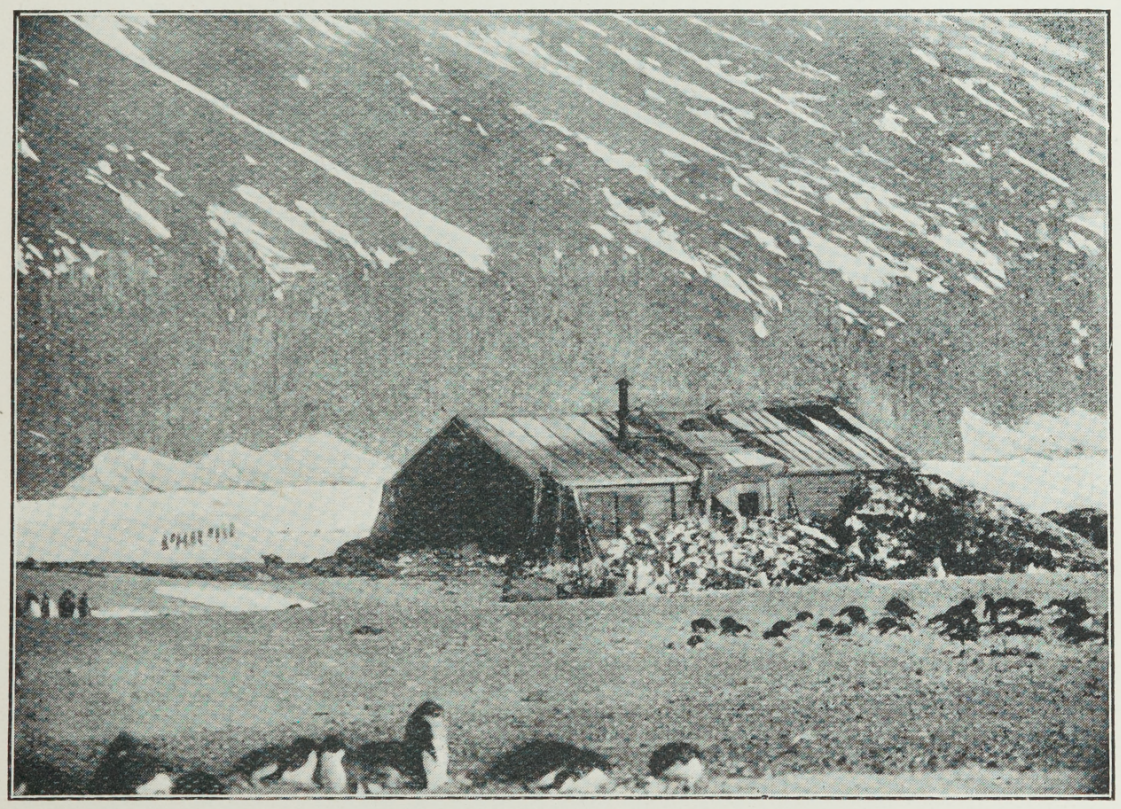

CAMP RIDLEY IN SPRING.

caused a small room to be made. On the right-hand of the entrance an instrument room and developing room for photographs; on the left-hand side a small room which I originally intended for my own use, but which I later gave to Mr. Evans as a taxidermist room. These two small rooms were lined with wool and fur, and were approached through small vertically sliding trap-doors, some two feet from the floor. The 


\section{$90 \quad$ British Antarctic Expedition.}

floor in the dwelling hut was doubled with papiermâché between the layers of planks. The walls were lined with wood, also with papier-mâché between the outer timber and the inner pannelling. A double and horizontal

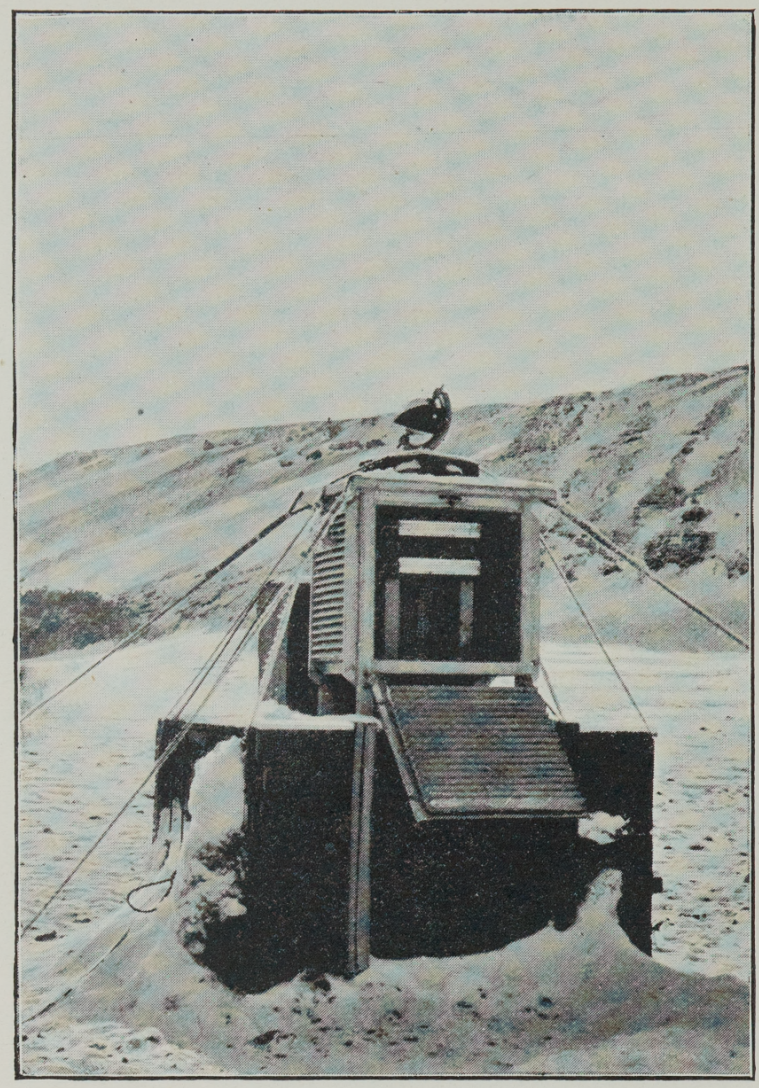

THE THERMOMETER SCREEN. roof was about seven feet high; in the middle of this a tra p-d o or led into a loft formed by the sloping roof. $\mathrm{Her}$ e a good deal of - clothing and provisions for im mediate use were kept; also physic and spirits, and any material which could

not stand much cold. In the dwelling room below, size I 5 feet by I 5 feet, ten bunks were fixed to the northern and eastern side walls; the window being towards the west, and consisting of a small double framework carrying double glass (the outer panes some three inches from the inner) and with a big, 
heavy snow-shutter outside. On the south-eastern side of this room, and to the left of the entrance, was a large square camp stove on four wheels, with a funnel worked through the roof, where thick asbestos packing was laid. A rough wooden table was fixed before the window with a wing running out at rightangles to the table at the window. On the ceiling were hanging guns, fishing tackle, knives, mittens, chains, and odds and ends. The bunks were closed after the plan followed by sailors on board whaling vessels, with a small opening, leaving yourself in an enclosure which can hold its own with our modern coffin ; and, like this, it is private; for some minds it is absolutely necessary to be alone, out of sight and entirely undisturbed by others. It was by special recommendation from the doctor that I made this arrangement and found that it answered well. In these small enclosures we had some books, our diaries, and several of us our writing materials. I myself did a good deal of my writing in my bunk during sleepless nights in the dark time, and so did the rest of the members. To work at the table with nine hungry minds, starved by the monotony of the Antarctic night, glaring at you through nine pairs of eyes at once indescribably vacant and intense, was impossible.

On the 23 rd February we were suddenly interrupted in our work by a strong gale from the S.E. The gale increased and came on in a blizzard, and at 12 midnight, after consultation with Captain Jensen, I ordered the rigging to be cut. Several of the bravest and best of the crew attempted to ascend, but owing to the strength of the wind, and 


\section{2 \\ British Antarctic Expedition.}

the hail of pebbles, it proved impossible. One by one they came to the bridge where Captain Jensen and myself were standing, declaring that they found it impossible to stick to the ropes, which were smooth as

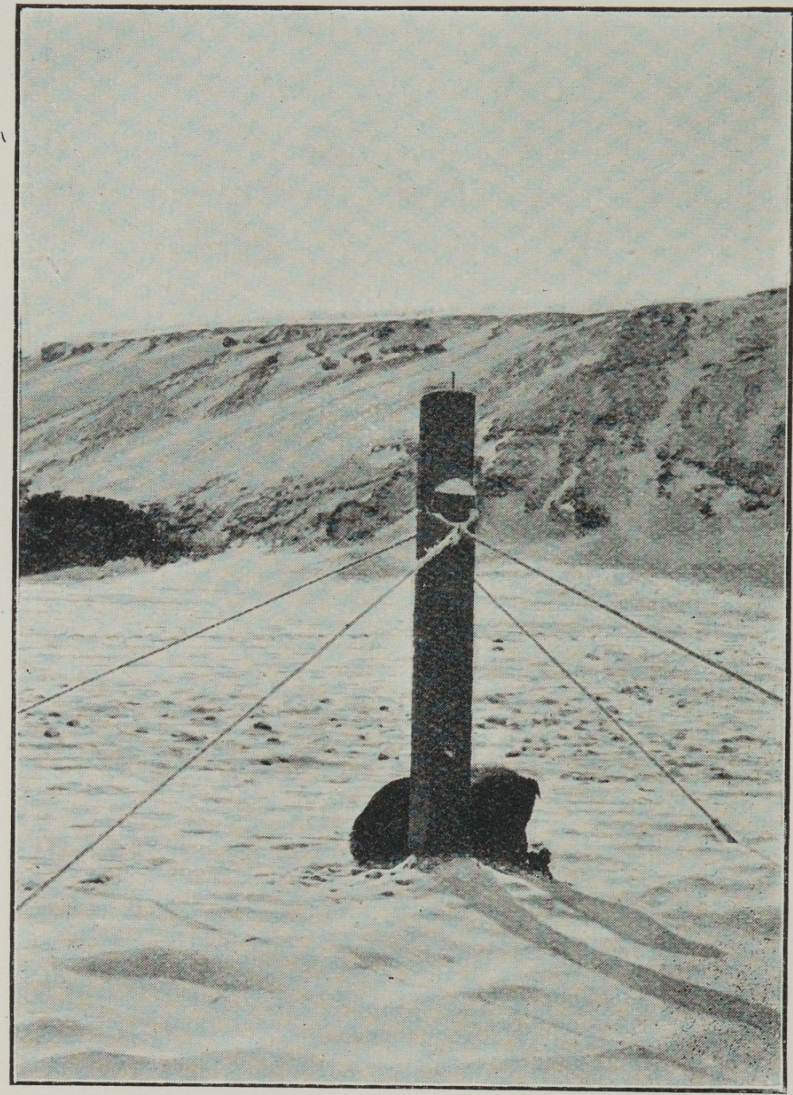

THE MERIDIAN POLE AT CAPE ADARE.

glass in their ice-covers ; indeed, it was difficult e $n$ o u $g$ h t $o$ w a $1 \mathrm{k}$ o n d e ck. Everything now depended upon the engines. Well I re$\mathrm{me} m \mathrm{~b}$ e $\mathrm{r}$ that night when I went $\mathrm{d}$ o w n to the engineroom, where the two splendid $\mathrm{st}$ o k e r s worked with feverish

haste, shovelling in coal to raise the pressure in the boilers to its limit; while even down there the howling of the tempest could be heard. The stern face of Mr. Olsen, our first engineer, as he asked me the question, "Drifting still?" and the stokers simultaneously stopping their shovelling for a second 
to hear my answer, stands clear in my memory to-day; and how calmly and resolutely those four in the engine-room worked after hearing that we, having lost an anchor, were driven by the furious gale among rocks and icebergs, and that everything now depended upon what could be done by the engines! As the pressure of steam was brought to

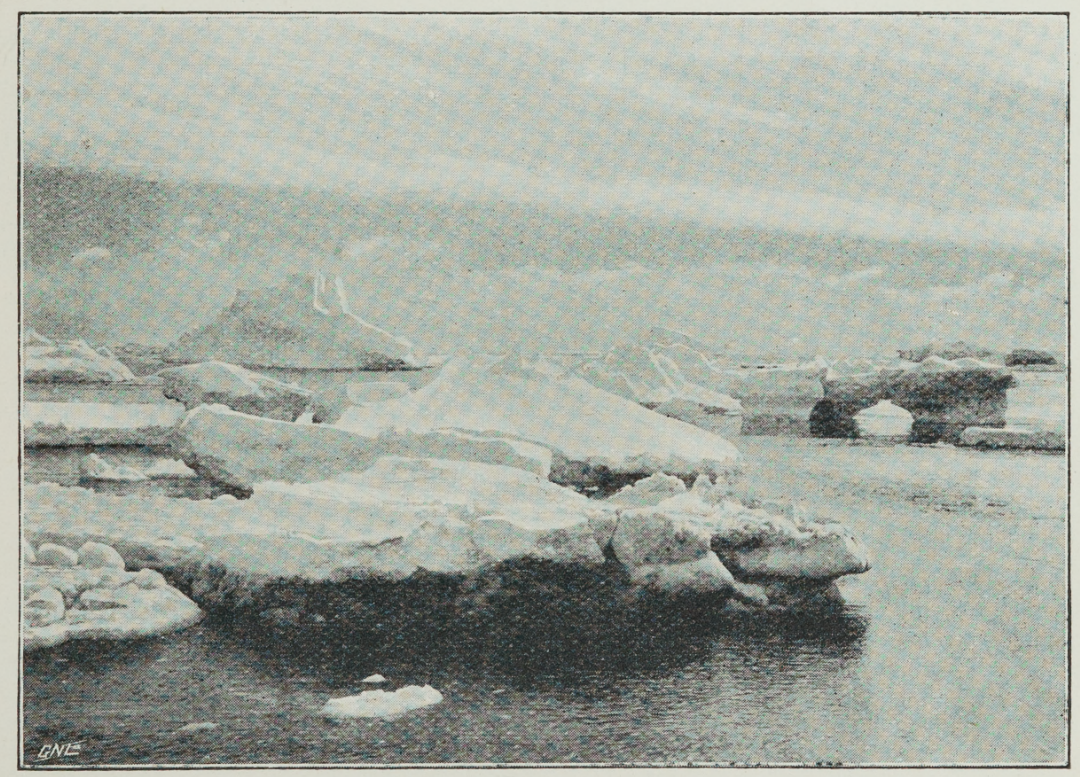

PACK IN ROBERTSON BAY.

a point when the boilers could stand no more, the regular pulsation of the engines quickened, the vessel seemed to have become a living being, while the heart-beats from the engine-room had become so strong that they were felt all over the vessel. All the night through we were in great anxiety, although the vessel, by the help of the engines at full speed, assisted by two new big anchors, just managed to keep its position in the 


\section{British Antarctic Expedition.}

bay. Towards dawn the gale lowered somewhat, and we steamed up to a big rock situated about a mile to the south-west of the peninsula, and about two chains from the perpendicular rock of Cape Adare. Through great risk, four sailors in a whaleboat succeeded in fastening two wire hawsers and an ordinary cable to this rescuing pillar.

The two Finns were destined to be the first to sleep on shore,

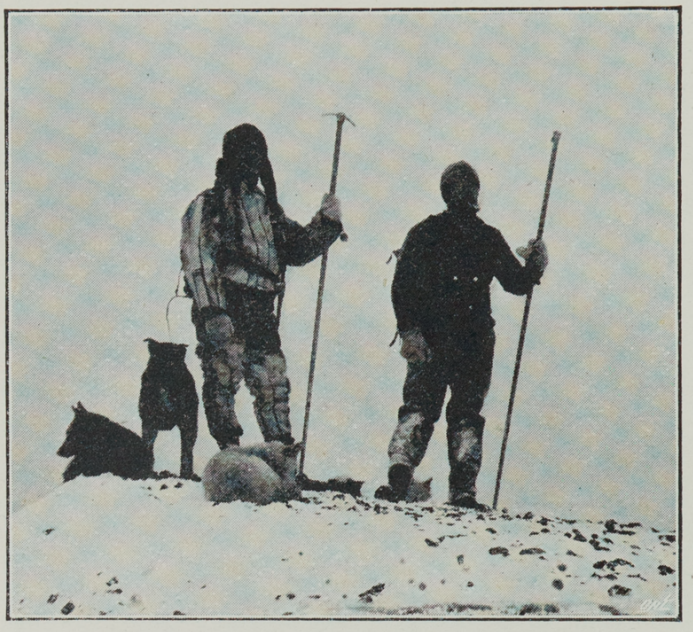

MR. BORCHGREVINK AND MR. HANSON ON THE TOP OF CAPE ADARE. as the gale prevented them from reaching the vessel, although on the following day some of $\mathrm{my}$ staff, at a great risk, managed to reach the land. It is curious that these two Lapps should happen to have been the first to inhabit that large southern continent, curious because they are natives of the corresponding latitudes on the Northern Hemisphere, and because they, as children of nature from the north, in a way replaced the want of natives in the south.

The next few days and nights were anxious ones for all of us, as well for those on board as for those on shore. The vessel lost two anchors, and was in imminent danger of being wrecked on the rocks, as all three hawsers fixed to the big rock snapped 
like so much thread. In addition to this, from the mountain towering above us showers of stones rained down upon our decks. Despite the piercing cold, however, all hands worked with a will, day and night, until the gale ceased.

On February 26th a gale was again blowing with great violence. While the two Finns were

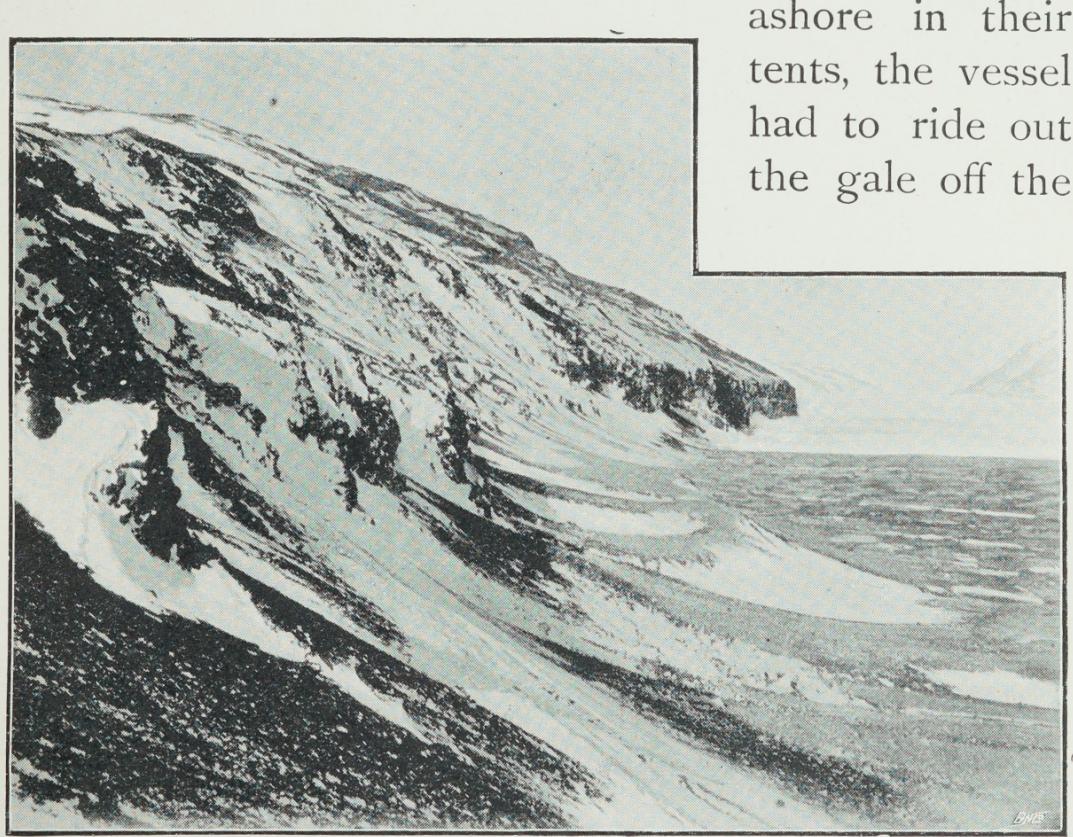

OUR APPROACH TO THE TOP OF CAPE ADARE.

rocks of Cape Adare. Captain Jensen and myself were continually on the bridge, and we had to exercise great caution in order to keep our position. The gale was from the S.E. To the leeward of the cape itself, and close to the perpendicular walls of the rocks, comparatively smooth water was found in a triangular area with its apex some two miles out at sea. However, from time to time heavy squalls struck the vessel from the east, and forced 
96 British Antarctic Expedition.

her towards the western extremity of this comparatively smooth area. I therefore had to steam towards the eastern side, stop the engines, drift down again towards the west, and so on the whole day long. By this means we were enabled to keep our position with the least possible consumption of coal. In the evening the gale had abated so much that we ran up into Robertson Bay, while the sea was still too heavy near the peninsula to make it possible for us to land more stores. To utilise the valuable time as much as possible, I decided to steam up to the end of Robertson Bay, where a big, broad, magnificent glacier descends into a cove terminating the bay. This glacier descended at a slope of about $50^{\circ}$ from a height of 2,000 feet, and is crossed by numberless crevasses. I named this glacier Sir George Newnes Glacier, and the glacier between Cape Adare and this place, which we passed running up towards this cove, and which forms a kind of saddle in the ridge stretching from Admiralty Range down to Cape Adare, I named Warning Glacier, because I noticed that before every gale from the S.E. a cloud of snow swept over it into Robertson Bay, giving a timely warning of the approaching gale. Immediately to the westward of Sir George Newnes Glacier a bold cape terminates a land some 3,500 feet high, which I named Cape Klövstad, after the medical officer on my staff, and to the westward of this land a broad glacier descends, which I named Sir John Murray Glacier, after my good friend the eminent scientist of the Challenger Expedition.

At the end of Robertson Bay, Mr. Hanson, 


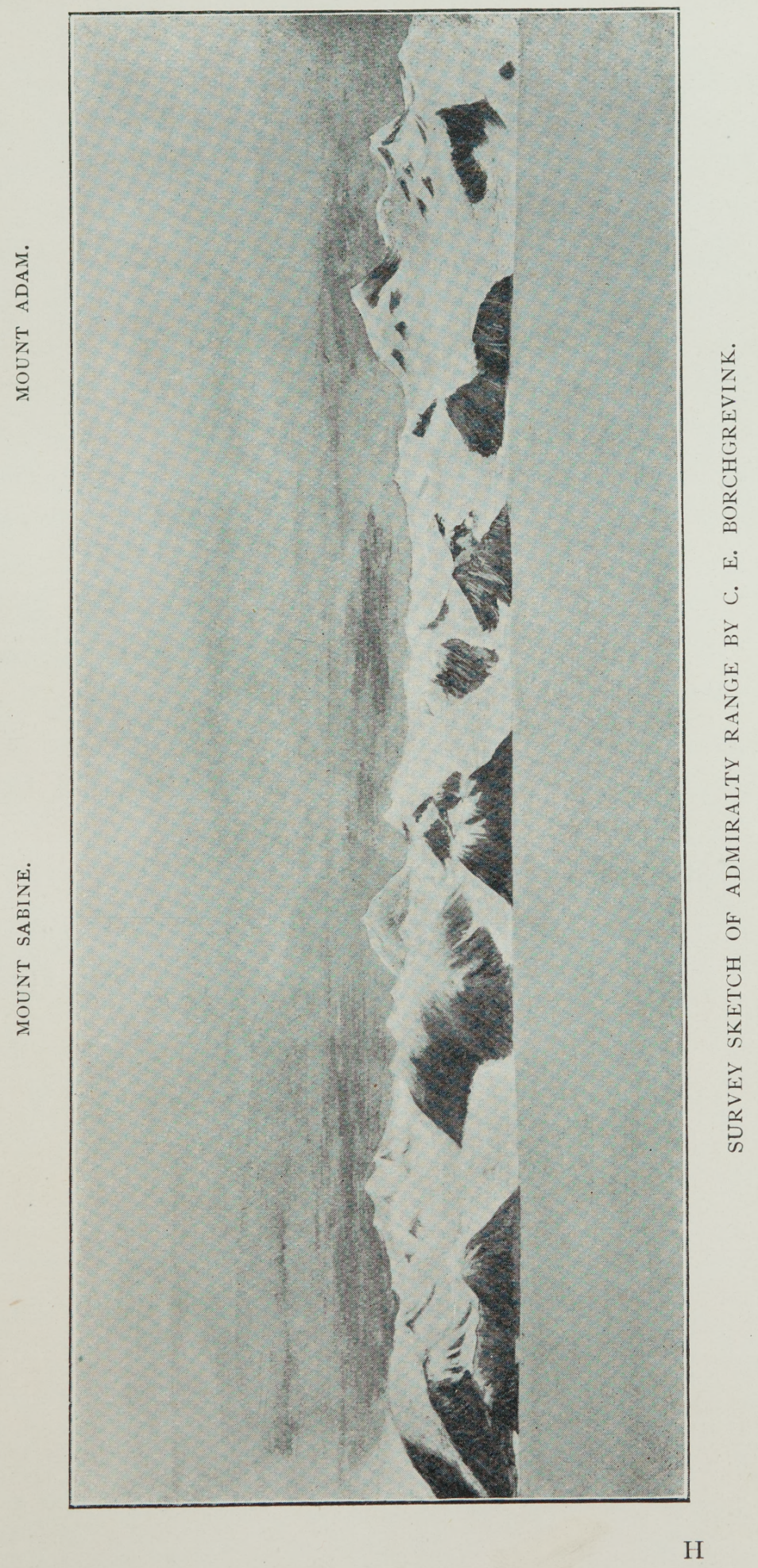



Mr. Fougner, Lieut. Colbeck, and a good mountaineer from amongst the crew named Yngvar, made an ascent of the mountain ridge, and reached the height of 3,000 feet, finding vegetation on their way to the very top. From the vessel in the cove we watched with interest their toilsome progress as they struggled over glaciers and up steep rocks. For a time I was anxious about them, but it soon became evident that the sailor Yngvar was an excellent mountaineering guide, and about midnight they returned, bringing with them a rich collection of rocks and mosses.

On March 2nd we hoisted the Union Jack presented by H.R.H. the Duke of York, at Cape Adare at 2 P.M, and greeted it with loud cheers from those on shore, and with a salute and with dipping of the flag from on board. Addressing the staff and crew, I said :-

"Hereby I have the honour of hoisting the first flag on the great Antarctic Continent. It is the Union Jack of Great Britain.' 


\section{CHAPTER IV.}

\section{Cut off From all the World.}

In the evening the Southern Cross left us at our pioneer settlement on Cape Adare, which I had christened Camp Ridley, ${ }^{*}$ with instructions to proceed to New Zealand, and to return to us as soon as possible in the New Year. Amongst other instructions, I laid great stress upon one, namely that Captain Jensen should not, even on his return voyage to us, shape a course to the west of longitude I $70^{\circ}$, and I was pleased to find that by this means he was able to proceed with but very little hindrance from ice.

We were cut off from all the world, 2,500 miles south of Australia, and all ten of us realised our isolation as the vessel steamed away with wishes and greetings to those we had left behind us. What would happen to the Southern Cross and to ourselves in the coming year? Would it be possible for human beings to exist there? The conditions we should live under, and the natural forces we were destined to fight, would they be too strong for human energy and endurance? Should the Southern Cross be crushed, how long then, in all probability, would we remain in Victoria Land? All this 
passed through my mind, and no doubt through the minds of all ten of us, as we silently returned to the hut when the vessel had been swallowed up in the darkness. However, were we destined to fall in our fight, we would not have given our lives in vain, for our sacrifice would, perchance, lead future expeditions on to success without further sacrifice.

On landing I had carefully selected and taken on shore with me the following members of my expedition-Lieutenant W. Colbeck, R.N.R., magnetic observer; Mr. Nikolai Hanson, zoological taxidermist ; Mr. Louis Bernacchi, magnetic observer, astronomer, and photographer; Dr. H. Klövstad, M.A., M.D. ; Mr. Hugh Evans, assistant zoologist; Mr. Anton Fougner, generally useful; Mr. Colbein Ellefsen, cook; the Finns Per Savio and Ole Must.

The following departments I divided among these, besides their special professional duties-Dr. Klövstad and Lieutenant Colbeck, charge of provisions; Mr. Bernacchi, charge of instruments and explosives; Mr. Fougner, charge of travelling gear; Mr. Evans and Mr. Hanson, charge of fuel, light, ammunition, and guns.

I cannot but at once add that in their special departments every one of these showed himself exceptionally zealous and capable, and during the year we fought shoulder to shoulder in those regions, there always existed an honourable rivalry in making each of their several departments as perfect as possible.

The two Finns attended to the dogs and harness, and, in addition, proved themselves excellent hunters. I never saw them idle. The Finn Savio made with 
his own hand some half a hundred Finn boots, without which our feet would undoubtedly have been severely frost-bitten. These two were also, with their characteristic sincerity and simplicity, delightful comrades on our sledge journeys. More faithful and devoted companions than them I do not think any commander could wish for.

On one occasion, a busy day, the Finn Ole Must was asked to hold for a moment a solar thermometer the bulb of which, through much trouble, had been successfully blackened with lampsoot by Mr. Bernacchi. Anxious to be useful, the Finn at once rubbed the soot off with his sleeve, much pleased to have cleaned the thermometer: it goes without saying that Mr. Bernacchi was not so pleased.

On the days following the departure of the Southern Cross, we had the arduous task of bringing the landed stores, provisions, coal, clothing, and timber up to the camping place, some three hundred yards up from the beach where it had been landed.

There were but few penguins left on the peninsula when we arrived, but very many seals were on the beach and swarming about in the water. They were the usual Antarctic seal, the Weddelli. They provided us at once with useful skins for our camp, and at the same time with fresh food for ourselves and the dogs.

I was glad I had sent the vessel away so soon after she had landed the stores, as the day after she had left Robertson Bay was already full of pack-ice, and the tidal currents raged.

On March I 2 th Mr. Bernacchi and I scaled 


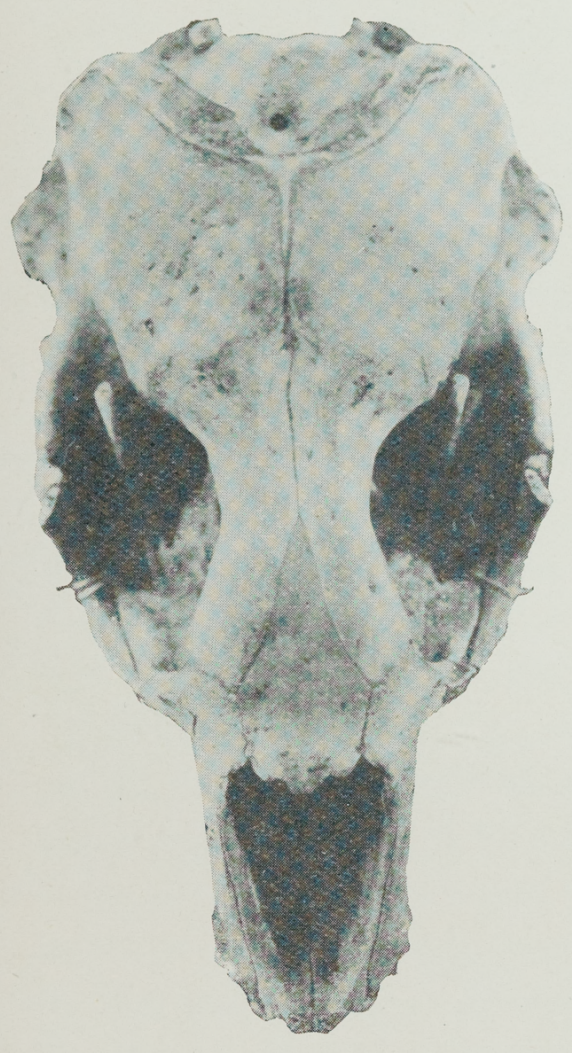

WEDDELLII.
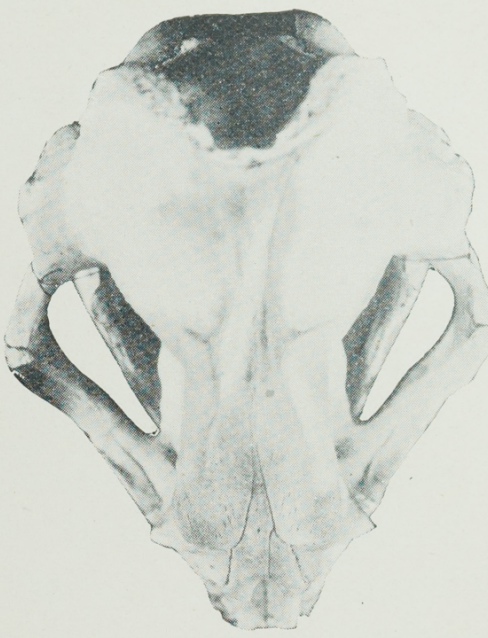

ROSSII.

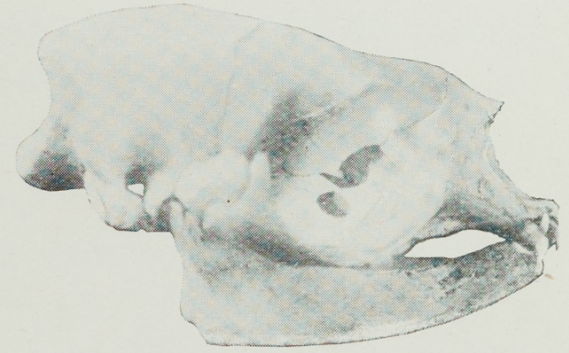

ROSSII.

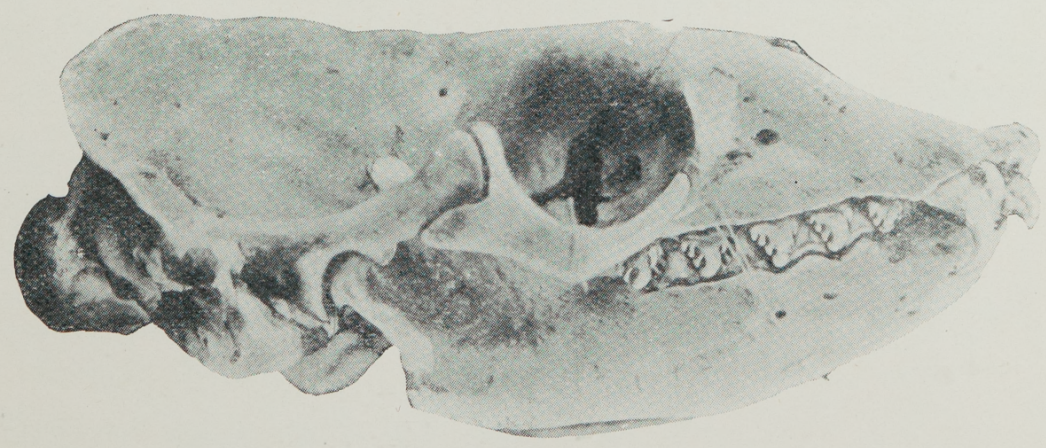

WEDDELLII. 

Cape Adare to the height of $3,670 \mathrm{ft}$., as indicated by the aneroid. The ascent was very steep for the first $800 \mathrm{ft}$, principally over worn rocks on the mountain side. On the top there were large mounds of pebbles and large boulders stretching from east towards west, on undulating ground. Here I found vegetation of the very same kind as that found on the lower rocks at Cape Adare in 1894. The penguins had been up as far as $\mathrm{I}, \mathrm{OOO} \mathrm{ft}$. I discovered no vegetation above $\mathrm{I}, \mathrm{O} 0 \mathrm{ft}$. in this locality. At the height of $3,000 \mathrm{ft}$. above the sea level there was a good deal of snow. We traversed some two miles south-westwards, and then again upwards in an easterly direction, and reached as far as the eastern side of the cape, where the perpendicular cliffs rose up from Ross's ice-free bay. Very little drift-ice was to be seen towards the south-west of the bay and in the immediate vicinity of the actual cape. A strong tidal wave passed near the cape north-westwards towards the western side of Robertson Bay, continued from there its run into the inner portion of that bay, and came back along the eastern coast. The whole of its course could be distinctly observed from the top, by the movement of the drift-ice.

On the I 3 th March most of the provisions were brought up to the house.

It was Sir George Newnes's birthday, and we celebrated it by hoisting the flag.

The temperature, which during the last few days had kept about $22^{\circ}$, now began to fall rapidly. Already on the I4th all the penguins had left us. The skuagulls (lestris), which were about in great 
numbers at our arrival, also began to get scarce. Mr. Bernacchi and Mr. Colbeck completed on this date their magnetic observatory in the large Finn tent, which was secured by stays of rope. The meteorological observatory, some 300 yards away from the huts, was also completed by this date. On the I $5^{\text {th }}$ March we saw the first Aurora Australis; it had the form of curtains waving from south towards east. On the i 7 th we brought up the last bags of coal. On the 18 th we prepared a preliminary expedition to the top of Cape Adare, whence I hoped to be able to reach the inner part of Robertson Bay. Already the first night came on with a hurricane. Mr. Fougner, Mr. Colbeck, and myself had cold and anxious hours, fighting hard not to be blown over the cliffs with all our outfit. The hurricane blew in fierce squalls with snow-drift, and as the weather continued bad I decided to return to the camp. On Monday we reached Camp Ridley, where I found that we had lost one of our boats. It had been lifted bodily up from the beach and smashed against the rocks. At Camp Ridley the wind had a velocity of eighty-seven miles per hour.

The Finns were busily engaged in making fur suits out of seal-skin, as I found that skin and fur is the only clothing which keeps the cold out on windy days; and on calm days the Jaeger suits were the most suitable. Robertson Bay now began to freeze. 'The days were spent in daily meteorological observations, which were taken every second hour, and whenever clear weather permitted astronomical observations were made. The magnetic work went on whenever the magnetic conditions were favourable; 


\section{Cut off from all the World.}

although some local attraction was experienced, it was less than expected.

The following is a table of the heights (in centimetres) and chest measurements (in centimetres) of the members of the Expedition, who were landed:-

Observations by Dr. Klöustad.

\begin{tabular}{|c|c|c|c|}
\hline & & Height. & $\begin{array}{l}\text { Chest } \\
\text { Measurement }\end{array}$ \\
\hline C. E. Borchgrevink & . & . $\quad 175.2$ & $.95 \cdot 7$ \\
\hline Louis Bernacchi & . & I69. I & 93.0 \\
\hline William Colbeck & . & 170.7 & $95 \cdot 5$ \\
\hline Hugh Evans . & . & I 8 I.4 & 102.5 \\
\hline Colbein Ellefsen & . & 176.1 & . 9 г .5 \\
\hline Anton Fougner . & & $165 \cdot 3$ & 94.2 \\
\hline Nikolai Hanson . & . & 178.8 & 93.0 \\
\hline Herlof Klövstad . & & I69.7 & 94.0 \\
\hline Ole Must . & . & г6г.5 & 90.5 \\
\hline Per Savio & & $\mathbf{1} 65.9$ & 90.0 \\
\hline Date & $28 / 3 / 99$ & & \\
\hline
\end{tabular}

Our few leisure hours were spent in shooting at targets, a sport which we, however, very soon had to give up as the barrel of the rifle became hot with the first few shots; the air surrounding it naturally stood in a quiver and produced a minor mirage, which had the effect of misplacing the sight of the rifle.

On March 22nd Mr. Bernacchi was going to take a photo of a magnificent seal which had managed to crawl far up on the peninsula near Camp Ridley. Enthusiastic as he always was, and eager to secure a striking photo of this seal, which was lying lazily and sleepily on the pebbles, looking almost as if it were lifeless, he repeatedly asked it to "look pleasant," "cheer up," "smile," and anything else he could 
Io8 British Antarctic Expedition.

think of, all the time moving closer towards it with the velvet cover over his head, and with the camera in front of his face, for the purpose of taking the

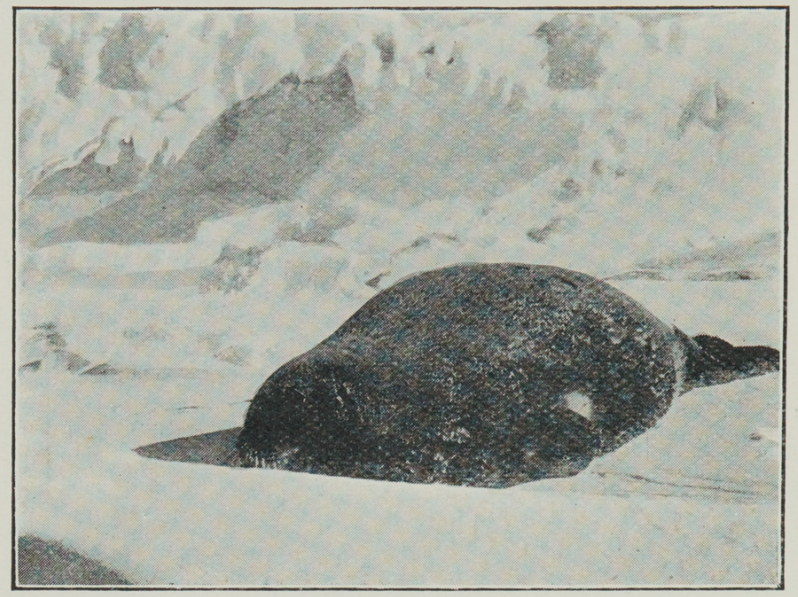

"HE REPEATEDLY ASKED IT TO LOOK PLEASANT." photo from the most advantageous side and in order to focus it. The seal continued to sleep. Vexed at its indolence, M r. B e rnacchi asked

Mr. Colbeck to give the brute a gentle kick, which he did, with the result that the seal, with a tremendous roar, rose on to its flippers and dashed towards the lens of the camera through which Mr. Bernacchi glared at it some three or four feet away. The scene was changed. It was now the seal taking a mental photo of Bernacchi lying on the ground with his legs in the air, but faithfully sticking to the camera, while the velvet cloth mercifully covered his face from the savage look of the seal, and the amused spectators.

On April ist we were again shooting with a rifle at a target in the morning. It was All Fools' Day, and we used the opportunity for all sorts of surprises by playing practical jokes on one another. $\mathrm{Mr}$. Hanson, who was in the hut at the time, was told that Mount Sabine was in eruption. He rushed out and 
looked with his naked eye for a considerable time, but could see neither fire nor smoke. On Fougner's advice he asked the doctor for a pair of field glasses ; whereupon the doctor, in his ordinary calm and sedate manner, handed him a gun-case and informed him that "Mount Sabine was in activity every ist of April." In the evening the doctor had the best of us all by telling us that it was his birthday, at which we all made a lot of him and found it a welcome excuse for extra rations.

On the 2nd April a gale was blowing at the rate of eighty-two miles an hour, with heavy snow-drift. On the 5th April a good deal of snow fell and the peninsula was for the time being completely covered. On the 7 th April, about 2 in the morning, a gale started again from the S.E. All the snow was swept from the peninsula. The snow squalls which plunged down from the cape wrapped Camp Ridley in a dense whirl of snow-drift ; the

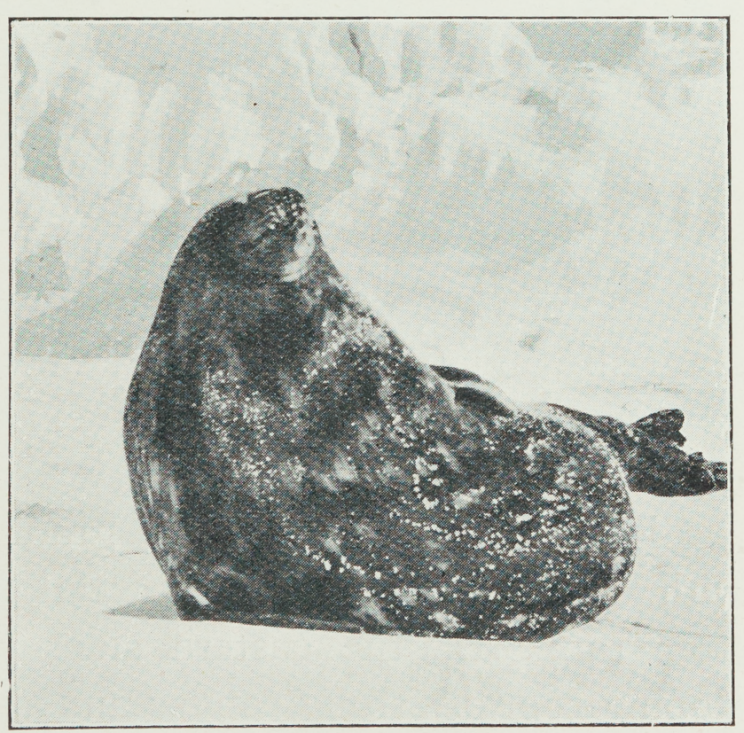

A WEDDELLII SEAL.

dogs were completely buried. The ice in the bay was ground up, and waves of snow, ice, and water dashed up against our beach, and sent the spray flying over 


\section{IO British Antarctic Expedition.}

the roof of the huts. On the 8th April, when the gale had abated, on going along the beach Mr. Hanson and myself were startled to find, washed on

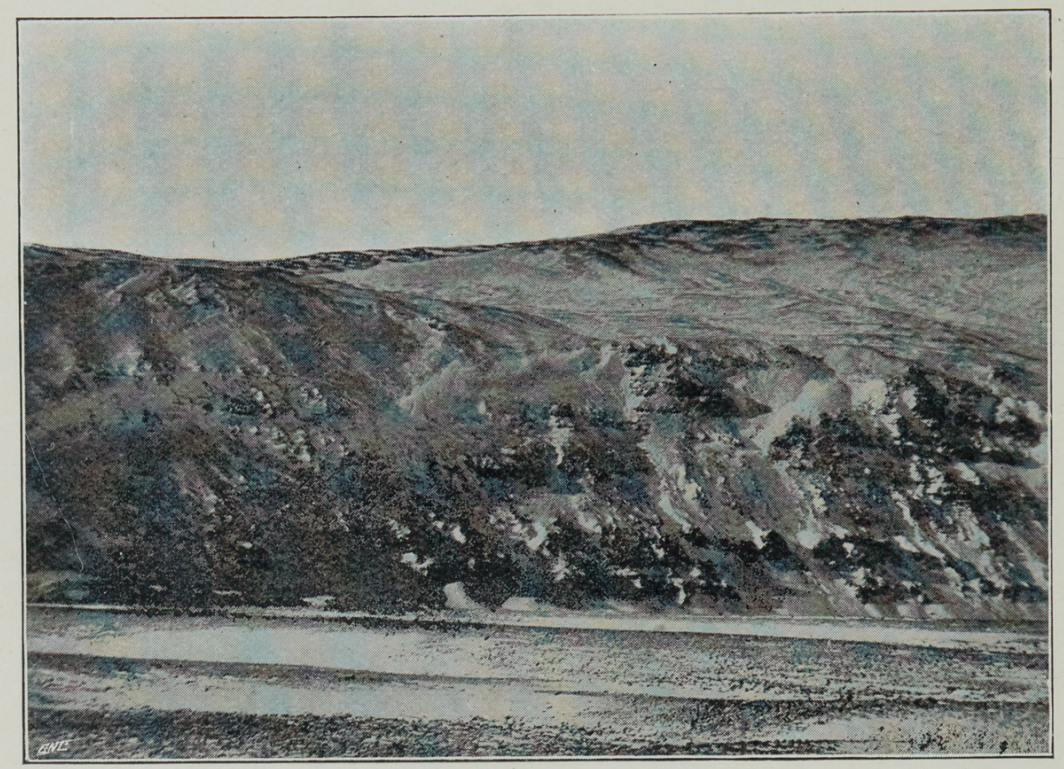

THE RIDGE OF CAPE ADARE.

shore, numberless specimens of medusæ, hydroids, star-fish and algæ. Should then, after all, an extensive shallow-water fauna exist within the Antarctic Circle?

The roof of our huts we gradually covered over with seal-skins, and, in expectation of further gales from the S.E., the eastern sides were fortified by a sloping roof of strong canvas and seal-skins, weighted down by numberless bags of coal and boulders. Hanson discovered on this day (April 8th) a fish, and shot a seal which had fragments of partially digested fish in its stomach. On the 9 th April I again visited the plateau of Cape Adare, and brought 
back very interesting geological specimens. The doctor was from time to time tapping us for blood, and making microscopic investigations thereof. The health up to that date had been excellent. It was remarkable to see the quick rise and fall in the temperatures, and considering the near approach of the winter, they kept comparatively high. We now caught many fish in the bay, some of which were over twelve inches long and about seven inches in girth. I had photographs taken of all the specimens, also of the various peaks on the coast within sight, and cinematograph photos taken whenever opportunity offered and incidents of interest occurred.

On the IIth April Mr. Hanson was using the handy small collapsible canvas boats for net-work, but the strong current near our peninsula did not facilitate $h$ is endeavours.

On the i2th April snow covered the ground. Hanson's eyes were bad; they were swollen, and looked as if they had a sty on them. He w a s a 1 w a s

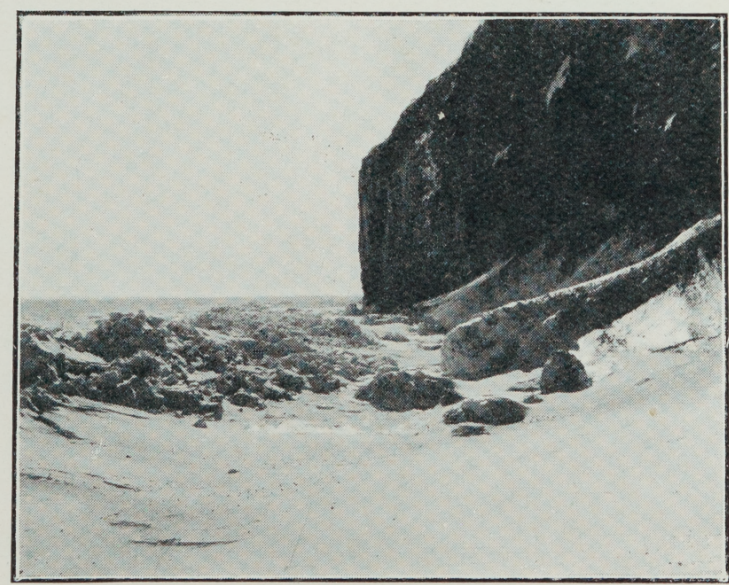

VIEW ON THE COAST. obliged to use "goggles" when out of the camp. On the I3th Hanson caught six fish of two different kinds, from six to eight inches long, in a 


\section{2 British Antarctic Expedition.}

depth of from five to eight fathoms. The fish were caught in the bay about two cables' length from the shore by a strong line with an ordinary Norwegian

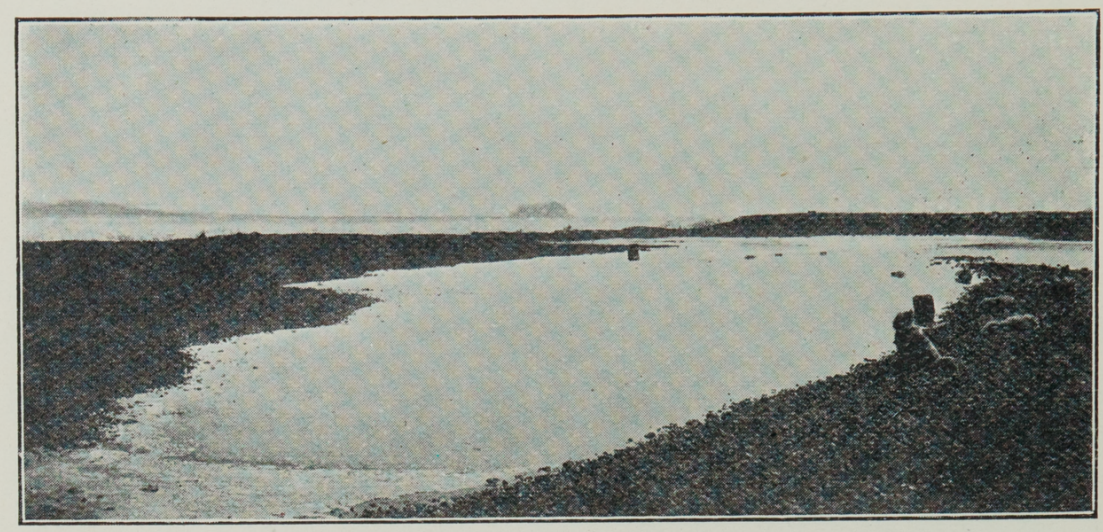

LAGOON AT CAMP RIDLEY.

"pilk" attached. Most of the fish were caught by this appliance, and without any bait.

On the I6th Fougner and Hanson were fishing on the floes. The former returned with fourteen fish, three of them being over twelve inches long, and with a girth of seven inches at the widest part.

On the igth April we discovered a very fine cave some eight feet high and stretching into the rocks of Cape Adare for some hundred yards. Beautiful icecrystals made the walls of this cave look as if formed by stalactites.

Mr. Evans, who in former days had been in Canada, had unlimited stories of all heights in store for stormy days. Once upon a time, he told us, he was driving cattle in Canada. It was on a big plain ; and he and a bosom friend had charge of some 500 cattle; they were riding leisurely along behind the 


\section{Cut off from all the World.}

tails of the oxen, enjoying an evening pipe under their broad-brimmed hats. It was just getting dusk when up rides a highwayman, pointing his revolver at them and demanding their money, watches, and, if I do not remember wrongly, their pipes also. "It was hard luck," Mr. Evans said, but they had to give up all as they had no weapons themselves, and resistance would have been useless. However, when the robber was about to depart, Mr. Evans conceived
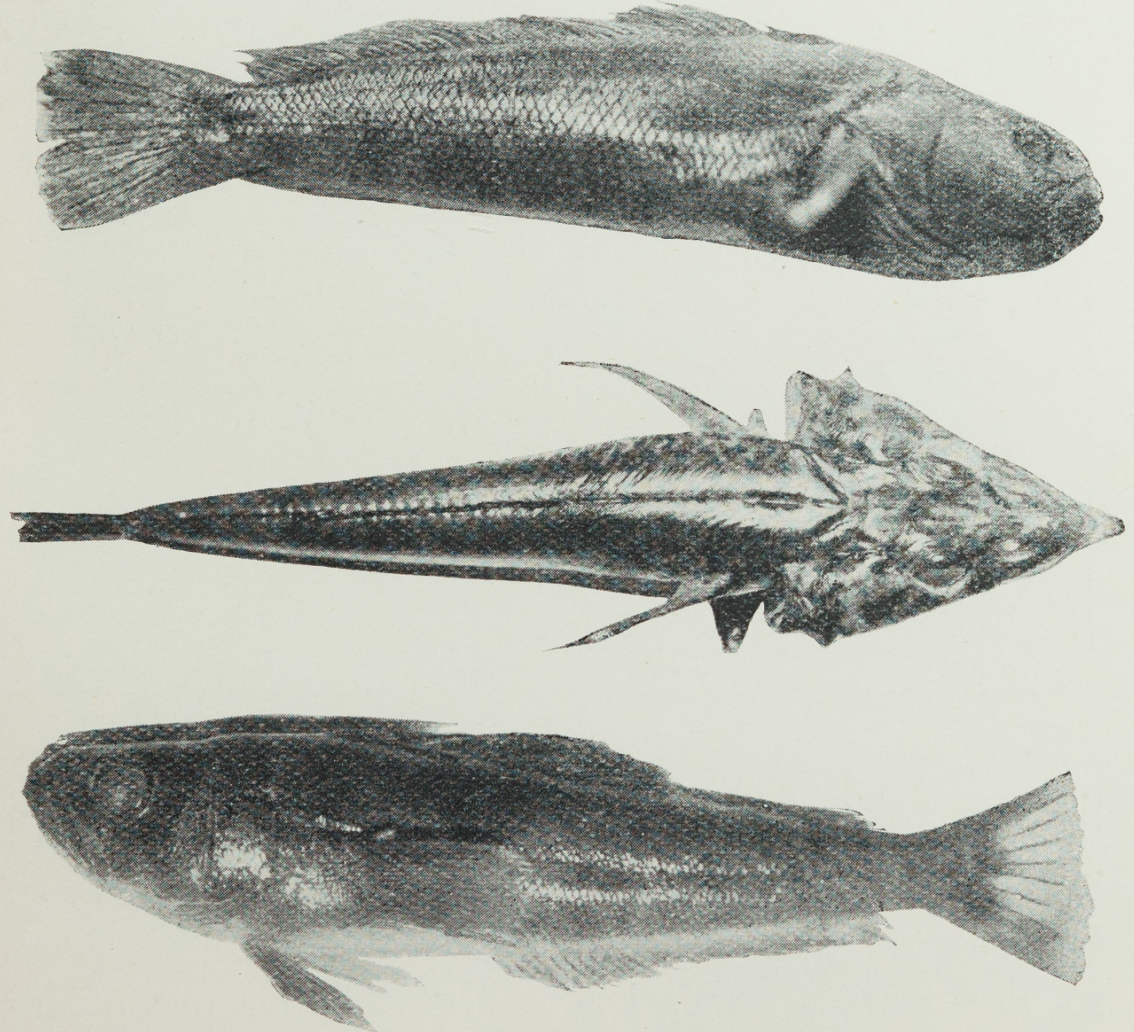

FISH FROM ROBERTSON BAY.

a bright idea. He drew out a pack of cards and invited the departing robber to make a third in a game, which he consented to do. Mr. Evans and 
I 4 British Antarctic Expedition.

his mate showed themselves as great experts in handling cards as their savage visitor in the handling of his revolver; they stuck to cards until, by the help of them, they had regained not only their watches and money, but also their pipes, and, in addition, became the possessors of the watch, money and revolver, horse and saddle, of the unfortunate

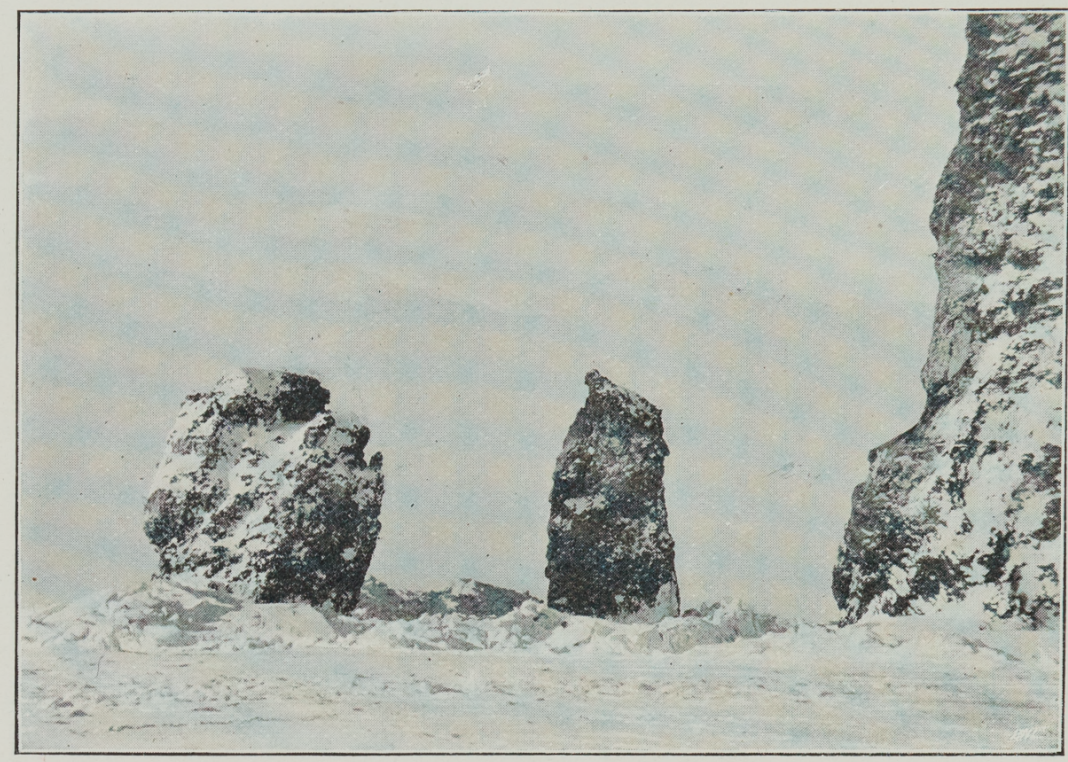

THE TWO SISTERS.

thief. "Poor fellow," Mr. Evans remarked with intense compassion, "he was fairly done, and when he told me he had not enough money to get back to the nearest town, I lent him a dollar out of his own purse!" For some minutes profound silence reigned round the table, then Mr. Bernacchi, who had heard similar stories in the Australian bush, had to remark, "Come, come, Mr. Evans, you do not mean to say that you were mean enough to pay him 
out of his own purse?" "Well, you see," Mr. Evans replied, "it was a fair game."

We observed great movement in the ice-pack in Robertson Bay during the middle of April. On the 22 nd I resolved to attempt my first penetration into Robertson Bay on the ice, which then, though young, was already about two-and-a-half feet thick. I took with me Mr. Fougner, Mr. Bernacchi, and the Finn Savio, provision for twenty days, twenty sledge-dogs, and one small collapsible boat. We left Camp Ridley at I. I A.M., and proceeded in the pack until darkness began to set in. The pack along the cliffs was rather small, and the ice which bound the floes together rather thin, so we had to proceed with great caution, and when I at last decided to camp on a small beach at the foot of the perpendicular wall of Victoria Land, we had great difficulty in reaching that little place. The beach or slope where we pitched our camp was not thirty yards at the widest part; it was some four feet above water, and had a crescent formed with the concave side some 15 chains in length. From the perpendicular wall of Victoria Land a kind of gravel rush had taken place, and formed a deep slope from the walls of the rocks down to the beach, with a slope of from sixty to seventy degrees, rising to a height of about thirty feet. Above us the perpendicular wall rose to about five hundred feet at places overhanging the little beach, which seemed completely isolated from everywhere, except by way of the bay. Shortly after landing a southerly wind rose, which continued to increase in force until it became a violent gale. We had pitched the silk tent, and 


\section{6 British Antarctic Expedition.}

my companions took their sleep whilst I kept watch. At 7 P.M. I had to wake them, as the ice began to break up. It was not a moment too

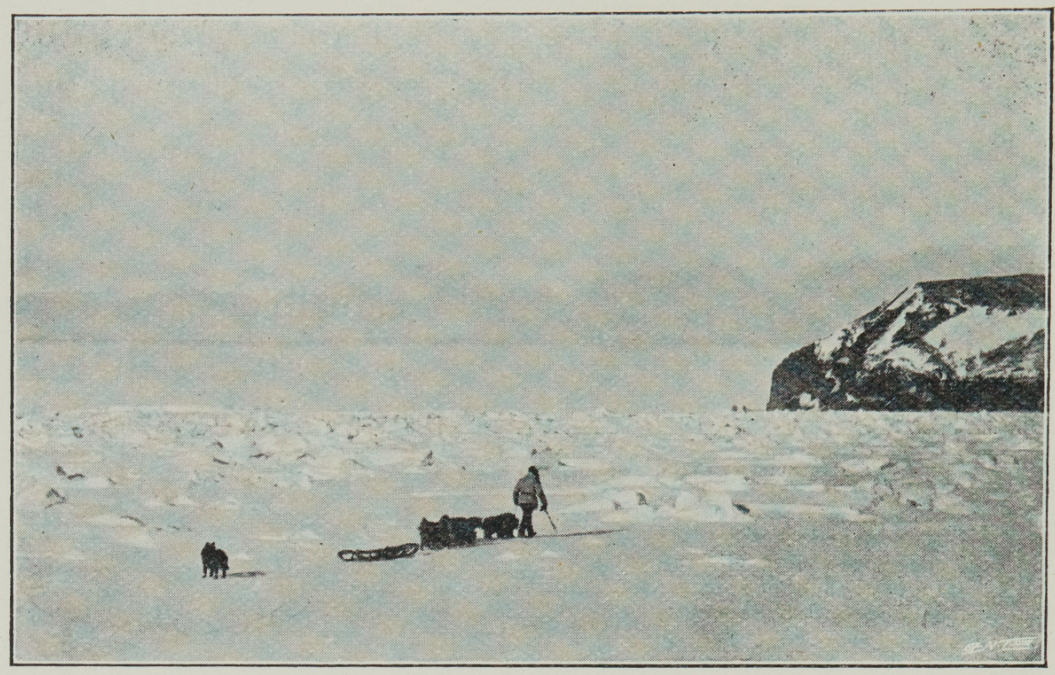

ON THE MARCH.

early; it just gave us time enough to save our provisions by carrying them on to the top of the gravel slope, where drift snow and ice had formed a sort of gallery, about six feet broad, immediately on to the mountain wall. The drift snow had also formed a kind of fence at the outside of this gallery to the height of about four feet. In the six-foot groove between this fence and the perpendicular wall of Victoria Land we pitched our tent, but before doing so we had an arduous task. We hauled away, suffering intensely from the cold, our fingers dying as we hung to the ropes while pulling provisions and travelling gear up to our limited accommodation. The huge breakers washed over the beach and sent spray about us; it froze 
immediately, and soon land and men were covered with a sheet of ice. Although everyone realised the awkward position, all worked calmly. On Monday night, the $23 \mathrm{rd}$, the bay was completely free from ice and was perfectly calm. I then sent Mr. Fougner and the Finn Savio towards Camp Ridley in the small blue collapsible boat, and with emergency rations sufficient for a few days. However, shortly after leaving us, and having gone out of our sight, they met with heavy ice drifting rapidly into the bay, which, as mentioned, it had left during the gale. Mr. Bernacchi and myself, who soon afterwards noticed the floating ice masses, were naturally very anxious about them, ignorant

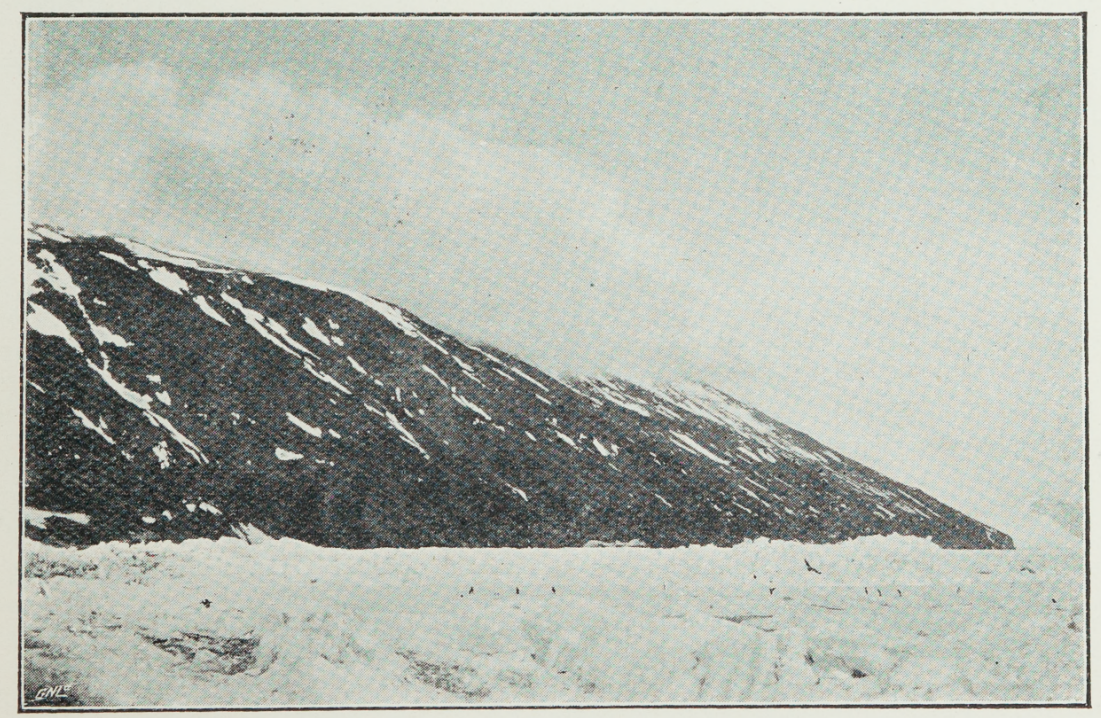

COAST-LINE IN ROBERTSON BAY.

as we were of their fate in the little canvas boat. We ourselves were without any craft whatever to take us away from our temporary place of refuge. 


\section{I18 British Antarctic Expedition.}

For two days we remained in ignorance of Mr. Fougner's and the Finn's fate; but in the evening of the 25 th both of them appeared on a very steep ice

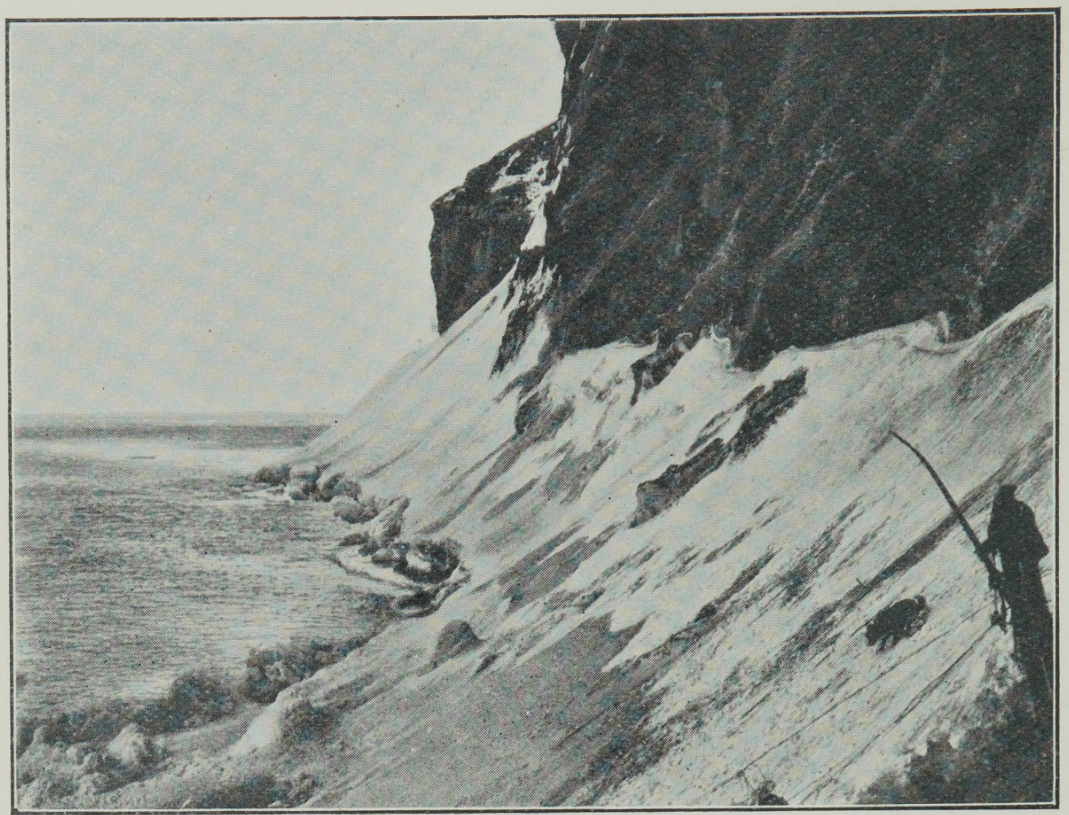

REFUGE CAMP.

swell, which descended from the perpendicular wall of Victoria Land. By help of a small axe and an alpenstock they cut footholds in the ice and then slowly approached us. I soon discovered that they were in a pretty weak condition, and while Mr. Bernacchi started to cook some food for them, I began to cut steps in the steep ice-slope to meet them. At night we were again all safe on our little campingplace. However, Mr. Fougner and the Finn had spent two days and nights under the shelter of the canvas boat, and thought they had discovered a possible place, or the only possible place, for an 
ascent to the ridge of Victoria Land some 5,000 feet above us. But the first 500 feet would necessarily involve great risk in the ascent. On the 27 th I decided to attempt the ascent. We started in the following order: the Finn Savio, Mr. Fougner, Mr. Bernacchi, and then myself, roped together. We had to cut footholds in the ice. By following in the steps by which Mr. Fougner and the Finn had reached us, we were enabled to attain the place where these two had camped under the small boat, and saw the spot likely to offer the only chance of escape. It was a kind of rough groove in the perpendicular cliff, partly covered with ice and snow. After having had a good feed of seal-beef we began the ascent. Some of our poor sledgedogs, which had ventured along with us on the s lop e, howled mela nc h o 1 y notes as they saw us ascend. Three of them had already

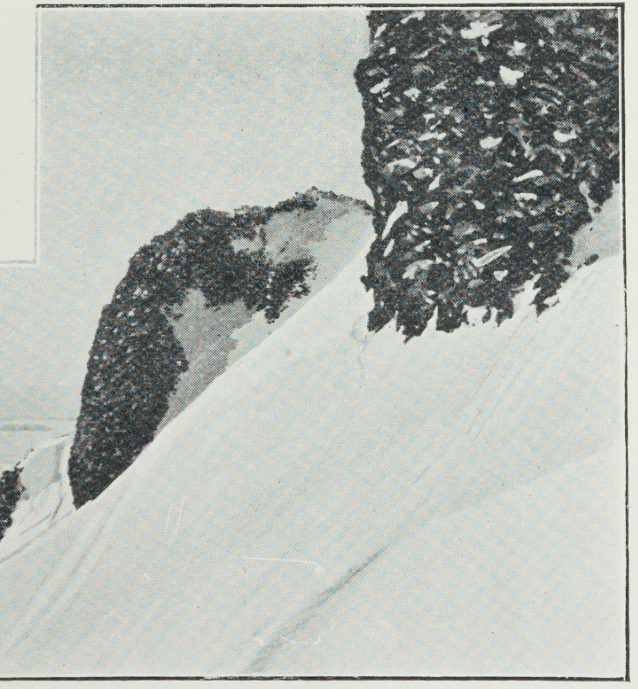

"WE HAD TO CUT FOOTSTEPS IN THE ICY SLOPE TO REACH THE RIDGE 5,OOO FEET ABOVE US." perished

by losing their foothold coming round the icy slope, and one was precipitated into the abyss below when we were some 200 feet up in the groove. Cautiously 


\section{20 \\ British Antarctic Expedition.}

and slowly we climbed upwards, while the lesser slope some 400 feet above us seemed always to grow further away as we slowly ascended towards it. All the night

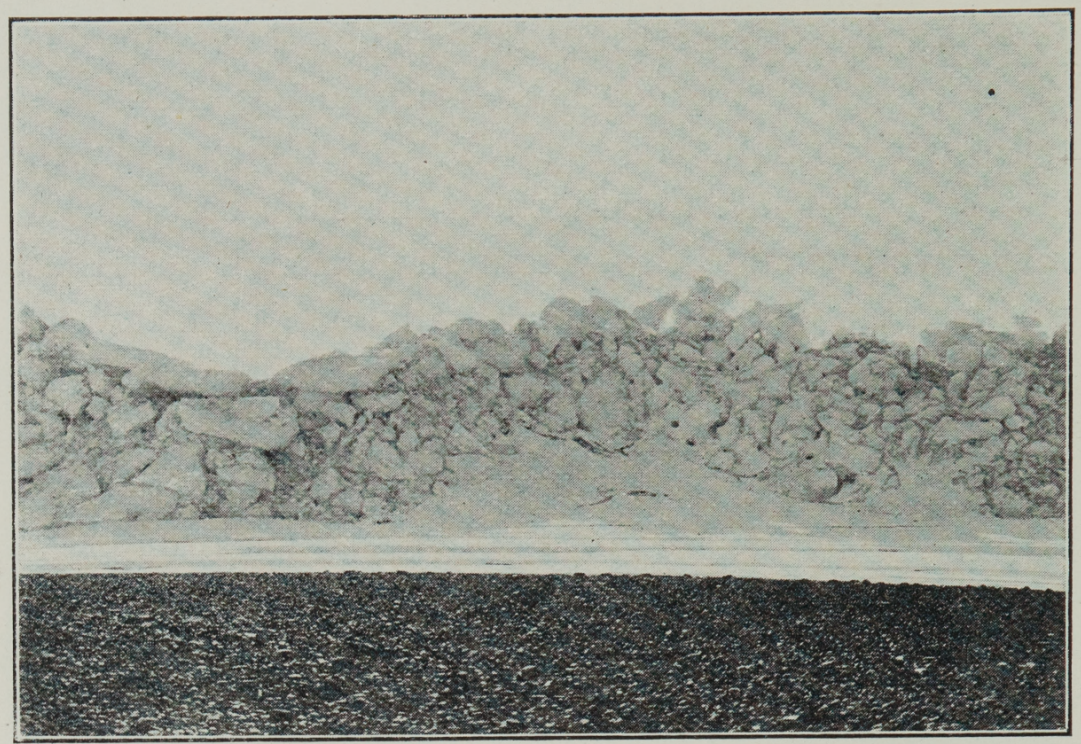

"IT WAS ONE MOVING WALL OF GRINDING ICE-BLOCKS."

through we continued to climb, while the cold increased as we got up in the heights. By way of the ridge we were cnabled to proceed towards Camp Ridley, where great anxiety had prevailed already on the day when the ice broke up, as they knew of no place where we could possibly have camped at the time.

There were many seals on the ice-floes, the flesh of which some of us ate raw. The Aurora Australis was seen nearly every clear night at this time.

On May 5 th seventy-one fish were caught. I saw that day one of the brown-backed petrels. In the evening while we were having a slight supper we heard roaring and crushing to the N.W. of our peninsula, and when we came near the beach we 
witnessed a scene of singular grandeur. The ice-fields were screwing, and at the beach the pressure must have been tremendous. Already a broad wall some 30 feet high rose the whole length of the $\mathrm{N}$.W. beach, and coming nearer we saw that the whole of this barrier was a moving mass of ice-blocks, each several tons in weight. The whole thing moved in undulations, and every minute this live barrier grew in height and precipitated large blocks on to the peninsula where we watched the interesting phenomena from a distance of a few yards. The roar of the screwing was appalling. The force and direction of the pressure seemed to alter from time to time, and the

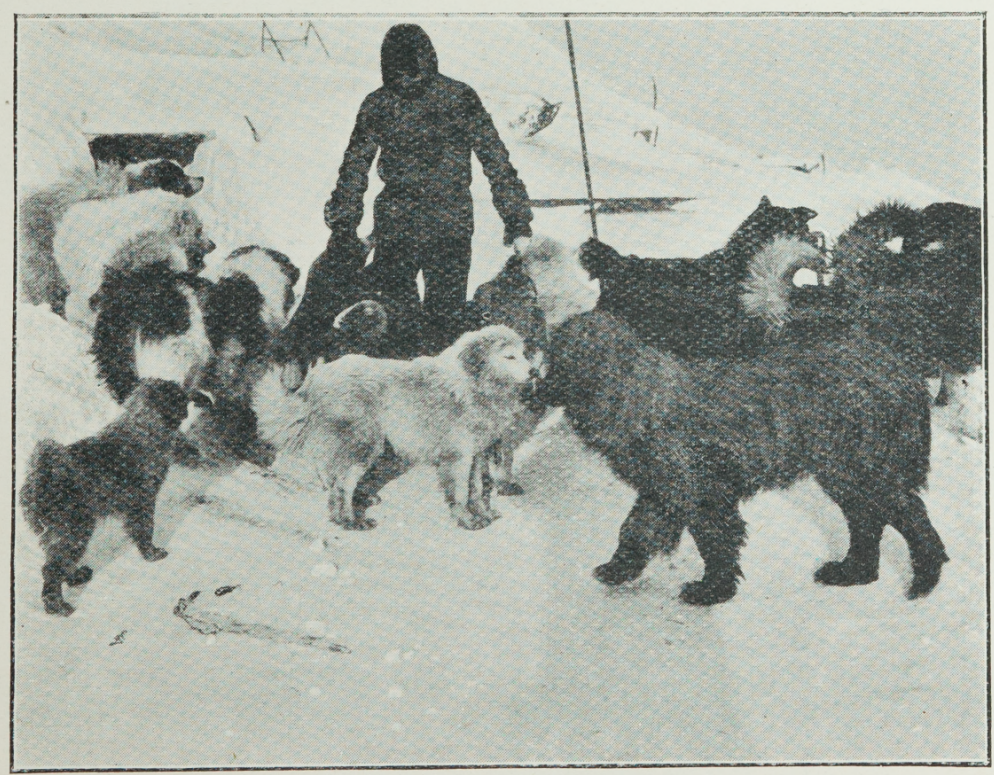

"THE DOGS WERE GREAT COMPANIONS."

change was visible in the movement of these icemasses. Like Antarctic gales, this roaring and gnashing might cease near the shore for some minutes, 
though we still heard it out at the horizon. During these minutes of silence the barrier seemed as firm as the rock of Cape Adare until the pressure again

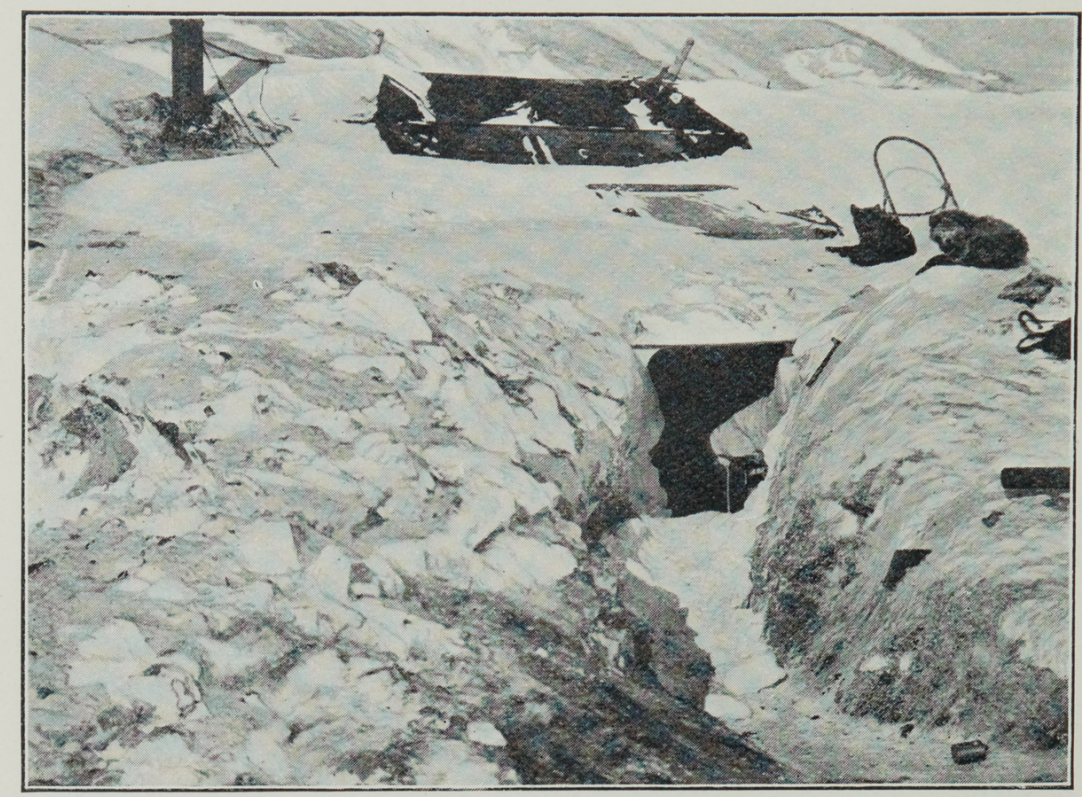

ENTRANCE TO THE HUT IN WINTER.

struck the peninsula, when the whole barrier seemed alive again and in motion. When the pressure ended, the barrier must have been between 40 and 50 feet high at its greatest. Towards midnight the screwing suddenly ceased. During the progress of this icepressure we began to wonder whether the whole peninsula would be covered by ice-blocks during the winter; and it was with a kind of relief that we witnessed the last of the interesting display.

During the coldest period, and often during gales, the dogs killed each other and ate their dead comrades. Being in nature like wolves, they hungered for fresh meat and blood. On board the vessel they 
had quarrelled occasionally, but being so closely under our eyes they had no opportunity to kill one another. It was otherwise on shore. On the very day that they were landed they seemed to have a general "day of reckoning." They fought furiously, and two or three good dogs were killed. It was not always the weakest dogs who succumbed in these fights, generally the reverse. They seemed with one accord to boycott a single dog for days and weeks, and that particular dog evidently knew the danger, as he generally sought refuge with us, and was so panicstricken, once he had been hunted by the others, that for days he would go without food. Then, driven by

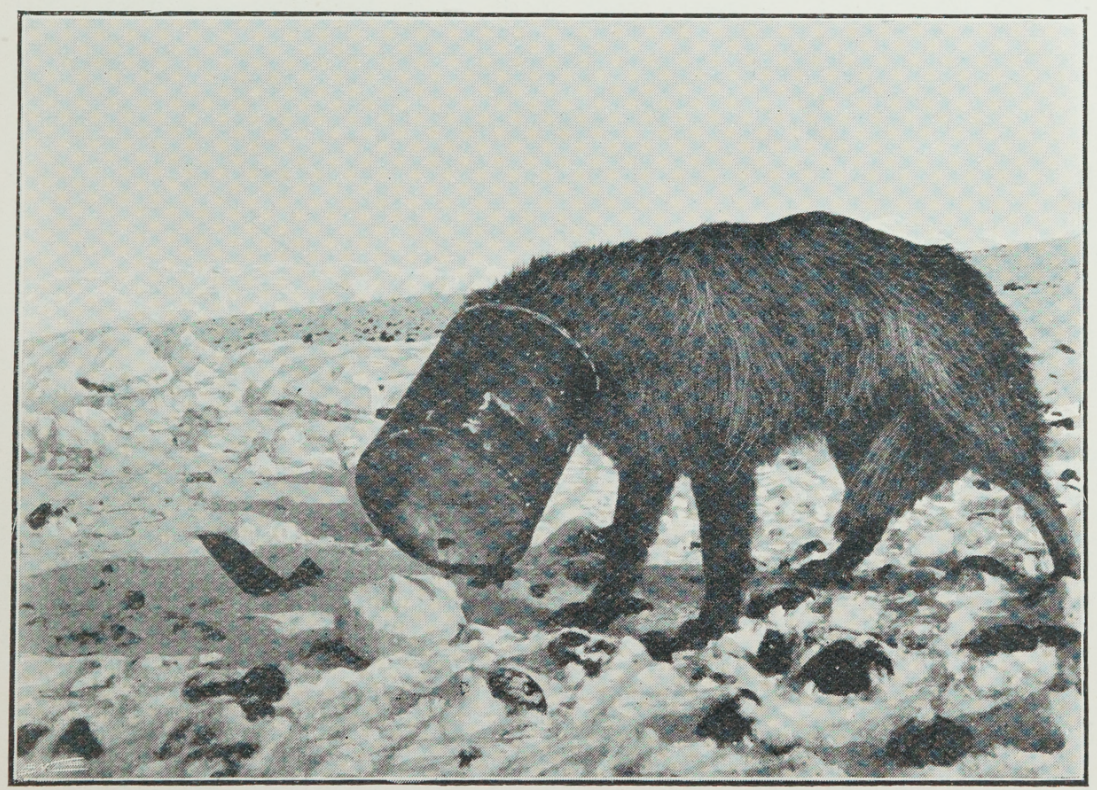

"THEIR TONGUE STUCK TO THE METAL, AND THEIR HOWLS BROUGHT THE PHOTOGRAPHER."

hunger, or forgetting for the moment that he was marked to be killed, he might show himself, even on the peninsula or far out on the ice. Off went the other 


\section{I24 British Antarctic Expedition.}

dogs like wolves in pursuit, nothing could stop them. Whips were useless, the "boycotted one" was doomed. They set upon him, and before anyone could help he was torn into pieces by forty or fifty of his comrades. Even if we had a chance, it was by no means an easy matter to extricate a dog thus brought to bay. Some of our best dogs were killed in the way described.

On May 6th we had already so many specimens of fish preserved in formalin and spirit that I decided to use at least some specimens as additions to our stock of provisions. The question naturally arose "Were these fish eatable?" and we drew lots as to who was going to risk the first fried fish, with the result that when the first dozen fish, hot and fried, appeared on the table, we all started at once, and none of us will forget how refreshing a change this meal of fresh, excellent-tasting fish became to us, who for months had been living on tinned food.

On May 8th a very heavy gale was blowing with snow-drift. Ten feet of snow was outside the door. The elegant white petrel (Pagodroma Nivea) was seen from time to time soaring about the peninsula. The daylight was now very short. We were continually returning to camp with ears, noses, cheeks, hands and feet frozen.

On May 9th we caught fifty-eight fish with only a few hours' fishing. We had to cut holes through the ice to let the line down, and whilst sitting and watching the line we might be startled by a seal who saw a chance for a sniff of air suddenly shooting his nose up through the hole at the side of our line, glaring at us, and then quickly disappearing.

I saw four white petrels in the evening. 


\section{CHAPTER V. \\ The Winter in Victoria Land.}

ON May 1oth we had an entertainment. I gave a lecture with an account of our work up to date.

The following was the programme of this concert :-

Mr. BorChGrevink . . Lecture.

The Doctor . . . Showing magic lantern (very magic). The views were illustrated advertisements shown on the wall by the light of a bull's eye lantern.

Mr. Fougner . . . Broke down in his song ("Paddling down the Strcam.")

Mr. Hanson . . . . Song of a fisherman.

Colbein Elleffere . Norwegian song.

Mr. Evans ... . Two songs of a comical character.

Mr. Bernacchi . . . Songs and reading.

Mr. Colbeck . . . . Songs and reading.

Per Savio and Ole Must. Lappish duet.

After the entertainment we generally had some nuts, a glass of grog, and a pleasant smoke.

In the forenoon I had discovered a small white clear jelly-fish with a distinct blue cross in it. I named it the "Southern Cross" jelly-fish. Odd moments in Camp Ridley were now occupied by mending the sledges; we used spare ski as runners, 


\section{I26 British Antarctic Expedition.}

and laced them to the framework of the sledges by means of strips of seal-hide. In addition we mended and improved tents and clothing.

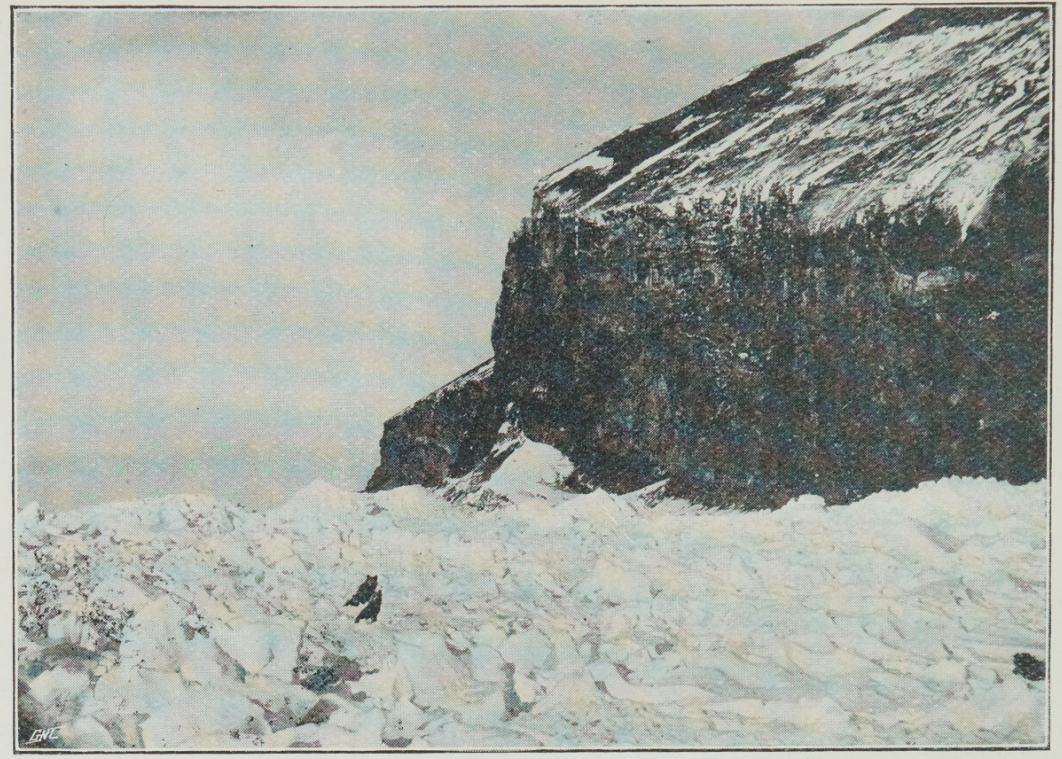

"IT WAS A ROUGH PAVEMENT ON WHICH TO TRAVEL."

On May $15^{\text {th }}$ we had the last greeting from the departing sun. The refraction of it appeared as a large red elliptical glowing body to the north-west, changing gradually into a cornered square, while the departing day seemed to revel in a triumph of colours, growing more in splendour as the sun sank, when the colours grew more dainty, and surpassed themselves in beauty. It imprinted itself upon the minds of us ten so strongly that it made life possible for us through those dark days and nights to come. The promising effect of that evening of the I5th May, I 899, lasted and cheered us until the returning sun again made the peaks and crevasses shine on the 27 th July. 
Both during the time the sun was low in its descent and when it rose again, a strong mirage effect was observed towards the west, showing images of icebergs far below our horizon, and Antarctic scenery only visible to us through this phenomenon. This strong mirage remained after the sun's return late in the summer, and the opening of the ice was prophesied to us in the mirage long before the ice-fields near Victoria Land broke.

It was very interesting to see the picture of far-away broken ice-fields, with their dark channels and towering icebergs, in the north-western sky; and

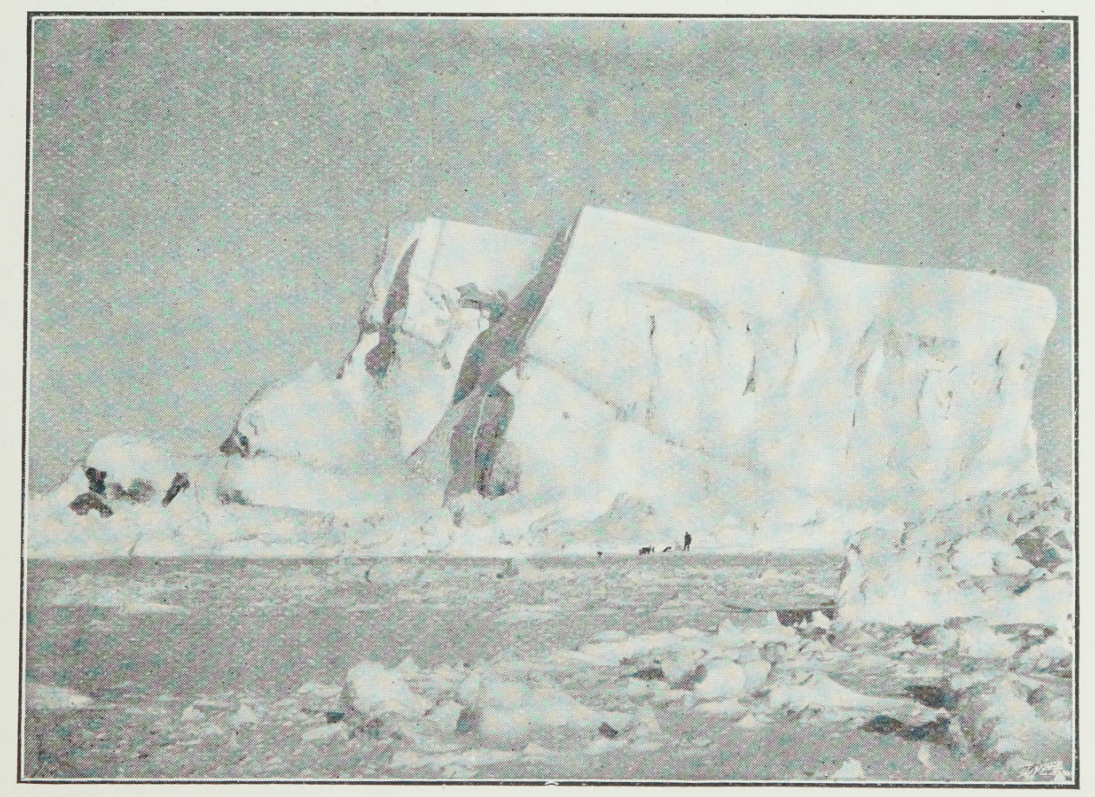

ANTARCTIC MONARCHS.

on several occasions towards the time when the vessel was expected back, members of my staff returned to the camp in enthusiasm, thinking to 
have discovered the masts of the Southern Cross in the mirage, so strongly did their hopes confirm the impression made by the wonderful creations in the air.

The temperature was $-25^{\circ}$ Fahr. on the 16 th May.

On the 17th May we all celebrated the National Day of Norway with a flag procession, and skijumping competition.

On the i8th a tremendous gale from the S.E. was blowing. Sledges, boxes, stones, etc., were flying about in the air. Heavy showers of pebbles descended upon our camp during the night. Our huts were now only approachable through a tunnel in the snow, and we had great trouble in keeping this only place of entrance open, as one night of snow-drift would fill it completely. Great screwing was going on in the bay. The one whose duty it was to read the meteorological observations approached the thermometer box with a rope round his waist, although the place was only 200 yards away. To give an instance of the strength of the wind, it may be mentioned that on the night of the I8th May the anemometer broke on its shaft, literally blown off. The lowest barometric reading during this gale was $28 \cdot 4 \cdot 4$. The days began to get very short and dark. It was a depressing feeling, like looking at oneself getting old. Chess, cards, and draughts were the most popular changes from work.

We were getting sick of one another's company; we knew each line in each other's faces. Each one knew what the other one had to say. Our whole 
repertoire was exhausted, but knowing the fact, all kept cheerful.

Already early in the Expedition the English members learnt to use the ski; although of course they never mastered them as thoroughly as the Norwegians did. We had a good deal of jumping just before the dark time set in, on a good snowcovered hill near Camp Ridley. We had most of us

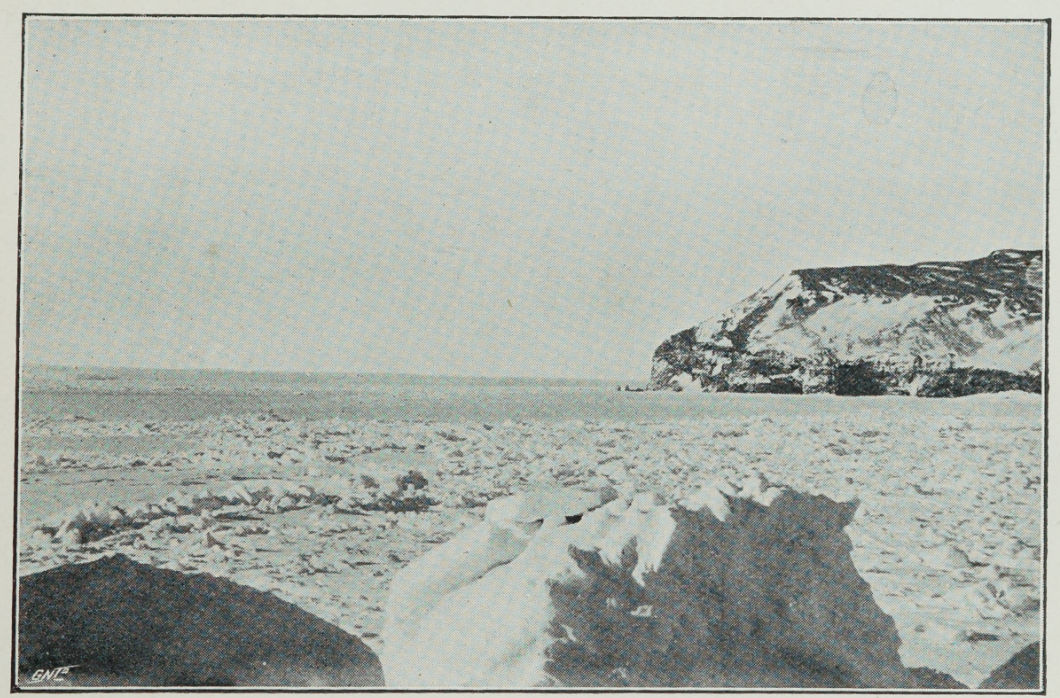

THE FROZEN SEA NEAR CAPE ADARE.

our triumphs, and also our downfalls, but we fell only to rise again. It was curious to see those who, for the first time in their lives in double quick speed, reach the boss of snow in the middle of the hill, where they left terra firma only to land in a cloud of snow some yards away. I believe that had some of the members known of the birth of that one-time new expression, they might have replaced some harmless swearing with "What ho! she bumps!" I do not 


\section{I30 British Antarctic Expedition.}

think that anyone, better than a novice on ski, realises the ups and downs of this life!

The dogs suffered a good deal from frozen feet. In spite of the great cold, however, six puppies born seemed to do well under the snow.

On the 24th May (H.M. the Queen's birthday), the Duke of York's flag waved on high, and three ringing cheers were given at the flagstaff.

On the $25^{\text {th }}$ a heavy gale was again blowing from the S.E. It blew in terrific gusts, carrying stones with it. The huts were shaking violently, and the snow-drift was blinding. Mr. Evans, whose duty it was to read off, was lost in crossing from the thermometer screen to the house, having for a minute let go his hold of the guiding rope which, as before mentioned, I had caused to be stretched between the camp and the screen. During that night we searched for him for three hours, in blinding snow-drift and great cold, before Mr. Fougner and the Finn Must succeeded in finding him. He was brought to the camp in an exhausted condition, vomiting severely. Under the tender treatment of the doctor, however, he soon recovered. During the search for Mr. Evans a comical incident occurred. In the tremendous snow-drift and dark, while the gale was at its strongest, it was very difficult to move about. All of us being out to look for Mr. Evans, I fought my way onwards, passing near to where a dog-kennel had been fastened to the ground. Hearing a remarkable noise in the kennel, and seeing two black legs moving hither and thither at the entrance, I thought it possible that Mr. Evans, in spite of his size, might have sought shelter there 
in an exhausted condition. However, on investigation, I found it was the Finn Savio, who, only half the weight and size of Mr. Evans, thought it most unfair that he should have to help to find the latter, whose weight was over thirteen stone, and as I was somewhat angry at finding him in the kennel and not assisting in the search, he most indignantly explained that if the wind blew Mr. Evans about, he was sure he would not himself remain very long on terra firma, as he had only half of his weight, and it would not be any advantage to lose him as well as Mr. Evans.

On June ist

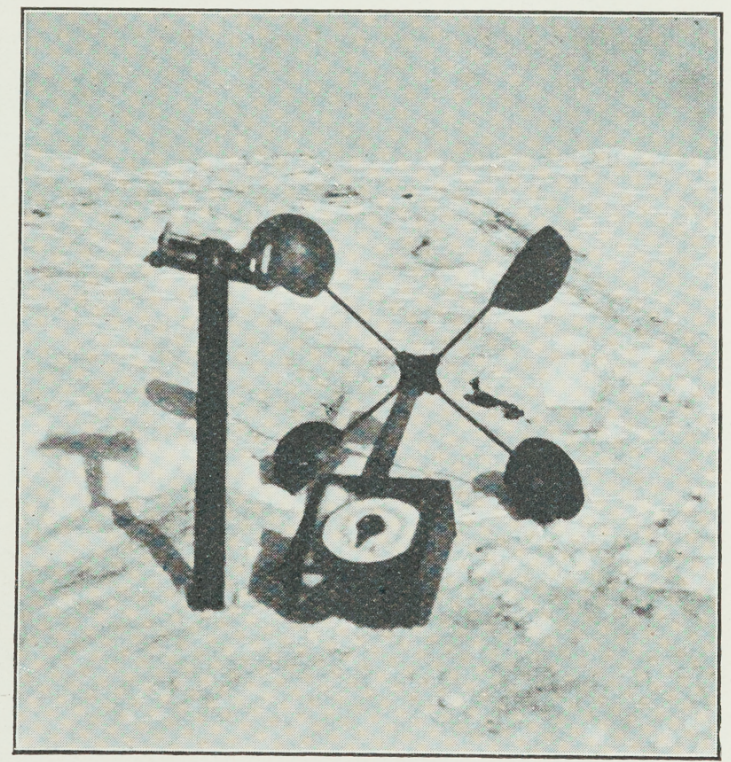

"THE ANEMOMETER SNAPPED IN TWO ON THE ROOF." the dogs had no less than sixteen fine strong puppies.

On June 3 rd the thermometer showed -3 I. Some of my staff had their extremities badly frozen. As it was H.R.H. the Duke of York's birthday, the Union Jack was hoisted, and although a beautiful Aurora waved in mighty curtains over Camp Ridley, moving and fading, only to appear again in brilliant streamers of dazzling light we 


\section{I32 British Antarctic Expedition.}

could not help igniting an empty paraffin barrel in honour of the occasion.

On June 4th I had the thermograph placed 2,000 ft. up on Cape Adare for the purpose of getting an opportunity to compare the curves at different heights.

At 6 o'clock in the morning of the r 4 th June, in complete darkness, I had to climb to the top of Cape Adare, and brought the thermograph down. It was very cold, and I had bad attacks of vomiting. The darkness made it very difficult for me to pick my way, and as the barometer was low I was anxious to reach camp as early as possible, for if I had been overtaken by a gale in those heights, without the aid of daylight, it would probably have been fatal.

The very next day, the I 5 th, a tremendous gale started in the morning, and prevented all but one morning reading. It started while Hanson was halfway between the thermometer screen and the camp, and he had great difficulty in reaching the hut. Mr. Evans and Mr. Bernacchi attempted to reach the screen in vain. They had to crawl back on all fours, and arrived in camp exhausted, Mr. Bernacchi with his hand badly frost-bitten. Later on I myself made a further attempt to reach the screen in company with one of the Finns by crawling along on all fours, but found it impossible to keep the safety lantern alight, as it blew out immediately we took it from the cover of our fur coats, and without its light we could not have read the observations, even had we been able to reach the screen. By evening the wind was blowing with the force of eighty-five miles an hour, roaring and tearing 
in the house, while the air was filled with pebbles. During the night the gale increased, if possible; the hut shook and shivered, and we expected every minute to see our camp lifted bodily into the air like a balloon. The metal stays by which we had anchored the huts to the ground sang lustily during the fierce squalls of the hurricane, in consequence of the strain

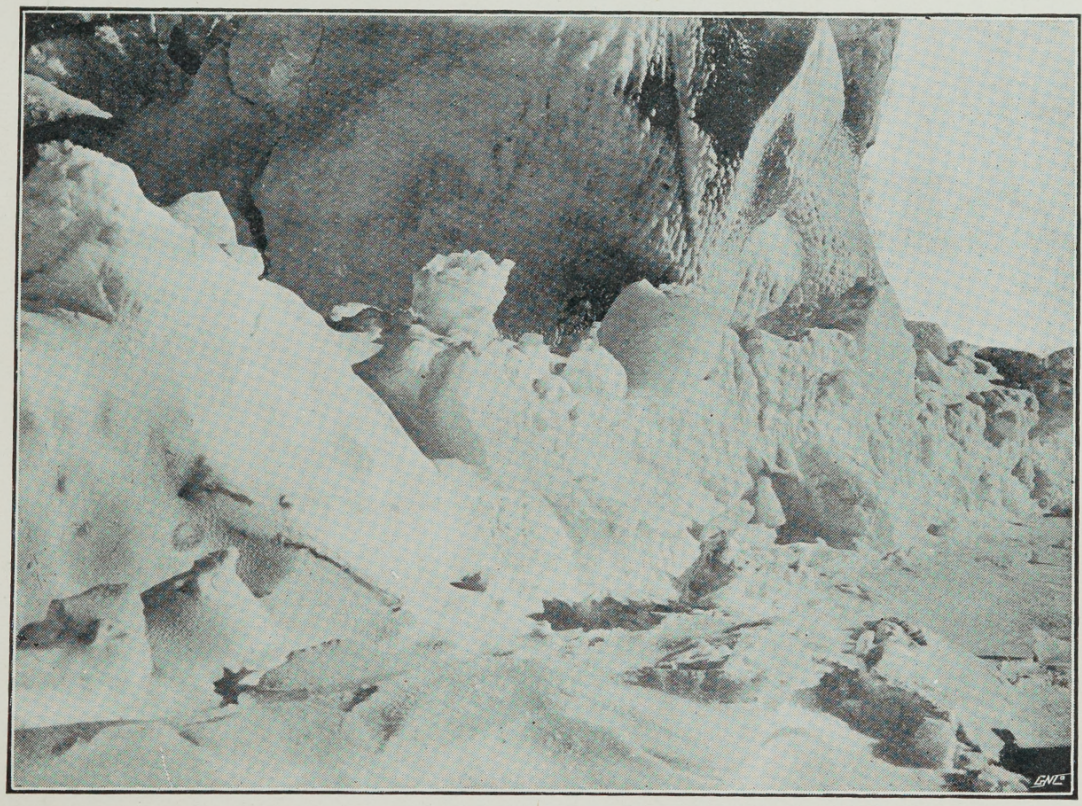

ICE FORMATIONS NEAR THE COAST-LINE.

brought to bear upon them; had they snapped we would probably have been shaken up like so many dice in a box. From time to time we consulted the barometer; it continually sounded "still falling," "still falling," and we earnestly began to consider our chances, while now and again a jocular suggestion was passed from bunk to bunk as to how we should best be able to steer our hut in 


\section{I34 British Antarctic Expedition.}

case it suddenly became an air-ship; would the metal stays be useful as guide ropes? and would the rapidly-revolving anemometer on the roof be useful as a propeller on an aerial journey? Down went the barometer, falling! falling! falling! until nearing 27.

During these gales a most remarkable thing used to happen: while the gale was at its highest it would suddenly cease for quite two or three minutes, instantaneously the roar and rush overhead would stop, and the absolute stillness of the Antarctic night would prevail, and the breathing of the wondering members could be distinctly heard keeping time with the regular tick, tick, tick of the barograph registering the interesting curves of the atmospheric pressure. Then, as suddenly as it had ceased, the gale would howl and rage again, if possible worse than before.

The wind continued until the $\mathrm{I}$ th June. As will be seen from our meteorological observations, a great and sudden rise in the temperature indicated the approach of a gale, and supported the correctness of the anti-cyclone theory. The days were now very dark indeed. The horizon towards the N.W. was, however, slightly crimson.

On several occasions I saw the great affection which arose between members of the staff and the dogs I gave to them. Mr. Fougner was particularly devoted to a puppy he had, whose name was "Halloa." We used to tease him with this; and well I remember when the dog died, how real was the grief depicted in Fougner's face. We found out later that, through great trouble and real hard work, 
he had picked and dug in the frozen rocky ground until he had found a suitable last resting-place for his puppy. He covered it over nicely, and put a pole in as a mark. He evidently thought that this characteristic mark of affection had been unnoticed by us, and when I later on alluded to the incident, he blushingly remarked that he had done it out of

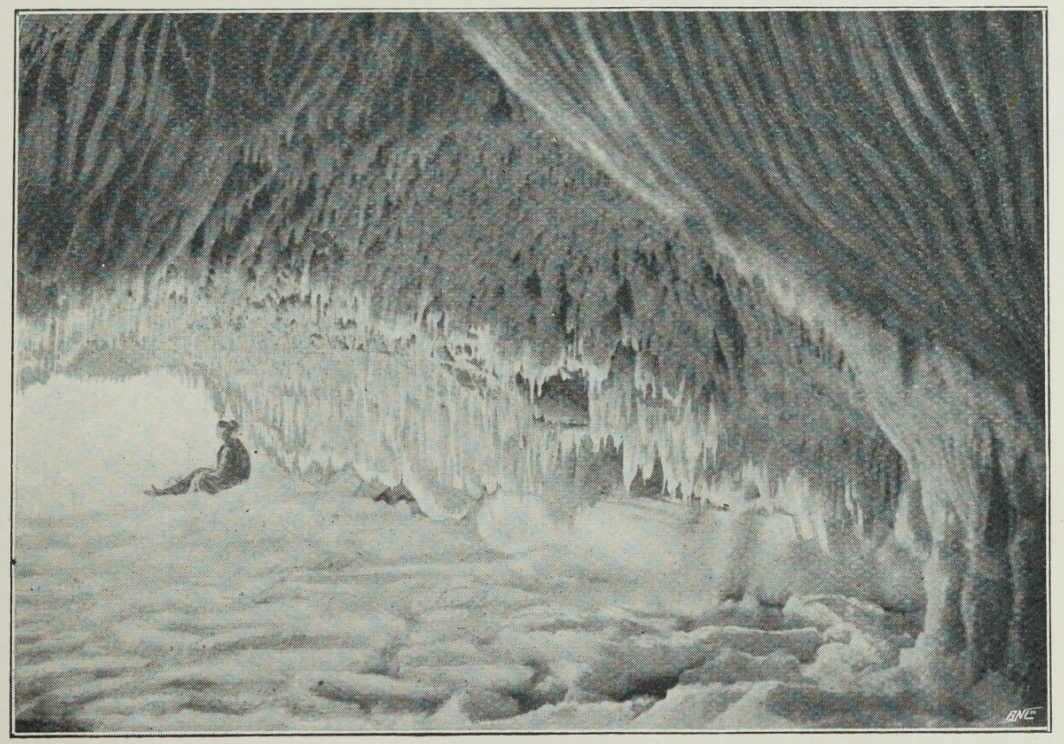

CAVE IN THE ROCK AT CAPE ADARE.

consideration for the other dogs. "They might have eaten my puppy," he said, "and become ill themselves." But we who knew his soft heart and liking for his young dog, ascribed this touching act to even more noble motives.

The darkness and the silence weighed heavily on one's mind. The silence roared in our ears; it was centuries of heaped-up solitude.

On June 3 oth one of our sledge dogs returned 


\section{I36 British Antarctic Expedition.}

after having been away for two months. The remarkable fact is that he was fat on his return. Probably he had drifted out to sea by the pack when the ice broke during a gale, and at the edge of the pack-ice further north had lived in luxury on penguin's flesh, until he was able to return over the frozen surf.

June $23 \mathrm{rd}$, I 899. - Total eclipse of the moon commenced at 10.58. It was fine and clear. We were all watching it through the big telescope, and $\mathrm{Mr}$. Bernacchi made a careful observation.

Remarks:- It was impossible to distinguish the entrance of the moon into the penumbra on account of the mist. So misty was it that at the beginning of the eclipse, only Jupiter and its stars, and Centauri, were visible through it. The disc of the moon, however, was fairly sharp when seen through the telescope. The crater and rays of Tycho, and craters Copernicus and Kepler, were visible on its surface. As the moon entered into the shadow the east limit was totally obscured, not being visible through the telescope. As the eclipse advanced the small stars of the constellations Saggita and Crux shone forth through the mist. Total occultation lasted nearly $\mathrm{I} \frac{\mathrm{I}}{2}$ hours. During this time there was absolutely no geographical detail observable on the lunar surface, and at no time was the whole of the disc visible. It was not possible to observe occultation of stars, as it was too misty. During the first half period of totality the western limit was of dull red colour, and the eastern quite invisible. During the latter half it was the reverse, the east limb being illuminated and the west hidden, 


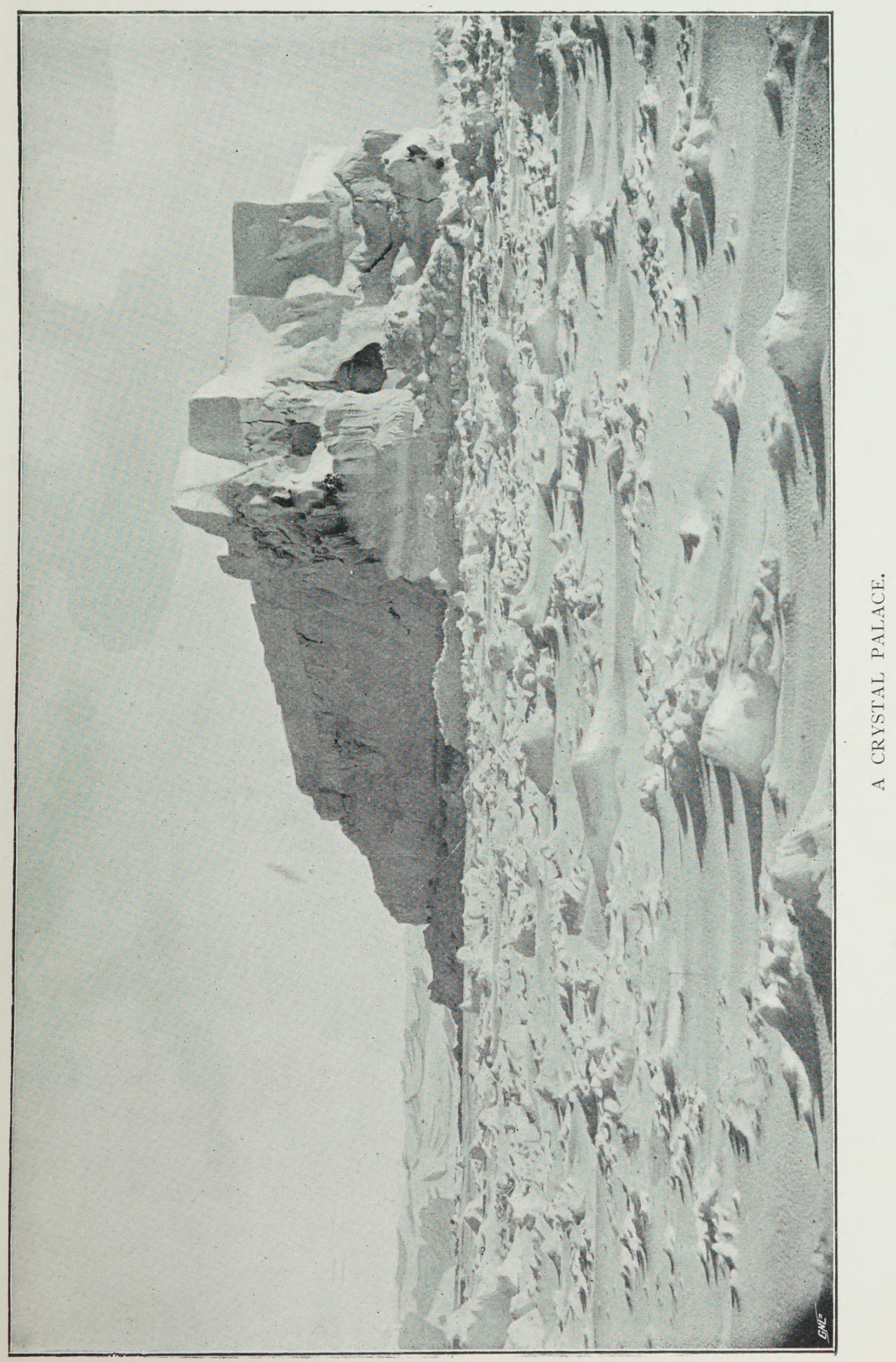


June 23 rd, i899. Lunar Total Eclipse. Cape Adare.

By chronometer No. 2262 by Brockbank, Atkins \& Moore.

Ist contact with shadow

$$
\text { H. M. S. D. H. M. S. }
$$

Beginning of total phase $13 \quad 33$ I 8 G.M.T. 23 I 32

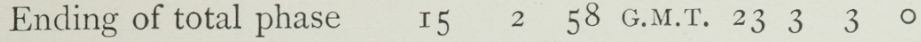

Temperature at II P.M. - I0.6

Temperature at I A.M. -10.8

June $24^{\text {th. }}$ Observation for Mean Time.

Misty. Temp. $18^{\circ}$ F. Barometer 29.048 in. Alt. Ther. $29^{\circ}$. Canopus

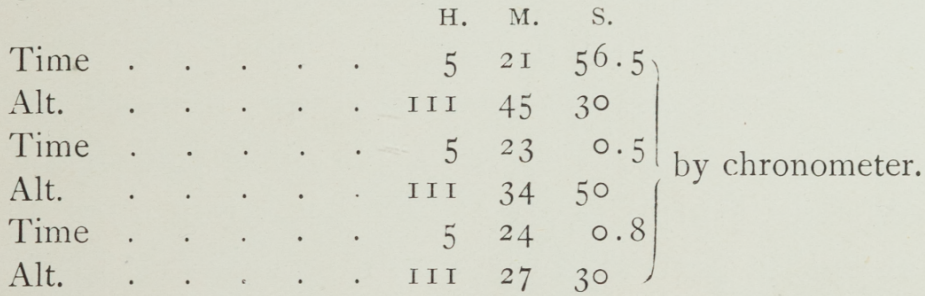

\section{Canopus}

$\left.\begin{array}{lllllllll}\text { Time } & . & . & . & . & . & 5 & 3 \mathrm{I} & \text { I3.7 } \\ \text { Alt. } & . & . & . & . & . & \text { I } 10 & \text { I } 5 & 20 \\ \text { Time } & . & . & . & . & . & 5 & 33 & 28.2 \\ \text { Alt. . } & . & . & . & . & . & \text { IO9 } & 53 & 20 \\ \text { Time } & . & . & . & . & . & 5 & 34 & 30.5 \\ \text { Alt. . } & . & . & . & . & . & \text { IO9 } & 43 & 40\end{array}\right\}$ by chronometer.

On the 3 rd July the temperature arose suddenly to zero. During July several smaller sledge journeys were accomplished on the coast of Victoria Land, the members of the expeditions suffering severely from the cold. Mr. Hanson was in a rather low condition; he lost feeling in his legs, and the flesh on them took lasting impressions from pressure. During the last sledge expeditions depôts were made at various places along the coast in Robertson Bay, and on the peninsula, on more elevated places than the camp, in case 


\section{I40 British Antarctic Expedition.}

high water should at times rise over the level where our camp was pitched.

On the I4th July we travelled towards Possession Island. At places the ice was very smooth, but mostly very heavy screwing was observed. We went out to sea and scaled an iceberg, and although the berg was Ioo ft. high, we failed to see Possession Island because of the mist towards the south. Near land, about five miles from the two rocks at Cape Adare, which I named The Sisters, we observed a great many large loose basaltic rocks on the ice, some as far as halfa-mile out from the walls of Victoria Land. They were on quite smooth, undisturbed sea ice, therefore they evidently had not been conveyed from the shore by drift-ice, but most likely had been thrown out by a minor volcanic eruption. It seems almost improbable that they should have rolled out so far by the speed attained in falling from the edge of the cliff some $600 \mathrm{ft}$. up; although, of course, a couple of miles rolling from the summit of Cape Adare, some 5,000 ft., might have started them off with great velocity. I took it as a fresh warning against trusting oneself near the steep rocks.

On the I8th July the house was completely buried in snow towards the west. Mr. Evans and Mr. Bernacchi were busily developing photographs during the evening. It was no easy task to develop photographs during those cold days and nights, when water had to be got by melting snow. The mercury froze in the thermometers, and chemicals and water were apt to freeze instantly if left alone. Still $\mathrm{Mr}$, Bernacchi stuck to his guns, and never gave 
in before a satisfactory result had been achieved. Seal liver and meat had now become a frequent repast, and I urged on the use of it as much as possible, as the want of fresh food began to tell upon us all.

On the 2Ist, anxious for further information, I left Camp Ridley at I 2 mid-day. I had with me Mr. Fougner and both the Finns. Thirty dogs pulled our sledges. It is difficult to keep one's

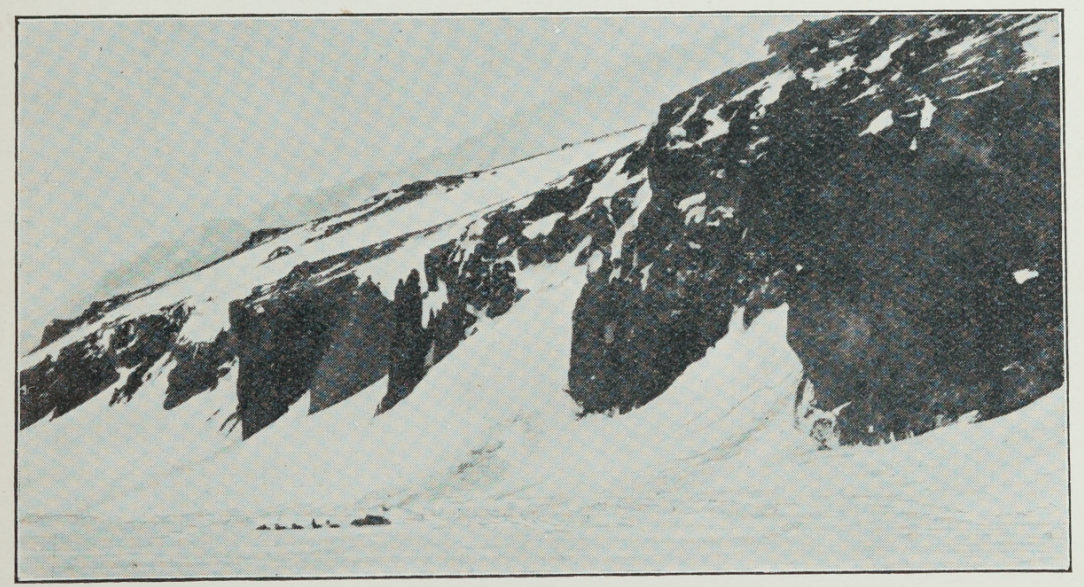

"THE MOUNTAINS FIRST SHOWED THEMSELVES IN THEIR FULL DEFIANCE AS WE ARRIVED AT THEIR FOOT."

temper while driving a team of dogs, especially when the ice is rough, the load heavy, and the temperature low. There are occasions when the most calm and placid natures would get fits of violent impatience, and strong measures are needed if you want to get on at all. Sometimes, when two teams of a dozen dogs each are pulling along at the side of each other, a savage dog of one team will discover an enemy of his in the other team; and while you had hitherto found it difficult to make the dogs move 


\section{I42 British Antarctic Expedition.}

the sledges onward at all, you would suddenly find they ignored the weight of them, and the two teams would rush together as quickly as lightning, and, before you were able to interfere, they would be one entangled mass of straps, dogs, provisions, ropes, and snow. When you at last, by using the whips and shouting, managed to calm the dogs somewhat, you might, after a most mixed work of pulling, lifting, cutting and mending, succeed in extricating the different particles of this complicated travelling gear; then off they are again, rolled in one bundle, biting and barking worse than ever. After a long day's march, when temperature and weather already had tried one's good nature near its limits, such incidents were apt to upset the equilibriums of the best-balanced tempers of the members.

We fought our way towards the cape amidst heavy and hummocky screwing. We had to pick our way carefully, thereby travelling double the distance we had to go. In the deep new drifts of snow the men and dogs had to work hard. We traversed some miles in a S.S.E. direction, and then I sent Fougner and the Finn Savio back to camp for some material which I deemed desirable for our journey, and which had been left behind. In the meanwhile Ole Must and I struggled onwards, covering some miles more on comparatively smooth ice. We reached a field of heavily screwed ice where the pointed blue rocks had reared on end with deep cracks in between; they were sharp like the edges of so many knives, ready to cut the slides of our sledges. Here we stopped to await the arrival of Mr. Fougner and the Finn Savio. We laid down 
in our furs and slept for an hour, while the moon hung like a large lamp above us, glaring at us each time the cold conquered the sleep of fatigue. Large bergs were floating about in the pack, most of them discharged from glaciers, generally square colossi, but occasionally pointed into towers. They were generally floating about in the pack either in an

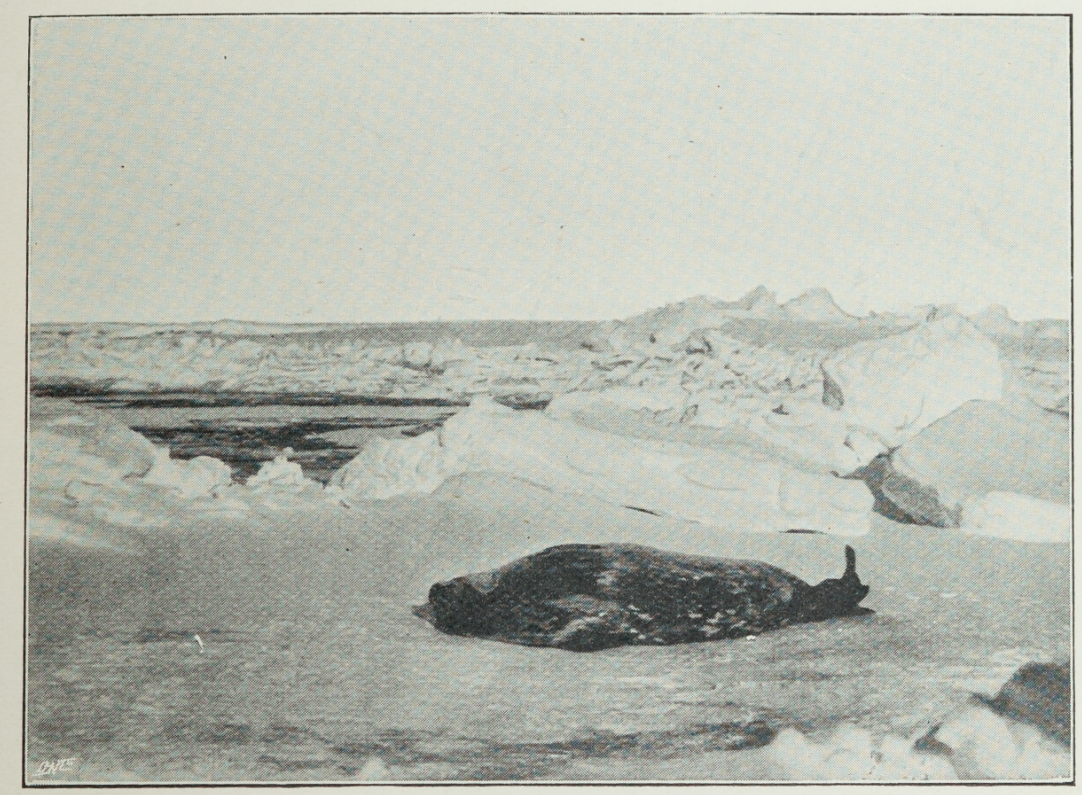

"THEY DID NOT KNOW THE BLOODTHIRSTINESS OF CIVILISATION."

open sheet of water or in a soft bed of ground-up ice. These brilliant blue monarchs seem entirely independent of their surroundings; here is their home where they glory; they move about against wind and tide; they plough their way through these tremendous ice-fields, while ice-blocks, several tons in weight, rise up and roll aside like foam before their glittering bows. But, independent as they 


\section{I44 British Antarctic Expedition.}

seem, it is the undercurrent, an irresistible force, a natural law-fate, if we prefer it so-which forces these nature's giants forward towards their destiny, against the reason of many, to the terror and destruction of those mortals who cross their path. These strong masterpieces of nature are driven into warmer climes, where obstacles disappear, the

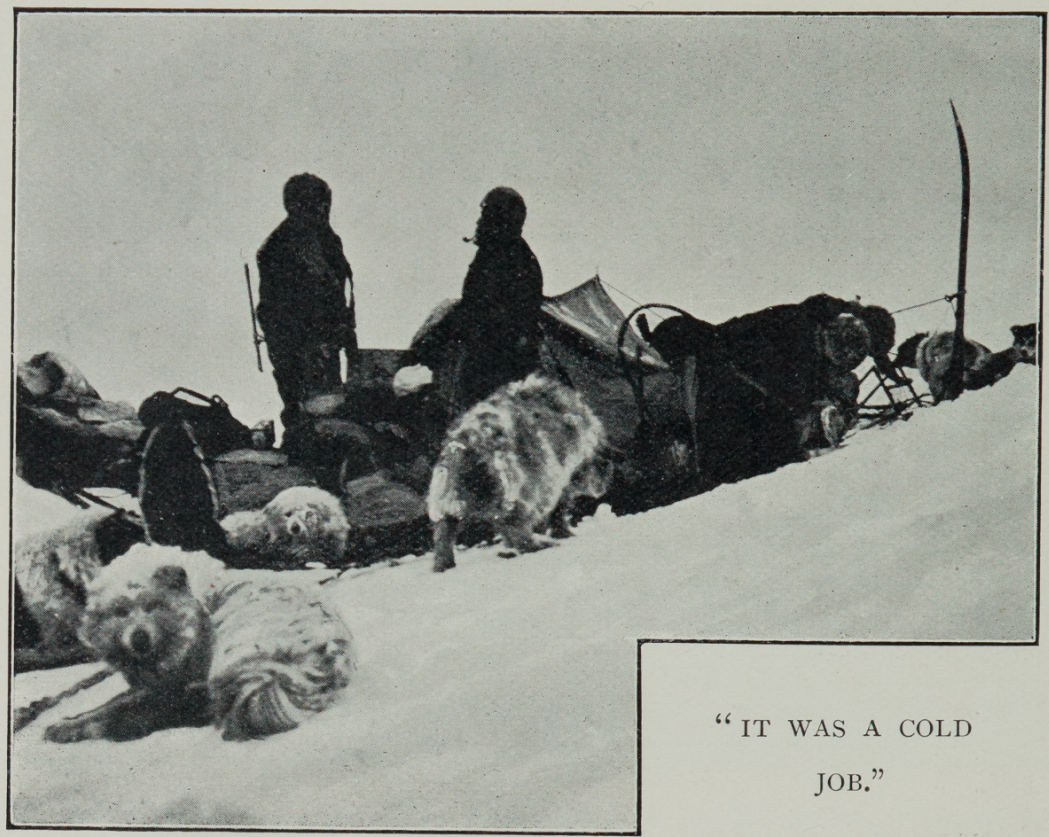

glorious fight of the forces has ceased, and, these mighty scouts from the Antarctic Regions, they melt away-die in the warm embrace of a summer sea.

The Finn and I slept in the snow when Fougner and Savio returned. The temperature was - I7 when we awoke; the sky was clear, and streamers of strong Aurora rose and fell towards 
the east. The track grew heavier and the pointed ice-blocks sharper the further we proceeded southwards. The slides of the sledges suffered greatly over the rough surface, and large fringes of torn wood began to protrude from underneath. At I I P.M. we camped. Savio, whose turn it was to prepare a meal, laid different utensils and tinned food on the top of a sleeping-bag, without noticing that Ole Must was within. It was bitterly cold, and so tired was Ole that he did not notice when I suddenly sat down upon his head, remaining there whilst I had my meal, thinking all the while I was sitting on a Dutch cheese, of which we had some with us, but which froze so hard that undoubtedly they would have been useful projectiles for a cannon.

No tent was pitched, but we slept on the top of the sledges in our fur, while two kept watch in case the ice should break up or heavy screwing commence. We kept about two miles from the perpendicular

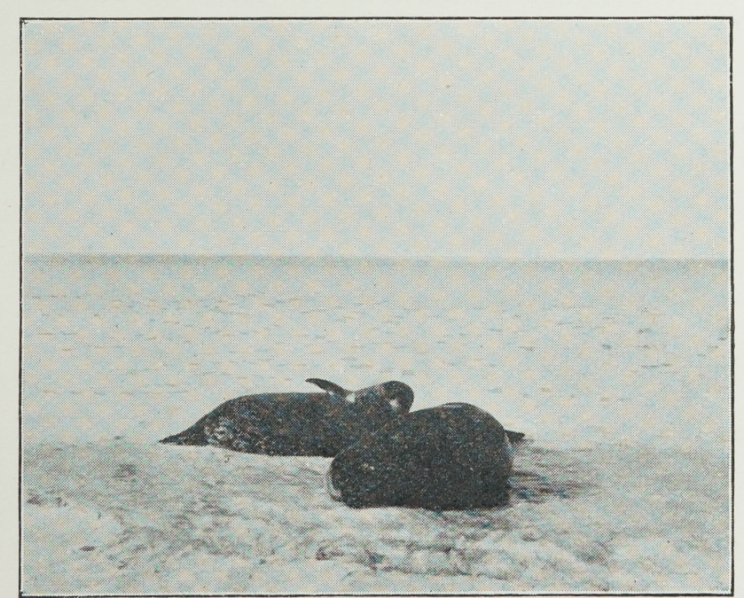

"SELDOM WERE THERE MORE THAN TWO TOGETHER."

walls of Victoria Land, where they rose to a height of about 5,000 feet.

At the foot of the rocks were large worn caves, while here and there I discovered small beaches 


\section{I46 British Antarctic Expedition.}

with steep slopes, formed by gravel rush from the porous volcanic rocks. They would be the only places of refuge in case a heavy screw should commence; but, unlike our situation at the gravel rush in Robertson Bay, here one would be entirely shut off from any chance of ascending the plateau, as the rock is either absolutely perpendicular or overhanging. Of course there were icebergs which might have offered us temporary shelter against heavy screw, but only a few of them were approachable, and in a sudden and general screw of the pack it would have been difficult to convey instruments and provisions to the top of these bergs. In the grey morning we made a light breakfast, harnessed our dogs, and started again, while a biting wind from the south descended the sides of the mountain. All metals stuck persistently to our fingers, and it was cold work before we had our travelling gear in working order again after camping. The track grew worse and worse; we pulled, lifted, pushed and shouted to the willing dogs, and slowly our four sledges rubbed over the rough surface towards the south. Mr. Fougner soon reported that the slides of his sledge were entirely worn through, as the rough screwing of the ice increased, and a general investigation of all the slides proved that most of them were worn through, consequently we had to return to Camp Ridley, and probably we should not have reached far, as open water was sighted to the south. We left the dogsledges where they stood, and started eastwards towards an iceberg which proved to be accessible, and from where a general view of the ice conditions was to be had. The loftiest pure white peaks of Victoria 
Land already blushed in the reflection of the returning sun, in promise of brighter days for our work. It was hard not to have reached further, as I had hoped to have gained Possession Island by risking this journey through the Antarctic winter; but little would have been gained by having worn out ourselves and our sledges for a purpose which could be better and more safely accomplished on the return of the Southern Cross, when our travelling gear would be required for more important work.

We returned to our sledges and struggled northwestwards again towards a flat ice-field. Here we arrived during the evening, and pitched one of our silk tents in a snow-drift, as usual in a square formed by the four sledges. The temperature was then found to be $-\mathrm{I} 3.2$. The reading on the aneroid barometer was 30. I 5, the highest barometric pressure we had had since our arrival at Victoria Land. A barometric pressure above 30 continued all through forty-six hours. During the night the temperature descended to - I 5 .

An open vapour cloud had kept soaring above the open sheet of water to the southward, and rather a remarkable phenomenon took place, as a kind of water-spout formed between the open water and a dark, deep-hanging cloud. It was evident that the cloud continually renewed its store of vapour from this open sheet of water. We could distinctly observe how from time to time the cloud diminished and increased in size and colour, as the trunks between cloud and water alternately were broken and renewed to keep the cloud satisfied with 
I48 British Antarctic Expedition.

vapour. I considered the phenomenon as an evidence of little open water in the vicinity of Victoria Land just then, a supposition which was also

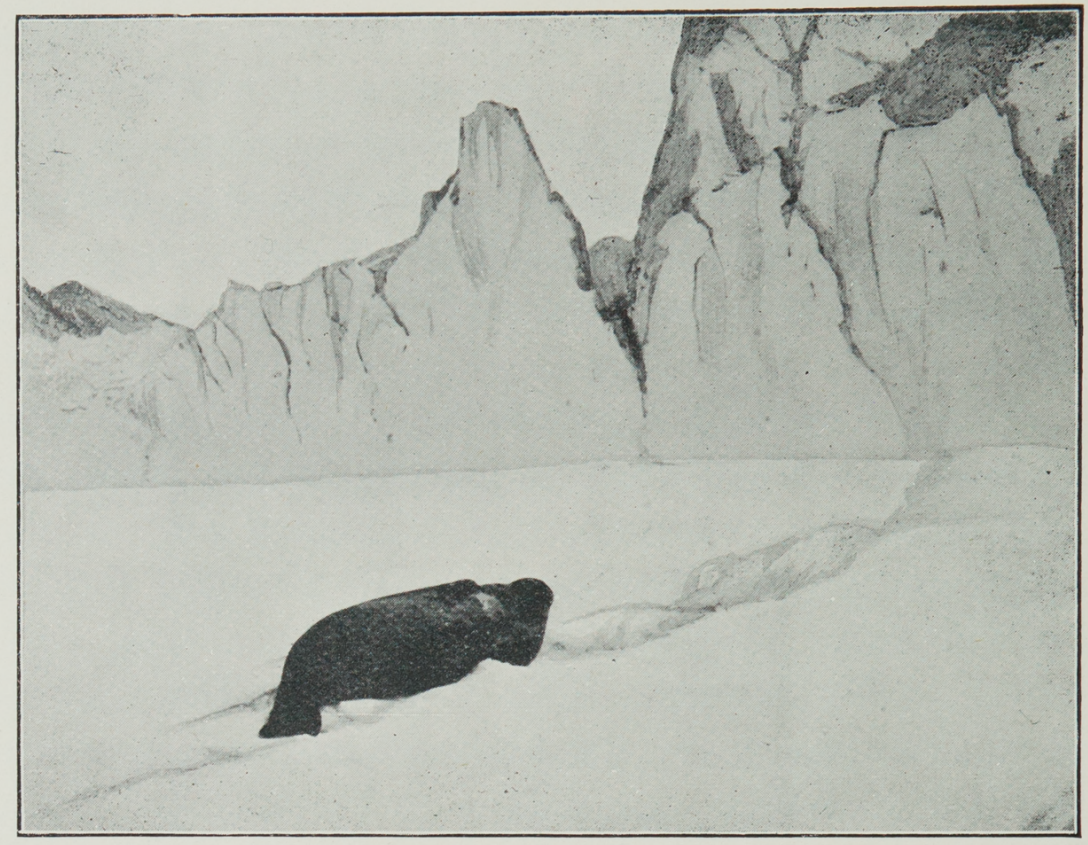

" THE SEALS LEAVE A SNAKE-LIKE TRACK IN THE SNOW."

strengthened by the many seals using the one and the same air-hole in the ice. I observed the greatest number of seals near the beds of the icebergs. Shortly after camping in the evening, the Finn Savio went off in search of a seal. Like most children of nature, he and Must seemed to have an instinct telling them when and where game was to be found; as usual he disappeared without saying a word to us. He had just ascertained that I was comfortably settled in my sleeping-bag when he went off. Shortly afterwards we heard a faint "Halloa," which was immediately responded to 
by Ole, and soon afterwards Ole followed in the track of the "Halloa," and joined Savio on an iceberg at some distance from our camp. Mr. Fougner and I, who just smoked away comfortably in our bags, soon heard them approaching, and driving a seal before them, just as peasants at home drive their cattle to market. We were delighted. The dogs had a good feed, and we had enough blubber for a large fire. There we four were lying, thousands of miles to the southward of the great struggling world, vast, stern Victoria Land lying dark towards the west, while the peaks

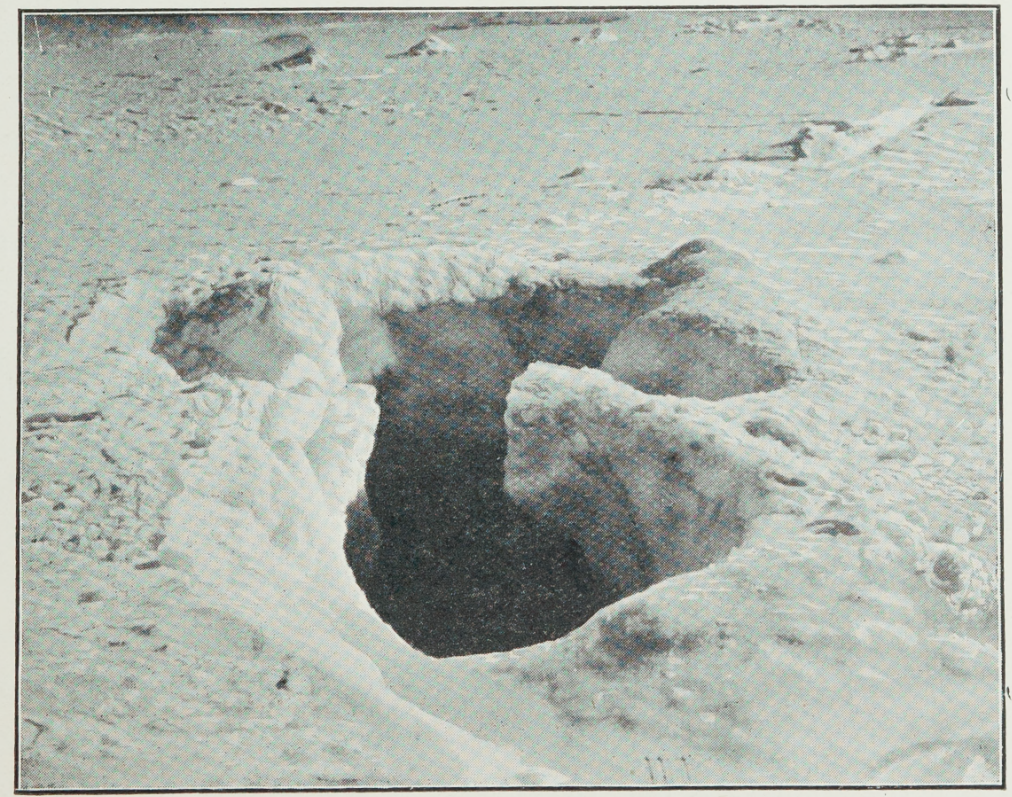

A SEAL BLOW-HOLE.

and icebergs caught the pale halo of light from the moon. We kept a watch, two at a time, as usual, sleeping six hours in turn. Towards 2 o'clock 


\section{I5O British Antarctic Expedition.}

in the morning heavy screwing roared towards the north.

At 6 in the morning we boiled some coffee, ate some biscuits and large slices of fat, and started again on our journey northwards. A strong wind descended from the mountains, wrapping us in a thick drift of snow. It was bitingly cold, and the sledges sank deep in the drifts as we struggled onwards. We had to keep two sledges close to each other to enable them to benefit by the track of the preceding one. The Finn Savio had his cheek severely frost-bitten: it was white and absolutely hard. When we arrived at the camp, I was glad to find that Mr. Hanson had greatly improved under the able treatment of the doctor, and I venture to believe that the arrival of a skull of Lobodon Carcinopaga (the white seal) helped to set new life in his partly paralysed legs. With characteristic energy he greeted the valuable addition to his zoological collection. The result of this short trip I consider by no means small, both with regard to the meteorological observations and the geological studies of Victoria Land itself, besides the hard experience in sledging in Antarctic pack.

One night in Camp Ridley we had a fire in the camp. I awoke through a suffocating smoke, and found that one of the members had his bunk on fire. He had kept a candle burning while reading, and had fallen asleep in his bunk, leaving it alight. It gave us rather a start, and I took extra precautions against fire. One arrangement was that after that time ten knapsacks full of provisions were hanging ready (one 
for each of us) in case we should have to leave the hut suddenly, and of course the nearest depott at the foot of Cape Adare would have given us shelter. There in a cavity we had, besides tents, a full outfit of provisions and fur to last for a few months, so with the additional provisions which we should have

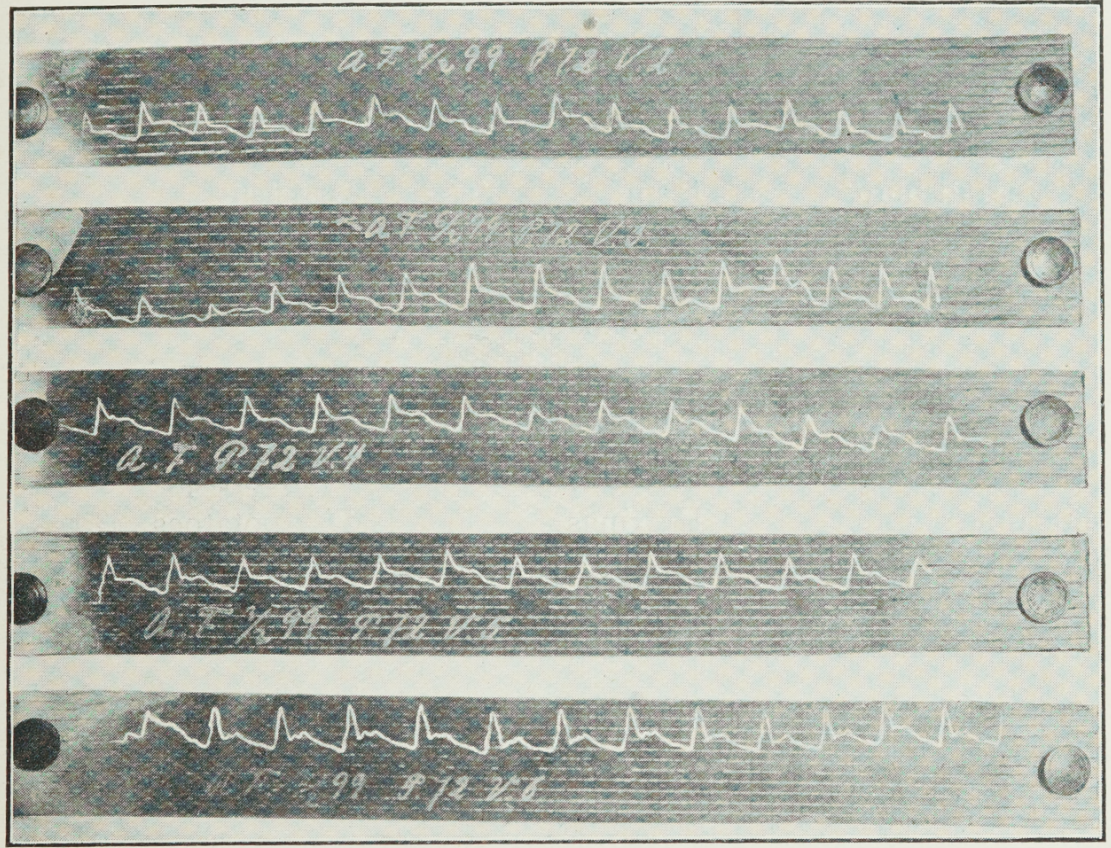

"DR. KLÖVSTAD FROM TIME TO TIME TESTED OUR PULSE WITH A PULSOMETER."

brought from the hut in the knapsacks, we should not have starved.

The health all through kept remarkably well up to this,-due greatly, I believe, to the great care with which I had selected the tinned food, and by the incessant toil of the doctor in the food department. Tins were always scrutinised by him, and carefully he made up the menus for the week. 
I52 British Antarctic Expedition.

With slight variations the following were the menus at Camp Ridley:-

\section{Breakfast.}

Bread and butter

Tea and coffee

Cheese

Sardines

Herrings

Porridge

Bread and butter

Bacon

Tea and coffee

Porridge

Ham

Bread and butter

Tea and coffee

Porridge

Bacon

Bread and butter

Tea and coffee

Porridge

Ham

Bread and butter

Tea and coffee

\section{Sunday.}

Lunch.

Cocoa

Biscuits

Tongue

Cheese

Jam

Marmalade

Monday.

Cocoa

Ham

Cabin biscuits

Jam

Marmalade

Tuesday.

Cocoa

Cabin biscuits

Herrings

Sardines

Cheese

Jam

Marmalade

WEDNESDAY.

Cocoa

Cabin biscuits

Ham

Cheese

Jam

Marmalade

Thursday.

Cocoa

Cabin biscuits

Herrings

Sardines

Cheese

Jam

Marmalade
Dinner.

Assorted soups

Pressed meat

Curry and rice

Dry potatoes

Porridge

Milk soup

Dry fish

Tinned potatoes

Sweet soup

Tinned tripe

Dry potatoes

Dry vegetables

Tinned plum pudding
Milk soup

Tinned salmon

Pressed potatoes
Peas

Salt meat

Dry potatoes

Dry vegetables 
FRIDAY.

\section{Breakfast.}

Porridge

Ham

Bread and butter

Tea and coffee
Lunch.

Cocoa

Cabin biscuits

Ham

Cheese

Jam

Marmalade

SATURDAy.

Cocoa

Cabin biscuits

Herrings

Sardines

Cheese

Jam

Marmalade
Dinner.

Milk soup

Dry fish

Pressed potatoes

Sweet soup

Army rations

Bread and butter

Seal beef and roasted penguin flesh became later a frequent repast, as we grew frightfully tired of tinned food.

The meals at Camp Ridley lasted, on great occasions, ten minutes; often less than five minutes on ordinary occasions. Pipes were lit after meals, and the doctor and I generally indulged in a game of chess if both of us happened to be in camp at the time.

The Finns played at "Sakko" (a kind of chess), a Finn game full of remarkable formalities to be observed. These two shouted and jumped during their game, and it was a wonder they did not upset the little board on which they played.

The most trying time within the Antarctic Circle was the dark period. The strongest man must needs feel the effect of it more or less. The sameness of those cold, dark nights attacks the minds of men like a sneaking evil spirit. We found that 


\section{British Antarctic Expedition.}

reading, playing chess, and cards, were very valuable pastimes during this period, when work did not require the full concentration of our minds; and occasionally we started, purposely, minor quarrels, when we found that a change was necessary, and I found the truth of the French proverb, "Les extrêmes se touchent"; it was easier to bring a weighed-down mind to a beneficial laugh after such little quarrel than before.

I remember well how welcome a discussion was started when we no longer could write Eighteen Hundred, and the question arose as to when the new century began, whether at the beginning of I 900 or I90I. With the utmost care I invented fresh arguments in favour of the losing side, only for the purpose of keeping a desirable dispute going.

From the Southern Cross we brought a musical box on shore with us, but we soon came to know its repertoire so well that we preferred for the time to have it silent; and when we again set it going it had become rusty, and played hymns when a valse was required, and vice versâ. In the limited space we had at our disposal it must be clearly understood that only exceptional precautions could prevent serious difficulties. Those who suffered least from the darkness were undoubtedly the Finns, who, from their homes in the north, were accustomed to it, but even these two changed considerably during the dark time. All of us were somewhat affected by the slow action of the heart. In the great cold, and depending upon the tinned food, the circulation became very slow, and repeatedly I had the same feeling as when I had lain 


\section{The Winter in Victoria Land.}

long on one limb and all the feeling had gone out of it. It would remain like that for hours, and had a depressing effect upon the mind. These symptoms I noticed in Mr. Hanson during his illness. The monotony of the life seemed to create amongst the members a most sensitive professional jealousy, if it may so be called. It was, however, an evident sign of the deep interest which they took in their different departments, and also formed a most interesting study. It is evident that in regions like those in which we lived-where the surroundings offered no great changes and no entertainment except that which each found in his special work, the material of which he had, with great difficulty, wrested from the earth's most inhospitable cornersuch work, for which we risked all, necessarily became the nucleus of our life, guarded passionately against intrusion. Nothing seemed to cheer melancholy members more than being consulted, and being asked to give information. 


\section{CHAPTER VI.}

\section{Sledge Journey in Winter.}

ON the 26th of July, I899, eager for active service again, I started a fresh sledge journey with the intention of attempting to reach the coast land to the west of Robertson Bay. At I 2 mid-day I started with Mr. Evans and both of the Lapps. I took provisions for thirty days, and twenty-nine dogs. We travelled among very heavy screwed ice. Large blocks heaped upon each other at times rendered our route almost impassable, and for some miles we had very rough travelling. A strong gale from the S.S.E. started, and at 4 P.M. we pitched our tent in the worn cave of an iceberg, and spent a very cold night there. In the early morning I scaled the berg and viewed the ice conditions to the southward. As these conditions appeared promising, I decided to send Mr. Evans back to Camp Ridley for the purpose of making Mr. Colbeck, Mr. Fougner, and Mr. Evans follow me up with more sledges and provisions. Mr. Evans took four dogs and a sledge and left for Camp Ridley. I started at once further south, accompanied by the two Lapps. We travelled all that night without pitching camp; the temperature was -30 . We passed over very rough ice and struggled hard between the ice- 


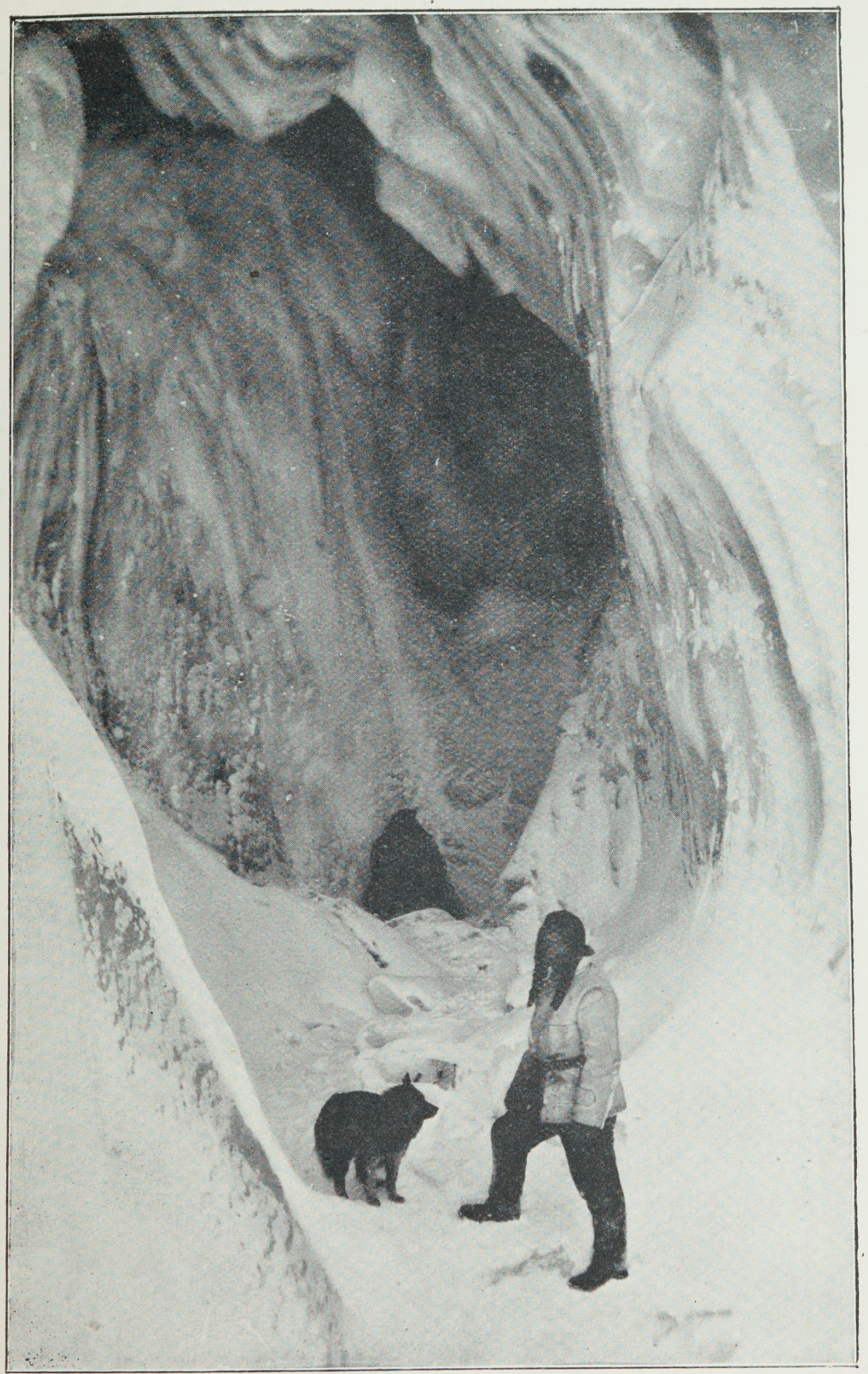

THE CAVE IN WHICH AN OAK CASK WITH A REPORT OF THE EXPEDITION WAS PLACED. 
blocks in the dark. At midnight we came across a seal (Weddelli), which was killed to feed the dogs. We lighted the skin and blubber, which shone like a lighthouse far away into the dark as we slowly drew further from it. In the morning the weather was misty. There was no appearance of land, and as I could get no observations I pitched the tent between

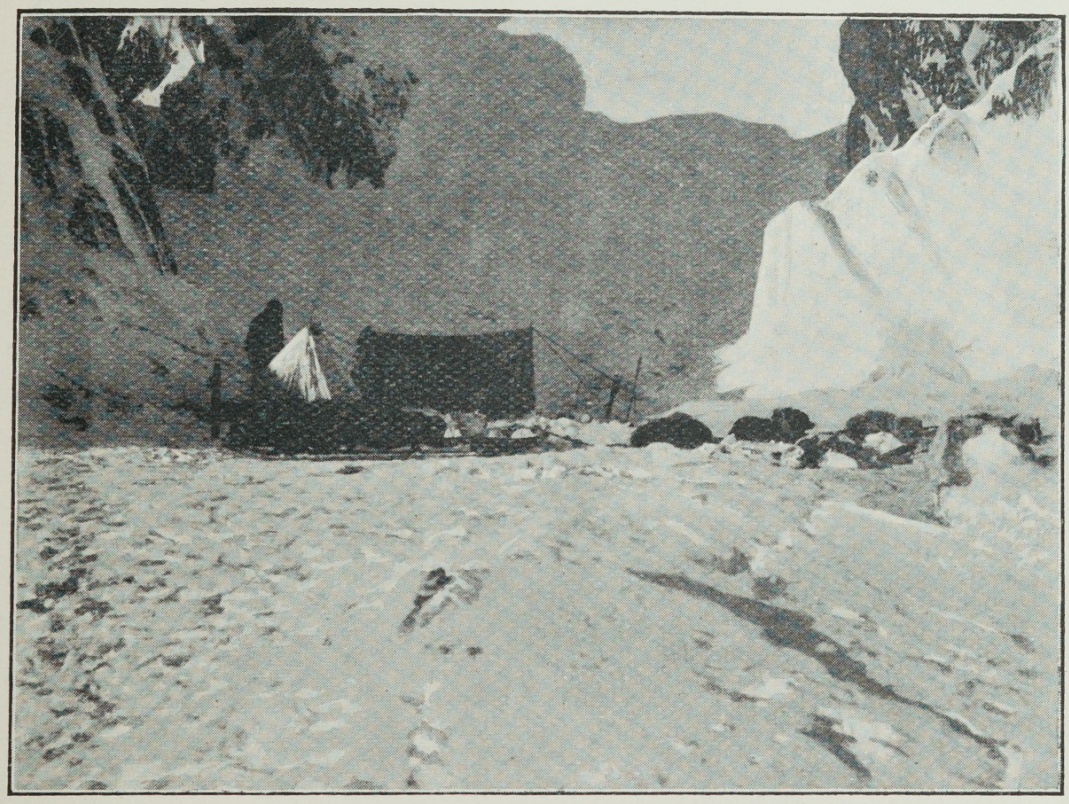

MIDWINTER CAMP.

two ice mounds in the pack. On the 28 th July it was still misty, and had started to blow with a low barometer. Towards evening a violent gale commenced, with heavy drift from S.E. We all had to remain inside the silk tent in our sleeping-bags during the next three days. It was bitterly cold, -40 , and we suffered greatly from frost-bites. Our reindeer sleeping-bags were unmanageable comforts after they 


\section{I60 British Antarctic Expedition.}

had been in use two or three times on a sledge journey. We got hot in them the first night, and the steam from our bodies made them damp; we packed them on the sledges in the morning, flat, with the provisions on the top of them. Then they froze hard, and when suddenly a gale surprised us, we had to thaw ourselves gradually into the bag, feet first, and their temperature did not always much differ from that of the frozen bag. Later we used to get the dogs to thaw them for us-they always liked to roll upon anything that was not snow or ice, even if it were but a thrown-away match-and when we had laid our frozen reindeer bags on the snow they generally clustered together on them at once, and half-an-hour later we could get into them.

The silk tent was rapidly filled with dense fog as we three camped in it, both on account of our breath, and because of the heat given off by the lantern. A thick layer of frost covered the inner walls of the tent in a short time, and beautiful snowcrystals shone down on us through the ventilation hole in the bag. The snow-drift soon buried the tent, and the snow pressure just left us space enough for our sleeping-bags.

That dark little spot which we formed on those vast white fields was blotted out. Men, dogs, sledges, all, disappeared, and the Antarctic gale found nothing new as it raged over us, only cold, white solitude.

For three nights and for three days we had to take turn in standing on all fours to prevent being smothered by the pressure of the snow. 
We roasted the heart of a seal, and the heart of another we ate raw.

The dogs were completely snowed down and froze fast to the ice. Some of them had eaten the straps of their harness to free themselves, but were still unable to move on account of being frozen to the

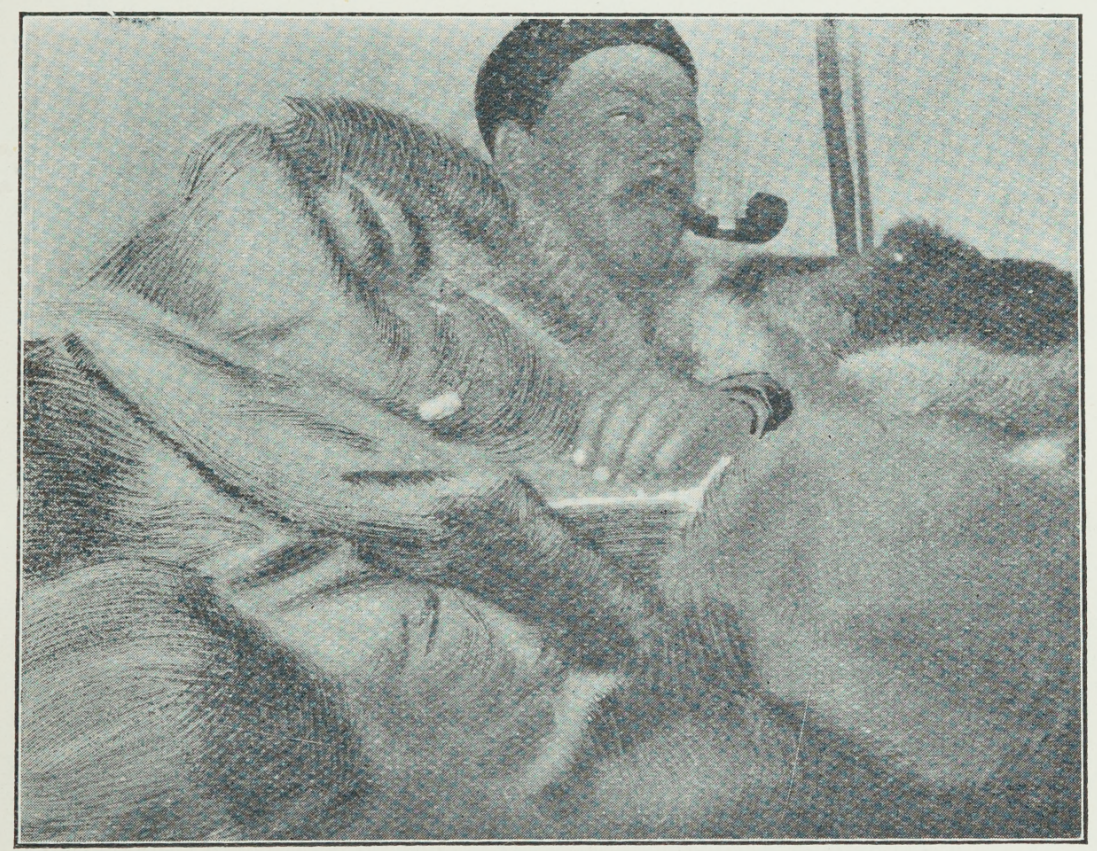

BORCHGREVINK IN HIS SLEEPING BAG.

ice. No land could be sighted anywhere. Up to the 3 Ist July I had seen nothing of the party which was to have followed us up. It was a cold job that morning to dig ourselves and our tent out of the drift. The temperature was -32 , and we suffered from frost-bites. We again proceeded onwards on comparatively good ice. In the evening I discovered an island to the south, and reached the western side of it an hour after dark. We were then very hungry and 
worn: -40 when we pitched camp. Early in the morning of the Ist August we killed two seals. Still nothing was seen of the party which was to assist us, and I anticipated rightly that they had been compelled to return to Camp Ridley by the violent gale which had nearly made an end of my two faithful companions and myself. I called the new camp Midwinter Camp, and the island I named, after H.R.H. the Duke of York, Duke of York Island. The island is situated in lat. $71^{\circ} 35^{\prime} \mathrm{S}$., long. $170^{\circ} 2 \frac{3^{\prime}}{4} \mathrm{E}$. On the 2nd August I resolved to investigate some of the coast line of this island; I took with me the Finn Must, leaving Savio in camp to construct a kind of Finn tent out of provision bags, seal-skins, and bags which he proposed stretching over our sledges, pitched on end; as we would then be enabled to utilize some of the seal blubber as fuel. The Finn Must and myself proceeded along the northern shore of Duke of York Island, and reached a bay which I named Crescent Bay. During the succeeding days I managed to make as thorough an investigation of the immediate surroundings of our camp as the cold weather permitted. As I began to get anxious about the party which was to have followed us, I took in stores of seal-beef and blubber. We suffered a good deal from frost-bites, although we managed to keep up a blubber fire in the conical tent, if it so may be called, constructed by Savio in the manner described above. It was not a question of being warm in the sleepingbags then, but of being less cold.

I found that the Lapps' method of never using socks in their Finn boots answered well. Socks are never used in Finnarken in winter time, but "senne 


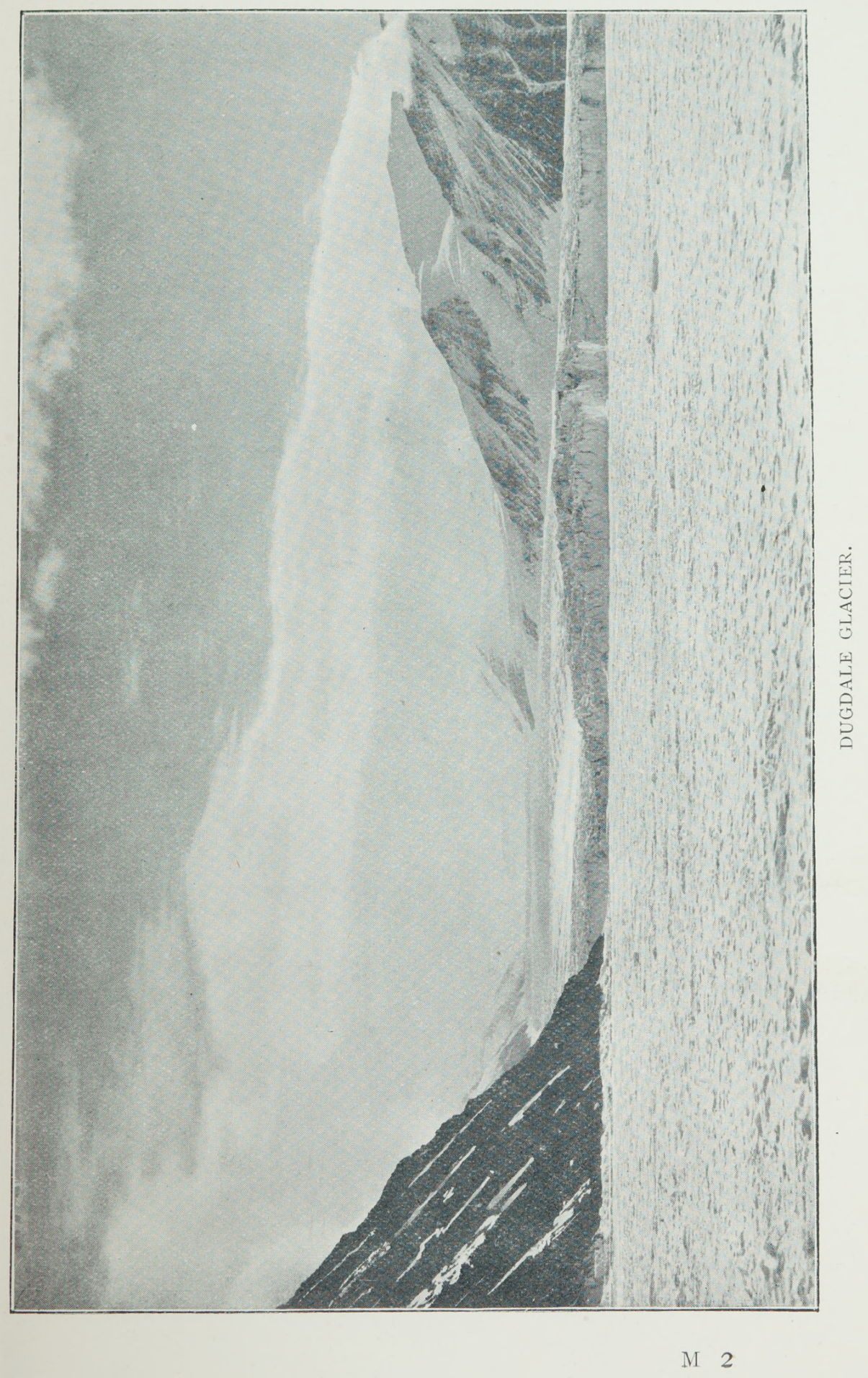



grass," which they, of course, through practice and tradition, had a special method of arranging in the "komager" (Finn boots). The "senne grass," of which we brought several bags, is dry, although fresh. It is a kind of wiry grass growing near the beach in the north of Norway, and which has obtained there a certain commercial importance because of its use instead of socks amongst the Lapps. If you get wet

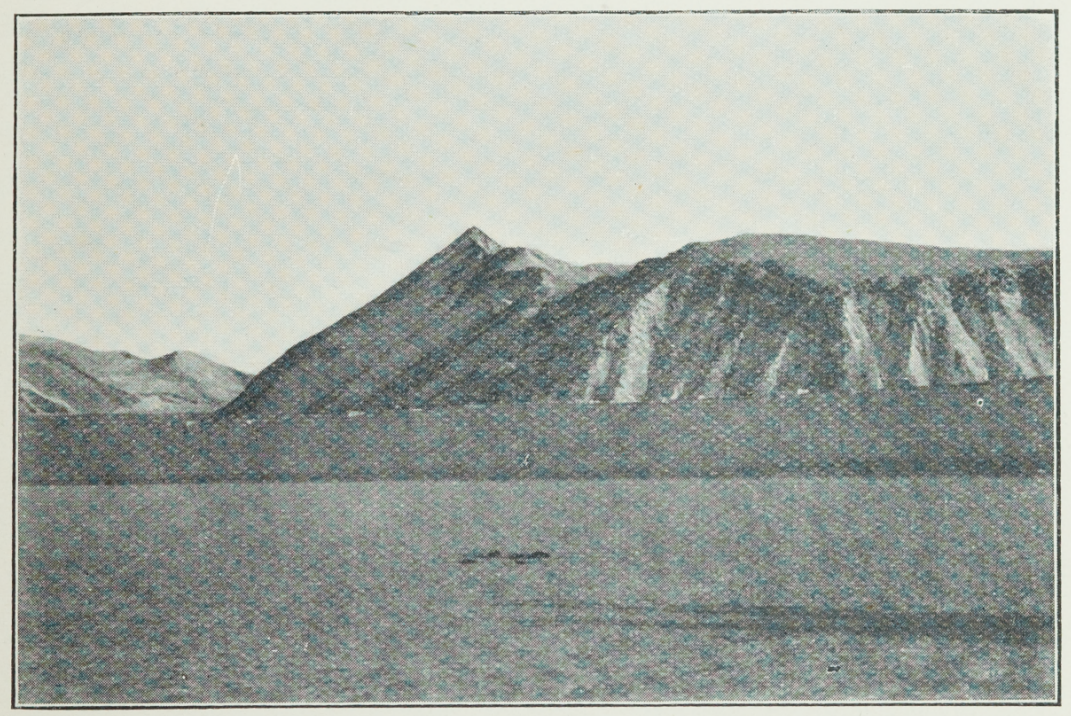

STERN VICTORIA LAND.

feet while wearing the grass in the "komager" you will be warmer than ever, as the fresh grass will, by the moisture and the heat of your feet, in a way start to burn, or produce its own heat by spontaneous combustion. The great thing seems to be to arrange the grass properly in the boots, and although we all tried to imitate the Finns in their skill at this work, none of us felt as warm on our feet as when they had helped us. 
166 British Antarctic Expedition.

Must suffered a good deal from the cold, and I had at times to use medical stimulants to keep him from passing away. I kept him alive principally

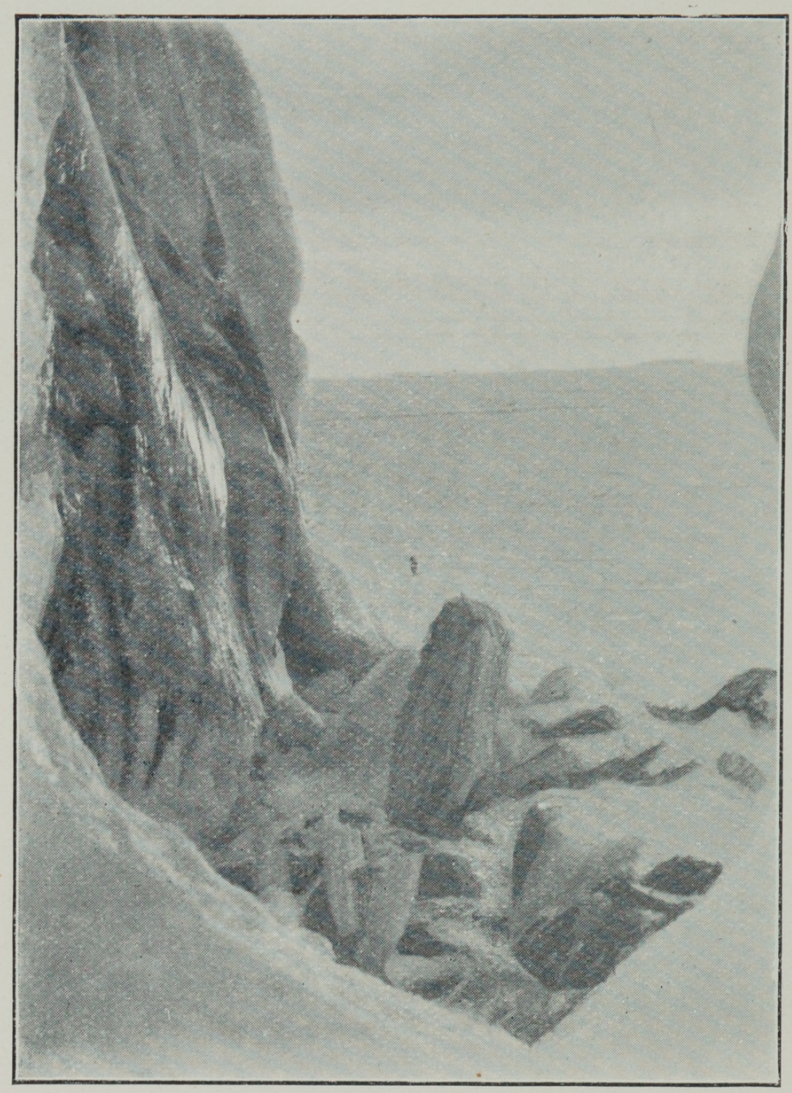

LOOKING TOWARDS CAPE ADARE FROM DUKE OF YORK ISLAND.

by giving him "Nao," a very fine essence of beef, which gradua 11 y became a ne ces s a r y part of our sledge pro$\mathrm{v}$ i s i n s. How e ver, both of $\mathrm{my}$ brave comrades kept up their courage and were always cheerful. A very valuable geological collection was secured and brought to Midwinter Camp. In the middle of August we started back to Camp Ridley. The temperature continued then to fall, the nights were very dark, and the track heavy. On this journey we experienced the lowest temperature we recorded; it was -52 , or $84^{\circ}$ of frost! At night we dug ourselves down in the snow, finding this warmer than being in 
the tent. We had to use our reserve hickory ski to make slides for our sledges.

On my return to Camp Ridley I decided to continue the explorations already begun in Robertson Bay, partly because I found that the locality in itself contained valuable scientific properties - not least in the geological department-and partly because I also hoped to find here a place whereby to reach further inland. Expeditions were despatched during the remainder of August and September under the alternate charge of members of my staff.

We had constructed a rough stone hut at Midwinter Camp some Io ft. in diameter. The roof

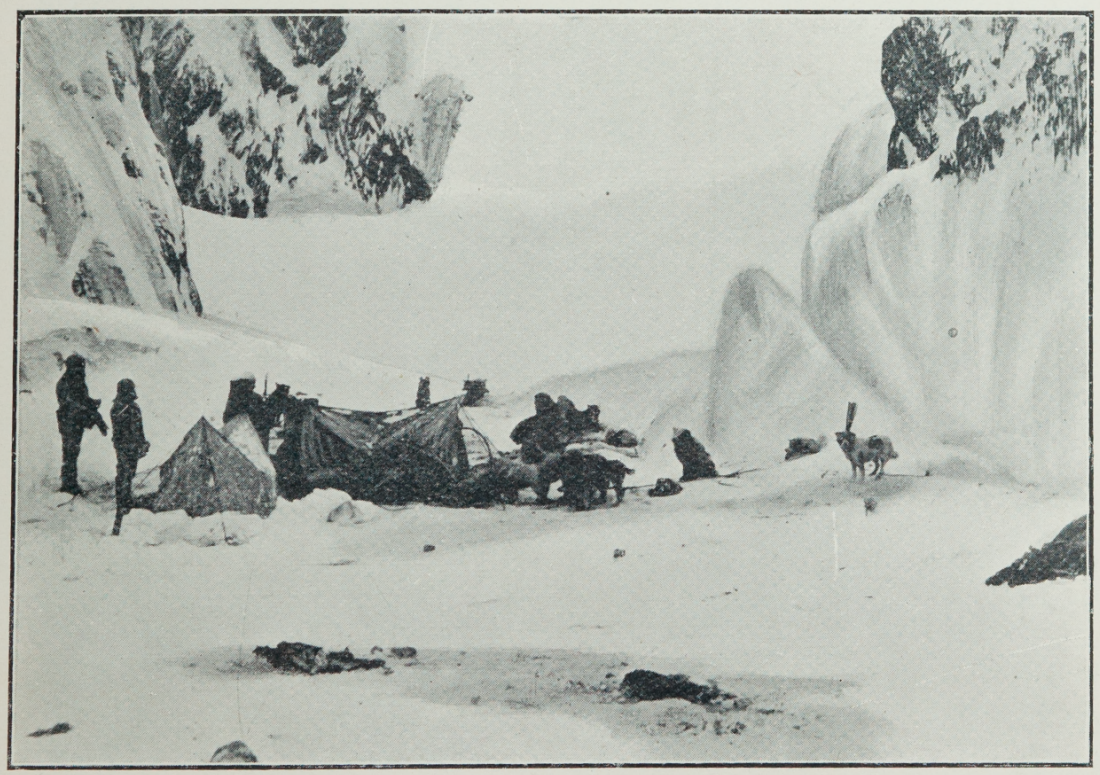

CAMP PITCHED NEAR DUKE OF YORK ISLAND.

we covered with seal-skin, canvas and rocks, and used spare ski to support it. The hut was placed in a corner where the rocks of Duke of York Island 
formed a comparatively sheltered place. It was a cold job building this hut. To get the material we had to carry rocks from far off, and break loose pieces

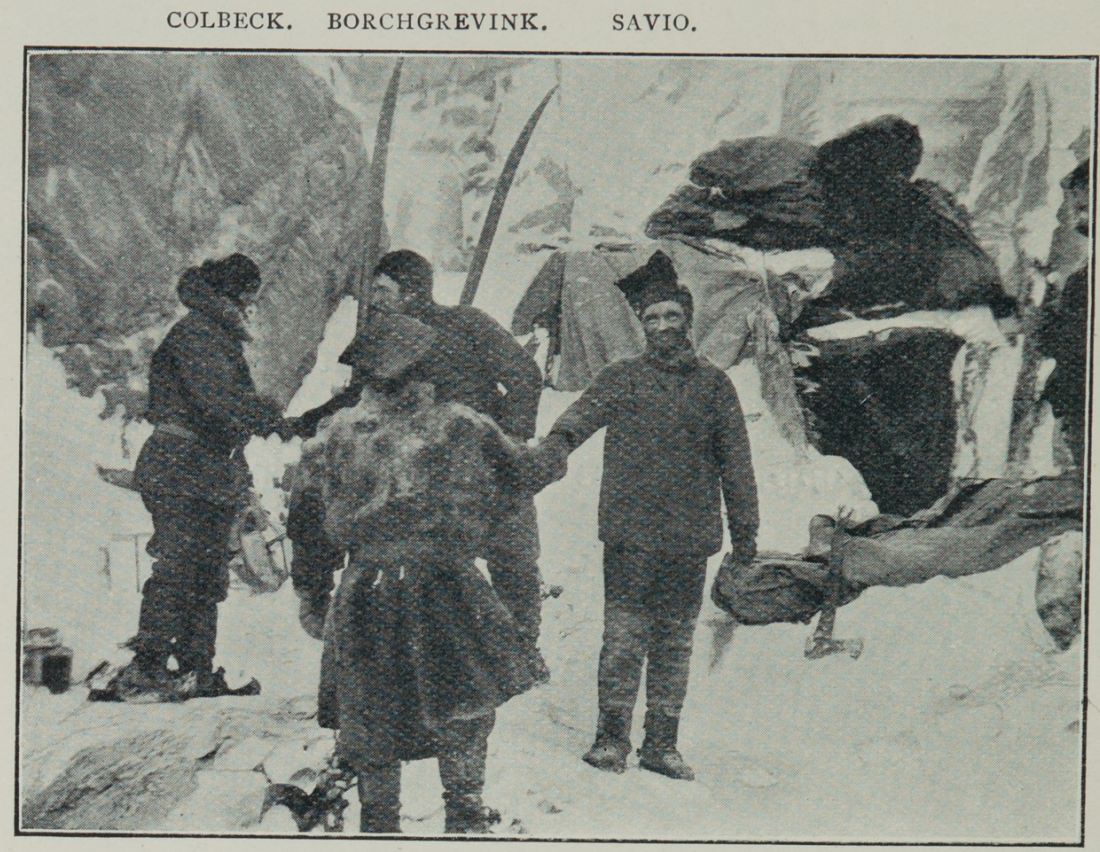

MUST.

MR. COLBECK AND THE FINN MUST LEAVING MIDWINTER CAMP, AT THE STONE HUT.

from the mountain side, where successive frost and thaw through ages had made our task possible. When we had finished the hut we covered it over completely with snow, only leaving a small space open to let the smoke out. The first gale with snow-drift buried it all. Our provisions were placed in a large cave which the Finns carved out of an immense drift. This cave was approachable through a winding tunnel some $30 \mathrm{ft}$. long, and would have formed a comparatively warm and safe place in case we should 
have been unable to keep the passage to the stone hut clear.

In the vicinity of Robertson Bay the nature of the land, with its great elevations reaching far above $\mathrm{I} 2,000 \mathrm{ft}$. in height, sometimes at an angle of about $50^{\circ}$, and crossed by innumerable crevasses, made our expeditions on the coast-line both arduous and risky. Savio and myself worked hard in the neighbourhood of Mount Sabine for more than seven weeks. Our main camp was at the time the stone hut. By burning blubber we managed to keep the temperature near freezing point, but at night it varied generally inside the hut between -35 and -45 . During the

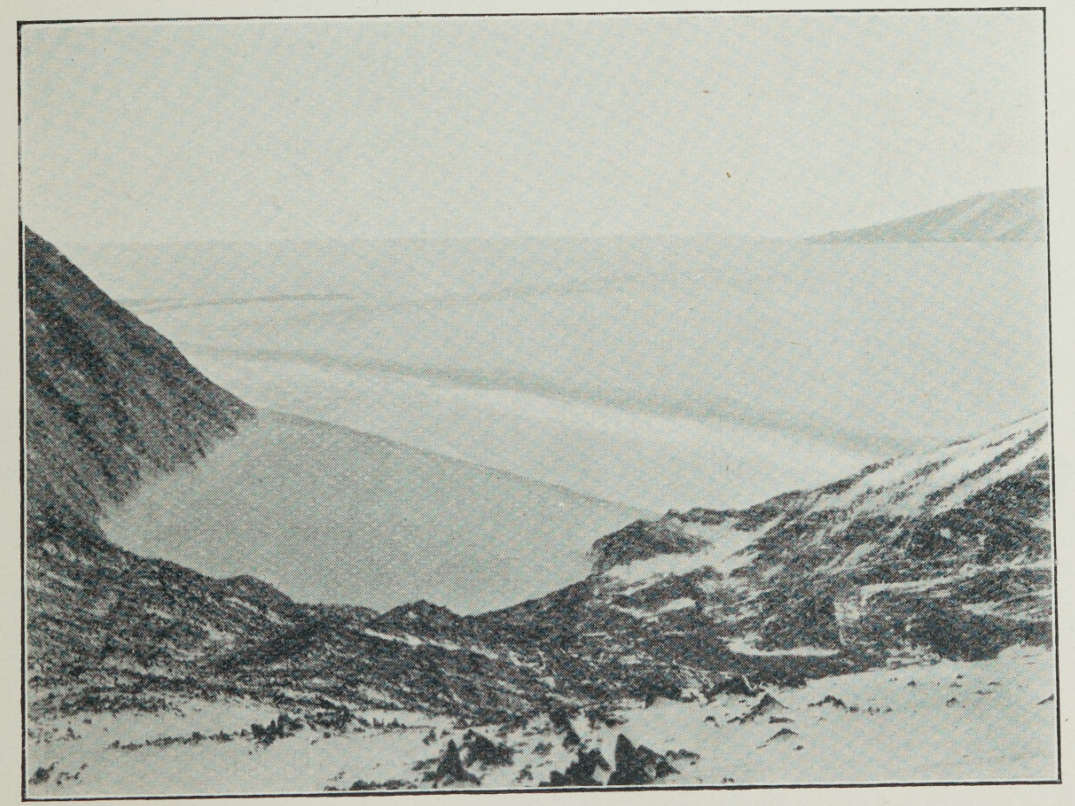

CRESCENT BAY, DUKE OF YORK ISLAND.

time we were settled here communication with Camp Ridley was continually kept up, and stores brought from there to form a depôt at Duke of York Island. 


\section{I70 British Antarctic Expedition.}

The dogs were invaluable to us on these journeys ; we fed them principally on blubber and seal-meat, and at the coast we secured enough fish both for specimens and food.

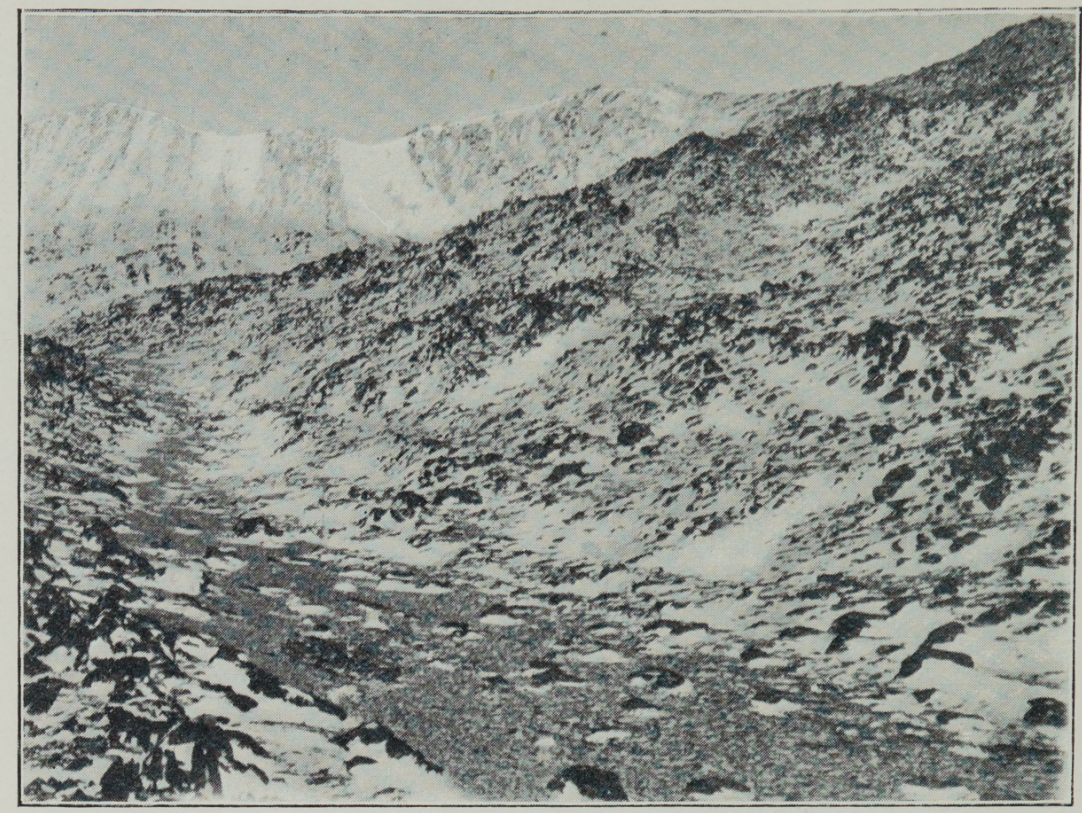

THE INTERIOR OF DUKE OF YORK ISLAND.

On September I Ith I killed a female seal near the edge of Dugdale Glacier. It was a leopard (Stenorhynchus Leptonyx). When I had skinned it, I cut it open, and, to my surprise, found a nearly full-grown male young one alive in her. After I had freed him he seemed quite happy as he rolled about on the ice in his soft, smooth coat. I put him on my sledge, and drove him to the stone hut, where we kept him alive on condensed milk until we were later on able to send him by sledge to Camp Ridley, where Dr. Klövstad fed him from the bottle! 
Mr. Bernacchi and Mr. Ellefsen were the last to bring food supplies to the depôt. They had a hard experience on their way. When overtaken by a furious gale in the ice pack, they had to take refuge in an iceberg. The thermometer was very low, and the gale so strong that they were unable to creep against the wind on all fours, and although it was still winter, with the ice about four or five feet thick, they expect e d every minute to see it break up, and in the midst of the gale climbed the berg and camped in a cavity until light allowed them to descend.

On one of our journeys on the glac-

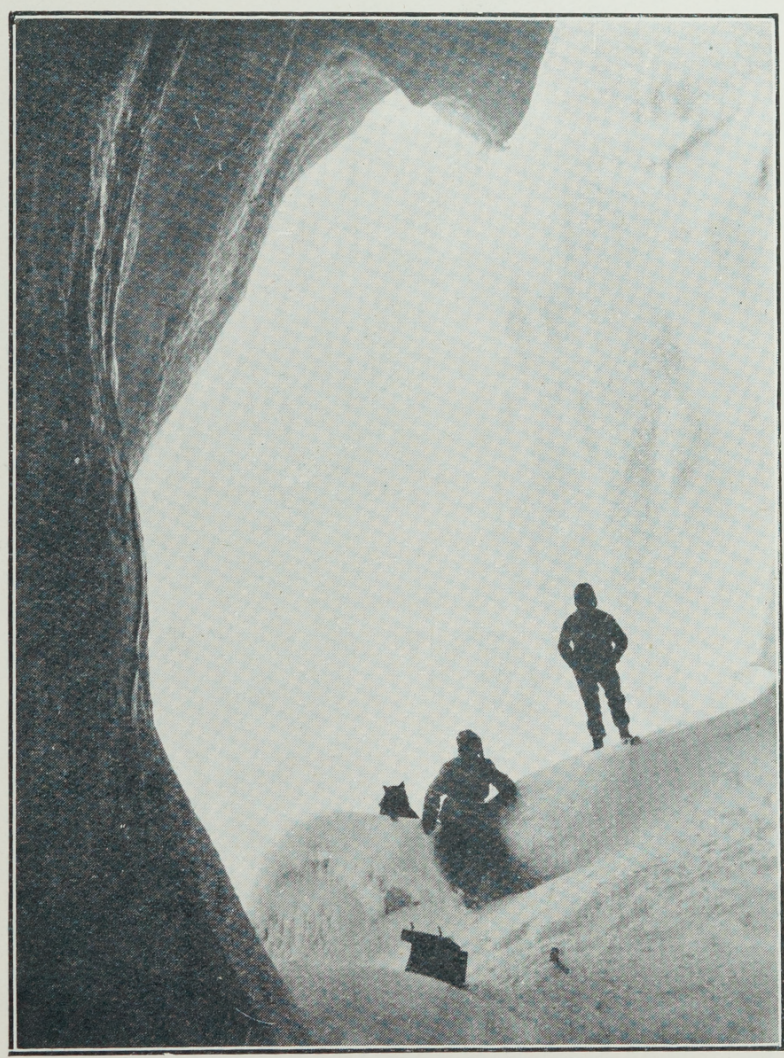

IN THE CENTRE OF AN ICEBERG. iers of Vic-

toria Land, in the vicinity of Duke of York Island, Savio very nearly lost his life. Carelessly, he had walked on alone, out of sight, onwards on the glacier without a guiding rope. New snow had fallen, and I 


\section{I72 British Antarctic Expedition.}

had already for a long time been using the utmost care in crossing the glaciers at this locality. The Finn, who had walked boldly along, suddenly felt the

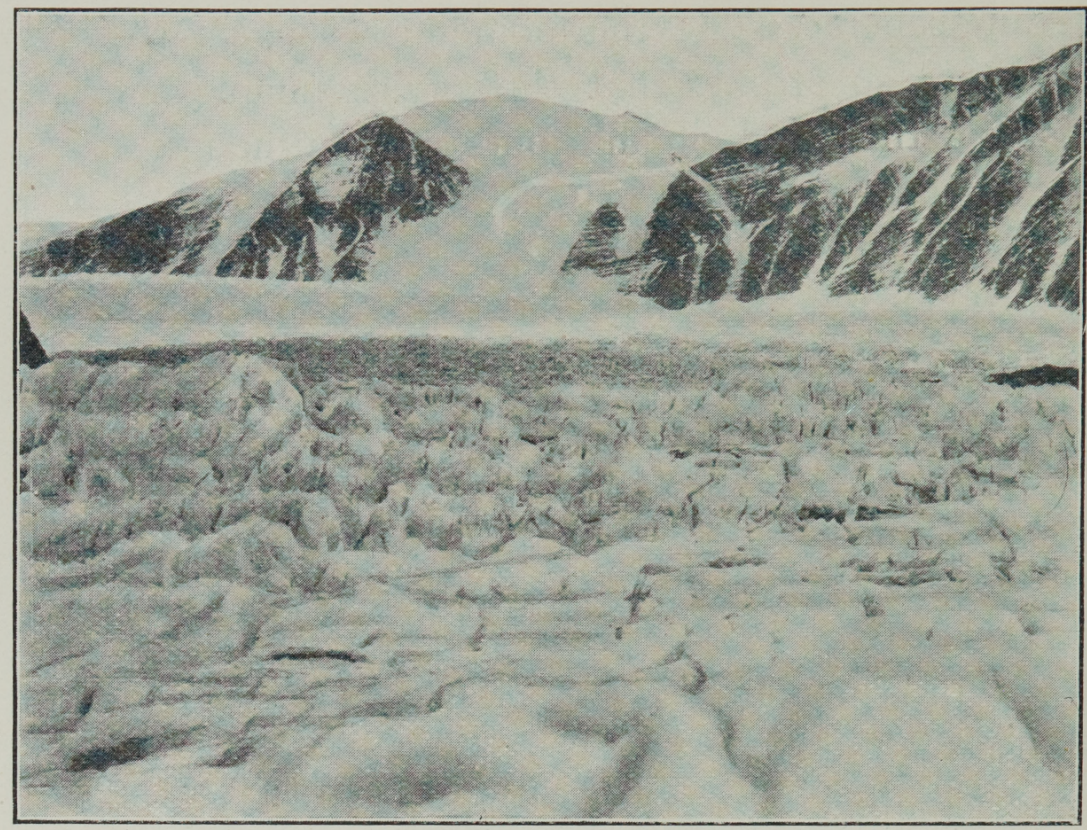

CREVASSES BLOCKED OUR ROAD.

snow give way beneath his feet, and fell headlong into a crevasse, turning three somersaults in the air before he was jammed, sixty feet below, head downwards. A dog which had followed him stood howling at the edge of the treacherous crevasse. Although he had managed to turn himself head upwards, Savio remained for hours in despair in his difficult position; the ice curved over his head, and shut off the edge from which he had fallen. The crevasse, which narrowed off at the place where the Finn was jammed, opened up a little to the right in an abyss, dark, wide, and of unknown depth. Had he 
fallen two feet further to the right, Savio would have been lost. What saved him was his coolness, presence of mind, and his never-failing store of resource. He found in his pocket a strong penknife, with which he slowly and carefully began to carve small supports for his feet; then, pushing his back up against the opposite wall of the crevasse, he gradually worked his way upwards, much in the way a chimney-sweep in the days gone by ascended a London chimney. The different widths, and the slippery, smooth ice wall presented great difficulties. However, Savio at length arrived at the top, but in an exhausted condition, and on meeting us was unable to speak on account of weakness. I

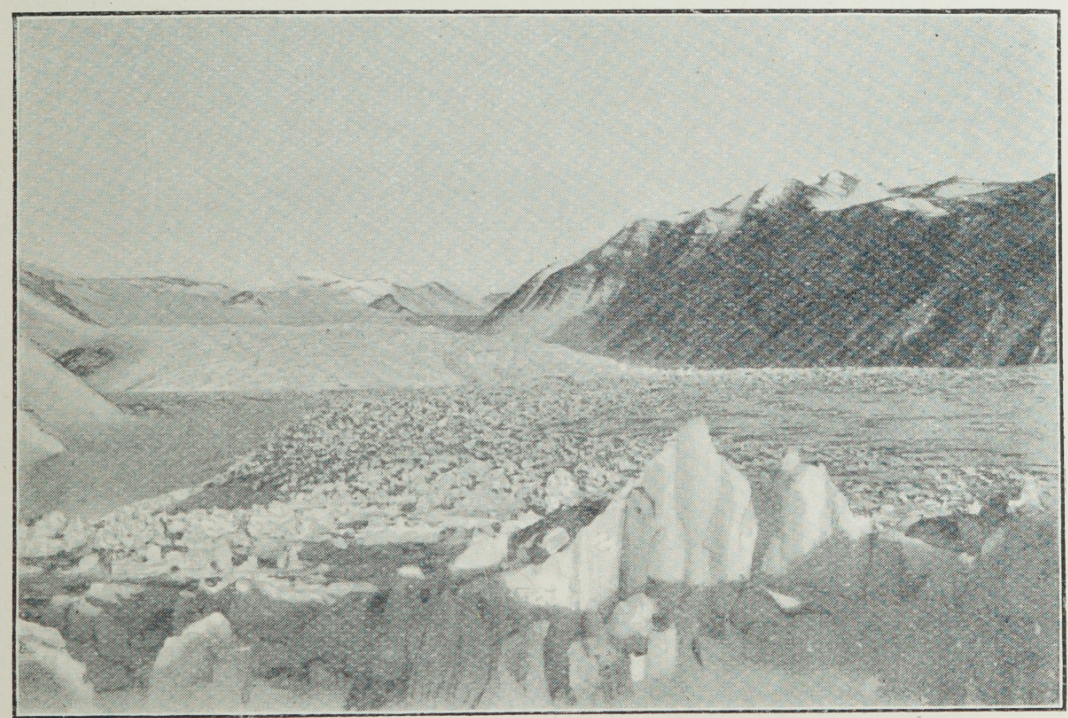

SIR JOHN MURRAY GLACIER.

made a thorough investigation of the crevasse by means of safety ropes, and ascertained the depth to which the Finn had fallen; also I saw the 


\section{I74 British Antarctic Expedition.}

marks of the ingenious way in which he had saved his life.

Towards the west of Duke of York Island a gentle slope led up to a height of about $70 \mathrm{ft}$.,

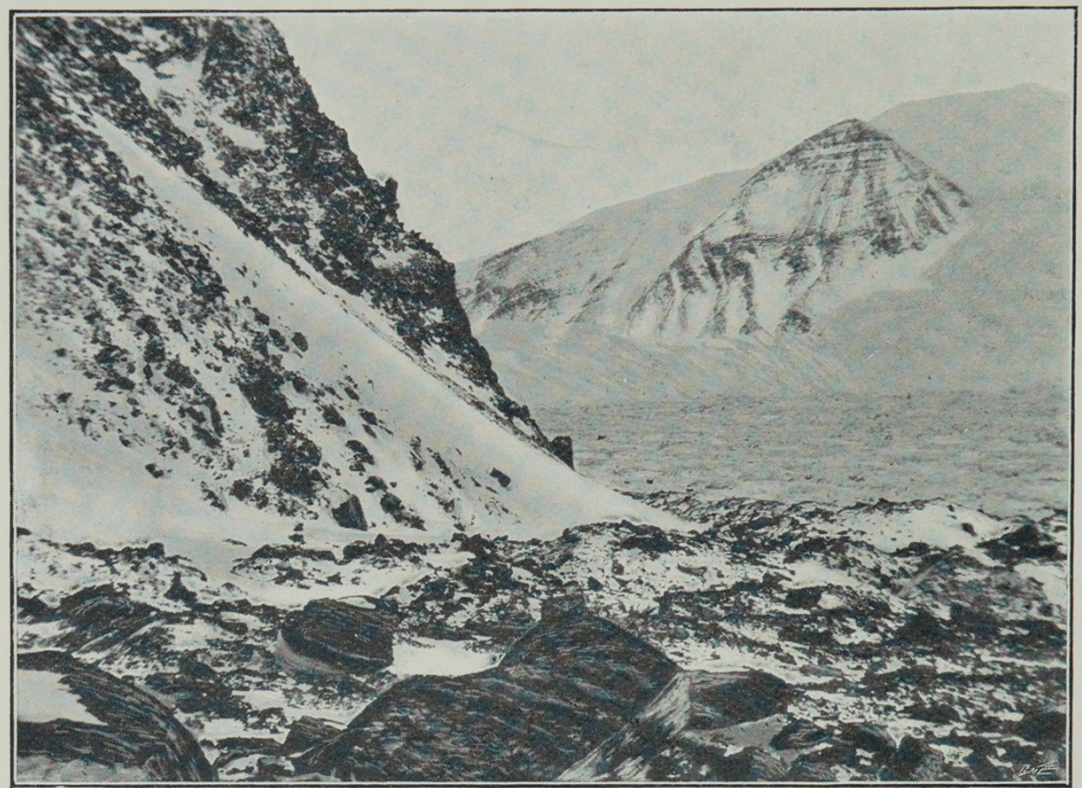

MORAINE AT GEIKIE LAND.

where we found ourselves on the top of a glacier, or rather, a junction of glaciers. Towards the south, in the Adniralty Range, a dark, high land rose, which stood out conspicuously against the white walls of Mount Sabine. It proved excellent travelling on the top of this glacier for some few miles until near the high land, which, towards the east, rose from Sir John Murray Glacier, and towards the west from an enormous glacier which I named Dugdale Glacier. It was on the junction of these two that we travelled towards this new land, which I named Geikie Land, after Sir Archibald Geikie. 
When we were about a mile from it we struck the medial moraine, consisting of large broken rocks, and following it in a somewhat easterly direction we crossed the moraine at about the middle of the base line of this new land. This was no easy task, as it was cut through everywhere by deep crevasses, covered over with snow, gravel, and rocks in a most treacherous way. In addition to these crevasses came the difficulty of conveying the loaded sledges onward safely on this cover. The rocks tore the slides of the sledges, and we had to carry most of our provisions over on to the solid rocks of Geikie Land roped together, and slowly feeling our way with alpenstocks.

A young dog, which had followed our sledges loose, fell into a crevasse. We heard it howl and went in search. Most of us had given him up for lost when we, through our glasses, discovered one of the Finns out in the middle of the glacier; he was lying flat on the ice, and evidently look-

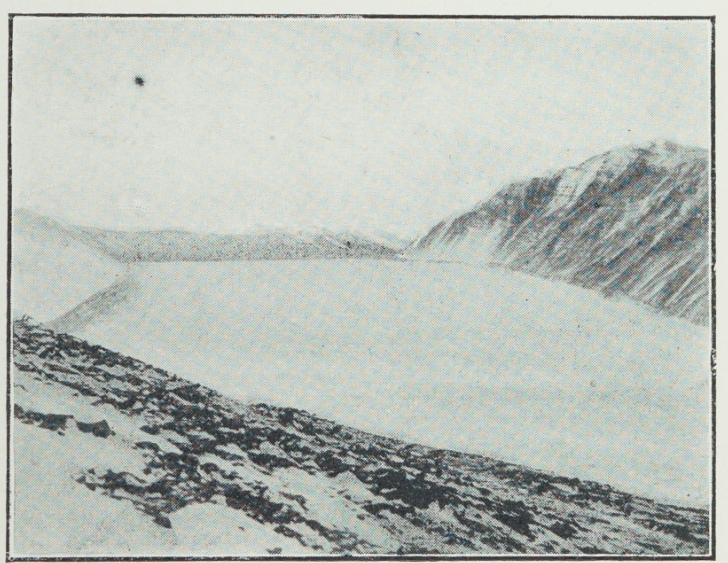

SIR JOHN MURRAY GLACIER. ing down a crevasse. Through our glasses we did not see more than one of them, so began to think that the other might have come to grief; however, we soon saw them both approach with the lost dog 
I76 British Antarctic Expedition.

between them. The brave, faithful fellows had risked much in saving that dog. Unwisely, they had not been roped together, neither had they any rope with them,

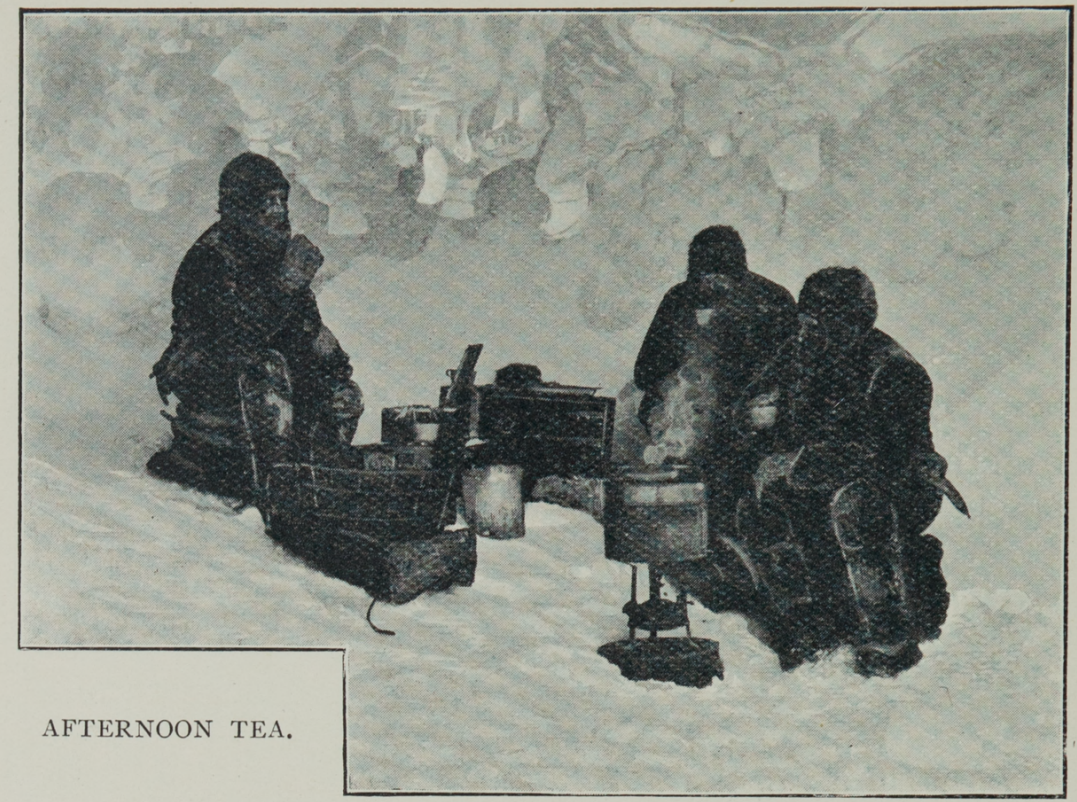

but when they discovered the dog in the crevasse, landed on a ledge some $15 \mathrm{ft}$. below, they unbuckled their belts, fastened them together, and Savio, lying on his stomach, lowered the Finn Must into the crevasse, from which he was luckily pulled up, together with the dog, by Savio. The crevasse was broad and seemed to be very deep, and had the dog not landed on the ledge he would have gone down some 80 or $100 \mathrm{ft}$. at least.

On I 2 th September the doctor, Lieut. Colbeck, Mr. Bernacchi, both Finns and myself, started at 7 o'clock in the morning from the stone hut. We scaled the glacier and traversed the distance to 
Geikie Land; and by following the moraine on the eastern side of Dugdale Glacier we succeeded in bringing our sledges with the outfit a considerable distance upwards. But the gradient got steeper and the crevasses more numerous, until progress by sledge was impossible; then we packed ourselves, roped together the doctor, Colbeck, myself and the Finn Savio, and cut our way upwards in the hard blue glacier. Step by step we rose until we were a few thousand feet up as indicated by the aneroid. At last the ascent became so steep that further progress was impossible, we all of us were then roped together at a place where our only foothold was that cut by the pick of the alpenstock, about the

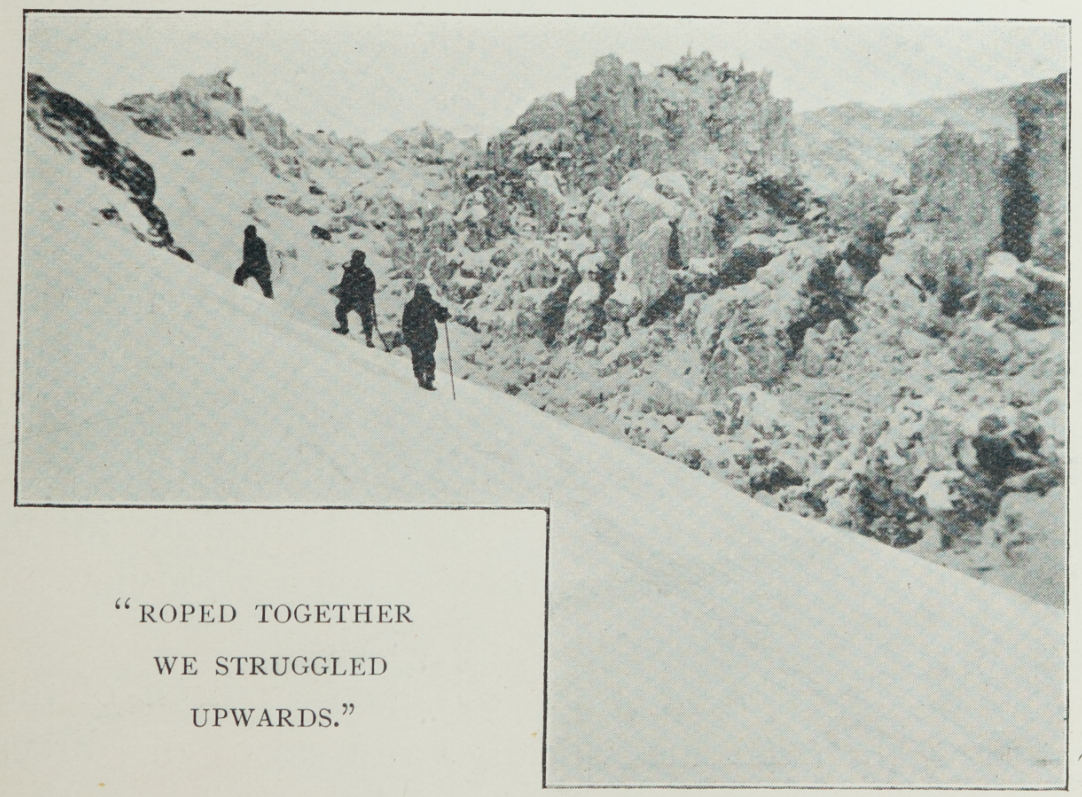

size of our hand. Towards the left an almost perpendicular wall rose; and to the right the glacier precipitated itself into a crevasse at a degree of about 
seventy. A slip of the foot of one of us would then probably have sent us all into eternity, and as the small lumps of snow and ice, with accelerating speed

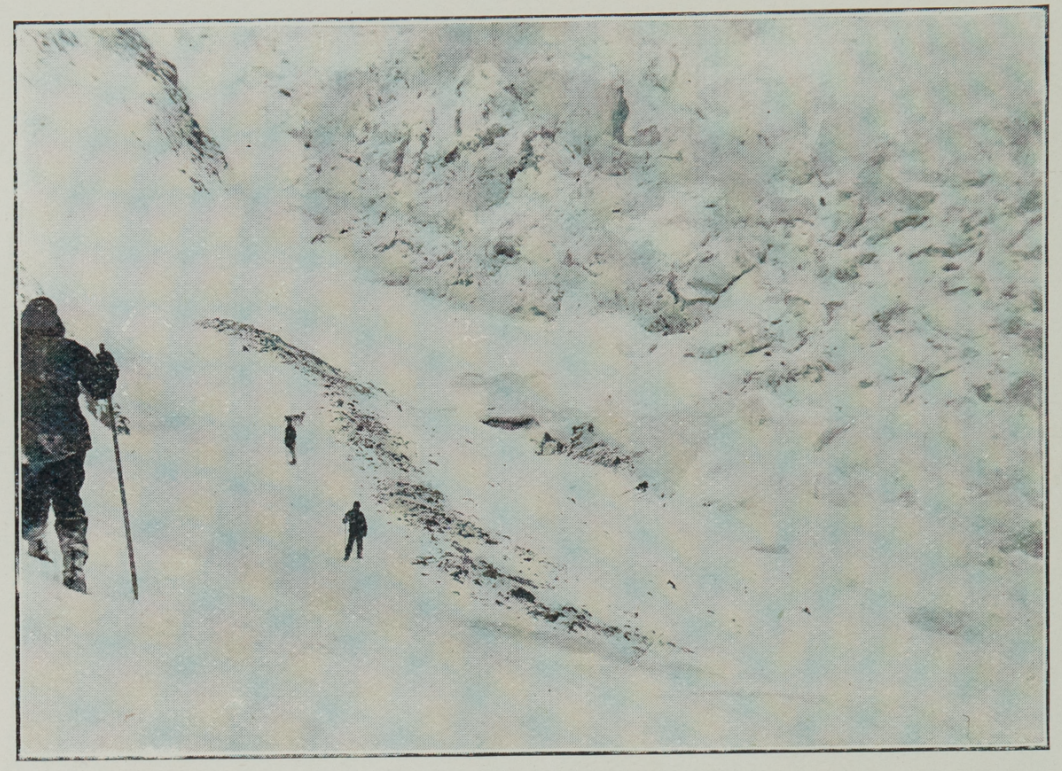

ON THE MORAINE OF DUGDALE GLACIER.

loosened by our feet, rushed downwards towards the crevasse below us, we could not but consider our chances in case we should go the same way. The worst of it would have been that we should have had such a long time before we arrived at our destination, and still had the certainty of destruction in view all the time while sliding speedily down.

Not only is Duke of York Island in itself of the greatest interest scientifically, and also of direct practical importance, but its position, similar to that of Doubtful Island-discovered by Sir James Clark Ross-illustrates that there is a remarkable land formation which, in close vicinity of great glaciers, 
makes it very difficult to decide whether the land really is an island or joined to the mainland as a peninsula.

The discovery of Duke of York Island throws a new light on the theory which, because of its uncertainty in my opinion, caused Sir James Clark Ross to name his discovered island Doubtful Island. Duke of York Island is cut through from east to west by broad deep quartz reefs. May it here suffice to say that minerals of value occur in this vicinity, and that undoubtedly, in time to come, science to a great extent will receive that support

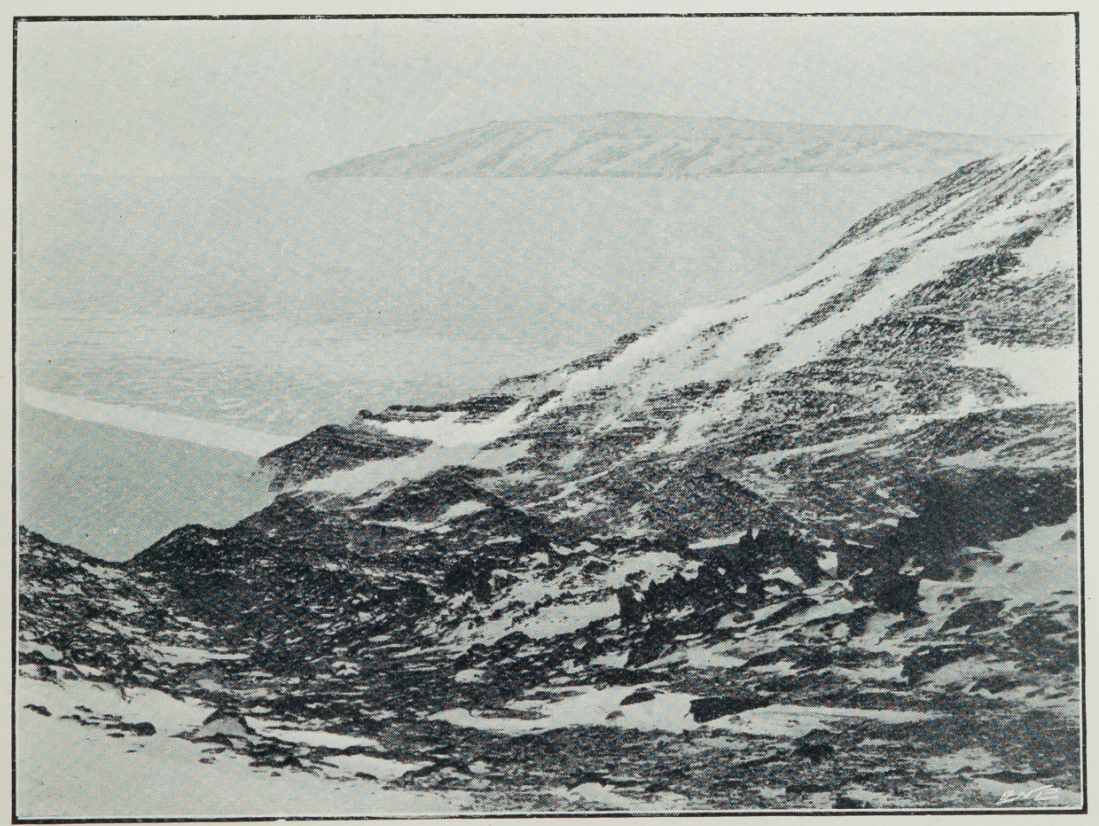

ON THE COAST OF DUKE OF YORK ISLAND.

from commerce which the progress of civilization justifies, and that future Antarctic exploration never will be in want of financial support. 
I80 British Antarctic Expedition.

The glacier formed by the union of the Murray Glacier and the Dugdale Glacier is covered by a very thick medial moraine at the N.W. side of Geikie Land, in breadth about one English mile, or perhaps somewhat less. The smooth and unbroken ice-sheet formed at this junction owes undoubtedly both properties to that great pressure which must

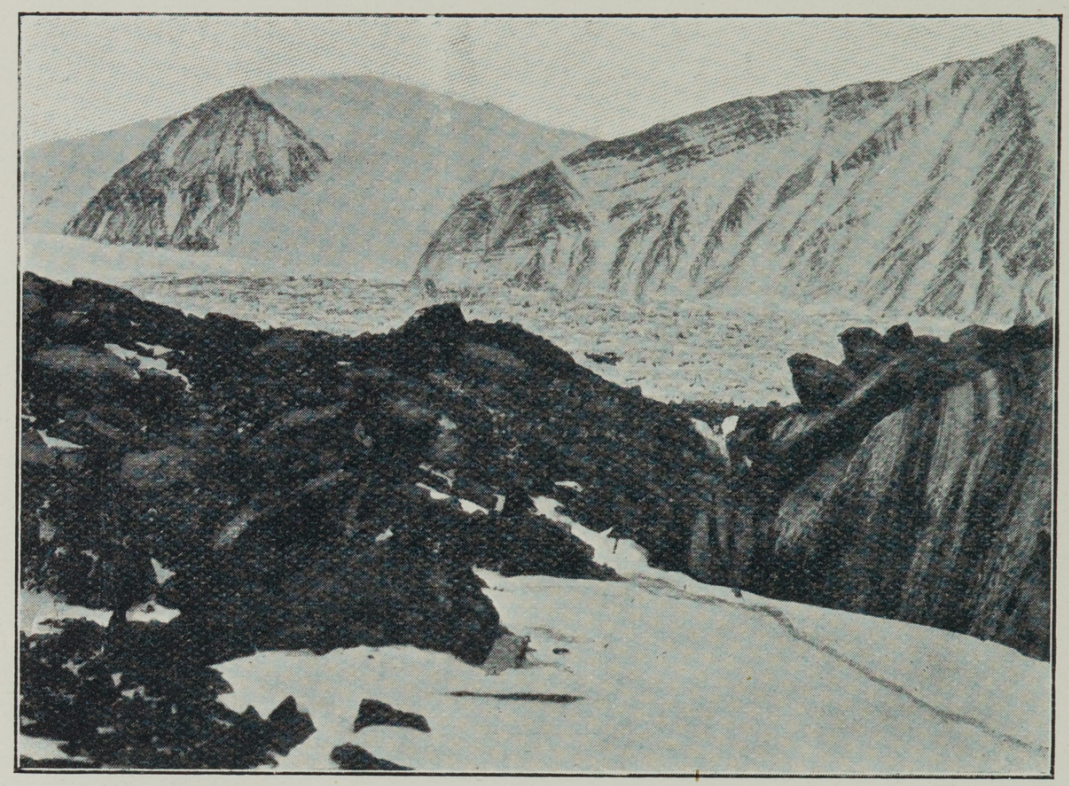

MORAINE STUDY.

needs prevail by the presence of Duke of York Island just projecting at the edge of this large inland ice-sheet. This land parts the descending ice-sheet into two separate broken glaciers which descend in a steep gradient into the sea.

Officially I took possession of Duke of York Island for Sir George Newnes, under protection of the Union Jack. 


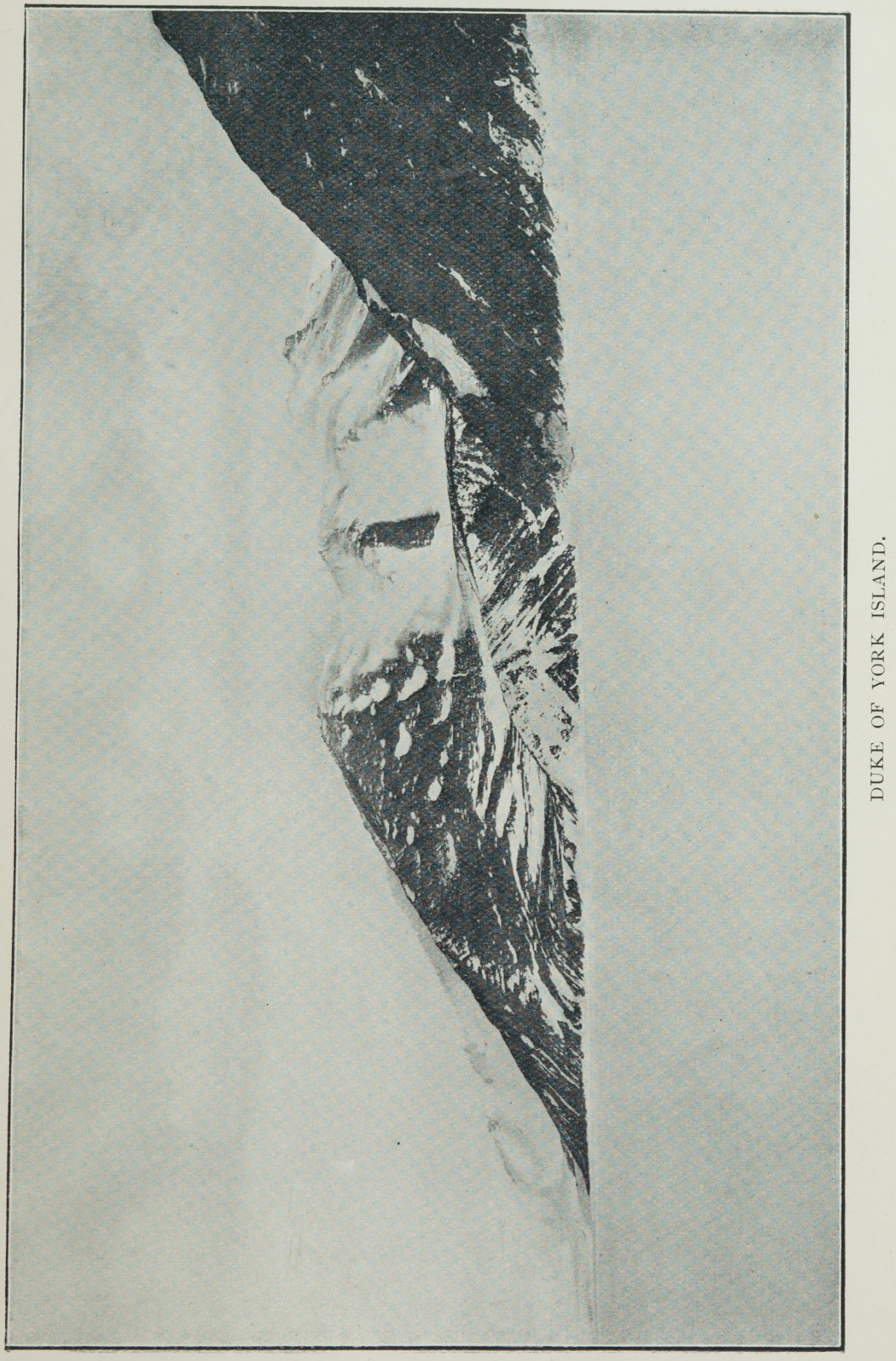



We continued to have a plentiful supply of fish. We caught very many of an unknown species just where the glacier to the west of Duke of York Island descends into the Bay. We generally caught them in cracks in the ice, near ice walls formed by the descending glacier.

I had at that time a narrow escape from falling into a crevasse in a glacier, but managed to save myself by throwing my alpenstock quickly across the mouth of the crevasse.

We experienced some very heavy gales on our sledge journey into Robertson Bay, the gusts of wind starting fields of snow in motion, which descended and completely buried our little stone hut.

The last report from Camp Ridley told that Mr. Hanson was in a rather low condition, he having lost feeling in his legs, and only able to walk with difficulty. He was under the treatment of the doctor, who applied the electric battery to his legs.

By one of the Lapps on ski I received the following letter from the doctor:-

Camp Rinley,

$$
\text { 20, 9, } 99 .
$$

Mr. C. E. Borchgrevink,

Commander of British Antarctic Expedition.

On my arrival in Camp Ridiey on the $3^{\text {th }}$ inst. I found Mr. Hanson in pretty good spirits, but not as well as I had hoped. The gas poisoning, about which Mr. Bernacchi gave you a report, had put his general health back somewhat. His appetite 
I84 British Antarctic Expedition.

is small, and his digestion is not quite satisfactory. His pulse is quick, and the swelling in his legs larger than it was. He seems to walk with more difficulty than before. After having treated him for a week I find him, however, now better.

According to your instructions,

$$
\text { (Signed) Dr. H. Klovstad. }
$$

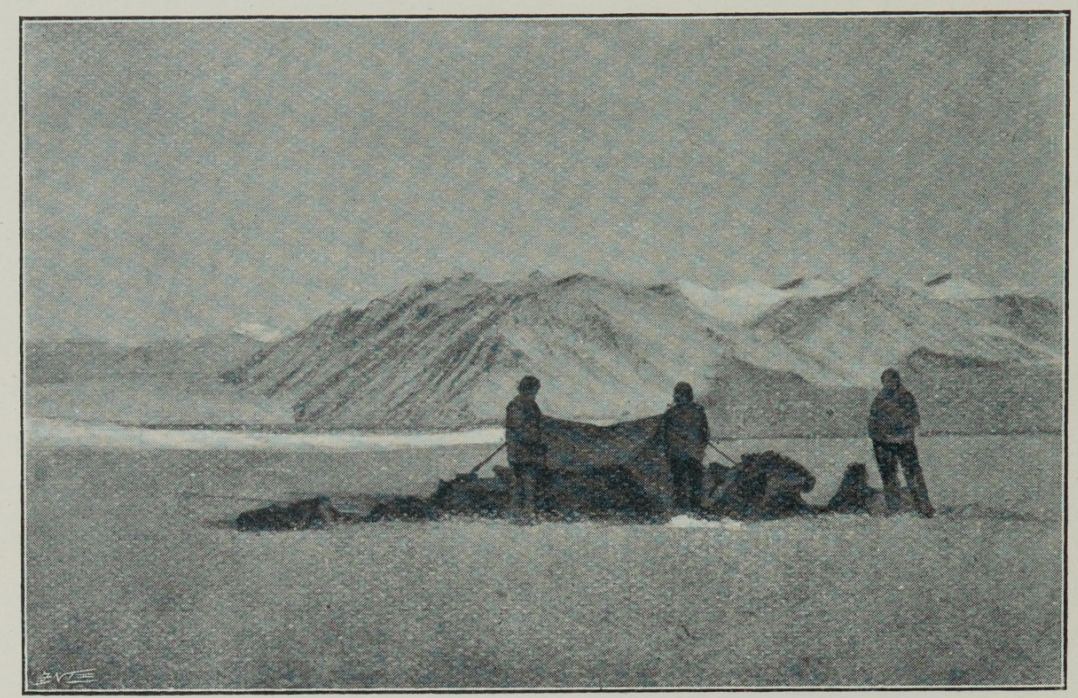

BEFORE 'THE SUN ROSE ABOVE THE HORIZON.

On 4th October I started back to Camp Ridley with Mr. Fougner. Ellefsen and Must we left behind for collecting purposes. They were to remain in the stone hut until some message was received from the main camp. With them I left ten dogs, three sledges, and a good supply of provisions.

On the young seal which we brought from Robertson Bay to Camp Ridley I discovered numerous ticks; they seemed to worry the seal considerably; I secured several of them in spirit. 
On arrival at Camp Ridley I found Mr. Hanson's condition very critical. He grew daily worse and worse, and took very little nourishment; he was also rather low-spirited.

I had then been away from Camp Ridley seven weeks, and already on the 7 th October, not trusting the ice conditions for sledge journeys much longer, and wishing to get Ellefsen and Must back to the

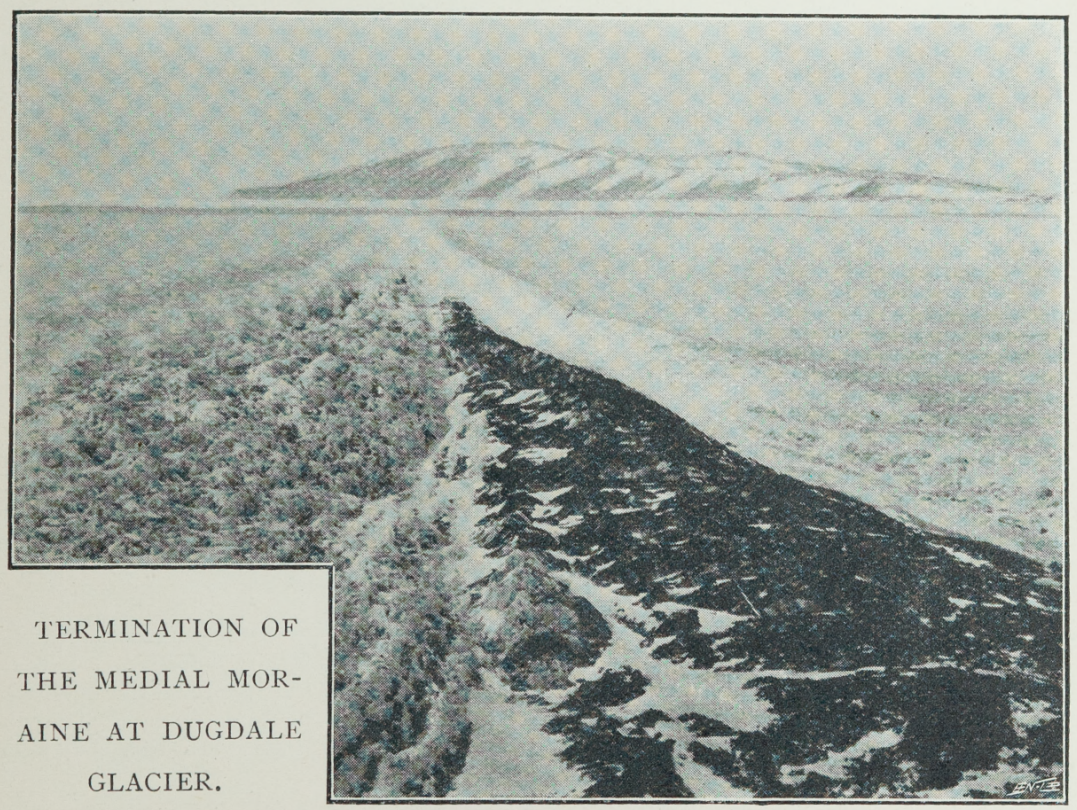

main camp, they being still at the stone hut, I decided to set out again alone with a team of dogs and some provisions, to assist them. On arriving at the stone hut in Midwinter Camp, I found them away. After a brief meal I wrote them the necessary instructions, left the dogs and sledges at the hut, packed some provisions in my knapsack, and started back on ski to the main camp, where 
I arrived at I I P.M., having that day covered more than forty-six miles.

On my arrival home I found Hanson very bad.

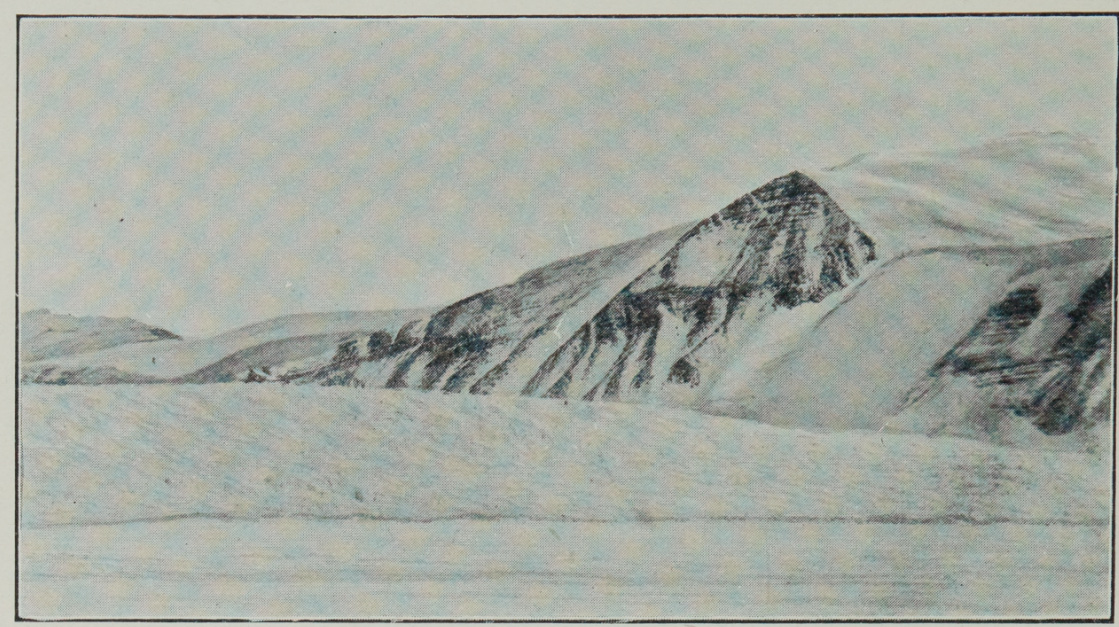

VIEW IN VICTORIA LAND.

On the 8th October the doctor thought Hanson so ill that he was obliged to sit up with him night and day. Mr. Hanson vomited continually. On the Ioth October Hanson was still very bad, and the doctor and I divided the night into two watches at his side. In spite of the doctor's care and attention. Hanson's condition kept getting daily worse.

On this day, Ioth October, Mr. Fougner brought to camp a new species of fish of extraordinary structure. In Robertson Bay there was an abundance of fish, and in all we discovered about five different kinds. One particular species was often over twelve inches long. The most remarkable one in the fish collection, however, is a fish about nine to ten inches long, with a body like that of the jack, and a very long underjaw reaching beyond that of the upper, and armed 
with two very sharp, comparatively long, backwardsinclined teeth. The head occupied nearly one-third of the entire length of the fish. It is greenish-grey colour above, while lighter underneath.

Another remarkable fish is one absolutely white, not of the usual white colour you see in the light spots of ordinary fish caught in the Northern Hemisphere, but a spotless, dull, milky white. It had much the shape of a herring.

Of lower organisms, caught principally by the dredge, Medusce were well represented. One large jelly-fish was caught near the peninsula, with arms, or extremities, about twelve yards long; its weight was

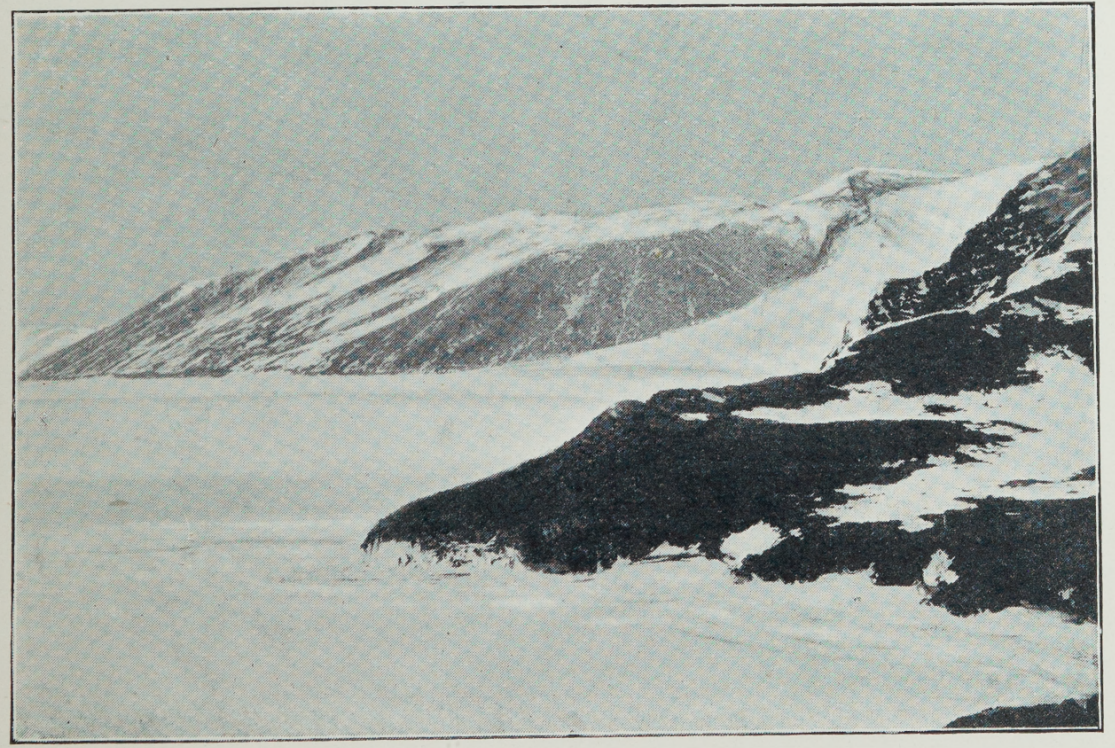

NEAR SIR JOHN MURRAY GLACIER.

90 1bs. Smaller jelly-fish, several kinds of star-fish, shells, sponges, and a variety of shrimps and crustacea were also secured. At the coast of Franklin Island, 
besides the above-mentioned species, a very fine coral was found.

The magnetic work was going on. Mr. Evans

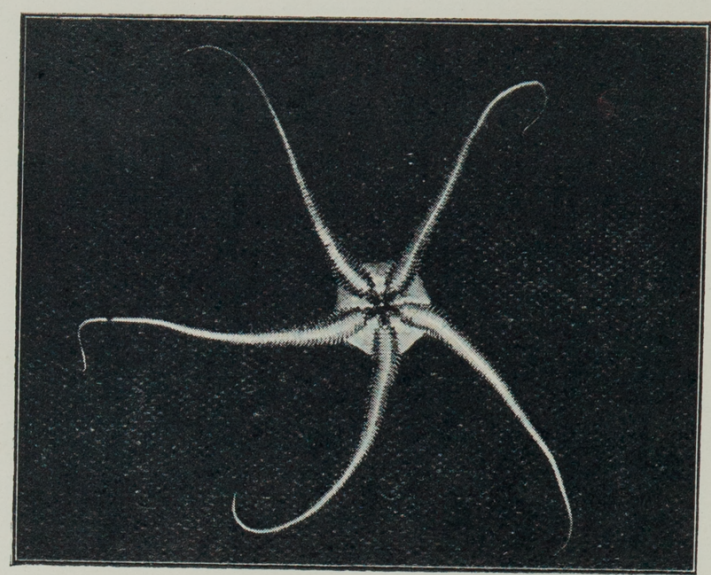

FROM TWENTY FATHOMS. attended now to the zoological taxidermist d e partment, while Fougner took over the marine fauna collecting.

On October I I th Mr. Hanson seemed to have become worse. The doctor took a few hours of highly-needed rest, while Fougner watched at the sick bed.

Early in the morning of the I th the doctor performed a slight operation on Mr. Hanson, who seemed to draw his breath with difficulty. I ordered all the members of my staff out of the hut with the exception of the doctor and his attendant, Mr. Fougner.

At midnight on the i $3^{\text {th }}$ October I crawled into my sleeping bag outside, but at 2 o'clock in the morning of the I 4 th the doctor called me and officially informed me that Mr. Hanson had not long to live, and that he had told Mr. Hanson of his condition, at which he had expressed a wish to say good-bye to us all. I went in and found him quiet and without pain. Calmly he bade me his last farewell, and confided to me his last wishes. He himself chose the place where he wished to be buried - at the foot of a 
big boulder I, ooo feet up on Cape Adare. The whole staff came in one by one, said good-bye, blessed him, and left the room. He thanked me for the kindness he had received at Camp Ridley, and told me that after all he was not sure whether it was not an advantage dying away from home: here he did not see the tears of relatives near and dear to him. He had, he said, a tickling sensation in his left arm, and drew his breath with difficulty, but of actual pain he assured me he had none. He also remarked to me that he had felt more moved when he had been saying good-bye at home in Norway when leaving with me

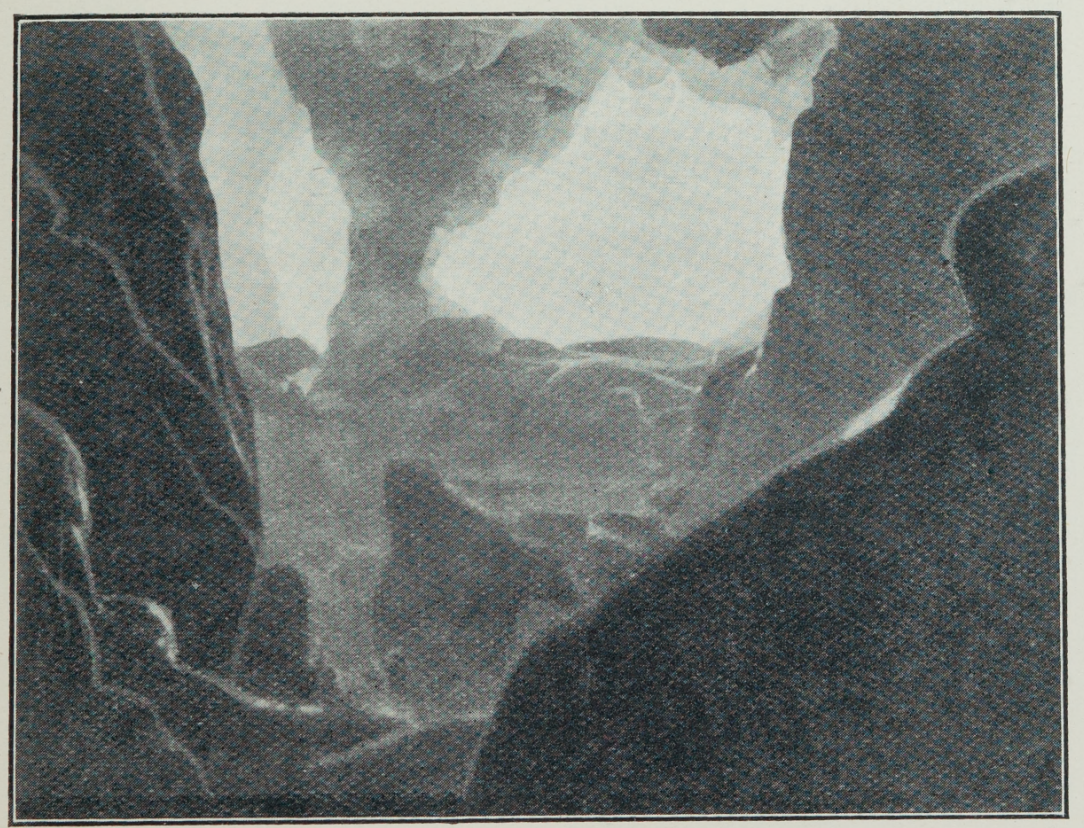

BEAUTIFUL CAVES.

for the South, than now when he was about to leave this world for ever. He had, he said, a feeling as if he were going to take a long journey. Mr. 
190 British Antarctic Expedition.

Hanson asked me that I might make his biography, if I was going to write such, as short and modest as possible. On the same day, about 3 o'clock in

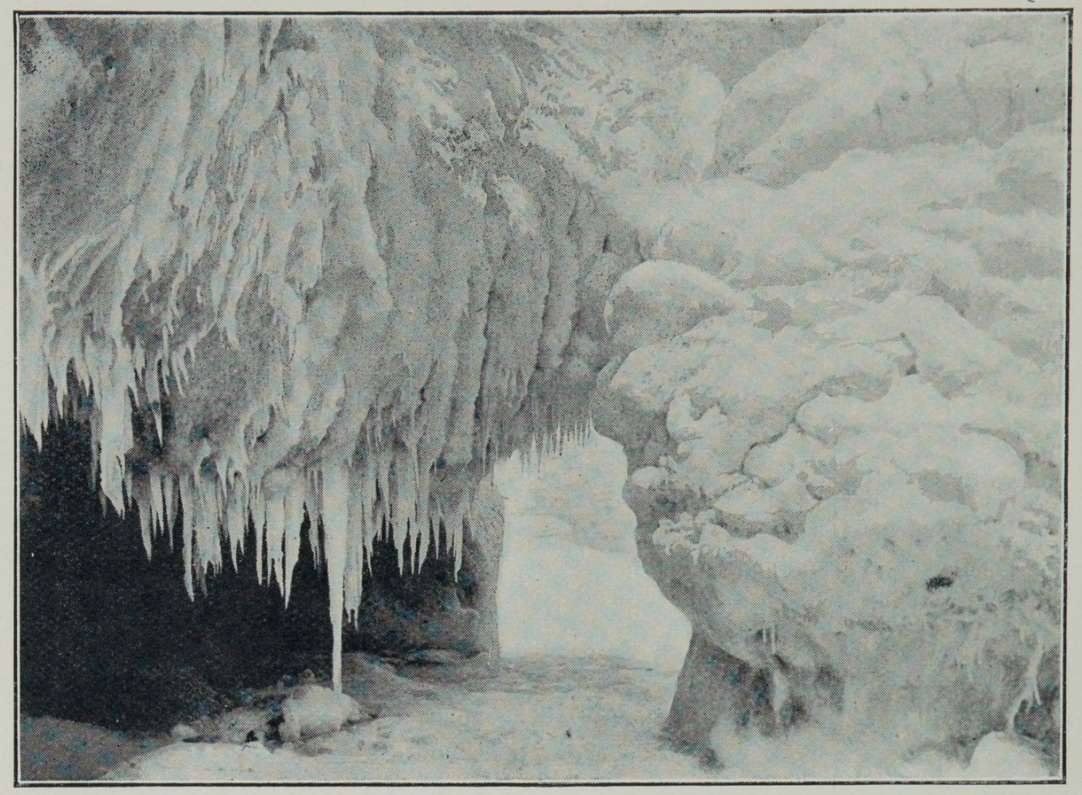

ICE-FORMATION.

the afternoon, Mr. Hanson died without pain, and remained conscious to the very last.

Half-an-hour before he died the first penguin came back. Enthusiastic as he had always been in his calling, he asked to see the bird, and on its being brought to him, he was delighted to examine it.

The doctor's official report says that Hanson died from occlusion of the intestines.

On the Igth October a great many penguins had arrived; some stood at their old nests, which they occasionally left to pick up pebbles, arranging them about their nests.

On the 2oth October we buried Mr. Hanson. 
Just before we closed the coffin, Mr. Fougner and I placed some pressed flowers, which Hanson's wife had sent in letters to Hobart before we left for the south, on Hanson's breast; and while we were thus occupied, the two Finns, according to their wish, held a Lappish service at the head of the coffin. It was touching to see these two simpleminded children of nature, in their native costumes, standing with bared heads in the cold, singing and talking alternately to Mr. Hanson's dead body.

We breakfasted early, and after the preliminary arrangements had been made, I read the Lord's Prayer over the coffin outside the hut. The coffin

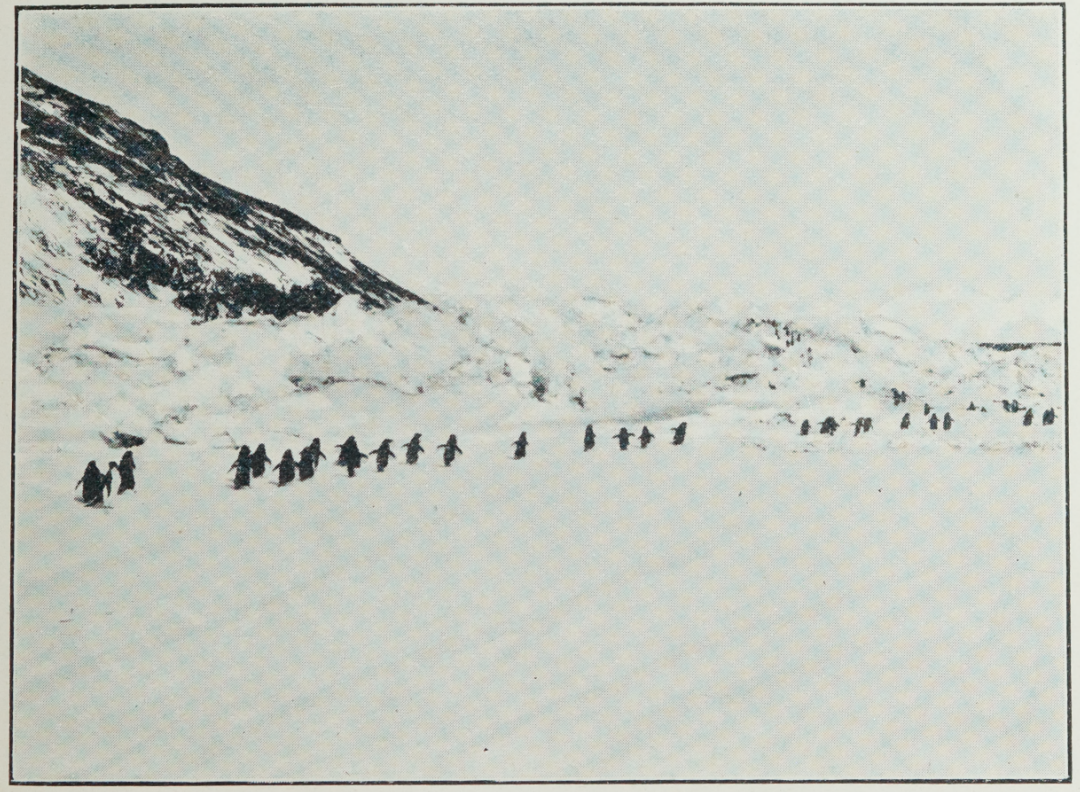

THE PENGUINS INVADING THE PENINSULA IN THE SPRING.

was then placed on a large sledge, and covered with the Union Jack. A light snow which had fallen during the night made our heavy task somewhat 
192 British Antarctic Expedition.

easier. We had to pull the sledge across the peninsula with ropes to the place where we used to ascend to the top of the cape. It was a sad and hard task to bring our dead comrade to his last

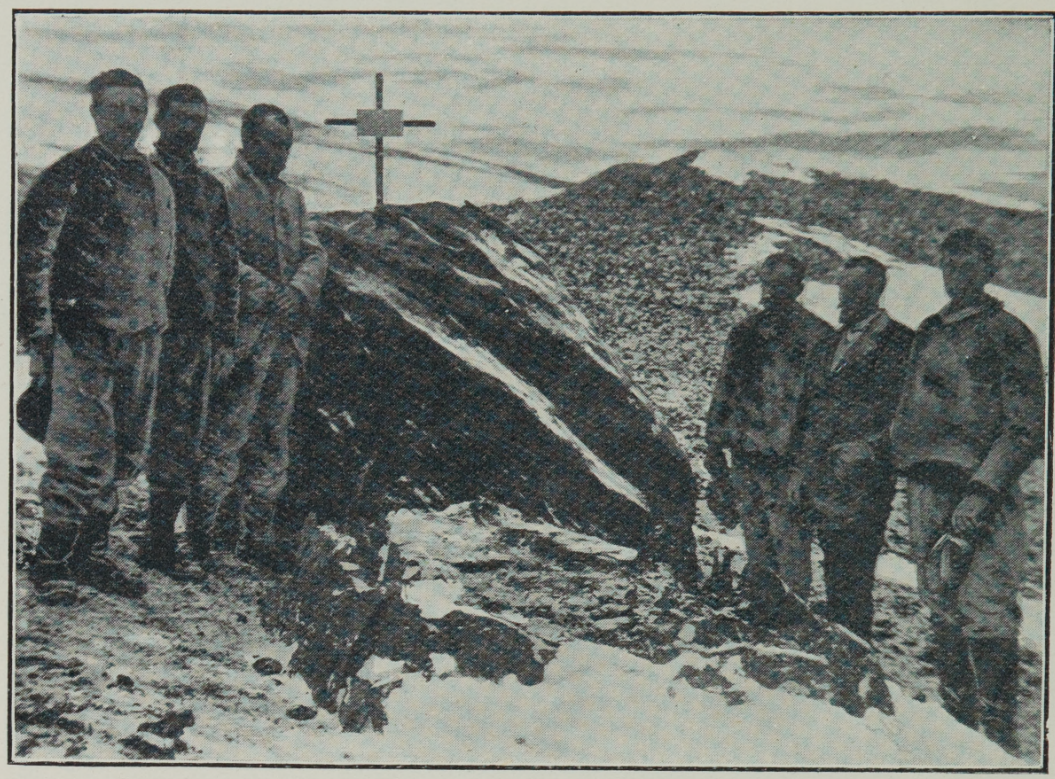

AT HANSON'S GRAVE.

resting-place. On arriving at the grave side I read a short funeral service; then we lowered him down, covered him over, and departed.

Penguins continued to arrive on the peninsula in great numbers, and we looked forward eagerly to the time when we might expect to get eggs. I continued during the remainder of October to send out expeditions in the vicinity of Robertson Bay, with satisfactory results.

On the 27 th a gale started which lasted for five days. The ice-pack seemed to begin to slacken at this date.

On October 28th Dr. Klovstad tested our sights 
by the range-finder. Roasted penguin now formed a repast at all meals, and sometimes on Sundays we ate their hearts only, which, when properly roasted-for us, at least-seemed a delicacy. On the 3 Ist I shot five skuagulls, all male birds.

I placed oak water-tight casks, with short reports of our proceedings, both in the hollows of icebergs and on the floes. The following is a copy of the communication placed in these casks:-

"Cape Adare, Victoria Land, November ist, I 899. - This is placed in the cave of an iceberg, situated two English miles west of Cape Adare,

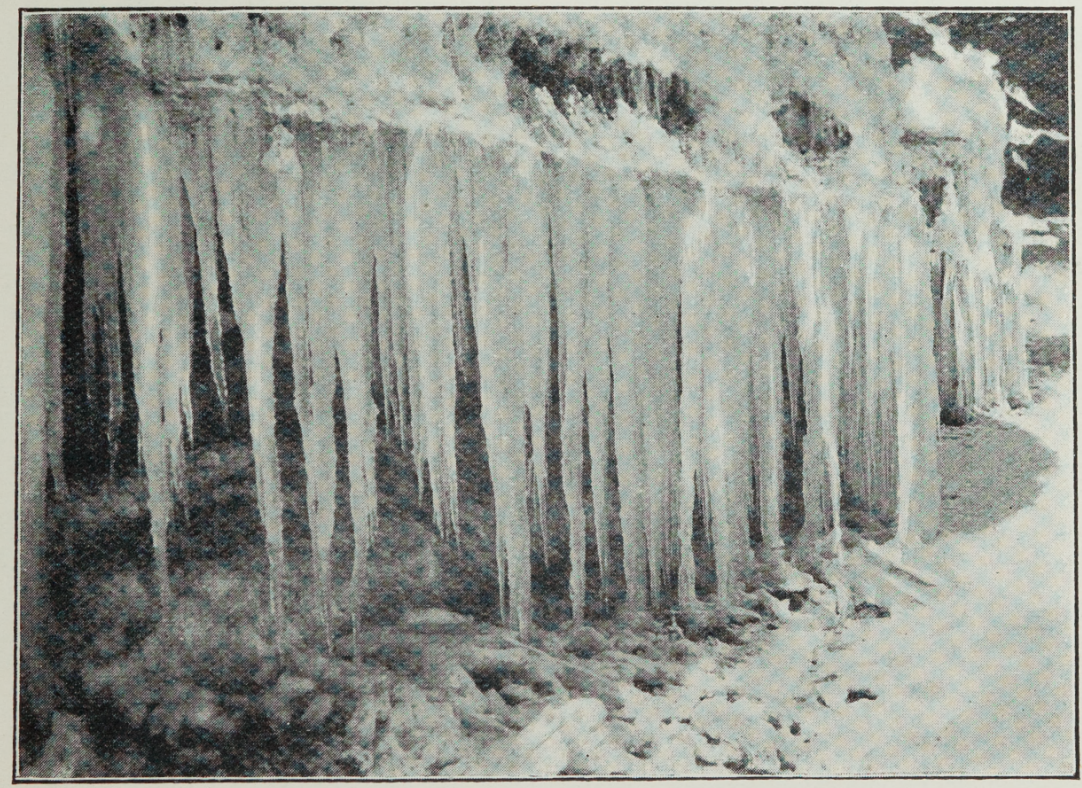

ICE-FORMATION.

the British Expedition under my command being successful in its object, but has lost one of its members, the zoologist Hanson, who died on the 
I94 British Antarctic Expedition.

I 4th October from occlusion of the intestines. Anybody who should find this is kindly requested to forward it as soon as possible to the Royal Geo-

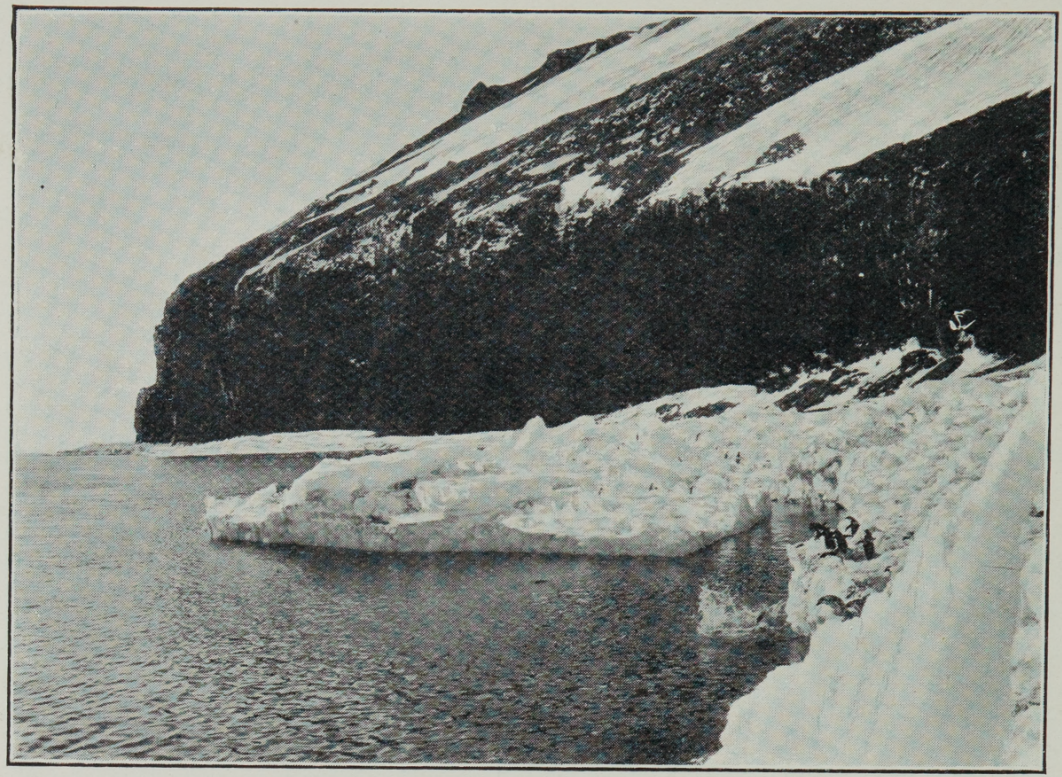

CAPE ADARE IN SPRING.

graphical Society of London, stating longitude and latitude where it was found, also conditions under which it was found, whether any icebergs were in sight, what wind and current prevailed at the time, and finally, the finder's name and address.

"C. E. Borchgrevink."

I enclosed also the photo of the iceberg.

The Greenland bitches had half-a-dozen puppies each, and all did very well. It was curious to watch the marked difference in the habits and manners of the Greenland dogs to that of their brethren from Siberia. The former were much more wild, and seldom or never 
mixed with the other dogs, nor did they attach themselves as much to man as the Siberian dogs did.

Lieutenant Colbeck and Mr. Evans arrived in good health on the morning of the 2nd November from an expedition in Robertson Bay, with a very good collection, and with the following meteorological notes by Mr. Colbeck:-

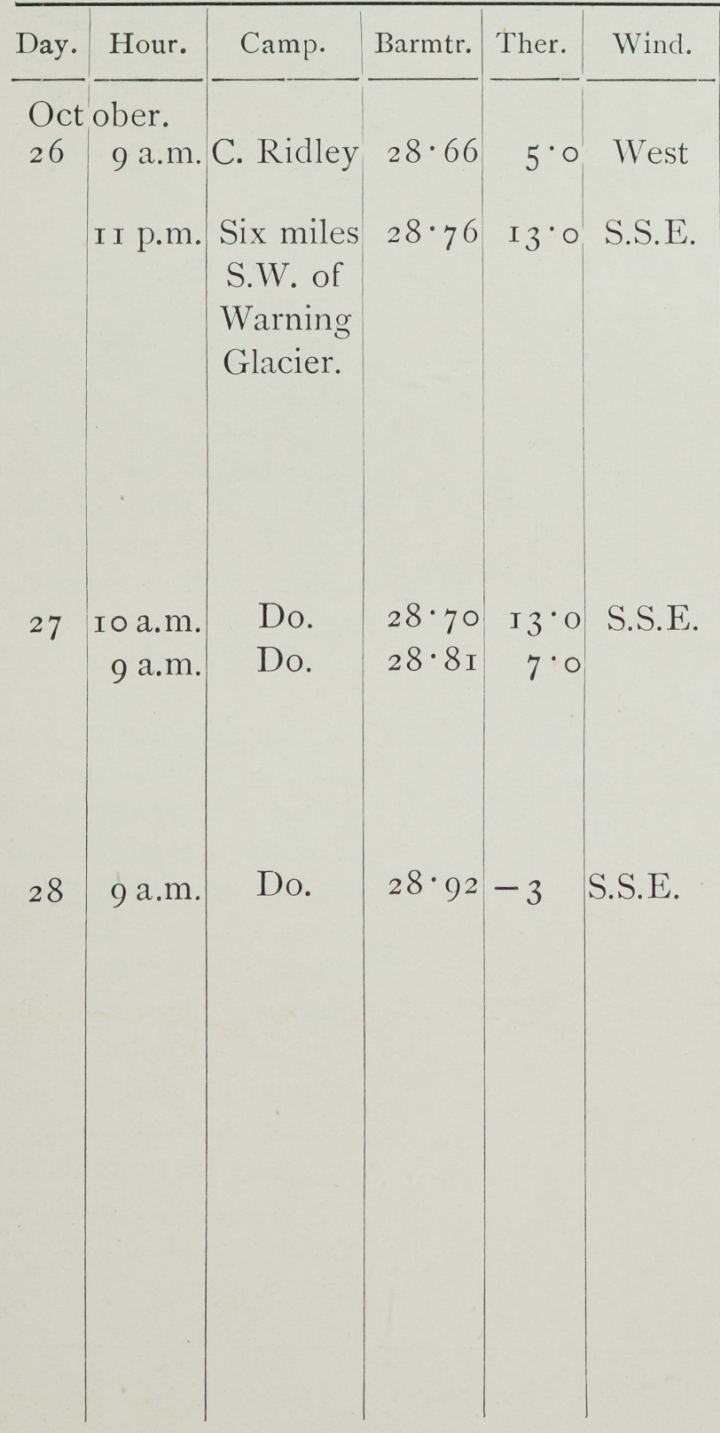

Light breeze, overcast, misty over mountains.

Strong gale with much drift snow. We had a slight southerly wind during the afternoon which freshened into a gale at 7 p.m. Pitched camp at 9 o'clock. During the afternoon the upper clouds were working up rapidly from N.W.

Strong gale, cloudy, quantities of snow drift, squalls of hurricane force at short intervals. In the evening barometer was oscillating between 28.7 and $28 \cdot 85$.

Strong gale with drift snow, sky partially clouded, struck camp at I I a.m., made for Protection Cove, following the edge of the barrier and coast line, thence to Crescent Bay. Examined the depôt and renewed our provisions, and then proceeded to Midwinter Camp. Gale moderating a little, sky clouded, drift snow on glacier. 


\section{I96 British Antarctic Expedition.}

\begin{tabular}{|c|c|c|c|c|c|c|}
\hline Day. & Hour. & Camp. & Barmtr. & Ther. & Wind. & Remarks. \\
\hline \multicolumn{7}{|c|}{ Oct ober. } \\
\hline $\begin{array}{l}29 \\
29\end{array}$ & $\begin{array}{l}9 \text { a.m. } \\
9 \text { p.m. }\end{array}$ & $\begin{array}{c}\text { Mid- } \\
\text { winter } \\
\text { Camp. } \\
\text { Do. } \\
\text { Do. }\end{array}$ & $\begin{array}{l}28 \cdot 83 \\
28 \cdot 70\end{array}$ & $\begin{array}{l}-I \\
-I\end{array}$ & $\begin{array}{l}\text { E.S.E. } \\
\text { S.S.E. }\end{array}$ & $\begin{array}{l}\text { Strong breeze E.S.E } \\
\text { in the forenoon, which } \\
\text { freshened into a strong } \\
\text { gale and hauled to the } \\
\text { S.S.E. later on in the } \\
\text { day. Heavy drift snow, } \\
\text { sky cloudy, terrific squalls } \\
9 \text { p.m. Strong gale, sky } \\
\text { cloudy, much drift snow. }\end{array}$ \\
\hline 30 & 9 a.m. & Do. & $28 \cdot 65$ & 2 & & $\begin{array}{l}\text { Similar wind and } \\
\text { weather. }\end{array}$ \\
\hline 30 & noon & Do. & $28 \cdot 58$ & & & Do. \\
\hline 30 & 9 p.m. & Do. & $28 \cdot 35$ & $-I$ & & Do. \\
\hline Nov & 9 a.m. & Do. & $28 \cdot 70$ & $I \cdot 3$ & S.E. & $\begin{array}{l}\text { Mod. gale and clear, } \\
\text { less drift snow. } 4 \text { p.m. } \\
\text { gale abated, and after a } \\
\text { short spell of calm, fresh- } \\
\text { ened from the N.N.W., } \\
\text { crossed the glacier to } \\
\text { Geikie Land in the even- } \\
\text { ing. } 9 \text { to I p.m. Mod. } \\
\text { gale N.N.W. sky clear. }\end{array}$ \\
\hline I & 9 a.m. & Do. & $29^{\circ} \mathrm{I} 3$ & $\begin{array}{c}26 \\
\text { Ther. } \\
\text { the }\end{array}$ & $\begin{array}{l}\text { Calm } \\
\text { being in } \\
\text { sun. }\end{array}$ & $\begin{array}{l}\text { Calm and cloudy, light } \\
\text { snowfall, struck camp at } \\
4 \text { p.m., and proceeded to } \\
\text { C. Ridley. Mod. N.N.W. } \\
\text { wind sprang up at } 5 \text { p.m. } \\
\text { snowing, coast-line ob- } \\
\text { scured, steering for } \\
\text { Warning Glacier, and } \\
\text { travelled close into shore. } \\
\text { Arrived in camp } 2 \text { p.m. } \\
\text { Passed several flocks of } \\
\text { penguins en route for the } \\
\text { western shore, and saw } \\
\text { about } 50 \text { seals on the trip } \\
\text { back to camp. }\end{array}$ \\
\hline
\end{tabular}




\section{Sledge Journey in Winter.}

The following are the meteorological observations taken at Camp Ridley during the same time:-

October, I899.

\begin{tabular}{|c|c|c|c|c|c|c|c|c|c|c|}
\hline Day. & Hour. & Barmtr. & $\begin{array}{l}\text { Alt. } \\
\text { Ther. }\end{array}$ & $\begin{array}{c}\text { Dry } \\
\text { Bulb. }\end{array}$ & $\begin{array}{l}\text { Wet } \\
\text { Bulb. }\end{array}$ & Wind. & Force. & Max. & . Min. & Remark \\
\hline \multirow[t]{2}{*}{26} & 9 a.m. & $28 \cdot 882$ & $37^{\circ} 4$ & $6 \cdot 2$ & $6 \cdot 0$ & S.W. & I & $6 \cdot 8$ & $3-0.5$ & \\
\hline & 9 p.m. & $28 \cdot 772$ & $2 \mathrm{I} \cdot 0$ & $6 \cdot 0$ & $5 \cdot 3$ & Calm & $\circ$ & . & 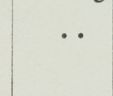 & $\begin{array}{l}\text { Snowir } \\
\text { (dri }\end{array}$ \\
\hline \multirow[t]{2}{*}{27} & 9 a.m. & $28 \cdot 664$ & $17^{\circ} 3$ & $14^{\circ} \mathrm{O}$ & 14.0 & E.S.E. & 7 & I $5 \cdot 6$ & $5 \cdot 0$ & \\
\hline & 9 p.m. & $28 \cdot 706$ & $19^{\circ} 0$ & $12 \cdot 0$ & I $2 \cdot 0$ & E.S.E. & 9 & . & .. & $\begin{array}{l}\text { Av. vel } \\
\text { wind }\end{array}$ \\
\hline 28 & $\begin{array}{l}9 \text { a.m. } \\
9 \text { p.m. }\end{array}$ & $\begin{array}{l}28 \cdot 862 \\
28 \cdot 802\end{array}$ & $\begin{array}{l}15 \cdot 0 \\
17.2\end{array}$ & $\begin{array}{l}10 \cdot 0 \\
\text { I } 1 \cdot 0\end{array}$ & $\begin{array}{l}10.0 \\
10.8\end{array}$ & $\begin{array}{l}\text { S.E. } \\
\text { E.S.E. }\end{array}$ & $\begin{array}{l}6 \\
2\end{array}$ & $15 \cdot 8$ & $6 \cdot 2$ & $=75 \mathrm{~m}$ \\
\hline \multirow[t]{2}{*}{29} & 9 a.m. & $28 \cdot 794$ & $12 \cdot 2$ & $4 \cdot 8$ & $4 \cdot 8$ & E.S.E. & 4 & $\mathrm{I} 2 \cdot 2$ & $2 \cdot 2$ & \\
\hline & 9 p.m. & $28 \cdot 702$ & $13 \cdot 0$ & $I \cdot O$ & $I \cdot O$ & E.S.E. & 6 & & & \\
\hline \multirow[t]{2}{*}{30} & 9 a.m. & $28 \cdot 5^{82}$ & $\mathrm{II}^{\cdot} 3$ & $I \cdot I$ & zero & E.S.E. & 7 & $7 \cdot 2$ & -0.7 & \\
\hline & 9 p.m. & $28 \cdot 478$ & $\mathrm{I} 2 \cdot \mathrm{I}$ & $2 \cdot 0$ & $\mathrm{I} \cdot 7$ & E.S.E. & 2 & $\cdots$ & . & $\begin{array}{l}\text { Squalls } \\
\text { force }\end{array}$ \\
\hline $3 \mathrm{I}$ & 9 a.m. & $28: 638$ & $8 \cdot 5$ & $I \cdot 2$ & $I \cdot 2$ & S.S.E. & 4 & $5 \cdot 2$ & $-2 \cdot 8$ & 5 \\
\hline \multicolumn{2}{|c|}{ November. } & & & & & & & & & \\
\hline I & I I a.m. & $29^{\circ} 072$ & I $8 \cdot 8$ & $7 \cdot 0$ & $6 \cdot 2$ & S. & 0.5 & $6 \cdot 8$ & $-2 \cdot 5$ & Snowing \\
\hline
\end{tabular}




\section{CHAPTER VII.}

\section{Among the Penguins.}

$\mathrm{ON}_{\mathrm{N}}$ the 3 rd November we gathered our first penguin eggs, which we devoured with eagerness. I at once ordered my staff to commence collecting eggs, which we put down in salt, in case the vessel should not return, and we should be left for a longer time than we expected.

When Dr. Klovstad heard that the first eggs were laid, he implored me in his calm way not to let the members eat fresh eggs just then, because he liked to study the progress of our health at the time; and seeing that we all very much required fresh albuminoids, although suffering severely himself from the want, he knew that the supply of eggs would detract from the valuable studies he was making of us at the time. This was an enthusiasm which I fully appreciated, as much, in fact, as the doctor appreciated a good feed of eggs himself the next morning! During the winter, both away from and in the main camp, we had lived chiefly on seal-beef; now penguin flesh and eggs formed a great repast. Mr. Fougner was now doing very valuable work in the marine fauna department. He returned from the ice with 
a very good catch in his net, including some new kinds of star-fish of spider-like appearance, and also some shrimps of unknown species. On the 6th November Mr. Fougner was busy placing his specimens in bottles with formalin and spirit, while Mr. Evans was busily occupied egg collecting.

The peninsula was now literally covered with penguins (Eudyptes Adeliae), and still a constant

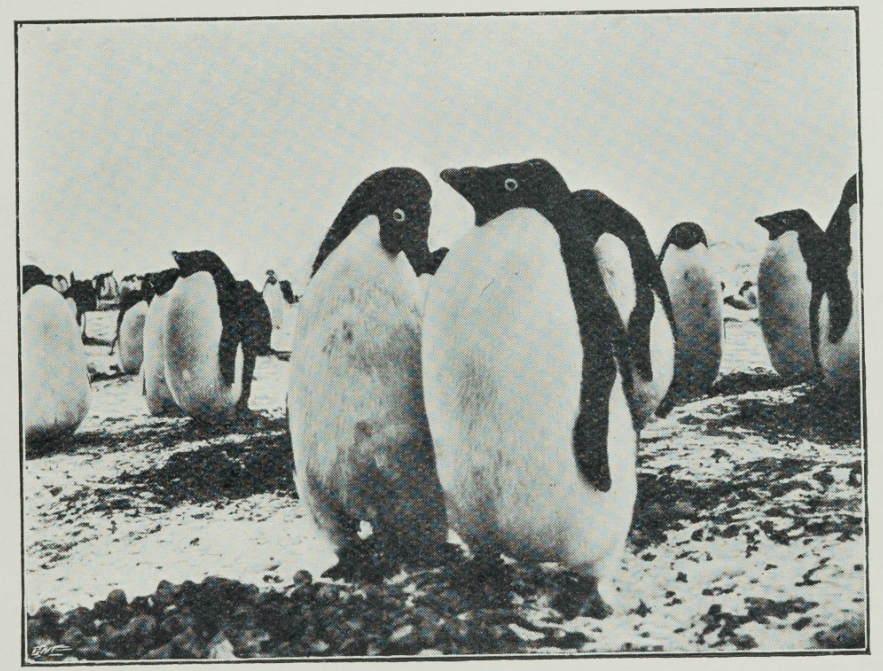

'WEDDED.' (Eudyptes Adeliae.)

stream of new arrivals could be seen far out on the ice, like a long, endless black snake winding in between the ice-floes. As no open water was to be seen anywhere, these welcome travellers must have had a long walk. In half an hour the two Finns collected 435 penguin eggs for reserve stores. I got daily reports now from the top of Cape Adare, to find out whether the ice conditions had changed, and for the purpose of securing reliable data in regard to the ice conditions in the bay. 


\section{British Antarctic Expedition.}

On the gth November, being the birthday of H.R.H. the Prince of Wales, the Union Jack was hoisted on the flagstaff.

On this day I took with me the Finn Must,

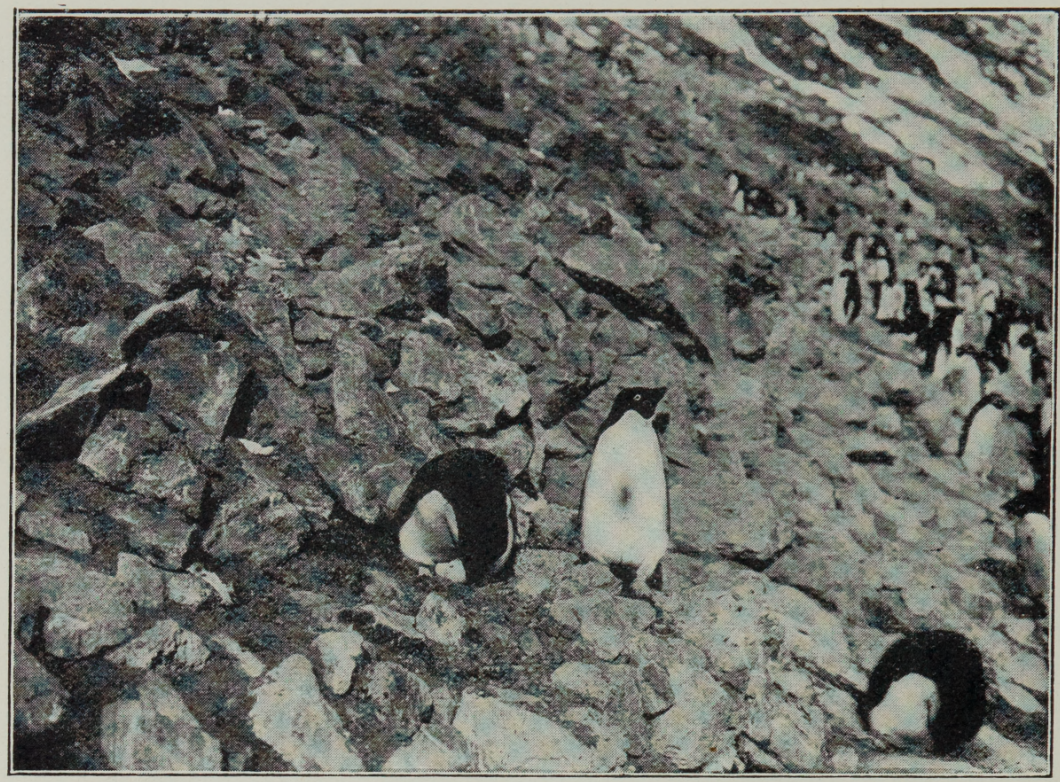

EUDYPTES ADELIAE IN THE ACT OF TURNING THEIR EGGS.

three sledges, and thirty dogs, and travelled to the eastward of Cape Adare amongst very heavy screw ice. Many Pagodroma Nivea were nesting among the rocks; they kept up a continual noise during the night. A large amount of gravel and stones continued to fall from the top of the cape. The collapsible canvas boats proved very useful on this journey. By sleeping in the unfolded boat much was gained in safety, as we were thus ready for any casualty which might happen when travelling in late spring on the ice. We let it stand on its keel, placed our sleeping-bags side by side on the 


\section{Among the Penguins.}

flat bottom inside, covered the boat over with the sail, which fitted both the boat and the sledge, and besides being secure against any accident, we laid absolutely dry.

On November Ioth we had a fairly good run for some miles on very smooth ice, and proceeded about twenty miles down the coast. Towards the north the continual roar of the breakers was kept up. At places we had only a mile of ice to travel on between the perpendicular walls of Victoria Land and the open, raging Antarctic Ocean. Large cracks blocked our road at places, and the boat had to be

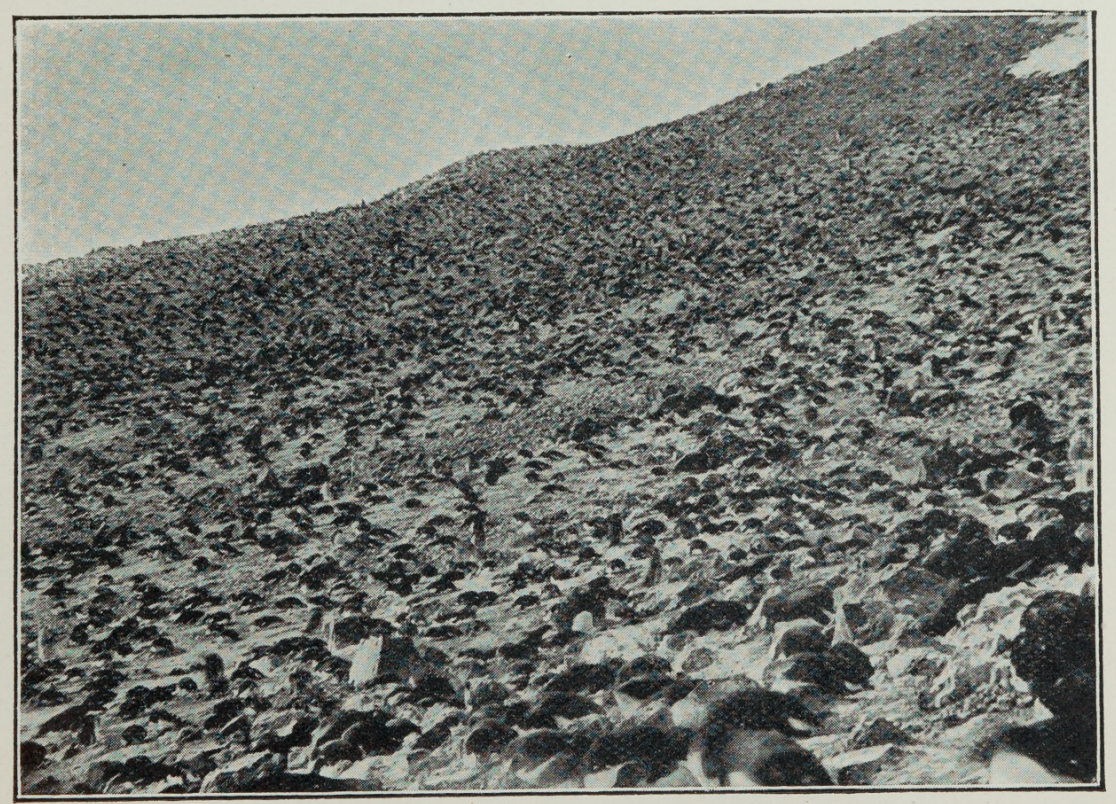

EUDYPTES ADELIAE ON THEIR NESTS.

taken from the sledge, expanded, and placed in the crack for the purpose of conveying dogs, sledges, and provisions to the other side. The average thickness of the ice was from two to three feet, 
strongly worn underneath by the current. A large finned whale rose out of a broad crack near our sledge, and its spouting sounded like escaping steam

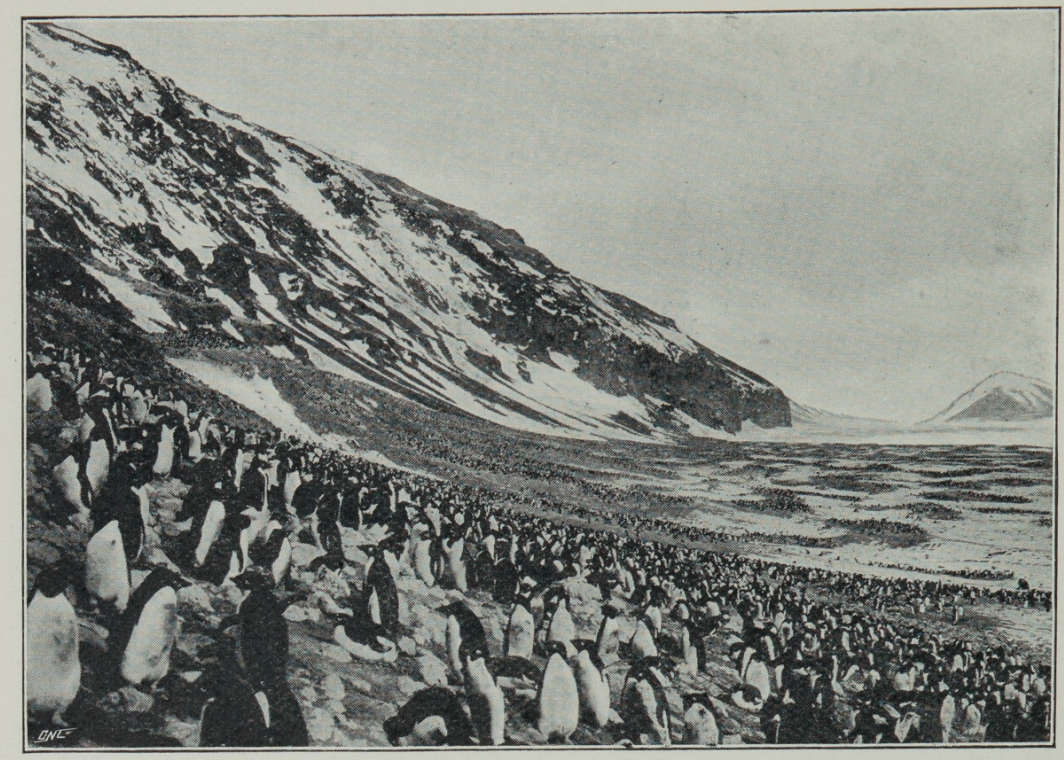

"THEIR NESTS WERE FOUND AS FAR AS I,OOO FEET UP."

from the boilers of a big liner. About 9 A.m. the loose ice masses in the ocean about a mile from us started to run south-eastwards with a speed of from five to six knots. Even minor icebergs were moving perceptibly in the same direction. The wind, which was of little force, blew from the S.E.

There was roar of screwing in the pack towards the E. Through the rise and fall in the temperature, pebbles and rocks from the perpendicular walls of Victoria Land were continually loosened, and great gravel rushes descended on to the ice, making it dangerous to travel near the mountain wall. We passed two white seals fighting fiercely with 
each other, the fore parts of their bodies covered with blood.

On the I Ith November, while travelling in the evening, my sledge broke through the ice, and it was with great difficulty that Must and myself managed to save the team and gear. The sledge went straight through, but one runner hung on to the edge of the ice. We took the twelve dogs from the other sledge as quickly as possible, hooked them on to the halfsubmerged sledge, and by dint of hard pulling we brought it on to the ice again ; but it was evident that ice travelling by this time had become very risky. The pack seemed to be clearing away towards the east.

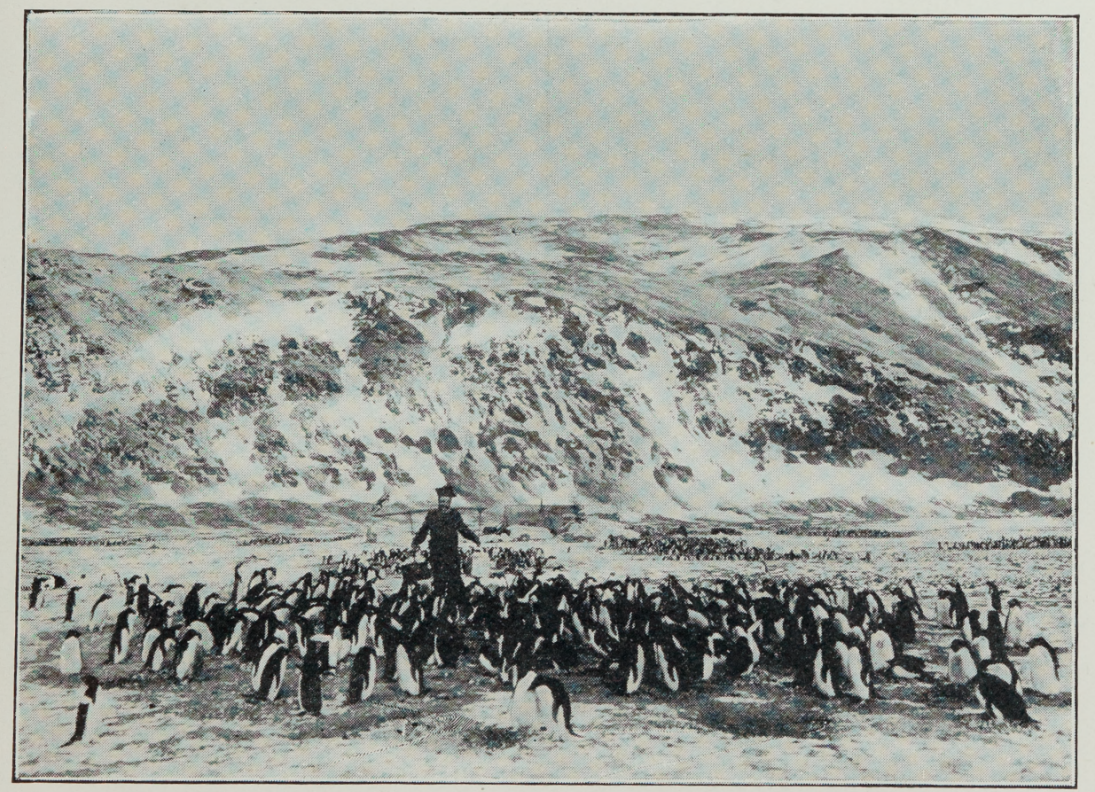

COLLECTING EGGS IN THE SPRING.

Projecting ice blocks were seen moving with the current towards the horizon. With short interruptions we had continually experienced heavy gales, some of 
204 British Antarctic Expedition.

which exceeded over ninety miles an hour. The gales naturally checked to a considerable degree the progress of sledge expeditions in Victoria Land in the vicinity of Cape Adare, where such meteorological conditions ruled. Nearly all the provisions had to be brought on sledges, as little bird life is seen beyond the coast-line, and the frequent gales will always necessitate a great percentage of idle camping days, when much of the provisions for the inland journey

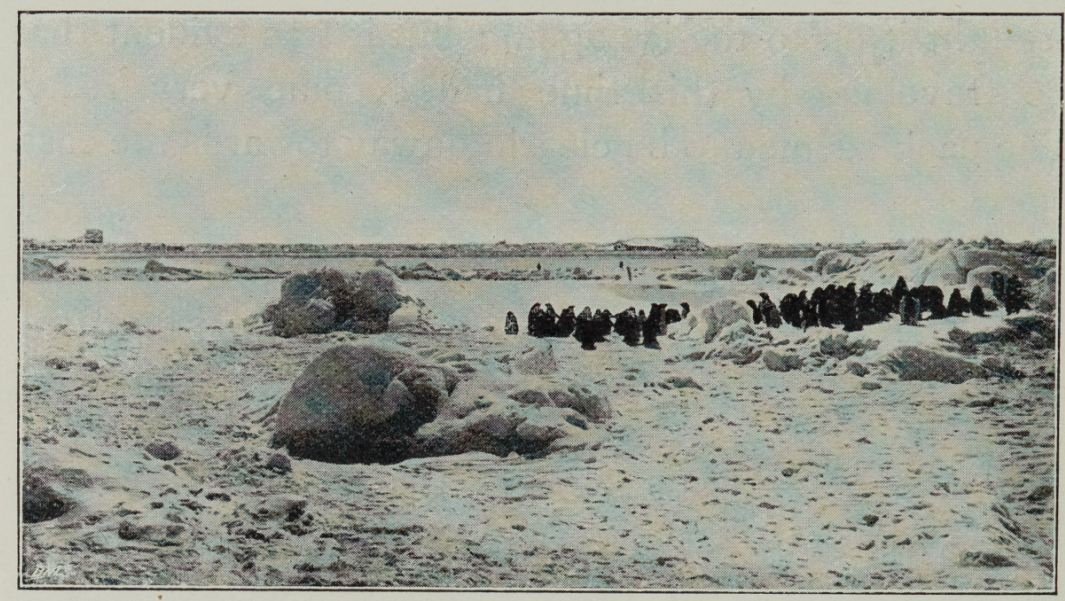

EUDYPTES ADELIAE ON THE ICE.

will be eaten without a corresponding distance having been travelled. According to our meteorological observations, no one ought, in my opinion, to start a sledge journey in those latitudes without taking into consideration the likelihood of getting at least 20 per cent. of checking gales. We had not here those aids which are found in the north, not the Arctic fauna, such as bears, foxes, musk-oxen and reindeer; here within the Antarctic Circle life depends entirely upon a careful selection of the necessary provisions, 


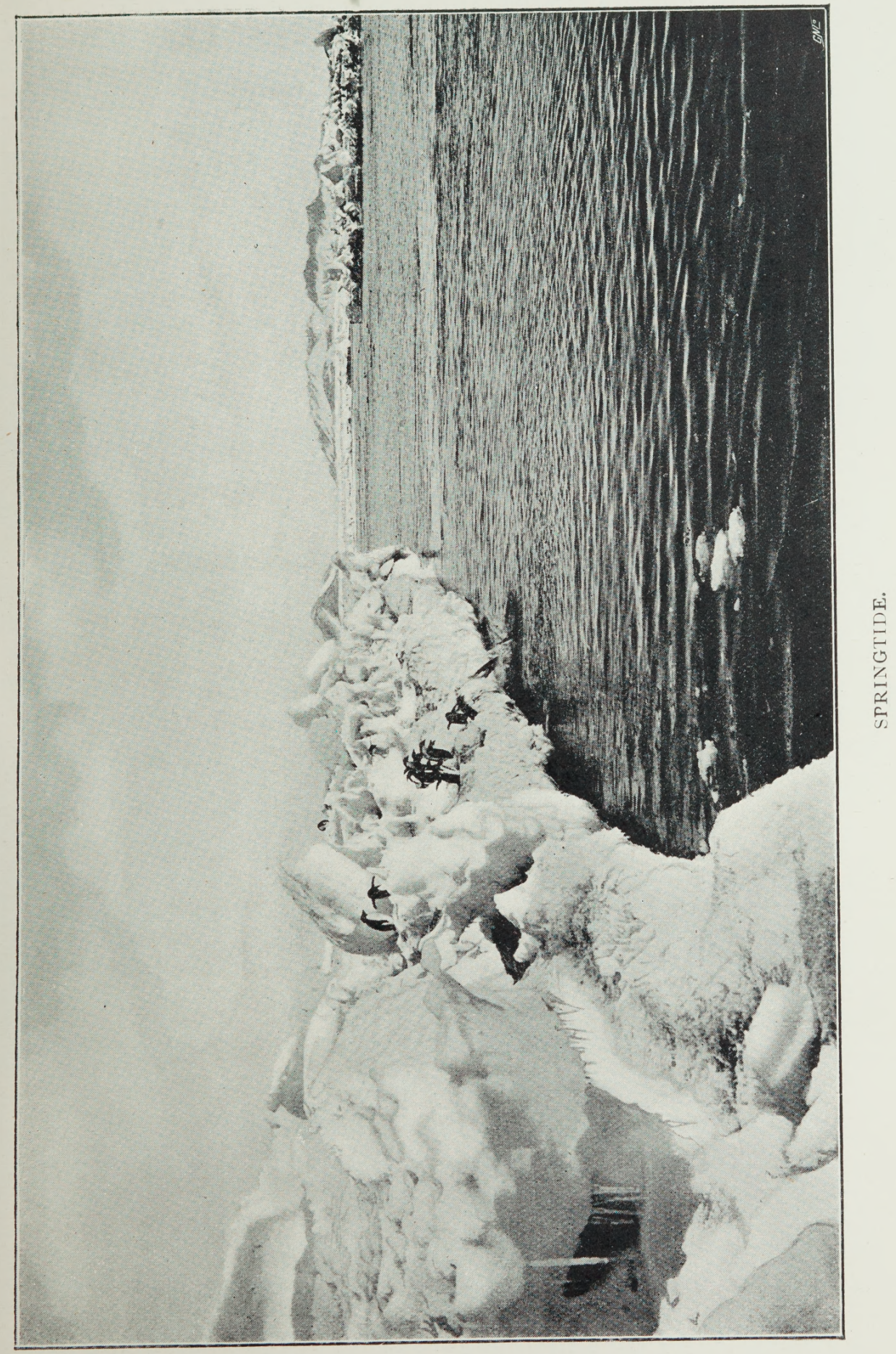



and without hampering oneself with too heavy loads, nearly double the quantity of provisions necessary for a certain distance to be travelled must be taken, just because of those heavy gales mentioned, which not only make it difficult to travel, but difficult to exist. These facts, besides the great heights of Victoria Land with its difficult glaciers, give the travelling within the Antarctic Circle quite another aspect to that of the Arctic. Also at sea in the pack-ice, it seems to me that the difficulties presented by the screwing must needs be greater than in the north. In the vicinity of Cape Adare, a position which corresponds to that of Northern Norway in the Northern Hemisphere, the ice and meteorological conditions afford much greater danger to the traveller than do those higher latitudes in the North which are ruled by average temperatures similar to those at Cape Adare.

It -seems as if an early break-up of the ice in the bay, eastwards of the land stretching from Cape Adare down to the active volcanos Erebus and Terror, takes place every year; and occasionally, I presume, the ice even breaks up for weeks at a time in late autumn and early spring; thus travelling at sea in the pack, as well as in Robertson Bay and the big Ross' Bay to the east, always will be a perilous undertaking. In my opinion, successful exploration within the Antarctic Circle must needs be local; I mean, confined to one locality. If too big a field for operations be attempted, the natural conditions and the varying Antarctic season would cause a failure. There ought also to be a close co-operation between 
208 British Antarctic Expedition.

expeditions on land and at sea, between vessel and sledges. These facts soon became evident to me as the season drew onwards.

$\mathrm{U}_{\mathrm{p}}$ to the middle of November very little change

CAMP RIDI.EY.

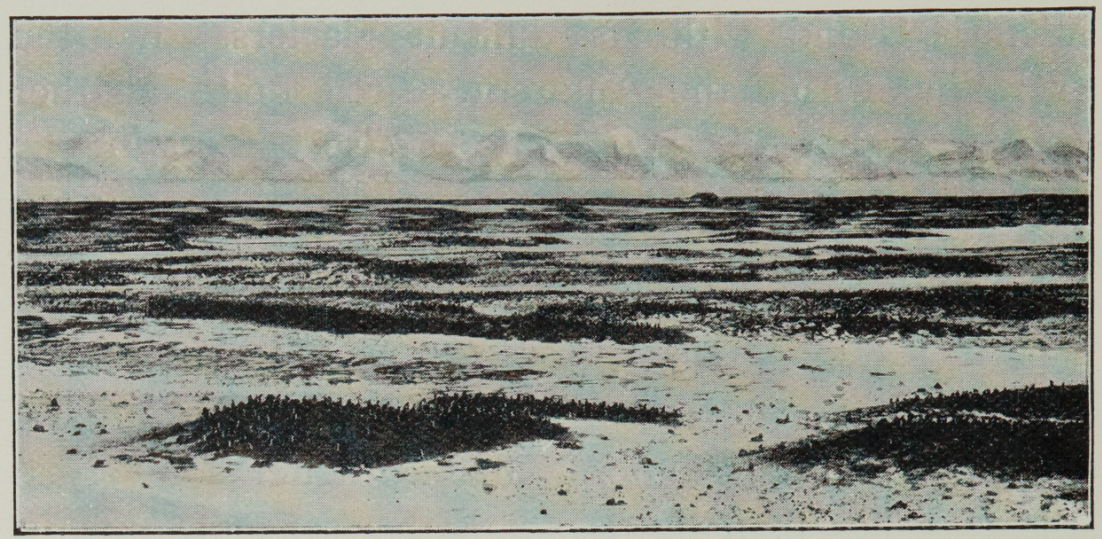

BIRD'S-EYE VIEW OF CAMP RIDLEY.

was to be seen in the general ice-pack, although some open canals were met with on a sledge journey which the Finn Must and myself carried on to the east of Cape Adare, principally for the purpose of studying the ice conditions. The canals closed again, however, and not until the end of November did noticeable changes take place in the general ice-pack.

Although the penguin colony seemed to fill the very ground of the peninsula, new arrivals continued even after the penguins which arrived first had been sitting on their eggs for a fortnight. The penguin rookery at the peninsula of Camp Ridley at Cape Adare was the same as when I visited it in 1894 . The penguins literally covered the ground; their 
nests lying on the top of the guano deposits, and consisting of small pebbles. I remember I often wondered, after my first visit, how the penguins managed to get the material for their nests, and I presumed that they brought it from the sea-shore. This, however, they seldom did. The pebble supply generally came down to the peninsula from the top of the cape, driven by the furious gales, and I could not but recollect the old proverb which runs: "It's an ill wind that blows nobody good ;" and the penguins usually had a very busy time after one of those very strong gales which we, however, did not appreciate. Those penguins

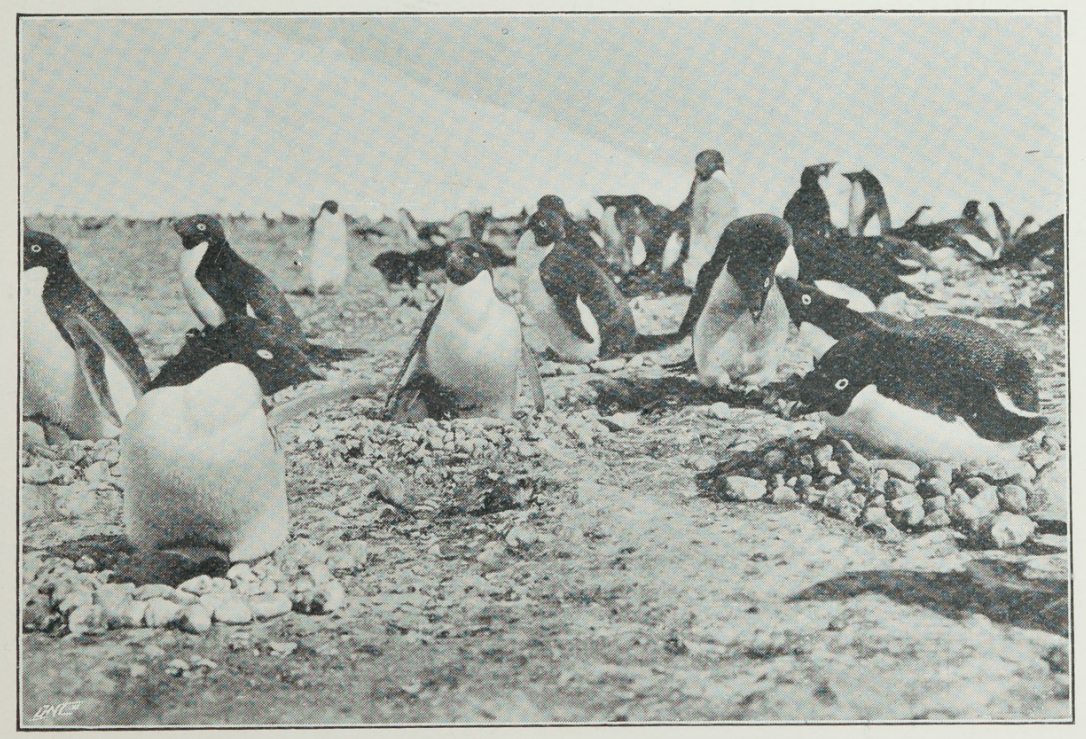

EUDYPTES ADELIAE WITH THEIR YOUNG ONES.

(Eudyptes Adeliae) which we met on the outward voyage have nearly all of them black throats, and so have the myriads on the peninsula at Cape Adare in the early spring. However, I was enabled 
to solve the question whether the black-throated penguin is of the same species as the white-throated one or not, later in the season, when the young ones were nearly full-grown. The full-grown young ones had more or less white throats, and no doubt at my first visit to Camp Ridley in I894, when I found the penguin colony consisted almost entirely of white-throated birds, they were evidently well-advanced young ones. The absence of the black-throated penguin at that time is easily explained by the fact that the old ones, uncharitable as it may seem, leave their young ones and go to sea towards the time their offspring should be able to look after themselves. Hence I believe that it had been a somewhat more favourable season for the penguin colony at the time of my first visit to Cape Adare, as the date of that visit was much earlier in the season than when the old penguins left their young ones in 1900. I noticed that the young birds generally found their mothers whenever they wanted food, and soon began to pay visits to their neighbours and mix amongst them; but a mutual understanding seemed to have been arrived at by the old penguins not to quarrel as much as at the time of love-making. They seemed to realise the necessity of falling into each other's peculiarities as much as possible.

When the old penguins left, the young ones, being able, like the rest of their kind, to live for a long while without food, remained on shore until starvation forced them to work for their own living, then they too went to sea and left their birthplaces until the next short summer. 
We all watched the life of the penguins with the utmost interest, and I believe and hope that some of us learnt something from their habits and characteristics. It was most curious to see these birds as they invaded the peninsula in the spring, long before the ice broke. From the I 4 th October one continual stream of penguins waddled over the ice towards their summer residence; like so many people, they walked after one another. Some
of them had evidently

LONDON ANTARCTICA.

come to grief in the screw-ice, having crushed feet and flippers. They at once started nest-making on their arrival, picking their old places and bringing new pebbles to the nest. During the time of lovemaking - when they were studied most attentively by my bachelor staff-it goes without saying that they had many hard fights. On sunny days the male bird stood erect in the old nest, his head stretched upwards, his beak towards the zenith, and while he 
moved his flippers backwards and forwards he produced a hoarse, suffocating sound. The female listened attentively to this Antarctic love-song.

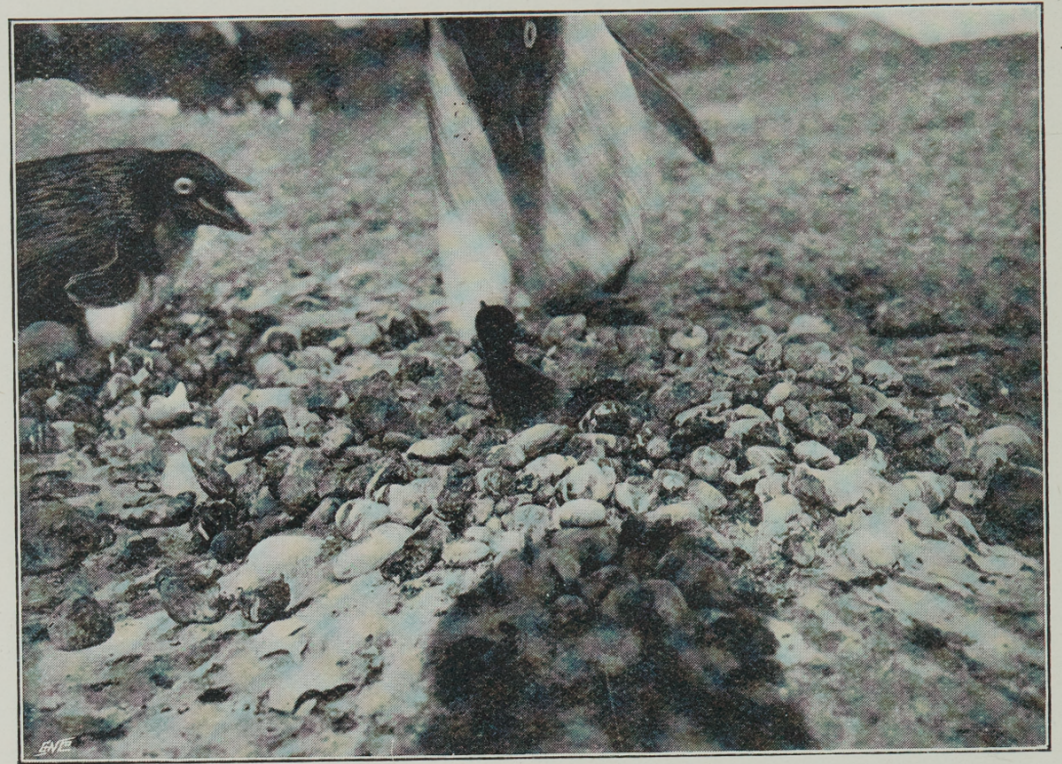

FAMILY TROUBLES.

It was curious to see how some lazy penguins picked those pebbles which, through the care and work of years, had been successfully accumulated by one when this one happened to turn his back; and the evident unconcern and innocent behaviour of these thieves when caught in the act was a source of great amusement. The rightful proprietor of the pebbles would pursue the culprit most energetically, running after it and hitting it with its flippers until both were quite exhausted and covered with blood. During this fight they generally seemed to remember the cause of the quarrel, but I noticed that, as a rule, the one who first gave in walked off with the 
pebble, while the victorious one, blinded by success, was left with the honour.

At all times the penguin life in the spring was most entertaining, showing that the inhabitants of the far South, while teaching much, have also much to learn. Considering the multitude, it must be said that, as a whole, they formed a most wellregulated and peaceful community.

Generally they lay two eggs; very seldom are three found in one nest. Both male and female divide their time on the eggs for a month. In the summer of 1899 they sat from the beginning of

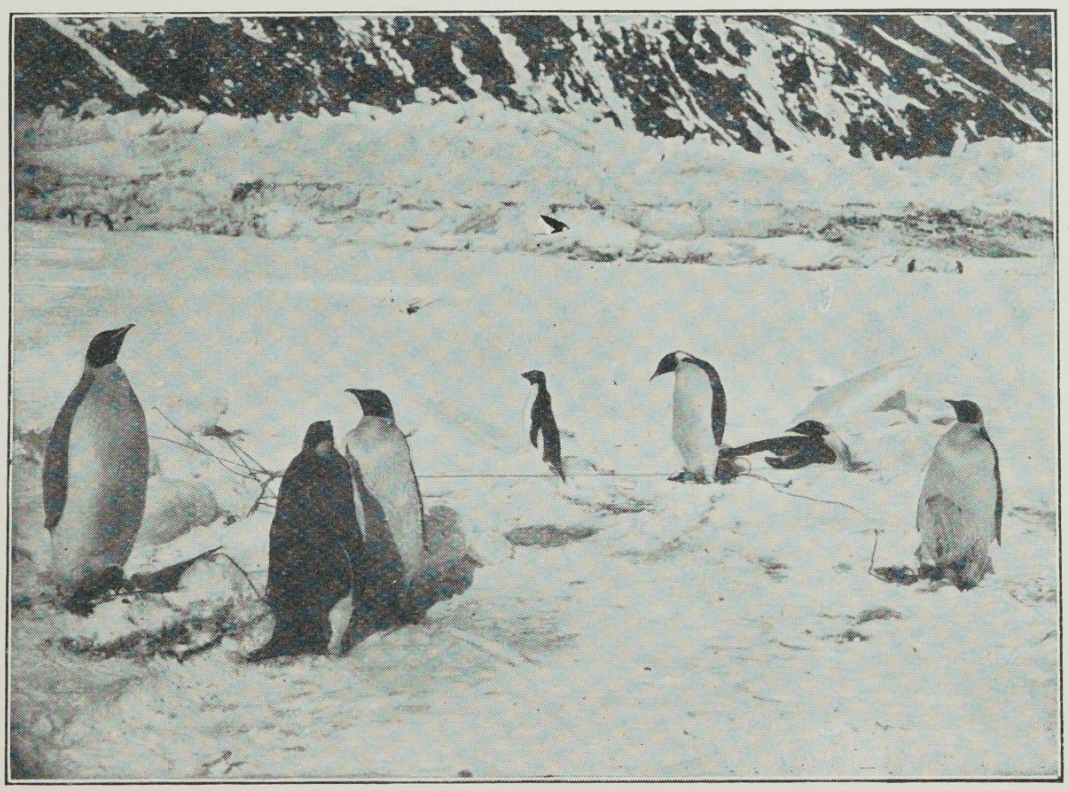

APTENODYTES FORSTERII.

November to the beginning of December. The young ones were covered in a large grey coat of soft down. They are well fed by the old ones until they are about half-grown; so well, indeed, are they fed 


\section{I 4 British Antarctic Expedition.}

that they were at times seen unable to move, and much resembled a small bag standing on the ground; and the food acted both as nourishment and as a necessary ballast during the heavy gales, when, however, very many of the young ones perished. The young penguins were most of them now large, grey and downy; though some were still in the egg. When the mother penguin feeds the young one, the latter puts the whole of its head into the beak of its parent and stuffs its beak right into the mother's throat, which, by a shaking movement, brings the food up. It was curious to see when a gale suddenly surprised the colony. Ordinarily the penguins sat upright, or lay on their nests with their heads in different directions, but immediately a gale began to blow they all laid down with their beaks towards S.E., from which direction we had the strongest gales. They looked like soldiers bivouacking on a battle-field. How well they must be able to maintain the necessary heat for the eggs. This change in their ways was a relief to our eyes, as the sameness, the want of vegetation, the lack of distractions told heavily upon all minds, and the very least change from the ordinary routine of that limited life which surrounded us at once acted as an entertainment. When the young penguins were about half grown they were strange to see, half covered by their down and half by their new quill plumage. Of course, the whole of the young penguin had a suit of new quills under its downy ulster when it was a little more than half grown, but the falling-off of the down in some places and not in others left the young bird in a most comical dress. I noticed that 
very few of the old penguins managed to keep both of their young ones alive, one generally succumbing to the benefit of the stronger. It was also curious to see how all the young ones flocked together in big patches as soon as the old on es began to go to sea, and e qu a 11 y strange was it to see how these parents of the young penguins, who in paternal affection still visited their young ones a few times before they finally left them, found their own offspring among so $\mathrm{m}$ a $\mathrm{n} \mathrm{y}$ thousands.

The worst

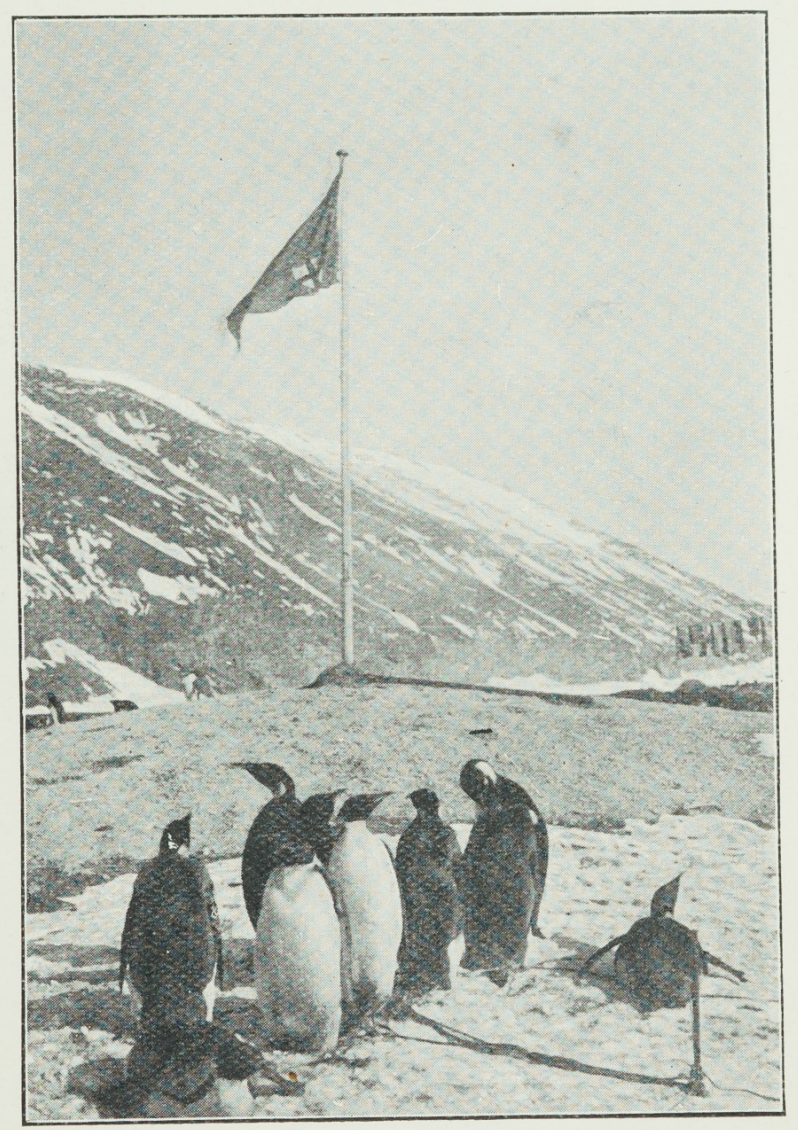

ROYAL LONDON YACHT CLUB'S ENSIGN AT CAPE ADARE

enemy of the penguin is the skuagull (Lestris), which constantly soared over their nests, watching for an opportunity when they might steal an egg or catch a young one. As I already observed in I895, I now also often saw two of these birds attack a 


\section{I6 British Antarctic Expedition.}

penguin family; whilst one kept the old ones away the other took the young one. The penguins were considerably more afraid of the skua gulls than they

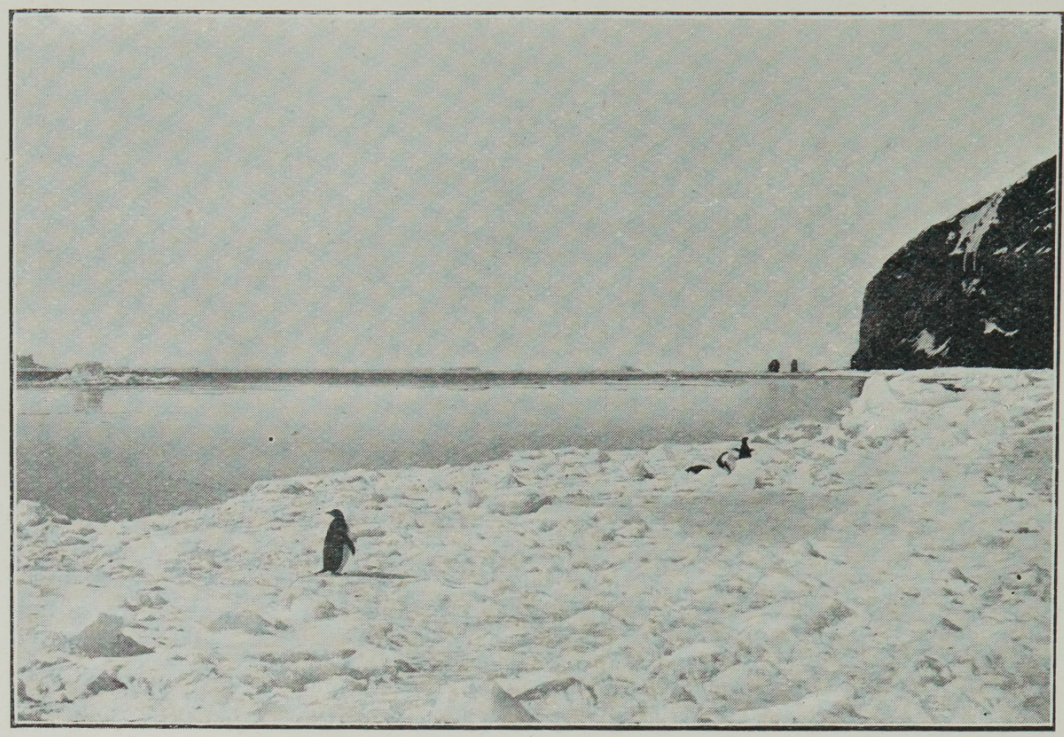

PROMISE UF SPRING.

were of us, although we gradually utilised the flesh of many of them for food. The flesh of the penguin was rather good, especially as we prepared it in the main camp, where we first boiled it, whereby it lost a good deal of the blubbery taste, and afterwards roasted it. When served on our wooden table under the name of "ptarmigan" it was considerably improved as an edible.

Of the King Penguin (Aptenodytes Pennanti) we did not see any.

I think it would be very wise as well as interesting if the next Expedition took out an incubator. We took the temperatures of the penguins while they were sitting, and I do not doubt that with care some 
very fine specimens of young birds, of all kinds, could be obtained in this way, besides giving an interesting occupation.

It seems to me evident that both the seals and the penguins obtain their great speed in water less by the propelling movement of their legs than by a snake-like movement through the water, vertically applied; it naturally changes the centre of gravity, and by this rapid falling from a higher to a lower level, aided by the propelling movement, they attain such speed that the quick rise to the same level again is easily accomplished. The seals use their fore flippers mainly to keep their balance and for steering purposes, while the penguins apply their wings to the same use. By constantly observing this movement of the seals and

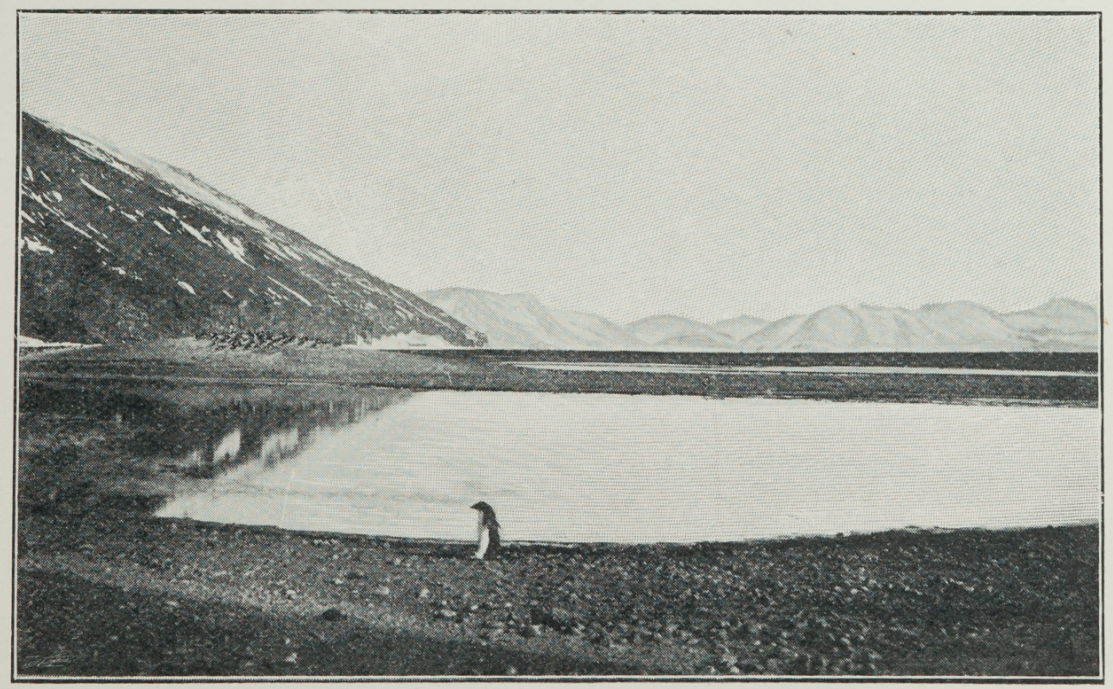

A LAGOON AT CAMP RIDLEY.

penguins I was compelled to compare it with the flight of birds. Already on the outward voyage I had keenly watched the albatross, which evidently 
also moves forward principally by a subtle change of its centre of gravity. The speed obtained in water by penguins is remarkable, and they repeatedly shot up through small cracks in the ice, sometimes a couple of yards in the air, and a good few yards on to the snow-covered ice-floes; and from the kayaks I often watched them in the crystal clear water as they rushed under me like so many torpedoes.

The skuagulls arrived somewhat later than the penguins, and their nesting also took place later. They had their nests in the heights, for instance, I, ooo feet up on Cape Adare, amongst the rocks ; while a small skua rookery was also to be found some 50 feet above the peninsula on a small rocky gallery close to the perpendicular wall of the cape. Their eggs were a greyish brown, with dark brown stains, generally two eggs were found in each nest. The young ones were exceedingly pretty in their fluffy coats of light grey down. The old skuas were very bold at ordinary times, and attacked us frequently with wings and beak when we climbed the rocks; but when they had young ones their indomitable courage and audacity surpassed that of any other bird of prey I have seen.

The Oceanites Oceanicus also hatched on Victoria Land. I found their nests in the cracks of the rocks, under stones and boulders. Although we secured eggs from them, we got no live young ones, but from the multitude of dead young ones in their old nests, I should say that very many perish every year. Like the rest of the petrels, they always spat out the yellow, evil-smelling oil from their beaks when in danger. I caught several of them on their nests, 


\section{Among the Penguins.}

and found that they behaved very much like the Pagodroma Nivea, the elegant white petrel, the life of which interested me even more than that of the penguins.

From the time we first entered the icy regions they had soared around the vessel. They were

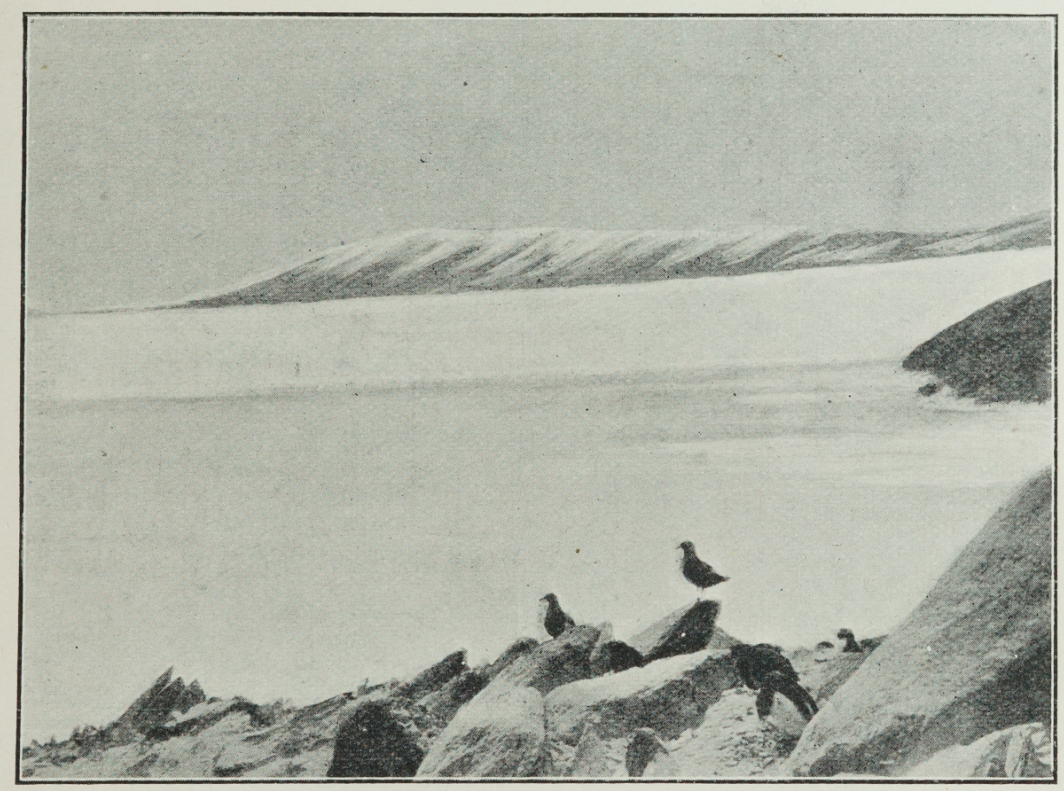

SKUA-GULL (Lestris) ON THE WATCH.

difficult to distinguish against the pure white snow. Spotless and white, this bird, with its large black eyes, black beak, and black webbed-feet, is perhaps the most striking bird of the Antarctic Regions. It seemed almost transparent as it sailed swiftly along in the rays of the midnight sun. The couple are greatly attached to one another, and the courage of the male bird to help his mate when in danger is marked. It builds its nest in cavities of the 
rocks, or cracks in the mountain side, and lays but one egg.

The brown-backed petrel, with white borders on

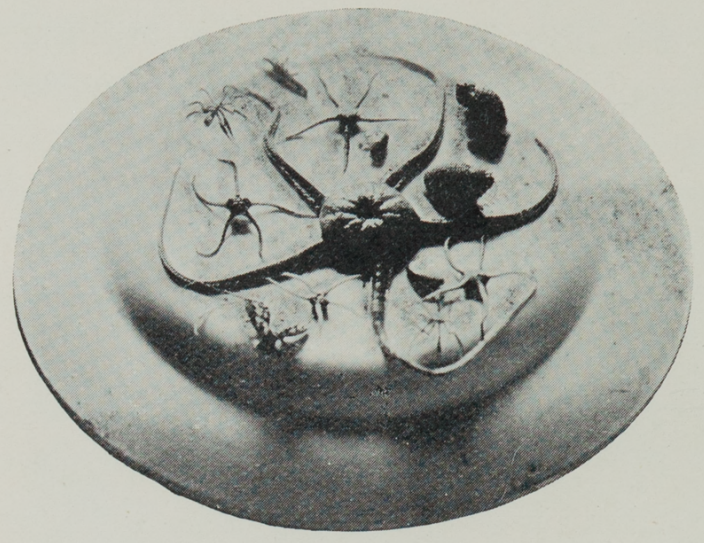

FOUND IN SHALLOW WATER. the wings, was also evidently nesting on Victoria Land. However, we never found it in its nest. When we first approached Cape Adare, dense flocks of them sailed about in the gales. During the summer we saw few of them, but in the autumn they again sailed about in the air at great heights, while during the gales they swept low over the peninsula like a cloud. Although I never found them on Geikie Land, I believe that they have their nests in that vicinity.

The Gigantic Petrels also visited Camp Ridley. They were very scarce during the summer, but we saw several of them during the autumn. We did not find one of their nests, and their visits to the peninsula were always short and interrupted; and, to a great extent, I ascribe their visits to Robertson Bay and our peninsula to strong gales at sea, which drove them in towards shore for shelter. In fact, during the strongest gale we had in the autumn, they arrived at Camp Ridley the day before the gale commenced, and left immediately after it was 


\section{Among the Penguins.}

over. So I, at least, came to look upon their arrival as the sign of an approaching gale. These large birds, which in their flight much resemble the albatross, vary somewhat in colour-perhaps as much as the lestris - from dark brown to light-faded brown, and albinos are occasionally seen. I secured one of these latter, and Captain Jensen secured another. We had both of us great difficulty in obtaining a specimen; a noble, rare bird as he is, he seemed to soar about higher and more lonely than the rest, and remarkable was it that an albino-although of exactly the same species as the dark one-was seldom or never seen in its company. Whether this is because the others combine against him and hunt

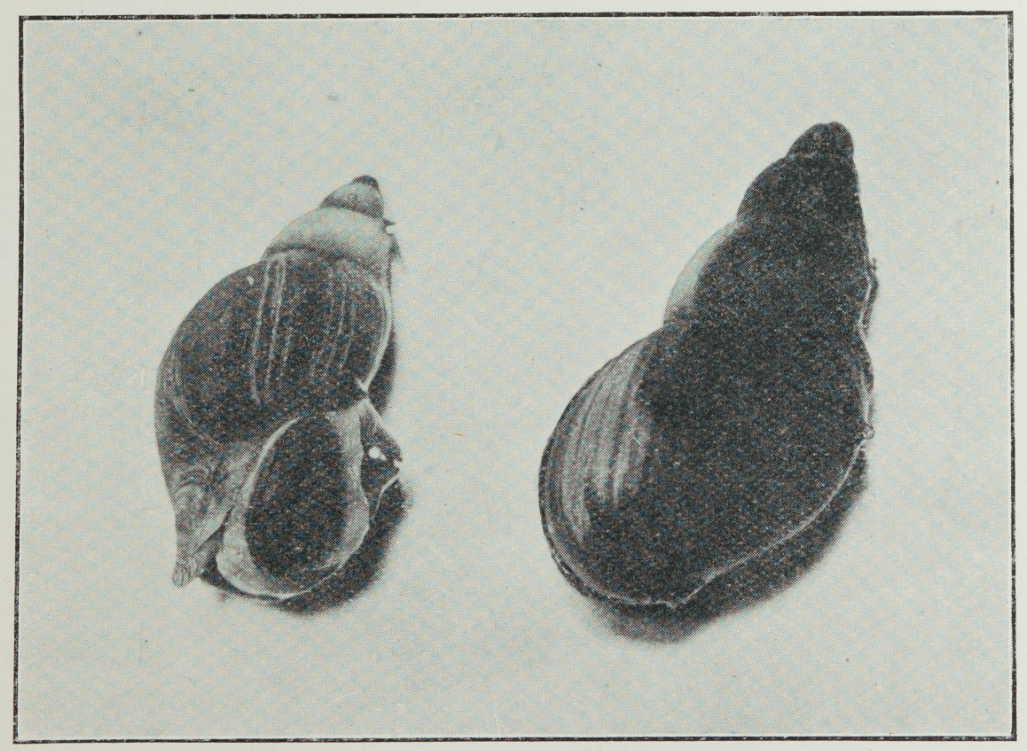

FROM SHALLOW WATER.

him because of his whiteness, or because he, in modest ignorance of his value, seeks his own sphere I do not know, but certain is it that he, willingly or 
compulsorily, soared about in higher regions than the rest.

On the isth November we had 4,000 penguin eggs secured in salt for reserve provisions.

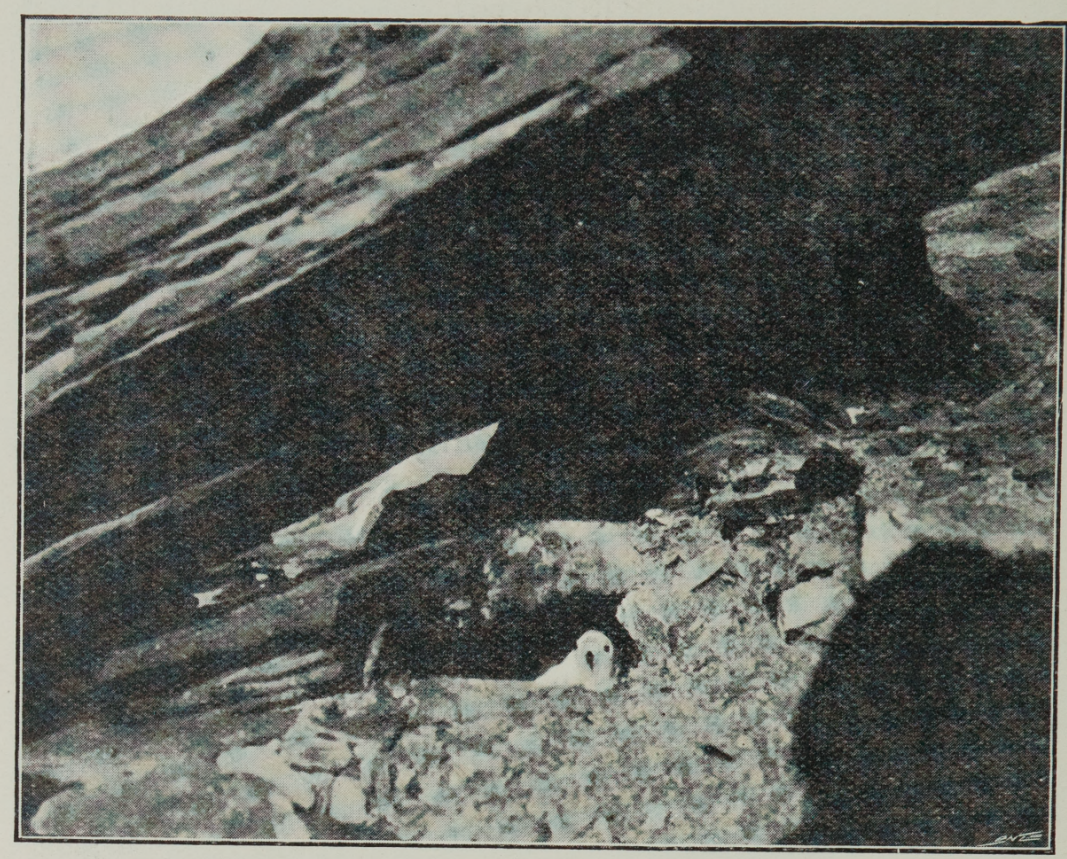

PAGODROMA NIVEA ON ITS NEST.

How different it was to travel on those bright nights, instead of having to work in the darkness as we did in the winter time.

Many of the Pagodroma Nivea were about, and the air sounded with their original and remarkable half-whistling, half-shrieking voices. They did not seem to have immediate intentions of settling down to the quiet family life of the season; they were still seen to flirt about in pairs in the air, though some of them began to repair their old nesting-places in cavities of the rocks. Their nests were still in many 
instances filled with snow, and the bird is gradually thawing a hollow downwards towards the rock by sitting at the place from time to time. They were, however, very restless, and I expected that still a fortnight would go by before they would begin to lay their eggs.

On the 2oth November I discovered a fine pagodroma on its nest some 300 feet above my tent. I at once set to work and managed to mine a hole through the roof of the cave in which it was resting, so that the light could come in for photographic purposes. We were unable to get a photo of the nest as it was, on account of the depth and darkness of the cave. But Mr. Bernacchi managed to get some very fine photos, showing the characteristic stratifications of the rocks.

We daily saw fresh proofs of the audacity of the skuagu 11 s. On several occasions they attacked the dogs, and nearly all of us were on more than one occasion also attacked by

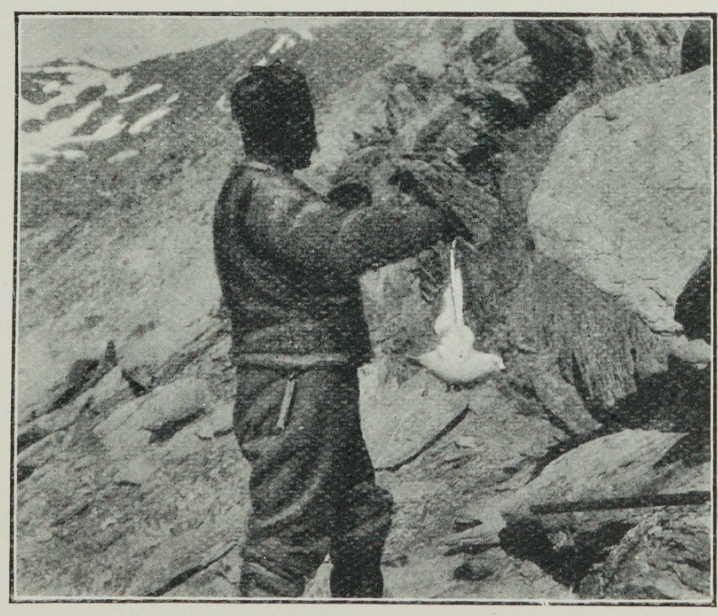

PAGODROMA CAUGHT ON ITS NEST.

them; they shot down from a great height in the air straight on to our heads, hit us with their wings, only to rise again and renew the attack. We killed several of them with short sticks. 
We saw comparatively few of the Emperor Penguins (A. Forsteri), and were not able to find their nesting-places. We came across odd ones in the pack at intervals, and not before the Antarctic autumn of I900 did we see several together. At the end of November we saw more than twenty (?) at a time. They were then walking slowly into Robertson Bay. I secured ten of these, and kept them for some time alive at Camp Ridley. They came in shoals, swimming just like the small penguins, with whom they, however, did not mix. Undoubtedly they were on their way to their old nesting-places, and some of them had pretty large eggs inside them. Their stomachs generally contained crustacea, very small fish, and a quantity of pebbles.

After the middle of November dark vapour clouds were continually to be seen towards the eastern horizon. On November 22nd the temperature was +18 . I went with the doctor towards the cape and found a large sheet of open water. There was a strong current running with a speed of from five to six knots. Shoals of penguins were jumping about in the open water. The ice evidently wore rapidly at this time The current increased in strength perceptibly from day to day. It did not seem probable that those abnormally violent gales would blow again before the autumn, the summer being so far advanced. As the bulk of the immense ice-pack still remained, with very small interruptions of open water as far as the eye could reach, we began seriously to think of the possibility of there being exceptionally unfavourable ice conditions, and that the Southern Cross, if all was 
well with her still, might be unable to reach us; and strict precautions were taken against using more than the necessary food, while we were continually adding to our store of provisions by seal-beef, penguins, and eggs. Clear, calm, and comparatively warm days now became frequent. On the roof of the
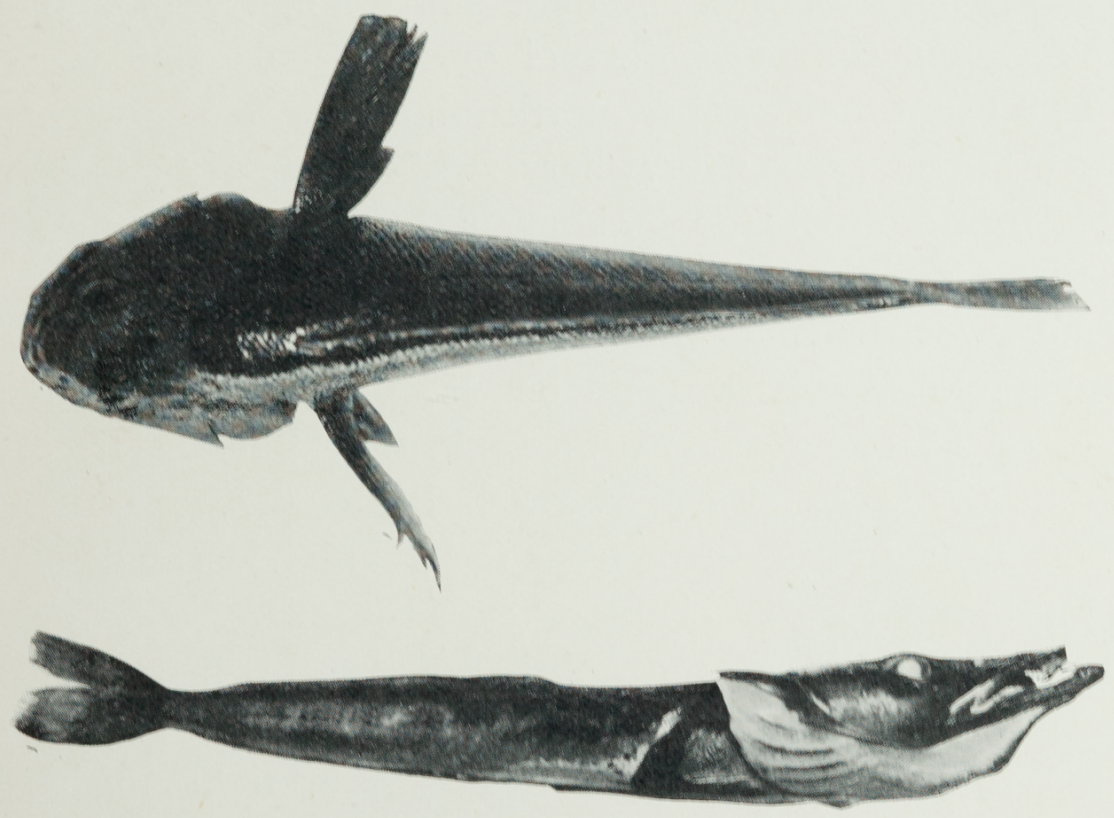

FISH FROM ROBERTSON BAY.

hut we felt quite warm, and from time to time the - members could be seen basking on the sloping canvas cover.

On November $23^{\text {rd }}$ Fougner and I were watching the rapidly changing ice conditions near Cape Adare. Near the open water we saw several penguins, streams of which were continually kept up to and from the peninsula at Camp Ridley. Those penguins coming from the shore were all soiled and dirty from the guano beds, while those jumping up like 
indiarubber balls from the sea were shining like silver in their white waistcoats.

It was difficult to determine much about the tide on account of the local disturbances and the unfavourable ice conditions. The current at midnight seemed to be settling westwards with great speed. The effect of the light of the midnight sun amongst some of the vapour clouds at the end of Robertson Bay was magnificent. Towards north and west open water was to be seen everywhere, while here and there icebergs were floating about in haloes of the most delicate pink and crimson imaginable. At the horizon there was a very strange mirage, telling of open navigable seas far beyond our limited horizon.

On November 25th a heavy gale started from the S.E. with a great deal of snow-drift. This drift and the dust from the guano-beds made it suffocating to get about outside the camp. Large flocks of Pagodroma Nivea and brown-backed petrels pierced the air.

On November 27th Mr. Evans brought in his first skuagull egg; the colour was light green, brown, or grey, with dark brown spots.

The average barometer reading showed a considerable rise since the winter. Mr. Bernacchi and Lieutenant Colbeck were making the final arrangements for observations of the total eclipse, which was to take place on December 3 rd.

On December ist the flag was run up in honour of the Princess of Wales, whose birthday it was; and as it was also my birthday, each member received double the allowance of biscuits.

Our expectations with regard to the eclipse were 
doomed to disappointment, the 3 rd December turning out overcast. We had the telescopes and other instruments in position, and Mr. Bernacchi and Lieut. Colbeck were in attendance; however, some interesting temperature records and time observations were recorded in connection with the eclipse.

The ice now began to break up in earnest. It

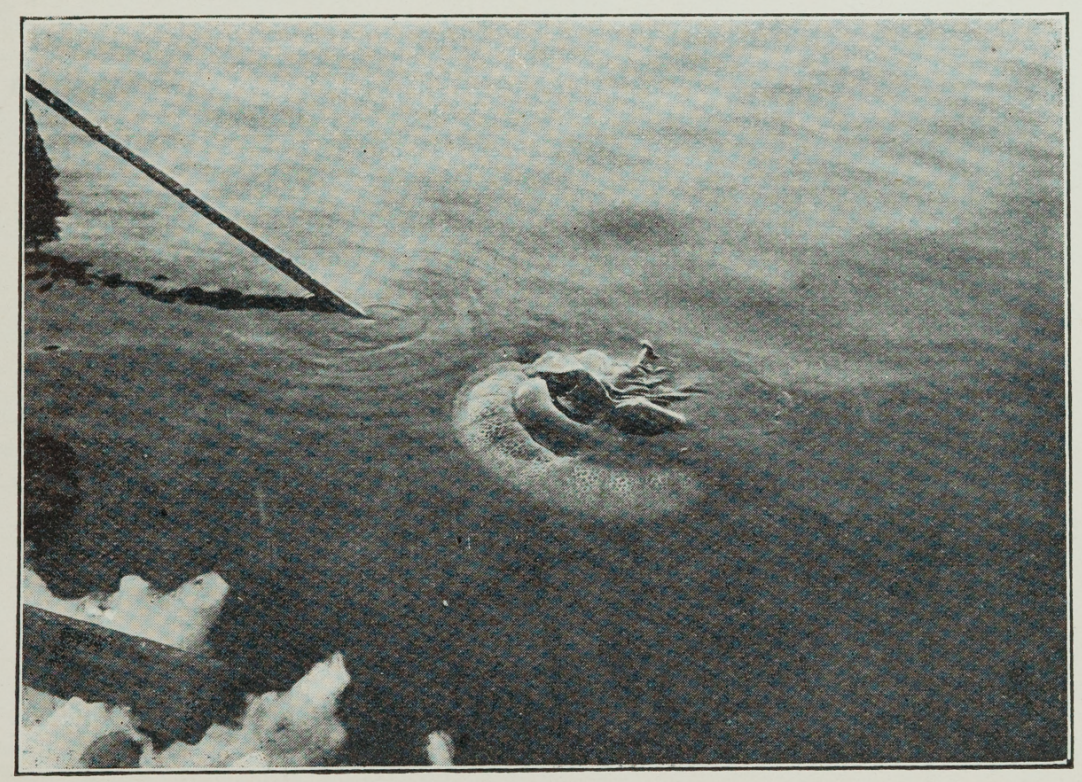

JELLY-FISH WEIGHING 90 LBS.

was clear that all the pack-ice must needs take a westerly course according to the prevailing wind, and a northerly according to the current. It is therefore likely that my instructions to Captain Jensen not to go further west than long. I $70^{\circ}$, and thus take an easterly course, would cause the Southern Cross to reach open water at a comparatively early part of the Antarctic summer.

On the 6 th December a broad strip was stretching 
from the point outwards towards the west. The wind had worn the ice and snow a good deal. The high ice barrier which rose through the screwing of the ice on the north-western side of our peninsula had diminished considerably.

In the open sheet of water the penguins who had a holiday from parental duties seemed to amuse themselves by water sports. They jumped about, dived and turned near the surface, and seemed also to be playing at hide-and-seek amongst the hummocky ice-floes; they did not seem to be in the water for feeding purposes at all; in fact, those penguins which were off eggs were seen to wash themselves in the cavities on the surface of the ice where the green polar ice formed both the bottom of this their natural tub, and a looking-glass for their toilet. The penguins seem very vain birds, and if one had a soiled spot on its white waistcoat, were it ever so small, it was at once noticed by the others and made the most of in their small way. It was very funny to see them seemingly criticising each other.

It was strange to see those penguins who had just arrived from the shore at the water's edge. They always came in shoals, and the first arrivals awaited until the complete number of their mates from the colony had arrived. Each shoal seemed to number from fifty to sixty. Arrived at the water's edge, the birds behaved just like some people before going into cold water; they hesitated, shivered, and generally seemed to pull themselves together before deciding to plunge into the cold crystal-clear water underneath. The remarkable 
thing was that they always insisted upon taking their own time at the edge of the bath before plunging in, and we could not even drive them in ; they would rather run back on the ice, or on to the shore, but if left alone they congregated in a thick cluster near the brink, discussed matters animatedly between themselves, whereupon one

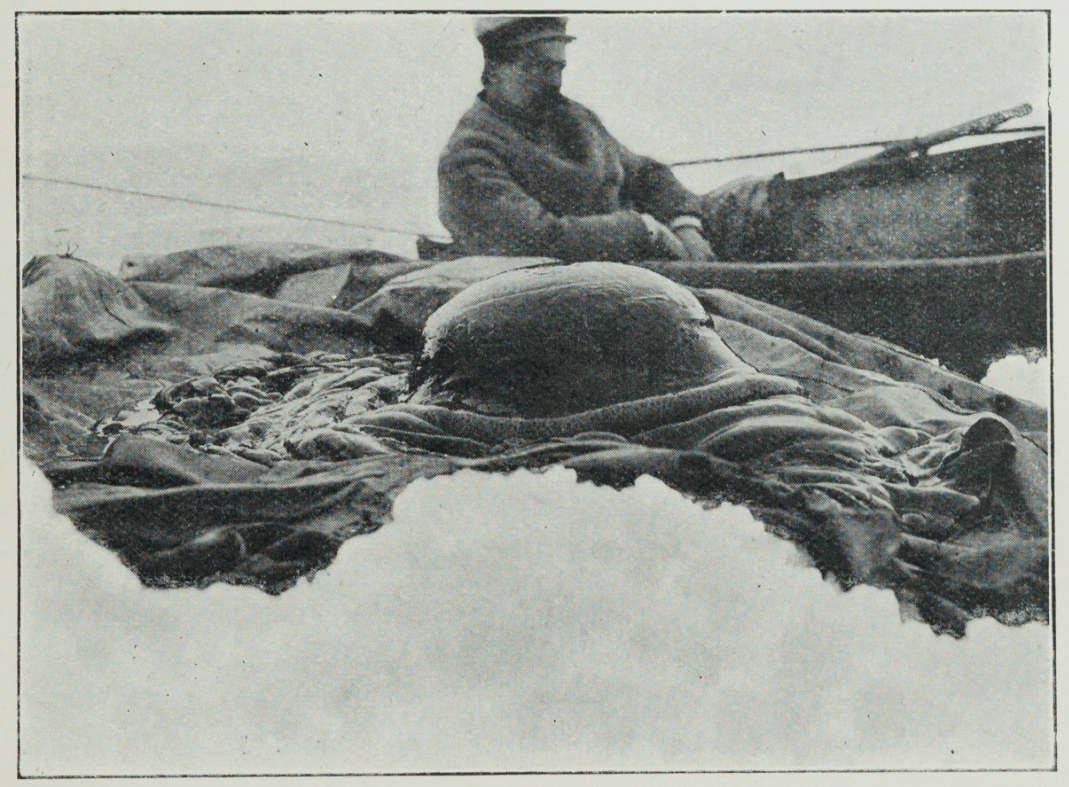

MR. FOUGNER WITH JELLY-FISH WEIGHING 90 LBS.

pioneer penguin, with a short "Quack-quack," dived in, which served as a signal for the rest to follow suit; and one by one they dived in at exactly the same spot in one continual stream, as if poured out of a bottle.

The penguins which build their nests in the steep rocks of Cape Adare, up to $\mathrm{I}, \mathrm{OOO} \mathrm{ft}$., must indeed work hard to keep their families in such elevated positions, where they had to carry food up 


\section{British Antarctic Expedition.}

from the sea. Risky must it also be during heavy gales, and when stones loosen and rush down in the springtime. Still, the young penguins seemed to

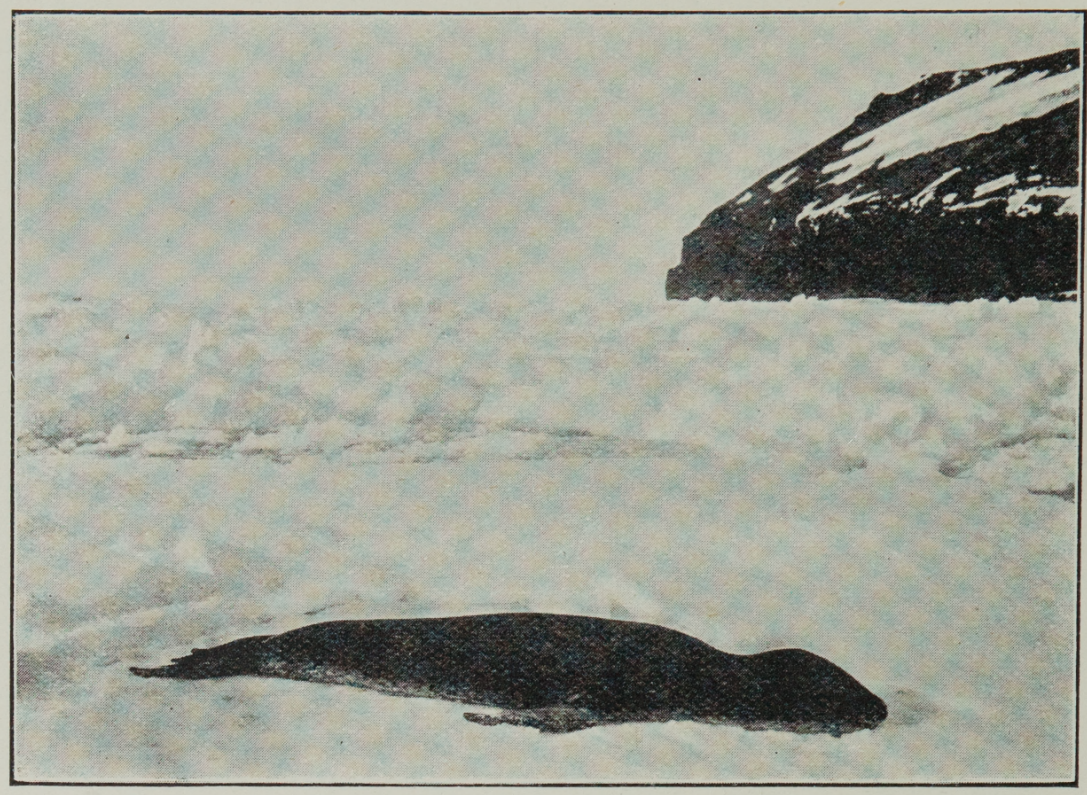

LEOPARD BASKING IN THE SUN.

thrive better in the nests on the mountain side than on the flat below, and the nesting-place for each pair did not cover more than a foot in diameter, with the precipitous rock on one side, and the perpendicular smooth rock on the other. They were also much more hunted by the skuas, who seemed to have even more pluck up in the heights, where the penguins were scarcer, than among the screeching myriads down on the peninsula.

On the Ioth December I started on my last sledge journey into Robertson Bay, principally for the purpose of securing eggs of the different birds. 
We secured Pagodroma eggs, and from the Oceanites Oceanicus we also obtained some very valuable photos of these birds on their nests. The egg hunt was arduous, and at times involved difficult climbing. On this sledge journey a remarkable discovery was made by Dr. Klovstad. I had sent him on a short expedition into Admiralty Range for the purpose of collecting some specimens of the vegetation on Geikie Land. When he returned he was proud to show me several insects. This discovery is naturally far-reaching in its information. The insects were found in the mosses, and their existence

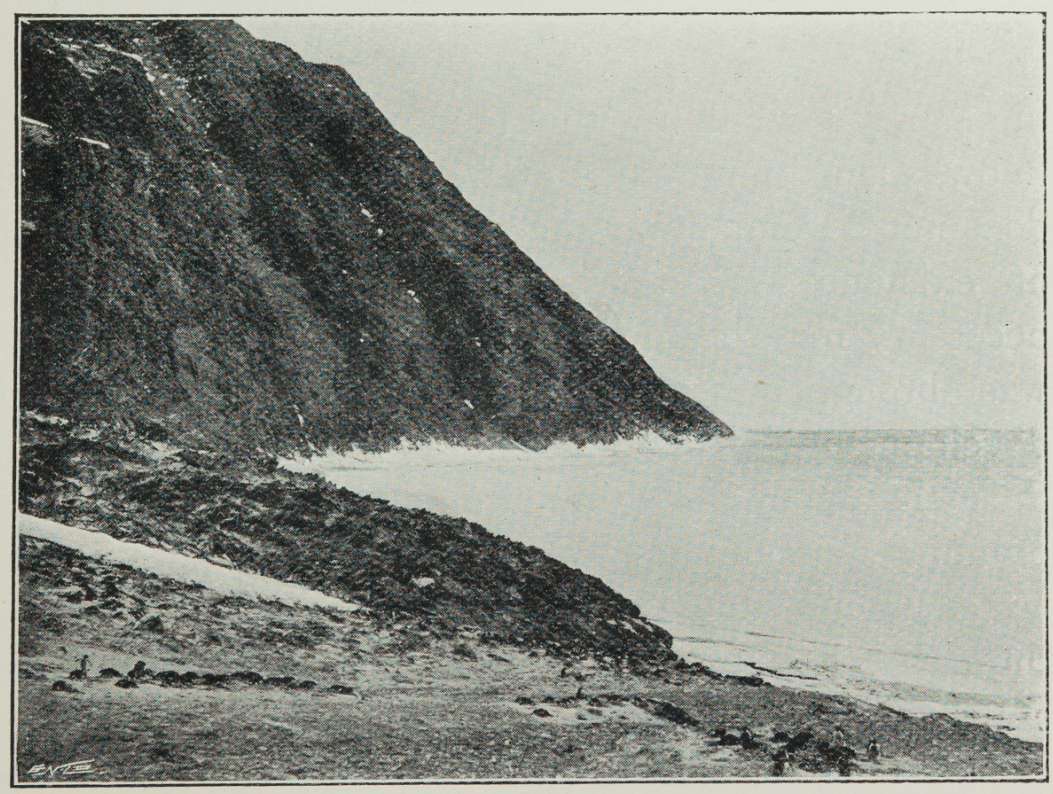

DUKE OF YORK ISLAND.

throws a satisfactory light on our meteorological work, as it is improbable that the temperatures about Geikie Land will go much below what we experienced, 
 \\ British Antarctic Expedition.}

otherwise the life of insects would not have been possible. Perchance we had experienced a comparatively cold winter? The insects were of three distinct types, and on return to Camp Ridley the doctor made some excellent microscopic preparations of them.

The Finn Savio, evidently put on his mettle by the doctor's discovery, shortly afterwards triumphantly entered Camp Ridley with an ordinary blow-fly; and, to say the truth, it did startle us at first, until we found that it was a dead stowaway in a jam-box from London!

It is important and curious that in both the marine fauna collection, and in the Algae collection, specimens were found proving the existence of bi-polarity; while in the land fauna, as far as we know, such do not exist. The existence of organisms does not develop from the presence of the possibility of existence for these, but because the element necessary for the development of these organisms was brought into conditions which favoured its development into a complete organism. It seems thus that the fount whence the element of these organisms rises exists both within the Arctic and Antarctic Circles, apparently without any communication through the intermediary zones. Quite different appear the land fauna, where bi-polarity does not exist. There are places on the Northern and Southern Hemispheres which seem to be ruled by the same climatic conditions and by the same meteorological conditions, and where any one might expect the same species to exist; but there must be lacking some conditions in the one place which are necessary 
for the existence of certain life in the other, and vice versâ. Organisms, again, which can be transferred from one hemisphere to the other, as well of animals as of plants, adopt quite another appearance and character by the transfer. It seems, however, that within the Arctic Circle and the Antarctic Circle there prevail not only for certain organisms the very

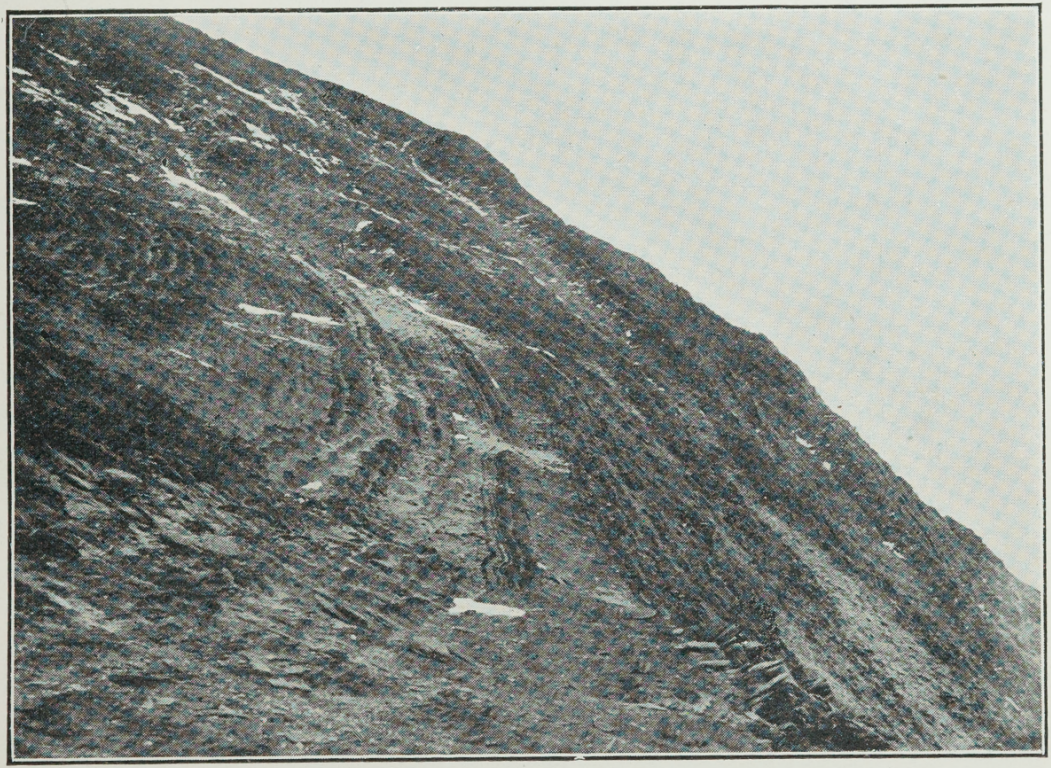

GEOLOGICAL FORMATION OF DUKE OF YORK ISLAND.

identical conditions favourable for the development of their elements, but the identical elements are also present, as, for instance, the presence of the lichen (reindeer moss) proves. It exists in both hemispheres, and its discovery within the Antarctic Regions by me has, for the first time, proved the existence of bi-polarity also in the flora. It seems to me that the existence, or non-existence, of certain organisms must needs, in many cases, depend upon the presence 
or the absence of some, for the development of one particular element, vital conditions, which, in many cases have as yet not been identified by us, but which, perhaps, would give us a valuable link in regard to the mystery of distribution of organisms.

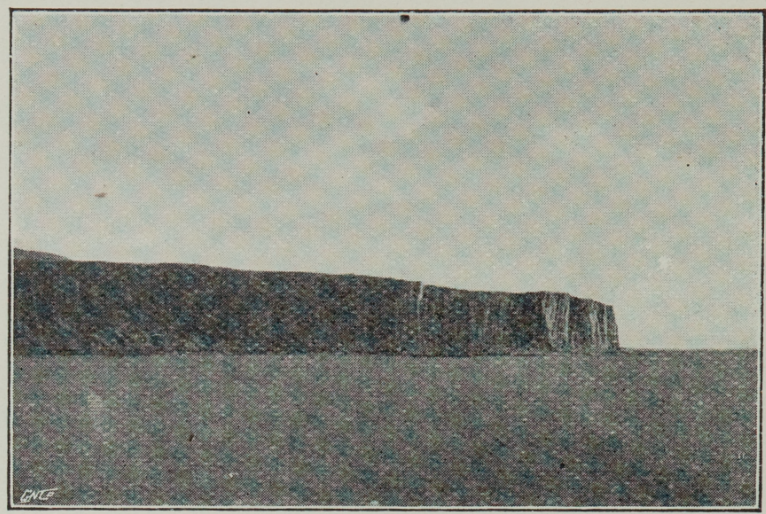

ICE BARRIER NEAR DUKE OF YORK ISLAND,

During the sledge journey on which the insects were discovered, we pitched our tent in Crescent B a y on Duke of York Island. From there we made a sledge journey into the bay to the S.E., an arm of Robertson Bay, at the end of which we found a very low approachable land. It was a kind of beach rising from the bay to a height of about $30 \mathrm{ft}$. This land was partly formed by the glacier, and partly through stone avalanches from the mountain side to the N.E. As a marking line between this work of the glacier and that of the mountain ravines, there was a small creek rippling down among the boulders and rocks from two small lakes which were formed through the melting of the great Murray Glacier.

I found a dead white seal on this beach, and 300 yards further up the beach was another seal of the white kind. Before we returned to Camp Ridley we thoroughly explored the vicinity to the height 
of 1,700 feet, at which height we found vegetation. When travelling back a good deal of water had accumulated near the coastline, which made the landing with sledges and gear difficult. During the time we were camped at the Murray Glacier a stone rush might have been fatal to us. Early in the morning Savio and I were awakened simultaneously by a strange noise on the mountain above us. It did not take us long to grasp the situation, and we quickly crawled towards the openings of our tents, dragging with us our sleeping-bags, from which we had had no time to extricate ourselves, and which

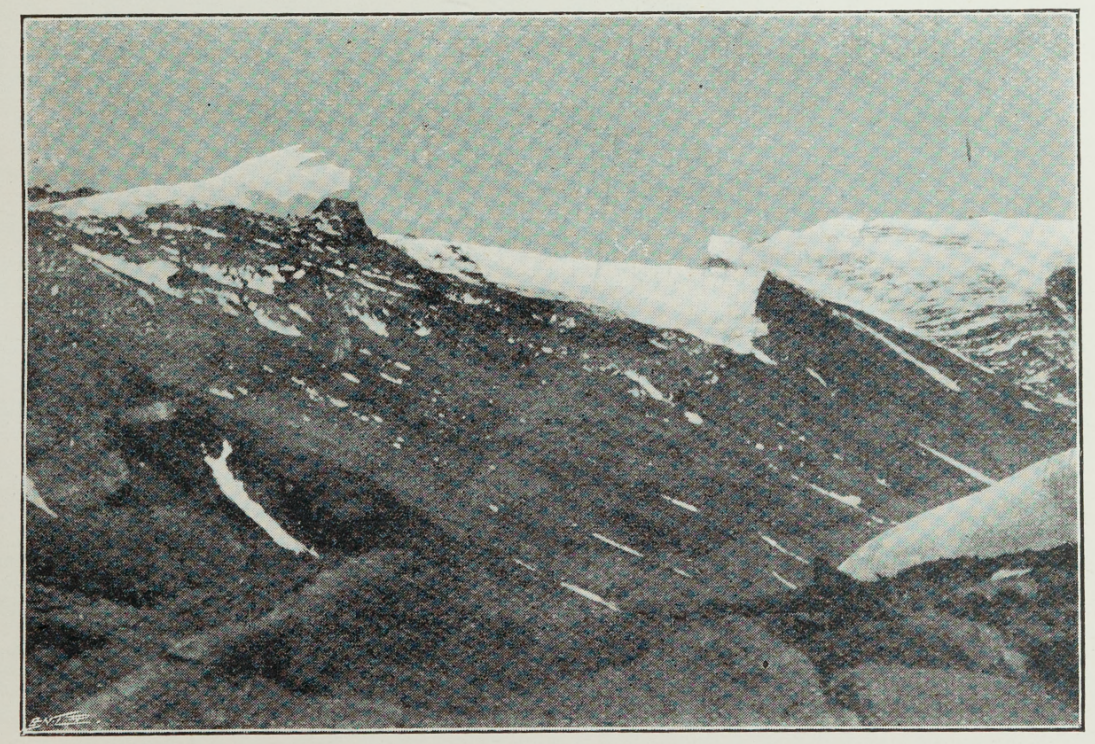

IN VICTORIA LAND NEAR SIR J. MURRAY GLACIER.

stuck to us like cocoons. I then saw and heard what was coming. Savio lost no time then, and quickly divested himself of his bag, jumping to the right and left, just after the fashion you may see over-polite people in the street who cannot make up 


\section{British Antarctic Expedition.}

their minds which side to pass a fellow-being. A large piece of rock about three feet thick, and like a wheel in shape, and as big as our tent, was making a bee-line for our camp with fearful velocity down the steep mountain side. It had got on to its edge, and was rolling like a hoop. No wonder Savio found a difficulty in making up his mind whether to jump to the right or to the left. Close by the camp the travelling monster took a westerly course, and settled in a bed of snow some twenty feet away from us.

As I remarked in I895, after my first Antarctic journey, it must strike anyone with an eye for geological science how the nature of Victoria Land speaks of evolution. One need only look at the moraines, the empty glacier beds, and the worn rocks of Victoria Land, to see how greatly these lands must have changed during comparatively recent periods.

On our way home we saw very many seals of the Weddelli kind.

The seals we encountered in the pack on the southward voyage were, as they have always been found in the Antarctic Regions, very few, all of them being hair seals. Besides the sea leopard, the $W e d d e l l i$ was the best represented species. Then we found the characteristic white seal of the Antarctic in greater numbers than I found them in $1894-5$, and Mr. Hanson made, at my special request, as good a study of this interesting species as time, specimens and opportunity allowed. As we proceeded southwards the number of seals basking together increased considerably, and in the vicinity of Coulman Island 
and Cape Constance we saw as many as 300 together. These were Weddelli. The Rossii was very poorly represented; we only secured four specimens of them altogether. These were three males and one female. In the vicinity of Cape Adare seals were to be found nearly all the winter, either on the ice near the blow holes or in the water at these holes, which they managed to keep open. The seals were in great numbers on the beach at Camp Ridley when we

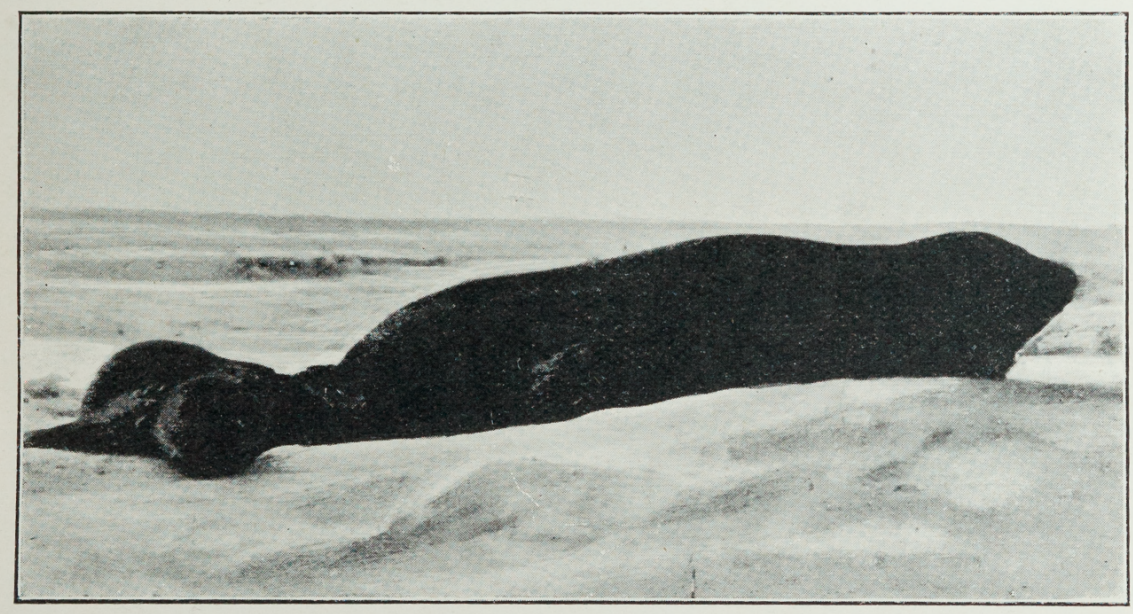

MOTHER AND CHILD (Weddelli).

landed in 1899 , and many dead dry seals were lying partly covered in the guano deposits. These were undoubtedly of the white kind, some of them having been quite young seals. I had hoped to have found that the white seal would breed in Robertson Bay, but was disappointed at finding this was not the case.

The Weddelli and sea leopard both bred in Robertson Bay, and we frequently found the young ones on the sledge journeys. They all seemed 


\section{British Antarctic Expedition.}

to live in luxury on fish in Robertson Bay. The seals, like the penguins, provided us with fresh food, and from time to time we killed them, and while the flesh was still warm and smoking, drank the blood as it spouted out from the wound made by the seal knife. It tasted blubbery, but I myself regarded it not alone as food, but as a great remedy against scurvy. Not unusually they attacked us in the kayaks, and it was with difficulty we prevented the kayaks from being torn. Generally we killed them by help of the seal knife, which, well handled, despatched them without pain. If the stroke was clean and bold at the heart, the seal would succumb almost immediately; but if hit in a less vital spot it would struggle considerably, and it was difficult to kill it with a knife if you had not succeeded at the first blow. Then they rose on their flippers and with blood-shot eyes they rushed for you, while their blood spouted out and stained the pure white snow. It is hard to kill a seal, I mean the task is hard to man, especially within the Antarctic Circle where the track of man is not yet marked by the blood of seals, and where men's bloodthirstiness is not yet known. Most of the seals allow you to get quite up to them without moving. Those who attack you are exceptions, but all of them look at you with two large, magnificent, moist dark eyes, in which the majesty of the creature defies you; then down plunges the steel of civilisation and the picture is spoilt.

I had ample opportunities of studying the Pagodroma Nivea (elegant white petrels) in their homes during the last sledge journey. Like its 
appearance, its habits are graceful and strikingly noble.

We had a very heavy journey to Camp Ridley; the snow on the pack was wet and in places the ice was treacherous. The dogs as usual pulled with a will, but we had continually to lift the sledges out of cracks and crevasses in the ice, and it was

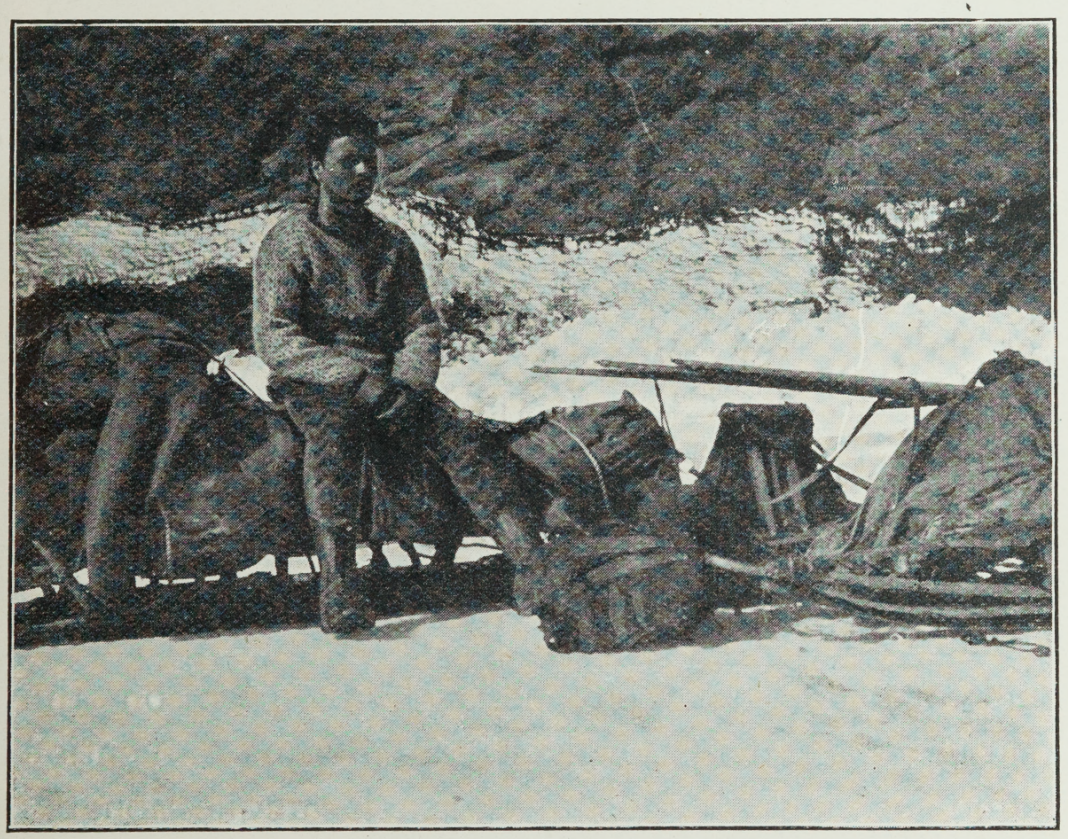

THE FINN SAVIO IN SPRING, I 900.

in an exhausted condition that we finally arrived at Camp Ridley. It was a surprise to us that we had been able to keep all our eggs in the collection from breaking as the sledges had been frequently upset.

As the time went on the daily reports from the top of Cape Adare told of improved ice conditions. 
On December 2 Ist the Finn Savio conceived rather a good idea of amusing himself; he caught a penguin, made a string fast to its legs, took it on board

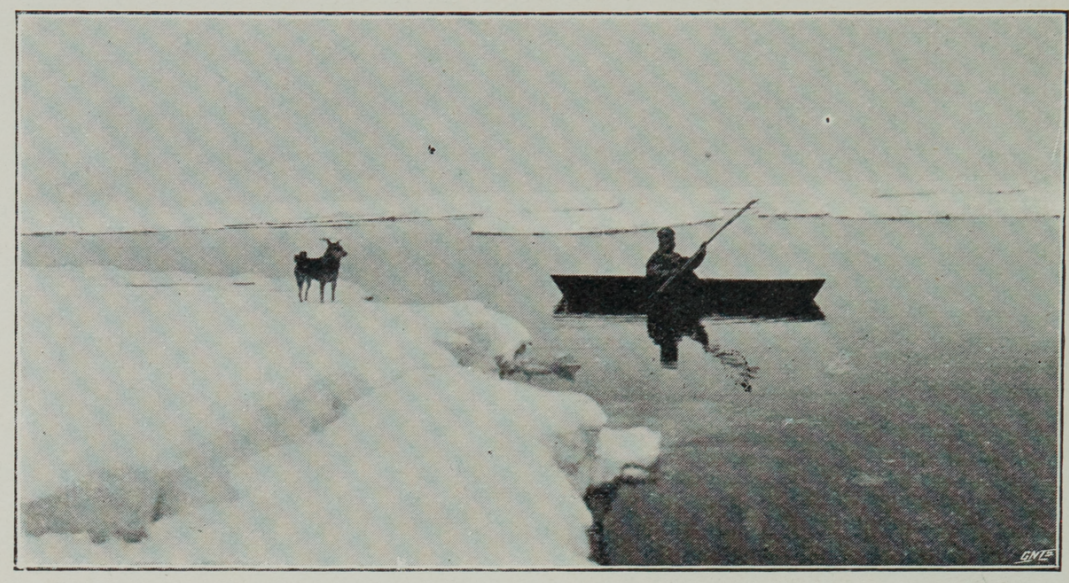

BORCHGREVINK IN KAYAK.

his kayak, and used it as motor power. The penguin dived and pulled Per and the kayak about at a great pace, and had he also invented a way of guiding the penguin, penguins for draught purposes would probably have fetched a high price on the Antarctic market. However, for me, his invention became of some importance, as it unquestionably supported my theory about the motion of the penguin in the water; its legs being arrested it evidently applied its weight for the motion, as the flippers (or rudimentary wings) are only used for balance, and would in any case not have sufficed to obtain such a great speed on the kayak.

Fougner to-day brought a very rich catch in his shallow-water net, amongst which was a medusa, very much the shape and colour of a lemon.

Christmas Eve was celebrated by speeches, 
Among the Penguins.

toddy, extra rations of biscuits, and a longing for home.

On Christmas Day we had tinned plum-pudding, and Mr. Evans, in honour of the occasion, baked cakes; and Mr. Ellefsen even surpassed himself in the excellence of his cooking.

All the water we drank and used for our cooking we had, of course, to make from the snow, and the longing for real water became at last intense.

The Finns, contrary to expectations, proved of very clean habits. In midwinter Per Savio dug himself an

FOUGNER.

EVANS.

COLBECK.

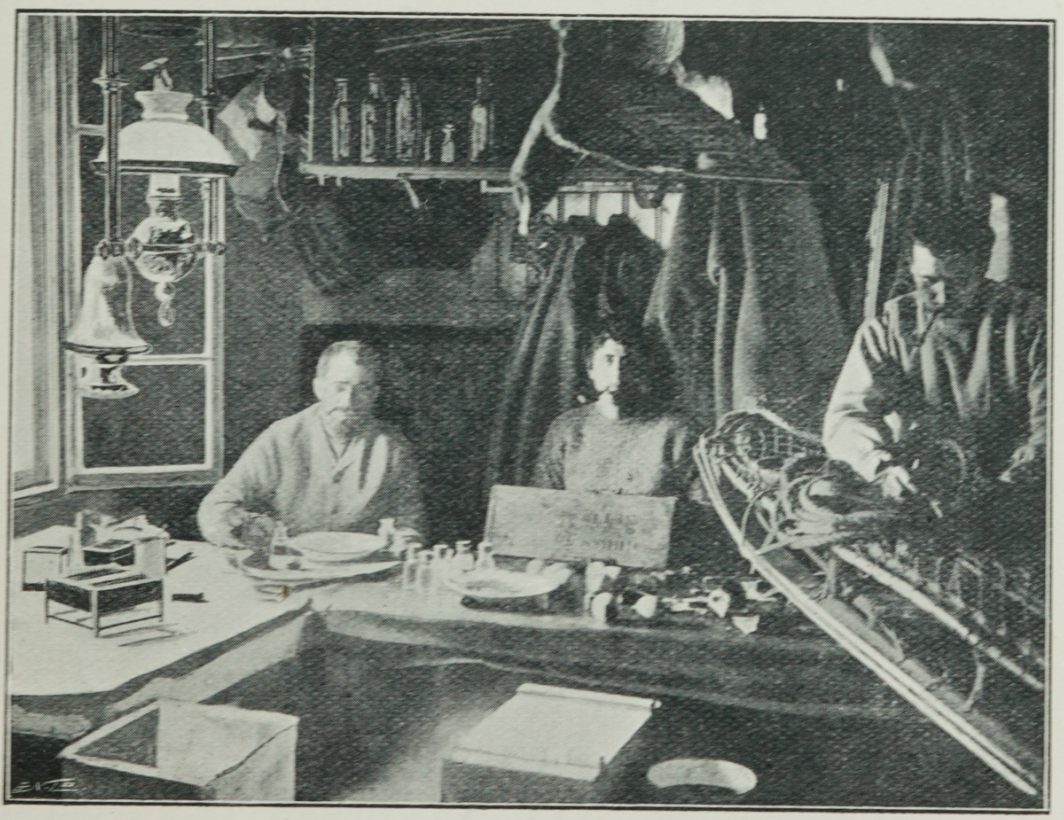

A BUSY DAY IN CAMP RIDLEY.

apartment under the snow, some ro feet square and 6 feet high. Here he placed a small iron stove, and put an iron funnel through the snow. He 
covered the entrance, made a big fire in the stove, and soon the place was covered with hot, moist steam. Here he completely undressed and remained thus for about an hour, just as people take steam baths in the luxuriously furnished baths in a European city. Still it was a remarkable feature that it was about $60^{\circ}$ of frost above this icy steam bath. They (the Finns) seemed to thrive well, and accustomed to the dark time from the north, their minds did not seem to suffer much.

On December $27_{\text {th }}$ the report from the top was to the effect that no ice was to be seen towards the north, not even through the telescope. Towards the north-west and also towards the west, much ice was however in view. Along the beaches of our peninsula it was getting un afe for travelling. Several young penguins were out of their shells, and Mr. Evans, who had taken over Mr. Hanson's department, collected specimens of the young ones from day to day in order to get the series in their growth. Mr. Fougner secured a magnificent specimen of a jelly-fish. When I went to the top of the cape I caught some very fine specimens of young skuagulls.

New Year's Day broke bright and clear with the Union Jack flying merrily at the flag-staff. We turned our shirts in the morning. We looked back with sentiments of pardonable pride on the work accomplished by us during the year just sped, feeling that as the young century was rising above the horizon like the sun after the long Arctic night, so was the light of knowledge illuminating the hidden mysteries of the last terra incognita on the 


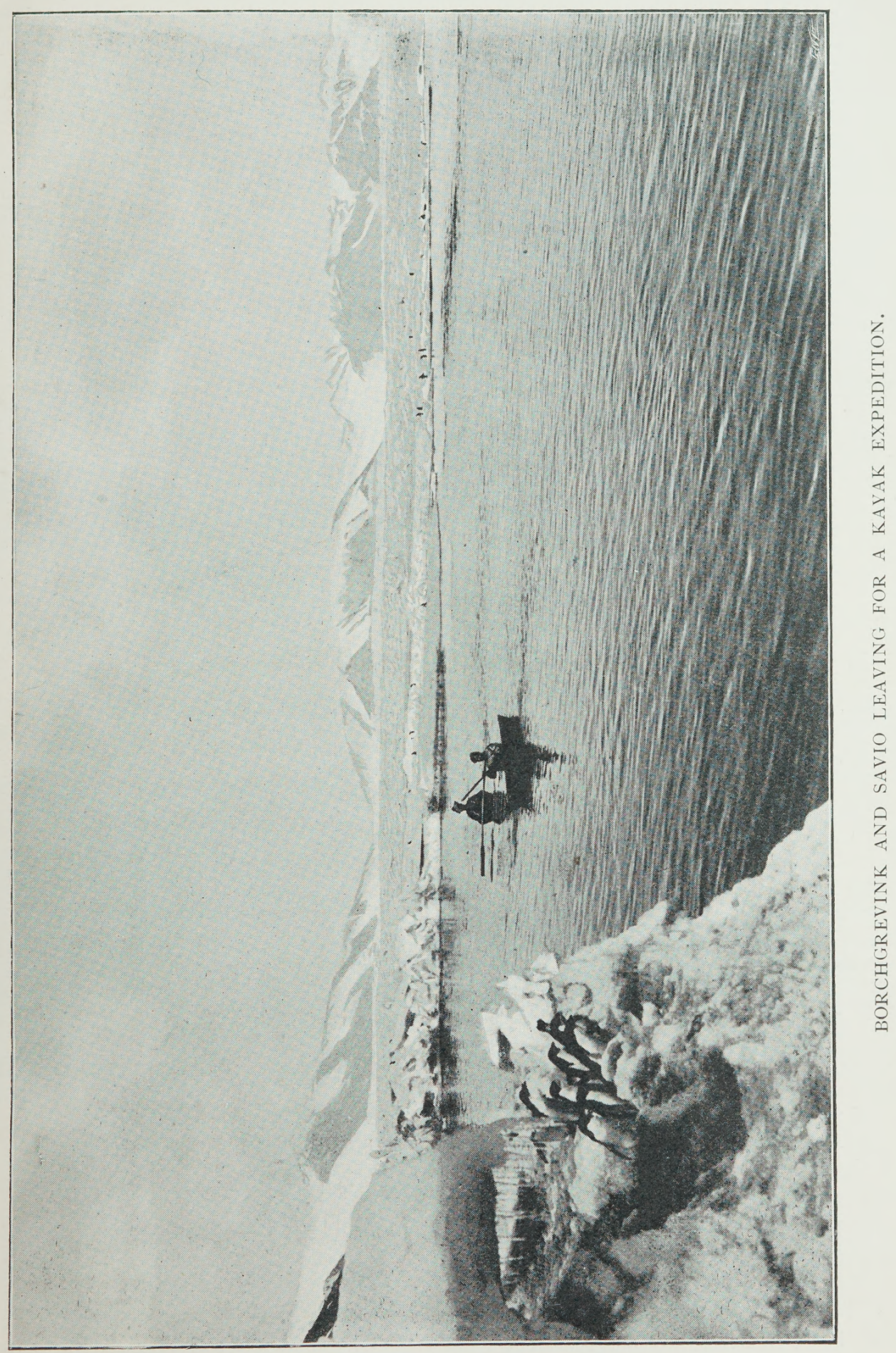

R 2 

face of the globe. A young Antarctic day was born, and we saw a vision of many bold bands of explorers in our wake, struggling on towards the goal of scientific certainty.

In the afternoon we had rifle shooting at the target at 50 yards range with the following result :-

Mr. Borchgrevink . Total.

L. Bernacchi

7,7, Іо, 5,4, го, $7,5,5,5$. 65

Lieut. Colbeck .

$7,3, \mathrm{I}, \mathrm{\circ}, \mathrm{O}, 9,8,3, \mathrm{I}, \mathrm{I}$

H. B. Evans

$7,4, \mathrm{I}, \circ, \circ, 8,7,6,3$, 。

40

A. Fougner .

$9,2, \circ, \circ, \circ, 8,7,6,3, \circ$

33

Dr. Klovstad

I, $5,5,7,9,2,3,4,6,6$

$5,4,3,3$, т, го, $8,4,4,5$

Colbein Ellefsen

$2,4,4,0,0, \mathrm{I}, 2, \mathrm{O}, \mathrm{O}, \mathrm{O}$

Ole Must

$7,7,6,5,2,5, \mathrm{x}, \mathrm{\circ}, \mathrm{o}, \mathrm{\circ}$

Per Savio

$9,7,4, c, 0,9,7,5,5, \circ$

46

On January 5 th, there was open water as far as the eye could reach towards north and east. We swept the horizon with the telescope, but no signs of the returning vessel were to be seen. I had hoped to have seen her back ere this, and although we had stores of resources in case we should be left for several more years, it was naturally an anxious time. The fate of the Southern Cross since she left us the previous year, was a sealed book to us, as also were the movements in the great civilised world. It was now very warm in the sun. On January Ioth open water was to be seen everywhere. The IIth January was the anniversary of the first sighting of Cape Adare by Sir James Clark Ross. What a profound admiration I have for that great British navigator who, without the valuable assistance of steam, accomplished so 
much. But how favourable must the ice conditions of that time have been to have enabled him to penetrate so far south at such an early date as this. Great spirit in man who was the successful pioneer in these regions, how little did I know that I was destined to be the first in this land, which you first told the world existed! In boyhood I read your difficulties with enthusiasm, and when I now read them, more than half a century has crowned your achievements, and I feel that reverence defines my appreciation. The difficulties were great at that time; they are now. Inventions have made the work lighter apparently, in one way; but to utilise those new inventions creates new difficulties, new risks, and fresh claims upon the human brain.

On January i8th a violent gale started with snowdrift from S.E. On the Igth it was still blowing; the wind increased in strength, with the barometer at $28 \cdot 830$; the dry bulb thermometer showed $26 \cdot 5$, the wet 26 , and the solar 27 . This gale continued until the 26 th and was the longest we had. The appearance of the air seemed threatening, and had the Southern Cross been near land at the time there would have been anxious hours for those on board. However, had I then known, as I now do, how local most of these gales are, I would, perhaps, have been more easy in my mind about her. Our abode at Cape Adare was, in fact, lying within a close elliptic isobar of the lowest barometric pressure within the Antarctic Circle. The ice had now broken up in Robertson Bay. During the gales we had experienced the greatest dryness, or rather the least humidity of the air that 
had been recorded. Although open water everywhere, a large number of monstrous icebergs were now seen drifting northwards past the cape. Some few seemed to be ruled by a strong undercurrent to visit Robertson Bay, where the larger ones ran aground. It was an interesting observation to witness those bergs sail into the bay straight against a heavy gale, and against the upper current. The Finn Savio and myself made several expeditions in kayaks, and secured valuable specimens of seals and birds.

On January 2ist we celebrated King Oscar's birthday and drank his health, while the flag was hoisted.

On January $23 \mathrm{rd}$, the anniversary of my first landing on the Antarctic continent in I894, I found that the season in regard to climate and ice conditions was not as favourable as in that year. The young penguins were not so far advanced now as then. On the $24^{\text {th }}$ most of the penguins had gone to sea again, and the oldest of the young ones ventured short trips of swimming exercise. It was insufferable inside now, as the smell of the guano deposits was very strong. The wet loose snow which settled in drifts during the recent long gale melted rapidly, and the vapour therefrom made the air muggy inside the huts. Besides, our humour always fell with the barometer, and did not always rise as quickly, especially now that, while waiting for the vessel, the time hung heavily on our hands, although there were so many matters to be considered and talked over. On the 27 th I took with me Savio and two kayaks, and provisions for about a week. I wanted to investigate a canine track which I had found in the snow on the slope on the eastern side of 
the range of Cape Adare. It had soon got clear to us all that this track, although undoubtedly left by a dog, was not that of a dog belonging to our pack. So keenly are one's senses sharpened in a community so small and so far removed from the outer world when you daily have to fight natural forces that you observe everything. We followed the track a few miles down into the bay and found that it did not return but led on to a great glacier. I rightly conjectured that the dog who left this track must have belonged to the Southern Cross or some other vessel in the neighbourhood of Victoria Land, as after the return of the Southern Cross later on I ascertained that the vessel had been in close proximity to Cape Adare just at the time, and having lost two dogs on the ice pack it was probably the track of one of these which we followed. When we could distinguish the track no longer, seeing no chance of following it up the steep glacier slopes, where the dog evidently had experienced great difficulty in proceeding, we camped on the very small beach where once Mr. Bernacchi, Mr. Fougner, Savio and myself had nearly lost our lives. On this occasion also the Lapp and I were destined to run a great risk. We had just finished a meal, and I had crawled into my kayak to have a sleep. At the time I had the kayak pulled up on a slope under the cliff, when suddenly an avalanche of stone and snow rushed down. The snow nearly buried my kayak, while some of the stones, of great size, settled only a few feet from the kayak in which I was lying. Although Savio had called out the moment he heard the avalanche, I was not able to extricate myself from the kayak before it was too 
late. The happy impulse which at once occurred to the Finn to secure my safety was to push my kayak down the slope into the sea. However, the avalanche was then already so far on the road that he only just managed to clear himself, while the kayak with myself in it had a most marvellous escape. Early on the morning of the 28th January Savio and I paddled back to Camp Ridley.

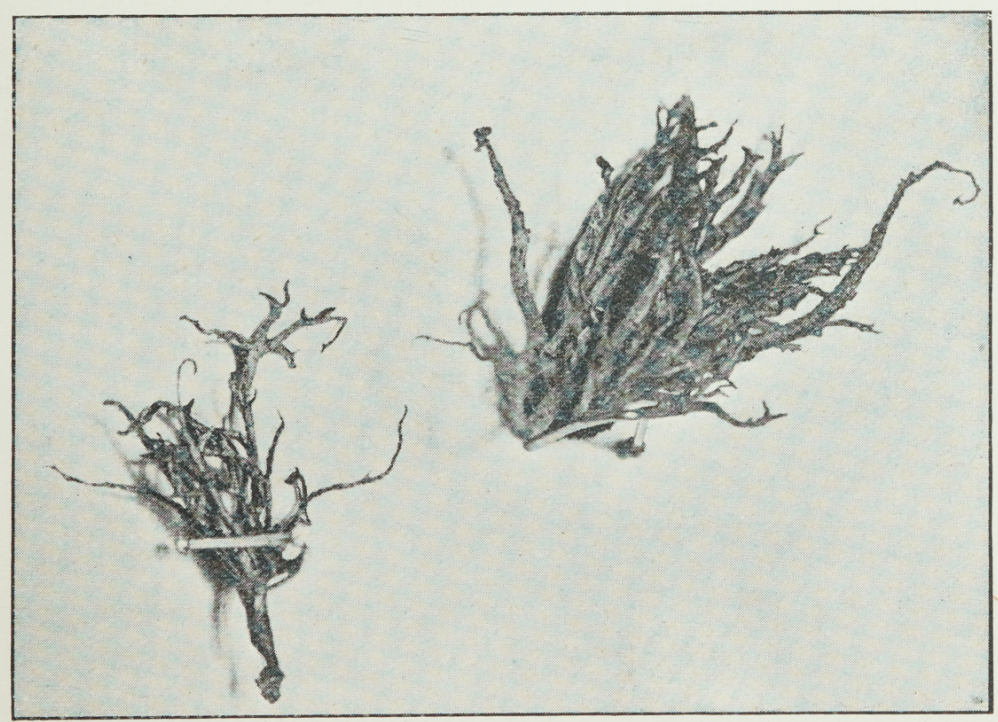

THE LARGEST VEGETATION FROM SOUTH VICTORIA LAND: REINDEER MOSS (LICHEN). 


\section{CHAPTER VIII.}

\section{Return of the "Southern Cross."}

WE were all asleep in the hut at Camp Ridley except Colbein Ellefsen. The Finn Savio and myself slept heavily after twenty-four hours hard pulling in the kayaks. Ellefsen had just gone out of the hut to pull in a bag of coal when he saw a strange man walking on the peninsula towards him. The effect upon him, as he afterwards related it to me, was that he wondered whether he was asleep or awake; suddenly to see a new being, a man not one of us nine-was it a large penguin, a larger species than the Emperor? However, he soon realised that it was Captain Jensen, who came along with the mailbag on his back. Hurriedly, and in few words, he ascertained the conditions at the camp, whereupon he quietly opened the door, banged the bag down upon the table, and said "Post!" When we looked out of our pigeon-holes we saw who it was. He had got old while he had been away. His responsible position had told upon him. It was a great moment as we again shook hands. Quickly the mail-bag was opened and emptied, and the members looked out for quiet corners where they, undisturbed, could satisfy their hunger for news from relatives at home, and from the great world which had been shut off from us for 
more than a year. Gradually we heard all the news-both private and public. Never did we realise more than then what a big part the daily newspaper plays in our life. We heard for the first time about the war in the Transvaal; about wonderful discoveries in telegraphy, and found how many alterations of conditions one year might cause. Interesting was it to hear about those active steps which had been taken to follow in

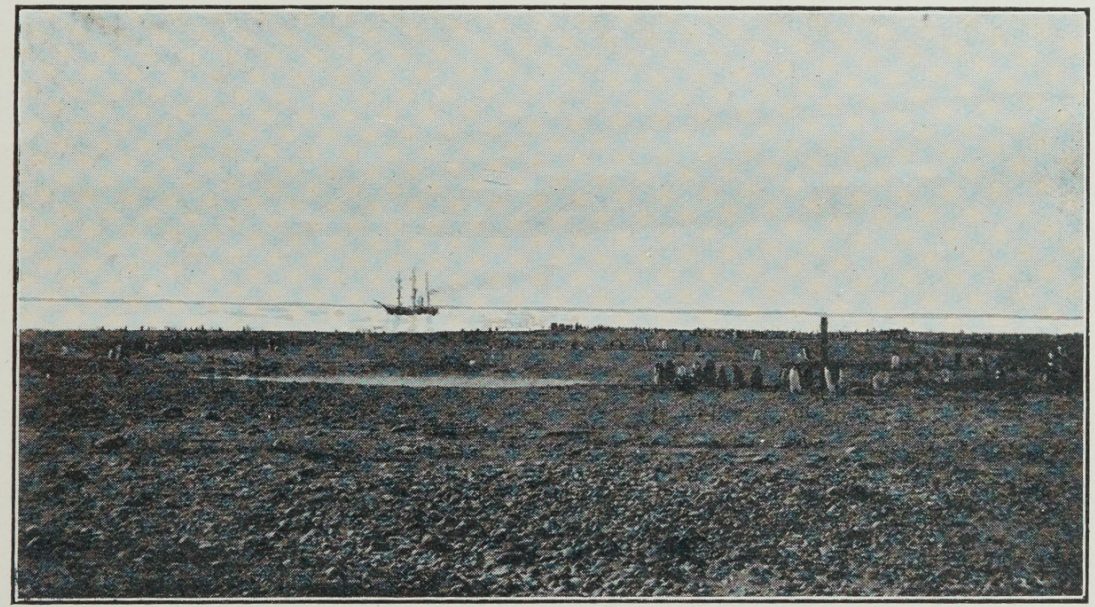

THE RETURN OF THE "SOUTHERN CROSS."

our wake in Antarctic research. We commenced at once to take those stores from Camp Ridley which were wanted for our southward journey. The dogs were taken on board, the sledges, instruments and fur, and after having visited Hanson's grave, we all went on board, leaving at Camp Ridley, however, the huts, a quantity of coal which would have kept us for another year, a considerable amount of provisions, and a small note from myself to the commander of the next expedition. 
The following is a detailed list of the provisions, etc., left at Cape Adare in February, I 900 :-

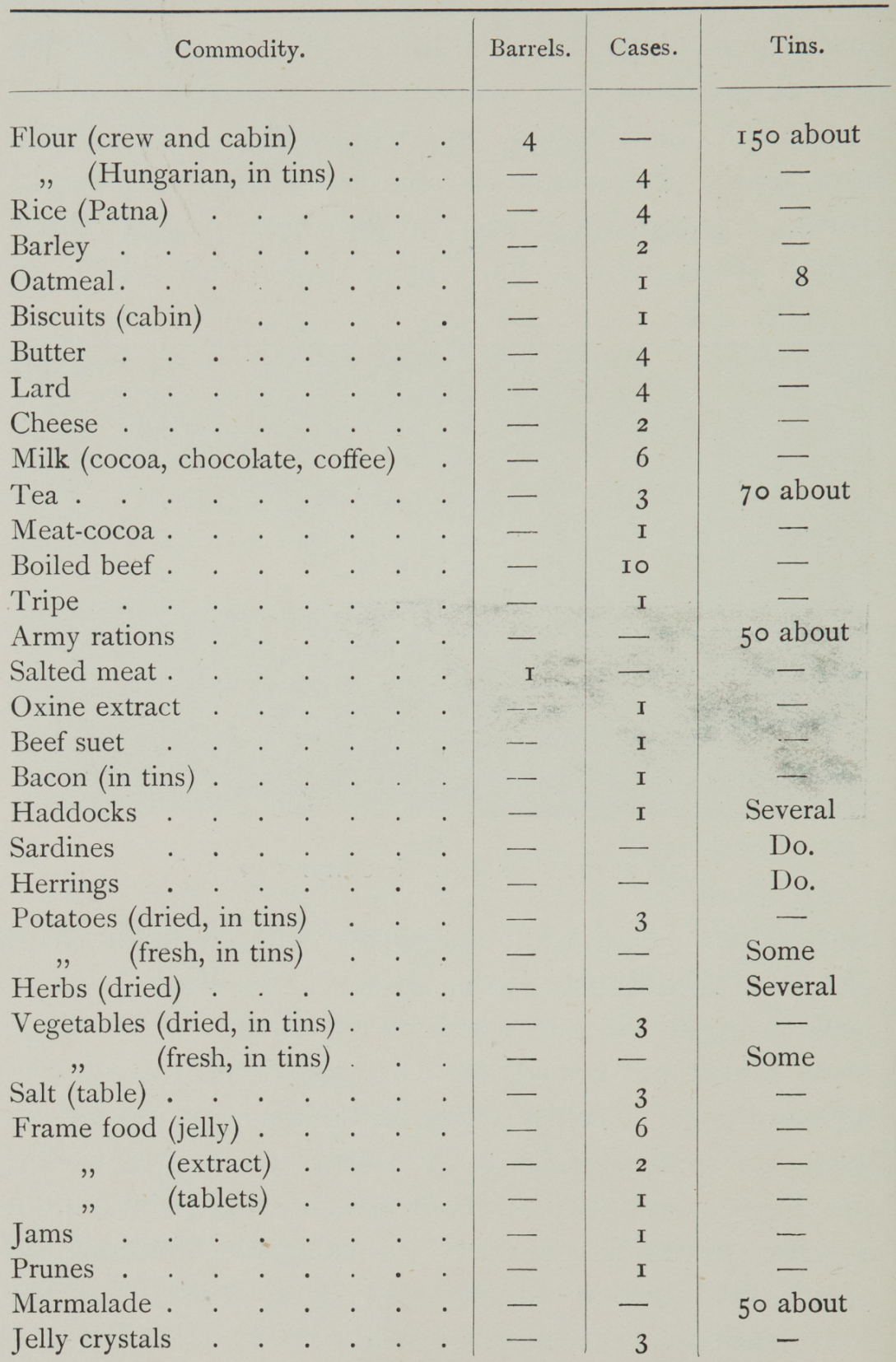




\section{Return of the Southern Cross. 253}

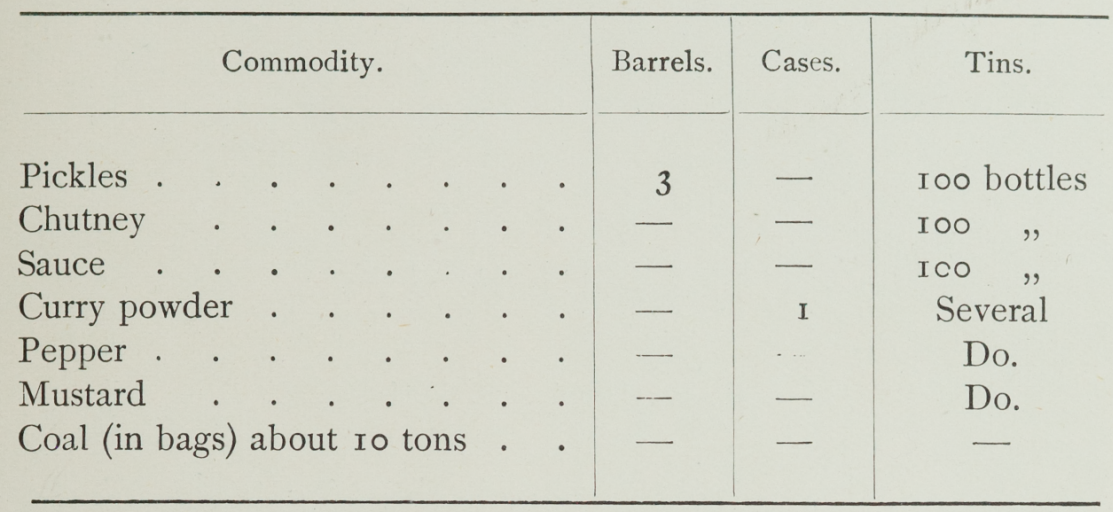

In the evening of the and February we steamed away from Camp Ridley, and I had again the collected Expedition of thirty souls under my command. 


\section{H A P T E R I X.}

\section{Farthest South.}

When once again on board the Southern Cross, Per Savio had been allowed to take up his abode in the small cupboard, if it may so be called, in the forecastle, where he made himself remarkably comfortable. He was lying resting after an arduous day's work, while his thoughts were far away up North where reindeer were running over the big flats, and where he hoped the girl he had left behind him was waiting for him. In these reveries he was suddenly interrupted and brought at once from poesie to prose by a large fat Australian rat which fell on to his face; and being as upset as Per was, the creature saw the refuge it needed in Per's sleeping bag. It goes without saying that Per was not slow in emerging from his cupboard.

While we continually took the bearings of Victoria Land for mapping purposes, we steamed southwards and sighted Possession Island at four in the morning of the 3rd February. As we drew near to the island everyone on board became greatly interested, especially when I, through my telescope, discovered that the pole with its iron box on the top of it, which had been left there in 1895 , was still standing in its solid foundation of rock. 


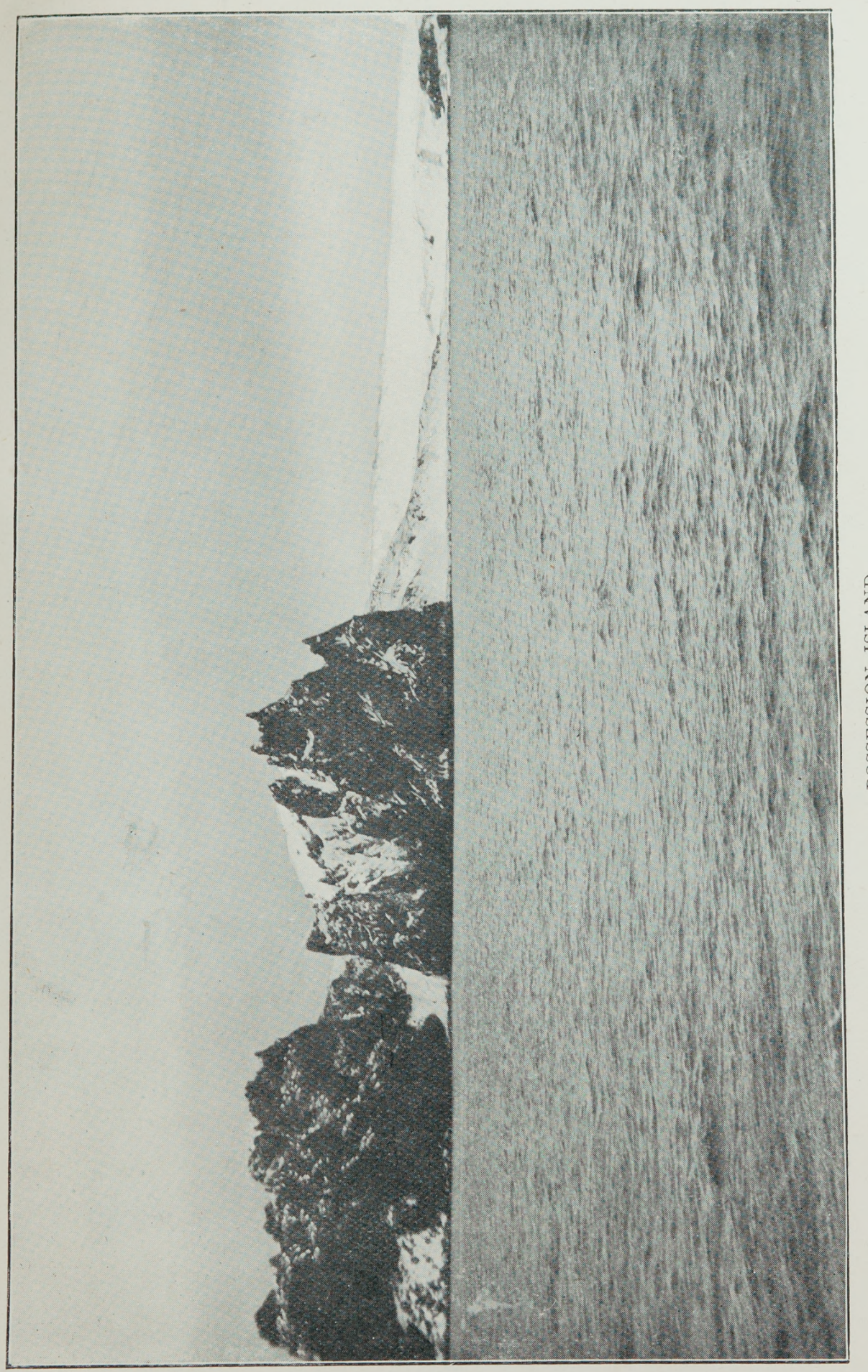

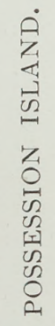



My entire staff accompanied me on shore, also four sailors. A rather big swell was running, so we had to use great care when we approached the stony beach. As we rapidly followed a big wave, we succeeded in reaching far up the beach. A couple of seals plunged into the water at our landing place, just where our boat struck. We jumped out

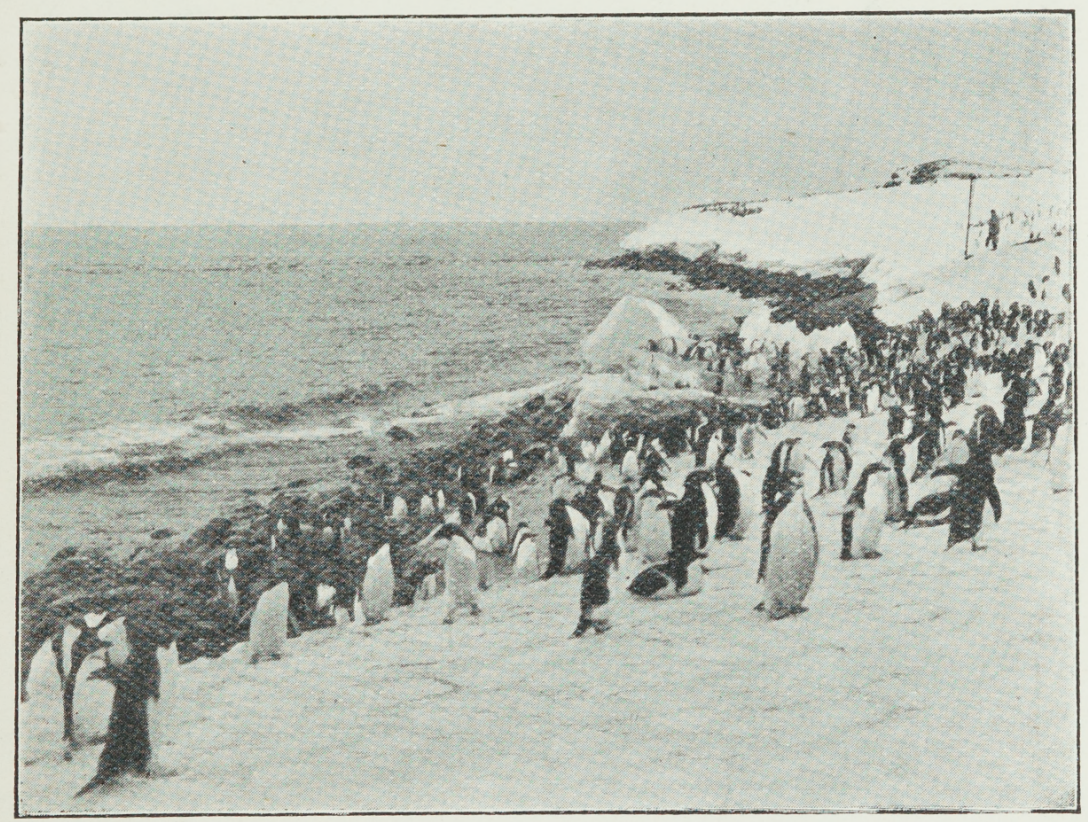

ON THE BEACH OF POSSESSION ISLAND.

and hauled the boat up, and succeeded in landing instruments, cameras, and guns. The island was covered with snow, and presented quite a different appearance to that which it bore during my landing in I894. Very few penguins were left, but some skuagulls were still soaring about. We approached the solitary pole which had faced the Antarctic gales for five years. Since I last closed the iron box, no 
258 British Antarctic Expedition.

human beings had been near it. It was an interesting moment as staff and crew surrounded this historical place, while I opened the box and read the letter

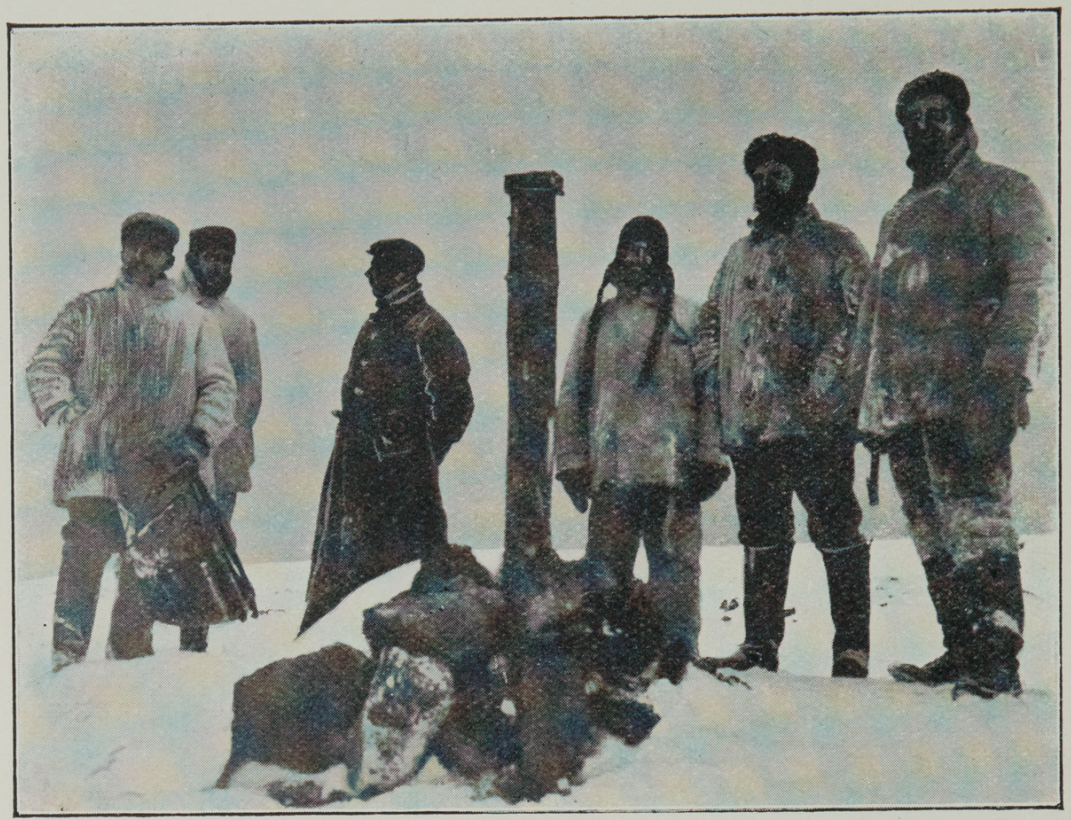

ON POSSESSION ISLAND AT THE POLE LEFT THERE IN I 895.

aloud. At the call of Captain Jensen, three cheers were given for me, and I responded in three cheers for the Southern Cross. Then all the members signed a fresh letter which I left in the box. Some of the members walked towards the eastern side of the island, while Captain Jensen, Fougner, and myself made southward towards the high ridge which rises boldly into Archer Peak. I again found vegetation, and secured very satisfactory specimens of it, as well as of the rocks. But these new rock specimens did not differ from those which I had collected in 1894 . 
On the 4th February we had a fine day-clear and magnificent, each undulation and white peak of Victoria Land standing defined against the sky.

Following the land as closely as possible, we mapped the coastline down to Coulman Island. Here also I effected a landing, although some difficulty was experienced owing to the heavy swell. Lieut. Colbeck and Mr. Bernacchi, with two sailors, accompanied me. This was the first time that man ever landed on Coulman Island. After having collected specimens of rocks and vegetation we returned to the vessel, and principally because of the magnetic observations, which would be invaluable in this locality, the course of the Southern Cross was laid westwards. Since leaving Cape Adare the temperature in the water had risen from 28 to 30. The land, some forty miles inland, appeared considerably lower than the ranges near Cape Adare, but, in $\mathrm{my}$ opinion, even here there would be no opportunity for a sledge party to proceed successfully far inland. $\mathrm{H}$ o w e ver, having penetrated as far as possible to-

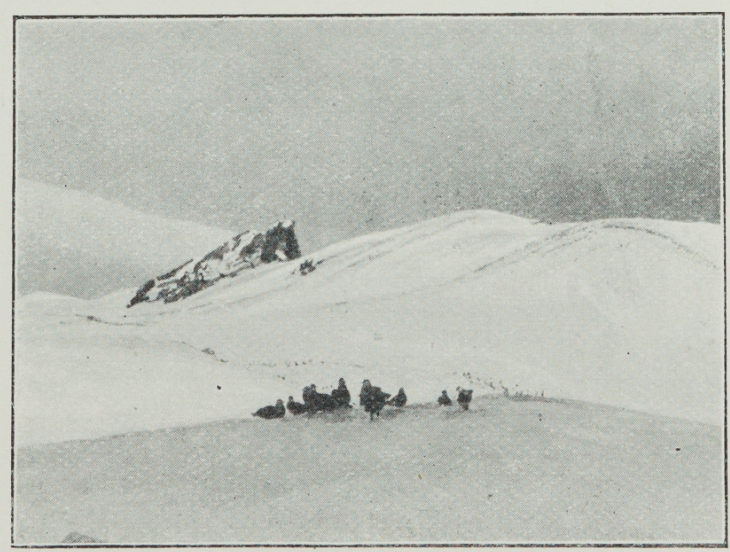

IN THE INTERIOR OF POSSESSION ISLAND.

wards the land to the west of Coulman Island, and to the south of a conspicuous cape, which I named Cape Constance (after my wife), we found a bay in 


\section{British Antarctic Expedition.}

an ice barrier, or rather in the seaward edge of the ice-sheet descending from Victoria Land. This was a place admirably suited for magnetic observations, and I named it Lady Newnes Bay.

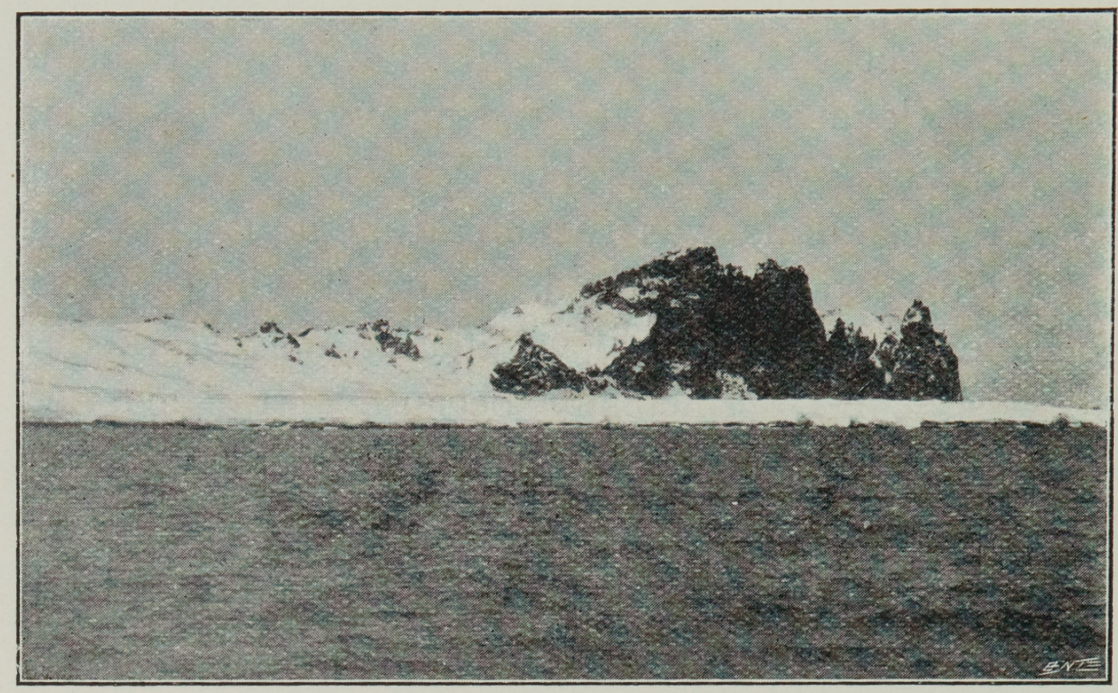

POSSESSION ISLAND WITH PEAK ARCHER.

Here, on the ice, Mr. Bernacchi and Lieut. Colbeck took some of the most important observations, without which we would have been unable, even with our later observations, to have located the present position of the South Magnetic Pole. The dip taken here was $87 \cdot$ I 8 . With sledges we drove up to the end of a barrier-bound, wedge-shaped bay. At the end of this we found very many seals of the Weddelli. On leaving this locality on the $4^{\text {th }}$ February we had considerable difficulty through approaching drift-ice. On the $5^{\text {th }}$ we steamed southwards, and saw a good deal of pack-ice towards the west, so the coastline here for some distance could not be distinctly mapped. On the 6 th we were in 
lat. $74^{\circ} 32^{\prime}$. We sighted land all towards the west, and as little pack-ice was seen, and as much dark land was within sight towards the north-west of Cape Washington, I decided to risk an investigation of the fjord to the north of the range which terminated in Cape Washington, as here also I hoped to be able to afford my magnetic observers the necessary opportunity for their work. Proceeding westwards for about twenty miles from the Cape, we discovered a promontory almost free of ice and snow. The place is a fine camping ground-a peninsula beach about 100 acres in extent. It extends towards north-west, while it leaves a cove, apparently a splendid winter harbour, to the southward, where Mount Melbourne rises to

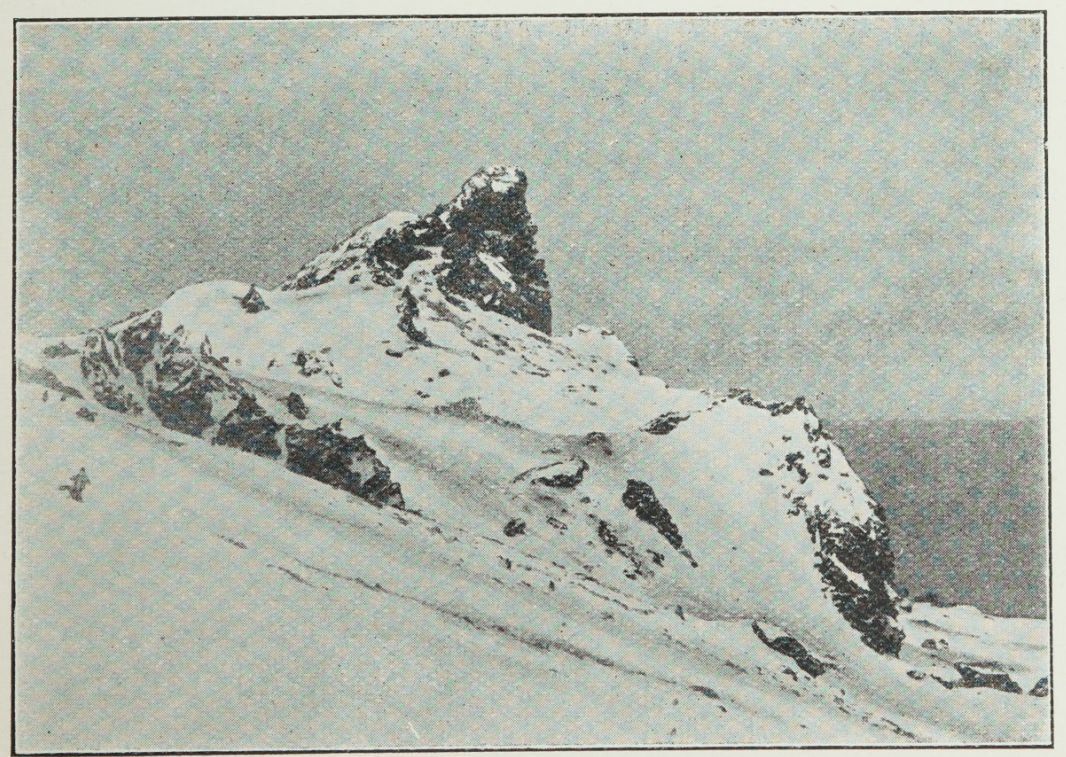

PEAK ARCHER.

a height of about I 2,000 ft.; its volcanic top was distinctly reflected into the clear cove, and reminded 
me of Mount Etna, while the midnight sun surpassed itself in splendour.

As we gradually drew near to this dark promontory, we were enabled more distinctly to ascertain the nature and appearance of it. Towards the west a low peninsula descended from some picturesque and wild-looking basaltic rocks, which stood sharply out against the white cover of Mount Melbourne. They towered up into the most fantastic shapes some $700 \mathrm{ft}$. high. At places the pinnacles seemed in the very act of falling, and evidently did not want a very great force brought to bear upon them for them to do so. Through the appearance of these rocks I gathered that they had been there for some time, and it is likely that the gales in this vicinity were considerably more moderate than those prevalent at Cape Adare. Towards the north-western side, and parted from the low peninsula on the western side through a small ridge with numerous passes, a small penguin colony was thriving, and as the young ones were not so far advanced as those few which were still left at Cape Adare when we departed, they did not seem to have any immediate intentions of leaving their breeding-place. At all events, they were evidently well protected by the cone of Mount Melbourne from the south. Although we had to use considerable care in approaching near this promontory with the Southern Cross, because of the drifting pack, we effected a landing in one of our whale boats without much difficulty. It was remarkable how the pebbly peninsula on which we landed resembled that at Camp Ridley. On this beach, however, there were no penguins, but a great many skuas with nearly 
full-grown young ones. It is evident that this low ground from time to time gets swamped by waves started in the small cove to the south, between it and the base of Mount Melbourne, where evidently large blocks of icebergs break off from the ice shest and plunge into the cove. Vegetation was found at the place where this peninsula rose towards the east ; here the ground con-

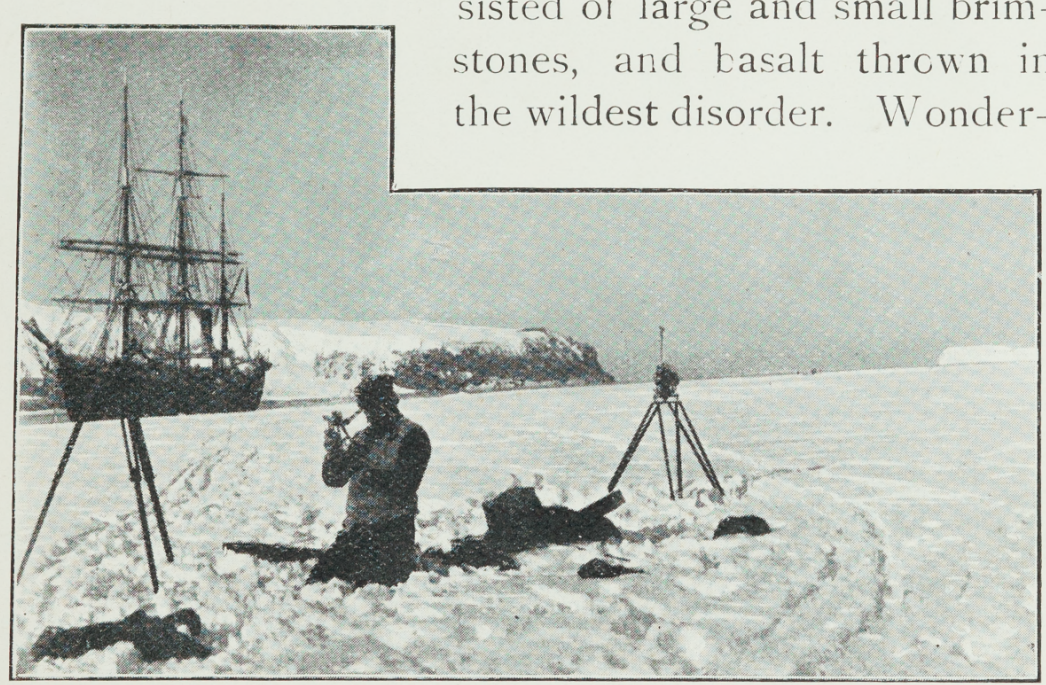

MR. COLBECK TAKING OBSERVATIONS WITH THE ARTIFICIAI HORIZON.

ful caves, passages and arches were found, and this dark land discovered in the middle of everlasting ice and snow, and surrounded by mighty peaks and crevasses, conveyed to our minds an idea of what one of Vulcan's gigantic workshops ought to be like.

I named this promontory and the land to the westward of it, Newnes Land, after the generous Mæcenas of the expedition, Sir George Newnes, Bart. 


\section{British Antarctic Expedition.}

While the magnetic observers were busily employed in taking their set of observations, the rest of us ascended towards the high ridges of this

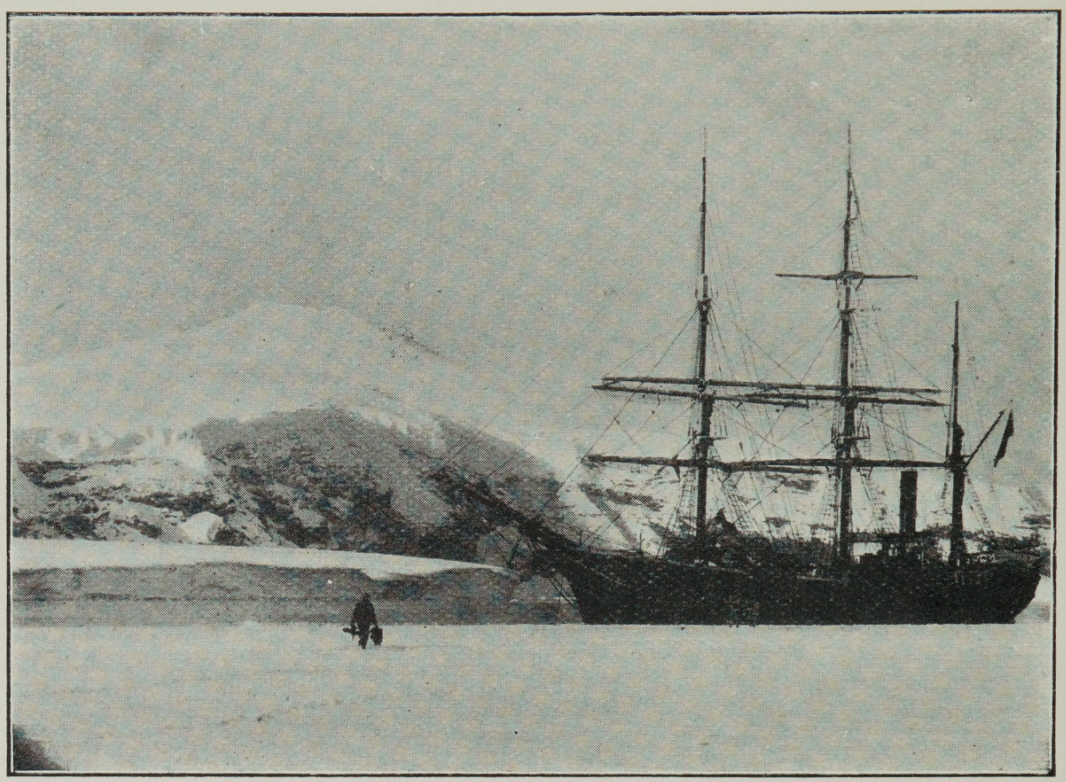

"SOUTHERN CROSS" IN LADY NEWNES BAY.

remarkable land. When we reached the crest some $700 \mathrm{ft}$. up, we were startled by looking straight over a precipice into a huge cauldron, the bottom of which was even below the sea level, but guarded against the waters of the cove to the west by a narrow ridge of brimstone. The south-east part of this cauldron was formed by the straight broken base of Mount Melbourne, and revealed the most interesting geological structures, while at its top the ice sheet descending from the cone of Mount Melbourne was cleft, displaying the structure and depth of the ice sheetsome $50 \mathrm{ft}$. Shortly after we had landed, the ice pack 
had become distinctly denser, and every minute large, heavy and hummocky ice-floes sailed into the bay, which I named Southern Cross Fjord. According to instructions left on board before my landing, the vessel moved out to the middle of the bay some five or six miles from where we were landed, and not a minute too early had this movement of the vessel been effected, as the ice-pack closed up to a dense field. After the necessary work had been done on shore, and the collections had been brought into the whale-boat, we launched it, but very soon had to pull it on to the hummocky ice,

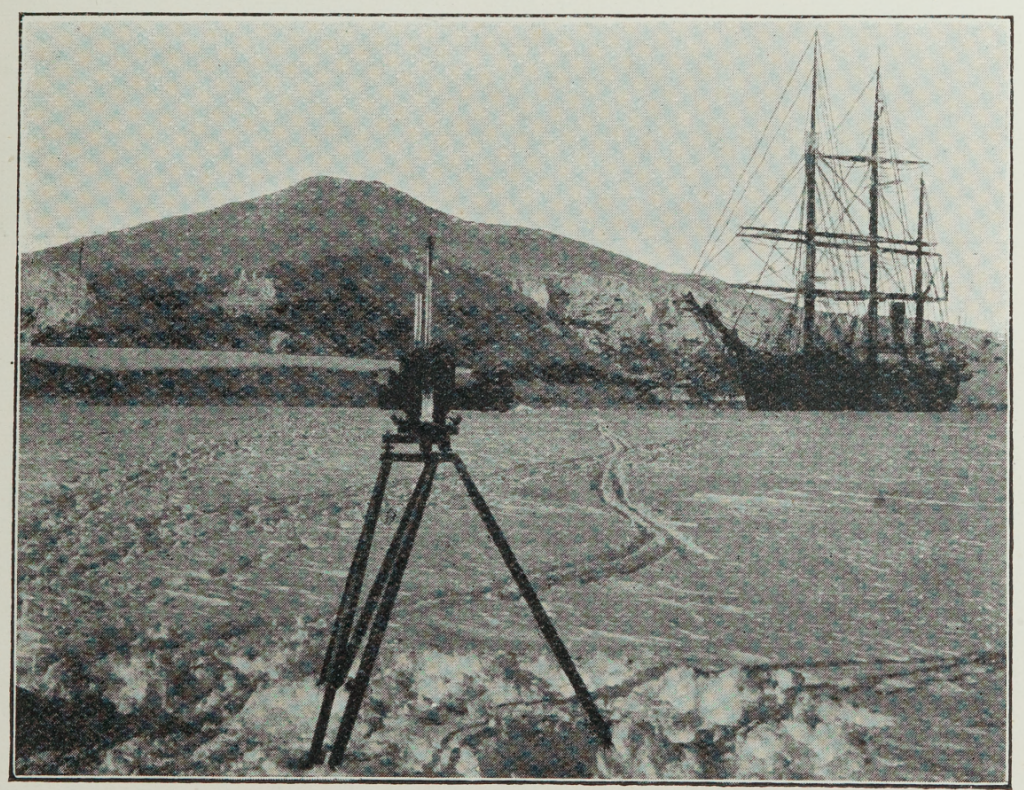

MAGNETIC WORK IN LADY NEWNES BAY.

where we dragged it along as best we could until a small space of open water again allowed us to use the oars; but several times the boat was nearly 
266 British Antarctic Expedition.

nipped amongst the rushing ice-floes, and even far out in the bay the pack scemed to close up rapidly as the Southern Cross, evidently through warning

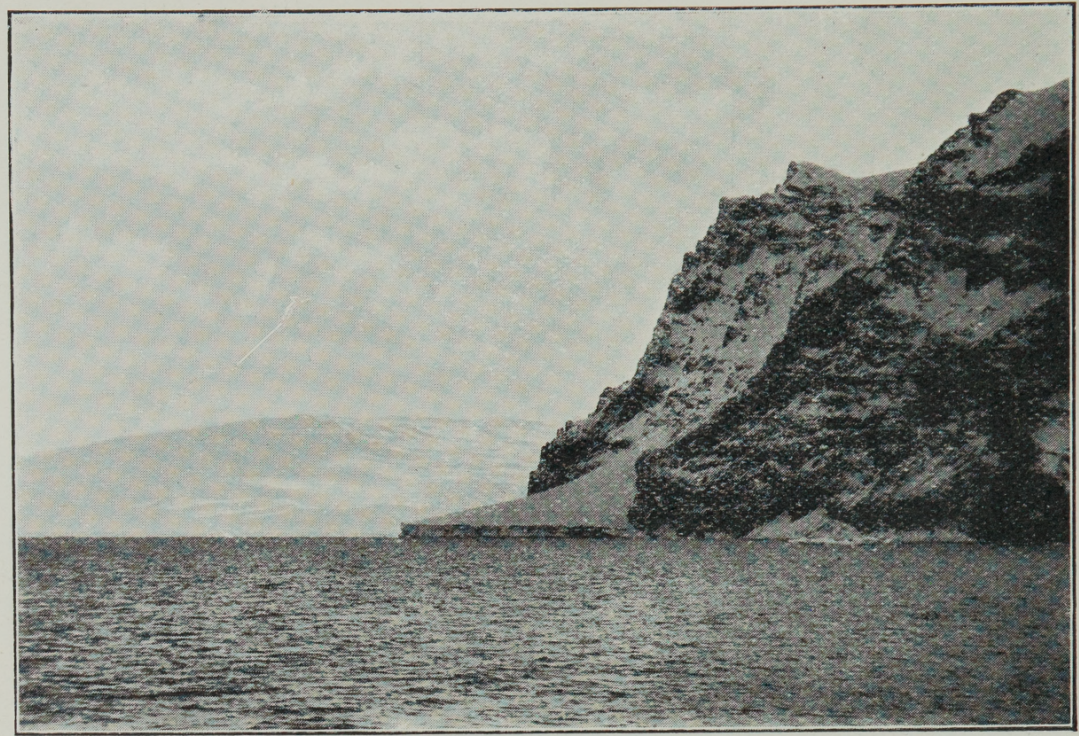

COULMAN ISLAND.

from the crow's nest, moved slowly out of the bay towards the sea. After many struggles and cold baths, we succeeded in reaching the vessel, and no time was lost in forcing south-eastward through the treacherous pack, which in a few hours had accumulated.

Gradually we drew near Cape Washington, where I was anxious to secure a photograph of this important Antarctic landmark, not the least because the well-known geographer and Arctic author, Mr. Shillinglaw, F.R.S., just before my departure from Hobart for the South had besought me to bring back a photo of this cape, which had been named by 
Sir James Clark Ross after his (Mr. Shillinglaw's) well-known step-father, Admiral Washington.

The coast line towards the S.W. was gradually growing lower.

After passing Cape Washington and proceeding southwards, we discovered, towards the west, and close to comparatively low coast land, two islands, situated in about $74^{\circ} 50^{\prime}$ and $74^{\circ} 55^{\prime}$ lat. S., and $163^{\circ} 30^{\prime}$ long. E., the northern one of which I had the honour of naming after His Majesty King Oscar of Norway and Sweden, and the southern after Sir Clements Markham, President of the Royal Geographical Society, London.

Here and there dark conspicuous rocks protruded from the enormous glaciers. At midnight on the 7 th Lieutenant Colbeck and Mr. Bernacchi were again able to take dip observations. On the gth February we passed through large tracts of ice. Mount

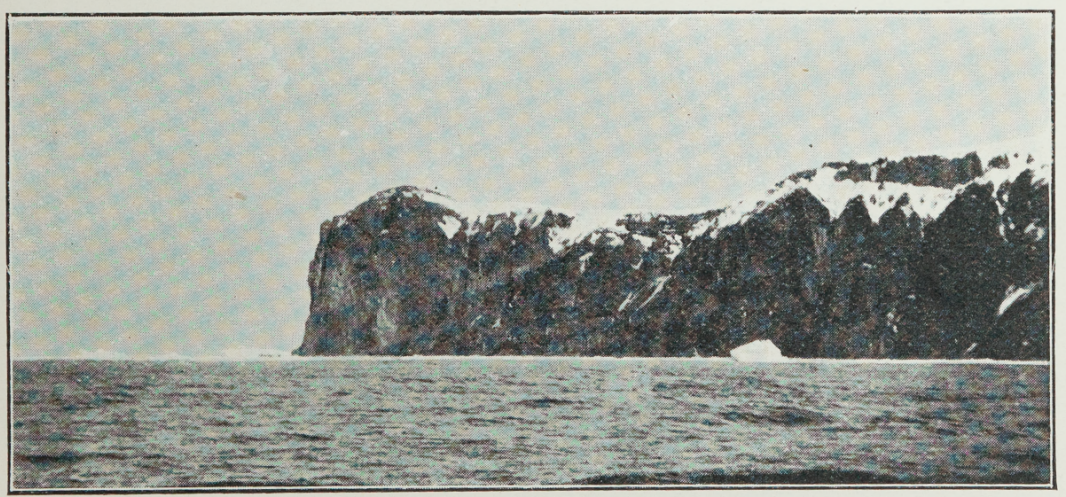

CAPE WASHINGTON.

Melbourne could still be distinguished through the misty air towards the north-west, while ahead Franklin Island was rapidly growing more distinct 
as we approached it. At 5 P.M. I effected a landing on the western side of Franklin Island. The landingplace was a pebbly beach very much like the peninsula at Cape Adare. On reaching shore we gave three cheers for Sir James Clark Ross. Those who followed me were Captain Jensen, Lieutenant Colbeck, Mr. Bernacchi, Mr. Evans, and two sailors. Here also Lieutenant Colbeck and Mr. Bernacchi took valuable magnetic observations. Vegetation was found on the rocks, and very interesting specimens of the rocks were collected, presenting new features to the geologist. There were very many penguins on the peninsula, many more than were left at Cape Adare when we said farewell to Camp Ridley. I named the south-eastern point of this island Cape Bernacchi, and some dangerous rocks which stretched some three or four miles out from this cape, Norway Rocks. The most interesting discovery was made, however, in the marine fauna department. Mr. Fougner secured a rich collection of the shallowwater fauna of that locality. Several photos were taken, and although only some few hours were spent on shore, rich results rewarded our efforts. On the Ioth at noon the Southern Cross was in lat. $77^{\circ} \mathrm{I} 7^{\prime}$ and long. $168^{\circ} \mathrm{E}$. We had, immediately towards the south, Mounts Erebus and Terror. The weather was but half clear, and some misty clouds were hanging round the tops of those mountains. The coast-line is ice-bound by a barrier about $7 \mathrm{ft}$. thick, and only here and there broken by a projecting rocky promontory. Cape Crozier was comparatively free from ice and snow. The Union Jack was under the gaff, and soundings were taken. We secured valuable photos 


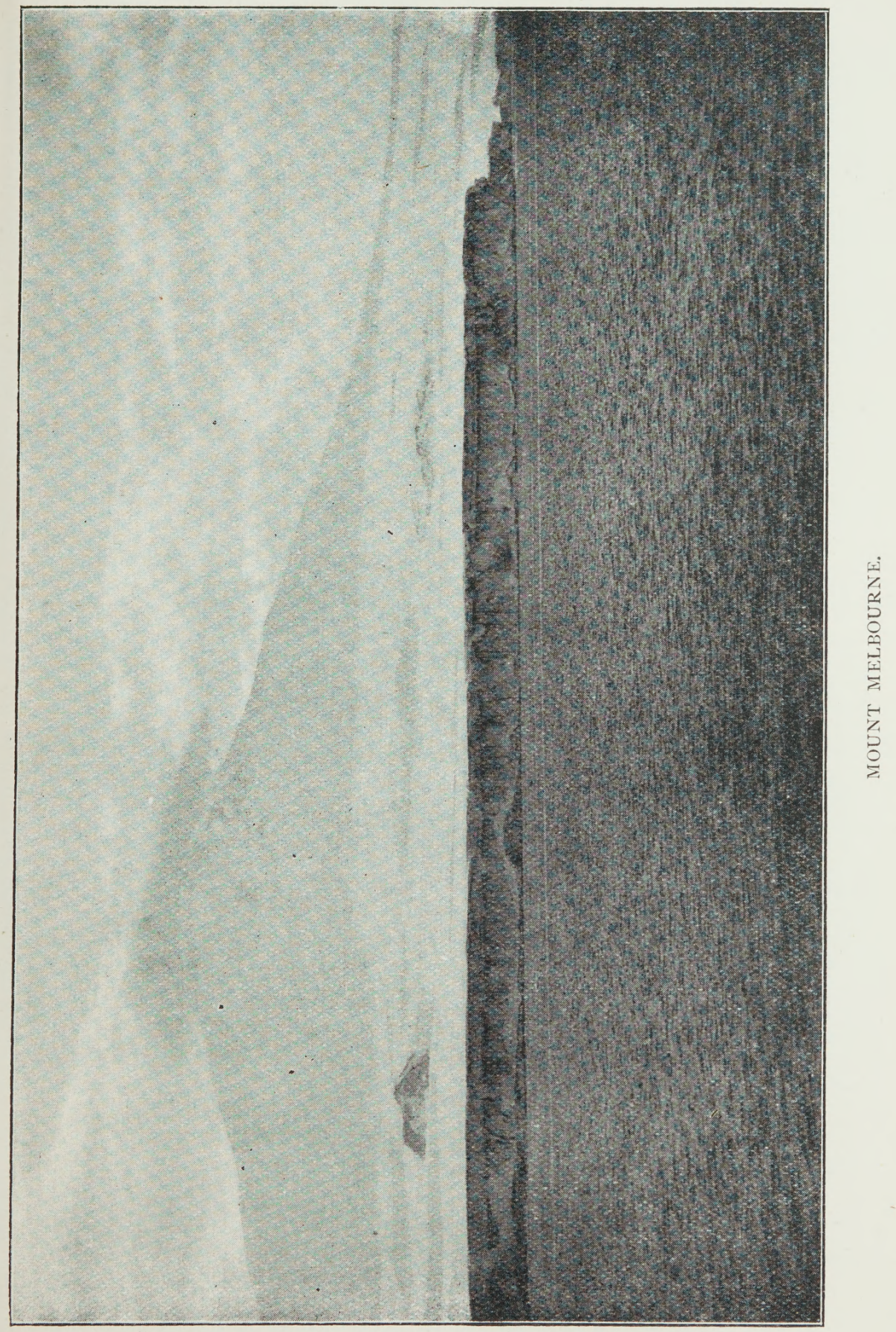



of Mounts Erebus and Terror, the former being in activity.

I effected a landing at the foot of Mount Terror, bringing with me Lieutenant Colbeck, Captain Jensen, and two sailors. It was a very low and narrow beach, formed by gravel rush from an overhanging rock about 500 feet above. The beach was about Io ft. broad, and the highest place about 4 it.

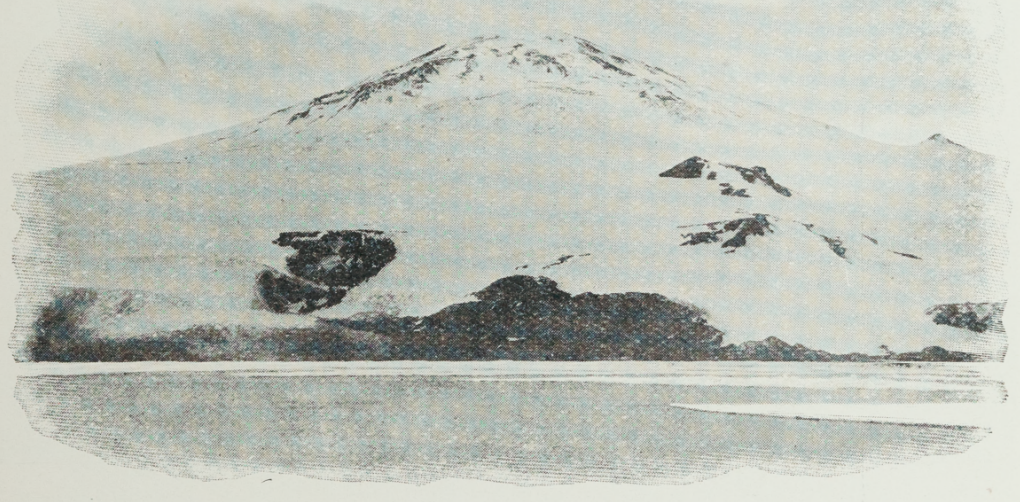

MOUNT MELBOURNE.

above the sea-level. We immediately collected some specimens of the rocks and vegetation, and here also we gave three cheers for our Union Jack and for Sir George Newnes. Shortly after landing Lieutenant Colbeck, at my request, went back with the two sailors in the boat to fetch a camera; meanwhile Captain Jensen and I were occupied collecting. Suddenly a roar started overhead - tremendous, overwhelming, terrible. In a second the thought passed through my mind that the overhanging rock 


\section{British Antarctic Expedition.}

was coming down upon us. In the next I realised the dangerous fact, and communicated it to Captain Jensen, who simultaneously recognised that the glacier immediately to the west of our little beach was giving birth to an iceberg. Quick as our thoughts the event followed. With a deafening roar a huge body of ice plunged into the sea, and a white cloud of water and snow hid everything before our eyes; the next seconds were trying for us two.

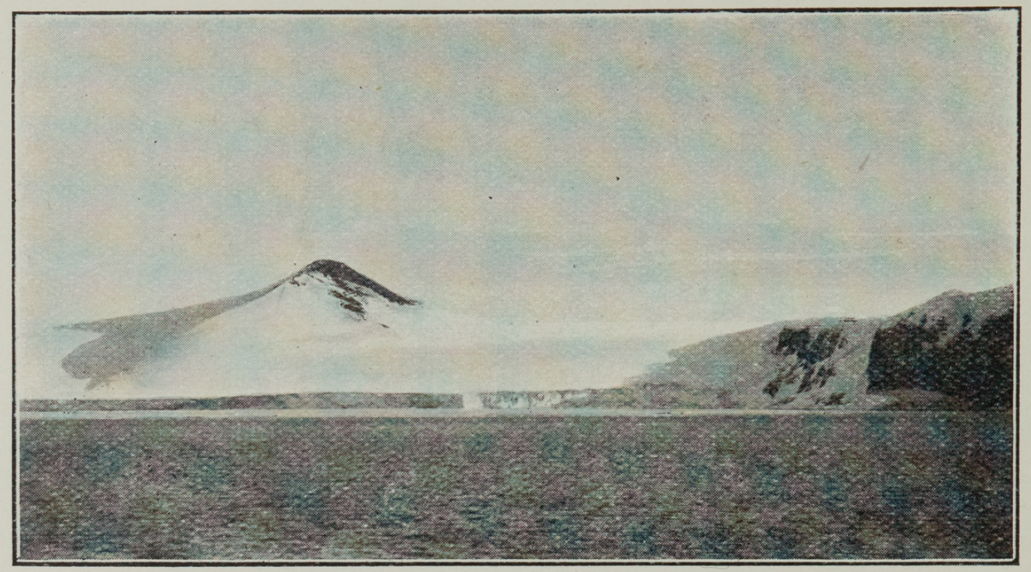

LAND NEAR MOUNT MELBOURNE.

For the first time in my life I felt that I was brought to bay by circumstances. Here were absolutely no resources, and we both foresaw what immediately afterwards followed. A tidal wave, if I may so term it, because of its similarity to such - a raging, rushing wave-rose like a wall from the plunge of this million of tons of ice mass. It seemed rapidly to grow as it hurried towards our ledge. We saw and heard all this magnificent but awful phenomenon, while we instinctively rushed to the highest part of our beach 


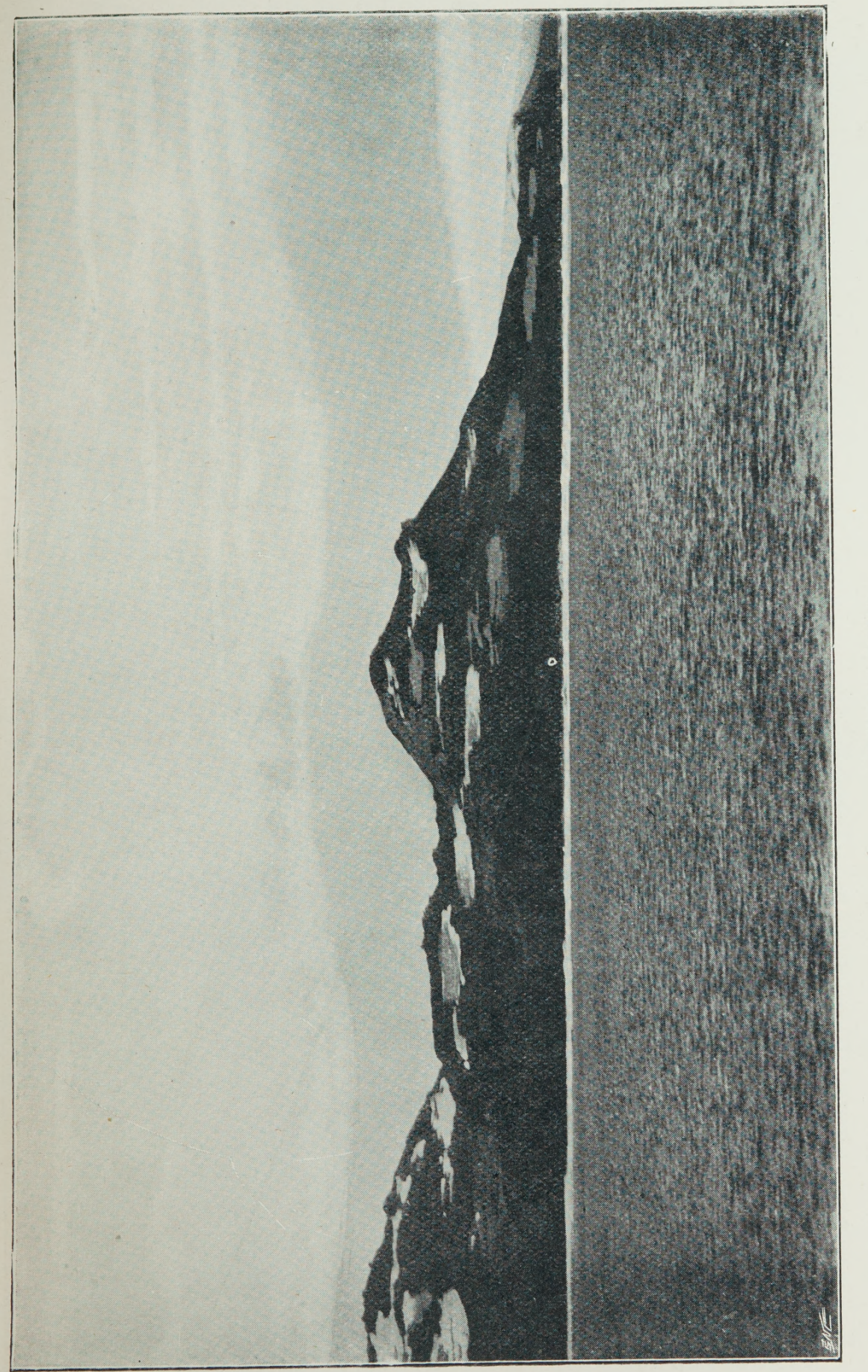

字 

and stood close to the perpendicular wall of the mountain. The time seemed long before the wave reached us, and when it came it must have been from $\mathrm{I} 5$ to $20 \mathrm{ft}$. in height. I called to Jensen to struggle for life as he stood beside me. The wave struck me first, lumps of ice dashed against my back, and I stuck to the rock until I felt that the blood rushed from beneath my finger-nails. I had just time to call out to Capt. Jensen to stick to the rock also when the icy water closed over my head. When it passed Jensen was still at my side. The next few waves were several feet smaller, and only washed us up to our armpits, but the drag of the water when it returned from the cliff tried us almost beyond our strength. Had it not been for the help of a projecting ice slope, which seemed to break the force of the wave in its advance, we would undoubtedly have been smashed against the rock; as where the wave, unchecked, hit the rock wall some ten yards beyond us, it tore stones loose, and left a mark of moisture some twenty feet above our heads, while the marks of the spray were to be seen still further up. Far out at sea the boat was returning with Lieut. Colbeck and the two sailors; they saw all that had happened to a greater advantage, and Lieut. Colbeck's description of the whole phenomenon, as observed from the boat, brings clear to my mind how anxious he must have been for our safety. He, of course, realised the full extent of the danger we ran, having himself with the greatest difficulty saved his boat from being swamped. We saw how rapidly their oars were moving as they approached the 


\section{British Antarctic Expedition.}

shore, where they were surprised to find us. From the Southern Cross also, some three or four miles from the coast, they had witnessed the incident with

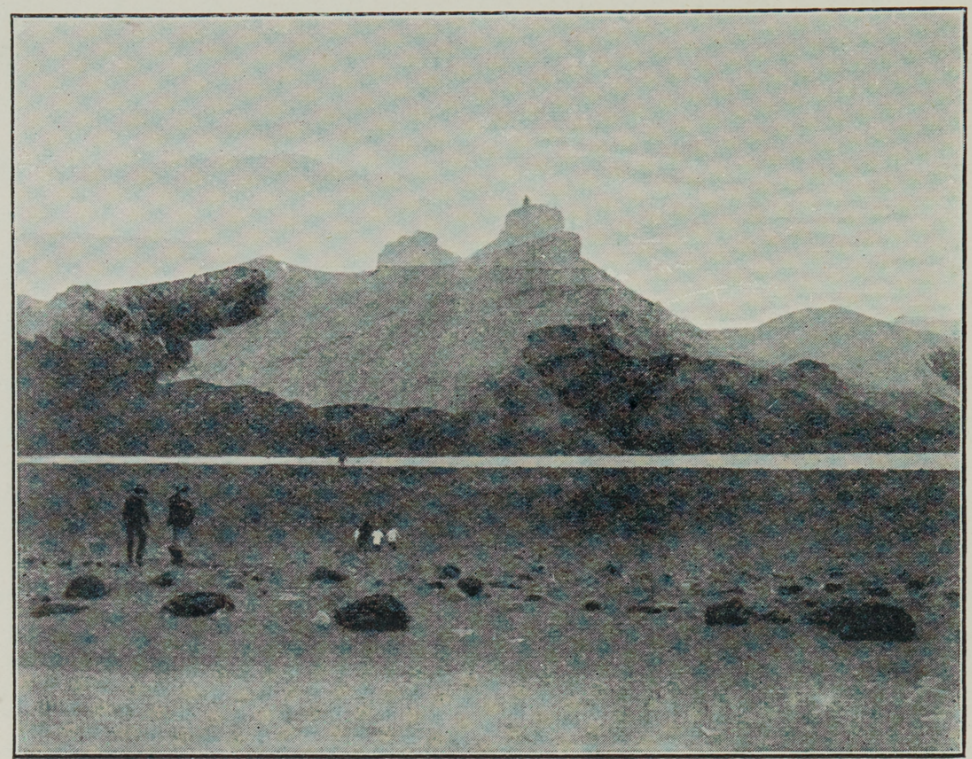

SIR GEORGE NEWNES LAND IN SOUTHERN CROSS FJORD.

great anxiety. As it was, both Capt. Jensen and myself escaped, only a good deal knocked about by the rocks, and of course wet to the skin, and not too warm, from the icy bath; but a splendid collection of rocks and vegetation soon made us forget the incident which might have ended so disastrously for us. I now decided to steam southwards. Towards the south-east Mount Terror ran into the ocean in rather a gentle slope, which, curiously enough, was free from ice and snow. Here a large penguin colony seemed to flourish. The cone of Mount Terror was covered in a mail of ice. No evidence of activity was noticed from this 
volcano. The eastern quarter of the coast-line of Mount Terror is not ice-bound by a barrier, but from the south-east cape a high continuous barrier stretches towards E.S.E., apparently about sixty feet high. A very biting breeze from the south was blowing. From the crater of Mount Erebus a dark smoke cloud from time to time shot up out into the frosty air. It was cold-several degrees below zero-the deck and sides of the vessel were covered in ice. Long icicles hung down from the rigging. The hours on the bridge and in the crow's nest were trying. We were slowly gaining some southing as we proceeded along the barrier. On the 12 th February we were in $78^{\circ} 4^{\prime}$; the barrier was still unbroken, but it seemed

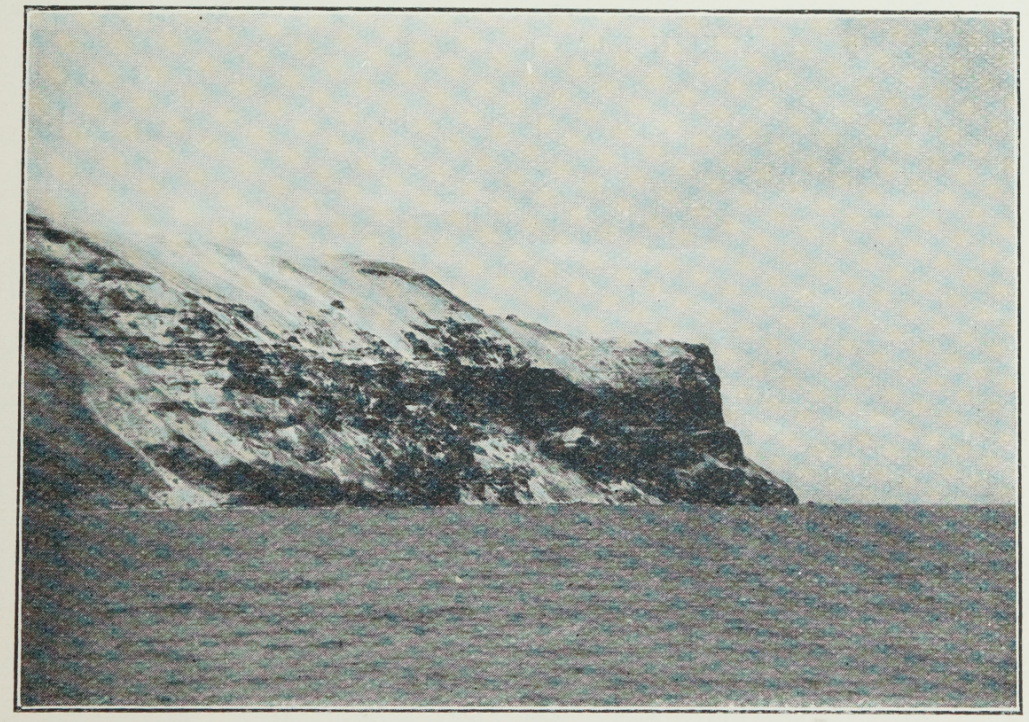

CAPE BERNACCHI ON FRANKLIN ISLAND.

now inclined to take a somewhat southerly bend. In the evening we must have been about $78^{\circ} \mathrm{IO} 0^{\prime}$. H.R.H. the Duke of York's Union Jack flew from the gaff. 
278 British Antarctic Expedition.

On the I 3 th a strong gale started with very heavy seas and thick snow-drift.

The Southern Cross had now several feet of ice on her decks,

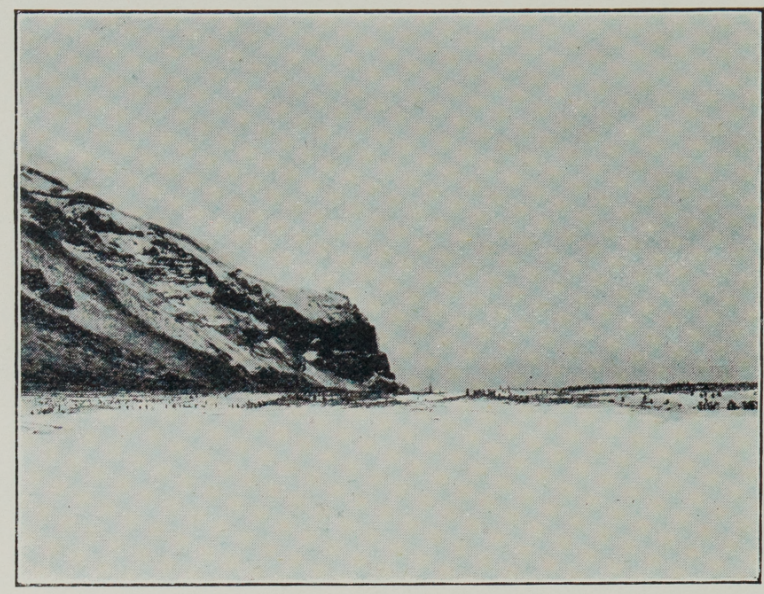

FRANKLIN ISLAND. bul warks, and sides, a $n$ d w e s u f f e red severe 1 y from the cold. In the in tervals between the thick snowsqualls tremendous icebergs hove in sight. On the Ith the gale abated somewhat. On the I6th we were still proceeding southwards with plenty of "pancake" ice around us. On that date I discovered a break in the barrier, with low ice towards the east. The break appeared in two conspicuous heads. They were about one mile apart, opening up into a large oval basin, some four or five miles in diameter. Towards the west the barrier was about the same height as we had found it all the way from Mount Terror eastwards, but towards the south it started to fall, and round -to the east it was quite low, only some two or three feet above the sea-level, rising gently towards south-east until it gained the normal height of the ice-sheet in the vicinity-some seventy feet. We entered, and reached lat. $78^{\circ} 34^{\prime} \mathrm{S}$., and long. 
$195^{\circ} 5 \mathrm{O}^{\prime} \mathrm{E}$. Captain Jensen and I had inspected the appearance of this natural harbour thoroughly before we decided to enter from the crow's nest, fully recognising the possible risk of being shut in in case the heads, through changes in the ice sheet, might close together. During the time we spent in this interesting harbour constant watch was kept in regard to movements and sounds in the ice. At a low place we moored the Southern Cross to the ice sheets by ropes and an ice-anchor. Here I effected a landing with sledges, dogs, instruments and provisions, and while I left the sledge in charge of Captain Jensen

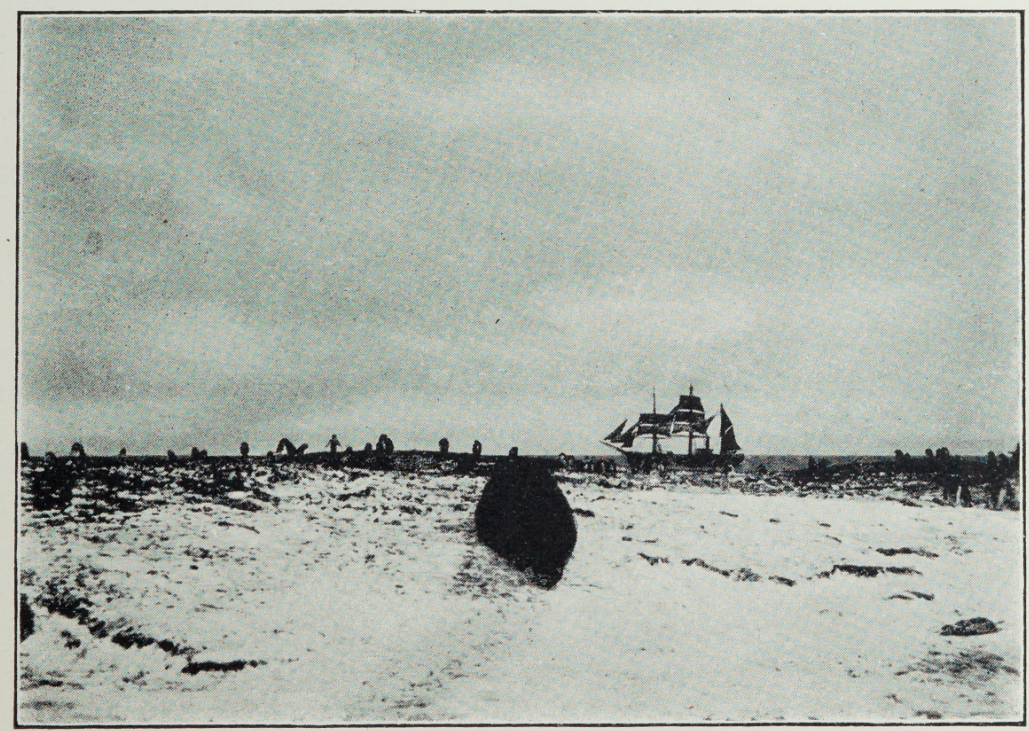

THE PENINSULA AT FRANKLIN ISLAND.

with the rest of the Expedition, I myself, accompanied by Lieut. Colbeck and Savio, proceeded southwards, reaching $78^{\circ} 5 \mathrm{O}^{\prime}$, the farthest south ever reached by man. 
The aspects of the Antarctic icebergs are distinctly two kinds, although they, in my opinion, have their similar origin. They are either discharged

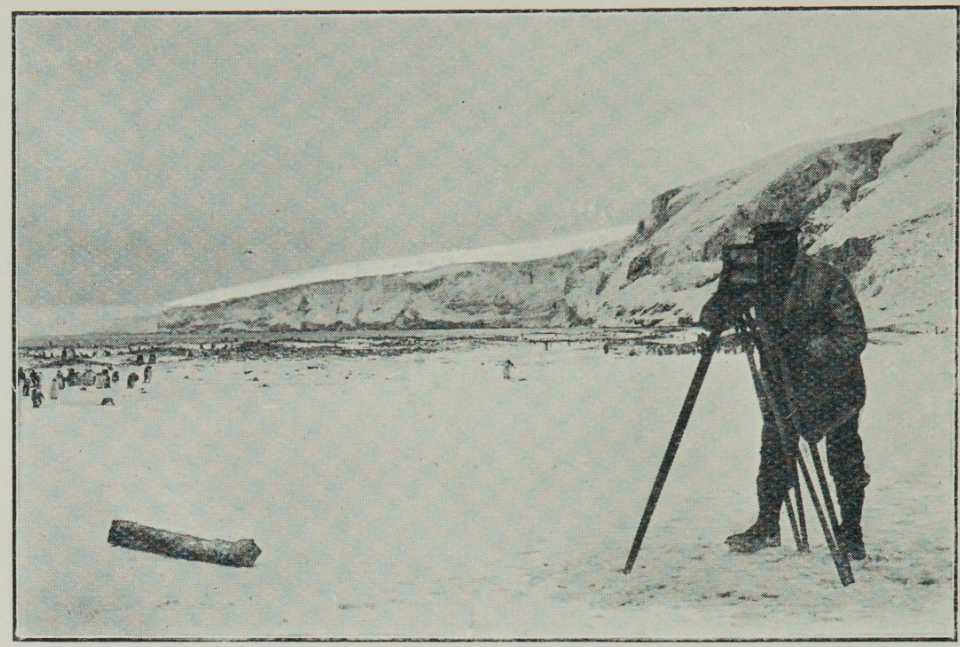

MR. COLBECK TAKING SLIP OBSERVATIONS ON FRANKLIN ISLAND.

from what ordinarily is understood as glacier, or broken from the big barrier in the extreme south. However, to my mind, the big barrier to the south is nothing more than the northern extremity of a great ice sheet sloping northwards from land near the South Pole. Although it must needs, on account of its appearance, be recognised as an ice sheet, it is nothing more or less than an immense glacier. The bergs discharged from a glacier, will, under great elevation and squeezed between immense peaks, naturally have a more rugged appearance than the bergs discharged from the gentle sloping ice sheet in the south. The former are cut through by crevasses, rubbed against rocks, and often overturned when borne into the sea. The latter gently break off 
through the great but steady pressure of the ice sheet, and the iceberg will, even after the "calving" has taken place, maintain the character of the barrier or ice sheet from which it sprang. The uppermost parts of the bergs broken from the barrier will generally carry a from 30 to $40 \mathrm{ft}$. thick horizontal layer of ice formed by snow-fall, which, through pressure of the wind, has quickly taken the nature of ice, but remains easily distinguishable, because of its whiteness of colour and soft structure, from that of the underpart, the crystal, clear green and blue, stratified, broken glacier ice.

Ruled by the prevail-

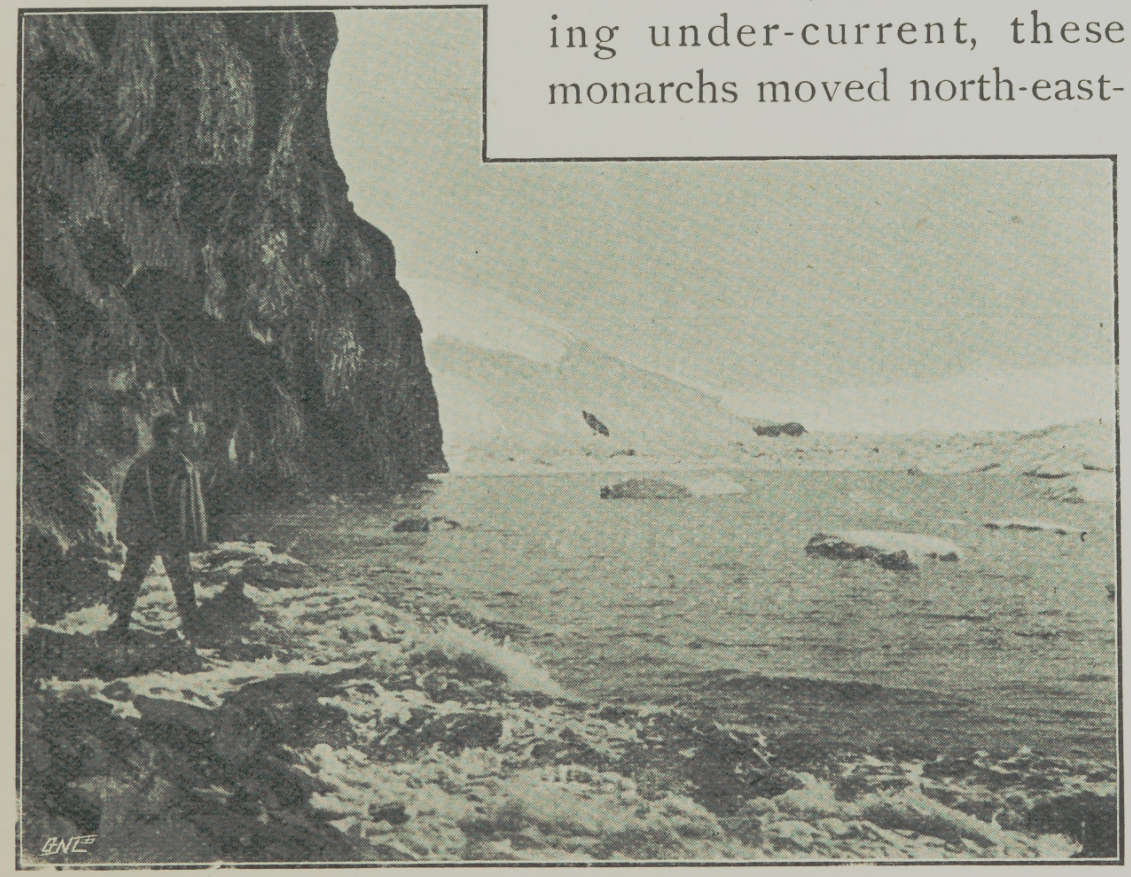

AT THE FOOT OF MOUNT TERROR, WHERE BORCHGREVINK AND JENSEN NEARLY LOST THEIR LIVES.

wards, but although only, in my opinion, one in their origin, these bergs with their different appearances are really brethren. The pack, however, showed 
distinctly two kinds of two different origins. It consisted of the ice which is formed by the freezing sea, and the smaller ice broken from glaciers, or from the extremity of the ice-sheet in the south. The difference between the two is not always so marked that it can be distinguished without careful observation, as the pressure and screw in the sea ice near the coast of the Antarctic Continent is so great that the blocks reared on end would appear, to a casual observer, like glacier ice, but a nearer investigation would quickly result in the discovery of the two distinctly different structures of ice. It is the land, or glacier ice, in the pack which is the most dangerous for ice navigation. Harder, and generally pointed and cornered, it is more difficult to ascertain its nature as the vessel forces its way. The flat sea ice, at least far from shore, is much alike, and although often of great thickness, it seldom protrudes in such treacherous rams under water as do occasionally blocks fallen from glaciers. The movement of the Antarctic ice-pack is, to my mind, north-easterly; this movement favoured both by wind and current. The open bay to the east of Victoria Land is undoubtedly due both to the heavy south-easterly gales and also to currents to the east of Victoria Land, and to the comparatively warm water in the locality. Undoubtedly active volcanoes, above and under the sea, take a not unprominent part in altering ice conditions. In travelling southwards towards my furthest south on the big barrier, or on the southern ice-sheet I noticed that here and there the ice-sheet rose in small cones, which at places were broken in rough walls of about thirty feet. At other places 


\section{Farthest South.}

the ice-sheet suddenly took terrace shape, but it was always, so to speak, local; and the nature of the ice-sheet on the top was one immense unbroken flat, with a scarcely noticeable rising towards the south. With a sufficient number of reindeer, sledges and dogs, and a very small party of scientific men, I believe that a great southern latitude may be reached on this ice-sheet in the proper longitude.

Undoubtedly a vessel bound for Victoria Land and having no geographical work similar to that I had

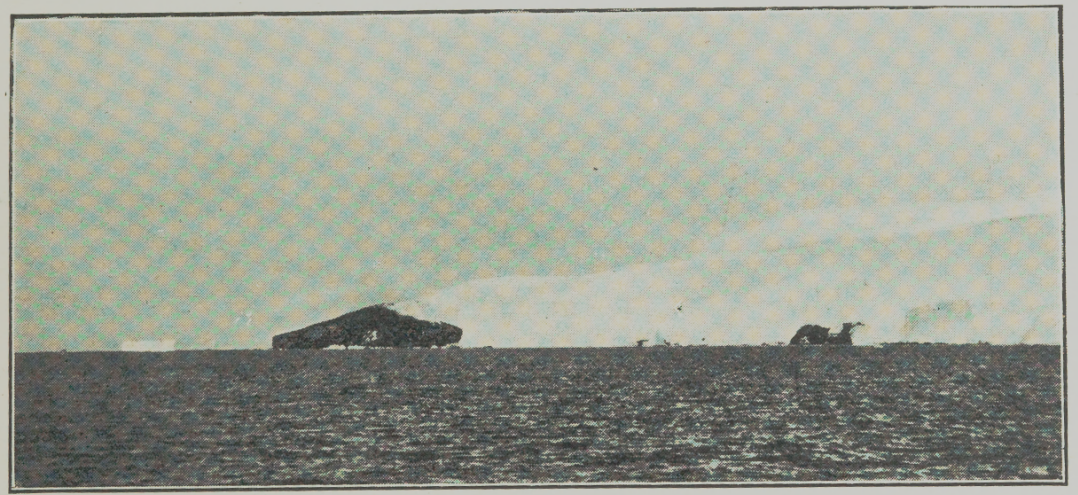

CAPE CROZIER.

to do about the vicinity of Balleny or westward of it, ought, in my opinion, not to proceed southwards westward of $170^{\circ}$ long. E. November and December I think the time when an expedition vessel ought to approach the Antarctic ice-pack. Near Victoria Land a general break-up of the ice does not take place before the end of January; and I do not think that, under normal conditions as a rule, a vessel would succeed in reaching Victoria Land much before the beginning of February.

I regard the success of Sir James Clark Ross, 


\section{British Antarctic Expedition.}

without the help of steam, unquestionably as a sign of exceptionally favourable ice conditions in the year when the Erebus and Terror penetrated into Antarctic ice-pack. In ice-pack, similar to that the Southern Cross encountered, sailing vessels would be

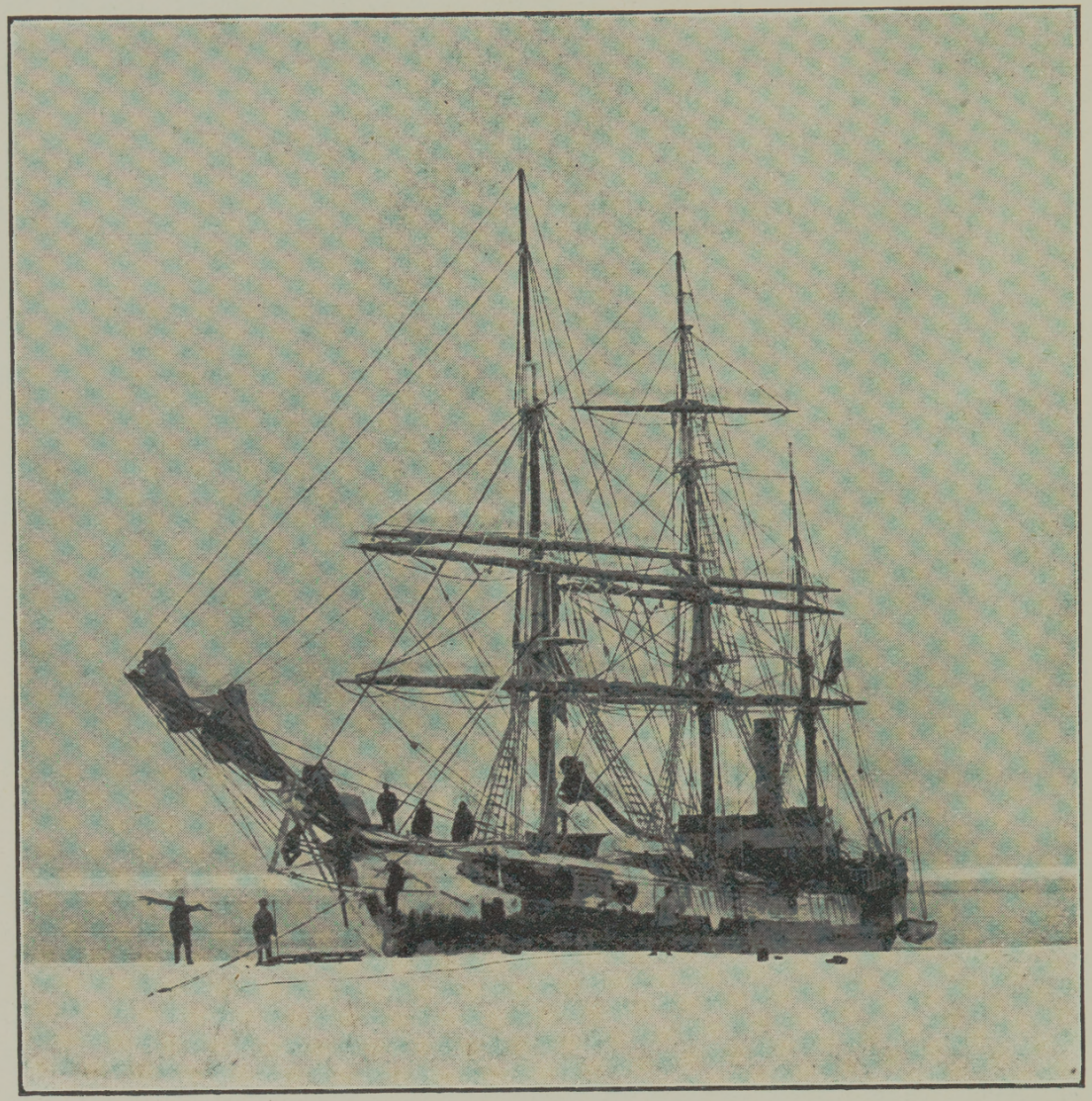

FAST AGAIN.

left hopelessly to its mercy. The progress of a vessel in the Antarctic depends, according to my experience, very much upon the locality in which the pack is attacked and also upon the meteorological conditions. Having no land to the northward, a day or two might alter the ice conditions entirely. 
The vessel may lay fast for weeks, while suddenly a favourable circumstance might allow the pack to open in slack ice, and the ship might reach a very high latitude. These are favourable conditions, but the absence of land to the north allows the big swell of the south-westerly trades to reach the Antarctic pack, which thus affords great danger to a vessel, whether it be near the edge of the pack where the grinding ice-blocks would chew her timber, or whether she be so far in the pack that the swell does not reach her directly; but owing to the pressure caused by the gales, and the swell from the north, met by heavy pressure from similar causes from the south, very

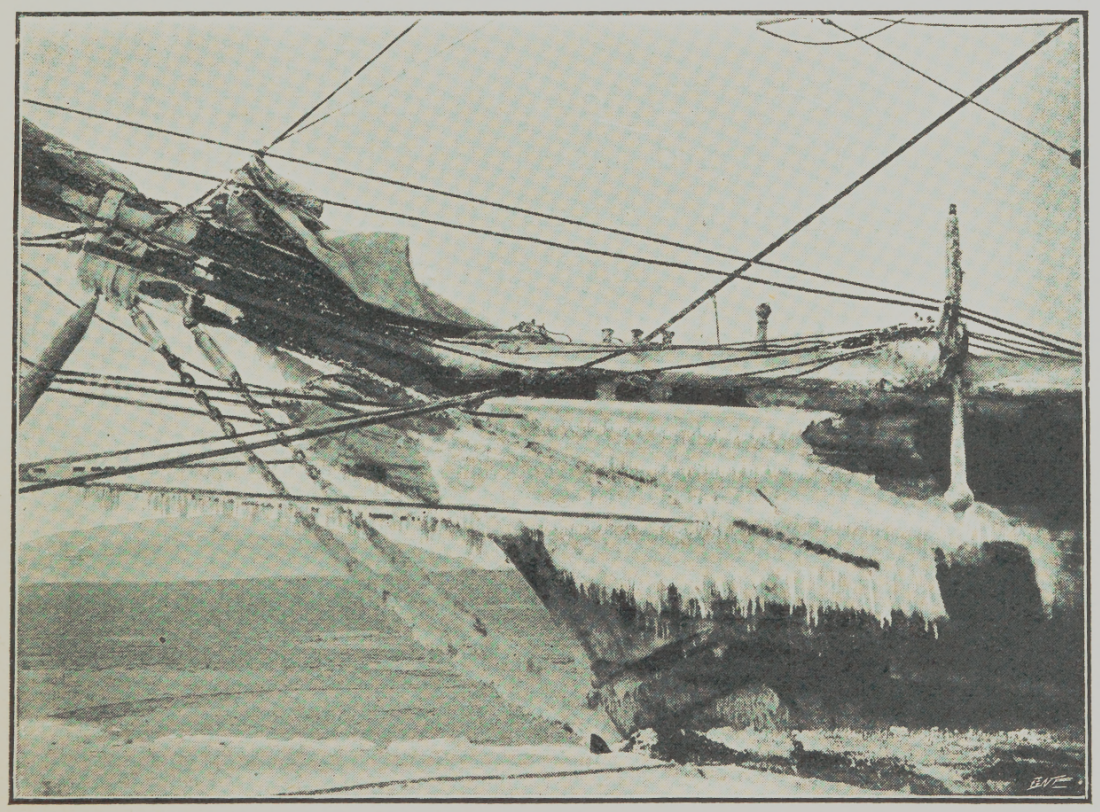

ICE WEIGHED HER DOWN.

heavy screw takes place and threatens to crush the staunchest of vessels. In winter time tremendous screwings take place in the Antarctic ice-pack, near 
land as well as out at sea, and the screwings which we encountered in our sledge journeys were so tremendous that at times they made it impossible to proceed. It happens also that even after the ice is 2 or 3 feet thick a gale of 100 miles an hour starts, and the ice, which might have been absolutely safe for travelling one hour, has disappeared and been ground up into furious rolling waves the next hour. Under such conditions, and with such risks, sledge journeys within the Antarctic Circle must be carried on. In Robertson Bay the ice did not get more than $5 \mathrm{ft}$. thick, and at places it was only $2 \mathrm{ft}$. thick all the winter through. I believe this to be greatly due to the strong currents which prevailed in and near the Bay.

On the sledge journey towards our farthest south we repeatedly heard noises in the ice-sheet; and seeing the irregular and abrupt rise and fall in it at places, I got the impression that great pressure prevails in that locality. As we entered this harbour in the barrier, an Emperor Penguin walked philosophically up and down upon the ice towards the E., and two of the ordinary penguins (Eudyptes Adeliae) discussed our boldness with the utmost interest. Towards the south some seals were basking on the ice. I sent a boat to the end of the bay after them, and found that they were Weddellii. A party of ski-runners which I despatched to the west came upon a large number of seals in a lake, or large, deep basin, formed in the plateau of the barrier. Although the plateau at that place fell with a gentle slope, it evidently reached the level of the sea, as the seals shot up through blow-holes in the ice at the water's edge. 


\section{CHAPTER X. \\ Towards Civilisation.}

ON February I9th, after having taken careful observation, the voyage towards civilisation commenced. My decision to return then I took because of the uncertainty of the weather in the late season, and the rapid fall of the temperature. Indeed, it was high time that we should sail for the north if we wanted to leave at all, and as it was, our engines had to force the Sonthern Cross through ice three inches thick as we steamed slowly out towards the head of this harbour.

My first intention was to make for Mount Terror, and if possible to get in the vicinity of Beaufort Island, but prevailing south-westerly and westerly gales prevented us from following this plan, and I decided to steer for Franklin Island, where we hoped to be able to obtain opportunities for a second set of magnetic observations. Ice was covering the deck and rigging, while a biting autumn gale was howling between the ropes. On the 22 nd the gale calmed down somewhat, but on the next day it was again on to us with very heavy sea. On the 24th the weather allowed us to steam up to Franklin Island, and at Io o'clock in the morning 
we hove to at the very place where we were lying last. A boat was lowered with both the magnetic observers, Mr. Evans, and two sailors. I warned them before they went on shore to keep a sharp look-out for the vessel in case I should find it expedient to call them back by signal. The weather was threatening, and the barometer fell rapidly. Shortly after they landed we had to call them back, and scarcely were they on board before a fresh gale was over us. The constant wash on deck made the ice-sheet grow on us.

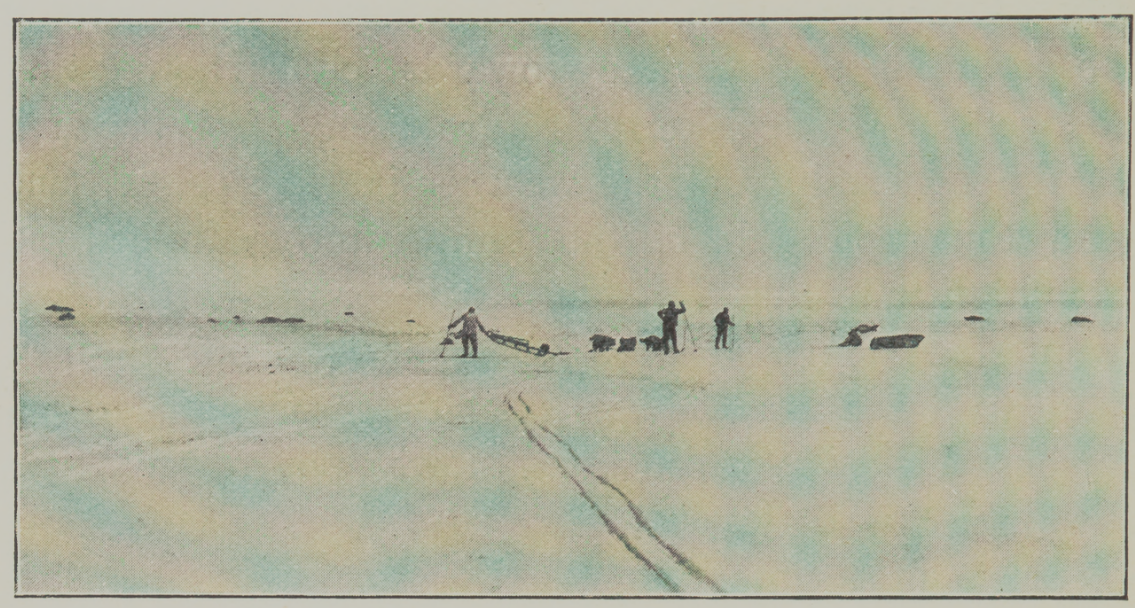

SEALS WERE DOTTED ABOUT ON THE WHITE CARPET.

The Southern Cross dived into the heavy surf, rose again and shook the raging waves aside, while the spray froze on men and spars, and hung down in long icicles from the sprit. A good deal of pack-ice was encountered drifting rapidly into the bay, and at places we found it difficult to proceed. On the 26th February we were in lat. $7 \mathrm{I}^{\circ} 33^{\prime} \mathrm{S}$., and long. $174^{\circ}$ I $3^{\prime}$ E. Some brown-backed petrels were about, also some molyhawks. It was then calm, but a large swell was running from the north, 

indicating that it was not likely that we should encounter much pack-ice to the north, if any at all. I think all of us realised the important moment when we passed the latitude of Cape Adare, bound for civilisation, and the talk in the cabin and in the forecastle generally dwelt upon home and home-coming. The members visited each other in their cabins and discussed the fact of returning, as every one now seemed to realise that another month might see us within the limits of the civilised world. A strong longing for sunny shores came over everyone; a longing to see something else but bare rocks and snow, to see other colours,

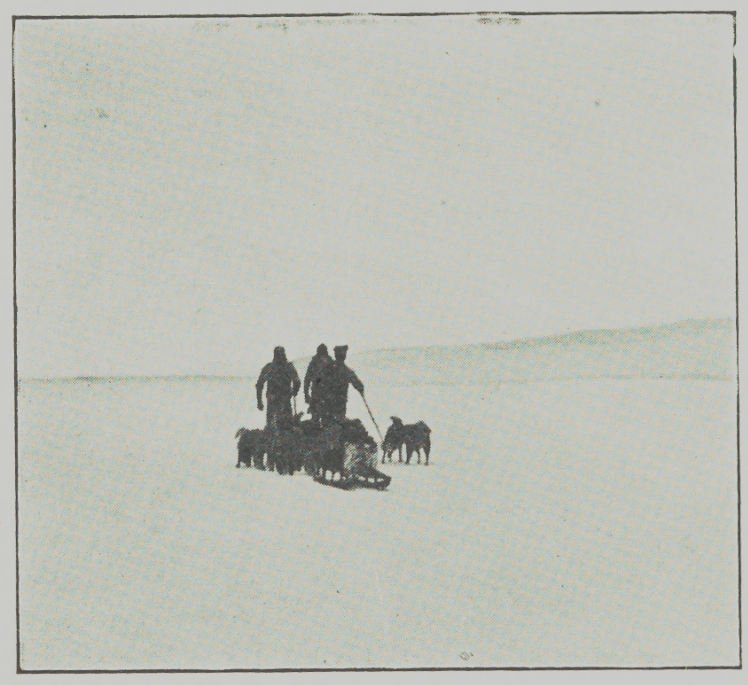

ON THE TOP OF THE GREAT BARRIER ON THE JOURNEY FARTHEST SOUTH. real green grass, and, above all, trees - real trees with stems, branches, and green leaves on which our eyes and minds could rest. Our thoughts turned involuntarily to country life on sunny shores, and the topics of the day were the life in fields and woods of Old England, or of the deep forests of Norway, where dainty birds of all kinds were whistling and singing in liquid tunes. What a change it would be from the hoarse scream of the penguin, or the cruel screech of the skuagull, or the wild howl of the Antarctic gales. 
On February 28th we passed the Antarctic Circle. The temperature rose quickly as we advanced northwards. One by one the layers of our thick clothing were dropped, and washing and shaving became almost an everyday event. On March 4 th I ordered our last live penguin ( $A$. Forsterii) to be thrown overboard, as he looked miserable, would not eat, and his spirits sank with the rise of the temperature.

On March 6th we had a strong gale from W.N.W. There was a heavy, choppy sea. One of the dogs was washed overboard, and the rough sea prevented us from rescuing it. Poor faithful fellow, he was doing his best; sometimes jumping almost clear out of the water when on the top of a breaker, and all the while keeping his intelligent eyes on the stern of the Southern Cross as she trod her way northwards. Soon he was lost in the raging surf.

On the $3^{\text {th }}$ we all assembled in the cabin and drank to the health of Sir George Newnes, whose birthday it was.

On the 2 Ist we dropped anchor in Port Ross on Auckland Island at 9 A.M. The island, which is covered with thick brushwood, is almost impenetrable except along the stony beaches, or on the banks of the creeks. Here and there we found the tracks of wild pigs, but were unable to secure any. We longed for fresh meat and would have welcomed one. However, during the time we were lying at anchor we secured a number of wild ducks and two goats. After having taken in fresh water and cleared the pipes of the boilers, we departed on March 28th.

At midnight on March 3oth, we arrived outside 
Paterson's inlet on Stewart Island. As the entrance to this splendid harbour is rather difficult, I decided to wait until morning, when we steamed slowly into Paterson Bay. Although a grey, rainy morning, it seemed beautiful to us all. Real, tall trees were before us, and as we came nearer a neatly-built house came in sight. One of my staff, through his field glasses, then

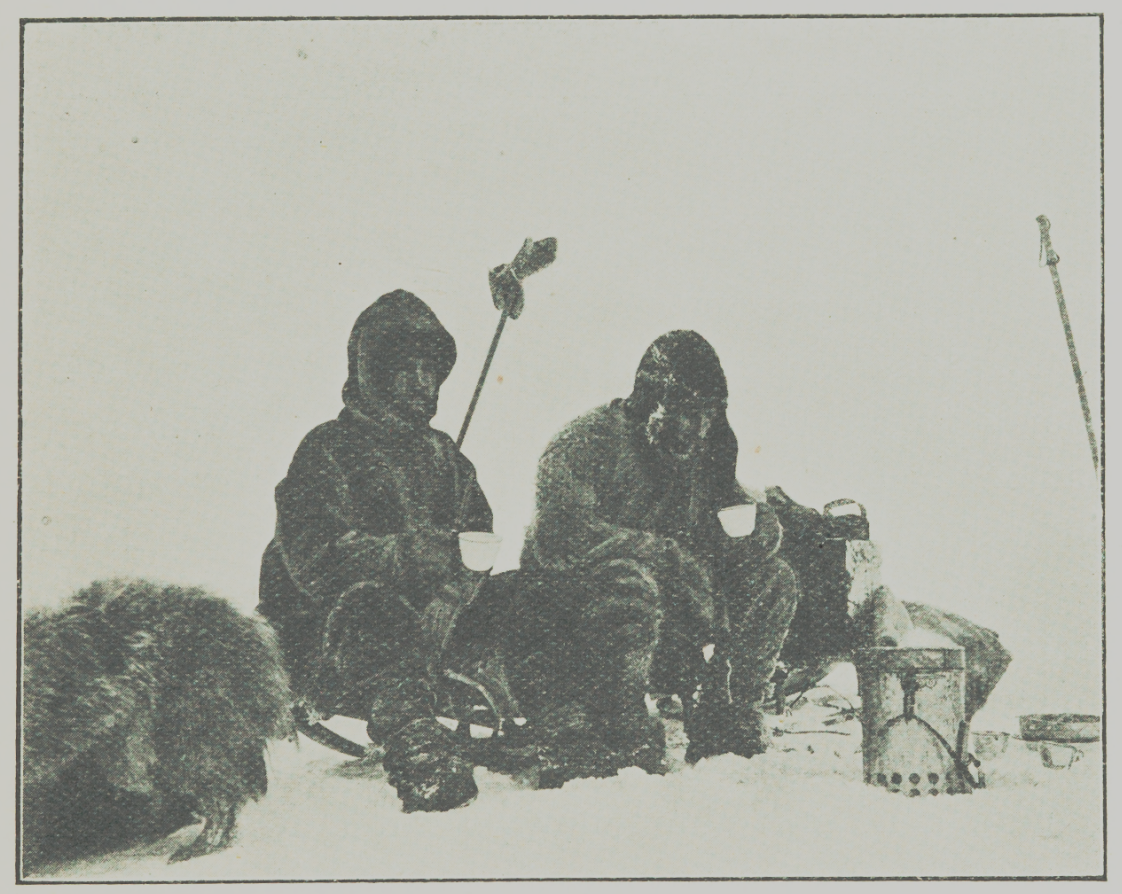

A HURRIED MEAL.

made a startling biological discovery - a woman! and soon my entire staff had seized their magnifying glasses. I at once went on shore, and after some hours' tramping about in the muddy jungle, I was able to secure a few fresh sheep and fresh vegetables. How starting was it to see a strange face again, and to hear a fresh voice. The first man I met shook me 
294 British Antarctic Expedition.

heartily by the hand when he heard that I came from the Southern Cross.

"Is Mr. Borchgrevink on board?"

"No,"-his face got long and worried-"talking to you!"

The man was delighted, and did his utmost to help me in my search for fresh food.

Later on we steamed round to Half-moon Bay, where a little settlement of houses is situated called Oban. During our stay there I made arrangements for landing the sledge-dogs on Native Island, a small island adjacent to Stewart Island, provided that I should obtain the necessary permission from the New Zealand Government.

On Sunday morning, April Ist, I went on board a small fore-and-aft schooner called the Ruruhau (a Maori word the meaning of which is "getting to windward"), under salute and cheers from the Southern Cross. We drifted over by the tide, and arrived at the Bluff at I I.3O P.M. The small town being wrapped in darkness, I proceeded at once to the telegraph office, where I succeeded in rousing the operator, and sent the following cable to Sir George Newnes:-

"Object of Expedition carried out. South Magnetic Pole located. Farthest south with sledge record $78^{\circ} 50^{\prime}$. Zoologist Hanson dead. All well on board.-BORCHGREVINK."

The clicking of his instrument went on while the operator made the necessary enquiries whether my cables could get through to Europe at once. 
Suddenly the clerk turned to inform me that some very distant official desired to congratulate me on my safe return, and wished very much to know whether I had found any people " down there."

The next morning, while enjoying my first civilised bath, somebody knocked furiously at the bath-room door and handed me a newspaper, in which it was announced that my wife had arrived that very night at Adelaide from Europe. The cable announcing my arrival at the Bluff had crossed the one announcing her arrival in Adelaide!

On April 3 rd the Hon. Mr. Ward, M.L.A., of New Zealand, who met me with the greatest courtesy and did

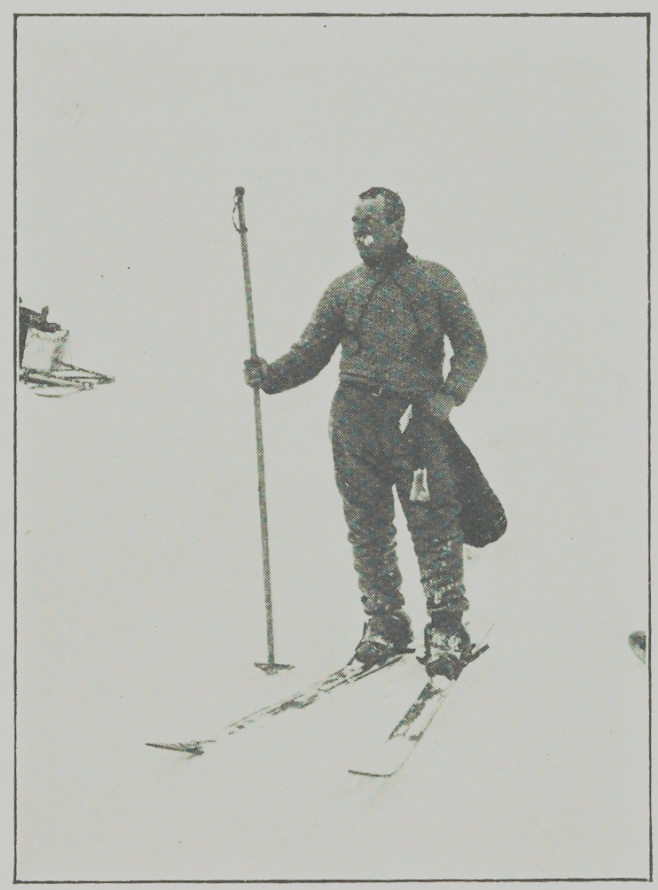

FARTHESI SOULH EVER REACHED BY MAN.

all in his power to assist me, informed me that he had communicated with His Excellency Mr. Seddon, the Premier of New Zealand, and that he had obtained for me permission from the Government to land the sledge dogs on Native Island.

On April 4th, after instructing Captain Jensen to proceed to Hobart at once after landing the dogs, I left in the Mokoia for Hobart. 
296 British Antarctic Expedition.

On the 6th I arrived in Hobart, where I met my wife, and the enthusiastic citizens welcomed me by cheers, and almost carried me to the carriage which awaited me. Ten days later the Southern Cross arrived safely, and a solemn thanksgiving service was held in the Hobart Cathedral, where all the members

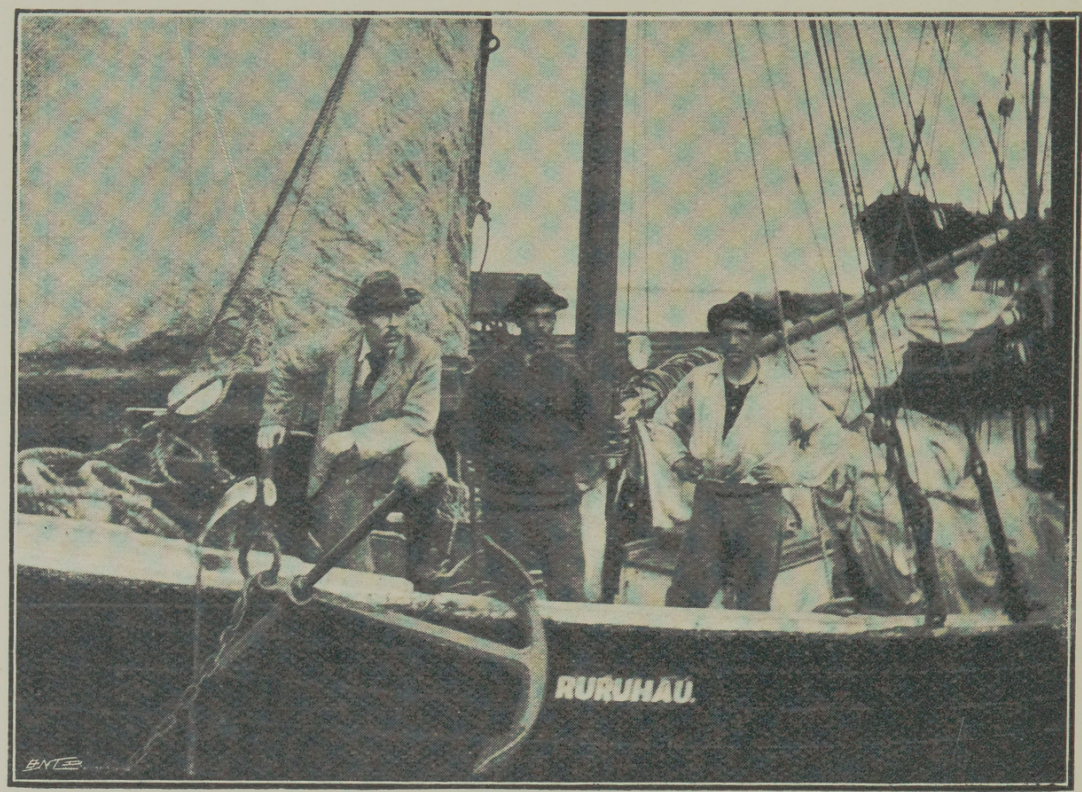

ON BOARD THE "RURUHAU."

of my staff and the crew were present. The service was conducted by the Bishop of Tasmania, the Dean and other clergy assisting him.

On April 7 th I called upon His Excellency Lord Gormanston and Lady Gormanston, who both received me with that characteristic kindness which they had shown us before our departure. 


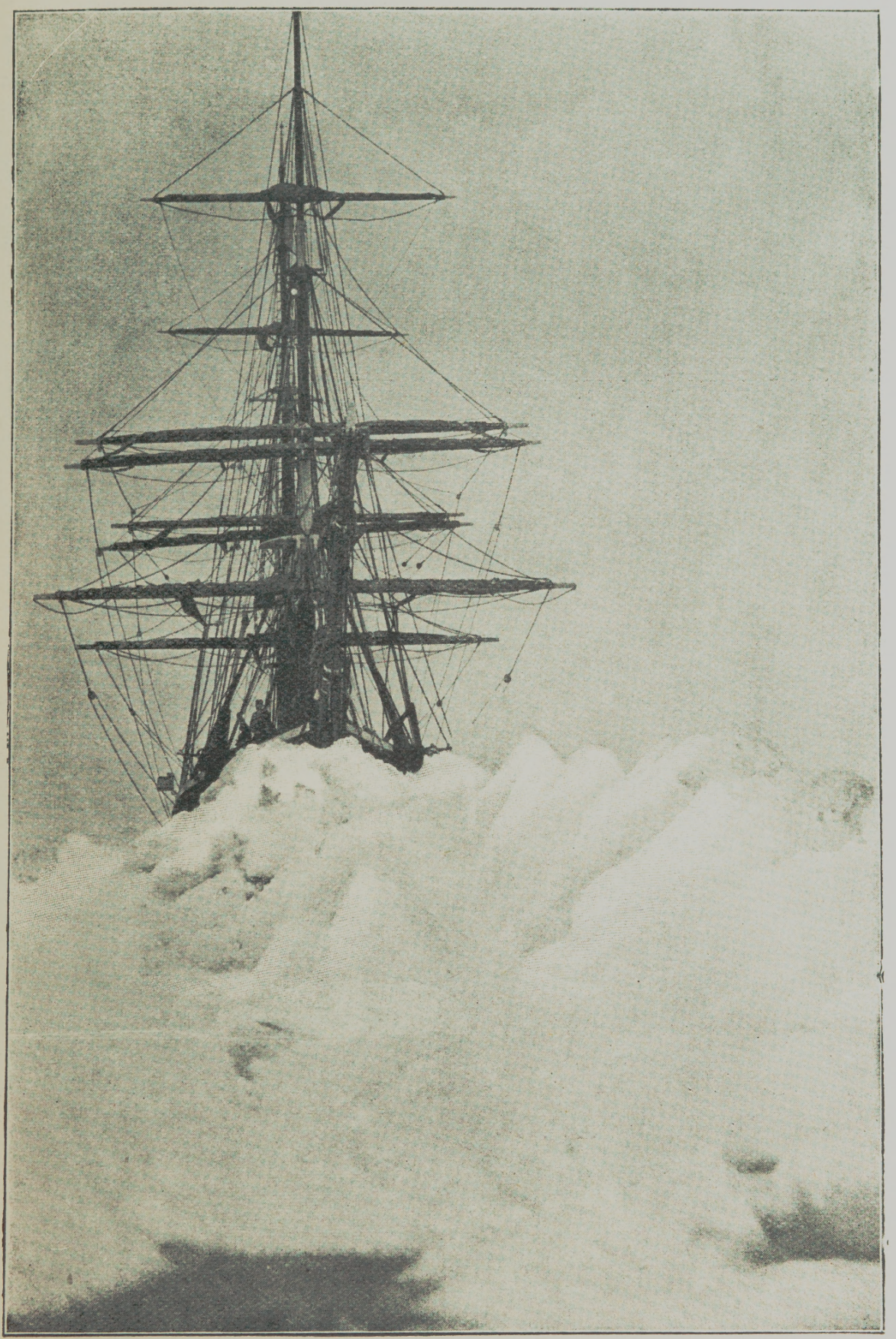

HEAVY SCREW IN THE PACK-ICE NEAR BALLENY ISLAND, 23RD OF JANUARY, I899. 



\section{APPENDIX I.}

By the Commander, C. E. Borchgrevink.

THE APPEARANCE OF VICTORIA LAND.

The impression of Victoria Land upon my mind is to-day almost the same as after my return from the Antarctic Regions to civilisation in I895. Large, elevated mountainous country, with peaks rising to the height of between $10,000 \mathrm{ft}$. and $\mathrm{I} 2,000 \mathrm{ft}$. above the sealevel, precipitating into the Antarctic Ocean and crossed by innumerable broad glaciers, cut through with deep yawning crevasses. The multitude of these crevasses naturally caused by the steep gradient under which they descend to the sea, affords, perhaps, the most unsurmountable barrier for the progress of the traveller. Like immense rivers these monstrous glaciers drain the fathomless icefields of South Victoria Land. At a great distance they seem to the traveller on the frozen sea as smooth highways between mighty domes, but when the traveller, hungry and exhausted, reaches the place where they descend from the heights, they appear in all their stern defiance. Step by step you can cut your way onwards and upwards in the smooth green ice-cover; but for a traveller on foot in those regions these elevations, with their obstacles, will devour his time and thus his food, as no life fit to support is to be found beyond the coast-line. Remarkable is it to see how free of ice and snow Victoria Land is at places near the coast, and the question why and wherefore forces itself upon the traveller. Cape Adare, Duke of York Island, Geikie Land, Doubtful Island, Possession Island, parts of Coulman Island, Cape Constance, Newnes 
Land, Cape Crozier, and innumerable places between these conspicuous Antarctic landmarks, are all free from ice and snow. Most of them in summer time carry vegetation. At Newnes Land a minor eruption at the side of Mount Melbourne may account, to some extent, for the hospitable appearance of this locality; but

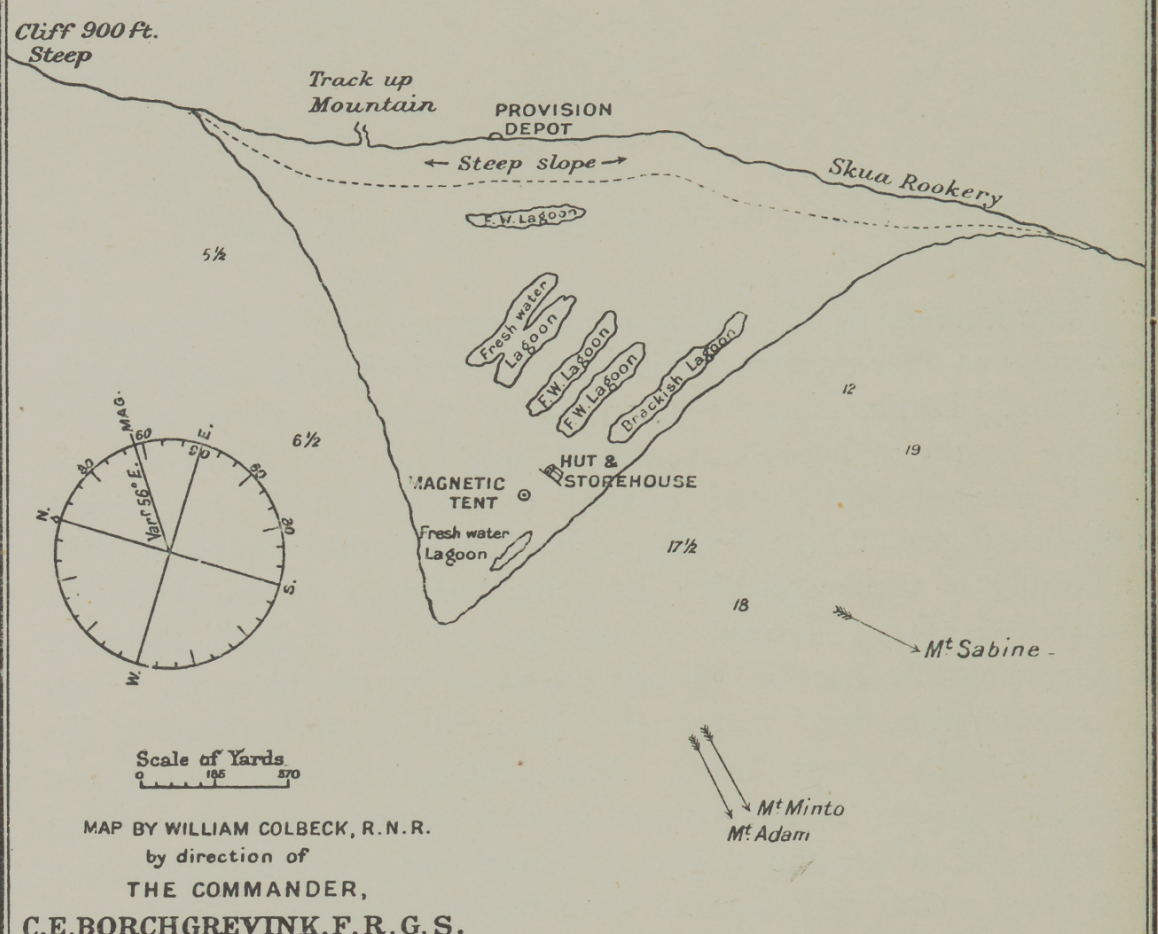

C.E.BORCHGREVINK, F.R.G.S.

London; Stanford's Geog? Istabt

the presence of the penguin colony in their old nests, and the vegetation, indicate that the place for some time past has been undisturbed by the forces within Mount Melbourne. Gales, of course, sweep the snow away from many places, but still few of those bare places can ascribe their lack of snow and ice merely to wind; in fact, some of them are rather sheltered, especially the camping 


\section{Appendix.}

ground at Newnes Land. 'The coast-line seemed to get somewhat lower south of this place, but through the telescope immense peaks were discovered in a chain far inland, and pack-ice prevented us from penetrating near into the land between Cape Washington and Mount Erebus. However, I regard Newnes Land and the vicinity of Cape Neumayer and Cape Gouss as of vast geographical importance, apart from the desirability of these places as magnetic stations. At Newnes Land a party ought to winter.

We observed many fjords which stretched into Victoria Land from the coast: in the vicinity of Newnes Land especially, where the inner part of Southern Cross Fjord still remains to be explored. Drift-ice was blocking Wood Bay and the former fjord when we were there. Southern Cross Fjord is, in my opinion, another place where an ice-vessel might over-winter with a scientific party.

\section{METEOROLOGY AND MAGNETISM.}

By Louis Bernacchi, F.R.G.S.

The following is an outline of the meteorological and magnetic observations taken by the Expedition in southern latitudes. The bulk of the observations being still unreduced, it is impossible to discuss them fully at present, and for this reason no readings of the barometer can be given to this report. These meteorological observations, taken at Cape Adare in lat. $7 \mathrm{I}^{\circ} \mathrm{I} 8^{\prime} \mathrm{S}$. during the entire year, from February, I899, to February, I900, cannot fail to be a valuable addition to our knowledge of the meteorology of the Antarctic regions. They were conducted on nearly the same lines as at a station of the first order, and as accurately and regularly as possible. During nine months of the year readings were taken two-hourly, from 9 A.M. to 9 P.M., and during the three winter months, June, July, and August, two-hourly observations were made day and night. Besides these bi-hourly readings, self-registering instruments furnished barograph and thermograph curves for the whole period; records of the amount of sunshine with the Campbell-Stokes sunshine recorder; maximum and minimum 
temperatures, and observations of solar radiation. The tables given below must be regarded as only first approximations ; however, they are sufficiently exact to indicate the general nature of the climate. Observations taken at Cape Adare are possibly affected to a certain degree by local accidents, such as the contour of the country and proximity to the sea; but they have the advantage of being taken at one spot, and not on board a ship, which is continually altering her geographical position.

Meteorological observations were taken on board ship every two hours, night and day, during the month (January, I899) she was beset in the ice-pack. The geographical area over which the observations were taken was between the parallels $63^{\circ} 38^{\prime} \mathrm{S}$., and $66^{\circ} 46^{\prime} \mathrm{S}$. of latitude, and meridians $160^{\circ} 6^{\prime} \mathrm{E}$. and $166^{\circ} 5^{\prime} \mathrm{E}$. of longitude.

The mean temperature of air for January was $29^{\circ} 94^{\circ} \mathrm{F}$., and of the sea $29.64^{\circ} \mathrm{F}$., the mean temperature for the second week being the highest in both cases, as is shown in the following table :-

TABle I.-Mean Temperature for JANUARY, I899.

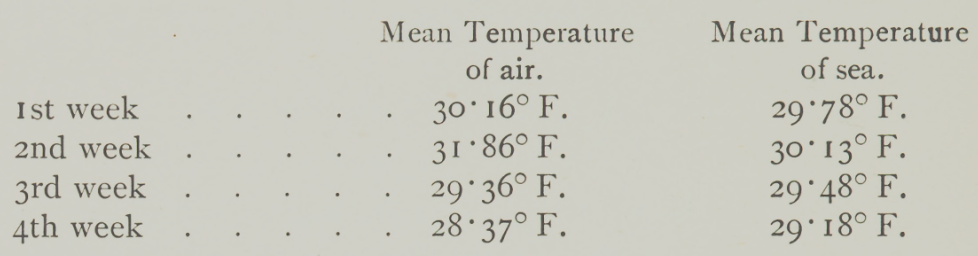

The lowest temperature for the month occurred on the $29^{\text {th }}$ at 3 A.м., when the thermometer indicated $16.8^{\circ} \mathrm{F}$. $\left(-8.8^{\circ} \mathrm{C}\right.$. $)$ in lat. $66^{\circ} 45^{\prime}$, and long. $165^{\circ} 25^{\prime} \mathrm{E}$., off one of the Balleny Islands.

The highest temperature for the month was $36^{\circ} 4^{\circ}$, at 5 P.M. on the I 2 th, lat. $65^{\circ} 3^{\prime}$, and long. $16 \mathrm{I}^{\circ} 42^{\prime} \mathrm{E}$.

The mean diurnal oscillation of temperature for the month was $5.20^{\circ} \mathrm{F}$. The greatest range between the maximum and the minimum of one day was $16^{\circ} \mathrm{F}$, the least $\mathrm{I}^{\circ} \mathrm{F}$.

Light variable winds prevailed most of the month, the force was rarely greater than 4, Beaufort's scale. Gales blew on the following days - 9th, I6th, $22 \mathrm{nd}$, and $23^{\mathrm{rd}}$ respectively, when the velocity of the wind exceeded thirty miles an hour. The weather may be summarised as:- five days' clear bright sunshine, thirteen days' snow and sleet, two days' rain, when the temperature rose above $3^{2}$, four days' mists and fogs, and the rest overcast. 
As will be seen from the table given below, the mean temperature at Cape Adare is above zero for six months in the year, and for six months below zero.

Table II.-MONThi, Mean TeMPeratures.*

\begin{tabular}{|c|c|c|c|c|c|c|c|}
\hline Month. & & $\begin{array}{l}\text { Mean } \\
\text { Tempera- } \\
\text { tures. }\end{array}$ & $\begin{array}{c}\text { Date } \\
\text { of Maxi- } \\
\text { mum. }\end{array}$ & $\begin{array}{l}\text { Maxi- } \\
\text { mum. }\end{array}$ & $\begin{array}{l}\text { Date } \\
\text { of Mini- } \\
\text { mum. }\end{array}$ & $\begin{array}{l}\text { Mini- } \\
\text { mum. }\end{array}$ & Range. \\
\hline $\begin{array}{l}1899 . \\
\text { February }\end{array}$ & & $\begin{array}{l}{ }^{\circ} \mathrm{F} . \\
26 \cdot 36+\end{array}$ & & F. & & $\begin{array}{l}{ }^{\circ} \mathrm{F} . \\
\ldots\end{array}$ & $\begin{array}{c}{ }^{\circ} \mathrm{F} \\
. .\end{array}$ \\
\hline March. & & $17 \cdot 72$ & $5^{\text {th }}$ & $3 ! \cdot I$ & 25 th & $-2 \cdot 5$ & $33 \cdot 6$ \\
\hline April . & & $10 \cdot 27$ & 2nd & $30^{\circ} 0$ & Igth & $-10^{\circ} \mathrm{O}$ & $40^{\circ} 0$ \\
\hline May. & . & $-4 \cdot 60$ & 4 th & $23^{\prime} 2$ & I3th & $-3 I \cdot I$ & $54 \cdot 3$ \\
\hline June . & . & - I I 82 & I Ith & $14 \cdot I$ & $3^{r d}$ & $-36 \cdot 0$ & 50.1 \\
\hline July . & ' & $-8 \cdot 65$ & I 8 th & $23 \cdot 8$ & $9^{\text {th }}$ & $-39^{\circ} 9$ & $63 \cdot 7$ \\
\hline August . & . & $-13 \cdot 36$ & I 5 th & $18 \cdot 9$ & $4^{\text {th }}$ & $-43^{\circ} I$ & $62 \cdot 0$ \\
\hline September & . & $-1 \mathrm{I} \cdot 9 \mathrm{I}$ & 7th & I I $\cdot 5$ & 3oth & $-36 \cdot I$ & $47^{\circ} 6$ \\
\hline October . & . & $-I \cdot 85$ & isth & $19 \cdot 6$ & 2nd & $-35 \cdot 5$ & $55^{\circ} \mathrm{I}$ \\
\hline November & . & $17 \cdot 80$ & 28 th & $45^{\circ} 7$ & Ist & $-4^{\circ} \mathrm{O}$ & $49^{\circ} 7$ \\
\hline $\begin{array}{c}\text { December } \\
\text { r9oo. }\end{array}$ & . & $31 \cdot 76$ & 25 th & $42 \cdot 2$ & I Ith & $20^{\circ} 4$ & $2 I \cdot 8$ \\
\hline January : & . & $32 \cdot 96$ & $23 \mathrm{rd}$ & $48 \cdot 9$ & Ioth & $22 \cdot 5$ & $26 \cdot 4$ \\
\hline
\end{tabular}

Mean temperature for the year $=7^{\circ} 05^{\circ} \mathrm{F}$.

August was the coldest month, the mean temperature being $-\mathrm{I} 3 \cdot 36^{\circ} \mathrm{F} .\left(-25^{\circ} 2^{\circ} \mathrm{C}\right.$. $)$.

The extreme minimum temperature occurred on August 4th, at 9 P.M., during perfectly calm and clear weather.

Table III. shows the fall of temperature during the afternoon of that day with the accompanying barometric pressure :-

TABLE III.

\begin{tabular}{|c|c|c|c|}
\hline Time. & Temp. Fahr. & Temp. Cent. & $\begin{array}{l}\text { Barometer (corrected to } \\
\text { Freezing-point only). }\end{array}$ \\
\hline $\begin{array}{ll}\text { I } & \text { P.M. } \\
3 & , \\
5 & " \\
7 & , \\
9 & ,\end{array}$ & $\begin{array}{l}-36 \cdot 0^{\circ} \\
-40^{\circ} 0^{\circ} \\
-41 \cdot 5^{\circ} \\
-42 \cdot 0^{\circ} \\
-43 \cdot I^{\circ}\end{array}$ & $\begin{array}{l}-37 \cdot 8^{\circ} \\
-40 \cdot 0^{\circ} \\
-40 \cdot 8^{\circ} \\
-41 \cdot I^{\circ} \\
-41 \cdot 7^{\circ}\end{array}$ & $\begin{array}{l}29 \cdot 292 \text { inches. } \\
29 \cdot 312 \quad, \\
29 \cdot 324 \quad, \\
29 \cdot 344 \quad, \\
29 \cdot 355 \quad,\end{array}$ \\
\hline
\end{tabular}

* Obtained by taking the means of maximum and minimum daily temperatures.

$\dagger$ Based on twelve days' observations, 16 th to 28 th. 
At these temperatures the mercury froze in the ordinary thermometers, and spirit ones had to be used. The above temperatures are means derived from three thermometers. At these low temperatures there was a slight diversity in the indications of the respective thermometers, even after applying the corrections as given upon the Kew certificates. The maximum temperature observed at Cape Adare was $48.9^{\circ}$ F., which occurred during a very heavy storm from the E.S.E. on January 23 rd, I900. This is quite exceptional. The mean monthly temperature is above freezing-point during one month of the year, viz., January. The temperature commenced to fall rapidly during the second week of May, and rise again even more rapidly in the second week of October.

The relatively high mean temperature for July is due to the number of gales from the E.S.E. and S.E. during that month, the temperature invariably rising with these winds. The extreme range of temperature was $92^{\circ} \mathrm{F}$, and the mean temperature for the year $7.05^{\circ} \mathrm{F}$. $\left(-\mathrm{I} 3.9^{\circ} \mathrm{C}\right.$.), which, compared to the mean annual temperature for the same northern latitude, is extremely low. The mean temperature for Lapland, which is in the same latitude north as Cape Adare is south, is about $32^{\circ} \mathrm{F}$., and the mean temperature for the north of Spitzbergen, which extends as far north as $82^{\circ}$, is about $10^{\circ} \mathrm{F}$.

Regarding June, July, and August as the winter months, and December, January, and February as summer, we may take it that the mean winter temperature is $-\mathrm{Ir}^{\circ} 3^{\circ} \mathrm{F}$, and the mean summer temperature $30^{\circ} 4^{\circ} \mathrm{F}$. The sun remained constantly above the horizon from November I6th to January 26 th, and below the horizon from May I5th to July 29th. It was not, however, absolutely dark all this time; for when the sky was not overcast the twilight produced a couple of hours daylight in the middle of the day, even at the winter solstice. The Antarctic winter is longer than the Arctic. In his annual round the sun tarries a week ( $7 \frac{3}{4}$ days) longer on the north than he does on the south side of the equator, and consequently, in the former case, the winter night is longer than in the latter. This is due to the earth being, during the Antarctic winter, at its greatest distance from the sun (aphalion), when it moves more slowly in its orbit.

November was the finest month. During that month storms were a minimum, and the amount of bright sunshine a maximum.

The temperature of the sea during the greater part of the year, that is, while the surface of the sea was frozen over, remained constant at $27.8^{\circ} \mathrm{F}$. In the summer months, December, January, and February, it rarely rose above $32^{\circ} \mathrm{F}$. 


\section{Appendix.}

During the winter months, or at least during the seventy-one days that the sun remained constantly below the horizon, the diurnal variations of the thermometer and barometer were scarcely perceptible, being almost, if not quite, concealed by the oscillations due to the passage of storms.

The intensity of solar radiation was measured with the black bulb thermometer in vacuo. This instrument was freely exposed to the sun by fixing it horizontally above the ground at the same height as the thermometer screen, viz., $4 \mathrm{ft} .6 \mathrm{in.}$ A temperature above $80^{\circ} \mathrm{F}$. was frequently recorded by this thermometer, whilst the temperature in the shade remained below freezing-point. These high readings were probably due to the hygrometric conditions of the atmosphere, the air, on account of the intense cold, being extremely dry.

Table IV. gives some of the highest readings with the solar radiation thermometer, and the temperature of air in the shade observed at the same time.

TABLE IV.

Date.

$\begin{array}{cc}\text { March } & \text { 3rd } \\ , & 6 \text { th } \\ , & \text { I4th } \\ , & \text { I6th } \\ , & \text { 26th }\end{array}$
Solar Thermometer. $88 \cdot 0^{\circ} \mathrm{F}$. $92.0^{\circ} \mathrm{F}$. $88 \cdot 3^{\circ} \mathrm{F}$. $92 \cdot 2^{\circ} \mathrm{F}$. $104 \cdot 2^{\circ} \mathrm{F}$.
Temperature

in shade. $24 . \mathrm{O}^{\circ} \mathrm{F}$ $22 \cdot 4^{\circ} \mathrm{F}$ $20.9^{\circ} \mathrm{F}$ $24 \cdot 5^{\circ} \mathrm{F}$ $8 \cdot 0^{\circ} \mathrm{F}$

Relative humidity between $40^{\circ}$ and $50^{\circ}$.

The most remarkable feature in the meteorological conditions of the Antarctic is the wind.

The prevailing E.S.E. and S.E. winds at Cape Adare, which is within the area of abnormally low pressure, tend to prove the existence of a great anti-cyclone stretching over the polar area, which in its turn necessarily implies the existence of upper currents from the northward, blowing towards and in upon the polar regions to make good the drain caused by the surface outblowing S.E. winds.

The frequency and force of these gales, and the persistency with which they blew-always from the same direction, E.S.E.--the invariably high rise in the temperature, and the sudden fall and rise of the barometer, the dryness of the winds-the relative humidity generally between $40^{\circ}$ and $50^{\circ}$-and the motion of the upper clcuds from the N.W., point to the fact that the South Pole is covered by what may be regarded practically as a great permanent anti-cyclone, more extensive in the winter months than in the summer. 
Nothing more appalling than these frightful winds, accompanied by tons of drift snow from the mountains above, can be imagined. On ninety-two days, or twenty-six per cent. of the time spent at Cape Adare, the wind blew from the E.S.E. and S.E. with a velocity above forty miles an hour, and on one or two occasions above ninety miles an hour, at which stage our Robinson anemometers were demolished.

A proper table of wind directions, velocities, and thermal windroses is not yet available, but the following tables will suffice to convey some idea of the conditions.

Table V. shows the number of days in each month when the velocity of the wind was above forty miles an hour :-

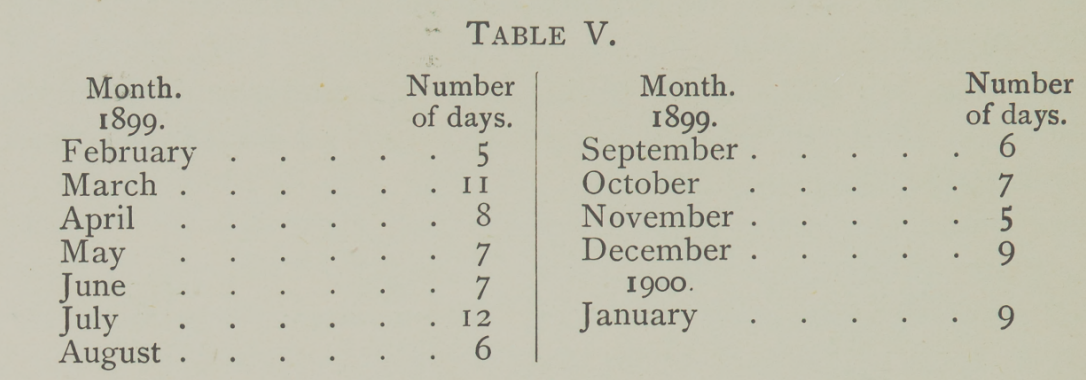

Table VI.-Number of ObServation Hours in Each Month WHEN WIND BLEW AS FOLLOWS :-

Anti-Cyclonic Storms.

\begin{tabular}{|c|c|c|c|c|c|c|c|c|c|c|c|c|c|c|c|c|c|}
\hline Month. & 之 & 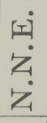 & $\begin{array}{l}\text { Ix } \\
\text { ż }\end{array}$ & 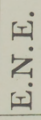 & 되 & 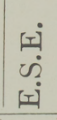 & $\begin{array}{l}\text { II } \\
\dot{2}\end{array}$ & $\begin{array}{l}\dot{v} \\
\dot{n} \\
\dot{\Omega}\end{array}$ & $\dot{\Omega}$ & $\begin{array}{l}3 \\
\dot{2} \\
\dot{2}\end{array}$ & $\vec{i}$ & $\begin{array}{l}3 \\
\dot{3} \\
3\end{array}$ & B & $\begin{array}{l}3 \\
z \\
z\end{array}$ & z & $\begin{array}{l}z \\
z \\
z \\
z\end{array}$ & $\frac{\tilde{g}}{\underbrace{\infty}}$ \\
\hline $\begin{array}{l}1899 . \\
\text { March }\end{array}$ & 0 & I & 30 & 5 & 9 & $3 \mathrm{I}$ & I 5 & 6 & I9 & 3 & 8 & 3 & 8 & 0 & I4 & 0 & 45 \\
\hline April . & 9 & 0 & I6 & I & 4 & 30 & I 6 & 9 & 17 & o & 5 & 3 & 7 & o & 7 & 10 & 70 \\
\hline May . & 9 & 2 & 3 & o & I & $3 \mathrm{I}$ & I 5 & I4 & I 8 & I & I & O & 2 & o & 3 & 3 & I 12 \\
\hline June . & 3 & $\mathrm{O}$ & 2 & o & o & 48 & 30 & I6 & I 8 & 3 & IO & 2 & 2 & o & 3 & o & I 53 \\
\hline July & 7 & 0 & 5 & o & 0 & 36 & 35 & 33 & 20 & $\mathrm{o}$ & 6 & I & 5 & 3 & 9 & I & I 8 I \\
\hline August & 6 & $\mathrm{O}$ & 3 & $\mathrm{O}$ & 0 & I9 & 26 & 20 & 29 & 3 & 0 & 0 & 2 & 0 & 6 & 4 & -80 \\
\hline September & 3 & I & 2 & $\mathrm{O}$ & I & 25 & 27 & I4 & 23 & 3 & 4 & 2 & I & I & 3 & I & {$[84$} \\
\hline October. & I & 0 & o & o & o & 43 & I I & 5 & I 4 & IO & 4 & I & 8 & I & 6 & 2 & 98 \\
\hline November & I & $\mathrm{O}$ & o & o & o & 6 & 22 & I6 & I6 & 7 & I 2 & $\mathrm{O}$ & 3 & 0 & I & $\mathrm{o}$ & IOI \\
\hline $\begin{array}{c}\text { December } \\
\text { I900 }\end{array}$ & 3 & I & $\mathrm{o}$ & $\mathrm{O}$ & 9 & 53 & 6 & I 2 & I7 & 6 & I I & 7 & 5 & 4 & I & 3 & 68 \\
\hline January . & 6 & 0 & I & 0 & 3 & 78 & $\mathrm{I} 2$ & 6 & I6 & 0 & 4 & 2 & 8 & 4 & 10 & 2 & 4I \\
\hline Totals & 48 & 5 & 62 & 6 & 27 & 400 & 215 & I $5 \mathrm{I}$ & 207 & 36 & 65 & $2 I$ & $5 \mathrm{I}$ & 13 & 63 & 26 & I033 \\
\hline
\end{tabular}




\section{Appendix.}

Table VI. shows the number of hours in each month when the direction of the wind was actually noted at the fixed observation times. It will be seen that the number of calms head the list, whilst the predominance of the E.S.E. winds is very evident.

Table Vil.-Mean Velocity of Wind in Miles Per Hour (APPROXIMATE).

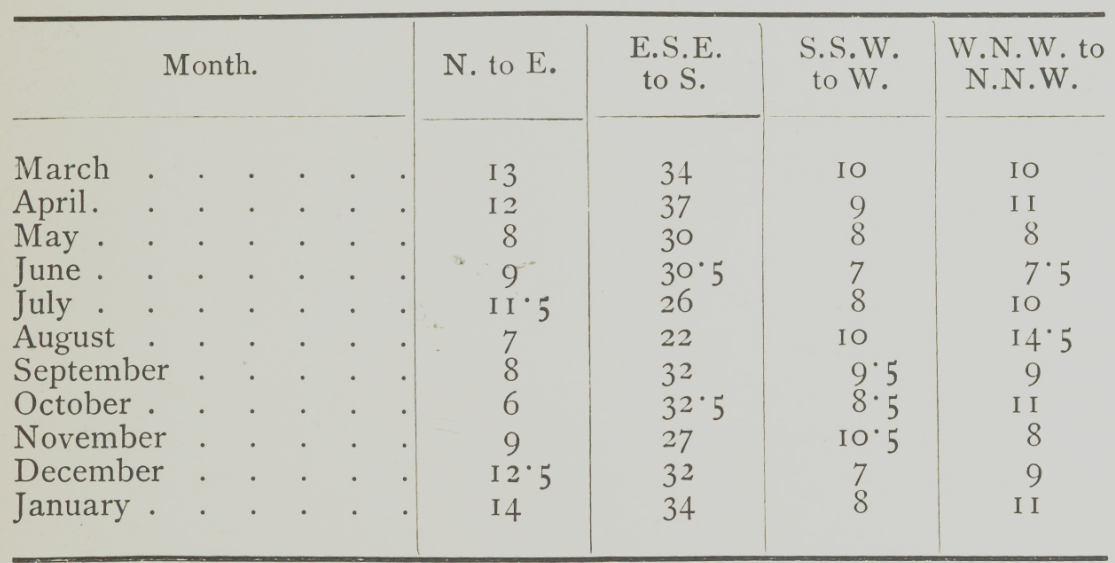

The average for winds from the E.S.E. only, is above forty miles an hour for nearly every month.

Table Vili.-Conditions during a Storm on April 2ND, i899.

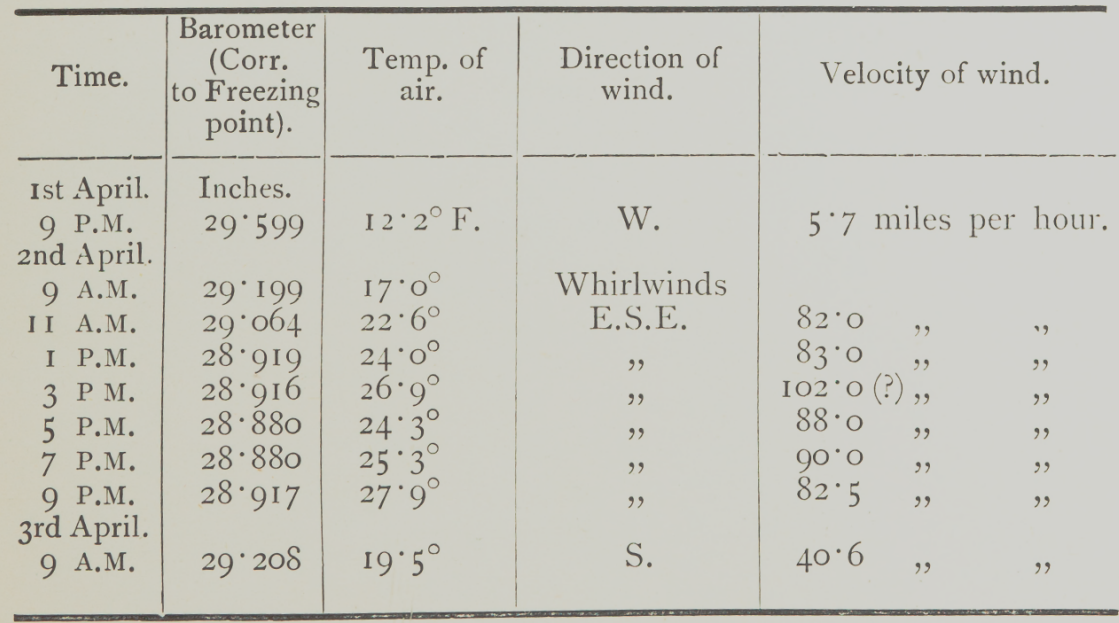

Maximum temperature during the gale was $3 \mathrm{I} \cdot 5^{\circ} \mathrm{F}$. During a gale on March Igth a Robinson anemometer was demolished when velocity of wind excelled ninety miles an hour; and another 
was destroyed on the night of the 18 th May, when it was impossible to estimate the velocity of the wind. The anemometers used were tested at the Kew Observatory prior to the departure of the Expedition from England, and were found to give results within $97 \%$ of the Kew instruments. It is evident, however, that the action of wear and tear on the instrument by these gales must have a very material influence on its indications. It would be advisable on future Antarctic expeditions to take pressure anemometers of the type Cator and Lind besides the Robinson pattern.

The mean barometric pressure for the winter months is much lower than the mean for the summer, but the means have not yet been determined, as there are some 4,000 observations to be dealt with. The highest barometric pressure occurred on July $22 \mathrm{nd}, \mathrm{I} 899$, when the barometer registered $30^{\circ} 182$ inches, and the lowest$27 \cdot 860$ inches-on September 9th, I899. Both of these readings are reduced to freezing-point only, and are not corrected for gravity.

Another important feature in the meteorological conditions is the very small amount of snowfall at the sea-level. A snow gauge was erected at some distance from the hut, and during the whole year it collected no more than 3 inches rain equivalent. The heaviest snowfall at one time occurred on April 5th, I899, when the gauge collected 0.19 inches; the depth of the snow on a level being 8 inches and exceedingly light.

Table IX.-The Number of Hours of Bright Sunshine Recorded By the Campbell-Stokes Instrument.

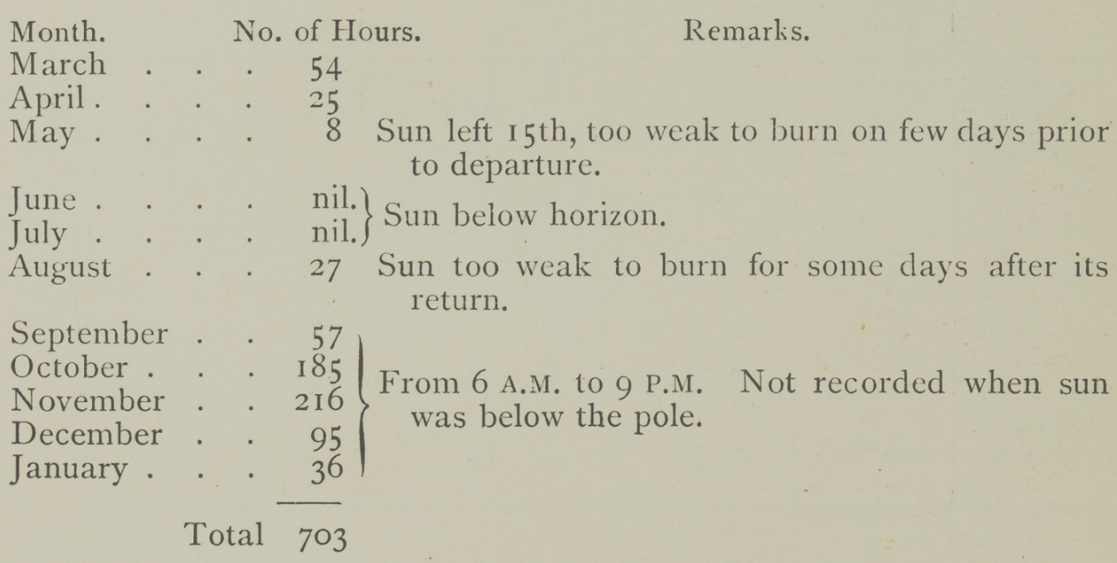

For high latitudes the Campbell-Stokes sunshine recorder should be constructed so as to burn when the sun is below the pole without any difficult readjustment of the instrument. 

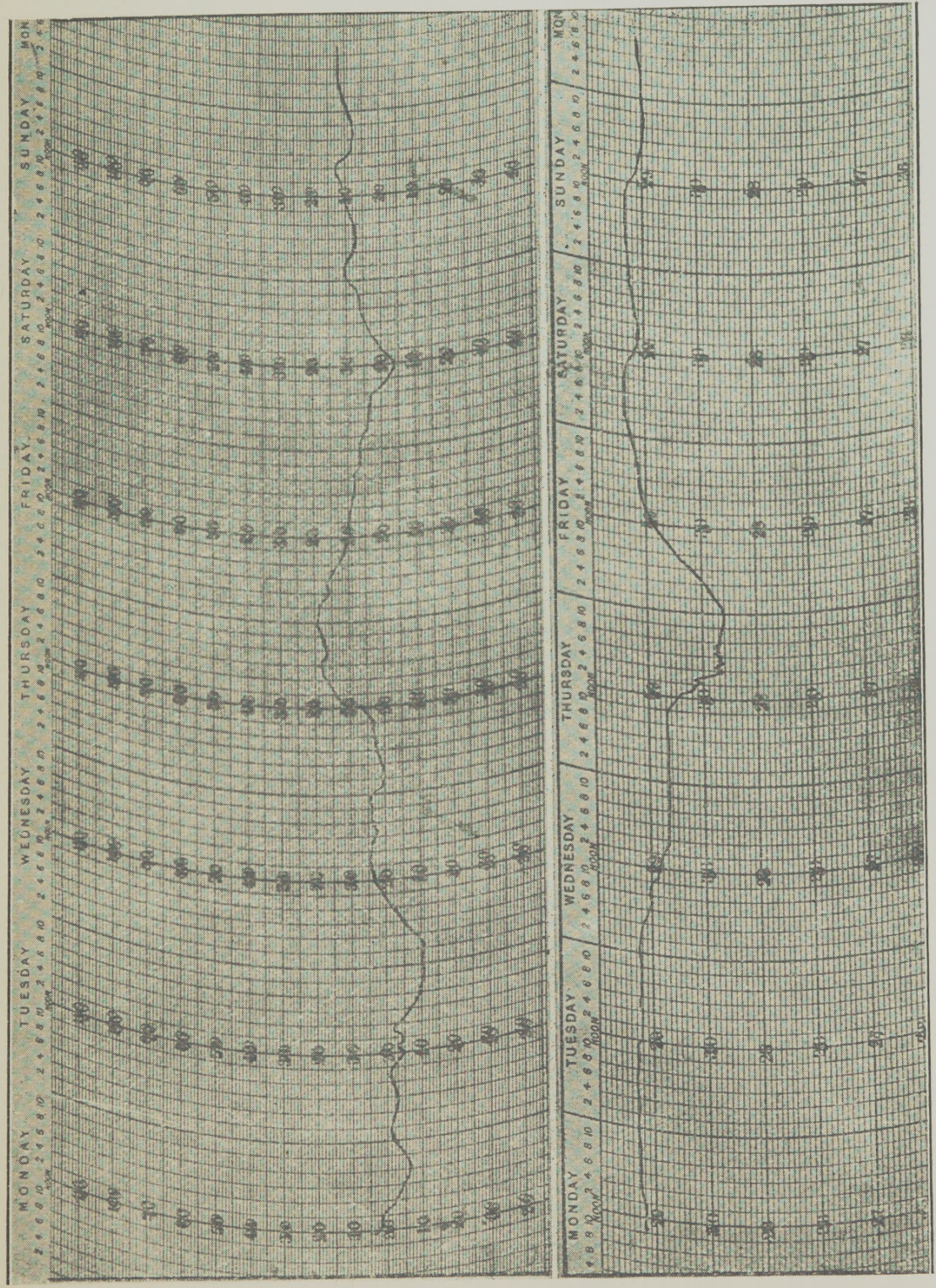
On the journey from Cape Adare southwards some most remarkably low temperatures were observed for the time of the year. Thus, off Mount Erebus on February IIth, I900, the temperature sank to $-6^{\circ} \mathrm{F}$., with a wind from the south straight off the Great Ice Barrier. Again, on February I $9^{\text {th, the minimum temperature was }}$ $-\mathrm{I} 2^{\circ} \mathrm{F}$. $\left(-24^{\circ} 4^{\circ} \mathrm{C}\right.$.), with a clear sky and a light wind from the south. So it is possible to form an idea from these temperatures what one would be likely to encounter in the way of cold on a sledge journey southwards from the edge of the Great Ice Barrier in the middle of the Antarctic summer.

\section{MAGNETISM.}

Magnetic observations taken in the vicinity of the south magnetic poles will always present great difficulties unless taken on board ship at some distance from the coast-line, and with instruments of the nature of the Fox Circle. The highly magnetic character of the rocks off the shores of Victoria Land not only renders the taking of magnetic observations extremely difficult, but the observations are themselves unreliable. Even far inland, where the ice-cap is some thousands of feet thick, the influence of the rocks if magnetic, as is most probable, would certainly be felt. Under such circumstances the Unifilar Magnetometer is the worst instrument that could possibly be taken to the Antarctic regions for the determination of intensity. Besides being a most delicate instrument, and therefore difficult for transport across ice, it is heavy, inconvenient to manage in a cold climate, and most sensitive to any form of disturbance. The ordinary Dip Circle, fitted with Lloyd needles for observations of total intensity, would possibly be the best instrument to use for isolated observations on shore; whilst differential instruments, fitted up in a small house built expressly for the purpose, and erected in Wood Bay, would doubtless be of considerable value, although the erection of the instruments would involve much trouble. A detailed magnetic survey of Victoria Land would, of course, be of immense value--of infinitely greater value than the determination of the spot where the needle stands vertical. In order to make such a survey, it would be necessary to take a number of observations surrounding the magnetic pole. The work would have to be done during the summer months by careful and determined observers, who must be fully prepared to meet with innumerable difficulties, and be physically capable of wrestling with them. The 
magnetic observations taken at Cape Adare during r899-r900 involved the three elements Declination, Inclination and Intensity, and were conducted in an open Lapp tent with great personal inconvenience, sometimes even at a temperature of $-25^{\circ} \mathrm{C}$. This tent was situated at a distance of about 2,000 yards from the base of a volcanic and highly magnetic range of mountains, which undoubtedly had considerable influence upon the magnets. The disturbances due to the occurrence of the aurora were also very great, so that very few of the observations taken with the Unifilar Magnetometer are entirely free from its influence. On account of the weak horizontal intensity in the deflexion observations for the moment of the vibrating magnet, distances $39 \mathrm{cms}$. and $52 \mathrm{cms}$. had to be used instead of $30 \mathrm{cms}$. and $40 \mathrm{cms}$., and as we had no correction to our deflexion bar for these distances, it was not possible to reduce the observations on the spot. In the vibration observations, every third transit was observed instead of every fifth, and in many cases it was impossible to observe torsion of the suspension thread on account of the agitation of the magnet. The horizontal force derived from a single observation taken on May I Ith, I899, assuming errors at $39 \mathrm{cms}$. and $52 \mathrm{cms}$. to be same as at $40 \mathrm{cms}$, gives ' 04086 C.G.S., dip at same time being $-86^{\circ} 35^{\prime} 20^{\prime \prime}$, and declination $55^{\circ} 46^{\prime} 55^{\prime \prime}$ E. at 5.30 P.M.

The mean of some forty dip observations taken at Cape Adare gives $-86^{\circ} 34^{\prime} \mathrm{I} 3^{\prime \prime}$, while the mean of some fifty declinations gives $56^{\circ} 2^{\prime} 0^{\prime \prime} \mathrm{E}$. 'The diurnal variations of magnetic conditions at Cape Adare appear to be very great, but the sudden and relatively large disturbances make the determination of the normal daily variations a difficult matter. The presence of large masses of basalt and other magnetic rocks, which magnetised by the induction of the earth's magnetic field, must deflect the magnet, and consequently the true magnetic declination may be assumed to be in error. Although it is not possible to eliminate errors due to this source, one may presume them to be constant. On April roth, I899, the declination was observed every twenty minutes right through the twenty-four hours. The maximum declination occurred at 4.5 A.M., and the minimum at a little after noon, the difference between maximum and minimum being $3^{\circ} 2^{\prime} 5^{\prime \prime}$. Again, on January 2 nd, I9o0, declination was observed every fifteen minutes. The maximum occurred at 6 P.M., and the minimum a little after noon, the difference between maximum and minimum being $\mathrm{I}^{\circ} 3^{8^{\prime}} \mathrm{IO}^{\prime \prime}$. The change in declination takes place in long oscillations or system of pulls from ${ }_{5}$ to 20 scale divisions to right and left of the centre, the 
interval of time being rather irregular. In order to give an idea of a disturbance, the following is an extract from the Magnetic Tournal:-

November 29th, I899:-_ "Impossible to take set of magnetic observations, on account of the extraordinary disturbed state of the magnets. Vibration magnet drawn as much as 20 and 30 on each side of the central division, and the whole scale would disappear from the field of view. At. 4.I0 P.M. the circle reading for declination was $157^{\circ} 44^{\prime} 50^{\prime \prime}$. At 4 . I 7 it was $156^{\circ} 32^{\prime} 30^{\prime \prime}$, the magnet being in the same position (erect), for both readings. Thus there is a difference of $\mathrm{I}^{\circ} \mathrm{I} \mathbf{2}^{\prime} \mathbf{2} \mathrm{O}^{\prime \prime}$, in the declination for an interval of seven minutes. The utter impossibility of taking observations under such conditions is obvious."

'Table X. gives magnetic dips at eight geographical positions :-

\begin{tabular}{|c|c|c|c|c|}
\hline Date & Latitude. & Longitude. & Dip. & Remarks. \\
\hline $\begin{array}{l}\text { Jan. 2nd, I } 899 \\
\text { Jan. 3rd, I } 899 \\
\text { March, I } 899 \text {, to } \\
\text { Feb., I } 900 . \\
\text { Feb. 4th, I900 } \\
\text { Feb. 6th, I } 900 \\
\text { Feb. 8th, I } 900 \\
\text { Feb. 8th, I } 900 \\
\text { Feb. 9th, I900 }\end{array}$ & $\begin{array}{ll}63^{\circ} & 4 \mathrm{I}^{\prime} \mathrm{S} . \\
63^{\circ} & 4 \mathrm{O}^{\prime} \\
7 \mathrm{I}^{\circ} & \mathrm{I} 8^{\prime} \\
73^{\circ} & \mathrm{I} 7^{\prime} \\
74^{\circ} & 23^{\prime} \\
75^{\circ} & \mathrm{I} 8^{\prime} \\
75^{\circ} & 42^{\prime} \\
76^{\circ} & \mathrm{I} 2^{\prime}\end{array}$ & 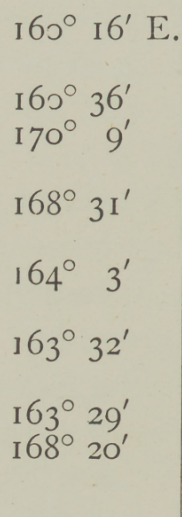 & 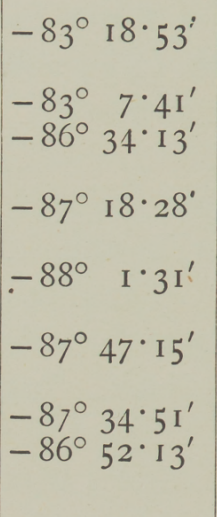 & $\begin{array}{l}\text { Taken in the ice } \\
\text { pack. } \\
\text { Ditto. } \\
\text { Mean of } 40 \text { (Cape } \\
\text { Adare). } \\
\text { I4 miles due W. of } \\
\text { Coulman Is. } \\
\text { Taken at foot of } \\
\text { Mt. Melbourne. } \\
\text { Taken on ice } \\
\text { barrier. } \\
\text { Ditto. } \\
\text { On Franklin Is., } \\
\text { W. side. }\end{array}$ \\
\hline
\end{tabular}

Sir James Clark Ross, in I $84 \mathrm{I}$, observed a dip of $-88^{\circ} 24^{\prime}$ some twelve miles to the north of Franklin Island, so that the decrease in fifty-nine years amounts to $\mathrm{I}^{\circ} 3 \mathbf{2}^{\prime}$, or an annual decrease of $\mathrm{I} \cdot 66^{\prime}$. There is very little doubt that the magnetic pole is much further $\mathrm{N}$. and W. than in $\mathrm{I} 84 \mathrm{I}$; but, of course, it is impossible to accurately locate its position from such seanty data.

\section{THE AURORA AUSTRALIS, OR POLARIS.}

The Aurora, as is well known, is a phenomenon at the same time cosmic and terrestrial, which on the one hand is confined within the atmosphere of our globe and stands in close connection with 


\section{Appendix.}

terrestrial magnetism, and on the other hand is dependent on certain changes in the envelope of the sun, the nature of which is as yet little known. At Cape Adare, which is probably within the circle of the greatest Aurora intensity in the Southern Hemisphere, particularly favourable opportunities are afforded for its study. During the cold months the atmospheric conditions are most favourable, the amount of cloud being small. During the winter the phenomenon was observed nearly every night, so it was possible to establish the diurnal period, for it usually manifested itself between 6 P.M. and 3 A.M., its maximum intensity being generally reached between 8 and 9 P.M. Of course there were exceptional cases. The intensity also appears to be greater at the time of the equinoxes than during the mid-winter months; the displays being more brilliant and more rapid in motion at the former time. They were, however, most frequently seen during July and August. At Cape Adare (lat. $7 \mathrm{I}^{\circ} \mathrm{I} 8^{\prime} \mathrm{O}^{\prime \prime} \mathrm{S}$.) the Aurora was always observed in the north, and it always manifested itself in exactly the same manner. Diffused Aurora light would first appear in the north about $3^{\circ}$ above the horizon; soon afterwards a gigantic luminous arc would form above the diffused Aurora, the extremities resting on the horizon, while the apex was situated a little to the west of the magnetic meridian.

The luminous arc generally formed the starting-point for the radiant draperies of rays, of variegated colours and with indescribably beautiful and graceful folds, which moved laterally and most rapidly from E. to W., and bodily across the zenith. Long shafts of light would shoot down towards the earth with incredible rapidity, the colour being of a much deeper red at the lower part of these shafts than at the upper. The intensity of the colour appears to have some connection with the altitude of the phenomenon, varying greatly with the density of the atmosphere. In other words, the colour of the Aurora beams is an indication of its height above the surface of the earth, being deep red at a low altitude, and of a pale nebulous whiteness at great altitudes. But what was of greatest interest in the observation of the Aurora was the connection which appeared to exist between it and an approaching atmospheric disturbance; a strong gale from the S.E. being almost invariably preceded by a most brilliant and rapid Aurora display. This was not a mere coincidence, but a fact repeatedly observed. It was also possible to predict an approaching storm many hours beforehand by the extreme agitation of the magnetic needle, both possibly being manifestations of the same cause. 
TAble XI.-Aurorae observed A'T CaPe Adare.

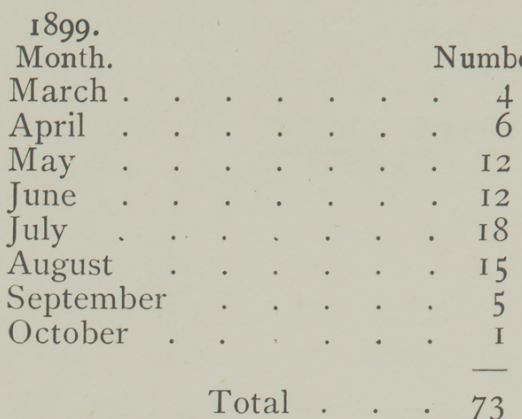

As mentioned before, the immense influence of the Aurora upon the magnetic needle made the taking of magnetic observations extremely difficult.

In order to form an idea of the extent of these disturbances the following table is given showing the relative position of the magnet with the position of the Aurora in the sky observed simultaneously during an Aurora display of very weak intensity, May 3Ist, I $900:-$

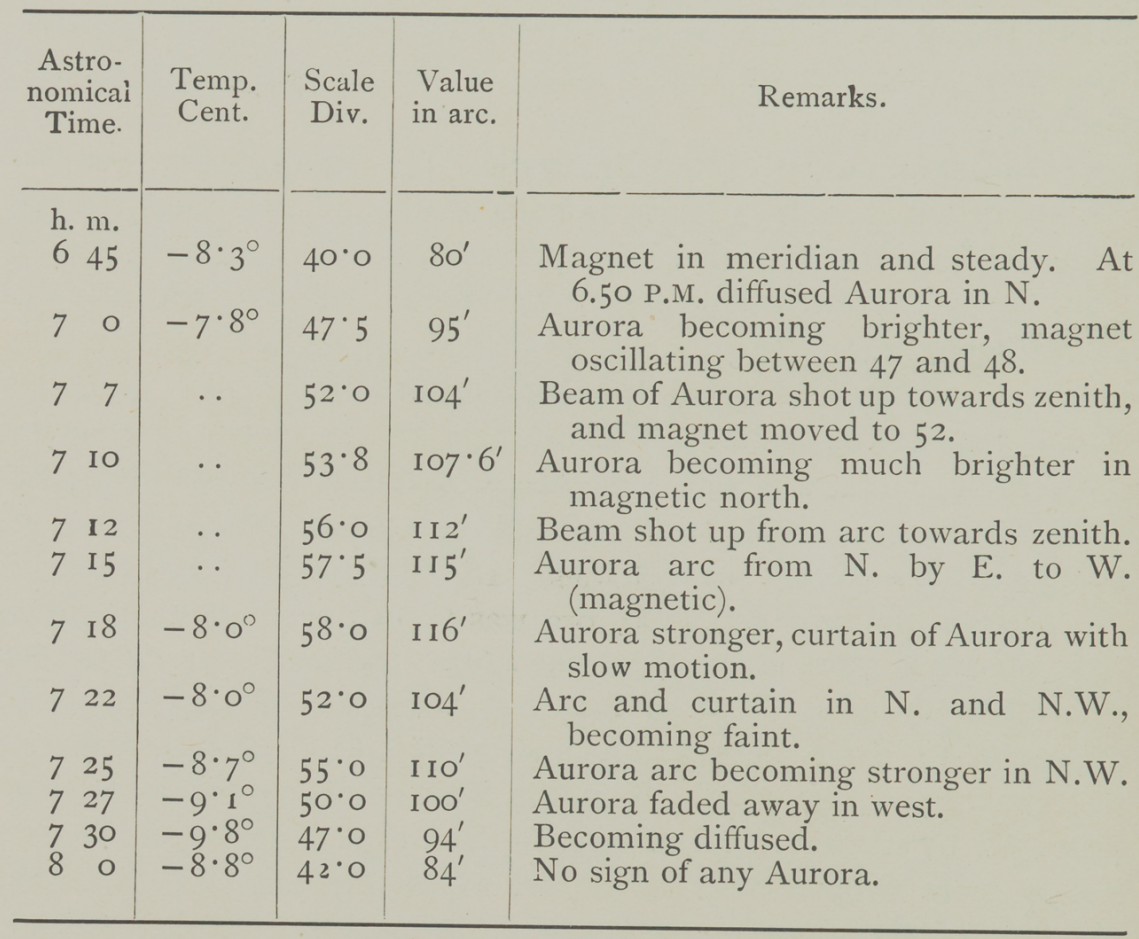

During the appearance of the Aurora the disturbance of the magnet lasted more than one hour. At no time was it brilliant or 
rapid in its movement. It was of quite an ordinary type as seen nearly every night. When it moved towards the west the disturbance appeared to be greatest. At times when the Aurora was fairly strong, but concentrated near the magnetic north, the needle was but little disturbed, nor did it appear to be much disturbed when the Aurora became diffused.

May 6th, I899. Short Extract from Meteorological Journal:-

"Very fine Aurora Australis, first visible at 6 P.M. in the form of an arc of light in the north. The centre of the arc was about 3 above the horizon, and bore about $\mathrm{N}$. by $\mathrm{E}$. The arc was of large radius, the inner side or base being of much greater intensity than the outer; much yellow and red in the base part. Curtains of vertical beams of light, always parallel to the original arc, commenced to move slowly and bodily towards the south. The lateral movement was very rapid, and always E. and W., and the bottom part of the beams denser and redder than the top. The curtains of light advanced no farther than about $15^{\circ}$ north of the zenith, the limit in the east being the planet Jupiter, and in the west the star Sirius. As the curtain of light moved south, the original arc became diffused but stationary and had little movement. The display reached its greatest intensity about 6.30 P.M., and ended at 7 P.M. A kind of diffused afterglow remained in the north for many hours. Temperature of air, $12{ }^{\circ} \mathrm{F}$. ; barometer, $29 \cdot 262$ inches."

August 4th, I 899. Short Extract from Meteorological Journal :-

"An Aurora was observed at a little before 6 P.м. in the form cf a double luminous arc in the north. The arcs were separated from one another by about $2^{\circ}$, the inner one being $8^{\circ}$ above the horizon. The west extremity of the arc bore about N.N.W. The east extremity was invisible, being hidden behind the cape. The arcs lay in the same plane and had a common centre. Winding curtains of Aurora afterwards manifested themselves in the usual way, moving towards the zenith and forming coronas there. Temperature of air, $-4 \mathrm{I} \cdot 5^{\circ} \mathrm{F}$.; barometer, $29 \cdot 200$ inches." 


\section{APPENDIX II.}

Copies of Notes written by Lieutenant Alexander J. Smith, R.N., on board H.M.S. Erebus, on an old Chart NOW in the possession of Mr. C. E. Borchgrevink.

"A bottle thrown from H.M.S. Erebus in lat. $53^{\circ} 59^{\prime} \mathrm{S}$., and long. $60^{\circ} 47^{\prime} \mathrm{W}$. at 8 P.M., $4^{\text {th }}$ April, I842. The same was picked up on Cape Liptrap, Port Phillip coast, about the middle of September, I $845 . "$

"Thermometer left at Deception Island by Capt. Forster in I 829 was found by William H. Smiley, master of a sealer, in February, 1842 , and carefully noted its minimum temperature, which was $5^{\circ}$ below zero; from Wilkes viz. ... ."

"H.M. Ships Ercbus and Terror attained the highest latitude ever reached, the 28 th January, I $84 \mathrm{I}$, viz., $78^{\circ}$ I $2^{\prime} \mathrm{S}$.; all progress to the south stopped by a perpendicular barrier of ice $180 \mathrm{ft}$. high, along which the ships ran 300 miles east by north. High mountains to the south and south-west."

"U.S. ship Peacock saw the first iceberg in lat. $6 \mathrm{r}_{\frac{1}{2}}^{\circ} \mathrm{S}$. and long. $\mathrm{I} 6 \mathrm{I}^{\circ} 5^{\prime} \mathrm{E}$., I $3_{\text {th }}$ January, $\mathrm{I} 840$; her last was in $55^{\circ}$, $25^{\text {th January." }}$

“Vincennes' first berg, lat. $6 \mathrm{I}^{\circ} 8^{\prime} \mathrm{S}$., and long. $\mathrm{I}_{62^{\circ}} 3^{2}$ E. ; last one 27 th February, $5 \mathrm{I}^{\circ} \mathrm{S}$."

"Ioth January, I 840. Vincennes and Porpoise in company saw first berg in lat. $61^{\circ} 8^{\prime}$ and long. $162^{\circ} 3^{2} \mathrm{E}$. On the Ist March the Porpoise saw the last berg, lat. $55^{\circ}$, and long. $140^{\circ} \mathrm{E}$. The American squadron under Wilkes reached their furthest lat. $65^{\circ}$, the end of January, I $840 . "$ 


\section{Appendix.}

\section{LAND PARTY.}

\section{Observations by Dr. Klovstad.}

Names.

Weights in English 1bs.

C. E. Borchgrevink . . I63, I62, I65, I67, I72, 170, 172, 173, 179, 17 1

Louis Bernacchi. . . I50, 149, I50, I52, I53, I55, I46, I44, I44, I45

William Colbeck. . . I53, I 55, I50, I 54, I 53, I64, I56, I 52, I 5 I, I 52

Hugh Evans . . . . I85, I73, I79, I82, I80, I83, I76, I75, I81, 172

Colbein Ellefsen. . . I60, I62, I62, I66, I65, I72, I64, I65, I66, I 69

Anton Fougner . . . I48, I 44, I45, I46, I45, I 50, I46, I 45, I48, I 47

Nicholai Hanson . . I80, I72, I83, I85, I90, 200

Herlof Klovstad . . I 55, I 45, I 48, I 53, I 56, I62, I 53, I 5 I, I 5 I, I 46

Ole Must . . . . . I30, I 20, I 23, I40, I42, I37, I 45, I36, I 41 I, I 40

Per Savio. . . . I 44, I 56 , I 44 , I 46 , I 50, I 52, I 50, I 43 , I 44 , I 40

Dates, I $899-28 / 3 /$, I6/5, 2 I/6, 3-Io/8, 28/8, 4/IO, I/I I, I/I2.

$1900-2 / \mathrm{I}, 2 / 2$.

Names.

C. E. Borchgrevink

Lung capacities in cubic centimetres.

Louis Bernacchi.

William Colbeck .

Hugh Evans

Colbein Ellefsen.

Anton Fougner

$\begin{array}{lll}\text { Nicholai Hanson . } & \text {. } & \text {. } 4400,4500,4400,4400 \\ \text { Herlof Klovstad . } & \text {. } \quad 4900,4900,4500,4900,4600,4600,4500,4403\end{array}$

Ole Must . . . . . 4700, 4600, $5 \mathrm{I00}, 5 \mathrm{I00}, 5000,5000,5000,5000$

Per Savio . . . . 5000, 5000, 5000, 5200, 4700, 5000, 5100,5500

Dates, I $899-28 / 3,19 / 5, * 22 / 6, \dagger$ IO $/ 8, \pm 3 /$ I0 $\$$ I/ I I , $2 /$ I 2. $1900-2 / \mathrm{I}$.

* Sun going. $†$ Midwinter. $\ddagger$ Sun returning. $\S$ After a sledge journey.

Approximate Position of South Magnetic Pole :

About $220 \mathrm{~W}$. by N. from Wood Bay.

Latitude . . . . . . $73^{\circ} 20^{\prime} \mathrm{S}$.

Longitude . . . . . . . . $146^{\circ} \mathrm{o}^{\prime} \mathrm{E}$

CAMP RIDLEY :

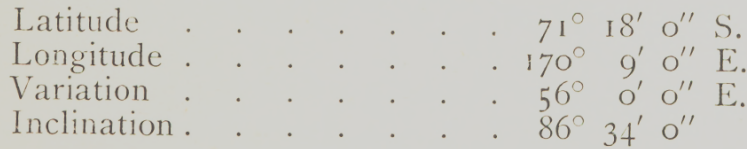

DUKE OF YORK ISLAND (Midwinter Camp):

Latitude . . . . . $7 \mathrm{I}^{\circ} 35^{\prime} \mathrm{O}^{\prime \prime} \mathrm{S}$.

Longitude. . . . . $170^{\circ} 2^{\prime} 45^{\prime \prime} \mathrm{E}$.

BEARINGS FROM CAMP RIDLEY:

Mount Adam . . . . S. $46^{\circ} \mathrm{W}$. True.

Mount Minto . . . . S. $43^{\circ} \mathrm{W}$.,

Mount Sabine . . . . S. I $8^{\circ}$ W. ",

Duke of York Island . . . S. $9^{\circ}$ W. ", 
OBSERVATIONS TAKEN FOR LATITUdE AND LONGITUDE AT VESSELS FURTHEST SOUTH.

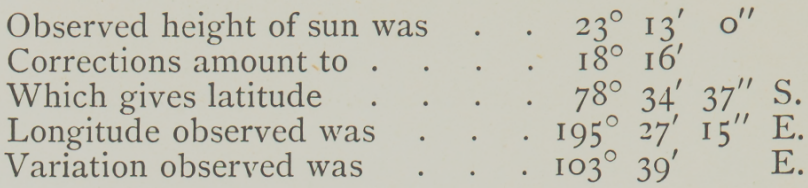

\section{MAGNETIC DiPS.}

Lat.
$71^{\circ} \mathrm{I}^{\prime}$
Long.

AT CAPE ADARE.

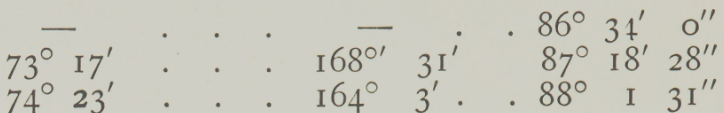

$$
\begin{aligned}
& \text { IN WOOD BAY. } \\
& 74^{\circ} 23^{\prime} \cdot \text {. } \quad 163^{\circ} 32^{\prime} \cdot .87^{\circ} 47^{\prime} \text { I } 5^{\prime \prime} \\
& 75^{\circ} 42^{\prime} . . \quad 163^{\circ} 29^{\prime} .87^{\circ} 34^{\prime} 5 \mathrm{I}^{\prime \prime}
\end{aligned}
$$

FRANKLIN ISLAND.

$$
\text { . } 86^{\circ} 52^{\prime} 13^{\prime \prime}
$$

Franklin Island Dip observed on the 9th February :--86 $56^{\prime}$ I $3^{\prime \prime}$. In I84I, Ross observed $88^{\circ} 24^{\prime}$ twelve miles to the north of the island, so that the decrease in fifty-nine years amounts to $\mathrm{I}^{\circ} 3 z^{\prime}$, or an annual decrease of $\mathrm{I} \cdot 66^{\prime}$.

Lowest barometric pressure on September 9th : 28.86 inches.

Highest barometric pressure on July 22 nd : $30^{\circ}$ I 34 inches.

NEW NAMES AFFIXED TO GEOGRAPHICAL POSITIONS BY THE COMMANDER OF THE SOUTHERN CROSS EXPEDITION.

\section{In Robertson Bay.}

Camp Ridley, $7 \mathrm{I}^{\circ}$ i $8^{\prime}$ S. lat., and $170^{\circ} 9^{\prime}$ E. long. Named after the Commander's mother's maiden name.

Large glacier at the end of Robertson Bay named after Sir George Newnes, Bart.

Island situated in lat. $7 \mathrm{I}^{\circ} 35^{\prime} \mathrm{S}$., and long. $170^{\circ} 2 \frac{3^{\prime}}{4}$ E., named after H.R.H. The Duke of York.

Sir John Murray Glacier, to the W. Sir George Newnes Glacier, named after Sir John Murray, of the Challenger. 


\section{Appendix.}

Land to the W. of Sir John Murray Glacier, called Geikie Land after Sir Archibald Geikie, the Scotch geologist.

To the W. of Geikie Land, Dugdale Glacier, named after Frank Dugdale, Esq., of Snitterfield, Stratford-on-Avon.

Westye Egeberg Glacier, named after the late Consul Westye Egeberg, of Christiania, Norway.

Scott Keltie Glacier, named after Dr. Scott Keltie, F.R.G.S., F.R.S.E., D.Sc., Hon. Secretary of the Royal Geographical Society of London.

Yngvar Nielson Glacier, named after Prof. Dr. Yngvar Nielsen, of Christiania University.

Ommanney Glacier, after Admiral Sir Erasmus Ommanney, K.C.B.

Dr. Reush Glacier, after Dr. Reush, President of the Royal Geographical Society, Christiania.

Haffner Glacier, after Colonel Haffner, Director of the Government Survey of Norway.

Frank Newnes Glacier, after Frank Newnes, Esq., the only son of Sir George Newnes, Bart.

A bay at the mouth of Sir John Murray Glacier, named Colbeck Bay, after Lieut. Colbeck, R.N.R., Magnetic Observer of the Expedition.

The end of Robertson Bay-Protection Grove.

Glacier S.E. of Camp Ridley-Warning Glacier.

\section{On the East Coast of Victoria Land.}

Conspicuous cape to the N.W. of Coulman Island, named Cape Constance, after Constance Borchgrevink, the Commander's wife. Lat. $73^{\circ}$ I $7^{\prime}$ S., long. $168^{\circ} 3 \mathrm{I}^{\prime} \mathrm{E}$.

Bay to the W. of Coulman Island, called Lady Newnes Bay.

The inner part of Wood Bay-lat. $74^{\circ} 23^{\prime} \mathrm{S}$., long. I $64^{\circ} 3^{\prime} \mathrm{E}$. named Southern Cross Firth, after the Expedition vessel, the Southern Cross.

Land to the S. and W. of Southern Cross Firth, r amed Newnes Land, after Sir George Newnes, Bart.

Island discovered to the S.W. of Mount Melbourne, named Oscar Island, after His Majesty King Oscar of Norway and Sweden.

An island still further south, called Markham Island, after Sir Clements Markham, K.C.B., President of the Royal Geographical Society, London.

A cape in about lat. $76^{\circ} \mathrm{S}$., called Cape Neumayer, after Prof. Dr. Neumayer, Director of the Seewarte, Hamburg. 
Cape S.W. of Franklin Island, called after Mr. Louis Bernacchi, magnetic observer to the Expedition.

Cape at the foot of Mount Terror, called Cape Tennyson, after the late Poet Laureate.

From ZOOLOGICAL NOTES by Mr. NICHOLAI HANSON. Octolier $5^{\text {th }}, \mathrm{I} 89^{8}$.

Temp. water, $68^{\circ}$; air, $67^{\circ}$; lat., $27^{\circ} 27^{\prime}$ S. ; long., $23^{\circ} 33^{\prime} \mathrm{W}$. The first Albatross (D. exulans) was seen to-day; otherwise the bird life has been remarkably poor. In the last few days only some small petrels (Oceanites oceanicus). Yesterday some few nearly white birds were seen, much like gulls in appearance. They were busily occupied in fishing; they were very much like Sterna hirundo in behaviour.

Octolier 6 th, 1898.

Water, $65^{\circ}$; air, $58^{\circ}$; lat., $28^{\circ} 29^{\prime}$ S. ; long., $21^{\circ} 23^{\prime} \mathrm{W}$. All day long no birds have been seen, until just before sunset, when a very small, grey-backed petrel came close to the vessel.

\section{October 7 th, 1898.}

Water, $64^{\circ}$; air, $56^{\circ}$; lat., $29^{\circ} 59^{\prime}$ г $3^{\prime \prime}$ S. ; long., $18^{\circ} 49^{\prime} 27^{\prime \prime} \mathrm{W}$. The small petrels which we saw on the 5 th followed us to-day in great numbers. A kind of Albatross, very much like a big $L$. fuscus, but a little bit larger, was seen to-day for the first time. Probably it was Diomedea melanophrys.

\section{October 8 th, 1898.}

Water, $63^{\circ}$; air, $56^{\circ}$; lat., $29^{\circ} 54^{\prime} 43^{\prime \prime}$; long., $15^{\circ} 54^{\prime} 48^{\prime \prime} \mathrm{W}$. A great many birds were seen round the vessel to-day-very many of the small petrels, two specimens of Diomedea culminata, as also some few Daption capensis.

\section{October $9^{\text {th }}, \mathbf{1} 898$.}

Water, $62^{\circ}$; air, $52^{\circ}$; lat., $30^{\circ} 28^{\prime}$ S. ; long., $13^{\circ} 9^{\prime} 30^{\prime \prime} \mathrm{W}$. A great many of the same birds we saw yesterday, especially Daption capensis, the latter watching keenly to catch eatable matter which might be thrown overboard. 


\section{Appendix.}

October г 2 th, 1898 .

Water, $62^{\circ}$; air, $56^{\circ}$; lat., $31^{\circ} 54^{\prime} \mathrm{S}$. ; long., $10^{\circ} 9^{\prime} \mathrm{W}$. No new birds were seen. The chief was out, and shot three albatrosses of the same kind as we saw on the 7 th and 8 th, as well as two grey-backed petrels.

\section{October I 3 th, 1898 .}

Water, $59^{\circ}$; air, $56^{\circ}$; lat., $30^{\circ} 37^{\prime} \mathrm{S}$; long., $9^{\circ} 45^{\prime} \mathrm{W}$. The birds are about the same in number to-day, but a new kind of petrel, Cymodroma melanogastra, has put in an appearance. We caught two specimens of Diomedea melanophry's ; they had in their stomachs partly digested octopus. A great many porpoises were seen, also two whales, but the latter were too far away for us to be able to determine what kind they were.

\section{Octoler i 5 th, I 898 .}

Water, $56^{\circ}$; air, $54^{\circ}$; lat., $37^{\circ}, 3 \mathrm{I}^{\prime} \mathrm{S}$. ; long., $8^{\circ} 5 \mathrm{I}^{\prime} \mathrm{W}$. Two Cape Pigeons were caught to-day and prepared. The contents of their stomachs were mainly an oily fluid, mixed with a substance like the roe of a fish.

\section{October I 6 th, I 898 .}

Water, $53^{\circ}$; air, $48^{\circ}$; lat., $38^{\circ} 29^{\prime}$ S. ; long., $5^{\circ} 5^{\prime} \mathrm{I}^{\prime} \mathrm{W}$. Two new kinds of birds were seen to-day. A petrel with a white head (Astrelata) as also a Lestris.

\section{October 18 th, I 898 .}

Water, $50^{\circ}$; air, $53^{\circ}$; lat., $40^{\circ} 27^{\prime}$ S. ; long., $0^{\circ} 2 \mathrm{I}^{\prime} \mathrm{E}$. We caught one Diomedea melanophrys, also seven Cape Pigeons. Most of the birds caught up to date have recently started moulting.

October I 9 th, I 898.

Water, $5^{\circ}$; air, $48^{\circ}$; lat., $39^{\circ} 55^{\prime} \mathrm{S}$. ; long., $3^{\circ}$ I $6^{\prime}$ E. Again, a new bird has been seen to-day (Puffinus). We have caught two of this species, and seven Cape Pigeons.

\section{October 20 th, I 898.}

Water $5 \mathrm{I}^{\circ}$; air, $54^{\circ}$; lat., $40^{\circ} 27^{\prime} \mathrm{S}$. ; long., $5^{\circ} 22^{\prime}$ E. Puffinus is about in hundreds to-day. 
October $2 \mathrm{i} s t, \mathrm{I} 898$.

Water, $5 \mathrm{I}^{\circ}$; air, 50 ; two petrels, Prion desolatus and Prion vittatus, have been seen for the first time to-day. All the old kinds are following us. Lat., $4 \mathrm{I}^{\circ} \mathrm{I} 4^{\prime} \mathrm{S}$. ; long., $8^{\circ} 44^{\prime} \mathrm{E}$.

October $22 n d$, I 898 .

Water, $48^{\circ}$; air, $45^{\circ}$; we saw some specimens of Diomedea fuliginosa, the first of this kind we have seen on the voyage. Lat., $4 \mathrm{I}^{\circ} 2 \mathrm{O}^{\prime} \mathrm{S}$.; long., $\mathrm{I} 3^{\circ} \mathrm{I}^{\prime} \mathrm{E}$.

\section{October 23 rd, 1898 .}

Water, $47^{\circ}$; air, $48^{\circ}$; lat., $42^{\circ} \mathrm{I}^{\prime} \mathrm{S}$., and long., $20^{\circ} 32^{\prime} \mathrm{E}$. One Cape Pigeon caught to-day. It had not started moulting.

\section{October 24 th, 1898 .}

Water, $56^{\circ}$; air, $50^{\circ}$; lat., $42^{\circ}, 23^{\prime}$ S. ; long., $20^{\circ} 32^{\prime}$ E. Several albatrosses and petrels were caught to-day. Among the birds shot to-day was a Cape hen (Majaqucus aquinoctialis) as also a small grey petrel. The specimens I got this day were Diomedea exulans, Diomedea fuliginosa, Diomedea culminata, and the two petrels mentioned above. The little grey-backed petrel, and the whitebellied petrel, as also Prion vittatus were caught. The stomachs of the albatrosses had all more or less digested octopuses, and all the petrels had the already-mentioned oily substance. Prion vittatus, as well as the small white-bellied petrel, had not started moulting. All the others had started, and some of the albatrosses were already far advanced in their moulting. We saw a small Penguin colony to-day at some distance from the vessel.

\section{October 26 th, 1898 .}

Water, $52^{\circ}$; air, $52^{\circ}$; lat., $43^{\circ} 23^{\prime}$ S. ; long., $27^{\circ} 25^{\prime} \mathrm{E}$. We saw two light, nearly white birds to-day. As far as could be seen they had very narrow wings and a rounded tail, and were very much like Fulmarus glacialis.

\section{October 29 th, 1898 .}

Water, $42^{\circ}$; air, $39^{\circ}$; lat., $44^{\circ} 26^{\prime}$ S. ; long., $37^{\circ}$ E. A large Albatross (D. exulans) was caught to-day. It had evidently eaten a great deal of octopus, which it left on the deck as soon as it was hauled on board. All in all I found the beaks of seventeen octopuses in them. The Diomedea exulans has not been seen in great numbers, no more than eight have been seen at one time. 


\section{Appendix.}

October 30 th, 1898 .

Water, $40^{\circ}$; air, $40^{\circ}$; lat., $45^{\circ} \mathrm{I} 3^{\prime} \mathrm{S}$. ; long., $40^{\circ} 47^{\prime}$ E. Saw a white bird to-day about the size of the sooty albatross; it had some few dark spots on it under the wings and on the belly; it had a short light-coloured beak and a short high head, long and narrow wings and a square tail.

\section{November Ist, I898.}

Water, $39^{\circ}$; air, $40^{\circ}$; lat., $45^{\circ} 2 \mathrm{r}^{\prime} \mathrm{S}$. ; long., $49^{\circ} 3^{\prime} \mathrm{E}$. Some few penguins have been seen to-day, but of what kind could not be settled.

November 2 nd, I 898 .

Water, $38^{\circ}$; air, $40^{\circ}$; lat., $44^{\circ} 59^{\prime} \mathrm{S}$.; long., $52^{\circ} 34^{\prime}$ E. Some birds were caught to-day. Amongst them were Cape Pigeons, and in a female were found eggs one-and-a-third centimeter in diameter. A giant petrel was seen, also a small whale.

\section{November 3 rd, $\mathbf{1} 898$.}

Water, $43^{\circ}$; air, $46^{\circ}$; lat., $44^{\circ} 39^{\prime}$ S.; long., $56^{\circ} 50^{\prime}$ E. No Cape 'Pigeons were seen, and the Prion desolatus has also left us, and also the small grey-backed petrel.

November 7 th, I 898.

Water, $52^{\circ}$; air, $40^{\circ}$; lat., $44^{\circ} 24^{\prime}$ S.; long., $72^{\circ} 5^{\prime} 30^{\prime \prime}$ E. Amongst birds caught to-day were four Cape hens; they are about in great numbers. Puffinus are about, but they are few in number.

\section{November $9^{\text {th }}, \mathbf{1} 898$.}

Water, $46^{\circ}$; air, $43^{\circ}$; lat., $45^{\circ} 9^{\prime}$ S., long., $77^{\circ}$ ro' E. A good many birds were caught and prepared yesterday, and amongst them were two specimens of Diomedea culminata which were quite different to any of the others I caught of this kind, they had quite black beaks, and had not such clean collars as those I previously caught. The grey collars of the heads of these two were sprinkled with white, especially on the sides; probably they were young birds from last year.

November roth, 1898 .

Water, $44^{\circ}$; air, $42^{\circ}$; lat., $45^{\circ} 7^{\prime}$ S.; long., $79^{\circ} 37^{\prime}$ E. Some few albatrosses of a different kind were caught to-day; amongst others I got a sooty albatross, which was a good deal darker than any I had 
caught before, it had also a white border on each side of the underpart of the beak; those caught before had all blue borders. This dark albatross had not yet started moulting.

\section{November I8th, I898.}

Water, $49^{\circ}$; air, $47^{\circ}$; lat., $45^{\circ} 45^{\prime}$ S. ; long., II ${ }^{\circ} 3^{\prime}$ E. Puffinus has left us, also the white-headed petrel. A flock of Diomedea melanophrys were lying on the sea.

November $25^{\text {th }}, \mathbf{1} 898$.

Water, $53^{\circ}$; air, $49^{\circ}$; lat., $44^{\circ} 32^{\prime} \mathrm{S}$.; long., I $39^{\circ} 6^{\prime} \mathrm{E}$. The white-headed petrel has turned up again, and a new kind of black petrel has been seen, much resembling the black swallow in flight, but about twice the size of that bird.

\section{November 26 th, 1898.}

Water, $52 \frac{x}{2}^{\circ}$; air, $52^{\circ}$; lat., $44^{\circ} 3^{\prime}$ S. ; long., $142^{\circ} 55^{\prime} \mathrm{E}$. A great many albatrosses have been seen. Diomedea exulans have been about in great numbers.

\section{November 27 th, 1898.}

Water, $56^{\circ}$; air, $56^{\circ}$. We sighted land at 5 A.M. The old birds, except the Diomedea exulans, have now left us, but some new species have put in an appearance, amongst them a large albatross with a white head, dark back and short tail. Then we have a Sula, very much like Sula bassana, but with a black tail. The southern blackbacked Larus dominicanus, as also its small relation Xema jamesonii, has been seen all along the coast, and the "mutton" birds, so well known in Australia, were seen in hundreds.

PRELIMINARY REPORT ON THE ROCK SPECIMENS COLLECTED BY THE SOUTHERN CROSS

\section{ANTARCTIC EXPEDITION.}

The collection consists mainly of specimens of basalt, and of a pale-green slate and quartz-grit, together with boulders of granite rocks.

Of the basalts, most of the specimens are very vesicular and scoriaceous, but some are of compact basalt, showing in some cases 


\section{Appendix.}

the vesicular and glassy surface of the lava-flow. Only a few specimens show porphyritic crystals, which consist of small augites and olivines, with very little felspar. A large mass of basalt from Franklin Island is remarkable for the number and large size of the olivine-nodules, such as occur, e.g., in many of the tertiary basalts of Rhenish Prussia.

Some of the basalts contain hornblende, and are similar to the glassy hornblende basalt from Possession Island, in the Ross Collection.

Of fragmental basaltic rocks, there are specimens of palagonite tuff, and of an agglomerate, consisting of large angular fragments of basalt bound together by a red calcareous cement.

Of volcanic rocks besides basalts, the collection contains one or two rounded fragments of dark phonolitic rocks, which present characters strikingly similar to phonolitic rocks from the Canary Islands and from the Rift Valley in the neighbourhood of McKenya, East Africa.

The pale-green slate from Duke of York Island, of which a large number of specimens was collected, contains much ironpyrites and is traversed by quartz veins. Probably connected with the slate are specimens of a pale-green fine grained quartz-grit.

Of the granitic boulders, one specimen is remarkable for the large size of the porphyritic felspar crystals, which measure as much as 2 ins. long by $\frac{3}{4}$ in. broad. A large specimen from Possession Island, showing pegmatitic structure, and containing muscovite and pink garnets, is similar to a specimen in the Ross Collection. It is probably a dyke rock, belonging to the Aplitepegmatite group.

Possibly in connection with these granites are specimens of pale hornstone-like felsites, some of which contain small phenocrysts of felspar and muscovite, while others are hälleflinta-like, without porphyritic constituents.

J. T. PRIOR. Min. Dep., Nov. 30th, I900. 


\section{APPENDIX BY Mr.W. COLBECK, R.N.R., Magnetic ObServer.}

January 27th, Cape Adare.

\section{INCLINATION.}

Setting of Azimuth Circle, $44^{\circ} 3^{\prime}$.

Needle No. IA.

A dipping times $\left\{\begin{array}{l}3.40 \text { P.M. } \\ 4 . \mathrm{I}\end{array} \quad\right.$ B dipping times $\left\{\begin{array}{l}4.48 \text { P.M. } \\ 5.7\end{array}\right.$

\begin{tabular}{|c|c|c|c|c|c|c|c|}
\hline \multicolumn{2}{|c|}{ Inwards. } & \multicolumn{2}{|c|}{ Outwards. } & \multicolumn{2}{|c|}{ Outwards. } & \multicolumn{2}{|c|}{ Inwards. } \\
\hline E. & W. & W. & E. & E. & W. & w. & E. \\
\hline $\begin{array}{r}86^{\circ} 39 \\
34 \\
38 \\
32\end{array}$ & $\begin{array}{r}86^{\circ} 29 \\
35 \\
30 \\
35\end{array}$ & $\begin{array}{r}86^{\circ} 22 \\
27 \\
24 \\
28\end{array}$ & $\begin{array}{r}86^{\circ} 46 \\
4 \mathrm{I} \\
45 \\
4 \mathrm{O}\end{array}$ & $\begin{array}{r}86^{\circ} 35 \\
30 \\
34 \\
30\end{array}$ & $\begin{array}{rr}86^{\circ} 39 \\
44 \\
38 \\
43\end{array}$ & $\begin{array}{rr}86^{\circ} & 2 \mathrm{I} \\
& 26 \\
2 \mathrm{I} \\
27\end{array}$ & $\begin{array}{r}86^{\circ} 55 \\
49 \\
53 \\
47\end{array}$ \\
\hline $86^{\circ} 35^{\circ} 75$ & $86^{\circ} \cdot 32 \cdot 25$ & $568^{\circ} 25^{\circ} 25$ & $5 \longdiv { 8 6 ^ { \circ } 4 3 }$ & $86^{\circ} 32 \cdot 25$ & $\overline{86^{\circ} 4 I}$ & $86^{\circ} 23 \cdot 75$ & $\overline{86^{\circ}} 5^{1}$ \\
\hline
\end{tabular}

Needle No. 3A.
A dipping times $\left\{\begin{array}{l}4.7 \text { P.M. } \\ 4.26\end{array}\right.$
B dipping times $\left\{\begin{array}{l}5.13 \\ 5.34\end{array}\right.$ P.M.

\begin{tabular}{|c|c|c|c|c|c|c|c|}
\hline \multicolumn{2}{|c|}{ Inwards. } & \multicolumn{2}{|c|}{ Outwards. } & \multicolumn{2}{|c|}{ Outwards. } & \multicolumn{2}{|c|}{ Inwards. } \\
\hline E. & IV. & W. & E. & E. & W. & W. & E. \\
\hline $\begin{array}{r}86^{\circ} 32 \\
29 \\
33 \\
30\end{array}$ & $\begin{array}{r}86^{\circ} 38 \\
42 \\
40 \\
44\end{array}$ & $\begin{array}{r}86^{\circ} 28 \\
32 \\
29 \\
33\end{array}$ & $\begin{array}{r}86^{\circ} 47 \\
42 \\
46 \\
42\end{array}$ & $\begin{array}{r}86^{\circ} 37 \\
34 \\
34 \\
30\end{array}$ & $\begin{array}{r}86^{\circ} 36 \\
40 \\
35 \\
38\end{array}$ & $\begin{array}{r}86^{\circ} 30 \\
33 \\
28 \\
32\end{array}$ & $\begin{array}{r}86^{\circ} 37 \\
-\quad 34 \\
38 \\
35\end{array}$ \\
\hline $86^{\circ} 3 \mathrm{I}$ & $86^{\circ} 4 \mathrm{I}$ & $86^{\circ} 30 \cdot 5$ & $86^{\circ} 44^{\circ} \cdot 25$ & $86^{\circ} 33^{\circ} 75$ & $86^{\circ} 37^{\prime} \cdot 25$ & $86^{\circ} 30^{\circ} 75$ & $86^{\circ} 36$ \\
\hline
\end{tabular}




\section{Appendix.}

\section{INCLINATION.}

February 4th. $\left\{\begin{array}{l}\text { Lat. } 73^{\circ} \text { I } 7^{\prime} \mathrm{S} . \\ \text { Long. } 168^{\circ} 3 \mathrm{I}^{\prime} \mathrm{E} .\end{array} \quad\right.$ Setting of circle, $86^{\circ} 54^{\prime}$.

Obs. taken near the ice barrier, W.N.W. of Coulman Island, I4 miles.

Fine clear weather, light S.Wly. airs, temp. $+3^{\circ} 5^{\prime} \mathrm{C}$.

Times $\left\{\begin{array}{l}3.15 \\ 3.33\end{array}\right.$ P.M. Times $\left\{\begin{array}{l}4.4 \text { P.M. } \\ 4.22\end{array}\right.$

B dipping Needle No. 3A. A dipping.

\begin{tabular}{|c|c|c|c|c|c|c|c|}
\hline \multicolumn{2}{|c|}{ Inwards. } & \multicolumn{2}{|c|}{ Outwards. } & \multicolumn{2}{|c|}{ Outwards. } & \multicolumn{2}{|c|}{ Inwards. } \\
\hline E. & W. & W. & E. & E. & W. & W. & E. \\
\hline $\begin{array}{r}87^{\circ} 28 \\
23 \\
26 \\
22\end{array}$ & $\begin{array}{rr}87^{\circ} & \text { IO } \\
& \text { I } 5 \\
& \text { I I } \\
& \text { I } 6\end{array}$ & $\begin{array}{r}87^{\circ} 17 \\
22 \\
20 \\
24\end{array}$ & $\begin{array}{rr}87^{\circ} & 22 \\
& 18 \\
& 19 \\
& 15\end{array}$ & $\begin{array}{r}87^{\circ} 27 \\
24 \\
25 \\
20\end{array}$ & $\begin{array}{rr}87^{\circ} & \text { I } 5 \\
& \text { I2 } \\
& \text { I } 5 \\
& \text { I I }\end{array}$ & $\begin{array}{rr}87^{\circ} & \text { I9 } \\
& \text { I } 4 \\
& \text { I6 } \\
& \text { I2 }\end{array}$ & $\begin{array}{r}87^{\circ} 20 \\
16 \\
2 \mathrm{I} \\
\mathrm{I} 7\end{array}$ \\
\hline $87^{\circ} 24 \cdot 75$ & $587^{\circ} \mathrm{I} 3$ & $87^{\circ} 20 \cdot 7$ & $87^{\circ}$ I 8 & $587^{\circ} 24$ & $87^{\circ} \mathrm{I} 3 \cdot 25$ & $87^{\circ} 15 \cdot 25$ & $87^{\circ} 18 \cdot 5$ \\
\hline & $\begin{array}{l}87^{\circ} \text { I9' } \\
\text { Times }\end{array}$ & $\left\{\begin{array}{l}3 \cdot 35 \\
3 \cdot 52\end{array}\right.$ & $\mathrm{m} .=$ & $87^{\circ}$ I $8^{\prime}$ & Times \{ & $\begin{array}{l}87^{\circ} \text { I } 7^{\prime} 45^{\prime \prime} . \\
4.26 \text { P.M. } \\
4.45\end{array}$ & \\
\hline
\end{tabular}

Needle No. IA.

\begin{tabular}{|c|c|c|c|c|c|c|c|}
\hline \multicolumn{2}{|c|}{ Inwards. } & \multicolumn{2}{|c|}{ Outwards. } & \multicolumn{2}{|c|}{ Outwards. } & \multicolumn{2}{|c|}{ Inwards. } \\
\hline E. & W. & W. & $\mathrm{E}$. & E. & W. & W. & E. \\
\hline $\begin{array}{r}87^{\circ} \text { I6 } \\
\text { I2 } \\
\text { I7 } \\
\text { I2 }\end{array}$ & $\begin{array}{r}87^{\circ} 22 \\
26 \\
20 \\
25\end{array}$ & $\begin{array}{r}87^{\circ} 0 \\
5 \\
\\
\text { I } \\
6\end{array}$ & $\begin{array}{r}87^{\circ} 37 \\
32 \\
38 \\
33\end{array}$ & $\begin{array}{r}87^{\circ} 29 \\
25 \\
30 \\
25\end{array}$ & $\begin{array}{r}87^{\circ} 7 \\
10 \\
6 \\
10\end{array}$ & $\begin{array}{rr}87^{\circ} & \text { I I } \\
& \text { I } 4 \\
\text { I } 2 \\
\text { I } 5\end{array}$ & $\begin{array}{r}87^{\circ} 26 \\
20 \\
27 \\
21\end{array}$ \\
\hline $87^{\circ} \mathrm{I} 4 \cdot 25$ & $87^{\circ} 23 \cdot 25$ & $87^{\circ} 3$ & $87^{\circ} 35$ & $87^{\circ} 27^{\cdot} 25$ & $87^{\circ} 8 \cdot 25$ & $87^{\circ}$ I 3 & $87^{\circ} 23.5$ \\
\hline
\end{tabular}

$87^{\circ}$ I $8^{\prime} 52 \cdot 5^{\prime \prime}$.

$\mathrm{m} .=87^{\circ}{ }_{1} 8^{\prime} 26^{\prime \prime}$.

$87^{\circ}$ I $8^{\prime} \mathrm{O}^{\prime \prime}$.

Mean of both needles gives $87^{\circ} 18^{\prime} 28^{\prime \prime}$. 


\section{INCLINATION.}

February 6th, 1900.

Wood Bay $\left\{\begin{array}{l}\text { Lat. } 74^{\circ} 23^{\prime}, \mathrm{S} . \\ \text { Long. } 164^{\circ} 3^{\prime} \mathrm{E} .\end{array}\right.$

Setting of Circle $63^{\circ} 23^{\prime}$.

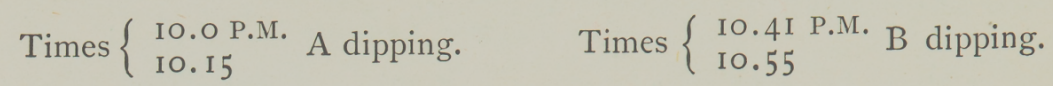

No. 3A.

\begin{tabular}{|c|c|c|c|c|c|c|c|}
\hline \multicolumn{2}{|c|}{ Inwards. } & \multicolumn{2}{|c|}{ Outwards. } & \multicolumn{2}{|c|}{ Outwards. } & \multicolumn{2}{|c|}{ Inwards. } \\
\hline E. & W. & W. & E. & E. & W. & W. & E. \\
\hline $\begin{array}{r}87^{\circ} 57 \\
54 \\
56 \\
52\end{array}$ & $\begin{array}{r}88^{\circ} \text { I9 } \\
\text { I3 } \\
\text { I7 } \\
\text { I0 }\end{array}$ & $\begin{array}{l}87^{\circ} 59 \\
88^{\circ} 2 \\
87^{\circ} 57 \\
59\end{array}$ & $\begin{array}{ll}88^{\circ} & \text { I } \\
87^{\circ} & 58 \\
88^{\circ} & 4 \\
88^{\circ} & 0\end{array}$ & $\begin{array}{r}88^{\circ} 8 \\
3 \\
9 \\
5\end{array}$ & $\begin{aligned} 87^{\circ} & 5 \mathrm{I} \\
& 53 \\
& 59 \\
88^{\circ} & \mathrm{I}\end{aligned}$ & $\begin{array}{c}87^{\circ} 59 \\
88^{\circ} \mathrm{I} \\
3 \\
6\end{array}$ & $\begin{array}{r}87^{\circ} 59 \\
57 \\
59 \\
56\end{array}$ \\
\hline $87^{\circ} 54^{\circ} 75$ & $588^{\circ} 14 \cdot 75$ & $87^{\circ} 59^{\cdot 25}$ & $88^{\circ} 0.75$ & $88^{\circ} 6 \cdot 25$ & $87^{\circ} 56$ & $88^{\circ} 2 \cdot 25$ & $87^{\circ} 57^{\cdot} 75$ \\
\hline
\end{tabular}

Im. $=88^{\circ} 2 \cdot 38^{\prime} . \quad$ m. of m. $=88^{\circ} \mathrm{I}^{\prime} 47^{\prime} . \quad \mathrm{m}_{.}=88^{\circ} \mathrm{o}^{\circ}{ }_{5}^{\prime}$.

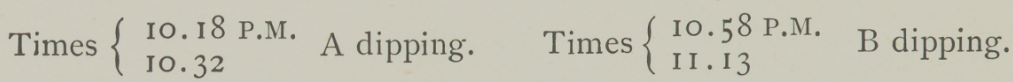

No. IA.

\begin{tabular}{|c|c|c|c|c|c|c|c|}
\hline \multicolumn{2}{|c|}{ Inwards. } & \multicolumn{2}{|c|}{ Outwards. } & \multicolumn{2}{|c|}{ Outwards. } & \multicolumn{2}{|c|}{ Inwards. } \\
\hline E. & W. & w. & E. & E. & w. & w. & E. \\
\hline $\begin{array}{c}88^{\circ} \text { I I } \\
7 \\
9 \\
4\end{array}$ & $\begin{array}{l}87^{\circ} 57 \\
88^{\circ} 0 \\
87^{\circ} 55 \\
57\end{array}$ & $\begin{array}{r}87^{\circ} 51 \\
54 \\
54 \\
56\end{array}$ & $\begin{array}{r}88^{\circ} \text { I } 5 \\
\text { I0 } \\
\text { I } 3 \\
9\end{array}$ & $\begin{array}{rr}88^{\circ} & \text { I9 } \\
& \text { I } 5 \\
& \text { I } \\
& \text { I } 4\end{array}$ & $\begin{array}{r}87^{\circ} 49 \\
54 \\
49 \\
55\end{array}$ & $\begin{array}{r}88^{\circ} 2 \\
6 \\
2 \\
5\end{array}$ & $\begin{array}{c}88^{\circ} \text { I I } \\
7 \\
7 \\
5\end{array}$ \\
\hline $88^{\circ} 7 \cdot 7$ & $87^{\circ} 57^{\circ}$ & $87^{\circ} 53$ & $88^{\circ}$ I I 75 & $88^{\circ}$ I6. & $87^{\circ} 51 \cdot 7$ & $88^{\circ} 3 \cdot 75$ & $88^{\circ} 7^{\circ} 5$ \\
\hline
\end{tabular}
m. $=88^{\circ} 2 \cdot 62^{\prime}$
m. of $\mathrm{m} .=88^{\circ} \mathrm{I} \cdot 56^{\prime}$
$\mathrm{m} .=88^{\circ} 0.5 \mathrm{o}^{\prime}$

Mean dip, $88^{\circ} I^{\prime} 3 I^{\prime \prime}$ 


\section{Appendix.}

\section{INCLINATION.}

Lat. $75^{\circ}$ I $8^{\prime}$ S. ; long. $163^{\circ} 32^{\prime}$ E. (between Cape Washington and Cape Gauss).

February 8th, I900. Taken on the ice barrier. Strong breeze from S.W., temp. $\times$ I $8^{\circ} \mathrm{F}$.

Needle No. 3A, Time 3.6 A.M. to 3.40 A.M. $\mathrm{B}$ dipping.

A dipping.

\begin{tabular}{|c|c|c|c|c|c|c|c|}
\hline \multicolumn{2}{|c|}{ Inwards. } & \multicolumn{2}{|c|}{ Outwards. } & \multicolumn{2}{|c|}{ Outwards. } & \multicolumn{2}{|c|}{ Inwards. } \\
\hline E. & W. & W. & E. & E. & W. & W. & E. \\
\hline $\begin{array}{r}87^{\circ} 34 \\
40 \\
34 \\
39\end{array}$ & $\begin{array}{r}87^{\circ} 53 \\
51 \\
52 \\
50\end{array}$ & $\begin{array}{r}87^{\circ} 45 \\
43 \\
44 \\
4 I\end{array}$ & $\begin{array}{r}87^{\circ} 54 \\
56 \\
51 \\
53\end{array}$ & $\begin{array}{r}87^{\circ} 40 \\
45 \\
45 \\
49\end{array}$ & $\begin{array}{r}87^{\circ} 5^{2} \\
49 \\
52 \\
50\end{array}$ & $\begin{array}{r}87^{\circ} 54 \\
5 \mathrm{I} \\
50 \\
48\end{array}$ & $\begin{array}{r}87^{\circ} 44 \\
49 \\
43 \\
46\end{array}$ \\
\hline
\end{tabular}

m. $87^{\circ} 46^{\cdot} 25^{\prime} . \quad$ m. of $\mathrm{m} .=87^{\circ} 47^{\prime} \mathrm{I} 5^{\prime} . \quad \mathrm{m} .=87^{\circ} 47^{\circ} 94^{\prime}$.

February 8th, I900. Taken on ice barrier between Cape Washington and Cape Gauss.

Lat. $75^{\circ} 42^{\prime}$ S. ; long. $163^{\circ} 29^{\prime}$ E. Strong breeze S.W., sleet.

Times II 35 A.M. to I 2 . I 5 A.M.
$\mathrm{B}$ dipping.
No. IA.
A dipping.

\begin{tabular}{|c|c|c|c|c|c|c|c|}
\hline \multicolumn{2}{|c|}{ Inwards. } & \multicolumn{2}{|c|}{ Outwards. } & \multicolumn{2}{|c|}{ Outwards. } & \multicolumn{2}{|c|}{ Inwards. } \\
\hline E. & W. & W. & E. & E. & W. & W. & E. \\
\hline $\begin{array}{r}87^{\circ} 37 \\
4 \mathrm{I} \\
45 \\
50 \\
\end{array}$ & $\begin{array}{rr}87^{\circ} & \text { I } 8 \\
& \text { I } 6 \\
\text { I2 } 2 \\
8\end{array}$ & $\begin{array}{r}87^{\circ} 4 \mathrm{I} \\
38 \\
47 \\
42\end{array}$ & $\begin{array}{r}87^{\circ} 42 \\
45 \\
4 \mathrm{I} \\
40 \\
\end{array}$ & $\begin{array}{r}87^{\circ} 42 \\
45 \\
4 \mathrm{I} \\
47 \\
\end{array}$ & $\begin{array}{r}87^{\circ} 38 \\
43 \\
35 \\
4 \mathrm{I}\end{array}$ & $\begin{array}{r}87^{\circ} \text { I } 5 \\
\text { I2 } \\
\text { I6 } \\
\text { I4 }\end{array}$ & $\begin{array}{r}87^{\circ} 39 \\
42 \\
38 \\
44\end{array}$ \\
\hline $87^{\circ} 43 \cdot 25$ & $87^{\circ}$ I $3 \cdot 5$ & $87^{\circ} 4^{2}$ & $87^{\circ} 4^{2}$ & $87^{\circ} 43^{\circ}$ & $5^{8} 87^{\circ} 39^{\circ}$ & $587^{\circ} \mathrm{I} 4 \cdot 25$ & $87^{\circ} 40^{\circ} 74$ \\
\hline
\end{tabular}

$\mathrm{m}_{.}=87^{\circ} 35^{\circ} 19^{\prime} . \quad \mathrm{m}$. of m. $=87^{\circ} 34^{\prime} 5^{\prime \prime} . \quad \mathrm{m}^{\prime \prime}=87^{\circ} 34^{\circ} 5 \mathrm{o}^{\prime}$. 


\section{INCLINATION.}

February 9th, I900.

Taken on Franklin Island.

Setting of Azimuth circle, $12^{\circ} 32^{\prime}$.

Times $\left\{\begin{array}{l}6.35 \\ 6.52\end{array}\right.$ P.M. A dipping. Times $\left\{\begin{array}{l}7.12 \text { P.M. } \\ 7.23\end{array} \quad\right.$ B dipping. No. 3 A.

\begin{tabular}{|c|c|c|c|c|c|c|c|}
\hline \multicolumn{2}{|c|}{ Inwards. } & \multicolumn{2}{|c|}{ Outwards. } & \multicolumn{2}{|c|}{ Outwards. } & \multicolumn{2}{|c|}{ Inwards. } \\
\hline E. & W. & W. & E. & E. & W. & W. & E. \\
\hline $\begin{array}{r}86^{\circ} 49 \\
52 \\
51 \\
55\end{array}$ & $\begin{array}{r}86^{\circ} 55 \\
50 \\
54 \\
49\end{array}$ & $\begin{array}{r}86^{\circ} 59 \\
54 \\
59 \\
55\end{array}$ & $\begin{array}{r}86^{\circ} 46 \\
5 \mathrm{I} \\
47 \\
5 \mathrm{I}\end{array}$ & $\begin{array}{r}86^{\circ} 53 \\
55 \\
53 \\
56\end{array}$ & $\begin{array}{r}86^{\circ} 49 \\
46 \\
48 \\
45\end{array}$ & $\begin{array}{rr}87^{\circ} & \text { I } \\
86^{\circ} 57 \\
59 \\
56\end{array}$ & $\begin{array}{r}86^{\circ} 42 \\
45 \\
42 \\
46\end{array}$ \\
\hline $86^{\circ} 5^{\circ}$ & $86^{\circ} 5^{2}$ & $86^{\circ} 56 \cdot 75$ & $86^{\circ} 48 \cdot 75$ & $86^{\circ} 54^{\cdot} \cdot 25$ & $86^{\circ} 47$ & $86^{\circ} 58 \cdot 25$ & $86^{\circ} 43^{\circ} 57$ \\
\hline
\end{tabular}

$$
86^{\circ} 52^{\prime} \mathrm{I} 8 \cdot 6^{\prime \prime} . \quad \mathrm{m} .=86^{\circ} 5 \mathrm{I}^{\prime} 33^{\circ} 6^{\prime \prime} . \quad 86^{\circ} 50^{\prime} 48 \cdot 6^{\prime \prime} .
$$

Times $\left\{\begin{array}{l}6.55 \text { P.M. } \\ 7.9\end{array}\right.$ A dipping. Times $\left\{\begin{array}{l}7.26 \text { P.M. } \\ 7.40\end{array}\right.$ B dipping. No. IA.

\begin{tabular}{|c|c|c|c|c|c|c|c|}
\hline \multicolumn{2}{|c|}{ Inwards. } & \multicolumn{2}{|c|}{ Outwards. } & \multicolumn{2}{|c|}{ Outwards. } & \multicolumn{2}{|c|}{ Inwards. } \\
\hline E. & W. & W. & E. & E. & w. & W. & E. \\
\hline $\begin{array}{r}86^{\circ} 52 \\
57 \\
52 \\
56\end{array}$ & $\begin{array}{r}86^{\circ} 55 \\
50 \\
56 \\
51\end{array}$ & $\begin{array}{r}87^{\circ} 9 \\
4 \\
7 \\
4\end{array}$ & $\begin{array}{r}86 \cdot 35 \\
40 \\
38 \\
43\end{array}$ & \begin{tabular}{|r|}
$86^{\circ} 35$ \\
40 \\
34 \\
40
\end{tabular} & $\begin{array}{r}87^{\circ} \text { I2 } \\
8 \\
\text { I } 3 \\
8\end{array}$ & $\begin{array}{r}86^{\circ} 47 \\
43 \\
47 \\
43\end{array}$ & $\begin{array}{rr}86^{\circ} & 55 \\
87^{\circ} & 0 \\
86^{\circ} & 57 \\
87^{\circ} & 2\end{array}$ \\
\hline $86^{\circ} 54 \cdot 25$ & $586^{\circ} 53$ & $87^{\circ} 575$ & $86^{\circ} 39$ & $86^{\circ} 37^{\cdot} \cdot 25$ & $87^{\circ} 10^{\circ} 25$ & $86^{\circ} 45$ & $87^{\circ} 5^{8 \cdot 5}$ \\
\hline
\end{tabular}




\section{N D E X}

Adare, 84

Adventure Bay, 49

Albatross, 54

Anemometer broken, I28

Antarctic, History of, 2

Appendix, 299

Ascent of Cape Adare, 105

Aurora Australis, see Appendix

Auckland Island, 292

Avalanche, 248

Balleny Island, 63

Barrier, Great, 279

"Belgica," 5

Bernacchi, 15

Bi-polarity, 232

Blizzard, 9 I

Blow-fly, discovery of, 232

Bluff, 294

Bunks, description of, 9I

Cable home, first, 294

Cape Crozier, 268

Cape Washington, 266

Carros, driving in, 39

Cave, snow, 168

Christmas Day, 24I

Christiania, departure from, 22

Colbeck, I 4

Congress, Geographical, 4

Coulman Island, 259

Crevasse, Fall in a, I7 I

Crew of Southern Cross, 18
Crow's nest, 57

Cruz, Sta., 46

Cut off from all the world, I 8

Daption Capensis, 64

Dark time, I 53

Departure, 29

Dogs, 4I

Dogs, fight of, 123

Drifting, Southern Cross, 92

Duke of York Island, Discovery of, 162

Duke of York Island, taking possession of, I80

Depression, I 55

Eclipse, Lunar, I36

Eclipse, Solar, 227

Eggs, collecting of, 203

Ellefsen, I7

Emperor penguin. (Aptenodyles

Forsterii), 71, 213

Engines of Southern Cross, I I

Engineer, chief, 22

Equator, Crossing of, 46

Eudyptes Adeliae, 208

Evans, I6

Fauna, shallow water, I Io

Fish, Discovery of, I I 2, I 20, I 86

Flag, Hoisting of, 99

Fougner, 16

Franklin Island, 268

Franklin, Sir John, 5 I 
Gales, 132

Geikie Land, I75

Gerlache, 5

Glacier, I 80

Glacier, ascent of, I77

Hanson, I7

Hanson's death and funeral, I90, I92

Hobart, 49

Huts, description of, 86

Icebergs, I 43, 282

Iceberg, Plunge of, 272

Ice-blink, 6I

Ice-navigation, 57

Ice-wall, rise of, I 2 I

Insects, $23 \mathrm{I}$

Jelly-fish, Large, 242

Jensen, Capt., I 3

Katharine's Docks, St., 24

Kayak, 240, 247

King Oscar Island, 267

Klövstad, Dr., I7

Komager, 165

Landing, 85

Lichen, Discovery of,

Luncheon, farewell, 24

Madeira, 39

Magnetic dips, 260, 264, 267, 268

Medusæ, 187

Menu, 152

Meteorological notes, Colbeck's, I95

Midwinter Camp, I62
Mirage, I27

Moraine, 175

Must, 19

Neptune, arrival of, 46

Newnes Land, 263

New Year's Day, 242

Ossifraga Gigantea, 64

Pagodroma Nivea, 222

Parrot, the grey, 45

Pea-rifle, 72

Penguins, Among the, 198

Penguins, flesh of, 2 I 6

Penguin's nests, material of, 209

Penguins, quarrel of, 2 I 2

Penguins, shoal of, 228

Petrel, gigantic, 220

Photographing seal, Bernacchi, I07

Porpoises, shoal of, 52

Possession Island, 257

Practical joke, 75

Puddings, 46

Refuge Camp, i I6

Report left in cask, I93

Return of Penguins, I9I

Robertson Bay, 84

Ridley, Camp, 89

Rossii, seal, 74

Savio, 19

Seal, killing of, 236

Seal, moulting of, 70

Shells, I 87

Shooting restrictions, 72

Ski, I 29

Skua-gull, egg of, 226

Skua-gill (Lestris), 2 I9

Sledge-breaking through the ice, 203

South, Farthest, 279 


\section{Index.}

Southern Cross Fjord, 26 I

Southern Cross' return, 250

Southern Cross' dimensions, IO

Sponges, I 87

Star-fish, I 87

Stewart Island, 293

Sun, departure of, 126

Target, Shooting at, 245

Terror, Mt., 27 I

Temperature, lowest, 166

Thanksgiving service, 296

Ticks on seal, 185
Vapour clouds, 224

Vegetation, I05

Victoria Land, evolution of, 236

Vincent, St., 46

Violent screwing in the pack, 77

Washington, Cape,

Warning glacier, 96

Weddellii, seal, IO2

White seal, 236

Wilkes, Capt., 55 



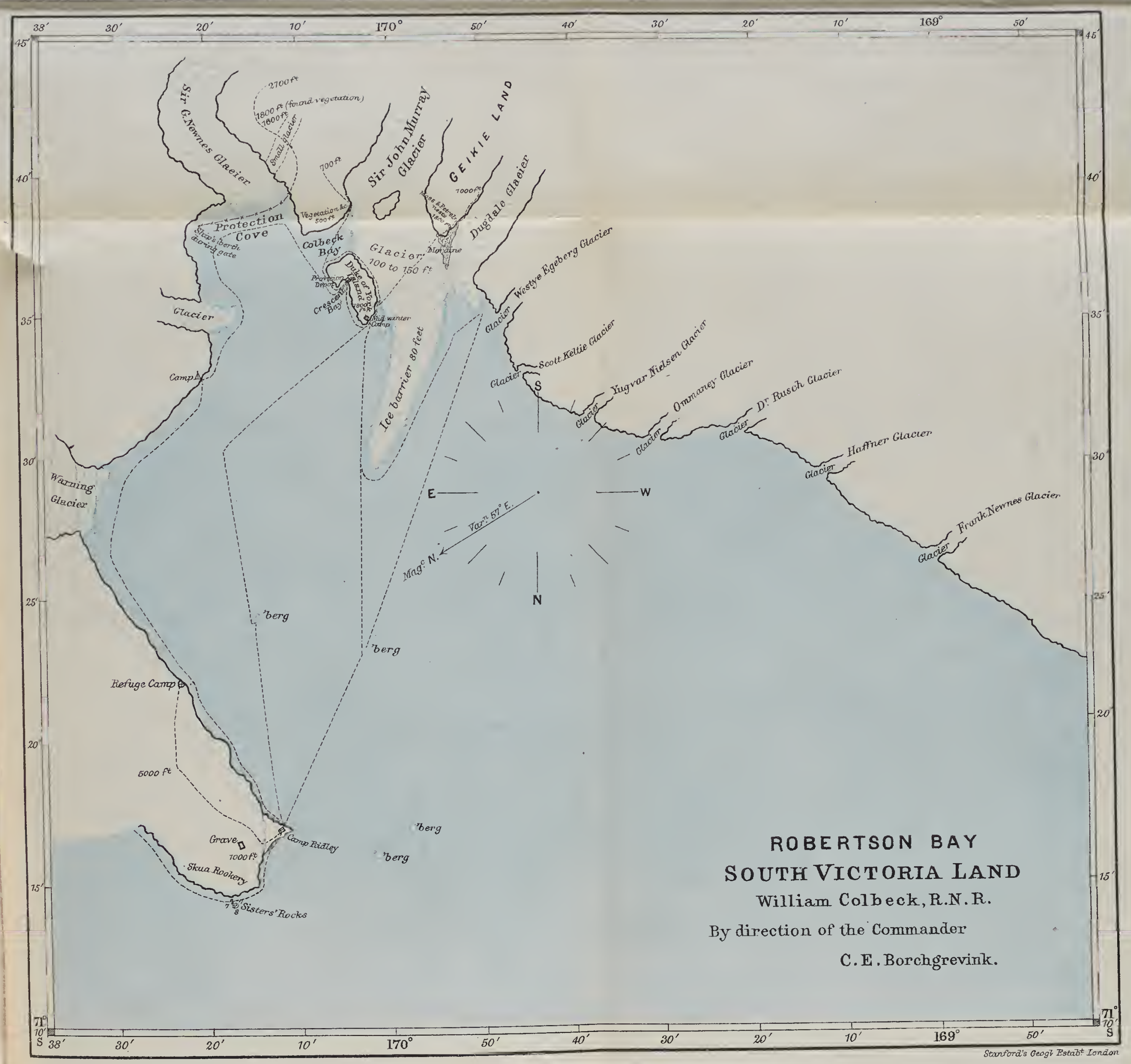





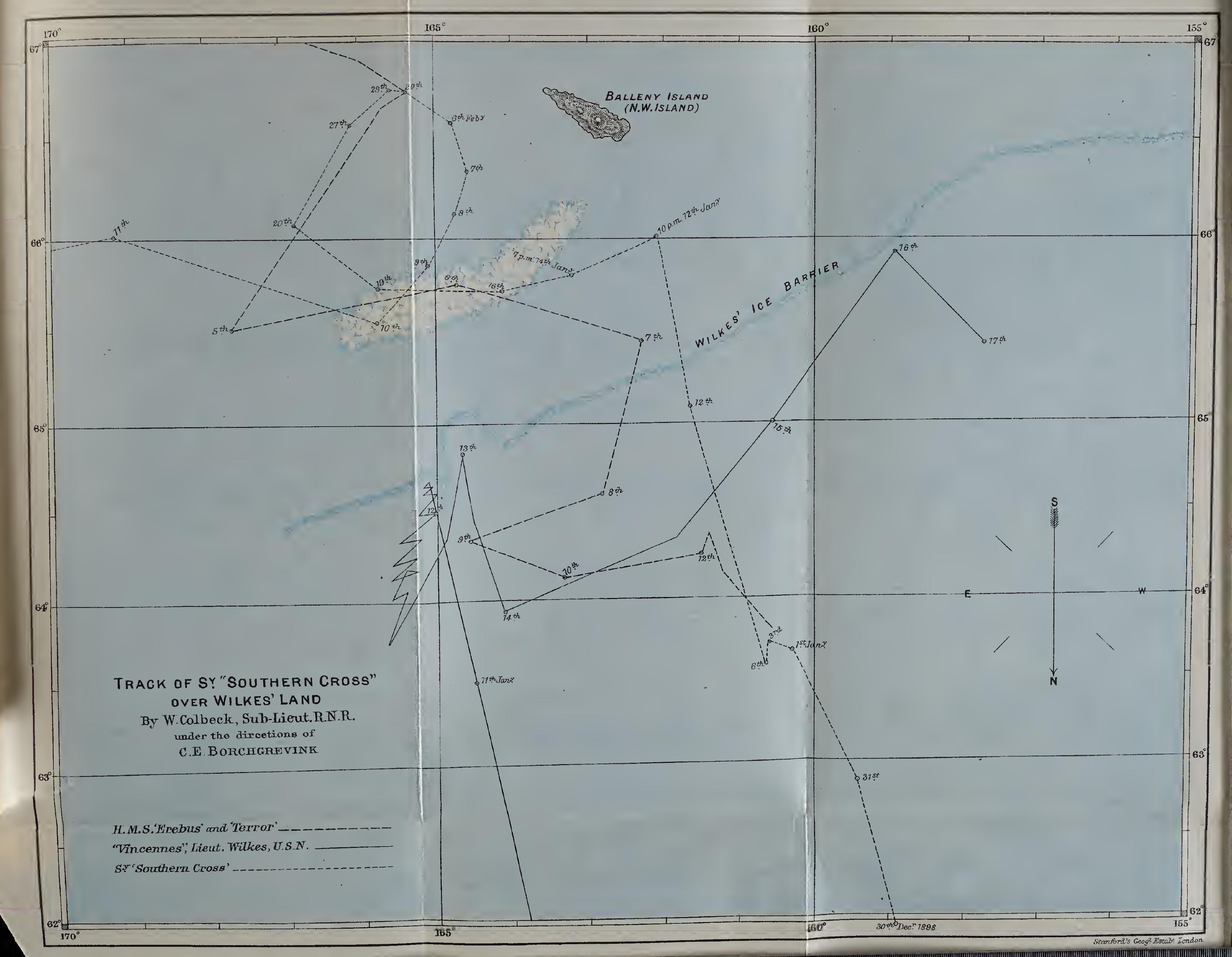





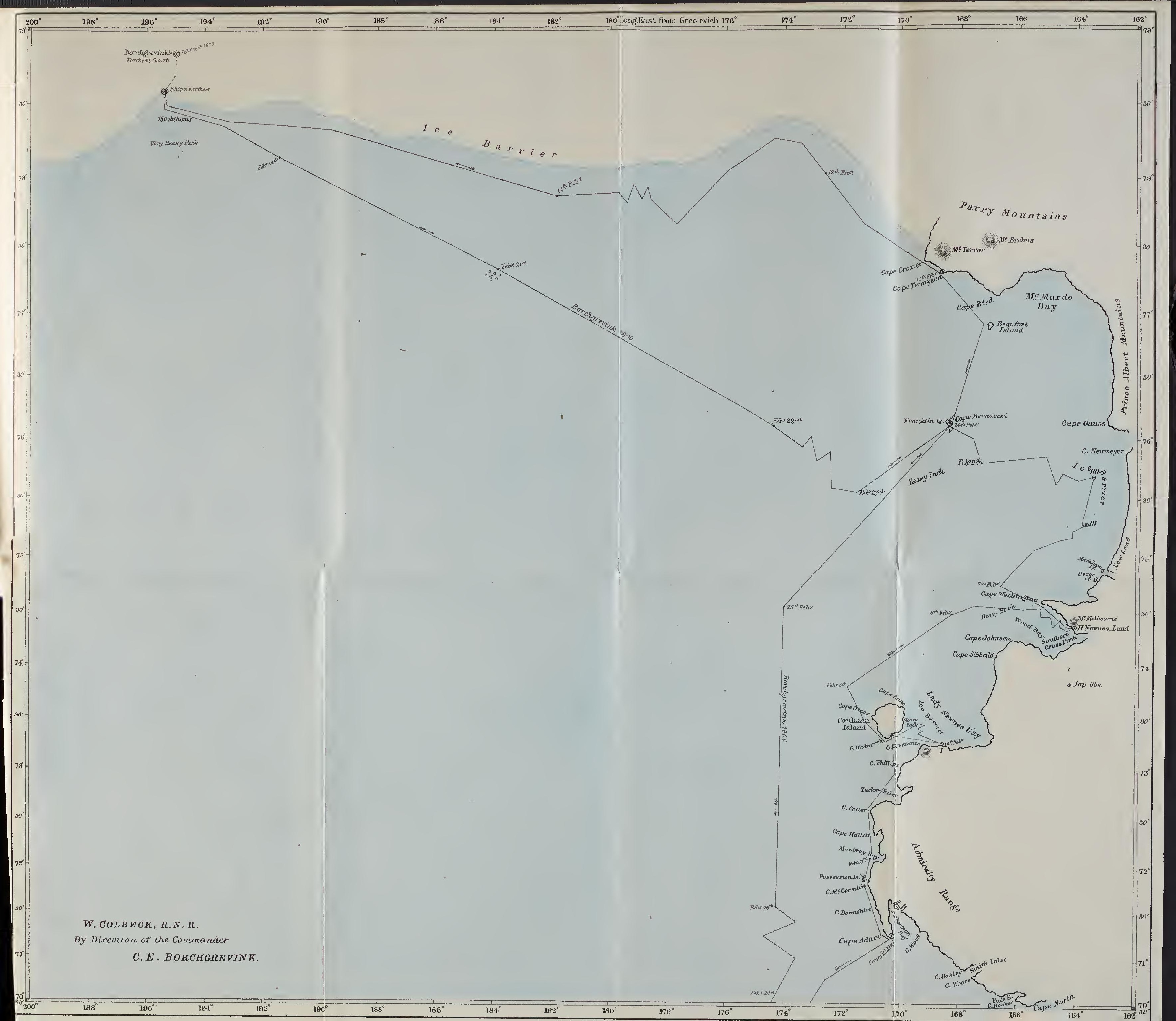





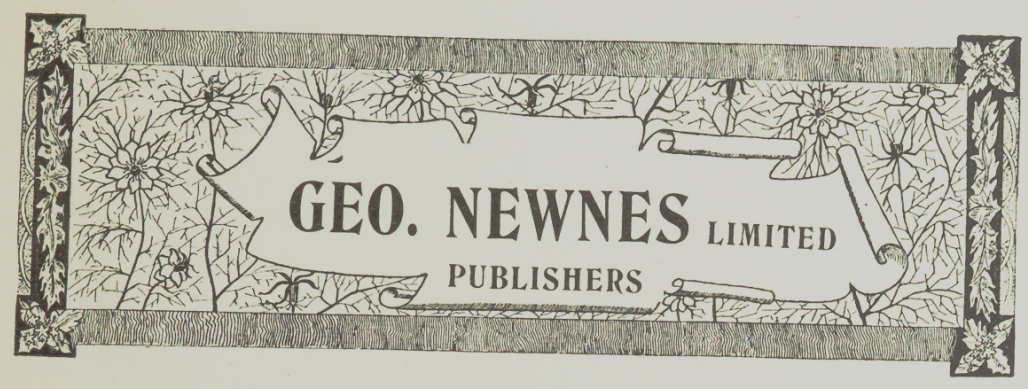

$7=12$ SOUTHAMPTON STREET, STRAND, W.C. 


\section{Publications of}

\section{George Newnes Limited}

\section{By HANS CHRISTIAN ANDERSEN.}

Fairy Tales.

With upwards of 400 Illustrations. By Helen Stratton. 4to, cloth extra, gilt, r2s.

The Arabian Nights Entertainments.

Demy 4to, with upwards of 500 original Illustrations. Printed on Superfine Art Paper. Price I5s.

By the Rev. WILLIAM ADAMS.

The Shadow of the Cross and the Old Man's Home.

Two Allegories. With Frontispiece to each Allegory. Cloth gilt, I6mo, $8 \mathrm{~d}$.

The King's Messengers and the Distant Hills.

Two Allegories. With Frontispieces, I6mo, cloth gilt, $8 \mathrm{~d}_{\text {, }}$ 


\section{George Newnes Limited}

\section{By GRANT ALLEN.}

\section{What's Bred in the Bone.}

Crown 8vo, cloth, 3s. 6d. Also a Cheap Edition, 6d.

\section{The Story of the Plants.}

With 49 Illustrations. Cloth, Is.

"A brightly written, clear and accurate summary of the functions and habits of plants."-Daily Chronicle.

\section{Flashlights on Nature.}

With I5o Illustrations by Frederick Enock. Crown 8vo, cloth extra, $6 \mathrm{~s}$.

"Charming and romantic scientific facts."-Revieze of Reviezes.

\section{In Nature's Workshop.}

With Illustrations by Frederick Enock. Crown 8vo, cloth extra, 3s. 6d.

\section{By R. E. ANDERSON, M,A.}

\section{The Story of Extinct Civilizations of the East.}

With Maps. Cloth, Is.

"An admirable compendium of a department of knowledge which has been greatly advanced by the research of recent years." - Aberdeen Free Press.

\section{By DOUglas ARCHIBALD, M.A.}

\section{The Story of the Earth's Atmosphere.}

With 44 Illustrations. Cloth, Is.

"One of the best of the Story series that we have read ... the author is frequently able from his wide travels to illustrate his remarks from his own personal experience in climates where meteorological manifestations can be witnessed on a grander scale than in our own country."-Nature. 


\section{Publications of}

\section{The Art Bible.}

Comprising the Text of the Old and New Testaments, printed in entirely new type, specially selected for its clearness and sharpness of outline, and with 850 Illustrations, Maps, \&c.

In one volume, 1360 pp. super royal $8 \mathrm{vo}$, handsomely bound in cloth, gilt leaves, I2s. : French morocco, bevelled boards, tooled in gold and blind, gilt leaves, I6s. ; plain Persian morocco, gilt leaves, I8s. ; Persian morocco, antique scroll in gold, gilt leaves, 2 rs. ; limp morocco, Yapp style, flexible back, solid gold leaves, 3os.; Turkey morocco, hand tooed in gold, solid gold leaves, $3^{8 s}$.

OLD TESTAMENT, with 660 Illustrat:ons, handsomely bound in clrth, gilt leaves, 9s.

NF:W TESTAMENT, with Igo Illustrations, handsomely bound in cloth gilt leaves, 5 s.

\section{The Story of the Mind.}

\section{By Professor J. M. BALDWIN.}

Cloth, is.

"We have seldom read a more thoughtful and suggestive little production. It can be strongly recommended to students of psychology, to the general reader, and to all who take an interest in the study and mental upbringing of the young."-Lancet.

\section{Edited by J. G. BARTHOLOMEW, F.R.G.S.}

\section{The Citizen's Atlas.}

Comprising Ioo Maps and Gazetteer. Crown folio, cloth extra, $16 \mathrm{~s}$. net; half-morocco, $18 \mathrm{~s} .6 \mathrm{~d}$. net.

"An admirable atlas."-Liverpool Courier.

\section{The Royal Atlas of England and Wales.}

I40 Pages of Plates, with Topographical Index and Statistics. Crown folio, cloth, I6s. net ; half-morocco, I8s. 6d. net.

"The most successful atlas of this country on a popular scale that has yet been issued."-Pall Mall Gazetie.

\section{The Hub Cycling Map of England and Wales.}

Printed in colours and folded in pocket case, $6 \mathrm{~d}$.; mounted on linen, is. 


\section{George Newnes Limited}

\section{By CONSTANCE BEERBOHM. \\ A Little Book of Plays, for Professional and Amateur Actors.}

With 22 Illustrations of Scenes. Paper covers, Is.

" An excellent collection of short dramaric sketches, suited to the requirements of amateurs."-Black and White.

\section{By C. F. BINNS.}

\section{The Story of the Potter.}

An Account of the Rise and Progress of the Principal Manufactures of Pottery and Porcelain. With 57 Illustrations. Cloth, is.

"We can recommend the whole volume to all who care to know something of one of the oldest and most universal of human arts." Guardian.

By Mrs. BISHOP.

\section{Unbeaten Tracks in Japan.}

With Map and 56 Illustrations. New and Revised Edition.

Cloth extra, gilt leaves, 6s. $6 \mathrm{~d}$.

\section{Photographs by GAMBIER BOLTON, F.Z.S., and others.}

\section{All About Animals.}

260 Illustrations of Animal Life. With explanatory text. Oblong 4to, cloth extra, gilt leaves, Ios. 6d.

"Not a dry and scientific work, but brightly written and well illustrated. Well illustrated it certainly is. Mr. Gamber Bolton's photographs of lions, tigers, leopards, and other feline creatures have never been surpassed, and hundreds of such pictures are to follow. It is really a wonderful production."-Army and $\Lambda$ avy Gazette. 


\section{Publications of}

By FRANCIS BOND, M.A., F.G.S., Hon. A.R.I.B.A.

\section{English Cathedrals Illustrated.}

With I8o Illustrations from Photographs. Second Edition.

Crown 8vo, cloth extra, 6s.

“'A practical, sensible, and well-informed book, beautifully illustrated. Its method is clear, rational, and helpful."-Bookman.

\section{By GEO. BORROW. \\ Lavengro: The Scholar-The Gypsy-The Priest. \\ Crown 8vo, cloth extra, 2s. $6 \mathrm{~d}$. \\ "A marvel of cheap excellence."-Weekly Sun.}

\section{The Story of Ice.}

\section{By W. A. BREND, B.A.}

In the Present and Past. With 37 Illustrations. Cloth, Is.

"As thus dealt with, the subject in its abstrusest aspects may be easily comprehended, even by those who have not hitherto devoted attention to the study of the Ice Age. It is prettily and profusely illustrated."-Scotsman.

\section{Shirley.}

\section{By CHARLOTTE BRONTË.}

Crown 8 vo, cloth, is. $6 \mathrm{~d}$.

\section{Jane Eyre.}

Crown 8 vo, cloth, is. $6 \mathrm{~d}$.

\section{BY FRANCES BURNEY. \\ Evelina; or, The History of a Young Lady's Entrance into the World. \\ With i6 Full-page Illustrations by Arthur Rackham. Crown 8vo, cloth extra, 2s. 6 d.}




\section{George Newnes Limited}

\section{The Captain.}

A Magazine for Boys and "Old Boys." Vols. I, 2, and 3. Profusely Illustrated. Cloth extra, gilt, 6s. each.

\section{The Century Book of Gardening.}

A Comprehensive Work for every lover of the Garden. Edited by E. T. Соок. With about 720 Illustrations. Specially designed Cover. Gilt leaves, large 8vo, 2 is. net.

\section{Celebrities of the Stage.}

A Series of Coloured Portraits of celebrated Actors and Actresses. With accompanying letterpress by Borı. L A W RENCE. Crown 4 to, cloth extra, ros. 6d. net.

\section{By PAUL DU CHAILLU.}

\section{The Land of the Midnight Sun.}

With all the original Illustrations, and some additions. Super royal 8vo. Handsomely bound in cloth, with silt edges. Price ios. 6d.

By G. F. CHAMBERS, F.R.A.S., Author of " Handbook of Descriptive and Practical Astronomy," \&c.

\section{The Story of the Stars.}

With 24 Illustrations. Cloth, is.

"Beginners in astronomy who wish to acquaint themselves merely with the outlines of a noble science will find this volumes of real service.' - Speaker.

". Told in a pleasing and attractive manner." - A thenoum. 


\section{Publications of}

\section{By G. F. CHAMBERS, F.R.A.S. \\ The Story of the Solar System.}

With 28 Illustrations. Cloth, Is.

"His descriptions possess the double quality of simplicity and attractiveness."-Nature.

\section{The Story of Eclipses.}

With special reference to the solar eclipse of 1900 . With I 9

Illustrations. Cloth, is.

"Writ en in a very interesting style and crammed with information."-University Correspondent.

\section{The Story of the Weather.}

With 50 Illustrations. Cloth, Is.

"An interesting volume about weather, and especially English weather, and presents facts, ideas, and suggestions which ordinary people will be glad to know. '-..-St. James's Budget.

By EDWARD CLODD, Author of "The Story of Creation," \&c.

\section{The Story of Primitive Man.}

With 88 Illustrations. Cloth, Is.

"Well printed, well bound, profusely illustrated, and in every respect capital nuaterial, on one of the most progressive of sciences." -Daily Chronicle.

\section{The Story of the Alphabet.}

With go Illustrations. Cloth, Is.

"The book shows how the alphabet was built up from picture writing, and is full of interest.-St. James's Gazette.

\section{"Confound that Boy."}

Manual of Book-keeping and Office Routine. Crown 8vo, cloth, Is. 


\section{George Newnes Limited}

\section{By H. W. CONN. \\ The Story of Germ Life: Bacteria.}

With 34 Illustrations. Cloth, Is.

" Though a popular work, the Story of Germ Life, as told by Prof. H. W. Conn, is so admirable for its lucidity, terseness, and the author's grasp of the subject, that it may be recomnended to any one who is desirous of becoming acquainted with the general features of bacterial life and the baneful and beneficial results of microbic growth and development." -Journal of Royal Microscopical Society.

\section{The Story of Life's Mechanism.}

With 50 Illustrations. Cloth, is.

"Very clearly written, and will give those who desire it an excelent conception of some of the problems which are engaging the attention of biologists at the present time."-Lancet.

\section{BY FENIMORE COOPER.}

\section{The Last of the Mohicans.}

Crown 8vo, cloth, is. 6 d.

By E. H. COUMBE, B.A. (Lond.)

\section{What Shall I Be?}

A Guide to Occupations for Men and Women. Crown 8vo, cloth, 3s. 6d. net.

\section{Country Life Illustrated.}

The Journal for all interested in Country Life and Country Pursuits. Profusely Illustrated. Vols. 5, 6, and 7, folio cloth, gilt leaves, 2 Is. each; half-morocco, $25 \mathrm{~s}$. each.

[Vols. 1, 2, 3, and 4 are out of print.

\section{By ROBERT CROMIE, Author of "The Crack of} Doom," \&c.

\section{The King's Oak, and Other Stories.}

Sewed, Is.; cloth, 2s.

"A capital collection of short stories."-Black and White. 


\section{Publications of}

\section{BY ROBERT CROMIE.}

\section{The Lost Liner.}

Crown 8vo, cloth, 3s. $6 \mathrm{~d}$.

By the Hon. ROBERT CURZON, Jun. (Baron de la Zouche).

\section{Visits to Monasteries of the Levant.}

With Sketch Maps and Illustrations. Crown 8vo, cloth extra, 2s. 6d.

"One of those fascinating books of travel which have taken a place in permanent literature."-Times.

\section{By WORDSWORTH DONISTHORPE. \\ Down the Stream of Civilization. \\ With Io4 Illustrations from Photographs. Crown 8vo, cloth extra, $6 \mathrm{~s}$. \\ "A book to be reconımended to the lonely diner, or anybody else in want of pleasant company. It might be described as the journal of a party of travellers in Egypt, Palestine, Greece, Italy, E'c. . . . Let it be understood that our ' $\mathcal{F}^{\circ} \mathrm{c}$.' includes a great deal, not only of other lands, but of amusing comment on things in general from the view of a good-humoured philosopher."-Guardian.}

\section{By A. CONAN DOYLE.}

\section{Adventures of Sherlock Holmes.}

With 25 Illustrations by Sidney Paget. Crown 8vo, cloth, 3s. 6d. Also a Cheap Edition, 6d.

\section{Memoirs of Sherlock Holmes.}

With Illustrations by Sidney Paget. Crown 8vo, cloth, 3s. 6d. Also a Cheap Edition, 6d.

\section{The Sign of Four.}

An Earlier Adventure of Sherlock Holmes. Crown 8vo, cloth, 3s. 6d. Also a Cheap Edition, 6d.

"For those to whom the good, honest, breathless detective story is dear, Dr. Doyle's books will prove a veritable godsend."-Athenæum. 


\section{George Newnes Limited}

\section{The Exploits of Brigadier Gerard.}

With 24 Illustrations by W. B. Wollen. Crown 8vo, cloth, 3s. 6d. Also a Cheap Edition, 6d.
"In these days of pessimistic problem novels, when the element of romance seems to be fading out of fiction, it is delightful to come upon these tales and glories of a soldier's life. They are buoyant, vital, steeped in the stir and freshness of the open air, abounding in tragedy and gaiety. ... It is a fascinating book, and one to be read."-Daily News.

By Mrs. EGERTON EASTWICK (Pleydell North).

The Rubies of Rajmar; or, Mr. Charlecote's Daughters.

A Romance. Cloth, 3s. 6d.

"Throughout the plot is well conceived, its trentment is terse and vigorous, and the series of exciting incidents by which the dénouement is reached form a narrative well worth reading. "-W. LE C UEUX, The Literary World.

By the Rev. W. H. FITCHETT ("Vedette").

Deeds that Won the Empire.

Historic Battle Scenes. 6d.

\section{Fights for the Flag.}

\section{Edited by C. B. FRY.}

\section{The Book of Cricket.}

A Gallery of Famous Players. 256 pages, crown folio, cloth gilt, I2s. 6 d. net.

\section{By W. C. GANNETT.}

\section{A Year of Míracle.}

A Poem in Four Sermons. With 4 Illustrations. I6mo, cloth, $8 \mathrm{~d}$. 


\section{Publications of}

\section{The Garden.}

Vol. 47. Ios. 6d. net.

\section{By Mrs. GASKELL.}

\section{North and South.}

Crown 8vo, cloth extra, 2s. 6 d.

"Capital edition of a charming story."-Manchester Courier.

\section{By Mrs. ALFRED GATTY.}

\section{Parables from Nature.}

Illustrated. I6mo, cloth, 8d.

\section{By W. E. GLADSTONE.}

The Impregnable Rock of Holy Scripture.

A Series of Old Testament Studies. $6 \mathrm{~d}$.

\section{By E. J. GOODMAN.}

\section{New Ground in Norway.}

Ringerike-Telemarken - Sætersdalen. With numerous

Illustrations. Demy 8vo, cloth extra, Ios. 6 d.

"Full of information as to the less frequented parts of Southern Norway. .. Well printed and capitally illustrated.' - Pall Mall Gazette.

\section{By MAXWELL GRAY.}

The Silence of Dean Maitland.

A Novel. 6d. 


\section{George Newnes Limited}

\section{By MAXWELL GRAY.}

The Reproach of Annesley.

A Novel. 6d.

By Mrs. GOODWIN GREEN.

\section{Raiders and Rebels in South Africa.}

With I4 Full-page Illustrations by the Author. Crown 8vo, cloth extra, $5 \mathrm{~s}$.

"Unpretentious, but interesting. Mrs. Green acted as a nurse in the Krugersdorp hospital at the time of the Jameson raid; afterwards she went on to Charterland in the same capacity, and was in touch with the chief incidents of the Matabele rebellion. A plain but stirring story is the result."-Literature.

By H. RIDER HAGGARD.

Jess: A Story of the Transvaal War of $1880-1$.

$6 \mathrm{~d}$.

She: A History of Adventure. $6 \mathrm{~d}$.

By BEATRICE HARRADEN.

Ships that Pass in the Night.

6d.

By HENRY HERMANN.

Hearts of Gold and Hearts of Steel. Cloth, 3s.6d. 


\section{Publications of}

By SYDNEY J. HICKSON, D.Sc., F.R.S., Professor of Zoology in the Owens College, Manchester.

The Story of Life in the Seas.

42 Illustrations. Cloth, Is.

"Such books as this lay the reader under a deep obligation to writers of Dr. Hickson's eminence in the scientific world." - Spectator.

\section{By G. LACY HILLIER.}

Wrinkles for Cyclists.

Small crown 8vo, is.

\section{Edited by EDWIN HODDER.}

The Life of a Century, 1800-1900.

With numerous Illustrations.

[To appear in 12 monthly parts.

\section{The Home Magazine.}

Vols. 2, 3, and 4, cloth, 5s. each.

[Vol. 1 is out of print

\section{By Mrs. HORSFALL.}

\section{Pretty Homes.}

With 6o Illustrations. 8vo, cloth, 3s. $6 \mathrm{~d}$.

\section{By N. L. JACKSON.}

\section{Association Football.}

With 20 Illustrations. Crown 8 vo, cloth, 6s.

"No such work in connection with the game has been published before; and, apart from the mere novelty of the thing, Mr. Jackson's effort will add lustre to the lib: ary of pastimes. 'The work, as a whole, is a credit to Association Football." - Athletic Nezes, 


\section{George Newnes Limited}

\section{The Story of Geographical Discovery.}

With 24 Maps, \&c. Cloth, Is.

"A very readable little book. . . . The author has collected his material with discrimination, and has evidently devoted nuch time and care to the preparation of this inspiring little volume. The recent marked development of imperial instincts should insure the book the popularity it nerits." -Nature.

BY HARRY A. JAMES.

Oddland, and other Fairy Tales.

Illustrated.

[In preparation.

\section{By Mrs. JAMESON.}

Shakspeare's Heroines: Characteristics of Women-Moral, Poetical, and Historical. Crown 8 vo, cloth extra, 2s. 6 d.

"The most charming of all the works of a charning writer." Blackwood's Magasine.

\section{By JOHN KEBLE.}

\section{The Christian Year.}

Thoughts in Verse for the Sundays and Holy Days throughout the Year. Crown 8vo, cloth extra, 2s. 6 d.

\section{Khaki in South Africa.}

An Album of Photographs illustrating the Chief Events of the War under Lord Roberts. Oblong 4to, cloth extra, $6 \mathrm{~s}$. 


\section{Publications of}

\section{The King.}

Vol. I. Cloth, gilt edges, I8s.

\section{Eothen.}

\section{By A. W. KINGLAKE.}

With 40 Illustrations by H. R. Millar. Crown 8vo, cloth extra, 2s. 6 d.

\section{By RUDYARD KIPLING.}

\section{Departmental Ditties, and Other Verses.}

Crown 8vo, cloth extra, 6s.; also a Cheap Edition, 6 d.

\section{The Siege of Ladysmith.}

A Collection of I20 Pictures from Photographic Negatives taken by $\mathrm{H}$. $\mathrm{KISCH}$, a Resident Photographer during the Siege, with Explanatory Text by H. St. J. Tugman, an eyewitness. Handsomely bound in marone leather, gilt leaves, with appropriate design embossed in gold on the side. Oblong 4 to, price 2is. net.

\section{By JOHN LEYLAND.}

\section{The Shakespeare Country Illustrated.}

Illustrated by over i 30 Photographs showing every feature of interest in connection with the Shakespeare Country and the surrounding Districts, so noted for their wonderful beauty of scenery. Ios. $6 \mathrm{~d}$. net. 


\title{
George Newnes Limited
}

\author{
By JOHN K. LEYS.
}

At the Sign of the Golden Horn.

Crown 8 vo, cloth, 3s. 6 d.

\section{By FRANCES H. LOW.}

\section{Queen Victoria's Dolls.}

With 40 Full-page Coloured Illustrations and numerous Sketches and Initial Letters by Alan Wright. Cheap Edition, crown 4 to, 5 s.

"No one who has not perused this entertaining record can in reality appreciate the diligent, alert child-life of Britain's truest gentlewoman. 'The full-page coloured illustrations, showing the dolls in their gorgenus costurnes and wooden attitudes, are almost as naïve as they are excellent." - The Gentlewoman.

\section{By CHARLES J. MANSFORD.}

Shafts from an Eastern Quiver.

With 25 Illustrations by Alfred Pearse. Cloth, 3s. 6d.

"Mr. Mansford has the gift of a story-teller, and he uniformly writes like a scholar. . . The illustrations, though small, are admirably executed, and enhance the piquancy-though that was hardly needed-of the letterpress."-Spectator.

\section{By THOMAS H. MAWSON.}

\section{The Art and Craft of Garden-Making.}

Profusely Illustrated by Plans, Perspective Views, and Photographs. Specially Designed Cover. 2Is. net.

\section{By Captain MARRYAT.}

\section{Mr. Mídshipman Easy.}

Crown 8 vo, cloth, is. 6 d. 


\title{
Publications of
}

\author{
By E. A. MARTIN.
}

\section{The Story of a Piece of Coal.}

With 38 Illustrations. Cloth, Is.

"Explains in simple and delightful fashion what coal is, whence it comes, and whither it goes, and in the concluding chapter shows how intimately it is connected with the interests of the botanist, the geologist, the physicist, the chemist, and the merchant."-Bradford Observer.

By L. T. MEADE.

\section{Daddy's Girl.}

With Illustrations by Gordon Browne. Crown 8vo, cloth extra, 3s. 6d.

[Just ready.

By L. T. MEADE and CLIFFORD HALIFAX, M.D.

Stories from the Diary of a Doctor.

With 24 Illustrations by A. Pearse. Cloth extra, 6s. Also a Cheap Edition, 6d.

"Cleverly-planned and brightly-told stories."-Bradford ( bserver.

" They are well told and salient in every feature."-Leeds Mercury.

\section{Edited by HUGH ROBERT MILL, D.Sc., F.R.S.E.}

\section{The International Geography.}

By Seventy Authors. With 488 Illustrations. Demy 8vo, cloth, I5s.

"Interest is maintained throughout the text-book before us, and the work may be taken as the only adequate exposition in English of the principles of the new Geography and their application to the facts which are embraced in the subject. Until a better enters the field this 'International Geography' must remain the standard textbook of the subject in our language."-Times. 


\title{
George Newnes Limited
}

\author{
By MIRANDA.
}

Aids to Health and Beauty.

A Complete Toilet Guide. Second Edition. Long 8vo, Is.

By the Rev. EDWARD MONRO.

\section{The Combatants.}

An Allegory. With Frontispiece. I6mo, cloth, 8d.

\section{By H. S. MORRISON}

\section{A Yankee Boy's Success.}

Being an Account of how an American Lad worked his way through Europe. With 7 Illustrations, and an Introduction by Chauncey M. Depew. 6 d.

\section{By J. E. MUDDOCK.}

\section{For God and the Czar.}

A Story of Jewish Persecutions in Russia. Cloth, 3s. 6d.

\section{Only a Woman's Heart.}

The Story of a Woman's Love: A Woman's Sorrow. Cloth, 3s. 6d.

"Has an air of heartiness about it, and its plot is well worked out."-Academy.

By M. M. PATTISON MUIR, M.A.

\section{The Story of the Chemical Elements.}

Cloth, is.

"One of the most perfect popular introductions to science extant." - British Medical Journal. 


\section{Publications of}

By M. M. PATTISON MUIR, M.A.

\section{The Story of the Wanderings of Atoms.}

Organic Chemistry. Cloth, is.

"Really a popular and interesting account of the chitef compounds of carbon." -Pharmaceutical Journal.

\section{By Miss MULOCK.}

John Halifax, Gentleman.

Crown 8 vo, cloth, Is. 6 d.

\section{By J. MUNRO.}

\section{The Story of Electricity.}

\section{With roo Illustrations. Cloth, Is.}

"Just the kind of book to give the general reader more correct views of the subject than many a pretentious tome." - The Electrical Engineer.

\section{The Story of the British Race.}

With 4 Maps. Cloth, Is.

"The first attempt to bring the important results and views of anthropologists before the general public in familiar language, and to a certain extent it is a correction of the traditions. . . . If the author seems to put the claims of anthropology too high, he has written a book that ought to stimulate inquiry and will guide the uninitiated to the lines on which anthropological research is being pursued."-Aberdeen Free Press.

\section{By Dr. NANSEN and Lieut. JOHANSEN.}

\section{Farthest North.}

Being the Record of a Voyage of Exploration of the ship Fram, 1893-96, and of a Fifteen Months' Sledge Journey. Popular Edition. In 2 vols., royal 8vo. With about 120 full-page and go text Illustrations. Coloured Plate and Map, cloth extra, I7s.

"The narrative of one of the most remarkable and adventurous voyages of discovery that have been made." - Scotsman.

"A masterpiece of story-telling."-Times. 


\section{George Newnes Limited}

\section{The Navy and Army Illustrated.}

Vols. 2, 3, and 5, bound in cloth extra, gilt leaves, I2s. each.

Vols. 7, 8, 9. and Io, I8s. each.

[Vols. 1, 4, and 6 are out of print.

\section{By Mrs. PRAGA.}

\section{Easy French Dishes for English Cooks.}

Small crown 8vo, cloth extra, 2s. 6d.

[ust ready.

\section{By EDWIN A. PRATT.}

\section{Pioneer Women in Victoria's Reign.}

Being Short Histories of Great Movements. Crown 8vo, cloth, 5s.; paper covers, Is.

"His chapters on Women's Work in Emigration and in Medicine are admirable."-Pull Mall Gazette.

\section{A Woman's Work for Women.}

Being an Account of the Philanthropic Work of Miss

L. M. Hubbard. Small crown 8vo, cloth, 2s. 6 d.

\section{By E. D. PRICE, F.G.S. \\ The British Empire Dictionary of the Eng- lish Language.}

To which are added selected lists of proper names, with phonetic pronunciation, and abbreviations in common use, with their meanings. Crown $8 \mathrm{vo}$, cloth extra, 3s. $6 \mathrm{~d}$.

"The aim is to include the words that are usually required in everyday life by business men and others, who do not want a dictionary full of technical words and etymology. The clear type and convenient size are to be commended."-Morning Post.

\section{The Story of Religions.}

Cloth, is.

"'The author's brief summaries of the different creeds are excellent. We have tried to find any sect not mentioned in the book, and have failed. This is the highest tribute we can pay to its completeness."Irish Church Times. 


\section{Publications of}

\section{By W. P. PYCRAFT.}

\section{The Story of Bird Life.}

With Illustrations. Cloth, Is.

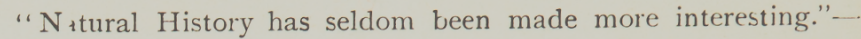
Scotsman.

\section{BY WILLIAM LE QUEUX. \\ England's Peril.}

A Novel. 6d.

\section{By G. B. RAWLINGS.}

\section{The Story of British Coinage.}

With 108 Illustrations from Coins in the British Museum. Cloth, is

"An excellent little handbook of a subject which should have an attraction for many Englishmen, even though they are not very ardent students in numismatics in general." - Times.

\section{By JAMES RODWAY, F.L.S.}

\section{The Story of Forest and Stream.}

With 27 Illustrations. Cloth, Is.

"Contains a short description of a tropical forest, together with some elementary lessons which can be learned by studying the incessant struggle for existence of its varied flora."-Academy.

\section{By LOUIS DE ROUGEMONT.}

\section{Adventures of Louis de Rougemont, as told} by Himself.

With 46 Illustrations. Crown 8vo, cloth extra, 6 s.

"That the story is interesting-even, one might say, exciting-is beyond doubt. What more need be asked?"-Spectator. 


\section{George Newnes Limited}

\section{Round the Coast.}

An Album of 284 Pictures from Recent Photographs of the Watering Places and Resorts in the United Kingdom, with descriptive text. Oblong 4 to, cloth extra, gilt leaves, ros. 6d.

"We know nothing at anything like the price that can be compared with these for giring to the sedentary traveller veracious glimpses of what the world or his own seashores contains that is interesting and picturesque."-Times.

\section{Round London.}

An Album of 284 Pictures from Photographs of the Chief Places of Interest in and around London, with descriptive text. Oblong 4to, cloth extra, gilt, Ios. $6 \mathrm{~d}$.

"The illustrations are taken from photographs of the most notable and characteristic of the metropolitan sights. Few quarters of London or aspects of London life are neglected; its business and its pleasures, its architecture and its street traffic receive illustration in all their phases. The photographs have been admirably reproduced."--Scotsman.

\section{Round the World, from London Bridge to Charing Cross, via Yokohama and Chícago.}

An Album of 284 Pictures from Photographs of the Chief Places of Interest in all Parts of the World, with descriptive text. Oblong 4to, cloth extra, gilt leaves, Ios. $6 \mathrm{~d}$.

“ $\mathrm{W}^{\top} \mathrm{e}$ are taken through all the principal cities and picturesque and historic places from Calais to Brindisi, we mentally travel up the Nile, we go through all the great commercial and historic scenes in India, Malaysia, China, and Japan before crossing to the American Continent; we are given views of the forests, rivers, and mountains of the New World, the cities that are dotted over its bosom, and all the sights from the Falls of Niagara down to the silver mountain of Potosi and the streets of Buenos Ayres."-The Stock Exchange. 


\section{Publications of}

By F. RYLAND.

The Story of Thought and Feeling.

Cloth, is.

[Just ready.

\section{By J. HOLT SCHOOLING.}

\section{A Peep into Punch.}

With about 480 Pictures from "Punch." "Crown 8 vo, cloth extra, 5 s. net.

"The book should be kept in a handy position for frequent consultation."-Sketch.

\section{By H. G. SEELEY, F.R.S.}

\section{The Story of the Earth in Past Ages.}

With 40 Illustrations. Cloth, Is.

"A simple and popular summing up of the results that have been reached by geological science."-Scotsman.

"Told plainly and pleasantly fora popular audience."-Bookman.

\section{By GEORGE R. SIMS.}

\section{Memoirs of a Mother-in-Law.}

Cloth, 2s. 6d.

"This is a pleasant sample of 'Dagonet's' semi-humorous writings. He has a peculiar talent of finding amusement in experiences relating to dwellings, servants, shopkeepers, tradespeople, and other folk connected with the domestic household, and the 'Motherin-Law' in his new book deals in a very masterful way with all the foregoing subjects, and many more besides."-Freeman's Journal. 


\section{George Newnes Limited}

\section{The Strat ford=on=Avon Shakespeare.}

\section{The Works of William Shakespeare.}

With Glossarial Side-notes. Complete in 12 vols., cloth extra, with cut edges, I2s., or limp lambskin, I8s. net, or bound in roan and in roan case, $25 \mathrm{~s}$. net.

"We can unhesitatingly say that the Newnes edition is quite the most handy and readable edition which we have as yet seen-and the number of editions with which we are acquainted is legion. A wise discretion has been exercised as to the size of the volume, which is not too small-as is the case with many existing 'pocket' editions -whilst the semi-antique 'laid' paper, and the absolutely perfect typography, reflect great credit both on the firm which initiated the work and on the printers who produced it. It is not encumbered with notes, but all needful glossarial explanations are ingen ously embedded in small type in the text."-Broad Arrow.

\section{By JOHN SKEAPING.}

\section{Light, Shade, and Shadow.}

With Model Drawing. With I55 Illustrations. Cloth, 3s. 6d.

It is the object of this book to give students an immediate acquaintance with the principles of Light, Shade, and Shadow, by explanation, analysis, and illustration. By this process of analysis and demonstration the knowledge gained is confirmed and enlarged, and permanently established, so that the student may, in any branch of the art, apply the principles with equal success, from the lrast even to the greatest.

\section{By Sir H. M. STANLEY.}

\section{Through the Dark Continent.}

With a New Introduction by the Author, and all the Original Illustrations and a Map. In 2 vols, super royal $8 \mathrm{vo}$, cloth, gilt edges, I5s. 


\section{Publications of}

\section{By HERBERT GREENHOUGH SMITH.}

\section{The Romance of History.}

292 pp., crown 8 vo, cloth, 3s. 6 d.

" Pre-eminently interesting, bright, clear and attractive."-Daily Chronicle.

\section{By A. T. STORY.}

\section{Golden Deeds of the War.}

With i6o Portraits, crown 8vo, cloth extra, 6s.

"Abounds with stirring descriptions of the most exciting incidents of the campaign. It will make a rare gift book for British boys." Daily Express.

\section{The Story of Photography.}

With Illustrations. Cloth, Is.

"Mr. Story does not profess to give instructions in the art: but his history of its progress, his description of the various forms of apparatus and the various processes, and his statements of the relation between photography and the finer aris cannot but impart an intelligent interest in this versatile handmaiden of sc ence." -Scotsman.

\section{The Strand Magazine.}

An Illustrated Magazine. Vols. I4 to I9, cloth extra, gilt leaves, 6s. 6d. each. [Vols. 1 to 13 are out of print.

\section{By CARLTON STRANGE.}

\section{The Beechcourt Mystery.}

Cloth, 3s. $6 \mathrm{~d}$.

"A novel and well-constructed plot."-Liverpool Courier. 


\title{
George Newnes Limited
}

\author{
Edited by A. G. TEMPLE, F.S.A.
}

England's History, as Pictured by Famous Painters.

An Album of 256 Historical Pictures, with descriptive text. Oblong 4to, cloth extra, gilt leaves, Ios. $6 \mathrm{~d}$.

"Notable scenes in our history as realised by artists of good standing."-Birmingham Daily Post.

\section{By W. M. THACKERAY.}

\section{Christmas Books.}

Mrs. Perkins's Ball, Our Street, Dr. Birch and his Young Friends, Rebecca and Rowena, The Kickleburys on the Rhine, The Rose and the Ring. In I vol. Crown 8vo, cloth extra, 2s. $6 \mathrm{~d}$.

"Another welcome reprint."-Morning Post.

\section{The Transvaal War Album.}

The British Forces in South Africa (Naval, Military, and Colonial). 272 pages, crown folio, I2s. 6d. net.

By Mrs. HUMPHRY WARD.

Robert Elsmere. $6 d$.

The History of David Grieve. $6 d$. Marcella. $6 d$.

\section{Wide World Magazine.}

Vols. 2 to 5, cloth extra, gilt leaves, 6s. 6d. each.

[Vol. 1 is out of print. 


\section{Publications of}

BY MARY SPENCER=WARREN.

\section{The Princess of Wales: A Biographical Sketch.}

With Portraits of the Princess at various periods, and Illustrations from Photographs taken in Denmark and at Sandringham, Marlborough House, \&c. With 53 Portraits and Illustrations. Crown $8 \mathrm{vo}$, cloth extra, $5 \mathrm{~s}$.

" An excellent biography . . . narrated with admirable simplicity and lucidity."--Westminster Review.

\section{By H. W. WEGUELIN, F.R.H.S.}

\section{Carnations and Picotees for Garden and Exhibition.}

With a Chapter concerning Pinks; and 12 full-page Illustrations. Crown 8vo, cloth extra, 3s. $6 \mathrm{~d}$.

"A very charmingly produced little book. . . . The chapter on carnations in town gardens will be useful to London amateurs."Academy.

\section{Wide World Adventure.}

True Narratives of Extraordinary Human Endurance. 256 pp., cloth, crown 8vo, 2s. 6 d.

\section{By F. WILKINSON, F.G.S.}

\section{The Story of the Cotton Plant.}

With 38 Illustrations. Cloth, Is.

"All that is known of the origin of the cotton plant, of its cultivation and plantation life, of the pests that infest it, and the countries where it is reared. . . The survey is wide and complete, and the story evolved therefrom is throughout most interesting." -North British Advertiser. 


\section{George Newnes Limited}

\section{Now in course of Publication.}

\section{OUR NEIGHBOURS.}

\section{Edited by W. H. DAWSON.}

A series of handy books descriptive of the Home and Social Life of Continental Peoples. They will not be statistical, political, or controversial, but will aim at describing in a friendly spirit such phases of life as are peculiar to each country.

Generally speaking, they may be said to deal with the Intellectual Life of the various peoples, their social divisions and distinctions, their manners and customs, wealth and poverty, their armies and systems of national defence, their Industrial Life, Rural Life, Religious Life, Home Life, Amusements, and Local Governments.

The following volumes will be ready at an early date, and others are already in preparation:-

\section{French Life in Town and Country.}

By Miss Hannah Lynch. Author of "Denys D'Auvrillac," "Dr. Vermont's Fantasy," \&c. [Ready.

\section{Dutch Life in Town and Country.}

By a Resident at The Hague.

\section{German Life in Town and Country.}

By W. H. Dawson, Author of "Germany and the Germans," \&c. [In March.

\section{Russian Life in Town and Country.}

By Francis H. E. Palmer. Sometime Secretary to H.H. Prince Droutskop-Loubetsky (Equerry to H.M. the Emperor of Russia).

In May. 


\section{Publications of}

\section{THE LIBRARY OF USEFUL STORIES. PRICE ONE SHILLING EACH.}

The Story of Thought and Feeling. By F. Ryland.

The Story of Bird Life. By W. P. Pycraft. With Illustrations.

The Story of the Alphabet. By EDwARD Clodd. With 90 Illus.

The Story of Life's Mechanism. By H. W. Conn. With 50 Illus.

The Story of the Wanderings of Atoms. By M. M. Patisison MUIR, M.A.

The Story of Ice in the Present and Past. By W. A. Brend. With 37 Illustrations.

The Story of Eclipses. By G. F. Chambers, F.R.A.S. With 19 Illustrations.

The Story of the British Race. By John Munro. With 4 Maps.

The Story of the Mind. By Prof. J. M. Baldwin.

The Story of Geographical Discovery: How the World Became Known. By JosepH JACOBS. With 24 Maps, \&c.

The Story of the Cotton Plant. By F. Wilkinson, F.G.S. With 38 Illustrations.

The Story of Religions. By the Rev. E. D. PrICE, F.G.S.

The Story of Photography. By A. T. STory. With 38 Illustrations.

The Story of Life in the Seas. By Sidney J. Hickson, F.R.S. With 42 Illustrations.

The Story of the British Coinage. By G. B. Rawlings. With 108 Illustrations.

The Story of the Potter. By C. F. Binns. With 57 Illustrations of Ancient and Modern Pottery.

The Story of Germ Life: Bacteria. By H. W. Conn. With 34 Illustrations.

The Story of the Earth's Atmosphere. By Douglas Archibald. With 44 Illustrations.

The Story of the Weather. By G. F. Chambers, F.R.A.S. With 50 Illustrations.

The Story of Forest and Stream. By James Rodway, F.L.S. With 27 Illustrations.

The Story of the Chemical Elements. By M. M. Patisison MUIR, M.A.

The Story of Extinct Civilizations of the East. By R. E. Anderson, M.A. With Maps.

The Story of Electricity. By J. Munro. With roo Illustrations.

The Story of a Piece of Coal. By E. A. Martin, F.G.S. With $3^{8}$ Illustrations.

The Story of the Solar System. By G. F. Chambers, F.R.A.S. With 28 Illustrations.

The Story of the Earth in Past Ages. By H. G. Seeley, F.R.S. With 40 Illustrations.

The Story of the Plants. By Grant Allen. With 49 Illustrations.

The Story of Primitive Man. By Edward Clodd. With 88 Illustrations.

The Story of the Stars. By G. F. Chambers, F.R.A.S. With 24 Illustrations. 


\title{
George Newnes Limited
}

\section{THE SIXPENNY SERIES OF COPYRIGHT BOOKS.}

England's Peril.

\author{
By WILLIAM LE QUEUX.
}

The Reproach of Annesley.

The Silence of Dean Maitland.

By the Rev. W. H. FITCHETT ("Vedette").

Deeds that Won the Empire.

Fights for the Flag.

What's Bred in the Bone.

By GRANT ALLEN.

By L. T. MEADE and CLIFFORD HALIFAX, M.D.

Stories from the Diary of a Doctor.

By RUDYARD KIPLING.

Departmental Ditties, and other Verses.

By H. RIDER HAGGARD.

She. A History of Adventure.

Jess. A Story of the Transvaal.

Robert Elsmere.

By Mrs. HUMPHRY WARD.

The History of David Grieve.

Marcella.

Adventures of Sherlock Holmes.

By A. CONAN DOYLE.

Memoirs of Sherlock Holmes.

The Sign of Four.

The Exploits of Brigadier Gerard.

By BEATRICE HARRADEN.

Ships that Pass in the Night.

With an Introduction by CHAUNCEY M. DEPEW.

A Yankee Boy's Success. Being an Account of how an Anerican Lad worked his way through Europe. By H. S. MorR ISON. With 7 Illustrations.

By the Late W. E. GLADSTONE.

The Impregnable Rock of Holy Scripture. A Series of Old Testament Studies. 


\section{Publications of George Newnes Ltd.}

\section{ADOPTED BY THE SCHOOL BOARD FOR LONDON.}

Tit-Bits Copy Books. In, Fifteen Books, containing 24 pages. Price 2 d. each.

A New Series of Copy Books designed to produce a clear, bold, and rapid writing. There are no flourishes or fanciful peculiarities. The style is simple, uniform, and entirely without exaggerations. Theslope is I $_{5}$ degrees from the vertical. There are at least two headlines on every page, so that the ris $\mathrm{k}$ of the scholar copying his own writings is reduced to a minimum.

Great care bas been taken in the preparation and arrangement of the headlines. In the earlier books the elements and combinations of letters have been carefully graded. 'In the higher bcoks the headlines are "Tit-Bits" from the Code Subjects : Interesting Facts ; Memorable Dates; Useful Information. The interest in what is being copied will thus be kept alive, and the style of writing will consequently be improved.

The Golden Rule Readers: Manners and Morals. Illustrating and enforcing by means of Proverbs, Maxims, Stories, Examples and Poems, the necessity for habits of punctuality, of good manners and language, the importance of cheerful obedience to duty, of consideration and respect for others, and of honour and truthfulness in word and act, the rela'ion of conduct, thrift, temperance, \&c., to success in life.

In Two Books for Standards III. to VI. Book I., Is. 3d. Book II., IS. $6 \mathrm{~d}$.

Flashlights on Nature. By Grant Allen. With I50 Illustrations by FrEDERICK ENOCK. Crown 8vo, cloth extra, 6s.

England's History, as Pictured by Famous Painters. Edited by A. G. TEMPLE, F.S.A. Oblong 4to, cloth extra, gilt leaves, ros. $6 \mathrm{~d}$.

Round the World, from London Bridge to Charing Cross, via Yokohama and Chicago. Oblong 4to, cloth extra, gilt leaves, Ios. 6d.

Round the Coast. Oblong 4to, cloth extra, gilt leaves, Ios. $6 \mathrm{~d}$.

Round London. Oblong 4to, cloth extra, gilt leaves, Ios. 6d.

All About Animals. 260 Illustrations from Photographs by GAMBIER BOLTON, F.Z.S., and others, with explanatory letter press. Cloth extra, gilt leaves, ros. $6 \mathrm{~d} .0$

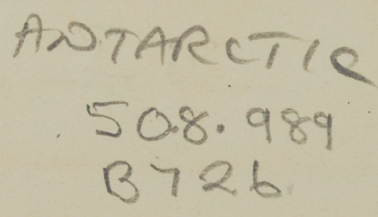


201409 



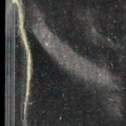

5.

(3) 

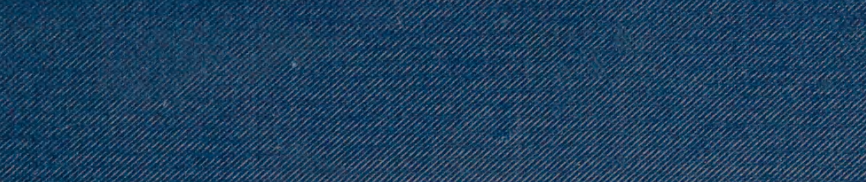

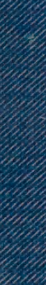

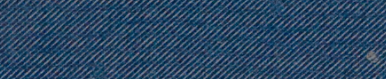

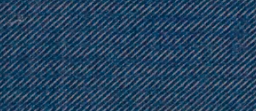

. 